ORP-56292

Revision 0

\title{
Final Report - Melt Rate Enhancement for High Aluminum HLW Glass Formulations, VSL-08R1360-1, Rev. 0, dated 12/19/08
}

Prepared for the U.S. Department of Energy

Assistant Secretary for Environmental Management

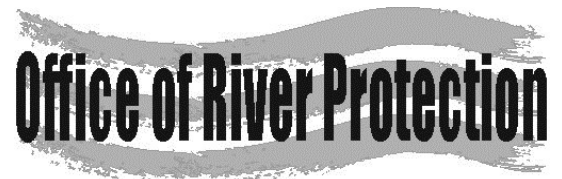

P.O. Box 450

Richland, Washington 99352 
ORP-56292

Revision 0

\section{Final Report - Melt Rate Enhancement for High Aluminum HLW Glass Formulations, VSL-08R1360-1, Rev. 0, dated 12/19/08}

A. A. Kruger

Department of Energy - Office of River Protection

I. L. Pegg

The Catholic University of America

M. Chaudhuri,

The Catholic University of America

W. Gong

The Catholic University of America
H. Gan

The Catholic University of America

K. S. Matlack

The Catholic University of America

T. Bardakci

The Catholic University of America

W. Kot

The Catholic University of America

Date Published

December 2008

Prepared for the U.S. Department of Energy Assistant Secretary for Environmental Management

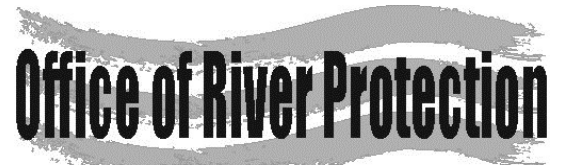

\section{P.O. Box 450}

Richland, Washington 99352

\section{APPROVED}

By G.E. Bratton at 1:20 pm, Nov 13, 2013 
ORP-56292

Revision 0

TRADEMARK DISCLAIMER

Reference herein to any specific commercial product, process, or service by tradename, trademark, manufacturer, or otherwise, does not necessarily constitute or imply its endorsement, recommendation, or favoring by the United States Government or any agency thereof or its contractors or subcontractors.

This report has been reproduced from the best available copy.

Printed in the United States of America 


\title{
Final Report
}

\section{Melt Rate Enhancement for High Aluminum HLW Glass Formulations}

\author{
prepared by
}

Keith S. Matlack, Hao Gan, Malabika Chaudhuri, Wing Kot, Weiliang Gong, Tevfik Bardakci, and Ian L. Pegg

\author{
Vitreous State Laboratory \\ The Catholic University of America \\ Washington, DC 20064 \\ and \\ Innocent Joseph \\ EnergySolutions Federal EPC, Inc. \\ Laurel, MD \\ for \\ Department of Energy \\ Office of River Protection
}

November 5, 2008

Rev. 0; 12/19/08 
The Catholic University of America Vitreous State L.aboratory
Melt Rate Enhancement for High Aluminum HLW Glass Formulations Final Report, VSL-08R1360-1, Rev 0

Document Title: Melt Rate Enhancement for High Aluminum HLW Glass Formulations

Document Number and Revision:

Issue Date:

Performing Organization: Vitreous State Laboratory, The Catholic University of America

Test Plan:
VSL-08R1360-1, Rev. 0

$12 / 19 / 08$

This report describes the results of testing specified by the above Test Plan. The work was performed in compliance with the quality assurance requirements specified in the Test Plan. Results required by the Test Plan are reported. The test results and this report have been reviewed for correctness, technical adequacy, completeness, and accuracy.

I.L. Pegg:

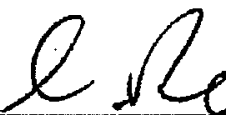

VSL Program Director/Principal(Investigator

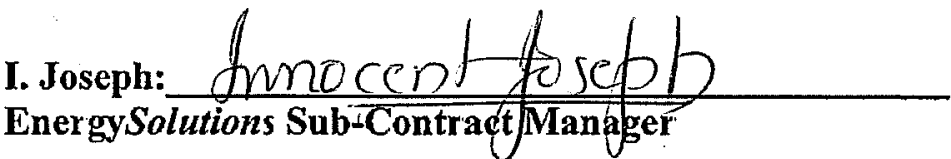

Date: $12 / 10 / 08$

Date: 12119108 
The Catholic University of America Vitreous State Laboratory
Melt Rate Enhancement for High Aluminum HLW Glass Formulations Final Report, VSL-08R1360-1, Rev. 0

\section{TABLE OF CONTENTS}

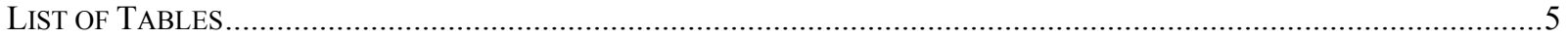

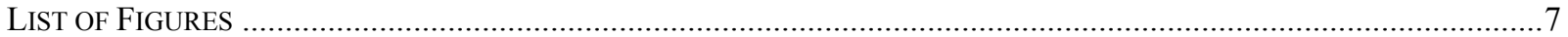

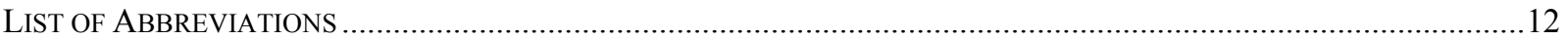

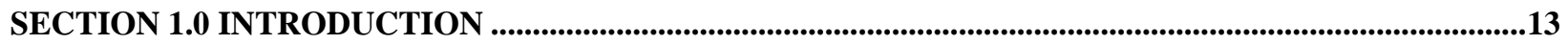

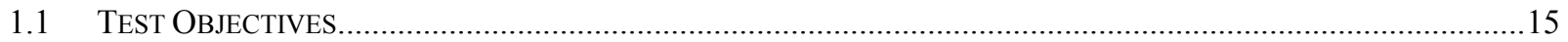

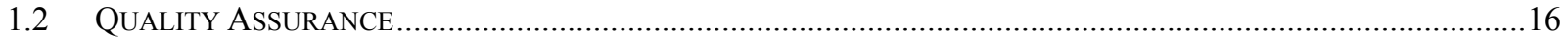

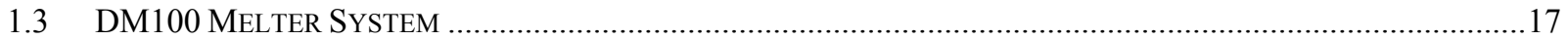

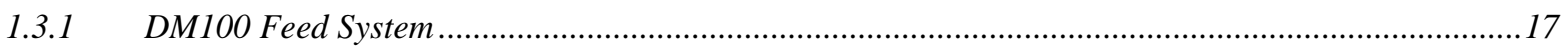

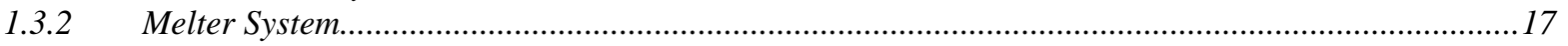

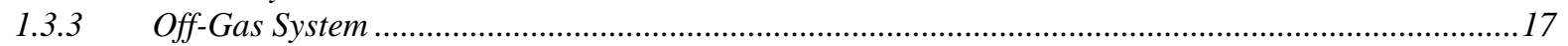

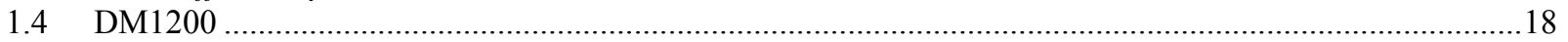

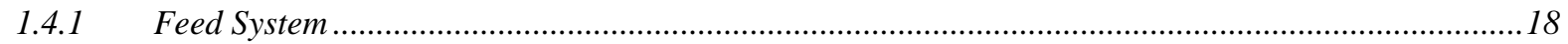

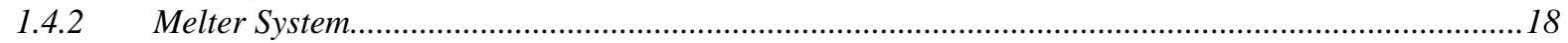

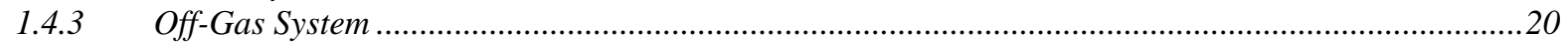

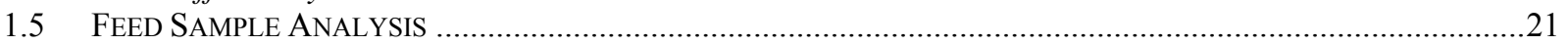

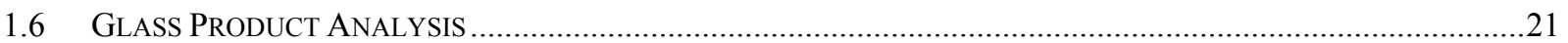

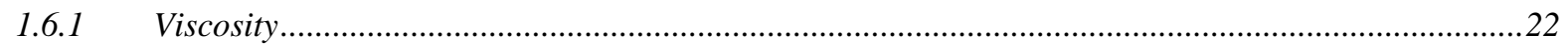

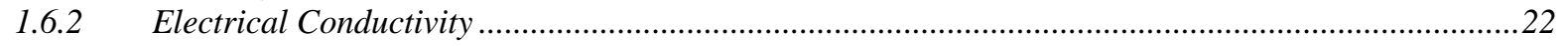

1.6.3 Product Consistency Test (PCT) ……………...............................................................................22

1.6.4 Toxicity Characteristic Leaching Procedure (TCLP) ....................................................................23

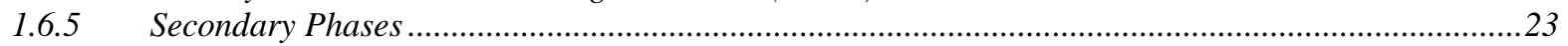

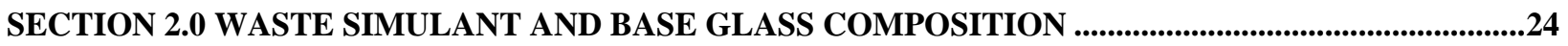

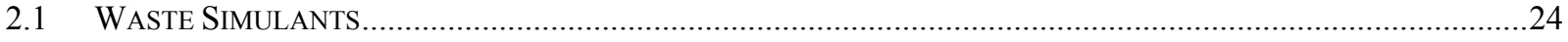

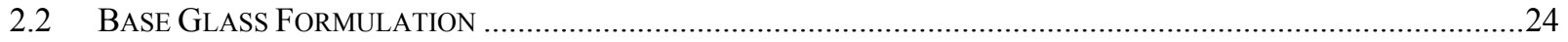

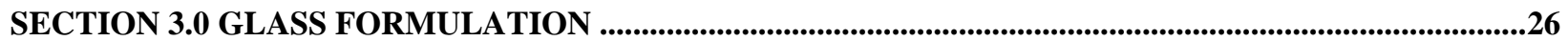

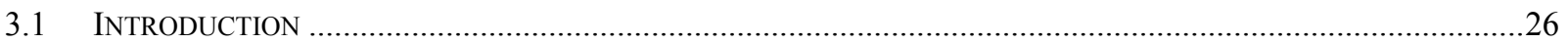

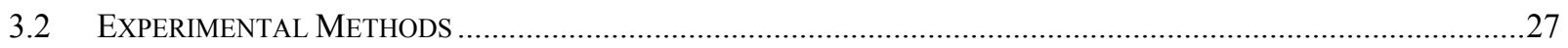

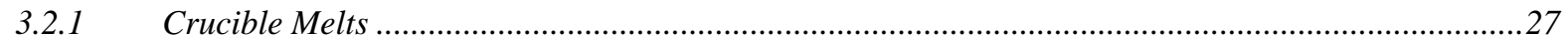

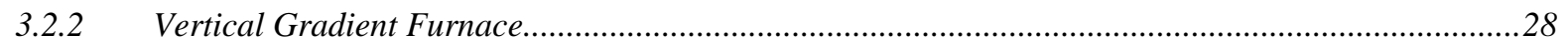

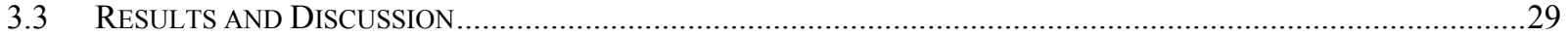

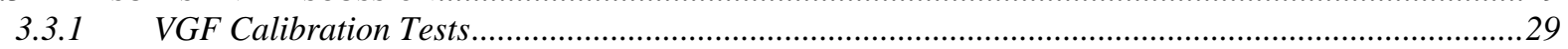

3.3.2 Component Effects on the HLW-E-Al-27 Formulation.......................................................................

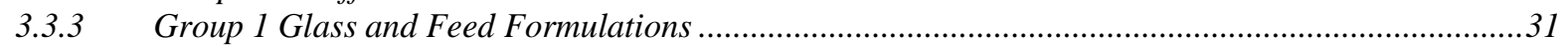

3.3.4 Group 2 Glass and Feed Formulations ……….............................................................................32

3.3.5 Group 3 Glass and Feed Formulations ……................................................................................32

3.3.6 Group 4 Glass and Feed Formulations ……….................................................................................33

3.3.7 Group 5 Glass and Feed Formulations ……....................................................................................33

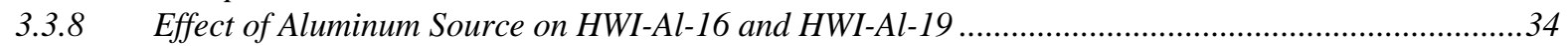

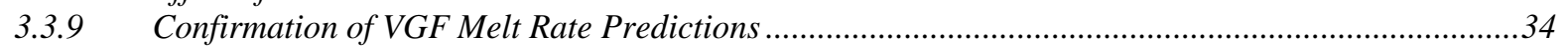

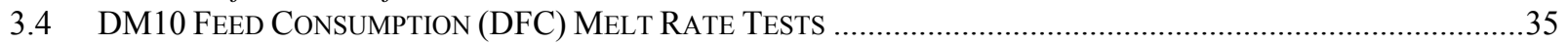

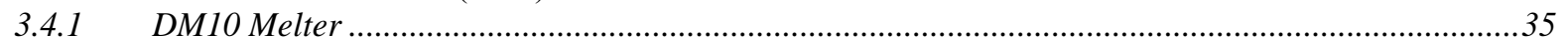

3.4.2 Methodology for DFC Melt Rate Tests .......................................................................................35

3.4.3 Feed Compositions Evaluated in DFC Tests ..............................................................................36

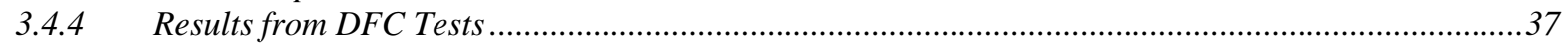

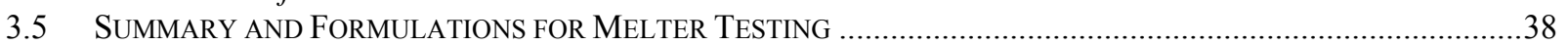

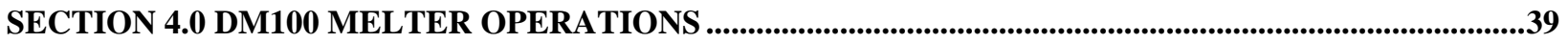




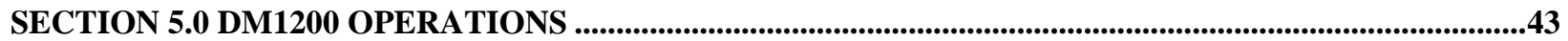

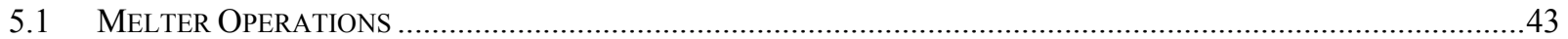

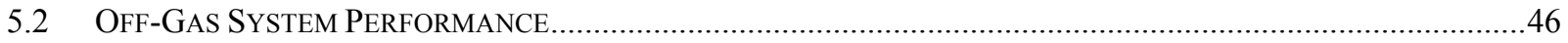

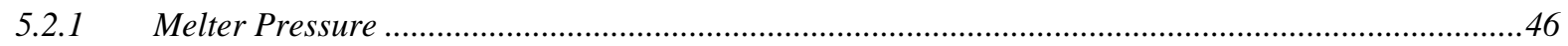

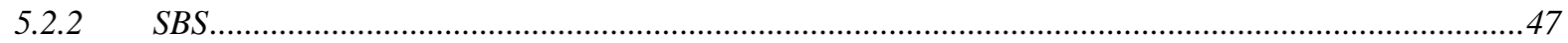

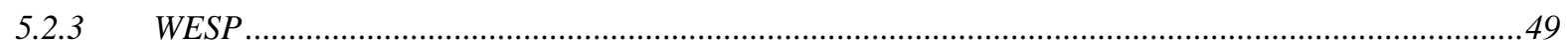

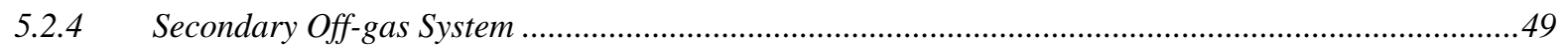

5.2.5 SBS, WESP, HEME, and PBS Process Fluids ............................................................................50

SECTION 6.0 FEED SAMPLE AND GLASS PRODUCT ANALYSIS...............................................................52

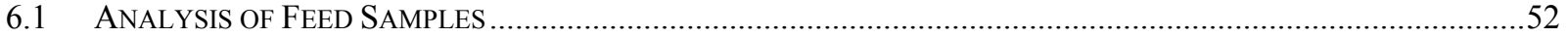

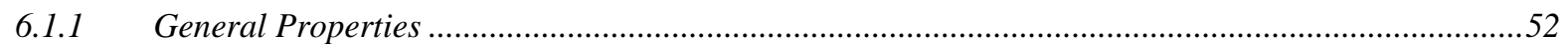

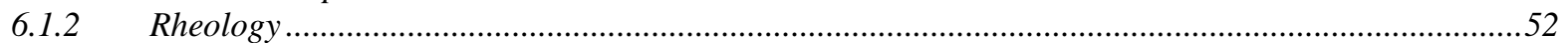

6.1.3 Chemical Composition.................................................................................................................53

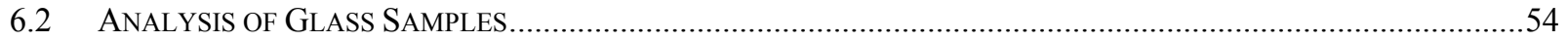

6.2.1 Compositional Analysis of Discharge Glasses ................................................................................54

6.2.2 Chemical Durability of Discharge Glasses ..................................................................................55

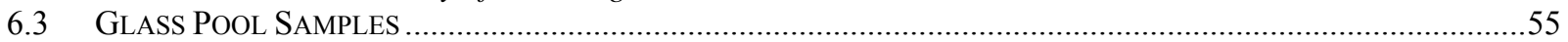

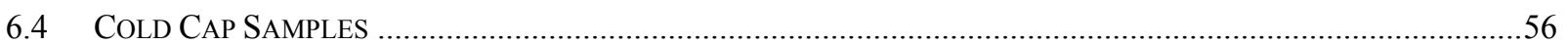

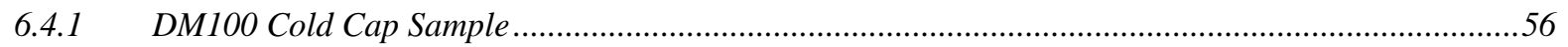

6.4.2 DM1200 Cold Cap Sample ............................................................................................................56

SECTION 7.0 MONITORED OFF-GAS EMISSIONS _.........................................................................................57

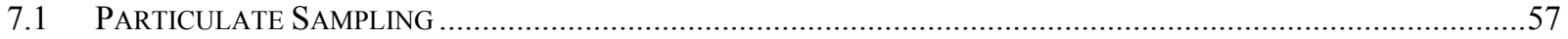

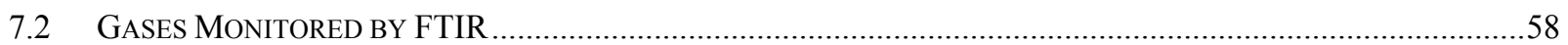

SECTION 8.0 SUMMARY AND CONCLUSIONS .....................................................................................................60

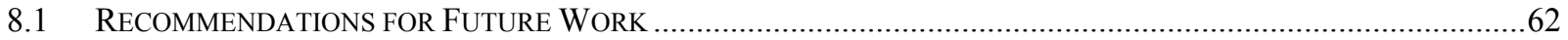

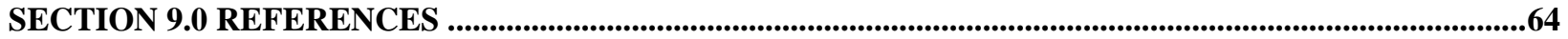




\section{List of Tables}

Table 2.1 Oxide Compositions of Limiting Waste Streams (wt $\%$ ).

$\underline{\text { Page \# }}$

Table 2.2

Compositions of the Al-Limited Waste (Oxide Basis) and the HLW

$\mathrm{T}-1$

Waste Simulant to Produce $100 \mathrm{~kg}$ of Waste Oxides $(20 \mathrm{wt} \%$ suspended solids) Using $\mathrm{Al}_{2} \mathrm{O}_{3}$ as the Aluminum Source.

$\mathrm{T}-2$

Table 2.3 Compositions of the Al-Limited Waste (Oxide Basis) and the HLW Waste Simulant to Produce $100 \mathrm{~kg}$ of Waste Oxides $(20 \mathrm{wt} \%$ suspended solids) Using $\mathrm{Al}(\mathrm{OH})_{3}$ as the Aluminum Source.

Table 2.4 Composition and Properties of Aluminum Limited Waste and Glass Formulation at $45 \%$ Waste Loading Used in Previous Melter Tests.

Table 2.5 Compositions of Melter Feed to Produce $100 \mathrm{~kg}$ of Target Glass HLW-E-Al-27 (Glass Yield $=500 \mathrm{~g} / \mathrm{L}$ Feed) from the Al-Limited Waste Simulant Using $\mathrm{Al}(\mathrm{OH})_{3}$ as the Aluminum Source.

Table 3.1 Summary of Glass Formulations and the Associated Feed Tests by VGF and Waste Glass Melters (DM100 or DM1200).

Target and XRF Analysis of HWI Glasses Tested 9wt\%).

Table 3.2

Table 3.3

Characterization of HWI Glasses.

Table $3.4 \mathrm{a}$

XRF Analysis (wt \%) of Four Melter Feeds Fused at $1150^{\circ} \mathrm{C}$ and After VGF Experiments.

$\mathrm{T}-16$

Table $3.4 \mathrm{~b}$ XRF Analysis (wt $\%$ ) of Group 1 Formulation Feeds Fused at $1150^{\circ} \mathrm{C}$ and After VGF Experiments.

$\mathrm{T}-17$

Table 3.4c XRF Analysis (wt\%) of Group 3 Formulation Feeds Fused at $1150^{\circ} \mathrm{C}$ and After VGF Experiments.

$\mathrm{T}-18$

Table $3.4 \mathrm{~d}$

XRF Analysis (wt\%) of Group 4 Formulation Feeds Fused at $1150^{\circ} \mathrm{C}$ and After VGF Experiments.

$\mathrm{T}-19$

Table 3.4e XRF Analysis (wt $\%$ ) of Group 5 Formulation Feeds Fused at $1150^{\circ} \mathrm{C}$ and After VGF Experiments.

$\mathrm{T}-20$

Table 3.4f XRF Analysis (wt \%) of Existing High Fe Melter Feeds and Variations of Baseline Feed for HLW-E-Al-27.

Table 3.5

Ranking Definition for Feed Conversion after 30 Minutes in VGF.

$\mathrm{T}-24$

Table 3.6. Compositions of the Al-Limited Waste (Oxide Basis) and the HLW Waste Simulant to Produce $100 \mathrm{~kg}$ of Waste Oxides $(20 \mathrm{wt} \%$ suspended solids) (from VSL report [2]).

Table 3.7 TCLP Results (ppm) for Selected HWI Glasses.

Table 3.8 Melt Rate Ranking of Feed Samples by VGF vs. Glass Production Rate by $\mathrm{DM} 100$ at $1150^{\circ} \mathrm{C}$.

Table 3.9 Crystalline Phases in the Partially Reacted Feed (VGF) Identified by SEM/EDS and XRD.

Table 3.10 Target Glass Compositions for Base Feeds Used During DM10 Melter Rate Tests (wt\%).

Table 3.11 Target Compositions for Vitrified Melter Feed with Various Additives During DM10 Melter Rate Tests (wt\%).

Table 3.12 Composition and Properties of Aluminum Limited Waste and Glass Formulation HWI-Al-16 with $43.65 \%$ Waste Loading (wt $\%$ ).

Table 3.13 Composition and Properties of Aluminum Limited Waste and Glass Formulation HWI-Al-19 with 45\% Waste Loading (wt \%). 
ORP-56292 Rev. 0

The Catholic University of America

Vitreous State Laboratory

Table 3.14 Composition of Melter Feed to Produce $100 \mathrm{~kg}$ of Target Glass HWI-Al-16 (Target Glass Yield $=500 \mathrm{~g} / \mathrm{L}$ Feed) from the Al-Limited Waste Simulant Using $\mathrm{Al}(\mathrm{OH})_{3}$ as the Aluminum Source.

$\mathrm{T}-33$

Table 3.15 Composition of Melter Feed to Produce $100 \mathrm{~kg}$ of Target Glass HWI-Al-16 (Target Glass Yield $=500 \mathrm{~g} / \mathrm{L}$ Feed) from the Al-Limited Waste Simulant Using $\mathrm{Al}_{2} \mathrm{O}_{3}$ as the Aluminum Source.

Table 3.16 Composition of Melter Feed to Produce $100 \mathrm{~kg}$ of Target Glass HWI-Al-19 (Target Glass Yield $=500 \mathrm{~g} / \mathrm{L}$ Feed) from the

Al-Limited Waste Simulant Using $\mathrm{Al}(\mathrm{OH})_{3}$ as the Aluminum Source.

$\mathrm{T}-35$

Table 4.1

Summary of Results from DM100 Tests.

$\mathrm{T}-41$

Table 4.2

Steady-State Production Rates Achieved with HLW Compositions on the DM100 at Melt Pool Bubbling of 9 lpm and Solids content near

500 g glass/liter.

Table 4.3

Table 5.1

Table 5.2

Table 5.3

Table 5.4

Summary of Measured DM100 Parameters.

$\mathrm{T}-43$

Summary of DM1200 Test Conditions and Results. T-46

Summary of Operational Events.

$\mathrm{T}-47$

Operator Observations of Cold Cap (CC).

$\mathrm{T}-50$

DM1200 Tests Performed with Final HLW Bubbler Configuration and Glass Temperature of $1150^{\circ} \mathrm{C}$.

T-67

Measured DM1200 Melter System Parameters (8/6/2008 - 8/16/2008). T-68

Table 5.5

Table 5.6

Table 5.7

Measured DM1200 Off-Gas System Parameters.

$\mathrm{T}-70$

Off-Gas Solution Volumes.

$\mathrm{T}-71$

Table 5.8

Analytical Results for Solutions from the DM1200 Off-gas System

Sampled at End of Testing (mg/L).

$\mathrm{T}-72$

Characteristics of Melter Feed Samples.

$\mathrm{T}-74$

Rheological Properties of Melter Feed Samples.

$\mathrm{T}-76$

Table 6.2

XRF Analyzed Compositions of Vitrified Melter Feed Samples (wt\%).

$\mathrm{T}-77$

Table 6.4

Listing of Glass Discharged, Masses, and Analysis Performed During

DM100 Tests.

$\mathrm{T}-80$

Table 6.5 List of Glass Discharged, Masses, and Analysis Performed during DM1200 Tests.

Table 6.6 XRF Analyzed Composition for Glass Discharged During DM100 Melter Test (wt \%).

$\mathrm{T}-84$

$\mathrm{T}-87$

Table 6.7 XRF Analyzed Composition for Glass Discharged During DM1200

Melter Test (wt\%).

T-96

Table 6.8 XRF and DCP Analyzed Compositions of Selected Glass Samples

Discharged during DM100 and DM1200 Melter Tests (wt\%).

$\mathrm{T}-98$

PCT Results for Melter Glasses

$\mathrm{T}-101$

TCLP Results for Melter Glasses (mg/L).

$\mathrm{T}-102$

Glass Pool Samples and Secondary Phase Observations. $\quad$ T-103

Table 6.11

Results from DM100 Off-Gas Emission Samples.

$\mathrm{T}-104$

Results from DM1200 Off-Gas Emission Samples.

$\mathrm{T}-108$

Table 7.3

Concentrations (ppmv) of Selected Species in DM100 Exhaust

Measured by FTIR Spectroscopy.

$\mathrm{T}-110$

Table 7.4 Concentrations [ppmv] of Selected Species in DM1200 Test 1

Exhaust Measured by FTIR Spectroscopy.

$\mathrm{T}-112$

Table 7.5 Concentrations [ppmv] of Selected Species in DM1200 Test 2

Exhaust Measured by FTIR Spectroscopy.

$\mathrm{T}-113$

Table 7.6 Concentrations [ppmv] of Selected Species in DM1200 Test 3

Exhaust Measured by FTIR Spectroscopy.

$\mathrm{T}-114$ 


\section{List of Figures}

Figure 1.2.a

Figure 1.2.b

Figure 1.2.c

Figure 1.3

Figure 1.4

Figure 1.5

Figure 1.6

Figure 1.7

Figure 3.1

Figure 3.2

Figure 3.3

Figure 3.4

Figure 3.5

Figure 3.6

Figure 3.7

Figure 3.8

Figure 3.9

Figure 3.10

Figure 3.11

Figure 3.12

Figure 3.13

Figure 3.14

Figure 3.15

Figure 3.16

Figure 3.17
Schematic diagram of DuraMelter 100 vitrification
Schematic diagram showing cross-section through the DM100-BL-melter.

F-2

F-3

DM100-BL melter.

DM100-BL melter.

Cross-section of the DM1200 melter through the discharge chamber. F-5 Cross-section through the DM1200 melter showing electrodes. $\quad$ F-6 Specifications of Double Outlet "J" Bubbler. Placement of double outlet bubblers. $\quad$ F-8

Schematic diagram of DM1200 off-gas system. $\quad$ F-9

Schematic drawing of vertical gradient furnace (VGF) for feed conversion test.

F-10

F-11 the Vertical Gradient Furnace (VGF).

F-12

VGF tests (30 minutes)

Preliminary evaluation of melt rate ranking by VGF as compared to the glass production rate determined by DM100 melter test using the same melter feed.

F-14

Time evolution of the baseline Al-limited melter feed (HLW-E-Al-27) after VGF tests

F-15

Impacts of boron and aluminum sources on melt rate in VGF experiments (45 minutes).

F-16

F-17 minute test in VGF.

F-18 minute test in VGF.

F-19 minute test in VGF.

F-20 minute test in VGF.

F-21

F-22

F-25

rate determined by DM100 melter test.

F-26

feed consumption tests.

$\begin{array}{ll}\text { and DM100 production rates for a wide variety of feed compositions. } & \text { F-27 } \\ \text { Comparison of Base Feeds from DFC melt rate screening tests. } & \text { F-28 }\end{array}$

Comparison of additives combined with HLW-E-AL-27 $\left(\mathrm{Al}_{2} \mathrm{O}_{3}\right)$

from DM10 small-scale melt rate screening tests. 
Figure 3.18 Comparison of additives combined with HLW-E-AL-27 $\left(\mathrm{Al}(\mathrm{OH})_{3}\right)$ from DFC melt rate screening tests.

F-30

Figure 3.19 Comparison of additives combined with HLW-E-AL-27

$\left(\mathrm{Al}_{2} \mathrm{O}_{3}+\right.$ boric acid/soda ash replacing borax $)$ from DFC

melt rate screening tests.

F-31

Figure 3.20

Comparison of additives combined with HLW-E-AL-27

$\left(\mathrm{Al}_{2} \mathrm{O}_{3}+\right.$ boric acid/potassium carbonate replacing borax $)$ from

DFC melt rate screening tests.

F-32

Figure 3.21

Comparison of additives and amounts combined with

HLW-E-AL-27 $\left(\mathrm{Al}_{2} \mathrm{O}_{3}\right)$ from DFC melt rate screening tests.

F-33

Figure 3.22 Comparison of additives and amounts combined with HLW-E-AL-27

$\left(\mathrm{Al}_{2} \mathrm{O}_{3}+\right.$ boric acid/potassium carbonate replacing borax $)$ from DFC melt rate screening tests.

F-34

Figure 3.23 Comparison of additives and amounts combined with HLW-E-AL-27 $\left(\mathrm{AlOH}_{3}\right)$ from DFC melt rate screening tests.

F-35

Figure 4.1.a Glass production rates (hourly moving averages) for DM100

Tests 1 and 2.

F-36

Figure 4.1.b Glass production rates (hourly moving averages) for DM100

Tests 3 and 4.

F-37

F-38

Tests 5 and 6.

F-39

Tests 7 and 8 .

Figure 4.2 Steady-state glass production rates during DM100 tests at constant bubbling rate, glass temperature $\left(1150^{\circ} \mathrm{C}\right)$, and feed solids content $500( \pm 50)$ g glass per liter feed.

F-40

F-41

F-42

Glass temperatures (hourly averages) during DM100 Tests 3 and 4.

Glass temperatures (hourly averages) during DM100 Tests 5 and 6.

F-43

$\begin{array}{ll}\text { Glass temperatures (hourly averages) during DM100 Tests } 7 \text { and } 8 . & \text { F-44 } \\ \text { Plenum temperatures (hourly averages) during DM100 Tests } 1 \text { and } 2 . & \text { F-45 }\end{array}$

Plenum temperatures (hourly averages) during DM100 Tests 3 and $4 . \quad$ F-46

Plenum temperatures (hourly averages) during DM100 Tests 5 and $6 . \quad$ F-47

Plenum temperatures (hourly averages) during DM100 Tests 7 and $8 . \quad$ F-48

Electrode temperatures and power (hourly averages) during DM100

Tests 1 and 2.

F-49

F-50

Tests 3 and 4.

Figure 4.5.c Electrode temperatures and power (hourly averages) during DM100

Tests 5 and 6.

F-51

F-52

Tests 7 and 8.

Figure 4.6.a Melt pool resistance and total electrode power during DM100

Tests 1 and 2.

F-53

F-54

Tests 3 and 4.

F-55 
Figure 4.6.d Melt pool resistance and total electrode power during DM100

Tests 7 and $8 . \quad$ F-56

Figure 5.1 Picture of cold cap through north view port showing the thickness of the cold cap. $\quad$ F-57

$\begin{array}{lll}\text { Figure 5.2.a Production rates for DM1200 Test } 1 . & \text { F-58 }\end{array}$

$\begin{array}{lll}\text { Figure 5.2.b Production rates for DM1200 Tests } 2 \text { and } 3 . & \text { F-59 }\end{array}$

Figure 5.3.a Glass temperatures (hourly averages) for DM1200 Test $1 . \quad$ F-60

Figure 5.3.b Glass temperatures (hourly averages) for DM1200 Tests 2 and 3. F-61

Figure 5.4.a Plenum temperatures and electrode power (hourly averages) for DM1200 Test 1.

F-62

Figure 5.4.b Plenum temperatures and electrode power (hourly averages) for DM1200 Tests 2 and 3.

Figure 5.5.a Electrode temperatures and power (hourly averages) for DM1200 Test 1.

Figure 5.5.b Electrode temperatures and power (hourly averages) for DM1200 Tests 2 and 3.

Figure 5.6.a Electrode power and glass resistance for DM1200 Test 1.

Figure 5.6.b Electrode power and glass resistance for DM1200 Tests 2 and 3.

Figure 5.7.a Glass density and level for DM1200 Test 1.

Figure 5.7.b Glass density and level for DM1200 Tests 2 and 3.

Figure 5.8.a Glass pool bubbling for DM1200 Test 1.

Figure 5.8.b Glass pool bubbling for DM1200 Tests 2 and 3.

Average gas temperatures along the DM1200 off-gas train during Test 1.

F-64

F-65

F-66

F-67

F-68

F-69

F-70

F-71

Figure 5.9.b Average gas temperatures along the DM1200 off-gas train during Test 2.

F-72

Figure 5.9.c Average gas temperatures along the DM1200 off-gas train during Test 3.

$\mathrm{F}-73$

$\begin{array}{ll}\text { Figure 5.10.a } & \begin{array}{l}\text { Melter pressure at instrument port and control air flow rate } \\ \text { during Test } 1 .\end{array}\end{array}$

Figure 5.10.b Melter pressure at instrument port and control air flow rate during Tests 2 and $3 . \quad$ F-76

Figure 5.11.a Differential pressure across the transition line and film cooler $\begin{array}{ll}\text { during DM1200 Test } 1 . & \text { F-77 }\end{array}$

Figure 5.11.b Differential pressure across the transition line and film cooler during DM1200 Tests 2 and $3 . \quad$ F-78

$\begin{array}{lll}\text { Figure 5.12.a } & \text { SBS inlet and outlet gas temperatures during Test } 1 . & \text { F-79 }\end{array}$

Figure 5.12.b SBS inlet and outlet gas temperatures during Tests 2 and $3 . \quad$ F-80

Figure 5.13.a SBS inlet, outlet, and differential pressures (hourly average values) during Test 1 . F-81

Figure 5.13.b SBS inlet, outlet, and differential pressures (hourly average values) during Tests 2 and $3 . \quad$ F-82

Figure 5.14.a SBS downcomer annulus pressure (hourly average values) during Test 1 .

Figure 5.14.b SBS downcomer annulus pressure (hourly average values) during Tests 2 and 3.

Figure 5.15.a Off-gas temperatures in the SBS downcomer and sump water temperatures (hourly average values) during Test 1.

Figure 5.15.b Off-gas temperatures in the SBS downcomer and sump water temperatures (hourly average values) during Tests 2 and 3. 
ORP-56292 Rev. 0

The Catholic University of America

Figure 5.16.a SBS cooling coil inlet, cooling coil outlet/jacket inlet and jacket outlet water temperatures (hourly average values) during Test 1.

Figure 5.16.b SBS cooling coil inlet, cooling coil outlet/jacket inlet and jacket outlet water temperatures (hourly average values) during Tests 2 and 3.

F-87

$\begin{array}{ll}\text { Figure 5.17.a } & \text { SBS cooling coil/jacket water flow rate (hourly average values) } \\ \text { during Test } 1 .\end{array}$

Figure 5.17.b SBS cooling coil/jacket water flow rate (hourly average values) during Tests 2 and 3.

F-88

Figure 5.18.a Calculated heat loads on the inner coil and jacket (hourly average values) during Test 1.

Figure 5.18.b Calculated heat loads on the inner coil and jacket (hourly average
values) during Tests 2 and 3.

Figure 5.19.a Accumulated SBS blowdown volume and accumulated feed water during Test 1.

Figure 5.19.b Accumulated SBS blowdown volume and accumulated feed water during Tests 2 and 3.

Figure 5.20.a WESP inlet and outlet gas temperatures during Test 1.

Figure 5.20.b WESP inlet and outlet gas temperatures during Tests 2 and 3.

Figure 5.21.a WESP differential pressure and outlet gas flow rate (hourly average values) during Test 1 .

Figure 5.21.b WESP differential pressure and outlet gas flow rate (hourly average values) during Tests 2 and 3 .

Figure 5.22.a Accumulated WESP blowdown volume, accumulated fresh spray water, and water removed from off-gas during Test 1.

F-89

F-90

F-91

F-92

F-93

F-94

F-95

F-96

F-97

F-98

Accumulated WESP blowdown volume, accumulated fresh spray

Figure 5.22.b water, and water removed from off-gas during Tests 2 and 3.

Figure 5.23.a Voltage and current across the WESP during Test 1.

Voltage and current across the WESP during Tests 2 and 3.

Figure 5.23.b

Outlet gas temperature and differential pressure for HEME \#1 during Test 1 .

F-100

F-101

Figure 5.24.a

Figure 5.24.b Outlet gas temperature and differential pressure for HEME \#1 during Tests 2 and 3.

F-102

F-103

F-104

Figure 5.25.a Outlet temperature and differential pressure for HEPA \#1 (hourly average values) during Test 1 .

F-105

Figure 5.25.b Outlet temperature and differential pressure for HEPA \#1 (hourly average values) during Tests 2 and 3 .

F-106

Figure 5.26.a Inlet gas temperature and differential pressure for PBS (hourly average values) during Test 1 .

F-107

Figure 5.26.b Inlet gas temperature and differential pressure for PBS (hourly average values) during Tests 2 and 3 .

F-108

Figure 5.27.a Sump temperature and $\mathrm{pH}$ for PBS (hourly average values) during Test 1.

Figure 5.27.b Sump Temperature and $\mathrm{pH}$ for PBS (hourly average values) during Tests 2 and 3.

Figure 6.1.a DM100 product and target glass compositions determined by XRF. DM100 product and target glass compositions determined by XRF. DM100 product and target glass compositions determined by XRF. 
Figure 6.2.b Figure 6.2.c Figure 6.3.a Figure 6.3.b

Figure 6.4 Figure 7.1

Figure 7.2

Figure 7.3

Figure 7.4

Figure 7.5

Figure 7.6

Figure 7.7

Figure 7.8
DM1200 product and target glass compositions determined by XRF. DM1200 product and target glass compositions determined by XRF. SEM image of cold cap sample from DM100 Test 8. SEM image of cold cap sample from DM100 Test 8. SEM image of cold cap sample from DM1200 Test 1. FTIR monitored NO and HF emissions during DM100 Tests 1 and 2. FTIR monitored NO and HF emissions during DM100 Tests 3 and 4. FTIR monitored NO and HF emissions during DM100 Tests 5 and 6. FTIR monitored NO and HF emissions during DM100 Tests 7 and 8. FTIR Monitored NO emissions during DM1200 Test 1. FTIR monitored HF emissions during DM1200 Test 1. FTIR monitored NO emissions during DM1200 Tests 2 and 3. FTIR monitored HF emissions during DM1200 Tests 2 and 3.
F-115

F-116

F-117

F-118

F-119

F-120

F-121

F-122

F-123

F-124

F-125

F-126

F-127 


\section{List of Abbreviations}

\begin{tabular}{|c|c|}
\hline AA & Atomic Absorption Spectroscopy \\
\hline ADS & Air Displacement Slurry \\
\hline ANL-LRM & Argonne National Laboratory - Low Activity Waste Reference Material \\
\hline AOD & Air Operated Diaphragm \\
\hline $\mathrm{CCC}$ & Canister Center Line Cooling \\
\hline DCP-AES & Direct Current Plasma Atomic Emission Spectroscopy \\
\hline DF & Decontamination Factor \\
\hline DFC & DM10 Feed Consumption (test) \\
\hline DM & DuraMelter ${ }^{\circledR}$ \\
\hline DOE & Department of Energy \\
\hline DRE & Destruction \& Removal Efficiency \\
\hline DWPF & Defense Waste Processing Facility \\
\hline EA & Environmental Assessment \\
\hline EPA & Environmental Protection Agency \\
\hline EDS & Energy Dispersive X-Ray Spectroscopy \\
\hline FTIR & Fourier Transform Infrared Spectroscopy \\
\hline $\mathrm{GC}$ & Gas Chromatography \\
\hline HEPA & High-Efficiency Particulate Air Filter \\
\hline HEME & High-Efficiency Mist Eliminator \\
\hline HLW & High Level Waste \\
\hline IHLW & Immobilized High Level Waste \\
\hline LAW & Low Activity Waste \\
\hline M & Molarity \\
\hline $\mathrm{N}$ & Normality \\
\hline NIST & National Institute of Standards and Technology \\
\hline ORP & Office of River Protection \\
\hline PBS & Packed Bed Scrubber \\
\hline PCT & Product Consistency Test \\
\hline QA & Quality Assurance \\
\hline QAPjP & Quality Assurance Project Plan for Testing Programs Generating Environmental Regulatory Data \\
\hline QAPP & Quality Assurance Project Plan \\
\hline RPP & River Protection Project \\
\hline SBS & Submerged Bed Scrubber \\
\hline SEM & Scanning Electron Microscopy \\
\hline SIPP & Semi Integrated Pilot Plant \\
\hline SOP & Standard Operating Procedure \\
\hline SRM & Standard Reference Material \\
\hline SRS & Savannah River Site \\
\hline TCLP & Toxicity Characteristic Leaching Procedure \\
\hline TCO & Thermal Catalytic Oxidation \\
\hline VGF & Vertical Gradient Furnace \\
\hline VSL & Vitreous State Laboratory \\
\hline W.C. & Water Column \\
\hline WESP & Wet Electrostatic Precipitator \\
\hline WTP & Hanford Tank Waste Treatment and Immobilization Plant \\
\hline WVDP & West Valley Demonstration Project \\
\hline XRD & X-ray Diffraction \\
\hline XRF & X-Ray Fluorescence Spectroscopy \\
\hline
\end{tabular}


The Catholic University of America Vitreous State Laboratory
Melt Rate Enhancement for High Aluminum HLW Glass Formulations

Final Report, VSL-08R1360-1, Rev. 0

\section{SECTION 1.0 INTRODUCTION}

This report describes the development and testing of new glass formulations for high aluminum waste streams that achieve high waste loadings while maintaining high processing rates. The testing was based on the compositions of Hanford High Level Waste (HLW) with limiting concentrations of aluminum specified by the Office of River Protection (ORP). The testing identified glass formulations that optimize waste loading and waste processing rate while meeting all processing and product quality requirements. The work included preparation and characterization of crucible melts and small scale melt rate screening tests. The results were used to select compositions for subsequent testing in a DuraMelter 100 (DM100) system. These tests were used to determine processing rates for the selected formulations as well as to examine the effects of increased glass processing temperature, and the form of aluminum in the waste simulant. Finally, one of the formulations was selected for large-scale confirmatory testing on the HLW Pilot Melter (DM1200), which is a one third scale prototype of the Hanford Tank Waste Treatment and Immobilization Plant (WTP) HLW melter and off-gas treatment system. This work builds on previous work performed at the Vitreous State Laboratory (VSL) for Department of Energy (DOE) to increase waste loading and processing rates for high-iron HLW waste streams [1] as well as previous tests conducted for ORP on the same high-aluminum waste composition used in the present work and other Hanford HLW compositions [2]. The scope of this study was outlined in a Test Plan [3] that was prepared in response to an ORP-supplied statement of work [4].

It is currently estimated that the number of HLW canisters to be produced in the WTP is about 13,500 (equivalent to 40,500 MT glass) [4]. This estimate is based upon the inventory of the tank wastes, the anticipated performance of the sludge treatment processes, and current understanding of the capability of the borosilicate glass waste form. The WTP HLW melter design, unlike earlier DOE melter designs, incorporates an active glass bubbler system. The bubblers create active glass pool convection and thereby improve heat transfer and glass melting rate. The WTP HLW melter has a glass surface area of $3.75 \mathrm{~m}^{2}$ and depth of $\sim 1.1 \mathrm{~m}$. The two melters in the HLW facility together are designed to produce up to $7.5 \mathrm{MT}$ of glass per day at $100 \%$ availability. Further increases in HLW waste processing rates can potentially be achieved by increasing the melter operating temperature above $1150^{\circ} \mathrm{C}$ and by increasing the waste loading in the glass product. Increasing the waste loading also has the added benefit of decreasing the number of canisters for storage.

The current estimates and glass formulation efforts have been conservative in terms of achievable waste loadings. These formulations have been specified to ensure that the glasses are homogenous, contain essentially no crystalline phases, are processable in joule-heated, ceramic-lined melters and meet WTP Contract terms. The WTP's overall mission will require the immobilization of tank waste compositions that are dominated by mixtures of aluminum (Al), chromium $(\mathrm{Cr})$, bismuth $(\mathrm{Bi})$, iron $(\mathrm{Fe})$, phosphorous $(\mathrm{P})$, zirconium $(\mathrm{Zr})$, and sulfur $(\mathrm{S})$ compounds as waste-limiting components. Glass compositions for these waste mixtures have been developed based upon previous experience and current glass property models. Recently, 
DOE has initiated a testing program to develop and characterize HLW glasses with higher waste loadings [4, 5]. Results of this work have demonstrated the feasibility of increases in wasteloading from about $25 \mathrm{wt} \%$ to $33-50 \mathrm{wt} \%$ (based on oxide loading) in the glass depending on the waste stream. It is expected that these higher waste loading glasses will reduce the HLW canister production requirement by about $25 \%$ or more [2].

DOE HLW treatment programs have featured joule heated ceramic melter technology for the vitrification of high level tank waste. The melter technology used at the West Valley Demonstration Project (WVDP) in New York and at the Defense Waste Processing Facility (DWPF) at the Savannah River Site (SRS) process(ed) HLW in ceramic melters at an operating temperature of $1150^{\circ} \mathrm{C}$. Historically, HLW melters are operated at temperatures of $1150^{\circ} \mathrm{C}$ to allow for sufficient temperature control for normal as well as upset conditions in an operating melter, while still protecting the electrodes from potential damage due to unanticipated high temperature swings. Since the HLW melters deployed in the United States at West Valley and DWPF do not actively mix the glass pool, temperature variations within the glass pool can be relatively large $\left(\sim \pm 75^{\circ} \mathrm{C}\right)$ with respect to the nominal operating temperature since natural convection within the glass pool is limited in the viscous molten glass. In advancing the technology, EnergySolutions/VSL have demonstrated on very large scale melters (EnergySolutions M-Area facility, RPP-WTP HLW Pilot Melter, and the RPP-WTP LAW Pilot Melter) that active mixing of the glass pool using our patented bubbler technology significantly reduces the temperature gradient within the glass pool and allows the melter to be controlled in a tighter operating band. As a result, the operating temperature of the melter can be modestly increased to about $1175^{\circ} \mathrm{C}$ with the current materials of construction, (and up to $1225^{\circ} \mathrm{C}$ with changes of electrode and bubbler materials) while maintaining the operating integrity of the melter at the higher temperature. Tests conducted with various HLW waste streams on the DM100 and DM1200 melters have demonstrated increases in glass production rates from 0 to 225 percent while increasing the processing temperature from $1150^{\circ} \mathrm{C}$ to $1175^{\circ} \mathrm{C}[2,6]$. Further increases in operating temperature to higher temperatures $\left(1200^{\circ} \mathrm{C}\right)$ have the potential to further increase processing rate as well as increased waste loading, both of which translate into significant cost savings.

Under a separate contract to support the WTP, the VSL is developing and testing glass formulations for WTP HLW waste compositions to provide data to meet the WTP contract requirements and to support system design activities [7-13]. That work is based upon small-scale batch melts ("crucible melts") using waste simulants. Selected formulations have also been tested in small-scale, continuously fed, joule-heated melters (DM100) [14-17] and, ultimately, in the HLW DM1200 Pilot Melter [6, 16-23]. More recently, a series of tests were conducted on the DM100 to determine the effect of systematic variations in various glass properties (viscosity and conductivity) and oxide concentrations on glass production rates with HLW feed streams [24, 25]. Such melter tests provide information on key process factors such as feed processing behavior, dynamic effects during processing, secondary phase formation, processing rates, off-gas amounts and compositions, foaming control, etc., that cannot be reliably obtained from crucible melts. This sequential scale-up approach in the vitrification testing program ensures that maximum benefit is obtained from the more costly larger-scale melter tests and that the most effective use is made of those test resources. 
The glass formulation and melter testing work described in this report led to the identification of glass compositions that achieve high processing rates while maintaining high waste loadings of a high-aluminum HLW stream; that HLW composition was one of the four waste streams previously specified by ORP [5]. The previous tests with these waste streams demonstrated substantial increases in waste loading; however, production rates with the aluminum limited waste stream and with a waste stream limited by aluminum in combination with sodium were only a third to a half of the rates obtained for chromium, and iron limited wastes. The goal of the current work was, therefore, to retain high waste loadings and acceptable glass properties for the aluminum limited waste while increasing the glass production rate through the manipulation of the glass formulations and glass forming additives. An extensive literature review was performed during the first phase of this work, the results of which were included in the final report [2]. In the present work, the literature was further reviewed with particular emphasis on factors affecting melt rates. Although directly relevant literature on increasing the processing rates of high aluminum waste vitrification feeds is very limited, the more general literature on melt rates and feed to glass conversion processes (see for example [26 - 43]) provided a useful starting point for the present work.

The results from this test program will provide ORP with a basis for projection of the amount of Immobilized High Level Waste (IHLW) to be produced at Hanford and the potential waste processing rate, and evaluation of the likely potential for future enhancements of the WTP over and above the present well-developed baseline. It should be noted that the compositions of the four ORP-specified waste streams differ significantly from those of the feed tanks (AZ-101, AZ-102, C-16/AY-102, and C-104/AY-101) that have been the focus of the extensive technology development and design work performed for the WTP baseline. In this regard, the work detailed in this report is complementary to and necessarily of a more exploratory nature than the work in support of the current WTP baseline. It should be noted, therefore, that considerable further work would be required to bring the level of confidence in the new glass composition regions to a similar level of maturity to that of the current WTP baseline. Additional testing at the crucible and melter scales will be needed to determine the robustness of the new compositions with respect to variations in the feed compositions that may results from process variations as well as for the collection of data to support engineering and permitting requirements using a WTP prototypic off-gas system. In addition, since the high waste loading glass compositions are in a new composition space as compared to the current WTP compositions, additional effort will be required to develop and extend the current qualified glass composition region and supporting models to include these new compositions.

\section{$1.1 \quad$ Test Objectives}

The principal objective of the work reported here was to develop and identify HLW glass compositions that maximize waste processing rates for the aluminum limted waste composition specified by ORP while maintaining high waste loadings and acceptable glass properties. This was accomplished through a combination of crucible-scale tests, confirmation tests on the DM100 melter system, and demonstration at pilot scale (DM1200). The DM100-BL unit was selected for these tests since it was used previously with the HLW waste streams evaluated in this study [2], was used for tests on HLW glass compositions [14-17] to support subsequent tests 
on the HLW Pilot Melter [6, 16-23], conduct tests to determine the effect of various glass properties (viscosity and conductivity) and oxide concentrations on glass production rates with HLW feed streams [24, 25], and to assess the volatility of cesium and technetium during the vitrification of an HLW AZ-102 composition [44]. The same melter was selected for the present tests in order to maintain comparisons between the previously collected data. These tests provide information on melter processing characteristics and off-gas data, including formation of secondary phases and partitioning. Once DM100 tests were completed, one of the compositions was selected for further testing on the DM1200; the DM1200 system has been used for processing a variety of simulated Hanford waste streams [6, 16-23]. Tests on the larger melter provide processing data at one third of the scale of the actual WTP HLW melter and, therefore, provide a more accurate and reliable assessment of production rates and potential processing issues.

The work focused on maximizing waste processing rates for high aluminum HLW compositions. In view of the diversity of forms of aluminum in the Hanford tanks, tests were also conducted on the DM100 to determine the effect of changes in the form of aluminum on feed properties and production rate. In addition, the work evaluated the effect on production rate of modest increases in melter operating temperature.

Glass composition development was based on one of the HLW waste compositions specified by ORP that has a high concentration of aluminum. Small-scale tests were used to provide an initial screening of various glass formulations with respect to melt rates; more definitive screening was provided by the subsequent DM100 tests. Glass properties evaluated included: viscosity, electrical conductivity, crystallinity, gross glass phase separation and the 7day Product Consistency Test (ASTM-1285). Glass property limits were based upon the reference properties for the WTP HLW melter. However, the WTP crystallinity limit $(<1$ vol\% at $950^{\circ} \mathrm{C}$ ) was relaxed slightly as a waste loading constraint for the crucible melts.

\subsection{Quality Assurance}

This work was conducted under a quality assurance program that is based on NQA-1 (1989) and NQA-2a (1990) Part 2.7 that is in place at the VSL. Recently, the quality assurance program was updated to be compliant with applicable criteria of 10 CFR 830.120; Office of Civilian Waste Management DOE/RW-0333P, Quality Assurance Requirements and Description (QARD) Revision 18; the American Society of Mechanical Engineers (ASME) NQA-1, 2000; and DOE Order 414.1 C, Quality Assurance. This program is supplemented by a Quality Assurance Project Plan for RPP-WTP work [45] that is conducted at VSL. Test and procedure requirements by which the testing activities are planned and controlled are also defined in this plan. The program is supported by VSL standard operating procedures that were used for this work [46]. In addition, the requirements of DOE/RW-0333P were applicable to the following specific aspects of this work:

- Crucible melt preparation

- Analysis of crucible melt glasses

- PCT 


\subsection{DM100 Melter System}

\subsubsection{DM100 Feed System}

A schematic diagram of the DM100 vitrification system is shown in Figure 1.1. The melter feed is introduced in batches into a feed container that is mounted on a load cell for weight monitoring. The feed is stirred with a variable speed mixer and constantly recirculated except for periodic, momentary interruptions during which the weight is recorded. Feed is normally introduced into the melter via a system designed to mimic the operation of an Air Displacement Slurry (ADS) pump, which is the present WTP baseline; however, a peristaltic pump was used in these tests in order to provide a uniform delivery of feed to the melt surface. In this system, a recirculation loop extends to the top of the melter where feed is diverted from the recirculation loop to the peristaltic pump and subsequently into the melter through a Teflon-lined feed line and water-cooled, vertical feed tube.

\subsubsection{Melter System}

Cross-sectional diagrams of the DM100-BL melter are shown in Figures 1.2.a-c. The DM100-BL unit is a ceramic refractory-lined melter fitted with five electrodes: two pairs of opposing Inconel 690 plate electrodes and a bottom electrode. Power can be supplied in either three-phase or single-phase configurations. All of the tests in the present work were performed with the upper and lower electrodes on each side connected together and powered by a single-phase supply; the bottom electrode was not powered. Melt pool agitation is achieved by either a removable lance entering from the top of the melter or a permanent bubbler installed through the bottom electrode. In these tests the lance bubbler was used. The glass product is removed from the melter by means of an airlift discharge system. The melter has a melt surface area of $0.108 \mathrm{~m}^{2}$ and a variable glass inventory of between $110 \mathrm{~kg}$, when only the bottom pair of electrodes is used, and about $170 \mathrm{~kg}$ when both pairs of electrodes are used, which was the case in the present tests.

\subsubsection{Off-Gas System}

For operational simplicity, the DM100-BL is equipped with a dry off-gas treatment system involving gas filtration operations only. Exhaust gases leave the melter plenum through a film cooler device that minimizes the formation of solid deposits. The film-cooler air has constant flow rate and its temperature is thermostatically controlled. Consequently, under steady-state operating conditions, the exhaust gases passing through the transition line (between the melter and the first filtration device) can be sampled at constant temperature and airflow rate. The geometry of the transition line conforms to the requirements of the 40-CFR-60 air sampling techniques. Immediately downstream of the transition line are cyclonic filters followed by conventional pre-filters and HEPA filters. The temperature of the cyclonic filters is maintained above $150^{\circ} \mathrm{C}$ while the temperatures in the HEPAs are kept sufficiently high to prevent moisture condensation. The entire train of gas filtration operations is duplicated and each train is used alternately. An induced draft fan completes the system. 


\subsection{DM1200}

\subsubsection{Feed System}

The feed material for these tests was prepared and controlled according to VSL specifications by a chemical supplier, as detailed in Section 2. Each batch of feed slurry was shipped to VSL in lined 55-gallon drums, which were staged for unloading into the mix tank. Both the mix tank and the feed tank are 750-gallon polyethylene tanks with conical bottoms that are fitted with mechanical agitators; the feed tank is also fitted with baffles to improve mixing. Any required feed additive can be added to the mix tank. Five calibrated load cells directly mounted on the legs of the feed tank are used to measure additions to, and removal from, the feed tank and are electronically monitored to determine the feed rate to the melter. The requisite amount of feed is pumped to the feed tank from the mix tank; measured amounts of water are combined by weight with the feed at this point to adjust the concentration of the melter feed. The material in the feed tank is constantly recirculated from the feed tank discharge outlet, at the tank bottom, to the tank inlet at the top, which provides additional mixing.

The feed is introduced into the melter using an ADS pump, which is the present WTP baseline. The feed transfer line extends from the outlet of the ADS pump in the feed tank to the top of the melter. Feed is introduced into the melter through an un-cooled feed nozzle that is located above the center of the glass pool. Only one feed tube is used to represent the planned number of feed tubes per unit melt surface area in the full-scale WTP HLW melter. The operation of the ADS pump is controlled from the melter computer control system. The ADS pump works by opening the pump reservoir to the feed tank using a double-acting air cylinder and mechanical link to actuate the poppet. The reservoir is filled with slurry by gravity. After sufficient time is allowed to fill the reservoir (a few seconds), the poppet is toggled to close the reservoir to the tank and open the transfer line. After a desired delay time (dependent on the desired feed rate) the reservoir is pressurized with air to transfer the slurry (about 1.6 liter/shot) to the melter. This cycle is repeated at the rate required to provide the desired feed rate.

When necessary, a backup system is used to introduce feed into the melter with an air operated diaphragm (AOD) pump system that simulates the pulsed feeding action of an ADS pump. The recirculation loop extends to the top of the melter where feed is diverted from the recirculation loop into the melter through a Teflon-lined feed line and water-cooled feed tube. Two computer-operated pinch valves, one on the feed line and one on the recirculation loop, are activated in a timed sequence to introduce feed into the melter at the desired rate. The feed rate is regulated by adjusting the length of each pulse, the time between each pulse, and the pressure applied to the recirculation loop.

\subsubsection{Melter System}

The DuraMelter 1200 (DM1200), which is the HLW Pilot Melter, was used for these tests. Cross-sectional diagrams of the melter illustrating the discharge chamber and electrode configuration are provided in Figures 1.3 and 1.4. The DM1200 is a Joule-heated melter with Inconel 690 electrodes and thus has an upper operating temperature of about $1200^{\circ} \mathrm{C}$. The melter 
shell is water-cooled and incorporates a jack-bolt thermal expansion system. The footprint of the melter is approximately $8 \mathrm{ft}$. by $6.5 \mathrm{ft}$. with a $4 \mathrm{ft}$. by $2.3 \mathrm{ft}$. air-lift discharge chamber appended to one end; the melter shell is almost $8 \mathrm{ft}$. tall. The melt surface area and the melt pool height are approximately 32 percent and 57 percent, respectively, of the corresponding values for the fullscale HLW melter. The discharge riser and trough are full-scale to verify pouring performance. Other aspects of the discharge system are also prototypical such as the chamber ventilation scheme. The glass contact refractory is Monofrax ${ }^{\circledR}$ K-3 while the plenum area walls are constructed of Monofrax ${ }^{\circledR} \mathrm{H}$ refractory. The surface of the glass pool is 34" by 54" with a nominal glass depth of 25". The resultant melt volume is approximately 45,000 cubic inches (735 liters), which represents a glass tank capacity of more than 1.7 metric tons of glass. However, since the typical operating glass level is closer to 29 inches, the effective glass volume during testing is actually about 849 liters, giving an inventory of about 2.0 metric tons. The DuraMelter $^{\mathrm{TM}} 1200$ is fitted with one pair of electrodes placed high on opposite walls of the melter as well as one bottom electrode. The side electrodes are 11" by 34" giving an electrode area for the pair of about $750 \mathrm{sq}$. in. Depending on the glass level, the plenum space extends about 33" to 36" above the melt surface resulting in a plenum volume ranging from about 43 to $46 \mathrm{ft}^{3}$.

The single-phase power supply to the melter electrodes ( $250 \mathrm{~kW}$ design power) is derived from the DuraMelter 1000 transformers by wiring them in parallel and using a single large silicon controlled rectifier. Current can be passed either from the side electrodes to the bottom electrode or between the two side electrodes only, by rearranging jumpers; only side-to-side operation was used for the present tests. Programmable process controllers are installed and can be used to control temperature or power. The melt temperature is controlled by configuring the process controller to maintain constant power and adjusting the power set-point as needed to maintain the desired operating temperature. Alarms can be set to detect out-of-range temperatures or power in the melter. Backup process controllers are installed to be used in case of failure of the main controllers. The entire system is supported by a back-up generator that is tripped on in the event of a power outage.

The DuraMelter 1200 has several other features. The lid refractory is prototypic and also includes a two-piece construction, which simulates the seam needed for the LAW lid that was planned to be fabricated in three pieces. Nozzles are provided for the off-gas film cooler, a standby off-gas port, discharge airlift, along with 11 ports available for top-entering bubblers, start-up heaters and other components as needed. In addition, a bubbler arrangement is installed in the bottom electrode with the objective of developing permanent bubblers for possible use on future melters. For the present tests the optimum bubbler configuration established during previous tests with HLW simulants [6] consisting of two double-outlet, top-entering bubblers was used, located in positions to mimic conditions in the WTP HLW melter. Figure 1.5 shows a schematic of the prototypical double-outlet bubbler design that was based on the combination of the results from these DM1200 tests [6] and room-temperature tests that were performed in a transparent fluid simulating the properties of the glass melt [47]. These bubblers have outlets 8 inches apart and were placed on the melter floor. The orientation of the bubblers in the melter, as shown in Figure 1.6, results in one of the bubbling outlets being 11.3 inches from the feed tube. 


\subsubsection{Off-Gas System}

The melter and entire off-gas treatment system are maintained under negative pressure by two Paxton external induced draft blowers. This negative pressure is necessary to direct the gases from the melter to the prototypical off-gas system. The off-gas treatment system, shown schematically in Figure 1.7, consists of a submerged bed scrubber (SBS); a wet electrostatic precipitator (WESP); a high-efficiency mist eliminator (HEME), a high-efficiency particulate air (HEPA) filter; a thermal catalytic oxidation unit (TCO); a $\mathrm{NO}_{\mathrm{x}}$ removal system (SCR); a caustic packed-bed scrubber (PBS); and a second HEME. Note that the PBS and the second HEME are not part of the WTP off-gas train, which effectively ends at the SCR. The HEME is used to limit entrained particle carryover into the balance of the VSL ventilation system. The system can be functionally divided into four subsystems:

Particulate Removal: $\quad$ Components from the SBS to the HEPA serve to remove essentially all of the particulate from the gas stream with an estimated removal efficiency of greater than $99.9999 \%$ for particles greater than $0.3 \mu \mathrm{m}$ in size. In the WTP facility, this provision serves to segregate the radioactive from the nonradioactive components in the system for maintenance and handling purposes.

VOC Control/Acid Gas: $\quad$ The TCO unit is designed to oxidize any hazardous organics that are present in the off-gas stream. This is followed by a SCR to remove $\mathrm{NO}_{\mathrm{x}}$ gases and a PBS to remove remaining acid gases.

Stack System:

The emergency/bypass exhaust system, which includes a second HEPA, and the primary off-gas system both feed into the building stack system for exhausting to the atmosphere.

Liquid Processing: Components including the water spray lines, liquid sampling and water storage tanks, as well as the effluent evaporator, function to sample and process the system liquids for recycle or discharge.

With minor exceptions, the DM1200 off-gas system processing sequence follows the design for the full-scale WTP HLW melter system, except for cooling of the off-gas stream discharged from the SCR unit (which is present in the WTP off-gas train, but absent in the DM1200 system). Per WTP direction, the SBS unit that was used for previous DM1200 testing was modified in early 2004. Installation of the new system was completed in March 2004 and that unit was used for the present tests. The changes were implemented to reflect modifications to the WTP SBS design that have taken place since the original DM1200 unit was installed. These modifications included changes to the diffuser plate design, down-comer jacket and connection to the diffuser plate, bed diameter, bed packing materials, cooling coils, and liquid overflow level.

Initial quenching of the melter exhaust gas stream is effected by the film cooler. Immediately upstream of the film cooler is the injection point for control air, which is used to 
regulate melter pressure. The gas entering the balance of the off-gas system is at a temperature of about 250 to $350^{\circ} \mathrm{C}$ and a flow rate of about $100-250 \mathrm{scfm}$, of which about $10-80 \mathrm{scfm}$ is water vapor. The off-gas is then rapidly quenched by direct liquid water contact in the SBS, which also effects removal of most of the larger particulates. The piping between the film cooler and SBS has a high superficial gas velocity to minimize particulate deposition. The gas stream leaving the SBS is at a low temperature (typically between $40-50^{\circ} \mathrm{C}$ ). Further mist and particulate removal is effected in the WESP, HEME and HEPA. The TCO and SCR follow the particle removal components and serve to destroy organic compounds and nitrogen oxides. These two units were off-line during the present tests due to the low concentrations of these components in the exhaust stream. Finally, the PBS provides acid gas removal. Water sprays are located in the WESP, PBS, and facility HEME to wash down deposits and dissolved species into their respective collection sumps from which they can be sampled. The system components are fabricated from corrosion resistant materials, including AL6XN and 316L stainless steel, and various plastics in less demanding locations. There are extensive provisions for sampling both the gas and liquid streams throughout the system in order to collect mass balance information and removal efficiency data for each treatment stage.

The off-gas system maintains the melter plenum under slight negative pressure, typically about -5 in. W.C. The plenum pressure is controlled by means of an air injection system that introduces a controlled air flow into the off-gas jumper just after the film cooler. The air is supplied by a blower through a diverter valve. The setting of the diverter valve, and therefore the air flow rate, is controlled by a process controller that responds to the signal from a melter pressure transducer. When the plenum pressure becomes more positive, the air injection flow rate is decreased, which tends to restore the pressure to the set-point. Conversely, the flow rate is increased when the plenum pressure becomes more negative.

\subsection{Feed Sample Analysis}

Feed samples were taken directly from the feed recirculation line during each test. Feed samples were poured into a platinum/gold crucible that was placed into a programmed furnace for drying and fusion to form a glass. The glass produced from this fusion was ground to less than 200 mesh and sealed in 20-ml vials for subsequent analysis by X-ray fluorescence spectroscopy (XRF), or by acid digestion followed by direct current plasma - atomic emission spectroscopy (DCP-AES) on the resulting solution. The feed samples were also characterized for their rheological properties, density, $\mathrm{pH}$, water content, and glass yield.

\subsection{Glass Product Analysis}

The glass product was discharged from the melter into either 5-gallon steel pails (DM100) or 55-gallon drums (DM1200) periodically using an air-lift system. The discharged product glass was sampled at the end of each test by removing sufficient glass from the top of the cans for compositional analysis and secondary phase determinations. In addition, the Product Consistency Test (PCT) and Toxicity Characteristic Leaching Procedure (TCLP) were performed on samples of the glass product from the DM100 melter tests. Prior to those tests, the PCT and 
TCLP were also performed on the crucible melt compositions that were selected for the melter tests to ensure their compliance with the present WTP contract requirements. All of these procedures are routinely conducted at VSL and, therefore, standard operating procedures (SOPs) are in place.

Sample preparation for chemical analysis typically involves size reduction and sieving. All samples were subjected to XRF to determine the concentration of all elements except boron and lithium. A series of National Institute of Standards and Technology (NIST) reference materials were used for confirmation of the XRF data. Boron and lithium were determined by total acid dissolution of ground glass samples in $\mathrm{HF} / \mathrm{HNO}_{3}$ and subjecting the resulting solutions to DCP-AES analysis.

\subsubsection{Viscosity}

The melt viscosity, $\eta$, was measured using a Brookfield viscometer. Measurements are performed in the temperature range of $950-1250^{\circ} \mathrm{C}$ and the data are interpolated to standard temperatures using the Vogel-Fulcher equation: $\ln \eta=\left[\mathrm{A} /\left(\mathrm{T}-\mathrm{T}_{\mathrm{o}}\right)\right]+\mathrm{B}$, where $\mathrm{A}, \mathrm{B}$, and $\mathrm{T}_{\mathrm{o}}$ are fitting parameters. The equipment is calibrated at room temperature using standard oils of known viscosity and then checked at $950-1250^{\circ} \mathrm{C}$ using a NIST standard reference glass (SRM 711). Both precision and accuracy of the viscosity measurements are estimated to be within \pm 15 relative $\%$.

\subsubsection{Electrical Conductivity}

The electrical conductivity, $\sigma$, of each glass melt was determined by measuring the resistance of the glass melt as a function of frequency using a calibrated platinum/rhodium electrode probe attached to a Hewlett-Packard model 4194A impedance analyzer. Measurements are performed over similar temperature ranges to those employed for the melt viscosity measurements. The results are analyzed and modeled to obtain the DC electrical conductivity. The electrical conductivity data are then interpolated to standard temperatures using the Vogel-Fulcher equation: $\ln \sigma=\left[\mathrm{A} /\left(\mathrm{T}-\mathrm{T}_{\mathrm{o}}\right)\right]+\mathrm{B}$, where $\mathrm{A}, \mathrm{B}$ and $\mathrm{T}_{\mathrm{o}}$ are fitting parameters. Estimated uncertainties in the electrical conductivity measurements are \pm 20 relative $\%$.

\subsubsection{Product Consistency Test (PCT)}

The product consistency test (PCT; ASTM C 1285) is used to evaluate the relative chemical durability of glasses by measuring the concentrations of the chemical species released from 100-200 mesh crushed glass $(75-149 \mu \mathrm{m})$ to the test solution (de-ionized water in this case). PCT tests on the HLW glasses are performed at $90^{\circ} \mathrm{C}$, in accordance with the current WTP contract requirement. The ratio of the glass surface area to the solution volume for this test is about $2000 \mathrm{~m}^{-1}$ (typically, $10 \mathrm{~g}$ of 100-200 mesh glass is immersed in $100 \mathrm{ml}$ deionized water). All tests are conducted in triplicate, in 304L stainless steel vessels, and in parallel with a standard glass included in each test set. The internal standard is the Argonne National Laboratory - Low 
Activity Waste Reference Material (ANL-LRM) reference glass [48] and/or the Defense Waste Processing Facility (DWPF)-Environmental Assessment (EA) glass, both of which have undergone round-robin testing. The leachates are sampled at predetermined times, the first of which is seven days. One milliliter of sampled leachate is mixed with $20 \mathrm{ml}$ of $1 \mathrm{M} \mathrm{HNO}_{3}$ and the resulting solution is analyzed by DCP-AES; another $3 \mathrm{ml}$ of sampled leachate is used for $\mathrm{pH}$ measurement.

\subsubsection{Toxicity Characteristic Leaching Procedure (TCLP)}

The TCLP was performed at VSL using SW-846 Method 1311, which employs leaching of crushed glass $\left(<3 / 8^{\prime \prime}\right)$ in a sodium acetate buffer solution for 18 hours at $22^{\circ} \mathrm{C}$ with constant end-over-end agitation. A mass of about 100 grams of glass is leached in 2 liters of TCLP extract, according to the extraction method for non-volatiles. The surface area to volume ratio for this test is about $20 \mathrm{~m}^{-1}$, which is about two orders of magnitude lower than that in the PCT. The leachates are analyzed by DCP-AES according to VSL standard operating procedures.

\subsubsection{Secondary Phases}

Secondary phases in the glass samples were determined by optical microscopy and scanning electron microscopy coupled with energy dispersive x-ray spectroscopy (SEM-EDS). Secondary phases due to crystallization and phase separation can be identified using these methods. Quantitative determination of the amount of crystals in glass samples were made by $\mathrm{SEM}$ in conjunction with image analysis. 


\section{SECTION 2.0 WASTE SIMULANT AND BASE GLASS COMPOSITION}

\subsection{Waste Simulants}

The waste stream compositions previously provided by DOE are given in Table 2.1 on an oxide basis [5]. The work described in this report focused exclusively on the aluminum limited waste stream in response to the comparatively low glass production rates achieved with this waste stream in the earlier tests [2]. Actual Hanford HLW tank wastes are aqueous solutions with suspended solids and dissolved salts including hydroxides, nitrates, nitrites, halides, and carbonates. For the purpose of the previous [2] and present work, the concentrations of the volatile components (i.e., carbonate, nitrite, nitrate, and organic carbon) are assumed to be similar to those found for the AZ-102 HLW waste [21]. With the waste composition defined, formulation of the HLW waste simulant proceeds in a straightforward fashion. In general, oxides and hydroxides are used as the starting materials, with slurry of iron (III) hydroxide (13\% by weight) as one of the major constituents. Volatile inorganic components are added as the sodium salts, whereas organic carbon is added as oxalic acid. Finally, water content was adjusted to target a glass yield of $500 \mathrm{~g}$ of glass per liter of feed. Two waste simulants were employed, with the only difference being the replacement of aluminum oxide by aluminum hydroxide in order to investigate the effects of variations in the form of aluminum in the Hanford HLW streams on feed properties and processing rates. The compositions of the waste simulants with aluminum oxide and aluminum hydroxide, formulated to produce $100 \mathrm{~kg}$ of waste oxides, are given in Tables 2.2 and 2.3 , respectively.

\subsection{Base Glass Formulation}

Several glass compositions spanning a range of waste loading were previously evaluated for suitability for the high aluminum simulated waste [2]. Based on those results, a glass with $45 \mathrm{wt} \%$ waste loading, HLW-E-Al-27, which employed moderate additions of alkali and alkaline earth oxides $\left(\mathrm{Na}_{2} \mathrm{O}, \mathrm{Li}_{2} \mathrm{O}\right.$, and $\left.\mathrm{CaO}\right), \mathrm{B}_{2} \mathrm{O}_{3}$, and $\mathrm{SiO}_{2}$, was selected as providing the best combination of high waste loading and glass and melt properties [2]. Table 2.4 presents the composition of this glass and the measured properties of the crucible glass, which meet all of the processing and product quality requirements. The glass contains $23.97 \mathrm{wt} \% \mathrm{Al}_{2} \mathrm{O}_{3}$, which is more than two times the WTP contract minimum for $\mathrm{Al}_{2} \mathrm{O}_{3}(11 \mathrm{wt} \%)$. All of the measured processing parameters are within acceptable ranges. The PCT leach rates are over an order of magnitude lower than those of the DWPF-EA glass and the TCLP leachate concentrations are all below the WTP delisting limits. Sodium aluminosilicate formation (e.g., nepheline) on heat treatment (especially canister centerline cooling (CCC) heat treatment) is a known concern with high-aluminum formulations and was the waste-loading-limiting factor in the formulation of HLW-E-Al-27. The selected glass produced very little crystallization ( $\sim 1.9$ vol\%) after CCC heat treatment and the PCT response of the heat treated glass also meets the PCT requirements by wide margins. 
Based on the results from the previous work [2], the HLW-E-Al-27 glass formulation was used as the starting point for the present work. Although the HLW-E-Al-27 glass formulation achieved high waste loadings, the results of DM100 melter tests showed that the glass production rates were lower than desired [2]. Therefore, the HLW-E-Al-27 glass formulation was used as the starting point for the glass formulation work in the present study with the objective of achieving increased glass production rates while maintaining the high waste loading. That work is described in Section 3. In addition, this glass formulation was used in DM100 melter tests to assess the effects of variations in the form of aluminum in the waste simulant by replacing aluminum oxide, which was used in the previous work [2], by aluminum hydroxide. The melter feed formulation for that case is presented in Table 2.5. The results of that and other DM100 melter tests are presented in Section 4. 
The Catholic University of America Vitreous State Laboratory
Melt Rate Enhancement for High Aluminum HLW Glass Formulations

Final Report, VSL-08R1360-1, Rev. 0

\section{SECTION 3.0 GLASS FORMULATION}

\subsection{Introduction}

The principal objective of the glass formulation and small scale melt rate testing work was identifying glass compositions that maximize processing rates for the Al-limited HLW waste stream specified by ORP. The previous tests [2] with the Al-limited waste steam demonstrated substantial increases in waste loading; however, the DM100 production rates were significantly lower than the rates obtained for typical iron limited wastes and, at the nominal bubbling rate and temperature, were also below the WTP target rate of $800 \mathrm{~kg} / \mathrm{m}^{2} / \mathrm{d}$ (corresponding to 3 MT of HLW glass per day per HLW melter). The goal of the current work was therefore to retain high waste loadings and acceptable glass properties for the aluminum limited waste while increasing the glass production rate through the manipulation of the glass formulations and glass forming additives.

In view of the above objectives, melt rate determination was a critical parameter in the glass formulation effort. Melt rates are affected by many factors and are the net result of a combination of many complex processes that occur in the feed-to-glass conversion process. The cold cap that forms when liquid slurry feed is introduced onto the melt surface is highly stratified in both temperature (from $\sim 100^{\circ} \mathrm{C}$ on the top to $\sim 1150^{\circ} \mathrm{C}$ at the bottom) and composition. In this region, water and other volatiles are evaporated, salts are decomposed and melted, various transient phases are formed and consumed, and finally, new glass is formed. In addition, these reactions are governed by the substantial flows of heat and mass through this region. In view of this complexity, continuous melter tests provide the most reliable means of capturing these phenomena and, therefore, for reliably determining melt rates; furthermore, such tests become increasingly more reliable as the melter scale and test duration are increased. However, because of the cost and schedule implications, such tests are not well suited for integration into a glass formulation development program in which a large number of formulation variations need to be assessed. For this reason, in the present work we have employed two types of melt rate screening tests that permitted rapid evaluation of relative melt rates. The results from these tests were used to refine the glass formulations and down-select a subset of glasses for DM100 melter testing. The results of the DM100 tests were then used to select one formulation for pilot scale testing on the DM1200 melter system.

The two melt rate screening tests used in this work were designed to capture many of the essential features of the feed-to-glass conversion process, albeit in a necessarily simplified fashion. In the Vertical Gradient Furnace (VGF) tests, dried feed is placed on top of pre-melted glass in a crucible and subjected to a vertical temperature gradient for predetermine times (see Section 3.2.2). The crucible is then quenched, sectioned, and examined to determine the nature and extent of the feed conversion process. In the DM10 Feed Consumption (DFC) tests, an aliquot $(\sim 1 \mathrm{~kg})$ of slurry feed is introduced onto the surface of the DM10 melter and the time to consume the feed is determined by a combination of visual observation and the change in 
plenum temperature (see Section 3.4). Both tests are well suited to quickly and efficiently screening relatively large numbers of composition variations. The tests successfully identified formulations with significantly improved melting rates and the results were subsequently confirmed in continuous melter tests at the DM100 and DM1200 pilot melter scale.

This section presents descriptions of the glass formulation approach, the test methods employed, and the results and conclusions from the melt rate screening tests and glass formulation development work.

\subsection{Experimental Methods}

The results from the earlier work on the aluminum limited waste [2], and specifically the glass formulation selected in that work (HLW-E-Al-27), provided the starting point for the present glass formulation effort. An iterative approach was employed in which composition modifications were designed that were intended to improve melt rates, crucible melts of those formulations were prepared, and characterization data were collected. The results were then analyzed and used to design additional formulations for testing. To improve efficiency, glass characterization was conducted in stages such that glasses that failed any processabilty or product quality requirement were not subjected to further testing. All glasses were tested for phase behavior, both as-melted and after heat treatment, since that was expected to be one of the most limiting constraints. Acceptable glasses were then subjected to testing with respect to PCT, melt viscosity, melt electrical conductivity, and TCLP. Glasses that met these requirements were then subjected to melt rate screening tests. In parallel, a series of DFC melt rate screening tests were performed on base glass formulations in which simple one or two component variations were made in order to collect information on component effects on melt rate (see Section 3.4). These results were also factored into the glass formulation design effort. The experimental methods that were employed in this program are described in the following sections.

\subsubsection{Crucible Melts}

Crucible melts of each glass were fabricated at VSL using reagent grade chemicals, mostly oxides and carbonates. Glass preparation began with a batching sheet that provided information on the required starting materials. The information included the chemicals needed, identification of the chemicals according to the vendors and catalog numbers, the associated purity, together with the amount required to produce a given amount of glass. Chemicals were weighed and batched according to the batching sheets. After the starting materials were weighed and batched, a blender was used to mix and homogenize the starting materials before they were loaded into platinum/gold crucibles that were engraved with individual identification numbers. The loaded platinum/gold crucible was placed inside a Deltech DT-28 (or DT-29) furnace, the heating of which was controlled by a Eurotherm 2404 temperature controller. The melting temperature was $1200^{\circ} \mathrm{C}$, at which the melt was kept for 2 hours. Mixing of the melt was accomplished mechanically using a platinum stirrer, beginning 20 minutes after the furnace 
temperature reached $1200^{\circ} \mathrm{C}$ and continuing for the next 90 minutes. The molten glass was poured at the end of 120 minutes onto a graphite plate to cool before recovery.

All of the as-melted glasses were inspected for signs of phase separation and completeness of melting; secondary phases were analyzed by SEM-EDS and optical microscopy, as described in Section 1.6.5. The composition was checked XRF and DCP analysis, as described in Section 1.6.

Selected glasses were subjected to heat treatment for 70 hours at $950^{\circ} \mathrm{C}$ and below $(900$, 850 and $800^{\circ} \mathrm{C}$ ). Glass samples (about 5 grams each) were heat-treated in platinum, platinumgold, or platinum-rhodium crucibles $(5 \mathrm{ml})$ at a pre-melt temperature of $1200^{\circ} \mathrm{C}$ for 1 hour, followed by heat treatment at the prescribed temperatures. At the end of the heat-treatment period, the glass samples were quenched by contacting the crucible with cold water. This quenching freezes in the phase assemblage in equilibrium with the melt at the heat-treatment temperature. The types and amounts (vol\%) of crystalline phases were determined by SEM-EDS.

Selected glasses were subjected to canister centerline cooling (CCC) heat treatment according to the WTP HLW CCC temperature profile [13]. As in the case of isothermal heattreatment, the glass samples in platinum crucibles were maintained at a pre-melt temperature of $1200^{\circ} \mathrm{C}$ for 1 hour before initiation of the CCC treatment. The samples recovered after CCC heat treatment were subjected to SEM-EDS examination.

Selected glasses were also characterized with respect to their melt viscosity and electrical conductivity, and PCT and TCLP leach testing, as described in Sections 1.6.1 - 1.6.4, respectively. The PCT was performed on both quenched samples and glass samples that had been subjected to CCC heat treatment.

Tables $3.1-3.3$ provide the identifications, compositions and properties of the glass formulations and crucible melts that were tested in this work.

\subsubsection{Vertical Gradient Furnace}

As described above, the cold cap in a continuously fed melter is subject to a large temperature gradient in the vertical direction. This gradient can drive heat and mass flows and leads to variations of reaction rates at different heights in the cold cap; the gradient is therefore a potentially significant factor in determining the melt rate. The design of the Vertical Gradient Furnace (VGF) melt rate screening test emphasizes the large temperature gradient in the vertical direction across the cold cap.

Figure 3.1 is a schematic diagram the VGF setup. The temperature gradient inside the VGF is maintained by two separate sets of heating elements, both of which are arranged in cylindrical form and aligned along their axis. The inner heater is set at $1150^{\circ} \mathrm{C}$, which is the nominal temperature of the glass pool, and the ambient heater is set at $600^{\circ} \mathrm{C}$, which is similar to the melter plenum temperature. A ceramic crucible ( 4 inches tall) is used to contain the reacting melter feed. The temperature gradient in the loaded furnace is shown in Figure 3.2. For a typical 
feed conversion test, a sample of dried melter feed equivalent to 20 grams of glass is introduced into the ceramic crucible, which already contained about 10 grams of pre-melted glass of the same composition that had been preheated in the inner heater. Feed reactions under the controlled temperature gradient are allowed to continue for the designated test duration and then stopped by rapid cooling in room temperature air. The top surface, and the cross section (by sectioning the crucible) of the reacted feed are then inspected and photographed. Samples of the partially reacted feed are taken for further characterization by SEM-EDS, X-ray diffraction (XRD), and XRF. The composition of the feed was confirmed by XRF analysis of samples that were fused at $1150^{\circ} \mathrm{C}$.

All of the melter feed samples were prepared using the same HLW simulant and preparation methods that were used for the melter tests, as described in Section 2. The only difference was that samples used for VGF tests were dried, crushed, and sieved, before use.

The VGF results were used to evaluate the melt rate on a relative scale using the degree of the melting that had occurred, the structure of the feed materials that were undergoing reaction and transformation, and the conversion progression with time. A numerical ranking of relative melt rate was assigned based on calibration tests using feeds whose melt rates had been determined previously in DM100 melter tests.

\subsection{Results and Discussion}

The identifications, compositions and properties of the glasses designed and tested in the present work are listed in Tables $3.1-3.3$. The feeds that were subjected to VGF testing are listed in Tables 3.1 and 3.4. These include the feeds corresponding to new glass formulations, several feeds from previous work that were used for calibration, and several feeds that are based on the earlier HLW-E-Al-27 formulation [2]. The results of the glass formulation, characterization, and melt rate tests are presented together below in groups according to the changes made in key glass formers with respect to the earlier HLW-E-Al-27 glass [2].

\subsubsection{VGF Calibration Tests}

As part of the system calibration and method development work, six melter feeds of known glass production rate (as determined in DM100 tests at $1150^{\circ} \mathrm{C}$ with nominal bubbling) were tested in the VGF. The DM100 glass production rates, glass compositions, and the feed recipes were reported previously [2, 24, and 25]. The same feed samples as those tested in the DM100 melter were used for the VGF tests. Two of the feeds were based on iron-limited glasses $[24,25]$ and the remaining four were based on $\mathrm{Cr}-$, Bi-, Al-, or $\mathrm{Al}+\mathrm{Na}$-limited HLW streams [2].

Figure 3.3 shows the top views and the cross sections of the six feed samples after VGF tests. It is apparent that the six melter feeds exhibit a wide range of feed conversion progress, from virtually completely melted (HLW-E-CrM) to development of a complete cold cap "dome" that has lost contact with the underlying glass and shows little sign of reaction on the surface 
The Catholic University of America Vitreous State Laboratory
Melt Rate Enhancement for High Aluminum HLW Glass Formulations

Final Report, VSL-08R1360-1, Rev. 0

(HLW-E-Al-27). Feed of HLW-E-Bi-6 shows greater melting progress than HLW-E_Al-27, but exhibits a partial dome structure. Similar to HLW-E-CrM, the two iron-limited feeds (Matrix 1$\mathrm{B} 1$ and Matrix 2-9) and the $\mathrm{Al} / \mathrm{Na}$-limited feed (HLW-E-ANa-22) display only traces of the once-present dome, with remnants of rims folded on the side wall and undergoing melting. On a relative scale, using the slowest (HLW-E-Al-27) at one end and the fastest (HLW-E-CrM) at the other end, the degree of conversion of the dried melter feed materials after 30 minute VGF experiments can be divided into several intermediate stages based on the top views and cross sections. Table 3.5 lists the key observations for each stage and their assigned ranking on a relative scale. It should be emphasized that these assignments are simply rankings; a melt rate ranking of 2 should not be interpreted to mean two times faster than a melt rate ranking of 4 .

The results for the six feed samples in terms of their ranking values are plotted against the glass production rates of the same melter feeds as by determined in DM100 tests in Figure 3.4. A more or less linear trend is defined by the two extreme feed samples and three intermediate samples. It is not clear why the result for HLW-E-ANa-22 feed falls off this trend. However, the DM100 rate of $400 \mathrm{~kg} / \mathrm{m}^{2} / \mathrm{d}$ is unusually low and, in fact, is the lowest rate ever measured under these test conditions. Furthermore, the increase in the DM100 rate result when the temperature was increased from $1150^{\circ} \mathrm{C}$ to $1175^{\circ} \mathrm{C}$ was unusually large $(125 \%$ vs. the more typical $25 \%)$ [2]; based on the measured rate at $1175^{\circ} \mathrm{C}$ and the more typical change with temperature, a rate of about $720 \mathrm{~kg} / \mathrm{m}^{2} / \mathrm{d}$ at $1150^{\circ} \mathrm{C}$ would have been expected, which would be much more consistent with the VGF trend. It is possible that other atypical effects were involved in the unusually low rates in the $1150^{\circ} \mathrm{C}$ DM100 test. Further tests would be useful to clarify this issue. Nevertheless, the general trend proved to be adequate to render the VGF test a useful screening tool for the development of glass and feed formulations with improved melt rates. This is particularly so when the VGF is used in combination with the DFC screening test results, as was the case in the present work.

\subsubsection{Component Effects on the HLW-E-Al-27 Formulation}

The high waste loading glass (HLW-E-Al-27) developed for the aluminum limited waste in the earlier work [2] was used as the starting point for the melt rate improvement work. During DM100 tests [2] the phenomenon of "shelving" or "bridging" in the cold cap region was observed. The slurry feed had a tendency to develop a shelf-like structure of hardened feed materials that could attach to the side walls of the DM100 melter. Without intervention, the shelf could extend and form a bridge above the glass line. The separation between the melter feed and the hot glass melt can cause the melt rate to decrease. It is interesting to note that a similar phenomenon was also observed in the partially reacted melter feed of HLW-E-Al-27 in VGF tests. As shown in Figure 3.5, a closed dome-like structure developed after 30 minutes in the VGF. The partially molten inner lining of the dome apparently provides a sufficient seal to allow the gas from the feed materials closer to hot glass surface to cause the cold cap to balloon upwards and loose contact with the underlying glass melt. As the dome expands, the temperature drops because of the vertical temperature gradient and the dome hardens. Feed materials on the top of the dome are relatively insulated from the hot glass surface by the dome and intervening gas. As shown in the top view, the granular feed materials do not exhibit much sign of 
reaction/transformation after 30 minutes in the VGF. Eventually, sufficient heat is delivered to melt away part of the dome and a vent emerged after 45 minutes in the VGF. As the reaction/melting continues, the dome structure softens and collapses to the side wall of the ceramic crucible. The similarity of the evolution of the dome-like structure observed in a series of VGF experiments and the cold cap behavior in the DM100 tests suggests that the VGF tests indeed capture some of the key features of the melt rate determining processes.

The chemicals used in Al-limited HLW simulant in the previous melter test are listed in Table 3.6. The typical glass former additives are lithium and sodium carbonates, borax or boric acid, and simple oxides such $\mathrm{SiO}_{2}$ and $\mathrm{ZnO}$. The development of a dome-like structure in VGF tests suggests a need for more lower-melting or more reactive components in the HLW-E-Al-27 glass/feed formulation. The original feed formulation used aluminum oxide and borax [2]. The selection of aluminum oxide was based a conservative (in terms of melt rate) interpretation of the form of aluminum in the waste; more likely forms are the hydroxide (gibbsite), oxy-hydroxide (boehmite), and various silicates. Therefore tests were performed with the feed of HLW-E-Al-27 reformulated using aluminum hydroxide and/or boric acid (sodium carbonate was used to compensate the sodium difference). Three slurry feeds of the same target glass composition HLW-E-Al-27 were prepared with different combinations of $\mathrm{Al}(\mathrm{OH})_{3}$ and borax, $\mathrm{Al}_{2} \mathrm{O}_{3}$ and boric acid, and $\mathrm{Al}(\mathrm{OH})_{3}$ and boric acid (Table 3.1). The feed materials were tested in the VGF under the same experimental conditions for 45 minutes (Figure 3.6). The results suggest that both substitution (aluminum hydroxide for aluminum oxide or boric acid for borax) improve the melt rate. The best result was obtained for the feed that includes both aluminum hydroxide and boric acid. The VGF feed conversion results strongly suggest that boric acid should be used instead of borax as the primary boron source.

In summary, boric acid appears to be preferred as the primary boron source. Also, in view of the variability and uncertainty with respect to the form of aluminum in the waste, it is reasonable to include both aluminum oxide and aluminum hydroxide versions in the melt rate evaluation to provide reasonable bounds. In the subsequent VGF tests, all of the melter feeds for the new glass formulations were prepared using boric acid and $\mathrm{Al}_{2} \mathrm{O}_{3}$. The two formulations that were later selected for DM100 melter tests were also tested using the corresponding $\mathrm{Al}(\mathrm{OH})_{3}$ versions.

\subsubsection{Group 1 Glass and Feed Formulations}

The glass formulation and feed test results are presented in groups according to changes made in key glass formers with respect to the baseline glass HLW-E-Al-27.

After reviewing the chemistry of HLW-E-Al-27, $5 \mathrm{wt} \% \mathrm{CaO}$ added as a glass former was suspected as a likely a contributor to the overall slow melt rate observed in the DM100 melter tests. The calcium addition was found to be effective in suppressing spinel formation, which allowed higher waste loadings to be achieved. Therefore, many of the new glass formulations in this work investigated the phase behavior of high-Al glasses at different levels of $\mathrm{CaO}$ (zero is not possible because the Al-limited waste contains small amounts of $\mathrm{CaO}$ ) and their melt rate as 
determined by VGF. In the first variation, HWI-Al-1 has the same $45 \mathrm{wt} \%$ waste loading as the baseline glass but with the $\mathrm{CaO}$ additive replaced by $\mathrm{B}_{2} \mathrm{O}_{3}$ and $\mathrm{Li}_{2} \mathrm{O}$; this glass contained minor amounts of crystalline phase (spinel) in the quenched glass (Tables 3.2 and 3.3). More spinel crystallized after heat treatment at temperatures from 950 to $800^{\circ} \mathrm{C}$ (Table 3.3). Although the substitution of $\mathrm{B}_{2} \mathrm{O}_{3}$ and $\mathrm{Li}_{2} \mathrm{O}$ for $\mathrm{CaO}$ increased crystallization near the glass melting temperature, it improved the melt rate, as shown in Figure 3.7 and Table 3.3.

At a reduced waste loading of $40 \mathrm{wt} \%$, glass HWI-Al-9 was homogeneous as-melted and developed little crystallization after heat treatment at temperatures from 950 to $800^{\circ} \mathrm{C}$ and under CCC conditions (Tables 3.2 and 3.3). In this case, the reduced waste loading coupled with higher sodium contributed to the suppression of spinel crystallization. The results from VGF testing indicate similar melt rates for feeds of HWI-Al-9 and HWI-Al-1. HWI-Al-10 was formulated in a manner similar to HWI-Al-9 but with minor adjustments in $\mathrm{B}_{2} \mathrm{O}_{3}$ and $\mathrm{Li}_{2} \mathrm{O}$ concentrations. Since very similar heat treatment result were obtained (Tables 3.2 and 3.3), no further tests were performed on this glass.

The results for the three glasses investigated in this group highlight one of the challenges involved in modification of the baseline glass formulation. Although the melt rate for HWI-Al-9 by VGF is considerably faster than for the baseline feed, the reduction in waste loading needed to suppress crystallization is undesirable. In the four groups of formulations presented below, other glass forming additives are investigated for their roles in achieving the overall goal of improving the melt rate while suppressing crystallization of spinels, without reducing the waste loading.

\subsubsection{Group 2 Glass and Feed Formulations}

Two glasses, HWI-Al-2 and HWI-Al-3, were formulated with an additional one percent of $\mathrm{P}_{2} \mathrm{O}_{5}$ and at similar levels of $\mathrm{Na}_{2} \mathrm{O}$ and $\mathrm{B}_{2} \mathrm{O}_{3}$ to HWI-Al-9. Both glasses showed signs of phase separation in the quenched samples (Tables 3.2 and 3.3) and therefore no further testing was performed.

\subsubsection{Group 3 Glass and Feed Formulations}

In this group, $\mathrm{CaO}$ as an additive in HLW-E-Al-27 was partially or completely replaced by $\mathrm{MgO}$ to produce glasses HWI-Al-5 and HWI-Al-7, respectively (Tables 3.2 and 3.3). Spinel crystallization near the glass melting temperature that was observed in many low $\mathrm{CaO}$ glasses in this work was not present in either of the $\mathrm{MgO}$-added glasses (Table 3.3). However, more crystalline phases developed after heat treatment at temperatures from 950 to $800^{\circ} \mathrm{C}$ and under CCC conditions (Table 3.3). Similar to the baseline feed, the melt rates of the both formulations in VGF tests were rather slow (Figure 3.8 and Table 3.3). Although a well developed dome structure was not present, the $\mathrm{MgO}$-added feeds appeared to soften but were resistive to further melting. In view of the increased crystallization and limited indication of improved melting, substitution of $\mathrm{MgO}$ for $\mathrm{CaO}$ was not further pursued. 
ORP-56292 Rev. 0

The Catholic University of America

\subsubsection{Group 4 Glass and Feed Formulations}

The effect of $\mathrm{K}_{2} \mathrm{O}$ was investigated in this group. One of the motivations for introducing $\mathrm{K}_{2} \mathrm{O}$ into the glass formulations is to suppress the formation of iron-chromium spinel near the glass melting temperature, which was employed in previous work with high-iron HLW [1]. In addition, the results from DFC melt rate screening tests (Section 3.4) suggested some improvement in melt rates with additions of $\mathrm{K}_{2} \mathrm{O}$.

Three glasses, HWI-Al-4, HWI-Al-6 and HWI-Al-8, were formulated with different levels of $\mathrm{K}_{2} \mathrm{O}(4,6$, and $8 \mathrm{wt} \%$ respectively; Table 3.2) largely in place of $\mathrm{CaO}$. However, all three glasses showed clear signs of secondary phases in the quenched samples (Table 3.3). Additional $\mathrm{Li}_{2} \mathrm{O}$ and $\mathrm{B}_{2} \mathrm{O}_{3}$ in HWI-Al-20 failed to suppress the formation of secondary phases, although the VGF melt rate was significantly improved compared to the baseline formulation (Tables 3.2 and Table 3.3; Figure 3.9).

At a similar level of $\mathrm{CaO}$ as in the baseline glass but with additional $\mathrm{K}_{2} \mathrm{O}$ in place of $\mathrm{Na}_{2} \mathrm{O}$ (HWI-Al-13, HWI-Al-14) or $\mathrm{B}_{2} \mathrm{O}_{3}$ (HWI-Al-15), crystallization of spinel in the quenched glasses was reduced considerably for HWI-Al-13 and HWI-Al-14 and little changed for HWI-Al-15 (Tables 3.2 and 3.3). HWI-Al-13 displayed increased crystallization of spinel and apatite after heat treatment at temperatures from 950 to $800^{\circ} \mathrm{C}$ (Table 3.3). Reducing the waste loading in HWI-Al-17 (to $43.6 \mathrm{wt} \%$ ) did not significantly reduce spinel crystallization (Tables 3.2 and 3.3). VGF tests on HWI-Al-13 and HWI-Al-17 showed only minor improvement from the baseline feed and presence of extensive foam layer (Figure 3.9).

In summary, addition of $\mathrm{K}_{2} \mathrm{O}$ was not effective in suppressing spinel crystallization in formulations without $\mathrm{CaO}$ as an additive and did not improve melt rates at higher $\mathrm{CaO}$ concentrations.

\subsubsection{Group 5 Glass and Feed Formulations}

From the results of the above tests, it is apparent that a certain level of $\mathrm{CaO}$ as glass forming additive is needed in order to suppress spinel crystallization near the glass melting temperature if high waste loadings are to be maintained. Five glasses in Group 5 were formulated to investigate the effect of increased boron content in glasses at two levels of $\mathrm{CaO}$. The beneficial effects of higher boron content on melt rate is suggested by both VGF and DFC (see Section 3.4) melt rate screening test results.

Two glasses, HWI-Al-11 and HWI-Al-12, were formulated with increased $\mathrm{B}_{2} \mathrm{O}_{3}$ at moderate amounts of $\mathrm{CaO}$ ( 2 and $3 \mathrm{wt} \%$, respectively; Table 3.2). Phase separation was observed in the quenched glass samples (Table 3.3) and therefore no further characterization was performed.

Two glasses, HWI-Al-16 and HWI-Al-19, were formulated at similar CaO concentrations as in the baseline HLW-E-Al-27 glass (Table 3.2). HWI-Al-16 results from a renormalized 
The Catholic University of America Vitreous State Laboratory
Melt Rate Enhancement for High Aluminum HLW Glass Formulations

Final Report, VSL-08R1360-1, Rev. 0

mixture of the baseline glass and $3 \mathrm{wt} \% \mathrm{~B}_{2} \mathrm{O}_{3}$ at a reduced waste loading of $43.6 \mathrm{wt} \%$. HWI-Al-19 results from replacement of $3.5 \mathrm{wt} \% \mathrm{SiO}_{2}$ and $0.5 \mathrm{wt} \% \mathrm{CaO}$ by $4 \mathrm{wt} \% \mathrm{~B}_{2} \mathrm{O}_{3}$ at the same waste loading as the baseline glass (45 wt\%; Tables 3.2 and 3.3). Both HWI-Al-16 and HWI-Al-19 showed little evidence of phase separation in the quenched samples. The glass samples after heat treatment at temperatures of 950 to $800^{\circ} \mathrm{C}$ and under CCC conditions showed limited crystallization, mostly of spinel with minor amounts of apatite (Table 3.3). The VGF melt rates were considerably faster than most of the formulations investigated in this work (Table 3.3, Figure 3.10). HWI-Al-18 was formulated with an additional $3 \mathrm{wt} \% \mathrm{~B}_{2} \mathrm{O}_{3}$ based on HWI-Al16 , but at a further reduced waste loading of $42.4 \mathrm{wt} \%$ (Table 3.2). However, HWI-Al-18 displayed similar levels of crystallization and melt rate to those of HWI-Al-16 and HWI-Al-19 (Figure 3.10, Table 3.3).

The combination of higher boron while retaining modest additions of calcium was successful in improving the VGF melting rate while controlling spinel crystallization near the glass melting temperature. All three feeds formulated using $\mathrm{Al}_{2} \mathrm{O}_{3}$ as the aluminum source underwent transition/melting considerably faster than the baseline feed. These melt rate improvements were also supported by the results from DFC tests (Section 3.4). Since the HWI-Al-16 and HWI-Al-19 achieve only slightly lower and the same waste loadings as the baseline formulation, respectively, these were selected in consultation with ORP for DM100 melter testing. Characterization results for glasses HWI-Al-16 and HWI-Al-19 are summarized in Table 3.3. TCLP leachate concentrations are listed in Table 3.7.

\subsubsection{Effect of Aluminum Source on HWI-Al-16 and HWI-Al-19}

As discussed earlier, the choice of $\mathrm{Al}_{2} \mathrm{O}_{3}$ as the source of aluminum for the HLW-E-Al27 melter tests [2] represents a conservative scenario with respect to feed processing rate. The actual forms of aluminum in the waste are likely to be much less refractory. Therefore the feeds of target glasses HWI-Al-16 and HWI-Al-19 were reformulated using $\mathrm{Al}(\mathrm{OH})_{3}$ and subjected to VGF tests. The top and cross section views of the partially reacted feed samples after 30 minute VGF tests are shown in Figure 3.11 in comparison to their $\mathrm{Al}_{2} \mathrm{O}_{3}$ counterparts. Overall, the results indicate that the $\mathrm{Al}(\mathrm{OH})_{3}$ feeds tend to react and convert somewhat faster in VGF tests. The VGF rankings of the melt rates are listed in Table 3.8. Feed samples after 30 minute VGF tests were examined by SEM-EDS and XRD. Figure 3.12 shows SEM images of the crystalline phases observed on the surface of the partially reacted feed samples. Table 3.9 lists the major phases identified from analysis of the crystalline phases by SEM and XRD.

\subsubsection{Confirmation of VGF Melt Rate Predictions}

Based on the glass formulation work and melt rate screening using the VGF and DFC tests DM100 tests were performed on HWI-Al-16 $\left(\mathrm{Al}_{2} \mathrm{O}_{3}\right.$ and $\left.\mathrm{Al}(\mathrm{OH})_{3}\right)$ and HWI-Al-19 $\left(\mathrm{Al}(\mathrm{OH})_{3}\right)$; in addition the HLW-E-Al-27 formulation was tested with $\mathrm{Al}(\mathrm{OH})_{3}$ to further assess the effect of aluminum source. The tests are discussed in Section 4. The results from those DM100 tests are used here to evaluate the relative melt rate predictions made based on the VGF 
test results. The four additional data points were added to the original calibration plot shown in Figure 3.4 to produce Figure 3.13. As is evident from the plot, the new data are consistent with the expectations based on the original trend line, with the same single outlier. The results suggest that the VGF test provides a valuable screening tool in glass and feed formulation, which should improve as more data become available.

\subsection{DM10 Feed Consumption (DFC) Melt Rate Tests}

In view of the complexity of the feed-to-glass conversion process, a combination of small-scale tests was used to screen feed and glass composition variations with respect to projected melt rates in order to down-select the preferred compositions for subsequent melter testing. In addition to the VGF tests described above, a second test utilizes the DM10 melter to determine the relative rate at which feed is consumed into the glass melt. This test is referred to as the DM10 Feed Consumption (DFC) test. This procedure permits the evaluation of many feed compositions and additive blends in a relatively short amount of time. Data from these tests was used both to provide guidance and confirmation of the glass formulation process.

\subsubsection{DM10 Melter}

The DM10 unit is a ceramic refractory-lined melter fitted with two Inconel 690 plate electrodes that are used for joule-heating of the glass pool and a bubbler for stirring the melt. The glass product is removed from the melter by means of an air-lift discharge system. The DM10 unit has a melt surface area of $0.021 \mathrm{~m}^{2}$ and a glass inventory of about $8 \mathrm{~kg}$. In these tests, feed is introduced rapidly as a single charge using a peristaltic pump. For operational simplicity, the DM10 is equipped with a dry off-gas treatment system involving gas filtration operation only. Exhaust gases leave the melter plenum through a film cooler device that minimizes the formation of solid deposits. The film-cooler input air has constant flow rate and its temperature is thermostatically controlled. Consequently, under steady-state operating conditions, the exhaust gases passing through the transition line (between the melter and the first filtration device) can be sampled at constant temperature and air flow rate. The geometry of the transition line conforms to the requirements of the 40-CFR-60 air sampling techniques. Immediately downstream of the transition line are coarse particulate filters followed by conventional pre-filters and HEPA filters. The temperature of the filters is kept sufficiently high to prevent moisture condensation. An induced draft fan completes the system.

\subsubsection{Methodology for DFC Melt Rate Tests}

The DM10 is rapidly charged with a standardized amount of feed while maintaining standard operating conditions in the melter. The mass of feed used in these tests was $1 \mathrm{~kg}$. Once introduction of the feed charge is complete, bubbling is increased from near zero to $1.7 \mathrm{lpm}$. This rate corresponds to the $9 \mathrm{lpm}$ used for standardized melt rate testing on the DM100 (see Section 4). Visual observations of the cold cap and monitored plenum temperatures are used as indicators 
of the rate of feed consumption. An example of changes in plenum temperature over a series of DFC tests is provided in Figure 3.14. The abrupt drops in plenum temperature correspond to the additions of feed and the time required for the system to re-equilibrate is an indication of time required to consume each feed charge. The plenum temperature measurements are analyzed and compared to visual observations of the cold cap to generate a melt rate index. The melt rate index reported here is the time in minutes needed to fully consume $1 \mathrm{~kg}$ of feed in the DM10 melter at a bubbling rate of $1.7 \mathrm{lpm}$ and a nominal melt pool temperature of $1150^{\circ} \mathrm{C}$. The time needed to fully consume the feed is determined through observation of the cold-cap and analysis of the changes in the plenum temperature. Results from new feed formulations are compared to results obtained from feed samples with known DM100 processing rates to provide a projected melt rate. The relationship between production rates obtained from DM100 tests and melt rate index from this method is illustrated in Figure 3.15. As is evident from the figure, the technique is especially effective at distinguishing melt rate differences at the lower melter rates that are most important in the present work.

\subsubsection{Feed Compositions Evaluated in DFC Tests}

Six different base feed compositions were evaluated using the DFC method:

- HLW-E-Al-27 glass composition; $\mathrm{Al}_{2} \mathrm{O}_{3}$ as the aluminum source (see Table 2.2); 45 wt $\%$ oxide waste loading.

- HLW-E-Al-27 glass composition; $\mathrm{Al}(\mathrm{OH})_{3}$ as the aluminum source (see Table 2.3); $45 \mathrm{wt} \%$ oxide waste loading.

- HLW-E-Al-27 glass composition; $\mathrm{Al}_{2} \mathrm{O}_{3}$ as the aluminum source (see Table 2.2); boric acid + soda ash replacing borax; $45 \mathrm{wt} \%$ oxide waste loading.

- HLW-E-Al-27 glass composition; $\mathrm{Al}_{2} \mathrm{O}_{3}$ as the aluminum source (see Table 2.2); boric acid $+\mathrm{K}_{2} \mathrm{CO}_{3}$ replacing borax; $45 \mathrm{wt} \%$ oxide waste loading.

- HWI-Al-9 glass composition; $\mathrm{Al}_{2} \mathrm{O}_{3}$ as the aluminum source (see Table 2.2); $40 \mathrm{wt} \%$ oxide waste loading.

- HWI-Al-9KSM glass composition; $\mathrm{Al}_{2} \mathrm{O}_{3}$ as the aluminum source (see Table 2.2); $45 \mathrm{wt} \%$ oxide waste loading.

Glass compositions for each of these base feeds are provided in Table 3.10. These base feeds were tested as $1 \mathrm{~kg}$ batches for comparison to previously tested feeds and to each other. They were also processed at reduced masses with a variety of additives to bring the mass to $1 \mathrm{~kg}$ in order to evaluate the effect of these additives on melt rates. Additives evaluated on the base feeds were:

- Nitric acid and sugar

- Boric acid

- Borax

- Sodium carbonate

- Potassium carbonate 
- Calcium carbonate

- Lithium carbonate

- Silica

The combinations of base feeds and additives evaluated with the resulting glass compositions are provided in Table 3.11. It is important to note that, except for nitric acid and sugar, all of the additives result in slightly reduced waste loadings. The intent of these tests was to investigate which additives have the potential to improve melt rates and should therefore be given preference as additives in improved feed formulations. It is also worth noting that the glass compositions given in Tables 3.10 and 3.11 represent the feed compositions, not the glass pool composition. Therefore the DFC tests primarily evaluate reactions taking place in the cold cap and at the melt interface rather than effects extending throughout the melt pool.

\subsubsection{Results from DFC Tests}

The rate of feed consumption for the six base feeds is shown in Figure 3.16. Variations based on the original HLW-E-Al-27 feed formulation showed melt rate index variations from about 60 to 100; the base feed with both forms of aluminum gave indices of about 80 . Increasing the boron concentration in HWI-Al-9 and HWI-Al-9KSM reduced the melt rate index below the values for the original HLW-E-Al-27 composition, whereas simply changing the boron source increased it. The reason for the longer melt time when only the boron source was changed is unclear, particularly since HWI-Al-9 and HWI-Al-9KSM, which showed much faster melt rates, also used boric acid as the boron source. Also, previous DM100 tests evaluating the effect of boron (and sodium) source on production showed no effect on production rate [24]. However, these test results clearly indicate that feed formulations with higher boron concentrations have the potential for higher melt rates.

The effect of adding a variety of additives to four of the base feeds is illustrated in Figures $3.17-3.20$. In these tests, $50 \mathrm{~g}$ of each additive was combined with $950 \mathrm{~g}$ of the base feed to generate $1 \mathrm{~kg}$ of feed that was subsequently introduced into the melter. The results indicate that some of additives have the potential to reduce melting times, some show ambiguous results, and others appear to have no effect or increase melting times. The addition of nitric acid and sugar, silica, and calcium carbonate appear to have little or no benefit with respect to reducing melt times, particularly considering the decrease in waste loading when adding silica or calcium carbonate. Lithium and sodium carbonate dramatically increase melt times in some tests, have little effect in some, and significantly decrease melt time in others. This ambiguity may be attributable to foaming on the melt pool surface generated by carbonates, which complicated cold cap observations and isolates the plenum from the hot glass pool, which slows the temperature rise. Previous tests varying elemental concentrations with a single feed composition have shown that increasing concentrations of alkali metals increase production rates [25] supporting the notion that another mechanism other than the alkali increase is responsible for the slow melt times. Potassium carbonate in all four compositions and with both forms of boron for most compositions resulted in significant decreases in melt times; hence its selection for evaluation in the glass formulation work (Section 3.3.6). Both these observation are in keeping 
with previous tests that show production rate increases with increasing concentrations of alkali metals and boron [25].

Additional tests were conducted with three of the base formulations to determine if progressively increasing the concentration of borax, boric acid, and potassium carbonate provides continued melt rate improvements. The results of these tests are illustrated in Figures $3.21-3.23$. The addition of more boron in the form of borax or boric acid either maintains the initial reduction in feed consumption time from the nominal feed composition or continues to reduce the time with increasing proportion of the additives. Conversely, the feed consumption times increase with increasing proportions of potassium carbonate in the feed. The decreased effectiveness of potassium carbonate with increasing feed concentration may be due to foaming from the carbonate obscuring the results of the tests. However, potassium additions were not found to be effective in the VGF melt rate screening tests (Section 3.3.6).

The DFC tests results suggest that melt rate improvements are possible for high aluminum waste by appropriate feed and glass formulation changes. Based on the DFC test results, boric acid, borax, and potassium carbonate were identified as additives that have the greatest potential for increasing HLW feed processing rates whereas silica, calcium carbonate, and nitric acid plus sugar either have little effect or decrease melt rate.

\subsection{Summary and Formulations for Melter Testing}

An integrated approach has been developed to identify feed and glass formulations with improved melt rates. The approach employs two melt rate screening tests that have been developed (VGF and DFC) and confirmatory testing in continuous melters. The VGF and DFC tests methods are sufficiently rapid and cost effective to provide for effective integration into the overall glass formulation development, testing, and optimization program.

The test results identified several additives with the potential for improving melt rates but other factors, such as increased crystallization and reduced waste loadings, also need to be considered. The HWI-Al-16 and HWI-Al-19 formulations were identified as the preferred candidates for confirmatory DM100 melter testing. Both of these formulations emphasize increased boron concentrations to improve melt rates and compensating changes to maintain other glass properties in acceptable ranges. Of these two formulations, HWI-Al-19 has the additional advantage of higher waste loading; it achieves the same $45 \mathrm{wt} \%$ waste loading as the baseline glass formulation but is expected to exhibit a substantial improvement in glass production rate over the baseline formulation.

The composition and properties of the HWI-Al-16 and HWI-Al-19 formulations are listed in Tables 3.12 and 3.13. The melter feed compositions for the HWI-Al-16 formulation with $\mathrm{Al}(\mathrm{OH})_{3}$ or $\mathrm{Al}_{2} \mathrm{O}_{3}$ as the aluminum source are shown in Tables 3.14 and 3.15, respectively. The melter feed composition for the HWI-Al-19 formulation with $\mathrm{Al}(\mathrm{OH})_{3}$ as the aluminum source is shown in Table 3.16. 


\section{SECTION 4.0 DM100 MELTER OPERATIONS}

Melter tests were conducted on the DM100-BL between 2/4/08 and 6/27/08. These tests produced almost two metric tons of glass from over $3600 \mathrm{~kg}$ of feed. Prior to each change of feed composition, the glass inventory was reduced from about $170 \mathrm{~kg}$ to about $100 \mathrm{~kg}$ in order to decrease the feeding time required to change over the composition of the melt pool. The series of eight nominally 50-hour tests were divided as follows:

- HLW-E-Al-27 with aluminum hydroxide - $490 \mathrm{~kg}$ of glass produced

o $1200^{\circ} \mathrm{C}$ glass temperature, $9 \mathrm{lpm}$ bubbling, $500 \mathrm{~g}$ glass per liter feed.

o $1150^{\circ} \mathrm{C}$ glass temperature, 9 lpm bubbling, $500 \mathrm{~g}$ glass per liter feed.

- HWI-Al-16 with aluminum hydroxide $-506 \mathrm{~kg}$ of glass produced

o $1200^{\circ} \mathrm{C}$ glass temperature, $9 \mathrm{lpm}$ bubbling, $500 \mathrm{~g}$ glass per liter feed.

o $1150^{\circ} \mathrm{C}$ glass temperature, 9 lpm bubbling, $500 \mathrm{~g}$ glass per liter feed.

- HLW-Al-16 with aluminum oxide $-468 \mathrm{~kg}$ of glass produced

o $1200^{\circ} \mathrm{C}$ glass temperature, $9 \mathrm{lpm}$ bubbling, $500 \mathrm{~g}$ glass per liter feed.

o $1150^{\circ} \mathrm{C}$ glass temperature, 9 lpm bubbling, $500 \mathrm{~g}$ glass per liter feed.

- HLW-Al-19 with aluminum hydroxide $-484 \mathrm{~kg}$ of glass produced

o $1200^{\circ} \mathrm{C}$ glass temperature, $9 \mathrm{lpm}$ bubbling, $500 \mathrm{~g}$ glass per liter feed.

o $1150^{\circ} \mathrm{C}$ glass temperature, $9 \mathrm{lpm}$ bubbling, $500 \mathrm{~g}$ glass per liter feed.

Summaries of the tests are provided in Table 4.1. Attempts were made to replicate the melter configuration and operating conditions used for previous tests with HLW simulants [2, 14-17, 23-25, 44]. These conditions include a near-complete cold cap, which is between 80-95\% melt surface coverage for the DM100 since a 100\% cold cap tends to lead to "bridging" in smaller melters. The bubbling rate was fixed at $9 \mathrm{lpm}$ and the feed rate was adjusted to maintain a complete cold cap. This use of bubbling is in contrast to some previous tests where the production rate was fixed between 1000 and $1050 \mathrm{~kg} / \mathrm{m}^{2} /$ day and the bubbling rate was adjusted to maintain the complete cold cap [14-17, 44]. The approach used in the present tests, in which the bubbling rate is held constant, provides a more direct evaluation of the effects of waste aluminum form (hydroxide vs. oxide), glass temperature, and glass composition on production rate. The changes in glass composition that were tested were based on the results from the glass formulation development studies (see Section 3.0) and were intended to demonstrate faster waste processing rates in comparison to previous DM100 tests with the same high-aluminum waste.

Figures 4.1.a - 4.1.d illustrate the glass production rates as moving hourly averages throughout the tests. Steady-state production rates for current and previous tests $[2,14,15,23-$ $25,44]$ conducted at the same constant bubbling rate at similar feed solids content are tabulated in Table 4.2; Figure 4.2 displays the results for tests conducted at a melt pool temperature of 
$1150^{\circ} \mathrm{C}$. Taken together, the past and present test results show large differences in production rate with different waste/feed compositions and glass temperature. In previous tests [2], the effect of waste composition was greater than that of any other tested variable and this is further confirmed by the data from the current tests; in particular, the iron and chromium wastes were found to process at about twice the rate of aluminum limited wastes [2]. The higher processing rates are not only attributable to the differences in waste composition but also the lower waste loadings (24-28 vs. $45-47$ wt. \% oxide) used in many of the previous tests [14, 23]. Further, the current tests clearly demonstrate that feeds of the same composition but with the aluminum in the form of aluminum hydroxide instead of aluminum oxide process at faster rates. Comparison of tests conducted with both forms of aluminum using two different glass compositions (HLW-EAl-27 and HWI-Al-16) show an approximate thirty percent production rate increase when aluminum oxide is replaced by aluminum hydroxide.

Importantly, the test results also showed that significant rate enhancements were achieved as a result of manipulation of the glass forming additive blends and glass compositions:

- For both forms of aluminum, production rates increased by $\sim 30 \%$ by changing from the original HLW-E-Al-27 glass formulation to the new HWI-Al-16 glass formulation.

- A similar $\sim 30 \%$ rate increase was also observed with the new HWI-Al-19 glass formulation for the aluminum hydroxide based waste simulant (the only one tested with that glass formulation). This formulation has a higher waste loading than the HWI-Al-16 formulation.

- The highest production rates $\left(950\right.$ and $1500 \mathrm{~kg} / \mathrm{m}^{2} /$ day at 1150 and $1200^{\circ} \mathrm{C}$, respectively) were obtained for the HWI-Al-19 glass formulation, which also had the highest waste loading tested $(45 \mathrm{wt} \%)$.

These results corroborate the results from the glass formulation development studies, which indicated that higher melt rates could be achieved by manipulation of the blend of additives that are combined with waste. These rate enhancements are also consistent with previous DM100 tests, which showed a positive effect of increasing the boron concentration in the additives on the production rate [25].

As expected, glass production rates increased with increased glass pool temperature. Increases in response to the $50^{\circ} \mathrm{C}$ increase in melt pool temperature ranged from 47 to 86 percent in the current tests. The percentage melt rate increase per unit temperature increase of $\sim 1 \% /{ }^{\circ} \mathrm{C}$ is comparable to that obtained in previous work with WTP LAW feeds but, with the exception of the sodium and aluminum waste [2], somewhat larger than that obtained in previous DM100 tests with the Al-, Cr- and Bi-limited HLW simulants [2] (although it should be noted that a smaller temperature change $\left(25^{\circ} \mathrm{C}\right)$ was used in those tests).

Overall, there were no significant difficulties in processing these feed and glass compositions during these tests. Cold cap conditions were similar to the range of conditions observed in previous tests with HLW feeds [14-17, 23-25, 44], particularly those feeds high in aluminum [2]. The feeds had a tendency to adhere to melter walls to form "shelves" and "bridges," some of which required manual dislodging from the walls. The feed used in Tests 7 
and 8 formed a more fluid cold cap and formed softer deposits on the walls than the feeds used in the other tests. Interruptions during feeding totaled no more than about an hour for each test. These short interruptions were required in order to energize the top pair of electrodes, transfer feed to the feed tank, adjust the feed line in the peristaltic pump as a result of wear from the pump rollers, clear the feed tube, and, during Tests 1 and 6, to allow deposits in the plenum space to assimilate into the glass. There was no clear trend between feed composition (including aluminum source) and the need to clear the feed tube or dislodge deposits in the plenum. Spikes in feed rate often occurred immediately after feed transfers due to adjustments in tank mixer speeds and pump settings. During steady-state feeding periods, production rates typically varied by about ten percent from the mean rate. No foamy glass was observed in the glass discharge and no foam was observed on the melt pool surface or cold cap.

The results of various operational measurements that were made during these tests are given in Table 4.3. Glass temperatures are shown in Figures 4.3.a - 4.3.d, plenum temperatures in Figures 4.4.a - 4.4.d, electrode temperatures in Figures 4.5.a - 4.5.d, and glass resistance in Figures 4.6.a - 4.6.d; electrode power is included in the figures with electrode temperatures and glass resistance. The target bubbling rate of $9 \mathrm{lpm}$ was maintained throughout the tests. Bulk glass temperatures (measured at 5 and 10 inches from the bottom of the melt pool) were largely within $10^{\circ} \mathrm{C}$ of the target glass temperatures of $1200^{\circ} \mathrm{C}$ and $1150^{\circ} \mathrm{C}$ throughout the vast majority of the tests. The test-segment-average bulk glass temperatures were $1190-1203^{\circ} \mathrm{C}$ and 1135 $1157^{\circ} \mathrm{C}$ for tests targeting glass temperatures of $1200^{\circ} \mathrm{C}$ and $1150^{\circ} \mathrm{C}$, respectively. Glass temperatures closer to the top of the melt pool (measured at 16 and 27 inches from the bottom) are not reliable indicators of bulk glass temperatures as a result of their sensitivity to variations in the level of glass in the melter and gradients near the melt surface. As a result of the intentionally lower glass level, glass temperatures measured at these locations were even lower at the beginning of each test with a new feed composition, prior to the glass level in the melter being increased to above the upper pair of electrodes. Plenum temperatures typically ranged from 300 to $500^{\circ} \mathrm{C}$, which is lower than the 550 to $650^{\circ} \mathrm{C}$ target. The lower temperature ranges were the consequence of maintaining a more complete cold cap. Similar plenum temperatures were measured in previous tests with aluminum limited wastes that also featured similar cold cap conditions [2].

The lower pair of electrodes was hotter than the upper pair of electrodes at the beginning of each test with a new feed composition due to the lower starting glass level. Once the melter was filled with glass above the top electrodes, the two electrode pairs are 0 to $150^{\circ} \mathrm{C}$ colder than the glass pool, depending on the measured points in the glass pool and electrodes. The bottom electrode, which was not powered, was 350 to $400^{\circ} \mathrm{C}$ colder than the powered side electrodes. Power supplied to the electrodes averaged between 18 and $26 \mathrm{~kW}$ for tests conducted at melt pool temperatures of $1150^{\circ} \mathrm{C}$ and $1200^{\circ} \mathrm{C}$, respectively. The higher power requirement for the higher melt pool temperature also corresponds to higher production rates. The opposite trend is observed when power usage is normalized to glass production due to the amount of energy required to maintain the glass pool at the target melt temperature (i.e., the essentially constant idling power). The calculated glass pool resistance decreased dramatically as the melter was filled with glass, as would be expected. The melt pool resistance increased by about 0.015 to $0.02 \mathrm{ohms}$ as the glass pool temperature was decreased from $1200^{\circ} \mathrm{C}$ to $1150^{\circ} \mathrm{C}$. 
The gas temperature at the film cooler averaged between $275-287^{\circ} \mathrm{C}$ and depended on the plenum temperature, the amount of added film cooler air, and the temperature of the added film cooler air. Drops of less than seventeen degrees in gas temperature were observed across the (insulated) transition line; the high temperature is maintained in order to prevent condensation in the downstream filtration units.

Based on the results of the DM100 tests, the HWI-Al-19 glass formulation was selected for larger scale testing in the DM1200 HLW pilot melter. This formulation showed the highest productions rates, showed no processing issues in the DM100 test, meets all of the processing and product quality requirements, and has the highest waste loading. 


\section{SECTION 5.0 DM1200 OPERATIONS}

Three tests with the high aluminum HLW simulant and the HWI-Al-19 glass composition were conducted between $8 / 6 / 08$ and 8/16/08, producing almost 9 metric tons of glass. The total testing duration, including the time for water feeding and cold-cap burn-off, was 157 hours, during which over 24 metric tons of feed was processed. A summary of the test conditions and results is provided in Table 5.1. The tests were conducted to determine glass production rates for a high aluminum waste and optimized glass composition at two glass temperatures and bubbling rates. The HWI-Al-19 glass selected for the DM1200 tests had the highest processing rate of those evaluated on the DM100 (950 and $1500 \mathrm{~kg} / \mathrm{m}^{2} /$ day at 1150 and $1200^{\circ} \mathrm{C}$, respectively) at the highest waste loading (45\%). Each DM1200 test was nominally two days in duration, employed double-outlet prototypical bubblers, and processed feed with a solids content of $500 \mathrm{~g}$ glass per liter. The tests are summarized below in the order they were conducted:

- Test 1: Melt pool bubbling rate and glass temperature were optimized to yield the maximum production rate.

- $\quad$ Test 2: Glass temperature held constant at $1150^{\circ} \mathrm{C}$ and melt pool bubbling rate adjusted to maintain a production rate of $1050 \mathrm{~kg} / \mathrm{m}^{2} /$ day.

- $\quad$ Test 3: Glass temperature held constant at $1175^{\circ} \mathrm{C}$ and melt pool bubbling rate adjusted to maintain a production rate of $1050 \mathrm{~kg} / \mathrm{m}^{2} /$ day.

The target glass production rate in Tests 2 and 3 was selected to provide direct comparisons with previous tests $[6,23]$.

\subsection{Melter Operations}

The DM1200 melter tests employed a prototypical ADS feed system, a single feed tube in the center of the melter, and a side-to-side electrode firing pattern. Two double ported bubblers (see Figure 1.5) positioned in a manner to mimic the WTP HLW melter (see Figure 1.6) were used throughout testing. In each test, the cold-cap-limited production rate was determined by visual observations of the cold cap and confirmed by the plenum temperature. The ADS feed system performed well in all tests. A summary of operational events is provided as Table 5.2. Operators observed the cold cap through view ports on the side of the melter on average every 20 minutes to guide melter operation, particularly the adjustment of bubbler air flow and feed rate. These observations are listed in Table 5.3.

Feeding was interrupted each day for about five minutes to collect feed samples. It was also paused once for eight minutes to remove a blockage in the film cooler, once for thirteen minutes to change a defective blower, and once for thirteen minutes to remove a blockage from the end of the feed tube. The majority of the film cooler deposits were readily removed by 
The Catholic University of America Vitreous State Laboratory
Melt Rate Enhancement for High Aluminum HLW Glass Formulations

Final Report, VSL-08R1360-1, Rev. 0

running a rod down through the film cooler and deposits on the feed tube were easily removed by tapping externally with a hammer. These feeding hiatuses did not compromise the objective of determining a steady production rate for any of the test segments. The feed used in these tests formed cold caps that often formed mounds, ridges, and cones under the feed nozzle. The aqueous feed was often observed boiling on the cold cap surface or running off onto the melt surface through holes in the cold cap generated from bubbling. A picture of one of these holes in the cold cap is provided in Figure 5.1. Ridges or mounds forming in the center of the melt pool often made direct observation of the melt surface opposite the view ports impossible. In these instances, the amount of cold cap was estimated by the amount of light visible as a result of openings in the cold cap. Ridges and mounds typically did not prevent free flow of the aqueous feed slurry across the cold cap surface and were managed by manipulating bubbler air flow. The configuration of the cold cap was constantly in flux throughout the tests; however, the extent of coverage was typically between 75 and 90 percent. The visual observations of the DM1200 melt pool is a key operational aspect of current DM1200 testing. In contrast to the operation of the LAW Pilot Melter, use of non-visual data, such as plenum temperature, have not been developed as reliable indicators of cold-cap conditions while processing HLW feeds [49]. In fact, high plenum temperatures can result from a high mound over a portion of the melt surface preventing feed from spreading across the melt surface and creating an opening on the glass surface. Without the visual evidence, an operator may conclude that feed rates should be increased, which could exacerbate the problem.

The glass production rates achieved during testing are provided in Table 5.1; these are illustrated in Figures 5.2.a and 5.2.b and are compared to rates achieved with other HLW feeds using the DM1200 with the optimized bubbling configuration in Table 5.4. The rate of $1500 \mathrm{~kg} / \mathrm{m}^{2} /$ day achieved during Test 1 was the highest production rate achieved with this configuration. This higher rate is due in part to higher feed solids content of $500 \mathrm{~g}$ glass per liter as opposed to 340 to $430 \mathrm{~g}$ glass per liter used in previous tests. Coincidently, the rate of $1500 \mathrm{~kg} / \mathrm{m}^{2} /$ day achieved on the DM1200 with optimized bubbling was the same rate obtained on the DM100 at $1200^{\circ} \mathrm{C}$. Previous DM100 tests with HLW simulants have shown that production rates can be doubled while optimizing the bubbling as opposed to using the standard $9 \mathrm{lpm}$ [2]. It is reasonable therefore that optimization of bubbling on the DM100 would have increased the rate of $950 \mathrm{~kg} / \mathrm{m}^{2} /$ day at $9 \mathrm{lpm}$ to about $1500 \mathrm{~kg} / \mathrm{m}^{2} /$ day. The target glass production rate of $1050 \mathrm{~kg} / \mathrm{m}^{2} /$ day was easily achieved at glass processing temperatures of 1150 and $1175^{\circ} \mathrm{C}$. This rate had been previously attained at $1150^{\circ} \mathrm{C}$ with $\mathrm{HLW}$ AZ-101 waste at $400 \mathrm{~g}$ glass per liter [6] with comparable bubbling (64 vs. $71 \mathrm{lpm}$ ), with HLW C-106/AY-102 waste at $340 \mathrm{~g}$ glass per liter [23] with more bubbling ( $90 \mathrm{vs} .71 \mathrm{lpm})$, and could not be obtained with HLW AZ-102 at $340 \mathrm{~g}$ glass per liter [23]. These results demonstrate that both waste composition and feed solids content have a big effect on production rate. Increasing the glass pool temperature by $25^{\circ} \mathrm{C}$ permitted the reduction of the bubbling rate by about forty eight percent (71 to $48 \mathrm{lpm}$ ) while maintaining a glass production rate of $1050 \mathrm{~kg} / \mathrm{m}^{2} /$ day. A reduction in bubbling of about thirty percent was observed with HLW AZ-101 waste at 400 g glass per liter with the same increase in glass temperature [6].

A variety of operational measurements recorded during these tests, including temperatures throughout the melter system, are given in Table 5.5. Data are collected and electronically logged every two minutes, and data and observations are also recorded manually 
The Catholic University of America Vitreous State Laboratory
Melt Rate Enhancement for High Aluminum HLW Glass Formulations Final Report, VSL-08R1360-1, Rev. 0

throughout the tests. The temperature for most of the glass pool was about $1150^{\circ} \mathrm{C}$ for the first two tests and about $30^{\circ} \mathrm{C}$ higher during the last test, as illustrated in Figures 5.3.a - 5.3.b. During the first test, the $1150^{\circ} \mathrm{C}$ melt temperature best suited the DM1200 power constraints while optimizing bubbling to achieve the maximum glass production rate. Conversely, the $1150^{\circ} \mathrm{C}$ glass temperature was targeted and successfully maintained during Test 2 while achieving the target glass production rate of $1050 \mathrm{~kg} / \mathrm{m}^{2} /$ day. The same targeted production rate was also maintained at the higher glass pool temperature of about $1180^{\circ} \mathrm{C}$ during Test 3 . Glass temperatures near the surface of the glass pool (27" from the floor) were lower due to the thermocouples being in or near the cold cap. Aside from this excursion, bulk glass temperatures were relatively constant throughout the glass pool. Glass temperatures measured on the east side were 2 to $11^{\circ} \mathrm{C}$ higher than those on the west side of the melter. Plenum temperatures, given in Figures 5.4.a and 5.4.b, spanned a larger range during the testing, 300 to $900^{\circ} \mathrm{C}$, than the 450 to $550^{\circ} \mathrm{C}$ target given in the Test Plan. The test segment and steady state average temperatures ranged from 482 to $714^{\circ} \mathrm{C}$, which is much closer to this target range. Higher plenum temperatures were observed at the beginning of each test as the cold cap was being formed and as the thermowell and exposed thermocouple are exposed to openings in the cold cap. Conversely, lower plenum temperatures were observed when the thermowell or exposed thermocouple was encased in cold cap material. An example of the feed encasing a thermowell occurred during Test 3 at about 70 hours run time. Notice in Figure 5.4.b that the lower plenum temperature in the thermowell at $17^{\prime \prime}$ below the melter lid dropped to as low as $200^{\circ} \mathrm{C}$ due to cold cap material covering that portion of the thermowell, while locations higher on the thermowell and the exposed thermocouple showed measured temperatures of about $700^{\circ} \mathrm{C}$ due to openings in the cold cap.

The east and west side electrode temperatures were about 10 to $15^{\circ} \mathrm{C}$ below the glass temperatures on the respective side of the melter. These temperatures typically varied by no more than $20^{\circ} \mathrm{C}$ from the mean during each test, as shown in Figures 5.5.a - 5.5.b. The closeness of the side electrode to the glass temperature was a factor limiting the glass temperature used during Test 3 . The bottom electrode, which was not powered during these tests, was about $60^{\circ} \mathrm{C}$ lower than the west electrode. The difference between the two side electrode temperatures was less during Test 1 due to the increased bubbling of the melt pool, which created better mixing. The discharge chamber and riser temperatures were largely maintained above $950^{\circ} \mathrm{C}$ throughout the tests. (The riser thermocouple is located about 4 inches above the bottom of the riser pipe, which is about 7.5 inches above the melter floor.) Gas temperatures at the outlet of the filmcooler were $50-250^{\circ} \mathrm{C}$ lower than the measured plenum temperature as a result of film-cooler and control-air dilution and depending on the position of the thermocouple in the plenum with respect to the cold cap. The film cooler was rinsed by a water spray every 12 hours during testing, resulting in a short-duration reduction to about $75^{\circ} \mathrm{C}$ in the film cooler outlet temperature.

Conditions in the glass pool are illustrated for electrical properties in Figures 5.6.a 5.6.b, level and density in Figures 5.7.a - 5.7.b, and bubbling in Figures 5.8.a - 5.8.b. Power supplied to the electrodes was highest during Test 1, averaging $224 \mathrm{kV}$ in response to higher bubbling and glass production rates. Power averaged $175 \mathrm{~kW}$ in both Tests 2 and 3 due to the glass production rate in both tests being $1050 \mathrm{~kg} / \mathrm{m}^{2} /$ day, even though the glass temperature was higher during Test $3\left(1175\right.$ vs. $\left.1150^{\circ} \mathrm{C}\right)$ and bubbling was higher during Test 2 (71 vs. 48 lpm). 
Supplied power was relatively constant once the cold cap was established, varying by only about $10 \mathrm{~kW}$ from the average steady state value. The glass pool resistance decreased with bubbling over the course of these tests: Test $1-0.099$ ohms at $124 \mathrm{lpm}$ bubbling, Test $2-0.093 \mathrm{ohms}$ at $71 \mathrm{lpm}$ bubbling, and Test $3-0.083 \mathrm{ohms}$ at $48 \mathrm{lpm}$ bubbling. Conversely, average glass pool density at steady state conditions during testing decreased with bubbling: Test $1-2.22 \mathrm{~g} / \mathrm{cc}$ at $124 \mathrm{lpm}$ bubbling, Test $2-2.29 \mathrm{~g} / \mathrm{cc}$ at $71 \mathrm{lpm}$ bubbling, and Test $3-2.33 \mathrm{~g} / \mathrm{cc}$ at $48 \mathrm{lpm}$ bubbling. This decrease was observed even though the glass temperature increased, indicating that the effect of bubbling on glass density is greater than glass temperature. The resistance and density may also have been affected as the glass pool composition changed over to the target composition during testing. Glass pool depth varied between 30 and 34 inches in response to the continuous feeding of the melter and the periodic discharging of glass. Lance bubbling rates decreased over the course of testing, from an average high of $125 \mathrm{lpm}$ while achieving maximum production rates during Test 1 , to $48 \mathrm{lpm}$ while maintaining $1050 \mathrm{~kg} / \mathrm{m}^{2} /$ day at an elevated glass pool temperature. Frequent changes to the bubbling rate as well as the distribution of bubbler air between the double ported lances were made to create an even cold cap across the melt pool surface.

\subsection{Off-Gas System Performance}

Tests on the DM1200 system at VSL have been used extensively to evaluate the performance of a pilot scale off-gas system that is prototypical of that designed for the WTP by BNI engineering $[6,16-23,50]$. In the current tests, data objectives primarily related to glass production rate and melter conditions required to achieve these production rates, not the performance of prototypical off gas system components. However, data for each of the off-gas system components and samples of solutions from the off gas system were collected and evaluated and are provided in this final report. Data are collected and electronically logged every two minutes and data and observations are also recorded manually throughout the tests. The average, minimum, and maximum values of the measured off-gas system parameters are given in Table 5.6. Target operational conditions for the system components such as sump temperatures, unit spray rates, and sump $\mathrm{pH}$ values that were not specified [3] were adapted from previous tests conducted on DM1200. The catalyst unit was bypassed in these tests. Plots of the typical sequence of gas temperatures through the DM1200 off-gas system at various locations are given in Figures 5.9.a, 5.9.b and 5.9.c for Test 1, Test 2, and Test 3, respectively. In summary, plenum gas from the melter is cooled by dilution with film cooler air to between 400 and $450^{\circ} \mathrm{C}$, drops another $100^{\circ} \mathrm{C}$ by control air dilution and heat loss along the transition line, is quenched to 30 to $40^{\circ} \mathrm{C}$ in the SBS, and reheated to about $75^{\circ} \mathrm{C}$ to prevent condensation in the HEPA filtration unit. The exhaust is heated by another 5 to $10^{\circ} \mathrm{C}$ by the Paxton blowers, then quenched to 25 to $35^{\circ} \mathrm{C}$ in the PBS.

\subsubsection{Melter Pressure}

A vacuum on the melter of three to three and half inches of water was targeted and maintained throughout the tests. This is achieved by setting blower speeds and using a control air 
system which constantly monitors the vacuum on the melter and injects sufficient air into the transition line immediately downstream of the film cooler to maintain a relatively constant vacuum on the melter. The computer-logged melter pressures measured at the instrument port and calculated control air flow rates for Test 1 and Tests 2 and 3 are plotted in Figures 5.10.a and $5.10 . \mathrm{b}$, respectively. The range of control air flow rates of up to $80 \mathrm{scfm}$ reflect the changes of melter exhaust volume in response to changes in the cold cap and feed rate, including pulsing of the feed (due to the ADS pump) throughout the tests.

The differential pressure across the film cooler and transition line is given in Figures 5.11.a and 5.11.b for Test 1 and Tests 2 and 3, respectively. The film cooler clogged and required manual cleaning once during Test 1 and once during Test 3 . The film cooler was also rinsed every 12 hours with 5 liters of water. The typical film cooler and transition line differential pressures ranged between one and two and half inches water column and two and five inches water column, respectively. Measured values outside these ranges resulted from either manual or spray cleaning of the film cooler, blockage of the film cooler, particularly around 10 hours run time during Test 1, clogged sensor lines, opening of ports in the transition line and melter lid for sampling activities, and small pressure surges resulting from either the pulsed nature of feeding or changing conditions in the cold cap.

\subsubsection{SBS}

The SBS quenches the melter exhaust, condenses much of the water from the melter feed, and removes the majority of the particulate in the exhaust stream. Many parameters of the SBS were recorded during testing, including inlet and outlet gas temperatures, pressures, and flow rates, pressure drops, sump temperature, heat exchanger inlet and outlet water temperatures, and flow rates. The amounts of heat removed by the SBS jacket, and the SBS inner cooling coil were calculated from the measured data, using the hourly averaged cooling water temperature increases (outlet temperature minus supply temperature) across the SBS inner cooling coil and cooling jacket multiplied by the same time-averaged water flow rate through each.

The SBS inlet and outlet gas temperatures are plotted in Figures 5.12.a and Figure 5.12.b for Test 1 and Tests 2 and 3, respectively. The average SBS inlet and outlet gas temperatures were $341^{\circ} \mathrm{C}$ and $46.2^{\circ} \mathrm{C}, 292^{\circ} \mathrm{C}$ and $39.3^{\circ} \mathrm{C}$, and $303^{\circ} \mathrm{C}$ and $39.4^{\circ} \mathrm{C}$ during Test 1 , Test 2 , and Test 3, respectively. The higher temperatures during Test 1 were in response to the higher concentration of exhaust gases from feed resulting from the higher melter feed rate.

SBS inlet, outlet, and differential pressures are plotted in Figures 5.13.a and 5.13.b. During Test 1, the inlet gas pressure averaged -8.9 in. W.C., the outlet pressure averaged -41.2 in. W.C. and the pressure drop across the SBS averaged about 32.3 in. W.C. During Test 2, the inlet gas pressure averaged -7.9 in. W.C., the outlet pressure averaged -39.5 in. W.C. and the pressure drop across the SBS averaged about 31.6 in. W.C. During Test 3, the inlet gas pressure averaged -8.0 in. W.C., the outlet pressure averaged -40.2 in. W.C., and the pressure drop across the SBS averaged about 32.2 in. W.C. 
The Catholic University of America Vitreous State Laboratory
Melt Rate Enhancement for High Aluminum HLW Glass Formulations

Final Report, VSL-08R1360-1, Rev. 0

The SBS down-comer annulus pressures are given in Figure 5.14.a and 5.14.b for Test 1 and Tests 2 and 3 respectively. The SBS off-gas temperatures in the down-comer measured at various depths (from 3 to 58 inches) and the SBS sump water temperature are given in Figures 5.15.a and 5.15.b, respectively. For Test 1 and Tests 2 and 3, the average SBS sump temperatures were $39.2^{\circ} \mathrm{C}, 33.1^{\circ} \mathrm{C}$, and $33.0^{\circ} \mathrm{C}$, which are $7.0^{\circ} \mathrm{C}, 6.2^{\circ} \mathrm{C}$, and $6.4^{\circ} \mathrm{C}$ less than the SBS outlet gas temperatures, respectively. The measured off-gas temperatures decrease as the depth from the SBS lid increases due to cooling of the gas in the down-comer pipe by the surrounding SBS liquid.

Water temperatures at the SBS inner cooling coil inlet, inner cooling coil outlet/jacket inlet, and jacket outlet are given in Figures 5.16.a and 5.16.b for Test 1 and Tests 2 and 3, respectively. The average water temperature difference was $15.5^{\circ} \mathrm{C}$ across the SBS inner cooling coil and $3.9^{\circ} \mathrm{C}$ across the jacket during Test 1 . The average water temperature difference was $12.4^{\circ} \mathrm{C}$ across the SBS inner cooling coil and $2.9^{\circ} \mathrm{C}$ across the jacket during Test 2 . The average water temperature difference was $12.0^{\circ} \mathrm{C}$ across the SBS inner cooling coil and $3.2^{\circ} \mathrm{C}$ across the jacket during Test 3 .

The SBS cooling coil/SBS jacket water flow rates are plotted in Figures 5.17.a and 5.17.b and averaged $28.7 \mathrm{gal} / \mathrm{min}, 27.0 \mathrm{gal} / \mathrm{min}$, and $27.8 \mathrm{gal} / \mathrm{min}$ for Tests 1 , 2, and 3, respectively. The corresponding amounts of heat removed by the SBS inner coil and jacket are shown in Figures 5.18.a and 5.18.b. For Test 1, heat removal averaged $95.9 \mathrm{~kW}$ by the SBS inner cooling coil and $15.5 \mathrm{~kW}$ by the cooling jacket. This corresponds to about $86 \%$ of the heat load to the SBS being removed by the inner cooling coil and about $14 \%$ by the cooling jacket. For Test 2, heat removal averaged $72.0 \mathrm{~kW}$ by the SBS inner cooling coil and $16.6 \mathrm{~kW}$ by the cooling jacket. This corresponds to about $81 \%$ of the heat load to the SBS being removed by the inner cooling coil and about $19 \%$ by the cooling jacket. For Test 3, heat removal averaged $71.5 \mathrm{~kW}$ by the SBS inner cooling coil and $19.2 \mathrm{~kW}$ by the cooling jacket. This corresponds to about $82 \%$ of the heat load to the SBS being removed by the inner cooling coil and about $18 \%$ by the cooling jacket.

One of the functions of the SBS is to condense water that originated in the waste feed. Figures 5.19.a and 5.19.b compare the amount of water fed to the total volumetric accumulations in the SBS over the course of each test. The amount of water fed into the melter is proportional to the amount of water in the feed and the slurry feed rate; hence, Tests 2 and 3 which targeted the same feed rate showed constant water feed rate to the melter. The difference between the amounts of SBS water coming from the feed and the amounts blown down from the SBS sump represents the amount of water carried out in the off-gas stream as a result of it being saturated at the SBS sump temperature, as well as a small amount of entrained droplets. This amount is largely determined by the SBS sump water temperature, which was about $6^{\circ} \mathrm{C}$ higher during Test 1 than in Tests 2 and 3. As a result this temperature difference, the total volume of water exiting the SBS was about the same for Test 1 and the combined volume for Tests 2 and 3, despite the difference in run time. 


\subsubsection{WESP}

The WESP is used primarily to remove fine, often water soluble particles from the exhaust stream that are not efficiently removed by the SBS. The inlet and outlet gas temperatures, differential pressure across the WESP, and the WESP current and voltage were measured and recorded by the computer data acquisition system. The WESP inlet and outlet gas temperatures are plotted in Figures 5.20.a and 5.20.b for Test 1 and Tests 2 and 3, respectively. A one to two degree increase in temperature is observed in the exhaust temperature as gas passes through the WESP. The periodic downward spikes in the WESP outlet temperature are a result of the daily deluge of the WESP to wash collected deposits off the electrodes and into the WESP sump. The WESP differential pressures and outlet gas flow rates are plotted in Figures 5.21.a and 5.21.b for Test 1, and Tests 2 and 3, respectively. A pressure drop of about two and a half inches across the WESP was observed during testing. The typical wet gas flow rate exiting the WESP was about $230 \mathrm{scfm}$.

The amount of liquid accumulated in the WESP is plotted as a function of run time in Figure 5.22.a and Figure 5.22.b, where it is compared with the amount of fresh water sprayed into the WESP during Test 1 and Tests 2 and 3, respectively. The inlet spray water was targeted at $2.0 \pm 0.2 \mathrm{gph}$; however, the actual spray water flow rate was $\approx 1.7 \mathrm{gph}$ because of the limitations of the spray nozzle. As evident from both figures, spray water accounts for the majority of the liquid accumulation in the WESP. The difference between accumulated liquid and fresh water sprayed is equal to the amount of liquid removed from the off-gas, which is also plotted in Figure 5.22.a and Figure 5.22.b. The WESP electrodes were deluged daily, as planned, with water at a nominal rate of $12 \mathrm{gpm}$ for 3.33 minutes.

The WESP voltage and current are plotted as functions of run time in Figure 5.23.a and Figure 5.23.b for Test 1 and Tests 2 and 3, respectively. The current was set at $17 \mathrm{~mA}$ with voltage not to exceed $32 \mathrm{kV}$ prior to introducing water into the melter. The current was subsequently adjusted to that target during testing to the extent possible. During Test 1 , the target current was approximated but it could not be reached during Tests 2 and 3 within the $32 \mathrm{kV}$ voltage limit. The power stabilized shortly after the daily deluges.

\subsubsection{Secondary Off-gas System}

A HEME filtration unit (HEME 1) follows the WESP in the off-gas system to remove water droplets that may be present in water-saturated gas exiting the WESP. For Test 1, and Tests 2 and 3, the outlet gas temperature and differential pressure are plotted in Figure 5.24.a and 5.24.b. The typical pressure drop across HEME 1 during testing was about 1.5 in W.C.

The HEME is followed in the off-gas system by a heater, a HEPA filter (HEPA 1), and a Paxton blower (Blower 1). The purpose of the heater is to ensure that water-saturated gas exiting HEME 1 is heated above its dew point before passing through the HEPA filter in order to prevent moisture condensation in the HEPA filter. The outlet gas temperature and the pressure differential across the HEPA filter are the two parameters monitored by the off-gas data acquisition system; for Test 1 and Tests 2 and 3, these are shown in Figure 5.25.a and 5.25.b, 
respectively. The typical pressure drop across the HEPA filter was about half an inch water column throughout testing.

A vacuum is maintained on the melter by a pair of redundant Paxton blowers (Blowers 701 and 702) immediately downstream of the HEPA filtration unit and a blower (Blower 801) downstream of the packed bed scrubber. During Test 2 at 23.1 hours, Blower 701 failed and Blower 702 was placed in service while the head on Blower 701 was replaced. Also, the speed of the redundant blowers was increased and the speed of Blower 801 was increased to reduce the temperatures in the redundant blowers.

Downstream of the HEPA filter and Paxton blowers in the off-gas train is the packed bed caustic scrubber (PBS) to remove iodine and acid gases from the off-gas stream. The PBS sump solution is derived from process water; caustic solution $(25 \% \mathrm{NaOH})$ is added to control the solids content and $\mathrm{pH}$ of the scrubber liquid. The PBS inlet gas temperature, pressure drop across, sump temperature, and sump $\mathrm{pH}$ for Test 1 and Tests 2 and 3 are shown in Figures 5.26.a and 5.26.b, respectively. The typical pressure drop across the PBS during testing was two and a half inches water column. The inlet gas at about $80-85^{\circ} \mathrm{C}$ was quenched to about $25-30^{\circ} \mathrm{C}$ in the PBS during testing. The saw tooth appearance of the measured $\mathrm{pH}$ values around 9 and 10 results from the automated additions of $\mathrm{NaOH}$ solution to maintain the relatively constant $\mathrm{pH}$.

\subsubsection{SBS, WESP, HEME, and PBS Process Fluids}

One-liter samples were collected from the SBS, WESP, PBS, and HEME sumps at the end of testing. Samples were subjected to total dissolved solids (TDS) and total suspended solids (TSS) determinations by gravimetric analysis of filtered material and the evaporated filtrate. An additional sample was filtered to generate solids and filtrate for complete chemical analysis, which included $\mathrm{pH}$ determination, direct current plasma atomic emission spectroscopy (DCP-AES) analysis for metals, and ion chromatography for anions; the dried filtered solids underwent microwave-assisted acid dissolution prior to chemical analysis. The terminal SBS, WESP, PBS, and HEME sump samples as well as the total volume of solution removed from each sump are listed in Table 5.7; the first letter in the sample name is " $\mathrm{S}$ ", "W", " $\mathrm{H}$ ", and "P" for the SBS, WESP HEME, and PBS samples, respectively. The " $\mathrm{A}$ " and "B" suffixes in the name of the WESP samples correspond to samplings immediately before and after the 40-gallon deluge. The "1" or " 2 " after the " $\mathrm{H}$ " in the HEME sample name correspond to the first HEME located downstream of the WESP and the second HEME located downstream of the PBS, respectively. The analyzed chemical compositions for samples taken at or near the end of each test are provided in Table 5.8.

The amount of solution removed from the first HEME (immediately downstream of the WESP) at the end of each test and corresponding chemical analysis is given in Table 5.8. The HEME was continuously sprayed at $\sim 0.2 \mathrm{gal} / \mathrm{hr}$, resulting in the addition of about 10 gallons of water for each of the three nominally 50 hour tests. The liquid volume accumulated during each of the tests was five to ten gallons greater than the amount sprayed as a result condensation. The PBS was blown down as required to maintain constant volume. 
The Catholic University of America Vitreous State Laboratory
Melt Rate Enhancement for High Aluminum HLW Glass Formulations

Final Report, VSL-08R1360-1, Rev. 0

The $\mathrm{pH}$ of sump solutions is affected by constituents removed from the exhaust by each component and the amount of process water or sodium hydroxide added. Feed processed in the current tests contains relatively higher ratios of halides, sulfate, nitrate, and boron to alkali metals, reductants, and silica, as compared to other HLW feeds previously processed [16-23]. As a result, the $\mathrm{pH}$ in the primary off-gas system effluents were significantly more acidic than in previous tests on DM1200 with HLW feeds. The $\mathrm{pH}$ values of less than 2 are more similar to values measured while processing some LAW wastes than to those for HLW wastes, which typically result in near-neutral solution $\mathrm{pH}$ values. The $\mathrm{pH}$ of the post deluge WESP solution is closer to neutral due to dilution with the deluge tap water than is the solution sampled from the WESP prior to the deluge. The $\mathrm{pH}$ of the solution from the HEME that follows the WESP is very similar to that of the WESP solution, whereas the $\mathrm{pH}$ of the solution from the HEME that follows the PBS is very similar to that of the PBS solution. The $\mathrm{pH}$ of the PBS sump is maintained around 9 during testing by the addition of $25 \%$ sodium hydroxide solution, which is reflected by measured $\mathrm{pH}$ values near 9 in the PBS solutions.

The chemical composition as well as the distribution between dissolved and suspended solids fractions was measured on sump solutions from the end of testing and is provided in Table 5.8. Most of the chemical species measured in off-gas system solutions were dissolved due to the efficiency of the SBS at removing coarse particles, which are often insoluble, and the acidic conditions in the primary off-gas system components. As expected, the most abundant solids in the SBS solution were soluble species such as halogens, boron, alkali metals, nitrate, and sulfate. These species are readily volatilized from the glass and cold cap in the melter as soluble salts. Similar results were obtained from analysis of SBS solutions in tests with other HLW simulants $[6,16-23]$. Dissolved chlorine and fluorine were observed in significant proportions in all of the tests, even though chlorine was not targeted in the feed, indicating that these halides were present in the feed as a contaminant. In contrast to previous tests with HLW simulants [6, 16-23], aluminum was also abundant in these solutions as a dissolved species due to the relatively high concentration in the feed and the acidic conditions in the sump solution. The WESP solutions contain mainly volatile salts (alkali halides, borates, and sulfates) carried over from the SBS, and contaminants from previous tests. Impurities in the feed and tap water are major constituents in the WESP solutions. The concentration of suspended solids in the WESP post-deluge sample is over an order of magnitude higher than for pre-deluge solutions; this material was presumably material that was dislodged from the electrodes. Conversely, the dissolved solids concentration in the post-deluge sample is about a third of the pre-deluge sample due to dilution by the deluge water. The chemical analysis of solution from the first HEME indicates that the solutions are essentially diluted WESP solutions, which is consistent with the HEME collecting mist carried over from the WESP. Nitrate and nitrite are higher in the HEME solutions than the contemporaneous WESP solutions, suggesting that the HEME is more efficient at removing these constituents from the exhaust stream. The relatively high concentrations of sodium, halides, nitrogen oxides, and sulfate in the PBS indicate that the PBS is functioning as intended. The chemical analysis of solution from the second HEME indicates that the solutions are essentially diluted PBS solutions, which is consistent with the HEME collecting mist carried over from the PBS. Since many of the components include tap water sprays or are initially charged with tap water, elements common in tap water, such as calcium, are over represented in the solutions as compared to the amounts in the target feed composition. 


\section{SECTION 6.0 \\ FEED SAMPLE AND GLASS PRODUCT ANALYSIS}

\subsection{Analysis of Feed Samples \\ 6.1.1 General Properties}

Feed samples from each test were analyzed to confirm physical properties and chemical composition. Samples were taken during melter testing from an inline sampling port. Sample names, sampling dates, and measured properties are given in Table 6.1. Density and $\mathrm{pH}$ were measured on all samples; at least one sample per unique waste composition from the DM100 tests and all DM1200 samples were analyzed for water content, glass conversion ratio, rheological properties, and oxide composition by XRF. The measured glass conversion ratios for all feed samples except one were within ten percent of the target on a weight per weight basis, validating the use of the target conversion ratio for calculating glass production rates. Samples from the DM100 tests were closer to the target values due in part to more water being used to flush feed lines during transfers to the DM1200 feed tanks. The water content, density, glass yield, and $\mathrm{pH}$ varied within a narrow range except for the $\mathrm{pH}$ values for DM100 Tests 1 and 2. The higher $\mathrm{pH}$ in these samples is attributable to the boron source; borax was the source of boron in the first two DM100 tests whereas boric acid was the boron source in all other tests. Changing of the aluminum source from oxide to hydroxide increased the $\mathrm{pH}$ by only a quarter of a unit.

\subsubsection{Rheology}

Samples of the melter feeds that were used for these tests were also subjected to rheological characterization. The results from rheological characterization of a variety of other melter feeds and waste simulants, as well as the effects of a range of test variables, are described in detail in a separate report [51]. Melter feeds were characterized using a Haake RS75 rheometer, which was equipped with either a Z40DIN or a FL22-SZ40 sensor. A typical set of measurements consists of identifying the flow characteristics of the slurry by measuring the shear stress on the slurry at controlled shear rates and temperatures. In these measurements, the shear rate values are preset and are increased stepwise from $0.01 \mathrm{~s}^{-1}$ to $200 \mathrm{~s}^{-1}\left(70 \mathrm{~s}^{-1}\right.$ for FL22-SZ40) with a sufficient delay (typically 15 to 30 seconds) between steps to ensure that the shear stress is allowed to fully relax and therefore is measured at equilibrium. This approach is somewhat different from the "flow curve" approach in which the shear rate is ramped up to some maximum value and then ramped back down to produce a hysteresis curve that is dependent on the selected ramp rate. The viscosity of the sample as a function of the shear rate is then calculated as the ratio of the shear stress to the shear rate. The yield stress data for the melter feeds were measured using a controlled-stress mode in which the torque on the rotor was slowly increased while the resulting deformation of the fluid was monitored. The discontinuity in the measured deformation-torque curve was identified as the yield stress. It should be noted that this direct measurement of the yield stress can be quite different from the value that is often reported 
as the yield stress, which is obtained by extrapolation of the shear stress-shear rate curve to zero shear rate. All of the measurements in this work were made at $25^{\circ} \mathrm{C}$; previous work [51], which examined a range of temperatures, showed a relatively weak effect of temperature.

Measured values for viscosity at selected shear rates and the yield stress are shown in Table 6.2. The data indicate that the change of the form of aluminum in the waste and the changes in the additive blends do not have substantial effects on the rheological properties of the feed samples. A small increase in feed viscosity and yield stress may be attributable to changing the boron source from borax to boric acid. All feeds were processed by the feed system without significant difficulties.

\subsubsection{Chemical Composition}

The methods used for analysis of feed sample chemical compositions are described in Section 1.5. The boron, fluorine, and lithium oxide target values were used for normalizing the XRF data since their concentrations were not determined by XRF. These results, compared to the target composition in Table 6.3, generally corroborate the consistency of the feed compositions and show good agreement with the target compositions for the major elements. All oxides with target concentrations greater than one percent deviated by less than $10 \%$ from target for feed samples from DM1200 tests. Similarly, most oxides in feed samples from DM100 tests also passed this criterion; however, phosphorus and bismuth deviated by as much as sixteen percent from target. However, the absolute deviation for bismuth and phosphorus oxides was always less than $0.18 \mathrm{wt} \%$. The iron oxide concentration in the feed sample from DM100 test 5 was about nineteen percent above the target value; however, glass made from this feed during melter testing had measured iron concentrations within ten percent of the target value. This deviation may be attributable to contamination during sampling or crucible melting. The composition of this feed is further corroborated by comparison to the product glasses (see Section 6.2.1), which shows all oxides with concentrations greater than $1 \mathrm{wt} \%$ in the target composition to be within about $10 \%$ of the target, except for phosphorus during some tests.

Low concentrations of manganese, neodymium, and strontium in some feed compositions, were measured, even though they are not included in the target composition. Also, common elements such as magnesium, titanium, zirconium, potassium, barium, and chromium, when targeted at low concentrations, were typically above these targets. These positive deviations are often observed in melter feeds due to their ubiquity in the raw materials used to make up the simulants and in the glass forming additives. Analysis of the product glass using a method other than XRF (see Section 6.2.1) indicates that cadmium is present at the low target concentrations; however, these concentrations are below the sensitivity of the XRF for these glass matrices. Analyzed sulfur concentrations are below target concentrations due to volatilization during sample preparation. Lead, which was targeted at low levels in the glass product (0.40-0.41 $\mathrm{wt} \%$ ), was measured at about ninety percent of target in the feed samples. None of these small deviations would affect the determination of glass processing rates or negatively impact product quality. 


\subsection{Analysis of Glass Samples}

In the DM100 and DM1200 tests, almost two metric tons and nine metric tons of glass were produced, respectively. The glass was discharged from DM100 periodically into 5-gallon carbon steel pails and from DM1200 into 55 gallon drums, using airlift systems in both cases. The discharged product glass was sampled at the end of each test by removing sufficient glass from the top of the cans for total inorganic analysis. Product glass masses, discharge date, and analysis performed are given in Tables 6.4 and 6.5. Glass samples were also obtained by dipping a rod into the glass pool at the beginning and end of each test. These "dip samples" underwent visual examinations to detect the presence of separate sulfate or crystalline phases on the glass surface.

\subsubsection{Compositional Analysis of Discharge Glasses}

All discharge glass samples were crushed and analyzed directly by XRF. The target values for boron and lithium oxides, which are not determined by XRF, were used for normalizing the XRF data to $100 \mathrm{wt} \%$. Fluorine analysis by XRF required a polished monolith as opposed to the standardized ground glass preparation used for the other elements. Approximately, every fifth discharged glass sample was directly analyzed for fluorine; fluorine concentrations of other glasses were interpolated in between the measured values. The XRF analyzed compositions of discharged glass samples are provided in Tables 6.6 and 6.7. The majority of the XRF analysis results compared very favorably to their corresponding target values and feed sample analyses (see Section 6.1.3). Oxides with a target concentration greater than one weight percent showed around, or below, 10\% deviation from the target values. The only exception is phosphorus oxide which had an absolute deviation of no more than $0.15 \mathrm{wt} \%$. Similar to the feed sample analyses, common elements such as magnesium, titanium, zirconium, and potassium targeted at low concentrations were above their respective targets. Several elements were present in the melt pools prior to these tests but were not included in the current target compositions. Most notable was strontium oxide at about four weight percent in the first glass discharged from the DM100 tests; other elements at much lower concentrations were cerium and neodymium in the DM100 melt pool, and lanthanum, neodymium, antimony, and strontium in the DM1200 melt pool. Sulfur and fluorine are below target for almost all glasses due to volatilization from the glass pool and cold cap.

Corroborative analysis using DCP on solutions of acid-dissolved glass was performed on select glasses produced from each test; the results are compared to the XRF analysis in Table 6.8. Values for all the major oxides compare favorably with the XRF analysis and target composition except for sodium, which often exhibits a low bias using this procedure [19, 52]. Low biases for aluminum and chromium using the DCP method were observed in previous tests with high aluminum concentrations [2]. It is possible that the aluminum concentrations in these glasses may be higher than the sample preparation method can dissolve or keep in solution with the acid mixture currently being used. Consequently, the XRF values are to be preferred. The closeness of the DCP boron and lithium analyses to the target (deviations less than 10\%) validates the use of the target boron and lithium concentrations for normalizing the XRF data. 
Compositional trends for selected constituents shown in Figures 6.1.a-6.1.c for DM100 tests and 6.2.a-6.2.c for DM1200 tests illustrate the closeness to targets at the end of tests with each composition. Exceptions include volatile species such as sulfur and fluorine, which remain significantly below their target concentrations as a result of significant release to the melter exhaust. Fluorine concentrations also decreased during idling periods in between DM100 tests. At the onset of testing, aluminum, calcium, and fluorine increase in concentration at the expense of silicon, iron, zirconium, and zinc as the steady-state composition is approached. Although not depicted in the figures, oxides present in the melt pool at the beginning of testing but not present in the target glass composition decrease in concentration to the point of being non-detectable by the end of testing. The concentrations of most oxides do not change significantly from composition to composition during DM100 testing since the waste composition is constant, the waste loading changes are very small, and significant additive changes occur for only boron and silica. Complete compositional turnover of the DM1200 melt requires the majority of the test duration due to the approximate two metric ton capacity of the melt pool; therefore the melt pool composition is evolving toward the target composition over nearly the entire DM1200 testing period.

\subsubsection{Chemical Durability of Discharge Glasses}

Glass discharge samples from the end of each DM100 test were evaluated for chemical durability using the PCT and TCLP methods. The PCT results are compared to those for the benchmark DWPF-EA glass in Table 6.10 and the TCLP results are compared to the WTP delisting limits [53, 54] and Universal Treatment Standard (UTS) limits in Table 6.11. The chemical durability determined by both of these methods is excellent for the melter glasses. All measured PCT concentrations and normalized leach rates on discharge glass samples are at least one hundred forty times lower than the corresponding values for the DWPF-EA glass. All regulated TCLP leachate concentrations are less than $1 \mathrm{mg} / \mathrm{l}$ and more than a factor of nine less than WTP delisting limits. All measured concentrations are also well below the UTS limits. The chemical durability of these glasses is similar to that for those previously produced from aluminum limited waste and better than that for those produced from aluminum plus sodium limited waste [2]. These results confirm that glasses can be formulated from a variety of waste loading limiting constituents without compromising the quality of the vitrified product.

\subsection{Glass Pool Samples}

A list of all dip samples including sample names, sampling dates, target glass pool temperature, and visual observations of secondary phases is provided in Table 6.11. These samples were used to detect the presence of any secondary phases on the melt pool surface. There was no visual evidence of secondary phases in any of the samples as either material adhering to the sampling rod indicative of a surface layer or macroscopic features indicative of crystalline phases in the glass. 


\subsection{Cold Cap Samples}

Samples from DM100 Test 8 and DM1200 Test 1 were taken from the cold cap using a "spoon" device that was introduced into the melter from the top. The spoon penetrated the cold cap and was lowered into the melt, then withdrawn in such a way that it captured a piece of the broken cold cap while allowing the glass melt to drain as much as possible. The sample is then withdrawn from the melter, allowed to cool to room temperature, removed from the sampling device and prepared for SEM-EDS analysis. The samples obtained in this manner are typically a composite of desiccated melter feed, glass, and transitional phases in between these two extremes. Examination of the transitional phases can provide insight into the slower melting components of the melter feed.

\subsubsection{DM100 Cold Cap Sample}

The DM100 cold-cap was collected and split into two samples labeled BLZ-O-35A and BLZ-O-37A. Figure 6.3.a shows the majority of undigested particles, including quartz and calcium silicate. These particles are embedded in the fine mixture phase that is high in $\mathrm{Al}, \mathrm{Si}, \mathrm{Ca}$, and Fe. Regions in dark contrast are a glass that is rich in light elements such as sodium, boron, lithium, aluminum, and silicon.

Figure 6.3.b shows a region close to the glass phase in the sample. At this location, at least $85 \%$ of the melter feed was converted to glass. Undigested particles include quartz and hematite in two forms: tiny needles of hematite aggregated to $20-100 \mu \mathrm{m}$ in size and individual needles of about 10-30 $\mu \mathrm{m}$ in length. These hematite crystals usually contain nickel, chromium, or titanium. Crystals of Fe-Cr-Ni spinel are present as larger 5 to $20 \mu \mathrm{m}$ crystals as well as smaller 1-2 $\mu \mathrm{m}$ crystallites associated with hematite. Other crystals include zirconia-rich phases, presumably zircon, and chromium oxide.

\subsubsection{DM1200 Cold Cap Sample}

The DM1200 sample was identified as O-12J-106A. Figure 6.4 shows undigested particles of $\mathrm{Al}_{2} \mathrm{O}_{3}, \mathrm{ZrO}_{2}, \mathrm{Fe}_{2} \mathrm{O}_{3}$ and $\mathrm{CaSiO}_{3}$. Undigested particles rich in $\mathrm{Al}_{2} \mathrm{O}_{3}$ are the most abundant. These particles are cemented together by a fine mixture phase with small bright particles rich in iron, chromium, and zirconium. 


\section{SECTION 7.0 \\ MONITORED OFF-GAS EMISSIONS}

\subsection{Particulate Sampling}

The melter exhaust was sampled for metals/particles according to 40-CFR-60 Methods 3, 5, and 29 at steady-state operating conditions during each test segment. The concentrations of off-gas species that are present as particulates and gaseous species that are collected in impinger solutions were derived from laboratory data on solutions extracted from air samples (filters and various solutions) together with measurements of the volume of air sampled. Particulate collection required isokinetic sampling, which entails removing gas from the exhaust at the same velocity that the air is flowing in the duct (40-CFR-60, Methods 1-5). Typically, a sample size of 30 dscf was taken at a rate of between 0.5 and $0.75 \mathrm{dscfm}$. Total particulate loading was determined by combining gravimetric analysis of the standard particle filter and chemical analysis of probe rinse solutions. An additional impinger containing $2 \mathrm{~N} \mathrm{NaOH}$ was added to the sampling train to ensure complete scrubbing of all acid gases and, particularly, iodine. The collected materials were analyzed using direct current plasma atomic emission spectroscopy for the majority of the constituents and ion chromatography (IC) for anions. Melter emission fluxes are compared to feed fluxes in Table 7.1 for DM100 tests and Table 7.2 for DM1200 tests. Notice the distinction that is made between constituents sampled as particles and as "gas". The "gaseous" constituents are operationally defined as those species that are scrubbed in the impinger solutions after the air stream has passed through a $0.3 \mu \mathrm{m}$ heated filter. All samples but one are well within the $90-110 \%$ limits for isokinetic sampling. The particle filter during the last sample occluded shortly after the start of sampling, which limited the duration and resulted in a less than isokinetic sample.

Particulate emissions from both melters constituted 0.04 to 0.29 percent of feed solids. This level of carry-over is less than that measured for previous tests with chromium, bismuth, aluminum, and aluminum plus sodium limited HLW wastes $(0.06-0.57)$ [2], HLW AZ-102 (0.57 - 1.47 percent) [44], and HLW C-106/AY-102 SIPP (0.61 to 0.81 percent) [15] simulants processed on the same melter. The higher carry-over in many of the previous tests is due to higher proportions of volatile species in the feed such as rhenium, cesium, and halogens. The carry-over is lower but still comparable to previous tests conducted with HLW AZ-101 simulants while bubbling the melt pool [14]. In all paired DM100 tests with the same feed, particulate emissions were higher at the higher glass temperature of $1200^{\circ} \mathrm{C}$ than at $1150^{\circ} \mathrm{C}$. An increase in particulate emissions was also observed on the DM1200 with a glass pool temperature increase of only $25^{\circ} \mathrm{C}$ and, separately, with an increase in melt pool bubbling. These trends are in contrast to the lack of clear emissions trends as a function of glass temperature and bubbling in the earlier DM100 tests with $\mathrm{Al}, \mathrm{Al}+\mathrm{Na}, \mathrm{Bi}$, and $\mathrm{Cr}$ limited HLW streams [2] but in keeping with numerous studies using HLW streams that show increased particulate carry-over with increased melt pool

bubbling [6, 16-21] and previous tests showing increased particulate melter emissions with increasing glass processing temperature [14, 55-58]. It is possible that on the DM100 the effect of the smaller $25^{\circ} \mathrm{C}$ increase in temperature in the earlier tests [2] may be within the variability 
of the measurements $[1,58]$ whereas the $50^{\circ} \mathrm{C}$ increase in the current tests was sufficient to observe increased emissions. No trend of increased particulate emissions with increasing boron concentration was observed despite the somewhat volatile nature of boron; larger increases in feed boron concentration may be required to see this effect. The amount of moisture collected in each sampling train was proportional to the feed rate; therefore, in the DM100 paired tests, the amount of moisture collected in the tests conducted at a $1200^{\circ} \mathrm{C}$ melt temperature was always higher than moisture collected in tests conducted at $1150^{\circ} \mathrm{C}$.

As expected, the feed elements emitted at the lowest melter DF were clearly fluorine and sulfur. Another element exhibiting some volatile behavior was boron. The relative volatility of barium, cadmium, and titanium are difficult to evaluate due to the low target concentrations in the feed. Emissions of chlorine were measured during all tests even though they were not included in simulant recipes or in the analyzed compositions. Chlorine has frequently been observed in melter emissions when not present in feed recipe or at levels exceeding the amount in the feed recipe due to its ubiquity in raw materials, presence in tap water, and high volatility at glass melting temperatures. Boron, sulfur, and the halides were the only elements detected in the impinger solutions collected downstream of the heated particle filter in the sampling train, which constitutes the "gas" fraction of the melter emissions.

\subsection{Gases Monitored by FTIR}

Melter emissions were monitored in each test for a variety of gaseous components, most notably $\mathrm{CO}$ and nitrogen species, by Fourier Transform Infra-Red Spectroscopy (FTIR). The off-gas system temperature is maintained well above $100^{\circ} \mathrm{C}$ beyond the sampling port downstream of the DM100 HEPA filter to prevent analyte loss due to condensation prior to monitoring. The data, therefore, represent the relative concentrations of volatile gaseous species in the melter exhaust. During the DM1200 tests, the exhaust stream was sampled at the outlets of several prototypical components (melter, SBS, WESP, and PBS) to discern the effect these components have on the volatiles in the exhaust stream. It should be noted, however, that the off-gas system component most responsible for the removal of nitrogen oxide and volatile organics, the TCO-SCR catalyst unit, was bypassed in these tests due to the relatively low concentrations of these components in the exhaust stream. Also, a single FTIR unit was used for all of the measurements and, therefore, locations were sampled sequentially and not simultaneously.

A summary of the range and average concentrations of gaseous species monitored during the DM100 tests is provided in Table 7.3; similar information for the DM1200 tests is provided in Tables 7.4-7.6. The concentrations of two of the monitored species are plotted in Figures 7.1 - 7.8. The analytes listed in Tables $7.3-7.6$ are those that were thought likely to be observed during the tests based on previous work; no other species were detected in the off-gas stream by FTIR. Generally, emissions from the DM100 were relatively low as a result of the low concentrations of nitrogen, organic carbon, ammonia, and halogens in the feed. The most abundant nitrogen species monitored was NO, which is in keeping with previous melter tests with both HLW and LAW feeds. No nitrogen was detected as other species, except for $\mathrm{NO}_{2}$, which was 10 to 20 times lower in concentration than NO. Similar trends were observed in 
melter emissions during the DM1200 tests with a greater proportion of nitrogen oxides as $\mathrm{NO}_{2}$ (approximately 6:1, NO: $\mathrm{NO}_{2}$ ) and very low concentrations of $\mathrm{N}_{2} \mathrm{O}$, nitric acid, and nitrous acid in some of the tests. The variability in the NO concentrations shown in Figures $7.1-7.4$ is attributable to the dynamic conditions in the cold cap and is in keeping with previous melter tests. The concentration of water in the melter exhaust increased with increasing feed rate in both the DM100 and DM1200 tests. Consistent with the gaseous fluorine concentrations observed using the Method 5-type sampling (see Section 7.1), HF was observed throughout the testing by FTIR. The variations in emissions over the course of each test segment are due in part to changes in the melt pool cold cap. Hydrogen fluoride concentrations were lower at the beginning of testing due to the lack of fluorine in the glass pool and the processing time required for the glass to reach steady-state concentration with respect to fluorine. Also consistent with the Method 5type results, low sulfur dioxide concentrations were monitored in each test; however, gaseous sulfur emissions can also be present in forms other than sulfur dioxide that are not monitored by the FTIR, such as sulfuric acid. Measured concentrations for most constituents through the DM1200 exhaust system were very similar. This confirms the expectation that the SBS, WESP, HEME, and PBS do not remove significant proportions of nitrogen and carbon oxides. Conversely, moisture and some minor components such as $\mathrm{HF}$ and $\mathrm{SO}_{2}$ are greatly reduced in concentration by removal in the SBS. These trends can be readily discerned by comparing NO concentrations in Figures 7.5 and 7.7, which do not show significant differences at the various sampling localities, and HF concentrations in Figures 7.6 and 7.8, which are noticeably higher in the melter exhuast. Another aspect of the NO emissions is the high degree of variation during testing throughout the off-gas system, as can be discerned from the concentration ranges. 


\section{SECTION 8.0 SUMMARY AND CONCLUSIONS}

A series of tests was conducted to develop HLW glass compositions for the aluminum limited waste composition specified by ORP that maximize processing rates while maintaining high waste loadings and acceptable glass properties. This was accomplished through a combination of crucible-scale tests, confirmation tests on the DM100 melter system, and demonstration at pilot melter scale (DM1200). New glass formulations and additive blends were developed with the objective of increasing processing rates while maintaining high waste loadings. The formulations used for melter testing were selected based on the test results from Vertical Gradient Furnace tests, DM10 Feed Consumption tests, and a series of crucible melt glasses that were prepared and characterized. Each of the selected formulations meets all of the product quality, processability, and waste loading requirements. The DM100 melter tests evaluated the effects of a $50^{\circ} \mathrm{C}$ increase in glass processing temperature, aluminum waste form $\left(\mathrm{Al}_{2} \mathrm{O}_{3}\right.$ vs. $\left.\mathrm{Al}(\mathrm{OH})_{3}\right)$, and optimized additive blends on glass production rates. This same melter was used in previous tests with aluminum limited and other HLW wastes thus providing comparisons between the previously collected data on melter processing characteristics, partitioning to off-gas, and formation of secondary phases. Once DM100 tests were completed, one of the compositions was selected for further testing on the DM1200; the DM1200 system has been used for processing a variety of simulated WTP waste streams. Tests on the larger melter provide processing data at one third of the scale of the actual WTP HLW melter and therefore provide a more accurate and reliable assessment of production rates and potential processing issues.

For each of the four selected feed formulations, DM100 melter testing was performed in two 50-hour test segments. These test segments employed glass pool temperatures of $1150^{\circ} \mathrm{C}$ and $1200^{\circ} \mathrm{C}$, bubbling rates of $9 \mathrm{lpm}$, and $500 \mathrm{~g}$ glass per liter feed solids concentration. Over three and a half metric tons of feed was processed to produce almost two metric tons of glass. Analysis was performed on discharge and glass pool samples throughout the tests for total composition. All of the melter tests were successfully completed with no evidence of processing issues. Glass production rates with the aluminum limited waste at a glass pool temperature of $1150^{\circ} \mathrm{C}$ were increased from $550 \mathrm{~kg} / \mathrm{m}^{2} /$ day in the previous tests to $950 \mathrm{~kg} / \mathrm{m}^{2} /$ day as a result of changes to the feed composition while maintaining the same high waste loading (45 wt $\%)$. Glass production rates as high as $1500 \mathrm{~kg} / \mathrm{m}^{2} /$ day were achieved at the glass pool temperature of $1200^{\circ} \mathrm{C}$. Data collected during DM100 tests also demonstrated the effect of the aluminum source on production rates, with significantly higher rates observed with aluminum hydroxide than with aluminum oxide. Tests with the aluminum limited waste on the DM1200 demonstrated glass production rates of $1500 \mathrm{~kg} / \mathrm{m}^{2} /$ day at $1150^{\circ} \mathrm{C}$ melt pool temperature with optimized bubbling. The target production rate of $1050 \mathrm{~kg} / \mathrm{m}^{2} /$ day was easily obtained with a modest amount of bubbling and the nominal glass pool temperature of $1150^{\circ} \mathrm{C}$ as well as with an even lower bubbling rate at a modestly higher glass pool temperature of $1175^{\circ} \mathrm{C}$. No significant processing problems were encountered on the DM1200 while producing almost 9 metric tons of glass from over 24 metric tons of feed. 
The Catholic University of America Vitreous State Laboratory
Melt Rate Enhancement for High Aluminum HLW Glass Formulations

Final Report, VSL-08R1360-1, Rev. 0

During each test, melter exhaust was sampled for particulate and gaseous species to determine the effect of the variations in feed composition and glass temperature on emissions. Total particulate carry-over from both melters into the off-gas stream was only 0.04 to 0.29 percent, which is below the range measured previously on the DM100 and DM1200 when processing other HLW simulants. Melter DFs were determined for most elements in the feed for all eight test segments performed. The most volatile species were sulfur and fluorine, which is typical. Particulate emissions from the melter increased with increasing glass pool temperature and bubbling rate but no obvious change was observed with feed composition. Gaseous emissions of nitrogen oxides and byproducts of incomplete combustion, such as carbon monoxide and ammonia, were very low due to the lack of nitrates and organic carbon in the feed.

The new glass formulations meet all processing and product quality requirements for each of the developed compositions, with waste loadings ranging from 43.6 to $45 \mathrm{wt} \%$ on a waste oxide basis. Glass samples from the crucible and melter tests were subjected to leach testing using the PCT and TCLP methods in order to evaluate product quality. Despite the high waste loadings, the glass products significantly out-performed the DWPF-EA benchmark glass on the PCT leaching procedure by factors of at least 140 and exhibited TCLP leachate concentrations that were well below the WTP delisting limits. Overall, the results from the melter tests and the associated processing and product quality data support the viability of the proposed HLW enhancement approaches. In addition, the results from the DM100 and DM1200 melter tests provided validation of the VGF and DFC melt rate screening tests that were developed and successfully integrated into the glass formulation methodology.

The characteristics of the HWI-Al-19 formulation developed in this work and tested on both the DM100 melter and the DM1200 pilot melter include:

- $45 \mathrm{wt} \%$ waste loading

- Limited by crystallization on CCC and impact on PCT; also spinel formation

- $\mathrm{Al}_{2} \mathrm{O}_{3}$ content $=23.97 \mathrm{wt} \%$ vs. WTP contract minimum of $11 \mathrm{wt} \%$, giving a $54 \%$ reduction in the volume of glass produced from this waste

- Melt rate significantly exceeds the WTP target of $800 \mathrm{~kg} / \mathrm{m}^{2} / \mathrm{d}$ (corresponding to $3 \mathrm{MT} / \mathrm{d}$ per WTP HLW melter) under nominal conditions

- Melt rate of $1500 \mathrm{~kg} / \mathrm{m}^{2} / \mathrm{d}$ demonstrated with optimized bubbling, representing an $87 \%$ increase over the WTP target rate.

In view of the importance of aluminum limited waste streams at Hanford (and also Savannah River), the ability to achieve high waste loadings without adversely impacting melt rates has the potential for enormous cost savings from reductions in canister count and the potential for schedule acceleration. Consequently, the potential return on the investment made in the development of these enhancements is extremely favorable. 


\subsection{Recommendations for Future Work}

The results of the testing presented herein clearly demonstrate the viability of the enhancement and optimization strategies that have been developed. Furthermore, the results have the potential for enormous savings in cost and schedule. As a result, it is recommended that testing and evaluation of these strategies be continued in order to provide a solid basis for their broad implementation in order to maximize the cost and schedule benefits while minimizing technical risk. Some of the elements of such a program are summarized below. While the discussion is centered around Hanford HLW streams, many of these enhancement strategies would also be applicable to other HLW streams, such as those being treated at the DWPF, with the potential for similarly large benefits.

- $\quad$ Other WTP HLW Waste Types: The present testing was based on a single high aluminum HLW composition from the Hanford tanks. While these results are also relevant to waste from several tanks, the diversity of the Hanford tank wastes means that there are several such waste-loading-limiting constituents (and combinations thereof), each of which needs to be addressed in order to maximize the benefit from these enhancements. As a starting point, a similar test program to the one performed in the present work should be performed for each of the principal waste-loading-limiting constituents. Particular attention should be paid to waste streams containing sulfur due to the potential of forming secondary phases on the melt pool surface. In addition, production rates and feed rheology are affected by the form of the major constituents in the waste stream. Melter tests conducted on likely forms of major waste constituents would permit more accurate estimates of potential production rates and processing problems.

- Throughput: A key risk area addressed in the present work relates to the strong dependence of glass production rates on waste composition. The extent of this variation across the full spectrum of HLW waste types needs to be quantified in order to accurately project waste treatment rates. The vast majority of the previous testing for the WTP has been performed on iron-limited wastes and those results have formed the basis for vitrification system capacity projections. The results of the present work suggest that this basis may not be appropriate for other waste types. Testing also needs to be performed to develop approaches to mitigate the potential short-fall in glass production rates.

- Formulating Glasses with higher crystal contents: Previous tests with HLW iron-limited wastes showed that allowing a higher crystal content product can allow significantly increased waste loadings. Evaluation of this enhanced "operational liquidus temperature" approach for other waste streams would result in further waste loading increases.

- Scale-Up Testing: As in the present work, testing should be extended to larger-scale melter systems in order to address potential risks associated with scale-up, particularly with respect to processing rates. Testing should be conducted at the DM1200 WTP HLW Pilot Melter scale $\left(1.2 \mathrm{~m}^{2}\right)$. Optimization of bubbling rate is a critical variable and therefore testing with bubblers in the prototypical orientation at larger scale is required to confirm these findings. 
- Integrated System Testing: Testing on the DM1200 WTP HLW Pilot Melter system provides data from a one-third scale system with a prototypical feed delivery system and off-gas treatment train. Such testing is necessary to evaluate potential interactive effects on system operation arising from implementation of the enhancement strategies and to provide data on the performance of each unit operation, input for flow-sheet models and regulatory requirements, and information of recycle streams.

- Longer-Duration Testing: After validated at larger scale, the duration of testing should be extended in order to address and quantify any chronic issues, such as the slow accumulation of crystals in the melter cavity, any degradation in the ability to discharge glass, and effects on off-gas line plugging.

Finally, it is likely that the maximum production rate for each set of test conditions would have been significantly impacted for most of the tests if the cold cap conditions were not monitored visually. Consequently, it is recommended that the ability to maintain production rates without use of visual information be evaluated, if that is the planned WTP operating mode. 


\section{SECTION 9.0 REFERENCES}

[1] "HLW Enhancement Tests on the DuraMelter" 10 with Hanford AZ-102 Tank Waste Simulants," K.S. Matlack, W.K. Kot, H. Gan, W. Gong and I.L. Pegg, Final Report, VSL-06R6260-1, Rev. 0, Vitreous State Laboratory, The Catholic University of America, Washington, DC, 2/28/06.

[2] "High Level Waste Vitrification System Improvements," K.S. Matlack, H. Gan, W. Gong, I.L. Pegg, C.C. Chapman and I. Joseph, Final Report, VSL-07R1010-1, Rev. 0, Vitreous State Laboratory, The Catholic University of America, Washington, DC, $4 / 16 / 07$.

[3] "High Level Waste Glass Development Testing," K.S. Matlack, W.K. Kot, and I.L. Pegg, Test Plan, VSL-07T1360-1, Rev. 0, Vitreous State Laboratory, The Catholic University of America, Washington, DC, 1/25/08.

[4] "HLW Glass Development Testing," Contract Number DE- RP27-07RV14884, US Department of Energy, Office of River Protection, Richland, WA, 2007.

[5] "Test and Evaluate High Level Waste (HLW) Vitrification System Improvements," Contract Number DE-AC27-06RV14790, US Department of Energy, Office of River Protection, Richland, WA, April, 2006.

[6] "Integrated DM1200 Melter Testing of Bubbler Configurations Using HLW AZ-101 Simulants," K.S. Matlack, W. Gong, T. Bardakci, N. D’Angelo, W. Lutze, R. A. Callow, M. Brandys, W.K. Kot, and I.L. Pegg, Final Report, VSL-04R4800-4, Rev. 0, Vitreous State Laboratory, The Catholic University of America, Washington, DC, 10/5/04.

[7] "Glass Formulation and Testing with RPP-WTP HLW Simulants," W.K. Kot, and I.L. Pegg, Final Report, VSL-01R2540-2, Rev. 0, Vitreous State Laboratory, The Catholic University of America, Washington, DC, 2/16/01.

[8] "Glass Formulation to Support Melter Runs with HLW Simulants," Final Report, W.K. Kot, K. Klatt, and I.L. Pegg, Final Report, VSL-03R3760-2, Rev. 0, Vitreous State Laboratory, The Catholic University of America, Washington, DC, 8/8/03.

[9] "HLW Glass Formulation to Support C-106/AY-102 Actual Waste Testing," W.K. Kot and I.L. Pegg, Final Report, VSL-04R4770-1, Rev. 0, Vitreous State Laboratory, The Catholic University of America, Washington, DC, 8/12/04.

[10] "Development of Phase 1 IHLW Models for PCT Response and One-Percent Crystal Fraction Temperature ( $\left.\mathrm{T}_{1 \%}\right)$," W.K. Kot, H. Gan, Z. Feng, F. Perez-Cardenas, I.L. Pegg, S.K. Cooley, and G. F. Piepel, Final Report, VSL-05R5780-1, Rev. 0, Vitreous State Laboratory, The Catholic University of America, Washington, DC, 4/12/05. 
[11] "Preparation and Testing ( $\mathrm{T}_{1 \%}$ and PCT) of HLW Matrix Glasses to Support WTP Property-Composition Model Development," W.K. Kot, H. Gan, and I.L. Pegg, Final Report, VSL-05R5780-2, Rev. 0, Vitreous State Laboratory, The Catholic University of America, Washington, DC, 10/12/05.

[12] "Summary and Recommendations on Viscosity and Conductivity Model Forms to Support HLW Vitrification," H. Gan, Z. Feng, and I.L. Pegg, Letter Report, VSL04L4780-1, Rev. 0, Vitreous State Laboratory, The Catholic University of America, Washington, DC, 9/8/04.

[13] "Preparation and Testing of HLW Algorithm Glasses to Support Small Scale Melter Testing," W.K. Kot and I.L. Pegg, Final Report, Final Report, VSL-07R1240-1, Rev. 0, Vitreous State Laboratory, The Catholic University of America, Washington, DC, $8 / 24 / 07$.

[14] "Melter Tests with AZ-101 HLW Simulant Using a DuraMelter 100 Vitrification System," K.S. Matlack, W.K. Kot, and I.L. Pegg, Final Report, VSL-01R10N0-1, Rev. 1, Vitreous State Laboratory, The Catholic University of America, Washington, DC, $2 / 25 / 01$.

[15] "DuraMelter 100 HLW Simulant Validation Tests with C-106/AY-102 Feeds," K.S. Matlack, W. Gong and I.L. Pegg, Final Report, VSL-05R5710-1, Rev. 0, Vitreous State Laboratory, The Catholic University of America, Washington, DC, 6/2/05.

[16] "Integrated DM1200 Melter Testing of HLW C-106/AY-102 Composition Using Bubblers," K.S. Matlack, W. Gong, T. Bardakci, N. D’Angelo, W. Kot and I.L. Pegg, Final Report, VSL-03R3800-1, Rev. 0, Vitreous State Laboratory, The Catholic University of America, Washington, DC, 9/15/03.

[17] "Integrated DM1200 Melter Testing of HLW C-104/AY-101 Compositions Using Bubblers," K.S. Matlack, W. Gong, T. Bardakci, N. D’Angelo, W. Kot and I.L. Pegg, Final Report, VSL-03R3800-3, Rev. 0, Vitreous State Laboratory, The Catholic University of America, Washington, DC, 11/24/03.

[18] "DM1200 Tests with AZ-101 HLW Simulants," K.S. Matlack, W. Gong, T. Bardakci, N. D'Angelo, W.K. Kot, and I.L. Pegg, Final Report, VSL-03R3800-4, Rev. 0, Vitreous State Laboratory, The Catholic University of America, Washington, DC, 2/17/04.

[19] "Start-Up and Commissioning Tests on the DM1200 HLW Pilot Melter System Using AZ-101 Waste Simulants," K.S. Matlack, M. Brandys, and I.L. Pegg, Final Report, VSL01R0100-2, Rev. 1, Vitreous State Laboratory, The Catholic University of America, Washington, DC, 10/31/01. 
[20] "Tests on the DuraMelter 1200 HLW Pilot Melter System Using AZ-101 HLW Simulants," K.S. Matlack, W.K. Kot, T. Bardakci, T.R. Schatz, W. Gong, and I.L. Pegg, Final Report, VSL-02R0100-2, Rev. 0, Vitreous State Laboratory, The Catholic University of America, Washington, DC, 6/11/02.

[21] "Integrated DM1200 Melter Testing of HLW AZ-102 Compositions Using Bubblers," K.S. Matlack, W. Gong, T. Bardakci, N. D’Angelo, W. Kot and I.L. Pegg, Final Report, VSL-03R3800-2, Rev. 0, Vitreous State Laboratory, The Catholic University of America, Washington, DC, 9/24/03.

[22] "Integrated DM1200 Melter Testing of Redox Effects Using HLW AZ-101 and C-106/AY-102 Simulants," K.S. Matlack, W. Gong, T. Bardakci, N. D’Angelo, W. Lutze, P. M. Bizot, R. A. Callow, M. Brandys, W.K. Kot, and I.L. Pegg, Final Report, VSL-04R4800-1, Rev. 0, Vitreous State Laboratory, The Catholic University of America, Washington, DC, 5/6/04.

[23] "Integrated DM1200 Melter Testing Using AZ-102 and C-106/AY-102 HLW Simulants: HLW Simulant Verification," K.S. Matlack, W. Gong, T. Bardakci, N. D’Angelo, M. Brandys, W.K. Kot, and I.L. Pegg, Final Report, VSL-05R5800-1, Rev. 0, Vitreous State Laboratory, The Catholic University of America, Washington, DC, 6/27/05.

[24] "Small Scale Melter Testing of HLW Algorithm Glasses: Matrix 1 Tests," K.S. Matlack, W.K. Kot, W. Gong and I.L. Pegg, Final Report, VSL-07R1220-1, Rev. 0, Vitreous State Laboratory, The Catholic University of America, Washington, DC, 11/12/07.

[25] "Small Scale Melter Testing of HLW Algorithm Glasses: Matrix 2 Tests," K.S. Matlack, W.K. Kot, W. Gong and I.L. Pegg, Final Report, VSL-08R1220-1, Rev. 0, Vitreous State Laboratory, The Catholic University of America, Washington, DC, 6/27/08.

[26] "Dissolution in Ceramic Systems: I. Molecular Diffusion, Natural Convection, and Forced Convection,” A.R. Cooper and W.D. Kingery, J. Am. Ceram. Soc., 47, 37 (1964).

[27] "Dissolution in Ceramic Systems: III. Boundary Layer and Concentration Gradient," Y. Oishi, A.R. Cooper and W.D. Kingery, J. Am. Ceram. Soc., 48, 88 (1965).

[28] "Direct and Indirect Dissolution of Sapphire in Calcia-Magnesia-Alumina-Silica Melts: Dissolution Kinetics," K.H. Sandhage and G.J. Yurek, J. Am. Ceram. Soc., 73, 3633 (1990).

[29] A.R. Cooper in "Encyclopedia of Materials Science and Engineering," Ed. M.B. Bever, Pergamon Press, Oxford (1986).

[30] "Fundamentals of Inorganic Glasses," A.K. Varshneya, Academic Press, Inc., San Diego, CA (1994). 
[31] "Melting Rate of Soda-Lime Glasses as Influenced by Grain Sizes of Raw Materials and Additions of Cullet," J.C. Potts, G. Brookover, O.G. Burch, Proc. Am. Ceramic Soc. Annual Meeting (1943).

[32] "Effect of Fine Grinding of Glass Batch on the Rate of Melting, Glass and Ceramics," I.D. Tyachinsky and M.B. Romanovsky, Glass and Ceramics, Vol. 13, Number 1, Springer, New York (1956).

[33] "Electric Melting of Glass," L. Penberthey, Chapter 6, The Handbook of Glass Manufacture, F.V. Tooley, Editor, Books for Industry, Inc., New York (1974).

[34] "BOC Convective Glass Melting System," J. Leblanc, R. Marshall, G. Prusia, T. Clayton, A. Richardson, and N. Simpson, 62nd Conference on Glass Problems: Ceramic Engineering and Science Proceedings, Vol. 23, Issue 1, J. Kieffer, Ed. (2008).

[35] "Advances in Oxy-Fuel Fired Glass Melting Technology," H. Kobayashi, XX International Congress on Glass (ICG), Kyoto (2004).

[36] "Glass Melting Technology: A Technical and Economic Assessment," C.P. Ross and G.L. Tincher, Technical Report, \#DE-FC36-021D14315, M. Rasmussen, Editor, Glass Manufacturing Industry (2004).

[37] "Computation Fluid Dynamics Simulations of a Glass Melting Furnace," A. Egelja and S.A. Lottes, Energy 2000: The Beginning of a New Millenium: Energex 2000, P.J. Catania, N. Balaban, B. Golchert, Proceedings of the 8th International Energy Forum, Las Vegas (2000).

[38] "CFD Applications in Glass Melting Systems," C.Q. Jian, Energy 2000: The Beginning of a New Millenium: Energex 2000, P.J. Catania, N. Balaban, B. Golchert, Proceedings of the 8th International Energy Forum, Las Vegas (2000).

[39] “Prediction for Waste Glass Melt Rate", L. M. Lee, Waste Management, '87, Vol. 1, p 591, Arizona Board of Regents, Tucson, AZ (1987).

[40] "Control of Radioactive Waste Glass Melters: II, Residence Time and Melt Rate Limitations", D.F. Bickford, P. Hrma and B.W. Bowan, II, J. Am. Ceramic Soc., 73, 2093 (1990).

[41] "Behavior of Simulated Hanford Slurries During Conversion to Glass", J.G. Darab, E.M. Meiers, and P.A. Smith, Mat. Res. Soc. Proc., Vol. 556, 215 (1999).

[42] "Waste Glass Melting Stages," L.D. Anderson, T. Dennis, M.L. Elliott, and P. Hrma, Ceramic Transactions, Vol. 39, p 213 (1993). 
[43] "Melt Rate Improvement for DWPF Macrobatch 3: Summary and Recommendations," D.P. Lambert, T.H. Lorier, D.K. Peeler, and M.E. Stone, WSRC-TR-2001-00148, Westinghouse Savannah River Company, Aiken, SC (2001).

[44] "Technetium/Cesium Volatility in DM100 Tests Using HLW AZ-102 and LAW SubEnvelope A1 Simulants," K.S. Matlack, W.K. Kot, and I.L. Pegg, Final Report, VSL04R4710-1, Rev. 0, Vitreous State Laboratory, The Catholic University of America, Washington, DC, 9/28/04.

[45] "Quality Assurance Project Plan for RPP-WTP Support Activities Conducted by VSL," Vitreous State Laboratory, QAPP Rev. 9, Vitreous State Laboratory, The Catholic University of America, Washington, DC, 6/5/07.

[46] "Master List of Controlled VSL Manuals and Standard Operating Procedures in Use," QA-MLCP, Rev. 29, Vitreous State Laboratory, The Catholic University of America, Washington, DC, 7/15/08.

[47] "High-Level Waste Melter Alternate Bubbler Configuration Testing," R.K Mohr, C.C. Chapman and I.L. Pegg, Final Report, VSL-04R4800-3, Rev. 0, 6/18/04.

[48] "Round Robin Testing of a Reference Glass for Low-Activity Waste Forms," W.L. Ebert and S.F. Wolf, Department of Energy report ANL-99/22, Argonne National Laboratory, Argonne, IL, 1999.

[49] "Summary of DM1200 Operation at VSL," K.S. Matlack, G. Diener, T. Bardakci, and I.L. Pegg, Final Report, VSL-06R6710-2, Rev. 0, Vitreous State Laboratory, The Catholic University of America, Washington, DC, 9/7/06.

[50] "Regulatory Off-Gas Emissions Testing on the DM1200 Melter System Using HLW and LAW Simulants," K.S. Matlack, W. Gong, T. Bardakci, N. D'Angelo, M. Brandys, W. Kot, and I.L. Pegg, Final Report VSL-05R5830-1, Rev. 0, Vitreous State Laboratory, The Catholic University of America, Washington, DC, 10/31/05.

[51] "Physical and Rheological Properties of Waste Simulants and Melter Feeds for RPPWTP HLW Vitrification," Final Report, K. Kot, H. Gan, and I.L. Pegg, VSL-00R2520-1, Rev. 0, Vitreous State Laboratory, The Catholic University of America, Washington, DC, $10 / 31 / 01$.

[52] "Review of Properties of Simulated Feeds Used for Melter Testing," K.S. Matlack, W. Gong, and I.L. Pegg, Final Report, VSL-06R6410-1, Rev. 0, Vitreous State Laboratory, The Catholic University of America, Washington, DC, Washington, D.C., 8/16/06.

[53] "New Delisting Limits for Arsenic and Chrome," D. Blumenkranz, e-mail message to J. Westsik, CCN 069211, River Protection Project, Waste Treatment Plant, Richland, WA. 9/15/03. 
[54] "Data Quality Objectives Process in Support of LDR/Delisting at the WTP," J. Cook and D. Blumenkranz, 24590-WTP-RPT-ENV-01-012, Rev. 2, River Protection Project, Waste Treatment Plant, Richland, WA, 3/26/03.

[55] "High-Temperature Melter Tests for Vitrification of BNFL Nuclear Wastes," K.S. Matlack, I.S. Muller, C. Ahearn, R.K. Mohr, and I.L. Pegg, Final Report to BNFL, plc, Vitreous State Laboratory, The Catholic University of America, Washington, DC, May 1998.

[56] "Vitrification," I.L. Pegg and I. Joseph, Chapter 4.2 in "Hazardous and Radioactive Waste Treatment Technologies Handbook,” Ed. C.H. Oh, CRC Press, LLC, 2001.

[57] "Vitrification Testing for Fernald CRU4 Silo Wastes," S.S. Fu, K.S. Matlack, R.K. Mohr, C. Paul, I.L. Pegg, and P.B. Macedo, Final Report, Vitreous State Laboratory, The Catholic University of America, Washington, DC, 9/27/96.

[58] "Small Scale Melter Testing to Assess Impact of Higher Temperature Melter Operations," K.S. Matlack, W. Gong, and I.L. Pegg, Final Report to Dept. of Energy, Office of River Protection, VSL-04R4980-1, Rev. 0, Vitreous State Laboratory, The Catholic University of America, Washington, DC, 2/13/04. 
Table 2.1. Oxide Compositions of Limiting Waste Streams (wt\%).

\begin{tabular}{|c|c|c|c|c|}
\hline $\begin{array}{c}\text { Waste } \\
\text { Component }\end{array}$ & Bi Limited & Cr Limited & Al Limited & $\begin{array}{c}\text { Al and } \mathrm{Na} \\
\text { Limited }\end{array}$ \\
\hline $\mathrm{Al}_{2} \mathrm{O}_{3}$ & $22.45 \%$ & $25.53 \%$ & $49.21 \%$ & $43.30 \%$ \\
\hline $\mathrm{B}_{2} \mathrm{O}_{3}$ & $0.58 \%$ & $0.53 \%$ & $0.39 \%$ & $0.74 \%$ \\
\hline $\mathrm{CaO}$ & $1.61 \%$ & $2.47 \%$ & $2.21 \%$ & $1.47 \%$ \\
\hline $\mathrm{Fe}_{2} \mathrm{O}_{3}$ & $13.40 \%$ & $13.13 \%$ & $12.11 \%$ & $5.71 \%$ \\
\hline $\mathrm{Li}_{2} \mathrm{O}$ & $0.31 \%$ & $0.36 \%$ & $0.35 \%$ & $0.15 \%$ \\
\hline $\mathrm{MgO}$ & $0.82 \%$ & $0.16 \%$ & $0.24 \%$ & $0.44 \%$ \\
\hline $\mathrm{Na}_{2} \mathrm{O}$ & $12.97 \%$ & $20.09 \%$ & $7.35 \%$ & $25.79 \%$ \\
\hline $\mathrm{SiO}_{2}$ & $12.04 \%$ & $10.56 \%$ & $10.05 \%$ & $6.22 \%$ \\
\hline $\mathrm{TiO}_{2}$ & $0.30 \%$ & $0.01 \%$ & $0.02 \%$ & $0.35 \%$ \\
\hline $\mathrm{ZnO}$ & $0.31 \%$ & $0.25 \%$ & $0.17 \%$ & $0.36 \%$ \\
\hline $\mathrm{ZrO}_{2}$ & $0.40 \%$ & $0.11 \%$ & $0.81 \%$ & $0.25 \%$ \\
\hline $\mathrm{SO}_{3}$ & $0.91 \%$ & $1.52 \%$ & $0.41 \%$ & $0.44 \%$ \\
\hline $\mathrm{Bi}_{2} \mathrm{O}_{3}$ & $12.91 \%$ & $7.29 \%$ & $2.35 \%$ & $2.35 \%$ \\
\hline $\mathrm{ThO}_{2}$ & $0.25 \%$ & $0.04 \%$ & $0.37 \%$ & $0.04 \%$ \\
\hline $\mathrm{Cr}_{2} \mathrm{O}_{3}$ & $1.00 \%$ & $3.07 \%$ & $1.07 \%$ & $1.44 \%$ \\
\hline $\mathrm{K}_{2} \mathrm{O}$ & $0.89 \%$ & $0.37 \%$ & $0.29 \%$ & $1.34 \%$ \\
\hline $\mathrm{U}_{3} \mathrm{O}_{8}$ & $3.48 \%$ & $7.59 \%$ & $7.25 \%$ & $4.58 \%$ \\
\hline $\mathrm{BaO}$ & $0.02 \%$ & $0.03 \%$ & $0.11 \%$ & $0.06 \%$ \\
\hline $\mathrm{CdO}$ & $0.00 \%$ & $0.01 \%$ & $0.05 \%$ & $0.02 \%$ \\
\hline $\mathrm{NiO}$ & $3.71 \%$ & $1.06 \%$ & $0.82 \%$ & $0.20 \%$ \\
\hline $\mathrm{PbO}$ & $0.48 \%$ & $0.48 \%$ & $0.84 \%$ & $0.18 \%$ \\
\hline $\mathrm{P}_{2} \mathrm{O}_{5}$ & $9.60 \%$ & $3.34 \%$ & $2.16 \%$ & $4.10 \%$ \\
\hline F- & $1.58 \%$ & $2.00 \%$ & $1.37 \%$ & $0.46 \%$ \\
\hline Total & $100.00 \%$ & $100.00 \%$ & $100.00 \%$ & $100.00 \%$ \\
\hline
\end{tabular}


Table 2.2. Compositions of the Al-Limited Waste (Oxide Basis) and the HLW Waste Simulant to Produce $100 \mathrm{~kg}$ of Waste Oxides (20 wt\% suspended solids) Using $\mathrm{Al}_{2} \mathrm{O}_{3}$ as the Aluminum Source.

\begin{tabular}{|c|c|c|c|}
\hline \multicolumn{2}{|c|}{ Al-Limited Waste Composition } & \multicolumn{2}{|c|}{ Al-Limited HLW Waste Simulant } \\
\hline Waste Oxide & Wt\% & Starting Materials & Target Weight (kg) ${ }^{*}$ \\
\hline $\mathrm{Al}_{2} \mathrm{O}_{3}$ & $49.21 \%$ & $\mathrm{Al}_{2} \mathrm{O}_{3}$ & 49.707 \\
\hline $\mathrm{B}_{2} \mathrm{O}_{3}$ & $0.39 \%$ & $\mathrm{H}_{3} \mathrm{BO}_{3}$ & 0.700 \\
\hline $\mathrm{CaO}$ & $2.21 \%$ & $\mathrm{CaO}$ & 2.255 \\
\hline $\mathrm{Fe}_{2} \mathrm{O}_{3}$ & $12.11 \%$ & $\mathrm{Fe}(\mathrm{OH})_{3}(13 \%)$ Slurry $)$ & 99.643 \\
\hline $\mathrm{Li}_{2} \mathrm{O}$ & $0.35 \%$ & $\mathrm{Li}_{2} \mathrm{CO}_{3}$ & 0.888 \\
\hline $\mathrm{MgO}$ & $0.24 \%$ & $\mathrm{MgO}$ & 0.253 \\
\hline $\mathrm{Na}_{2} \mathrm{O}$ & $7.35 \%$ & $\mathrm{NaOH}$ & 4.235 \\
\hline $\mathrm{SiO}_{2}$ & $10.05 \%$ & $\mathrm{SiO}_{2}$ & 10.152 \\
\hline $\mathrm{TiO}_{2}$ & $0.02 \%$ & $\mathrm{TiO}_{2}$ & 0.020 \\
\hline $\mathrm{ZnO}$ & $0.17 \%$ & $\mathrm{ZnO}$ & 0.172 \\
\hline $\mathrm{ZrO}_{2}$ & $0.81 \%$ & $\mathrm{Zr}(\mathrm{OH})_{4} \cdot x \mathrm{H}_{2} \mathrm{O}$ & 2.093 \\
\hline $\mathrm{SO}_{3}$ & $0.41 \%$ & $\mathrm{Na}_{2} \mathrm{SO}_{4}$ & 0.735 \\
\hline $\mathrm{Bi}_{2} \mathrm{O}_{3}$ & $2.35 \%$ & $\mathrm{Bi}_{2} \mathrm{O}_{3}$ & 2.374 \\
\hline $\mathrm{ThO}_{2}$ & $0.37 \%$ & Th Surrogate & 0 \\
\hline $\mathrm{Cr}_{2} \mathrm{O}_{3}$ & $1.07 \%$ & $\mathrm{Cr}_{2} \mathrm{O}_{3} \cdot 1.5 \mathrm{H}_{2} \mathrm{O}$ & 1.273 \\
\hline $\mathrm{K}_{2} \mathrm{O}$ & $0.29 \%$ & $\mathrm{KNO}_{3}$ & 0.632 \\
\hline $\mathrm{U}_{3} \mathrm{O}_{8}$ & $7.25 \%$ & U Surrogate & 0 \\
\hline $\mathrm{BaO}$ & $0.11 \%$ & $\mathrm{BaCO}_{3}$ & 0.143 \\
\hline $\mathrm{CdO}$ & $0.05 \%$ & $\mathrm{CdO}$ & 0.051 \\
\hline $\mathrm{NiO}$ & $0.82 \%$ & $\mathrm{Ni}(\mathrm{OH})_{2}$ & 1.055 \\
\hline $\mathrm{PbO}$ & $0.84 \%$ & $\mathrm{PbO}$ & 0.848 \\
\hline $\mathrm{P}_{2} \mathrm{O}_{5}$ & $2.16 \%$ & $\mathrm{FePO}_{4} \cdot \times \mathrm{H}_{2} \mathrm{O}$ & 5.738 \\
\hline $\mathrm{F}$ & $1.37 \%$ & $\mathrm{NaF}$ & 3.044 \\
\hline Carbonate & $1.20^{\#}$ & $\mathrm{Na}_{2} \mathrm{CO}_{3}$ & 0.806 \\
\hline Nitrite & 0.50 & $\mathrm{NaNO}_{2}$ & 0.769 \\
\hline Nitrate & 2.00 & $\mathrm{NaNO}_{3}$ & 2.230 \\
\hline Organic Carbon & 0.05 & $\mathrm{H}_{2} \mathrm{C}_{2} \mathrm{O}_{4} \cdot 2 \mathrm{H}_{2} \mathrm{O}$ & 0.264 \\
\hline- & - & Water & 279.400 \\
\hline- & - & - & - \\
\hline TOTAL & $100.0 \%$ & TOTAL & 469.478 \\
\hline
\end{tabular}

${ }^{*}$ Target weights adjusted for assay information of starting materials

${ }^{\#}$ Unit for volatile components is $\mathrm{g} / 100 \mathrm{~g}$ of waste oxide

- Empty data field 
Table 2.3. Compositions of the Al-Limited Waste (Oxide Basis) and the HLW Waste Simulant to Produce $100 \mathrm{~kg}$ of Waste Oxides (20 wt\% suspended solids) Using $\mathrm{Al}(\mathrm{OH})_{3}$ as the Aluminum Source.

\begin{tabular}{|c|c|c|c|}
\hline \multicolumn{2}{|c|}{ Al-Limited Waste Composition } & \multicolumn{2}{|c|}{ Al-Limited HLW Waste Simulant } \\
\hline Waste Oxide & Wt\% & Starting Materials & Target Weight (kg) ${ }^{*}$ \\
\hline $\mathrm{Al}_{2} \mathrm{O}_{3}$ & $49.21 \%$ & $\mathrm{Al}(\mathrm{OH})_{3}$ & 76.052 \\
\hline $\mathrm{B}_{2} \mathrm{O}_{3}$ & $0.39 \%$ & $\mathrm{H}_{3} \mathrm{BO}_{3}$ & 0.700 \\
\hline $\mathrm{CaO}$ & $2.21 \%$ & $\mathrm{CaO}$ & 2.255 \\
\hline $\mathrm{Fe}_{2} \mathrm{O}_{3}$ & $12.11 \%$ & $\mathrm{Fe}(\mathrm{OH})_{3}(13 \%$ Slurry $)$ & 99.643 \\
\hline $\mathrm{Li}_{2} \mathrm{O}$ & $0.35 \%$ & $\mathrm{Li}_{2} \mathrm{CO}_{3}$ & 0.888 \\
\hline $\mathrm{MgO}$ & $0.24 \%$ & $\mathrm{MgO}$ & 0.253 \\
\hline $\mathrm{Na}_{2} \mathrm{O}$ & $7.35 \%$ & $\mathrm{NaOH}$ & 4.235 \\
\hline $\mathrm{SiO}_{2}$ & $10.05 \%$ & $\mathrm{SiO}_{2}$ & 10.152 \\
\hline $\mathrm{TiO}_{2}$ & $0.02 \%$ & $\mathrm{TiO}_{2}$ & 0.020 \\
\hline $\mathrm{ZnO}$ & $0.17 \%$ & $\mathrm{ZnO}$ & 0.172 \\
\hline $\mathrm{ZrO}_{2}$ & $0.81 \%$ & $\mathrm{Zr}(\mathrm{OH})_{4} \cdot x \mathrm{H}_{2} \mathrm{O}$ & 2.093 \\
\hline $\mathrm{SO}_{3}$ & $0.41 \%$ & $\mathrm{Na}_{2} \mathrm{SO}_{4}$ & 0.735 \\
\hline $\mathrm{Bi}_{2} \mathrm{O}_{3}$ & $2.35 \%$ & $\mathrm{Bi}_{2} \mathrm{O}_{3}$ & 2.374 \\
\hline $\mathrm{ThO}_{2}$ & $0.37 \%$ & Th Surrogate & 0 \\
\hline $\mathrm{Cr}_{2} \mathrm{O}_{3}$ & $1.07 \%$ & $\mathrm{Cr}_{2} \mathrm{O}_{3} \cdot 1.5 \mathrm{H}_{2} \mathrm{O}$ & 1.273 \\
\hline $\mathrm{K}_{2} \mathrm{O}$ & $0.29 \%$ & $\mathrm{KNO}_{3}$ & 0.632 \\
\hline $\mathrm{U}_{3} \mathrm{O}_{8}$ & $7.25 \%$ & U Surrogate & 0 \\
\hline $\mathrm{BaO}$ & $0.11 \%$ & $\mathrm{BaCO}_{3}$ & 0.143 \\
\hline $\mathrm{CdO}$ & $0.05 \%$ & $\mathrm{CdO}$ & 0.051 \\
\hline $\mathrm{NiO}$ & $0.82 \%$ & $\mathrm{Ni}(\mathrm{OH})_{2}$ & 1.055 \\
\hline $\mathrm{PbO}$ & $0.84 \%$ & $\mathrm{PbO}$ & 0.848 \\
\hline $\mathrm{P}_{2} \mathrm{O}_{5}$ & $2.16 \%$ & $\mathrm{FePO}_{4} \cdot \times \mathrm{H}_{2} \mathrm{O}$ & 5.738 \\
\hline $\mathrm{F}$ & $1.37 \%$ & $\mathrm{NaF}$ & 3.044 \\
\hline Carbonate & $1.20^{\#}$ & $\mathrm{Na}_{2} \mathrm{CO}_{3}$ & 0.806 \\
\hline Nitrite & 0.50 & $\mathrm{NaNO}_{2}$ & 0.769 \\
\hline Nitrate & 2.00 & $\mathrm{NaNO}_{3}$ & 2.230 \\
\hline Organic Carbon & 0.05 & $\mathrm{H}_{2} \mathrm{C}_{2} \mathrm{O}_{4} \cdot 2 \mathrm{H}_{2} \mathrm{O}$ & 0.264 \\
\hline- & - & Water & $279.400^{4}$ \\
\hline- & - & - & - \\
\hline TOTAL & $100.0 \%$ & TOTAL & $495.825^{4}$ \\
\hline
\end{tabular}

${ }^{*}$ Target weights adjusted for assay information of starting materials

${ }^{\#}$ Unit for volatile components is $\mathrm{g} / 100 \mathrm{~g}$ of waste oxide

- Empty data field 
Table 2.4. Composition and Properties of Aluminum Limited Waste and HLW-E-Al-27 Glass Formulation at 45\% Waste Loading Used in Previous Melter Tests (wt\%).

\begin{tabular}{|c|c|c|c|c|}
\hline- & $\begin{array}{c}\text { Al-Limited } \\
\text { Waste* }\end{array}$ & Waste in Glass & $\begin{array}{c}\text { Glass Forming } \\
\text { Additives }\end{array}$ & $\begin{array}{c}\text { Target Glass } \\
\text { HLW-E-Al-27 }\end{array}$ \\
\hline $\mathrm{Al}_{2} \mathrm{O}_{3}$ & 53.27 & 23.97 & - & 23.97 \\
\hline $\mathrm{B}_{2} \mathrm{O}_{3}$ & 0.42 & 0.19 & 15.00 & 15.19 \\
\hline $\mathrm{BaO}$ & 0.12 & 0.05 & - & 0.05 \\
\hline $\mathrm{Bi}_{2} \mathrm{O}_{3}$ & 2.54 & 1.14 & - & 1.14 \\
\hline $\mathrm{CaO}$ & 2.39 & 1.08 & 5.00 & 6.08 \\
\hline $\mathrm{CdO}$ & 0.05 & 0.02 & - & 0.02 \\
\hline $\mathrm{Cr}_{2} \mathrm{O}_{3}$ & 1.16 & 0.52 & & 0.52 \\
\hline $\mathrm{F}$ & 1.48 & 0.67 & - & 0.67 \\
\hline $\mathrm{Fe}_{2} \mathrm{O}_{3}$ & 13.11 & 5.90 & - & 5.90 \\
\hline $\mathrm{K}_{2} \mathrm{O}$ & 0.31 & 0.14 & - & 0.14 \\
\hline $\mathrm{Li}_{2} \mathrm{O}$ & 0.38 & 0.17 & 3.40 & 3.57 \\
\hline $\mathrm{MgO}_{\mathrm{Na} O}$ & 0.26 & 0.12 & - & 0.12 \\
\hline $\mathrm{Na}_{2} \mathrm{O}$ & 7.96 & 3.58 & 6.00 & 9.58 \\
\hline $\mathrm{NiO}_{2} \mathrm{O}_{5}$ & 0.89 & 0.40 & - & 0.40 \\
\hline $\mathrm{PbO}_{\mathrm{SiO}}$ & 2.34 & 1.05 & - & 1.05 \\
\hline $\mathrm{TiO}_{2}$ & 0.91 & 0.41 & - & 0.41 \\
\hline $\mathrm{SO}_{3}$ & 10.88 & 4.90 & 25.60 & 30.50 \\
\hline $\mathrm{ZnO}_{\mathrm{ZnO}}$ & 0.02 & 0.01 & - & 0.01 \\
\hline $\mathrm{Zrm}_{2}$ & 0.44 & 0.20 & - & 0.20 \\
\hline $\mathrm{Sum}^{2}$ & 0.18 & 0.08 & - & 0.08 \\
\hline $\mathrm{Re}$ & 0.88 & 0.39 & - & 0.39 \\
\hline
\end{tabular}

* Renormalized from Ref. [5] after removal of radioactive components

\begin{tabular}{|c|c|c|c|}
\hline \multicolumn{3}{|c|}{ Viscosity @1150, P } & 46 \\
\hline \multicolumn{3}{|c|}{ Conductivity@1150º, S/cm } & 0.26 \\
\hline \multicolumn{3}{|c|}{ Crystal Content, As Melted } & Trace \\
\hline \multicolumn{3}{|c|}{ Crystal Content, $72 \mathrm{hr}$ at $950^{\circ} \mathrm{C}$} & $\sim 1.0 \mathrm{vol} \%$ \\
\hline \multicolumn{3}{|c|}{ Crystal Content, CCC } & $\sim 1.9$ vol $\%$ \\
\hline \multicolumn{3}{|c|}{ TCLP } & Pass \\
\hline \multirow{4}{*}{ PCT, g/L } & - & DWPF-EA & HLW-E-Al-27 \\
\hline & B & 16.7 & 0.27 \\
\hline & $\mathrm{Li}$ & 9.6 & 0.44 \\
\hline & $\mathrm{Na}$ & 13.3 & 0.30 \\
\hline
\end{tabular}

- Empty data field 
Table 2.5. Compositions of Melter Feed to Produce $100 \mathrm{~kg}$ of Target Glass HLW-E-Al-27 (Glass Yield = $500 \mathrm{~g} / \mathrm{L}$ Feed) from the Al-Limited Waste Simulant Using $\mathrm{Al}(\mathrm{OH})_{3}$ as the Aluminum Source.

\begin{tabular}{|c|c|c|c|}
\hline \multicolumn{2}{|c|}{ Al-Limited Waste Simulant } & \multicolumn{2}{|c|}{ Glass-Forming Additives } \\
\hline Starting Materials & Target Weight (kg) $^{*}$ & Starting Materials & Target Weight (kg) $^{*}$ \\
\hline $\mathrm{Al}(\mathrm{OH})_{3}$ & 37.047 & - & - \\
\hline $\mathrm{H}_{3} \mathrm{BO}_{3}$ & 0.341 & $\mathrm{Na}_{2} \mathrm{~B}_{4} \mathrm{O}_{7} \cdot 10 \mathrm{H}_{2} \mathrm{O}$ & 37.292 \\
\hline $\mathrm{BaCO}_{3}$ & 0.070 & $\mathrm{H}_{3} \mathrm{BO}_{3}$ & 2.729 \\
\hline $\mathrm{Bi}_{2} \mathrm{O}_{3}$ & 1.156 & - & - \\
\hline $\mathrm{CaO}$ & 1.099 & $\mathrm{CaSiO}_{3}$ (Wollastonite) & 10.886 \\
\hline $\mathrm{CdO}$ & 0.025 & - & - \\
\hline $\mathrm{Cr}_{2} \mathrm{O}_{3}$ & 0.532 & - & - \\
\hline $\mathrm{NaF}$ & 1.483 & - & - \\
\hline $\mathrm{Fe}(\mathrm{OH})_{3}(13 \%$ Slurry $)$ & 48.539 & - & - \\
\hline $\mathrm{KNO}_{3}$ & 0.308 & - & - \\
\hline $\mathrm{Li}_{2} \mathrm{CO}_{3}$ & 0.432 & $\mathrm{Li}_{2} \mathrm{CO}_{3}$ & 8.625 \\
\hline $\mathrm{MgO}$ & 0.121 & - & - \\
\hline $\mathrm{NaOH}$ & 2.190 & - & - \\
\hline $\mathrm{Ni}(\mathrm{OH})_{2}$ & 0.514 & - & - \\
\hline $\mathrm{FePO}_{4} \cdot x \mathrm{H}_{2} \mathrm{O}$ & 2.795 & - & - \\
\hline $\mathrm{PbO}$ & 0.413 & - & - \\
\hline $\mathrm{Na}_{2} \mathrm{SO}_{4}$ & 0.358 & - & - \\
\hline $\mathrm{SiO}_{2}$ & 4.945 & $\mathrm{SiO}_{2}$ & 20.251 \\
\hline $\mathrm{TiO}_{2}$ & 0.010 & - & - \\
\hline $\mathrm{ZnO}$ & 0.084 & - & - \\
\hline $\mathrm{Zr}(\mathrm{OH})_{4} \cdot x \mathrm{H}_{2} \mathrm{O}$ & 1.020 & - & - \\
\hline $\mathrm{H}_{2} \mathrm{O}$ & 105.479 & - & - \\
\hline $\mathrm{Na}_{2} \mathrm{CO}_{3}$ & 0.314 & - & - \\
\hline $\mathrm{NaNO}_{2}$ & 0.346 & - & - \\
\hline $\mathrm{NaNO}_{3}$ & 0.984 & - & - \\
\hline $\mathrm{H}_{2} \mathrm{C}_{2} \mathrm{O}_{4} \cdot 2 \mathrm{H}_{2} \mathrm{O}$ & 0.119 & - & - \\
\hline - & - & - & - \\
\hline Simulant Total & 210.724 & Additives Total & 79.783 \\
\hline- & - & FEED TOTAL & 290.507 \\
\hline
\end{tabular}

*Target weights adjusted for assay information of starting materials

- Empty data field 
ORP-56292 Rev. 0

The Catholic University of America

Vitreous State Laboratory

Melt Rate Enhancement for High Aluminum HLW Glass Formulations

Final Report, VSL-08R1360-1, Rev. 0

Table 3.1. Summary of Glass Formulation and the Associated Feed Tests by VGF and Waste Glass Melters (DM100 or DM1200).

\begin{tabular}{|c|c|c|c|c|c|c|}
\hline Glass Name & Feed Name & $\begin{array}{l}\text { Aluminum } \\
\text { Source in } \\
\text { feed }\end{array}$ & $\begin{array}{l}\text { Boron Source } \\
\text { in feed }\end{array}$ & VGF Test & DM100 Test & DM1200 Test \\
\hline HLW-E-Al-27 & BLL-F-135A [2] & $\mathrm{Al}_{2} \mathrm{O}_{3}$ & Borax & Yes & Yes & No \\
\hline HLW-E-Al-27 & BLX-F-50 & $\mathrm{Al}(\mathrm{OH})_{3}$ & Borax & Yes & Yes & No \\
\hline HLW-E-Al-27 & F-Al-VAR-1 & $\mathrm{Al}_{2} \mathrm{O}_{3}$ & Boric acid & Yes & No & No \\
\hline HLW-E-Al-27 & F-Al-VAR-4 & $\mathrm{Al}(\mathrm{OH})_{3}$ & Borax & Yes & No & No \\
\hline HWL-E-Al-27 & F-Al-VAR-2 & $\mathrm{Al}(\mathrm{OH})_{3}$ & Boric acid & Yes & No & No \\
\hline HLW-E-ANa-22 & BLN-F-21A [2] & $\mathrm{Al}_{2} \mathrm{O}_{3}$ & Boric Acid & Yes & Yes & No \\
\hline HLW-E-Bi-6 & BLK-F-84A [2] & $\mathrm{Al}_{2} \mathrm{O}_{3}$ & Borax & Yes & Yes & No \\
\hline HLW-E-CrM & BLL-F-65A [2] & $\mathrm{Al}_{2} \mathrm{O}_{3}$ & Boric acid & Yes & Yes & No \\
\hline Matrix 1-B1 & BLS-F-7A [24] & $\mathrm{Al}_{2} \mathrm{O}_{3}$ & Borax & Yes & Yes & No \\
\hline Matrix 2-9 & BLV-F-132B [25] & $\mathrm{Al}_{2} \mathrm{O}_{3}$ & Borax & Yes & Yes & No \\
\hline HWI-Al-1 & F-HWI-Al-1B & $\mathrm{Al}_{2} \mathrm{O}_{3}$ & Boric Acid & Yes & No & No \\
\hline HWI-Al-2 & - & - & - & - & - & - \\
\hline HWI-Al-3 & - & - & - & - & - & - \\
\hline HWI-Al-4 & - & - & - & - & - & - \\
\hline HWI-Al-5 & F-HWI-Al-5 & $\mathrm{Al}_{2} \mathrm{O}_{3}$ & Boric Acid & Yes & No & No \\
\hline HWI-Al-6 & - & $\mathrm{Al}_{2} \mathrm{O}_{3}$ & Boric Acid & - & - & - \\
\hline HWI-Al-7 & F-HWI-Al-7 & $\mathrm{Al}_{2} \mathrm{O}_{3}$ & Boric Acid & Yes & No & No \\
\hline HWI-Al-8 & - & - & - & - & - & - \\
\hline HWI-Al-9 & F-HWI-Al-9 & $\mathrm{Al}_{2} \mathrm{O}_{3}$ & Boric Acid & Yes & No & No \\
\hline HWI-Al-10 & - & - & - & - & - & - \\
\hline HWI-Al-11 & - & - & - & - & - & - \\
\hline HWI-Al-12 & - & - & - & - & - & - \\
\hline HWI-Al-13 & F-HWI-Al-13 & $\mathrm{Al}_{2} \mathrm{O}_{3}$ & Boric Acid & Yes & No & No \\
\hline HWI-Al-14 & - & - & - & - & - & - \\
\hline HWI-Al-15 & - & - & - & - & - & - \\
\hline HWI-Al-16 & F-HWI-Al-16 & $\mathrm{Al}_{2} \mathrm{O}_{3}$ & Boric Acid & Yes & Yes & No \\
\hline HWI-Al-16 & F-HWI-Al-16B & $\mathrm{Al}(\mathrm{OH})_{3}$ & Boric Acid & Yes & Yes & No \\
\hline HWI-Al-17 & F-HWI-Al-17 & $\mathrm{Al}_{2} \mathrm{O}_{3}$ & Boric Acid & Yes & No & No \\
\hline HWI-Al-18 & F-HWI-Al-18 & $\mathrm{Al}_{2} \mathrm{O}_{3}$ & Boric Acid & Yes & No & No \\
\hline HWI-Al-19 & F-HWI-Al-19F & $\mathrm{Al}_{2} \mathrm{O}_{3}$ & Boric Acid & Yes & No & No \\
\hline HWI-Al-19 & F-HWI-Al-19B & $\mathrm{Al}(\mathrm{OH})_{3}$ & Boric Acid & Yes & Yes & Yes \\
\hline HWI-Al-20 & F-HWI-Al-9KSM & $\mathrm{Al}_{2} \mathrm{O}_{3}$ & Boric Acid & Yes & No & No \\
\hline
\end{tabular}

- Empty data field 
ORP-56292 Rev. 0

Table 3.2. Target and XRF Analysis of HWI Glasses Tested (wt\%).

\begin{tabular}{|c|c|c|c|c|c|c|c|c|}
\hline Glass Name & Al-Limited Waste [2] & $\begin{array}{c}\text { HLW-E-Al-27 } \\
{[2]}\end{array}$ & \multicolumn{2}{|c|}{ HWI-Al-1 } & \multicolumn{2}{|c|}{ HWI-Al-2 } & \multicolumn{2}{|c|}{ HWI-Al-3 } \\
\hline Waste loading \% & 100 & 45 & \multicolumn{2}{|c|}{45} & \multicolumn{2}{|c|}{45} & \multicolumn{2}{|c|}{42.5} \\
\hline- & Target & Target & Target & XRF & Target & XRF & Target & XRF \\
\hline $\mathrm{Al}_{2} \mathrm{O}_{3}$ & 53.27 & 23.97 & 23.97 & 22.16 & 23.97 & 22.14 & 22.64 & 20.88 \\
\hline $\mathrm{B}_{2} \mathrm{O}_{3}$ & 0.42 & 15.19 & 18.19 & 18.19 & 17.69 & 17.69 & 18.18 & 18.18 \\
\hline $\mathrm{BaO}$ & 0.12 & 0.05 & 0.05 & 0.06 & 0.05 & 0.05 & 0.05 & 0.05 \\
\hline $\mathrm{Bi}_{2} \mathrm{O}_{3}$ & 2.54 & 1.14 & 1.14 & 1.29 & 1.14 & 1.21 & 1.08 & 1.17 \\
\hline $\mathrm{CaO}$ & 2.39 & 6.08 & 1.08 & 1.21 & 1.08 & 1.13 & 1.02 & 1.09 \\
\hline $\mathrm{CdO}$ & 0.05 & 0.02 & 0.02 & - & 0.02 & - & 0.02 & - \\
\hline $\mathrm{Cr}_{2} \mathrm{O}_{3}$ & 1.16 & 0.52 & 0.52 & 0.68 & 0.52 & 0.64 & 0.49 & 0.62 \\
\hline $\mathrm{F}$ & 1.48 & 0.67 & 0.67 & NA & 0.67 & NA & 0.63 & NA \\
\hline $\mathrm{Fe}_{2} \mathrm{O}_{3}$ & 13.11 & 5.90 & 5.90 & 6.26 & 5.90 & 5.85 & 5.57 & 5.65 \\
\hline $\mathrm{K}_{2} \mathrm{O}$ & 0.31 & 0.14 & 0.14 & 0.14 & 0.14 & 0.14 & 0.13 & 0.12 \\
\hline $\mathrm{Li}_{2} \mathrm{O}$ & 0.38 & 3.57 & 4.57 & 4.57 & 2.17 & 2.17 & 3.16 & 3.16 \\
\hline $\mathrm{MgO}$ & 0.26 & 0.12 & 0.12 & 0.09 & 0.12 & 0.07 & 0.11 & 0.07 \\
\hline $\mathrm{Na}_{2} \mathrm{O}$ & 7.96 & 9.58 & 9.58 & 9.80 & 12.58 & 13.86 & 13.38 & 14.19 \\
\hline $\mathrm{NiO}$ & 0.89 & 0.40 & 0.40 & 0.42 & 0.40 & 0.37 & 0.38 & 0.39 \\
\hline $\mathrm{P}_{2} \mathrm{O}_{5}$ & 2.34 & 1.05 & 1.05 & 1.24 & 2.05 & 2.34 & 1.99 & 2.30 \\
\hline $\mathrm{PbO}$ & 0.91 & 0.41 & 0.41 & 0.41 & 0.41 & 0.37 & 0.39 & 0.38 \\
\hline $\mathrm{SiO}_{2}$ & 10.88 & 30.50 & 31.50 & 32.66 & 30.40 & 31.22 & 30.12 & 30.99 \\
\hline $\mathrm{TiO}_{2}$ & 0.02 & 0.01 & 0.01 & 0.03 & 0.01 & 0.02 & 0.01 & 0.02 \\
\hline $\mathrm{SO}_{3}$ & 0.44 & 0.20 & 0.20 & 0.23 & 0.20 & 0.22 & 0.19 & 0.23 \\
\hline $\mathrm{ZnO}$ & 0.18 & 0.08 & 0.08 & 0.12 & 0.08 & 0.10 & 0.08 & 0.10 \\
\hline $\mathrm{ZrO}_{2}$ & 0.88 & 0.39 & 0.39 & 0.38 & 0.39 & 0.35 & 0.37 & 0.36 \\
\hline Sum & 100.00 & 100.00 & 100.00 & 99.92 & 100.00 & 99.94 & 100.00 & 99.94 \\
\hline
\end{tabular}

- Empty data field 
Table 3.2. Target and XRF Analysis of HWI Glasses Tested (wt\%) (continued).

\begin{tabular}{|c|c|c|c|c|c|c|c|c|c|c|c|}
\hline Glass Name & \multicolumn{2}{|c|}{ HWI-Al-4 } & \multicolumn{2}{|c|}{ HWI-Al-5 } & \multicolumn{2}{|c|}{ HWI-Al-6 } & \multicolumn{3}{|c|}{ HWI-Al-7 } & \multicolumn{2}{|c|}{ HWI-Al-8 } \\
\hline Waste loading \% & 45 & & 4 & & 4 & & & 45 & & 4 & \\
\hline- & Target & XRF & Target & XRF & Target & XRF & Target & XRF & DCP & Target & XRF \\
\hline $\mathrm{Al}_{2} \mathrm{O}_{3}$ & 23.97 & 23.56 & 23.97 & 23.33 & 23.97 & 23.51 & 23.97 & 23.64 & 22.07 & 23.97 & 23.51 \\
\hline $\mathrm{B}_{2} \mathrm{O}_{3}$ & 17.69 & 17.69 & 15.19 & 15.19 & 15.19 & 15.19 & 15.19 & 15.19 & 16.51 & 15.19 & 15.19 \\
\hline $\mathrm{BaO}$ & 0.05 & 0.05 & 0.05 & 0.06 & 0.05 & 0.06 & 0.05 & 0.05 & 0.06 & 0.05 & 0.05 \\
\hline $\mathrm{Bi}_{2} \mathrm{O}_{3}$ & 1.14 & 1.22 & 1.14 & 1.22 & 1.14 & 1.22 & 1.14 & 1.18 & NA & 1.14 & 1.15 \\
\hline $\mathrm{CaO}$ & 1.08 & 1.11 & 1.08 & 1.18 & 1.08 & 1.12 & 3.08 & 3.24 & 3.05 & 1.08 & 1.11 \\
\hline $\mathrm{CdO}$ & 0.02 & - & 0.02 & - & 0.02 & - & 0.02 & - & NA & 0.02 & - \\
\hline $\mathrm{Cr}_{2} \mathrm{O}_{3}$ & 0.52 & 0.63 & 0.52 & 0.63 & 0.52 & 0.64 & 0.52 & 0.63 & 0.46 & 0.52 & 0.62 \\
\hline $\mathrm{F}$ & 0.67 & NA & 0.67 & NA & 0.67 & NA & 0.67 & NA & NA & 0.67 & NA \\
\hline $\mathrm{Fe}_{2} \mathrm{O}_{3}$ & 5.90 & 5.85 & 5.90 & 5.86 & 5.90 & 5.84 & 5.90 & 5.75 & 5.82 & 5.90 & 5.71 \\
\hline $\mathrm{K}_{2} \mathrm{O}$ & 4.14 & 3.82 & 0.14 & 0.14 & 6.14 & 5.94 & 0.14 & 0.13 & 0.17 & 8.14 & 8.03 \\
\hline $\mathrm{Li}_{2} \mathrm{O}$ & 2.17 & 2.17 & 3.57 & 3.57 & 2.57 & 2.57 & 3.57 & 3.57 & 4.08 & 2.17 & 2.17 \\
\hline $\mathrm{MgO}$ & 0.12 & - & 5.12 & 4.63 & 0.12 & 0.01 & 3.12 & 2.88 & 3.07 & 0.12 & 0.09 \\
\hline $\mathrm{Na}_{2} \mathrm{O}$ & 9.58 & 9.95 & 9.58 & 10.42 & 9.58 & 9.91 & 9.58 & 9.78 & 8.91 & 9.08 & 9.44 \\
\hline $\mathrm{NiO}$ & 0.40 & 0.37 & 0.40 & 0.39 & 0.40 & 0.38 & 0.40 & 0.37 & 0.38 & 0.40 & 0.36 \\
\hline $\mathrm{P}_{2} \mathrm{O}_{5}$ & 1.05 & 1.23 & 1.05 & 1.19 & 1.05 & 1.21 & 1.05 & 1.19 & 1.10 & 1.05 & 1.24 \\
\hline $\mathrm{PbO}$ & 0.41 & 0.37 & 0.41 & 0.39 & 0.41 & 0.38 & 0.41 & 0.38 & NA & 0.41 & 0.37 \\
\hline $\mathrm{SiO}_{2}$ & 30.40 & 31.21 & 30.50 & 30.97 & 30.50 & 31.17 & 30.50 & 31.27 & 33.72 & 29.40 & 30.20 \\
\hline $\mathrm{TiO}_{2}$ & 0.01 & 0.02 & 0.01 & 0.02 & 0.01 & 0.02 & 0.01 & 0.02 & 0.03 & 0.01 & 0.02 \\
\hline $\mathrm{SO}_{3}$ & 0.20 & 0.21 & 0.20 & 0.26 & 0.20 & 0.23 & 0.20 & 0.24 & NA & 0.20 & 0.23 \\
\hline $\mathrm{ZnO}$ & 0.08 & 0.10 & 0.08 & 0.10 & 0.08 & 0.10 & 0.08 & 0.10 & NA & 0.08 & 0.10 \\
\hline $\mathrm{ZrO}_{2}$ & 0.39 & 0.36 & 0.39 & 0.38 & 0.39 & 0.37 & 0.39 & 0.36 & 0.49 & 0.39 & 0.35 \\
\hline Sum & 100.00 & 99.92 & 100.00 & 99.94 & 100.00 & 99.87 & 100.00 & 99.97 & 99.92 & 100.00 & 99.94 \\
\hline
\end{tabular}


Table 3.2. Target and XRF Analysis of HWI Glasses Tested (wt\%) (continued).

\begin{tabular}{|c|c|c|c|c|c|c|c|c|c|c|c|c|}
\hline Glass Name & \multicolumn{3}{|c|}{ HWI-Al-9 } & \multicolumn{3}{|c|}{ HWI-Al-10 } & \multicolumn{2}{|c|}{ HWI-Al-11 } & \multicolumn{2}{|c|}{ HWI-Al-12 } & \multicolumn{2}{|c|}{ HWI-Al-13 } \\
\hline Waste Loading \% & & 40 & & & 40 & & 4 & & 45 & & 4. & \\
\hline- & Target & $\mathrm{XRF}$ & $\mathrm{DCP}$ & Target & $\mathrm{XRF}$ & $\mathrm{DCP}$ & Target & $\mathrm{XRF}$ & Target & $\mathrm{XRF}$ & Target & $\mathrm{XRF}$ \\
\hline $\mathrm{Al}_{2} \mathrm{O}_{3}$ & 21.31 & 20.76 & 19.46 & 21.31 & 20.62 & 19.42 & 23.97 & 23.36 & 23.97 & 23.46 & 23.97 & 23.41 \\
\hline $\mathrm{B}_{2} \mathrm{O}_{3}$ & 18.17 & 18.17 & 19.42 & 18.67 & 18.67 & 19.98 & 18.19 & 18.19 & 18.19 & 18.19 & 15.19 & 15.19 \\
\hline $\mathrm{BaO}$ & 0.05 & 0.06 & 0.05 & 0.05 & 0.06 & 0.05 & 0.05 & 0.05 & 0.05 & 0.05 & 0.05 & 0.06 \\
\hline $\mathrm{Bi}_{2} \mathrm{O}_{3}$ & 1.02 & 1.07 & NA & 1.02 & 1.12 & NA & 1.14 & 1.18 & 1.14 & 1.17 & 1.14 & 1.21 \\
\hline $\mathrm{CaO}$ & 0.96 & 1.00 & 1.21 & 0.96 & 1.04 & 1.20 & 3.08 & 3.20 & 2.08 & 2.14 & 6.08 & 6.24 \\
\hline $\mathrm{CdO}$ & 0.02 & - & NA & 0.02 & - & NA & 0.02 & - & 0.02 & - & 0.02 & - \\
\hline $\mathrm{Cr}_{2} \mathrm{O}_{3}$ & 0.46 & 0.59 & 0.50 & 0.46 & 0.60 & 0.50 & 0.52 & 0.63 & 0.52 & 0.62 & 0.52 & 0.63 \\
\hline $\mathrm{F}$ & 0.59 & NA & NA & 0.59 & NA & NA & 0.67 & NA & 0.67 & NA & 0.67 & NA \\
\hline $\mathrm{Fe}_{2} \mathrm{O}_{3}$ & 5.24 & 5.20 & 5.27 & 5.24 & 5.39 & 5.32 & 5.90 & 5.82 & 5.90 & 5.71 & 5.90 & 5.77 \\
\hline $\mathrm{K}_{2} \mathrm{O}$ & 0.13 & 0.12 & 0.17 & 0.13 & 0.12 & 0.18 & 0.14 & 0.13 & 0.14 & 0.14 & 4.14 & 4.07 \\
\hline $\mathrm{Li}_{2} \mathrm{O}$ & 3.15 & 3.15 & 3.55 & 3.65 & 3.65 & 4.05 & 3.57 & 3.57 & 3.57 & 3.57 & 3.57 & 3.57 \\
\hline $\mathrm{MgO}$ & 0.10 & 0.07 & 0.13 & 0.10 & 0.08 & 0.12 & 0.12 & 0.07 & 0.12 & 0.11 & 0.12 & 0.10 \\
\hline $\mathrm{Na}_{2} \mathrm{O}$ & 13.18 & 13.89 & 12.07 & 13.18 & 13.31 & 12.12 & 9.58 & 9.88 & 9.58 & 10.18 & 6.08 & 6.65 \\
\hline $\mathrm{NiO}$ & 0.36 & 0.35 & 0.38 & 0.36 & 0.37 & 0.38 & 0.40 & 0.37 & 0.40 & 0.36 & 0.40 & 0.38 \\
\hline $\mathrm{P}_{2} \mathrm{O}_{5}$ & 0.94 & 1.06 & 1.03 & 0.94 & 1.06 & 1.02 & 1.05 & 1.24 & 1.05 & 1.22 & 1.05 & 1.19 \\
\hline $\mathrm{PbO}$ & 0.36 & 0.34 & NA & 0.36 & 0.36 & NA & 0.41 & 0.37 & 0.41 & 0.37 & 0.41 & 0.38 \\
\hline $\mathrm{SiO}_{2}$ & 33.35 & 33.48 & 36.31 & 32.35 & 32.82 & 35.39 & 30.50 & 31.19 & 31.50 & 32.01 & 30.00 & 30.39 \\
\hline $\mathrm{TiO}_{2}$ & 0.01 & 0.02 & 0.02 & 0.01 & 0.02 & 0.03 & 0.01 & 0.02 & 0.01 & 0.02 & 0.01 & 0.02 \\
\hline $\mathrm{SO}_{3}$ & 0.18 & 0.22 & NA & 0.18 & 0.23 & NA & 0.20 & 0.24 & 0.20 & 0.23 & 0.20 & 0.25 \\
\hline $\mathrm{ZnO}$ & 0.07 & 0.09 & NA & 0.07 & 0.10 & NA & 0.08 & 0.10 & 0.08 & 0.08 & 0.08 & 0.09 \\
\hline $\mathrm{ZrO}_{2}$ & 0.35 & 0.34 & 0.42 & 0.35 & 0.35 & 0.44 & 0.39 & 0.35 & 0.39 & 0.34 & 0.39 & 0.37 \\
\hline Sum & 100.00 & 99.96 & 99.99 & 100.00 & 99.96 & 100.20 & 100.00 & 99.96 & 100.00 & 99.97 & 100.00 & 99.97 \\
\hline
\end{tabular}

NA - Not analyzed

- Empty data field 
Table 3.2. Target and XRF Analysis of HWI Glasses Tested (wt \%) (continued).

\begin{tabular}{|c|c|c|c|c|c|c|c|c|c|c|c|}
\hline $\begin{array}{l}\text { Glass } \\
\text { Name }\end{array}$ & \multicolumn{2}{|c|}{ HWI-AL-14 } & \multicolumn{2}{|c|}{ HWI-AL-15 } & \multicolumn{2}{|c|}{ HWI-Al-16 } & \multicolumn{2}{|c|}{ HWI-Al-17 } & \multicolumn{2}{|c|}{ HWI-Al-18 } & HWI-Al-18G ${ }^{*}$ \\
\hline $\begin{array}{c}\text { Waste } \\
\text { Loading }\end{array}$ & \multicolumn{2}{|c|}{45} & \multicolumn{2}{|c|}{45} & \multicolumn{2}{|c|}{43.6} & \multicolumn{2}{|c|}{43.6} & \multicolumn{3}{|c|}{42.4} \\
\hline- & Target & XRF & Target & XRF & Target & XRF & Target & XRF & Target & XRF & XRF \\
\hline $\mathrm{Al}_{2} \mathrm{O}_{3}$ & 23.97 & 23.60 & 23.97 & 23.49 & 23.25 & 22.71 & 23.25 & 22.50 & 22.57 & 21.89 & 21.73 \\
\hline $\mathrm{B}_{2} \mathrm{O}_{3}$ & 15.19 & 15.19 & 13.19 & 13.19 & 17.73 & 17.73 & 14.73 & 14.73 & 20.13 & 20.13 & 20.13 \\
\hline $\mathrm{BaO}$ & 0.05 & 0.07 & 0.05 & 0.07 & 0.05 & 0.06 & 0.05 & 0.05 & 0.05 & 0.04 & 0.06 \\
\hline $\mathrm{Bi}_{2} \mathrm{O}_{3}$ & 1.14 & 1.19 & 1.14 & 1.17 & 1.11 & 1.16 & 1.11 & 1.21 & 1.08 & 1.13 & 0.95 \\
\hline $\mathrm{CaO}$ & 5.08 & 5.21 & 5.08 & 5.16 & 5.89 & 6.05 & 5.89 & 6.06 & 5.72 & 5.94 & 5.76 \\
\hline $\mathrm{CdO}$ & 0.02 & - & 0.02 & - & 0.02 & - & 0.02 & - & 0.02 & - & NA \\
\hline $\mathrm{Cr}_{2} \mathrm{O}_{3}$ & 0.52 & 0.64 & 0.52 & 0.64 & 0.51 & 0.62 & 0.51 & 0.64 & 0.49 & 0.61 & 0.54 \\
\hline $\mathrm{F}$ & 0.67 & NA & 0.67 & NA & 0.65 & NA & 0.65 & NA & 0.63 & $\mathrm{NA}$ & NA \\
\hline $\mathrm{Fe}_{2} \mathrm{O}_{3}$ & 5.90 & 5.72 & 5.90 & 5.72 & 5.72 & 5.59 & 5.72 & 5.80 & 5.56 & 5.58 & 5.69 \\
\hline $\mathrm{K}_{2} \mathrm{O}$ & 5.14 & 4.96 & 5.14 & 5.06 & 0.14 & 0.13 & 3.14 & 3.07 & 0.13 & 0.16 & 0.16 \\
\hline $\mathrm{Li}_{2} \mathrm{O}$ & 3.57 & 3.57 & 3.17 & 3.17 & 3.46 & 3.46 & 3.46 & 3.46 & 3.36 & 3.36 & 3.36 \\
\hline $\mathrm{MgO}$ & 0.12 & 0.10 & 0.12 & - & 0.11 & 0.10 & 0.11 & 0.07 & 0.11 & 0.08 & 0.31 \\
\hline $\mathrm{Na}_{2} \mathrm{O}$ & 6.08 & 6.14 & 8.58 & 8.97 & 9.29 & 9.68 & 9.29 & 10.05 & 9.02 & 9.60 & 9.28 \\
\hline $\mathrm{NiO}$ & 0.40 & 0.38 & 0.40 & 0.37 & 0.39 & 0.37 & 0.39 & 0.39 & 0.38 & 0.37 & 0.36 \\
\hline $\mathrm{P}_{2} \mathrm{O}_{5}$ & 1.05 & 1.24 & 1.05 & 1.20 & 1.02 & 1.16 & 1.02 & 1.13 & 0.99 & 1.11 & 1.11 \\
\hline $\mathrm{PbO}$ & 0.41 & 0.37 & 0.41 & 0.37 & 0.40 & 0.36 & 0.40 & 0.39 & 0.39 & 0.35 & 0.35 \\
\hline $\mathrm{SiO}_{2}$ & 30.00 & 30.86 & 29.90 & 30.58 & 29.58 & 30.09 & 29.58 & 29.67 & 28.72 & 28.91 & 29.33 \\
\hline $\mathrm{TiO}_{2}$ & 0.01 & 0.04 & 0.01 & 0.02 & 0.01 & 0.02 & 0.01 & 0.02 & 0.01 & 0.02 & 0.04 \\
\hline $\mathrm{SO}_{3}$ & 0.20 & 0.22 & 0.20 & 0.25 & 0.19 & 0.23 & 0.19 & 0.23 & 0.19 & 0.23 & 0.20 \\
\hline $\mathrm{ZnO}$ & 0.08 & 0.10 & 0.08 & 0.10 & 0.08 & 0.10 & 0.08 & 0.10 & 0.08 & 0.11 & 0.08 \\
\hline $\mathrm{ZrO}_{2}$ & 0.39 & 0.36 & 0.39 & 0.38 & 0.38 & 0.35 & 0.38 & 0.38 & 0.37 & 0.33 & 0.48 \\
\hline Sum & 100.00 & 99.96 & 100.00 & 99.91 & 100.00 & 99.97 & 100.00 & 99.96 & 100.00 & 99.94 & 99.91 \\
\hline
\end{tabular}

* Identical to HWI-Al-18, melted from melter feed and boron additives

NA - Not analyzed

- Empty data field 
Table 3.2. Target and XRF Analysis of HWI Glasses Tested (wt \%) (continued).

\begin{tabular}{|c|c|c|c|c|c|}
\hline Glass Name & \multicolumn{2}{|c|}{ HWI-Al-19 } & \multicolumn{3}{|c|}{ HWI-Al-20 } \\
\hline Waste Loading \% & \multicolumn{2}{|c|}{45} & \multicolumn{3}{|c|}{45} \\
\hline- & Target & XRF & Target & XRF & DCP \\
\hline $\mathrm{Al}_{2} \mathrm{O}_{3}$ & 23.97 & 22.94 & 23.97 & 23.30 & 22.00 \\
\hline $\mathrm{B}_{2} \mathrm{O}_{3}$ & 19.19 & 19.19 & 18.19 & 18.19 & 18.85 \\
\hline $\mathrm{BaO}$ & 0.05 & 0.06 & 0.05 & 0.07 & 0.07 \\
\hline $\mathrm{Bi}_{2} \mathrm{O}_{3}$ & 1.14 & 1.34 & 1.14 & 1.20 & 1.30 \\
\hline $\mathrm{CaO}$ & 5.58 & 6.06 & 1.08 & 1.16 & 1.28 \\
\hline $\mathrm{CdO}$ & 0.02 & - & 0.02 & - & NA \\
\hline $\mathrm{Cr}_{2} \mathrm{O}_{3}$ & 0.52 & 0.69 & 0.52 & 0.64 & 0.50 \\
\hline $\mathrm{F}$ & 0.67 & NA & 0.67 & NA & NA \\
\hline $\mathrm{Fe}_{2} \mathrm{O}_{3}$ & 5.90 & 6.32 & 5.90 & 5.82 & 5.79 \\
\hline $\mathrm{K}_{2} \mathrm{O}$ & 0.14 & 0.16 & 5.14 & 5.26 & 4.61 \\
\hline $\mathrm{Li}_{2} \mathrm{O}$ & 3.57 & 3.57 & 3.17 & 3.17 & 3.58 \\
\hline $\mathrm{MgO}$ & 0.12 & 0.09 & 0.12 & - & 0.44 \\
\hline $\mathrm{Na}_{2} \mathrm{O}$ & 9.58 & 9.54 & 8.58 & 9.48 & 8.21 \\
\hline $\mathrm{NiO}$ & 0.40 & 0.42 & 0.40 & 0.38 & 0.39 \\
\hline $\mathrm{P}_{2} \mathrm{O}_{5}$ & 1.05 & 1.22 & 1.05 & 1.21 & 1.09 \\
\hline $\mathrm{PbO}$ & 0.41 & 0.43 & 0.41 & 0.39 & NA \\
\hline $\mathrm{SiO}_{2}$ & 27.00 & 27.10 & 28.90 & 28.94 & 31.16 \\
\hline $\mathrm{TiO}_{2}$ & 0.01 & 0.03 & 0.01 & 0.01 & 0.05 \\
\hline $\mathrm{SO}_{3}$ & 0.20 & 0.23 & 0.20 & 0.22 & NA \\
\hline $\mathrm{ZnO}$ & 0.08 & 0.12 & 0.08 & 0.10 & 0.08 \\
\hline $\mathrm{ZrO}_{2}$ & 0.39 & 0.42 & 0.39 & 0.38 & 0.53 \\
\hline Sum & 100.00 & 99.92 & 100.00 & 99.91 & 99.93 \\
\hline
\end{tabular}

- Empty data field 
Table 3.3. Characterization of HWI Glasses.

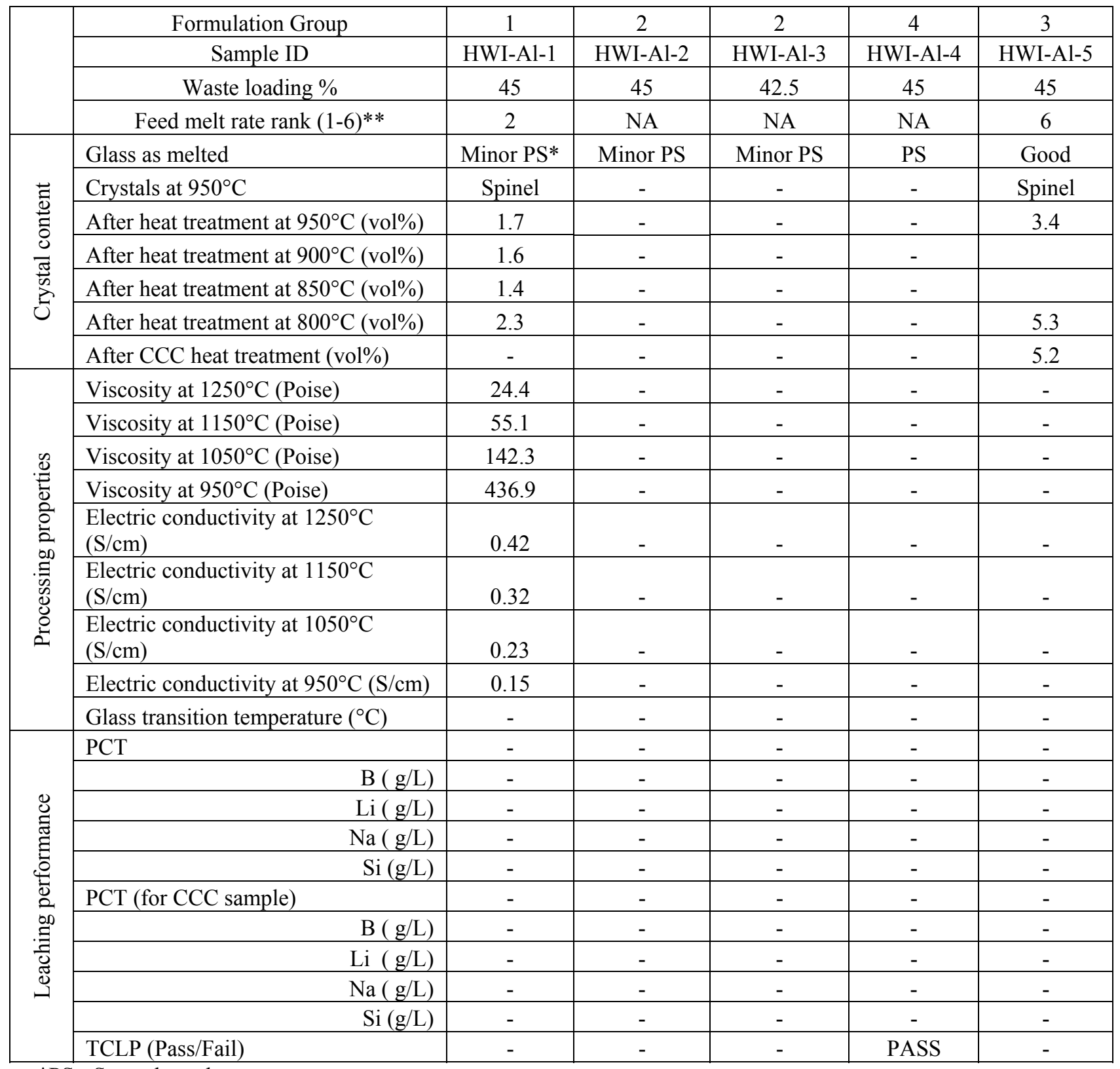

*PS - Secondary phases present

** - Refer to Table 3.5 for definition

- Empty data field 
Table 3.3. Characterization of HWI Glasses (continued).

\begin{tabular}{|c|c|c|c|c|c|c|c|}
\hline & Formulation Group & 4 & 3 & 4 & 1 & 1 & 5 \\
\hline & Sample ID & HWI-Al-6 & HWI-Al-7 & HWI-Al-8 & HWI-Al-9 & HWI-Al-10 & HWI-Al-11 \\
\hline & Waste loading \% & 45 & 45 & 45 & 40 & 40 & 45 \\
\hline & Feed melt rate rank $(1-6)^{* *}$ & NA & 5 & NA & 2 & NA & NA \\
\hline \multirow{7}{*}{ 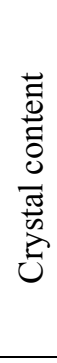 } & Glass as melted & Minor PS & Good & PS & Good & Good & PS \\
\hline & Crystals at $950^{\circ} \mathrm{C}$ & - & Spinel & - & Spinel & Spinel & - \\
\hline & After heat treatment at $950^{\circ} \mathrm{C}(\mathrm{vol} \%)$ & - & 2.7 & - & 0.7 & 0.4 & - \\
\hline & After heat treatment at $900^{\circ} \mathrm{C}(\mathrm{vol} \%)$ & - & 2.8 & - & 0.8 & 0.8 & - \\
\hline & After heat treatment at $850^{\circ} \mathrm{C}(\mathrm{vol} \%)$ & - & 3.2 & - & 0.9 & 0.9 & - \\
\hline & After heat treatment at $800^{\circ} \mathrm{C}(\mathrm{vol} \%)$ & - & 3.9 & - & 1.1 & 0.8 & - \\
\hline & After CCC heat treatment (vol\%) & - & 3.7 & - & 0.7 & 1.3 & - \\
\hline \multirow{9}{*}{ 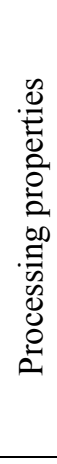 } & Viscosity at $1250^{\circ} \mathrm{C}$ (Poise) & - & 22.9 & - & 29.7 & - & - \\
\hline & Viscosity at $1150^{\circ} \mathrm{C}$ (Poise) & - & 60.6 & - & 63.2 & - & - \\
\hline & Viscosity at $1050^{\circ} \mathrm{C}$ (Poise) & - & 192.5 & - & 163.0 & - & - \\
\hline & Viscosity at $950^{\circ} \mathrm{C}$ (Poise) & - & 777.5 & - & 555.9 & - & - \\
\hline & Electric conductivity at $1250^{\circ} \mathrm{C}(\mathrm{S} / \mathrm{cm})$ & - & 0.35 & - & 0.44 & - & - \\
\hline & Electric conductivity at $1150^{\circ} \mathrm{C}(\mathrm{S} / \mathrm{cm})$ & - & 0.25 & - & 0.33 & - & - \\
\hline & Electric conductivity at $1050^{\circ} \mathrm{C}(\mathrm{S} / \mathrm{cm})$ & - & 0.17 & - & 0.23 & - & - \\
\hline & Electric conductivity at $950^{\circ} \mathrm{C}(\mathrm{S} / \mathrm{cm})$ & - & 0.11 & - & 0.14 & - & - \\
\hline & Glass transition temperature $\left({ }^{\circ} \mathrm{C}\right)(\mathrm{S} / \mathrm{cm})$ & - & - & - & - & - & - \\
\hline \multirow{11}{*}{ 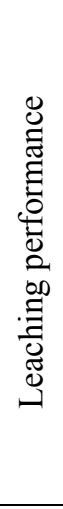 } & PCT & - & - & - & - & - & - \\
\hline & $\mathrm{B}(\mathrm{g} / \mathrm{L})$ & - & 0.267 & - & 1.435 & - & - \\
\hline & $\mathrm{Li}(\mathrm{g} / \mathrm{L})$ & - & 0.467 & - & 1.150 & - & - \\
\hline & $\mathrm{Na}(\mathrm{g} / \mathrm{L})$ & - & 0.305 & - & 0.777 & - & - \\
\hline & $\mathrm{Si}(\mathrm{g} / \mathrm{L})$ & - & 0.201 & - & 0.311 & - & - \\
\hline & PCT (for CCC sample) & - & - & - & & - & - \\
\hline & $\mathrm{B}(\mathrm{g} / \mathrm{L})$ & - & - & - & 3.501 & - & - \\
\hline & $\mathrm{Li}(\mathrm{g} / \mathrm{L})$ & - & - & - & 2.552 & - & - \\
\hline & $\mathrm{Na}(\mathrm{g} / \mathrm{L})$ & - & - & - & 1.383 & - & - \\
\hline & $\mathrm{Si}(\mathrm{g} / \mathrm{L})$ & - & - & - & 0.216 & - & - \\
\hline & TCLP (Pass/Fail) & - & PASS & - & - & - & - \\
\hline
\end{tabular}

*PS - Secondary phases present

** - Refer to Table 3.5 for definition

- Empty data field 
Table 3.3. Characterization of HWI Glasses (continued).

\begin{tabular}{|c|c|c|c|c|c|c|}
\hline & Formulation Group & 5 & 4 & 4 & 4 & 5 \\
\hline & Sample ID & HWI-Al-12 & HWI-Al-13 & HWI-AL-14 & HWI-AL-15 & HWI-Al-16 \\
\hline & Waste loading $\%$ & 45 & 45 & 45 & 45 & 43.6 \\
\hline & Feed melt rate rank $(1-6)^{* *}$ & NA & 4 & NA & NA & 3 \\
\hline \multirow{7}{*}{ 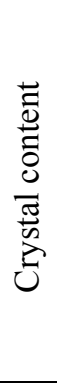 } & Glass as melted & PS & Minor PS & Minor PS & PS & Good \\
\hline & Crystals at $950^{\circ} \mathrm{C}$ & - & $\begin{array}{c}\text { Spinel + minor } \\
\text { Apatitite }\end{array}$ & - & - & Spinel+Apatite \\
\hline & After heat treatment at $950^{\circ} \mathrm{C}(\mathrm{vol} \%)$ & - & 2.5 & - & - & 1.6 \\
\hline & After heat treatment at $900^{\circ} \mathrm{C}(\mathrm{vol} \%)$ & - & 3 & - & - & 2.2 \\
\hline & After heat treatment at $850^{\circ} \mathrm{C}(\mathrm{vol} \%)$ & - & 3.4 & - & - & 2.8 \\
\hline & After heat treatment at $800^{\circ} \mathrm{C}(\mathrm{vol} \%)$ & - & 4.4 & - & - & 3.4 \\
\hline & After CCC heat treatment (vol\%) & - & 2.6 & - & - & 1.9 \\
\hline \multirow{9}{*}{ 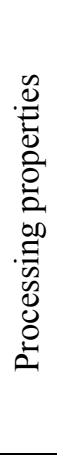 } & Viscosity at $1250^{\circ} \mathrm{C}$ (Poise) & - & - & - & - & 18.9 \\
\hline & Viscosity at $1150^{\circ} \mathrm{C}$ (Poise) & - & - & - & - & 43.1 \\
\hline & Viscosity at $1050^{\circ} \mathrm{C}$ (Poise) & - & - & - & - & 119.1 \\
\hline & Viscosity at $950^{\circ} \mathrm{C}$ (Poise) & - & - & - & - & 432.2 \\
\hline & Electric conductivity at $1250^{\circ} \mathrm{C}(\mathrm{S} / \mathrm{cm})$ & - & - & - & - & 0.35 \\
\hline & Electric conductivity at $1150^{\circ} \mathrm{C}(\mathrm{S} / \mathrm{cm})$ & - & - & - & - & 0.24 \\
\hline & Electric conductivity at $1050^{\circ} \mathrm{C}(\mathrm{S} / \mathrm{cm})$ & - & - & - & - & 0.16 \\
\hline & Electric conductivity at $950^{\circ} \mathrm{C}(\mathrm{S} / \mathrm{cm})$ & - & - & - & - & 0.09 \\
\hline & Glass transition temperature $\left({ }^{\circ} \mathrm{C}\right)$ & - & - & - & - & 475 \\
\hline \multirow{11}{*}{ 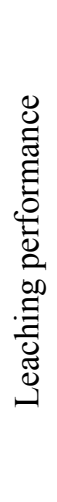 } & PCT & - & - & - & - & - \\
\hline & $\mathrm{B}(\mathrm{g} / \mathrm{L})$ & - & - & - & - & 0.314 \\
\hline & $\operatorname{Li}(\mathrm{g} / \mathrm{L})$ & - & - & - & - & 0.394 \\
\hline & $\mathrm{Na}(\mathrm{g} / \mathrm{L})$ & - & - & - & - & 0.285 \\
\hline & $\mathrm{Si}(\mathrm{g} / \mathrm{L})$ & - & - & - & - & 0.134 \\
\hline & PCT (for CCC sample) & - & - & - & - & - \\
\hline & $\mathrm{B}(\mathrm{g} / \mathrm{L})$ & - & 0.200 & - & - & 0.263 \\
\hline & $\operatorname{Li}(g / L)$ & - & 0.177 & - & - & 0.329 \\
\hline & $\mathrm{Na}(\mathrm{g} / \mathrm{L})$ & - & 0.215 & - & - & 0.237 \\
\hline & $\mathrm{Si}(\mathrm{g} / \mathrm{L})$ & - & 0.120 & - & - & 0.132 \\
\hline & TCLP (Pass/Fail) & - & - & - & - & PASS \\
\hline
\end{tabular}

*PS - Secondary phases present

** - Refer to Table 3.5 for definition

- Empty data field 
Table 3.3. Characterization of HWI Glasses (continued).

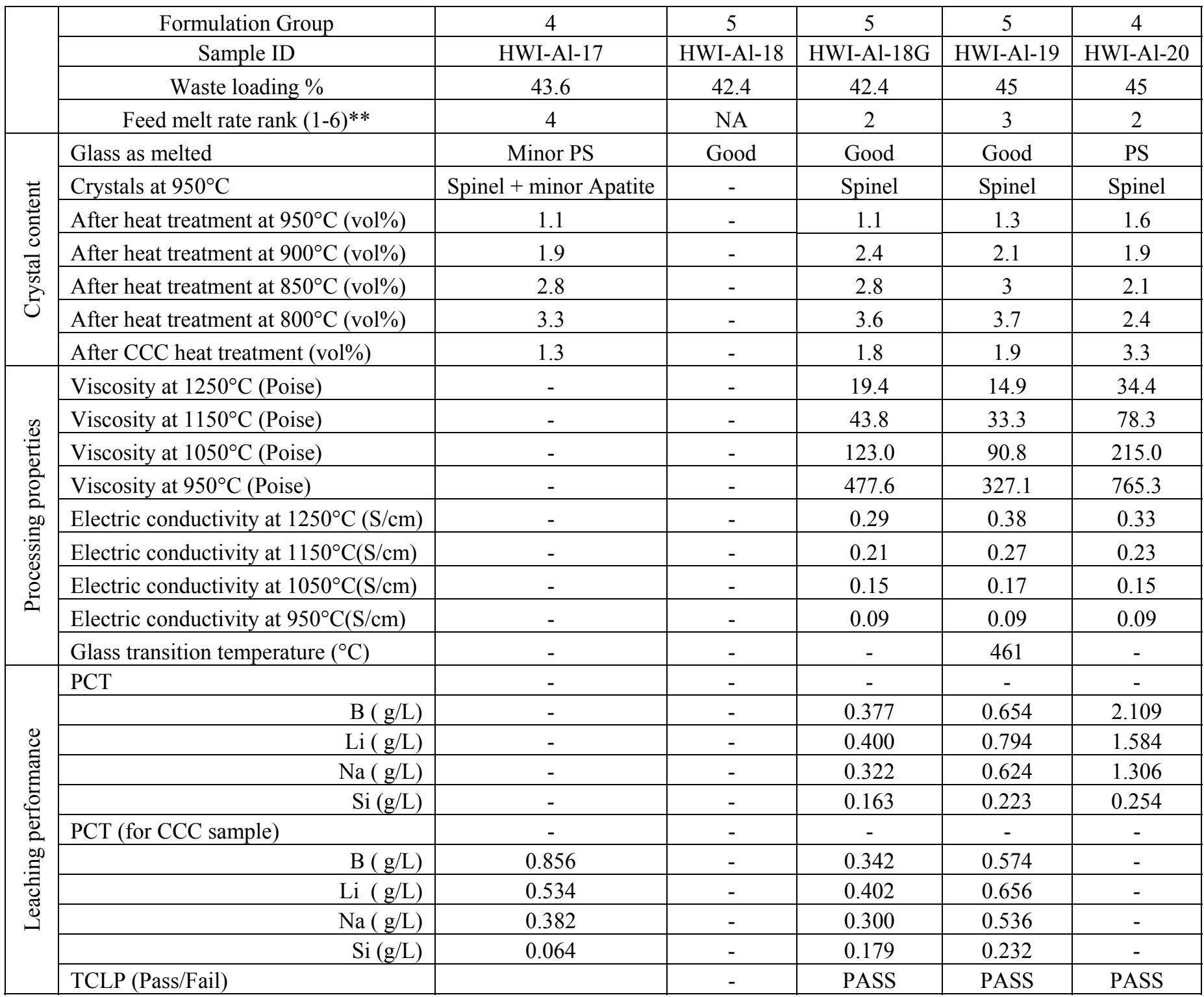

*PS - Secondary phases present

** - Refer to Table 3.5 for definition

- Empty data field 
Table 3.4a. XRF Analysis (wt \%) of Four Melter Feeds Fused at $1150^{\circ} \mathrm{C}$ and After VGF Experiments.

\begin{tabular}{|c|c|c|c|c|c|c|c|c|c|c|c|c|}
\hline & \multicolumn{3}{|c|}{ HLW-E-Al-27 } & \multicolumn{3}{|c|}{ HLW-E-ANa-22 } & \multicolumn{3}{|c|}{ HLW-E-Bi-6 } & \multicolumn{3}{|c|}{ HLW-E-CrM } \\
\hline & Target & VGF (45 min) & Fused $\left(1150^{\circ} \mathrm{C}\right)$ & Target & VGF (15 min) & Fused $\left(1150^{\circ} \mathrm{C}\right)$ & Target & VGF (45 min) & Fused $\left(1150^{\circ} \mathrm{C}\right)$ & Target & VGF (5 min) & Fused $\left(1150^{\circ} \mathrm{C}\right)$ \\
\hline $\mathrm{Al}_{2} \mathrm{O}_{3}$ & 23.97 & 22.20 & 22.40 & 21.34 & 21.04 & 20.56 & 11.66 & 11.04 & 10.91 & 8.98 & 8.76 & 8.71 \\
\hline $\mathrm{B}_{2} \mathrm{O}_{3}{ }^{*}$ & 15.19 & 15.19 & 15.19 & 18.37 & 18.37 & 18.37 & 11.30 & 11.30 & 11.30 & 16.17 & 16.17 & 16.17 \\
\hline $\mathrm{BaO}$ & 0.05 & 0.36 & 0.35 & 0.03 & 0.04 & 0.05 & 0.01 & 0.02 & 0.02 & 0.01 & 0.02 & 0.02 \\
\hline $\mathrm{Bi}_{2} \mathrm{O}_{3}$ & 1.14 & 1.16 & 1.24 & 1.16 & 1.22 & 1.22 & 6.71 & 6.45 & 6.63 & 2.56 & 2.63 & 2.69 \\
\hline $\mathrm{CaO}$ & 6.08 & 5.83 & 6.03 & 0.72 & 1.04 & 0.99 & 0.84 & 0.88 & 0.88 & 0.87 & 0.80 & 0.88 \\
\hline $\mathrm{Cr}_{2} \mathrm{O}_{3}$ & 0.52 & 0.53 & 0.57 & 0.71 & 0.83 & 0.86 & 0.52 & 0.59 & 0.64 & 1.08 & 1.13 & 1.25 \\
\hline $\mathrm{Fe}_{2} \mathrm{O}_{3}$ & 5.90 & 5.87 & 6.27 & 2.82 & 3.04 & 3.06 & 6.96 & 7.19 & 7.41 & 4.62 & 4.59 & 4.75 \\
\hline $\mathrm{K}_{2} \mathrm{O}$ & 0.14 & 0.34 & 0.33 & 0.66 & 0.69 & 0.69 & 0.46 & 0.53 & 0.53 & 6.05 & 5.24 & 5.68 \\
\hline $\mathrm{Li}_{2} \mathrm{O}^{*}$ & 3.57 & 3.57 & 3.57 & 3.58 & 3.58 & 3.58 & 0.16 & 0.18 & 0.16 & 3.68 & 3.68 & 3.68 \\
\hline $\mathrm{MgO}$ & 0.12 & 0.39 & 0.42 & 0.22 & 0.25 & 0.23 & 0.43 & 0.52 & 0.43 & 0.06 & 0.21 & 0.22 \\
\hline $\mathrm{Na}_{2} \mathrm{O}$ & 9.58 & 9.96 & 9.18 & 12.71 & 11.85 & 12.16 & 15.74 & 15.28 & 15.90 & 7.07 & 7.24 & 7.54 \\
\hline $\mathrm{NiO}$ & 0.40 & 0.35 & 0.39 & 0.10 & 0.12 & 0.12 & 1.93 & 1.72 & 1.87 & 0.37 & 0.47 & 0.39 \\
\hline $\mathrm{P}_{2} \mathrm{O}_{5}$ & 1.05 & 1.22 & 1.18 & 2.02 & 2.24 & 2.12 & 4.99 & 5.56 & 5.30 & 1.18 & 1.53 & 1.38 \\
\hline $\mathrm{PbO}$ & 0.41 & 0.35 & 0.37 & 0.09 & 0.10 & 0.10 & 0.25 & 0.29 & 0.30 & 0.17 & 0.15 & 0.15 \\
\hline $\mathrm{SO}_{3}$ & 0.20 & 0.26 & 0.20 & 0.22 & 0.25 & 0.22 & 0.48 & 0.69 & 0.52 & 0.53 & 0.50 & 0.44 \\
\hline $\mathrm{SiO}_{2}$ & 30.50 & 31.75 & 31.65 & 34.56 & 34.73 & 35.09 & 36.26 & 36.64 & 36.09 & 45.76 & 46.60 & 45.82 \\
\hline $\mathrm{TiO}_{2}$ & 0.01 & 0.04 & 0.03 & 0.17 & 0.18 & 0.18 & 0.16 & 0.19 & 0.19 & 0.00 & 0.03 & 0.00 \\
\hline $\mathrm{ZnO}$ & 0.08 & 0.08 & 0.09 & 0.18 & 0.18 & 0.17 & 0.16 & 0.19 & 0.19 & 0.09 & 0.10 & 0.10 \\
\hline $\mathrm{ZrO}_{2}$ & 0.39 & 0.46 & 0.49 & 0.12 & 0.18 & 0.18 & 0.21 & 0.39 & 0.40 & 0.04 & 0.07 & 0.06 \\
\hline
\end{tabular}

* Target values 
Table 3.4b. XRF Analysis (wt\%) of Group 1 Formulation Feeds Fused at $1150^{\circ} \mathrm{C}$ and After VGF Experiments.

\begin{tabular}{|c|c|c|c|c|}
\hline Glass Name & \multicolumn{2}{|c|}{ HWI-Al-1 } & \multicolumn{2}{|c|}{ HWI-Al-9 } \\
\hline Feed Name & $\begin{array}{c}\text { F-HWI-AL-1B- } \\
30 \mathrm{M}\end{array}$ & $\begin{array}{c}\text { F-HWI-AL-1B- } \\
\text { DHG }\end{array}$ & $\begin{array}{c}\text { F-HWI-AL-9- } \\
\text { 30M }\end{array}$ & $\begin{array}{c}\text { F-HWI-AL-9- } \\
\text { DHG }\end{array}$ \\
\hline Sample Condition & VGF (30 minutes) & Fused at $1150^{\circ} \mathrm{C}$ & $\begin{array}{l}\text { VGF (30 } \\
\text { minutes) }\end{array}$ & Fused at $1150^{\circ} \mathrm{C}$ \\
\hline $\mathrm{Al}_{2} \mathrm{O}_{3}$ & 22.68 & 23.08 & 20.79 & 20.32 \\
\hline $\mathrm{B}_{2} \mathrm{O}_{3}{ }^{*}$ & 18.19 & 18.19 & 18.17 & 18.17 \\
\hline $\mathrm{BaO}$ & 0.07 & 0.05 & 0.05 & 0.06 \\
\hline $\mathrm{Bi}_{2} \mathrm{O}_{3}$ & 1.23 & 1.05 & 1.10 & 1.12 \\
\hline $\mathrm{CaO}$ & 1.12 & 0.99 & 1.10 & 1.03 \\
\hline $\mathrm{Cr}_{2} \mathrm{O}_{3}$ & 0.63 & 0.60 & 0.58 & 0.59 \\
\hline $\mathrm{Fe}_{2} \mathrm{O}_{3}$ & 5.90 & 5.56 & 5.25 & 5.44 \\
\hline $\mathrm{K}_{2} \mathrm{O}$ & 0.17 & 0.15 & 0.14 & 0.14 \\
\hline $\mathrm{Li}_{2} \mathrm{O}^{*}$ & 4.57 & 4.57 & 3.15 & 3.15 \\
\hline $\mathrm{MgO}$ & 0.17 & 0.34 & 0.16 & 0.29 \\
\hline $\mathrm{Na}_{2} \mathrm{O}$ & 9.58 & 10.38 & 12.80 & 13.58 \\
\hline $\mathrm{NiO}$ & 0.38 & 0.36 & 0.35 & 0.40 \\
\hline $\mathrm{P}_{2} \mathrm{O}_{5}$ & 1.16 & 1.07 & 1.03 & 1.01 \\
\hline $\mathrm{PbO}$ & 0.38 & 0.29 & 0.35 & 0.37 \\
\hline $\mathrm{SO}_{3}$ & 0.26 & 0.29 & 0.24 & 0.25 \\
\hline $\mathrm{SiO}_{2}$ & 32.87 & 32.42 & 34.14 & 33.44 \\
\hline $\mathrm{TiO}_{2}$ & 0.04 & 0.05 & 0.05 & 0.07 \\
\hline $\mathrm{ZnO}$ & 0.10 & 0.08 & 0.09 & 0.09 \\
\hline $\mathrm{ZrO}_{2}$ & 0.43 & 0.42 & 0.40 & 0.45 \\
\hline
\end{tabular}

* Target values 
Table 3.4c. XRF Analysis (wt\%) of Group 3 Formulation Feeds Fused at $1150^{\circ} \mathrm{C}$ and After VGF Experiments.

\begin{tabular}{|c|c|c|c|c|}
\hline Glass Name & \multicolumn{2}{|c|}{ HWI-Al-5 } & \multicolumn{2}{|c|}{ HWI-Al-7 } \\
\hline Feed Name & F-HWI-AL-5-30M & F-HWI-AL-5-DHG & F-HWI-AL-7-30M & $\begin{array}{c}\text { F-HWI-AL-7- } \\
\text { DHG }\end{array}$ \\
\hline Sample Condition & VGF (30 minutes) & Fused at $1150^{\circ} \mathrm{C}$ & VGF (30 minutes) & Fused at $1150^{\circ} \mathrm{C}$ \\
\hline $\mathrm{Al}_{2} \mathrm{O}_{3}$ & 21.69 & 23.13 & 23.01 & 23.01 \\
\hline $\mathrm{B}_{2} \mathrm{O}_{3}{ }^{*}$ & 15.19 & 15.19 & 15.19 & 15.19 \\
\hline $\mathrm{BaO}$ & 0.06 & 0.05 & 0.05 & 0.05 \\
\hline $\mathrm{Bi}_{2} \mathrm{O}_{3}$ & 1.15 & 1.25 & 1.16 & 1.16 \\
\hline $\mathrm{CaO}$ & 1.16 & 1.17 & 3.16 & 3.16 \\
\hline $\mathrm{Cr}_{2} \mathrm{O}_{3}$ & 0.63 & 0.64 & 0.64 & 0.64 \\
\hline $\mathrm{Fe}_{2} \mathrm{O}_{3}$ & 5.71 & 6.02 & 5.57 & 5.57 \\
\hline $\mathrm{K}_{2} \mathrm{O}$ & 0.17 & 0.16 & 0.17 & 0.17 \\
\hline $\mathrm{Li}_{2} \mathrm{O}^{*}$ & 3.57 & 3.57 & 3.57 & 3.57 \\
\hline $\mathrm{MgO}$ & 4.68 & 4.63 & 2.80 & 2.80 \\
\hline $\mathrm{Na}_{2} \mathrm{O}$ & 10.06 & 9.59 & 10.12 & 10.12 \\
\hline $\mathrm{NiO}$ & 0.39 & 0.40 & 0.38 & 0.38 \\
\hline $\mathrm{P}_{2} \mathrm{O}_{5}$ & 1.16 & 1.13 & 1.13 & 1.13 \\
\hline $\mathrm{PbO}$ & 0.37 & 0.33 & 0.87 & 0.87 \\
\hline $\mathrm{SO}_{3}$ & 0.34 & 0.29 & 0.34 & 0.34 \\
\hline $\mathrm{SiO}_{2}$ & 32.97 & 31.78 & 31.15 & 31.15 \\
\hline $\mathrm{TiO}_{2}$ & 0.05 & 0.05 & 0.06 & 0.06 \\
\hline $\mathrm{ZnO}$ & 0.08 & 0.08 & 0.08 & 0.09 \\
\hline $\mathrm{ZrO}_{2}$ & 0.49 & 0.50 & 0.45 & 0.45 \\
\hline
\end{tabular}

* Target values 
Table 3.4d. XRF Analysis (wt\%) of Group 4 Formulation Feeds Fused at $1150^{\circ} \mathrm{C}$ and After VGF Experiments.

\begin{tabular}{|c|c|c|c|c|c|c|}
\hline Glass Name & \multicolumn{2}{|c|}{ HWI-Al-13 } & \multicolumn{2}{|c|}{ HWI-Al-17 } & \multicolumn{2}{|c|}{ HWI-Al-20 } \\
\hline Feed Name & F-HWI-AL-13-30M & F-HWI-AL-13-DHG & F-HWI-AL-17-30M & F-HWI-AL-17-DHG & F-HWI-AL-9KSM-30M & F-HWI-AL-9KSM-DHG \\
\hline $\begin{array}{c}\text { Sample } \\
\text { Condition }\end{array}$ & VGF (30 minutes) & Fused at $1150^{\circ} \mathrm{C}$ & VGF (30 minutes) & Fused at $1150^{\circ} \mathrm{C}$ & VGF (30 minutes) & Fused at $1150^{\circ} \mathrm{C}$ \\
\hline $\mathrm{Al}_{2} \mathrm{O}_{3}$ & 22.96 & 22.90 & 21.66 & 22.24 & 23.11 & 23.23 \\
\hline $\mathrm{B}_{2} \mathrm{O}_{3}{ }^{*}$ & 15.19 & 15.19 & 14.73 & 14.73 & 18.19 & 18.19 \\
\hline $\mathrm{BaO}$ & 0.07 & 0.06 & 0.07 & 0.06 & 0.06 & 0.06 \\
\hline $\mathrm{Bi}_{2} \mathrm{O}_{3}$ & 1.19 & 1.25 & 1.09 & 1.24 & 1.19 & 1.18 \\
\hline $\mathrm{CaO}$ & 6.17 & 6.31 & 5.89 & 6.09 & 1.08 & 1.07 \\
\hline $\mathrm{Cr}_{2} \mathrm{O}_{3}$ & 0.65 & 0.67 & 0.60 & 0.62 & 0.63 & 0.61 \\
\hline $\mathrm{Fe}_{2} \mathrm{O}_{3}$ & 5.63 & 6.03 & 5.46 & 5.93 & 5.87 & 5.84 \\
\hline $\mathrm{K}_{2} \mathrm{O}$ & 4.02 & 4.09 & 2.98 & 3.02 & 5.07 & 5.06 \\
\hline $\mathrm{Li}_{2} \mathrm{O}^{*}$ & 3.57 & 3.57 & 3.46 & 3.46 & 3.17 & 3.17 \\
\hline $\mathrm{MgO}$ & 0.26 & 0.28 & 0.33 & 0.31 & 0.29 & 0.27 \\
\hline $\mathrm{Na}_{2} \mathrm{O}$ & 6.10 & 6.24 & 9.81 & 9.60 & 8.83 & 9.05 \\
\hline $\mathrm{NiO}$ & 0.38 & 0.41 & 0.37 & 0.40 & 0.37 & 0.37 \\
\hline $\mathrm{P}_{2} \mathrm{O}_{5}$ & 1.28 & 1.13 & 1.18 & 1.13 & 1.10 & 1.08 \\
\hline $\mathrm{PbO}$ & 0.41 & 0.45 & 0.37 & 0.43 & 0.33 & 0.33 \\
\hline $\mathrm{SO}_{3}$ & 0.33 & 0.25 & 0.36 & 0.18 & 0.32 & 0.29 \\
\hline $\mathrm{SiO}_{2}$ & 31.13 & 30.48 & 31.13 & 29.98 & 29.86 & 29.63 \\
\hline $\mathrm{TiO}_{2}$ & 0.06 & 0.05 & 0.05 & 0.05 & 0.04 & 0.04 \\
\hline $\mathrm{ZnO}$ & 0.09 & 0.10 & 0.08 & 0.09 & 0.08 & 0.08 \\
\hline $\mathrm{ZrO}_{2}$ & 0.47 & 0.50 & 0.35 & 0.39 & 0.37 & 0.38 \\
\hline
\end{tabular}

* Target values 
Table 3.4e. XRF Analysis (wt \%) of Group 5 Formulation Feeds Fused at $1150^{\circ} \mathrm{C}$ and After VGF Experiments.

\begin{tabular}{|c|c|c|c|c|c|c|}
\hline Glass Name & \multicolumn{2}{|c|}{ HWI-Al-16 } & \multicolumn{2}{|c|}{ HWI-Al-16 } & \multicolumn{2}{|c|}{ HWI-Al-18 } \\
\hline Feed Name & F-HWI-AL-16-30M & F-HWI-AL-16-DHG & F-HWI-AL-16B-30M & F-HWI-AL-16B-DHG & F-HWI-AL-18-30M & F-HWI-AL-18-DHG \\
\hline $\begin{array}{c}\text { Sample } \\
\text { Condition }\end{array}$ & VGF (30 minutes) & Fused at $1150^{\circ} \mathrm{C}$ & VGF (30 minutes) & Fused at $1150^{\circ} \mathrm{C}$ & VGF (30 minutes) & Fused at $1150^{\circ} \mathrm{C}$ \\
\hline $\mathrm{Al}_{2} \mathrm{O}_{3}$ & 22.48 & 22.40 & 22.55 & 22.19 & 21.75 & 21.39 \\
\hline $\mathrm{B}_{2} \mathrm{O}_{3}{ }^{*}$ & 17.73 & 17.73 & 17.73 & 17.73 & 20.13 & 20.13 \\
\hline $\mathrm{BaO}$ & 0.05 & 0.07 & 0.05 & 0.06 & 0.06 & 0.06 \\
\hline $\mathrm{Bi}_{2} \mathrm{O}_{3}$ & 1.16 & 1.22 & 1.19 & 1.20 & 0.94 & 0.99 \\
\hline $\mathrm{CaO}$ & 5.83 & 5.77 & 6.07 & 6.00 & 5.73 & 5.86 \\
\hline $\mathrm{Cr}_{2} \mathrm{O}_{3}$ & 0.60 & 0.58 & 0.62 & 0.62 & 0.54 & 0.58 \\
\hline $\mathrm{Fe}_{2} \mathrm{O}_{3}$ & 5.43 & 5.38 & 5.73 & 5.82 & 5.60 & 5.90 \\
\hline $\mathrm{K}_{2} \mathrm{O}$ & 0.16 & 0.14 & 0.16 & 0.15 & 0.17 & 0.16 \\
\hline $\mathrm{Li}_{2} \mathrm{O}^{*}$ & 3.46 & 3.46 & 3.46 & 3.46 & 3.36 & 3.36 \\
\hline $\mathrm{MgO}$ & 0.21 & 0.25 & 0.19 & 0.31 & 0.28 & 0.30 \\
\hline $\mathrm{Na}_{2} \mathrm{O}$ & 9.87 & 9.67 & 9.52 & 9.00 & 9.06 & 9.18 \\
\hline $\mathrm{NiO}$ & 0.35 & 0.36 & 0.37 & 0.39 & 0.35 & 0.39 \\
\hline $\mathrm{P}_{2} \mathrm{O}_{5}$ & 1.12 & 1.12 & 1.11 & 1.14 & 1.14 & 1.13 \\
\hline $\mathrm{PbO}$ & 0.39 & 0.64 & 0.37 & 0.46 & 0.35 & 0.36 \\
\hline $\mathrm{SO}_{3}$ & 0.29 & 0.22 & 0.26 & 0.24 & 0.20 & 0.14 \\
\hline $\mathrm{SiO}_{2}$ & 30.23 & 30.36 & 30.05 & 30.64 & 29.64 & 29.37 \\
\hline $\mathrm{TiO}_{2}$ & 0.04 & 0.04 & 0.03 & 0.04 & 0.05 & 0.04 \\
\hline $\mathrm{ZnO}$ & 0.09 & 0.08 & 0.09 & 0.10 & 0.08 & 0.09 \\
\hline $\mathrm{ZrO}_{2}$ & 0.43 & 0.43 & 0.36 & 0.38 & 0.46 & 0.48 \\
\hline
\end{tabular}

* Target values 
Table 3.4e. XRF Analysis (wt\%) of Group 5 Formulation Feeds Fused at $1150^{\circ} \mathrm{C}$ and After VGF Experiments (continued).

\begin{tabular}{|c|c|c|c|c|}
\hline Glass Name & \multicolumn{2}{|c|}{ HWI-Al-19 } & \multicolumn{2}{|c|}{ HWI-Al-19 } \\
\hline Feed Name & $\begin{array}{c}\text { F-HWI-AL-19- } \\
\text { 30M }\end{array}$ & $\begin{array}{c}\text { F-HWI-AL-19- } \\
\text { DHG }\end{array}$ & $\begin{array}{l}\text { F-HWI-AL-19B- } \\
\text { 30M }\end{array}$ & $\begin{array}{c}\text { F-HWI-AL-19B- } \\
\text { DHG }\end{array}$ \\
\hline Sample Condition & VGF (30 minutes) & Fused at $1150^{\circ} \mathrm{C}$ & VGF (30 minutes) & Fused at $1150^{\circ} \mathrm{C}$ \\
\hline $\mathrm{Al}_{2} \mathrm{O}_{3}$ & 23.23 & 22.91 & 23.08 & 22.81 \\
\hline $\mathrm{B}_{2} \mathrm{O}_{3}{ }^{*}$ & 19.19 & 19.19 & 19.19 & 19.19 \\
\hline $\mathrm{BaO}$ & 0.05 & 0.05 & 0.05 & 0.07 \\
\hline $\mathrm{Bi}_{2} \mathrm{O}_{3}$ & 1.19 & 1.18 & 1.14 & 1.18 \\
\hline $\mathrm{CaO}$ & 5.62 & 5.60 & 5.66 & 5.71 \\
\hline $\mathrm{Cr}_{2} \mathrm{O}_{3}$ & 0.63 & 0.64 & 0.62 & 0.62 \\
\hline $\mathrm{Fe}_{2} \mathrm{O}_{3}$ & 5.80 & 6.00 & 5.40 & 5.63 \\
\hline $\mathrm{K}_{2} \mathrm{O}$ & 0.16 & 0.15 & 0.16 & 0.15 \\
\hline $\mathrm{Li}_{2} \mathrm{O}^{*}$ & 3.57 & 3.57 & 3.57 & 3.57 \\
\hline $\mathrm{MgO}$ & 0.23 & 0.33 & 0.31 & 0.29 \\
\hline $\mathrm{Na}_{2} \mathrm{O}$ & 10.05 & 10.00 & 10.47 & 10.51 \\
\hline $\mathrm{NiO}$ & 0.38 & 0.39 & 0.38 & 0.38 \\
\hline $\mathrm{P}_{2} \mathrm{O}_{5}$ & 1.11 & 1.10 & 1.09 & 1.10 \\
\hline $\mathrm{PbO}$ & 0.29 & 0.26 & 0.35 & 0.38 \\
\hline $\mathrm{SO}_{3}$ & 0.32 & 0.17 & 0.36 & 0.16 \\
\hline $\mathrm{SiO}_{2}$ & 27.63 & 27.77 & 27.67 & 27.69 \\
\hline $\mathrm{TiO}_{2}$ & 0.05 & 0.05 & 0.04 & 0.04 \\
\hline $\mathrm{ZnO}$ & 0.09 & 0.09 & 0.07 & 0.08 \\
\hline $\mathrm{ZrO}_{2}$ & 0.36 & 0.38 & 0.35 & 0.39 \\
\hline
\end{tabular}

* Target values 
Table 3.4f. XRF Analysis (wt\%) of Existing High Fe Melter Feeds and Variations of Baseline Feed for HLW-E-Al-27.

\begin{tabular}{|c|c|c|c|c|c|c|}
\hline Glass Name & \multicolumn{2}{|c|}{ HLW-E-Al-27 } & \multicolumn{2}{|c|}{ HLW-E-Al-27 } & \multicolumn{2}{|c|}{ HLW-E-Al-27 } \\
\hline Feed Name & F-AL-VAR1-45M & F-AL-VAR1-DHG & F-AL-VAR2-45M & F-AL-VAR2-DHG & F-AL-VAR4-45M & F-AL-VAR4-DHG \\
\hline $\begin{array}{c}\text { Sample } \\
\text { Condition }\end{array}$ & VGF (45 minutes) & Fused at $1150^{\circ} \mathrm{C}$ & VGF (45 minutes) & Fused at $1150^{\circ} \mathrm{C}$ & VGF (45 minutes) & Fused at $1150^{\circ} \mathrm{C}$ \\
\hline $\mathrm{Al}_{2} \mathrm{O}_{3}$ & 21.59 & 22.95 & 23.33 & 22.97 & 22.92 & 23.30 \\
\hline $\mathrm{B}_{2} \mathrm{O}_{3}{ }^{*}$ & 15.19 & 15.19 & 15.19 & 15.19 & 15.19 & 15.19 \\
\hline $\mathrm{BaO}$ & 0.08 & 0.08 & 0.05 & 0.07 & 0.06 & 0.07 \\
\hline $\mathrm{Bi}_{2} \mathrm{O}_{3}$ & 1.16 & 1.19 & 1.08 & 1.21 & 1.15 & 1.20 \\
\hline $\mathrm{CaO}$ & 6.06 & 6.14 & 5.93 & 6.12 & 5.88 & 5.93 \\
\hline $\mathrm{Cr}_{2} \mathrm{O}_{3}$ & 0.64 & 0.64 & 0.62 & 0.64 & 0.62 & 0.63 \\
\hline $\mathrm{Fe}_{2} \mathrm{O}_{3}$ & 5.76 & 5.98 & 5.54 & 6.09 & 5.70 & 5.90 \\
\hline $\mathrm{K}_{2} \mathrm{O}$ & 0.16 & 0.15 & 0.16 & 0.15 & 0.15 & 0.15 \\
\hline $\mathrm{Li}_{2} \mathrm{O}^{*}$ & 3.57 & 3.57 & 3.57 & 3.57 & 3.57 & 3.57 \\
\hline $\mathrm{MgO}$ & 0.34 & 0.29 & 0.33 & 0.30 & 0.37 & 0.36 \\
\hline $\mathrm{MnO}$ & 0.00 & 0.00 & 0.00 & 0.00 & 0.00 & 0.00 \\
\hline $\mathrm{Na}_{2} \mathrm{O}$ & 9.90 & 9.42 & 9.91 & 10.09 & 9.75 & 9.75 \\
\hline $\mathrm{NiO}$ & 0.38 & 0.39 & 0.37 & 0.41 & 0.37 & 0.38 \\
\hline $\mathrm{P}_{2} \mathrm{O}_{5}$ & 1.16 & 1.04 & 1.14 & 1.08 & 1.13 & 1.06 \\
\hline $\mathrm{PbO}$ & 0.34 & 0.36 & 0.27 & 0.31 & 0.28 & 0.29 \\
\hline $\mathrm{SO}_{3}$ & 0.39 & 0.29 & 0.37 & 0.24 & 0.35 & 0.27 \\
\hline $\mathrm{SiO}_{2}$ & 32.63 & 31.63 & 31.54 & 30.83 & 31.84 & 31.23 \\
\hline $\mathrm{TiO}_{2}$ & 0.04 & 0.04 & 0.04 & 0.04 & 0.04 & 0.05 \\
\hline $\mathrm{ZnO}$ & 0.07 & 0.08 & 0.08 & 0.09 & 0.08 & 0.08 \\
\hline $\mathrm{ZrO}_{2}$ & 0.48 & 0.50 & 0.42 & 0.51 & 0.46 & 0.49 \\
\hline
\end{tabular}


Table 3.4f. XRF Analysis (wt\%) of Existing High Fe Melter Feeds and Variations of Baseline Feed for HLW-E-Al-27 (continued).

\begin{tabular}{|c|c|c|c|c|c|c|}
\hline Glass Name & \multicolumn{2}{|c|}{ HLW-E-Al-27 } & \multicolumn{2}{|c|}{ Matrix 1-B1 } & \multicolumn{2}{|c|}{ Matrix 2-9 } \\
\hline Feed Name & BLX-F-50B-60M & BLX-F-50B-DHG & BLS-F-7A & BLS-F-7A & BLV-F-132B & BLV-F-132B \\
\hline $\begin{array}{c}\text { Sample } \\
\text { Condition }\end{array}$ & VGF (60 minutes) & Fused at $1150^{\circ} \mathrm{C}$ & $\begin{array}{l}\text { VGF (15 } \\
\text { minutes) }\end{array}$ & Fused at $1150^{\circ} \mathrm{C}$ & $\begin{array}{l}\text { VGF (5 } \\
\text { minutes) }\end{array}$ & Fused at $1150^{\circ} \mathrm{C}$ \\
\hline $\mathrm{Al}_{2} \mathrm{O}_{3}$ & 23.17 & 23.13 & 6.04 & 5.60 & 12.57 & 12.50 \\
\hline $\mathrm{B}_{2} \mathrm{O}_{3}{ }^{*}$ & 15.19 & 15.19 & 9.41 & 9.41 & 13.88 & 13.88 \\
\hline $\mathrm{BaO}$ & 0.06 & 0.07 & 0.00 & 0.00 & 0.00 & 0.00 \\
\hline $\mathrm{Bi}_{2} \mathrm{O}_{3}$ & 1.09 & 1.24 & 0.00 & 0.00 & 0.00 & 0.00 \\
\hline $\mathrm{CaO}$ & 5.85 & 6.12 & 0.46 & 0.46 & 0.31 & 0.35 \\
\hline $\mathrm{Cr}_{2} \mathrm{O}_{3}$ & 0.54 & 0.61 & 0.08 & 0.09 & 0.08 & 0.08 \\
\hline $\mathrm{Fe}_{2} \mathrm{O}_{3}$ & 5.43 & 6.02 & 11.92 & 12.39 & 10.30 & 10.66 \\
\hline $\mathrm{K}_{2} \mathrm{O}$ & 0.18 & 0.18 & 0.00 & 0.00 & 0.00 & 0.00 \\
\hline $\mathrm{Li}_{2} \mathrm{O}^{*}$ & 3.57 & 3.57 & 3.02 & 3.02 & 2.43 & 2.43 \\
\hline $\mathrm{MgO}$ & 0.23 & 0.23 & 1.26 & 1.22 & 1.26 & 1.22 \\
\hline $\mathrm{MnO}$ & 0.00 & 0.00 & 3.37 & 3.81 & 2.85 & 3.19 \\
\hline $\mathrm{Na}_{2} \mathrm{O}$ & 10.60 & 9.58 & 12.28 & 10.78 & 14.12 & 12.69 \\
\hline $\mathrm{NiO}$ & 0.34 & 0.38 & 0.15 & 0.17 & 0.13 & 0.15 \\
\hline $\mathrm{P}_{2} \mathrm{O}_{5}$ & 1.20 & 1.21 & 0.10 & 0.10 & 0.11 & 0.10 \\
\hline $\mathrm{PbO}$ & 0.34 & 0.37 & 0.13 & 0.13 & 0.11 & 0.11 \\
\hline $\mathrm{SO}_{3}$ & 0.25 & 0.20 & 0.00 & 0.00 & 0.00 & 0.00 \\
\hline $\mathrm{SiO}_{2}$ & 31.38 & 31.23 & 46.82 & 48.05 & 37.43 & 38.36 \\
\hline $\mathrm{TiO}_{2}$ & 0.04 & 0.04 & 0.22 & 0.22 & 0.23 & 0.23 \\
\hline $\mathrm{ZnO}$ & 0.08 & 0.09 & 1.85 & 1.98 & 1.55 & 1.64 \\
\hline $\mathrm{ZrO}_{2}$ & 0.34 & 0.40 & 0.28 & 0.31 & 0.25 & 0.27 \\
\hline
\end{tabular}

* Target values 
Table 3.5. Ranking Definition for Feed Conversion after 30 Minutes in VGF.

\begin{tabular}{|l|l|}
\hline 1 & Very Fast, all feed converted \\
\hline 2 & Fast with minor residue on side wall \\
\hline 3 & Moderate with foamy residue on side wall \\
\hline 4 & Slow with thick foam layer \\
\hline 5 & Slow with partially collapsed dome \\
\hline 6 & Very slow with fully developed dome \\
\hline
\end{tabular}


Table 3.6. Compositions of the Al-Limited Waste (Oxide Basis) and the HLW Waste Simulant to Produce $100 \mathrm{~kg}$ of Waste Oxides (20 wt \% suspended solids) (from [2]).

\begin{tabular}{|c|c|c|c|}
\hline \multicolumn{2}{|c|}{ Al-Limited Waste Composition } & \multicolumn{2}{|c|}{ Al-Limited HLW Waste Simulant } \\
\hline Waste Oxide & $\mathrm{Wt} \%$ & Starting Materials & Target Weight (kg) $^{*}$ \\
\hline $\mathrm{Al}_{2} \mathrm{O}_{3}$ & $49.21 \%$ & $\mathrm{Al}_{2} \mathrm{O}_{3}$ & 49.707 \\
\hline $\mathrm{B}_{2} \mathrm{O}_{3}$ & $0.39 \%$ & $\mathrm{H}_{3} \mathrm{BO}_{3}$ & 0.700 \\
\hline $\mathrm{CaO}$ & $2.21 \%$ & $\mathrm{CaO}$ & 2.255 \\
\hline $\mathrm{Fe}_{2} \mathrm{O}_{3}$ & $12.11 \%$ & $\mathrm{Fe}(\mathrm{OH})_{3}(13 \%$ Slurry $)$ & 99.643 \\
\hline $\mathrm{Li}_{2} \mathrm{O}$ & $0.35 \%$ & $\mathrm{Li}_{2} \mathrm{CO}_{3}$ & 0.888 \\
\hline $\mathrm{MgO}$ & $0.24 \%$ & $\mathrm{MgO}$ & 0.253 \\
\hline $\mathrm{Na}_{2} \mathrm{O}$ & $7.35 \%$ & $\mathrm{NaOH}$ & 4.235 \\
\hline $\mathrm{SiO}_{2}$ & $10.05 \%$ & $\mathrm{SiO}_{2}$ & 10.152 \\
\hline $\mathrm{TiO}_{2}$ & $0.02 \%$ & $\mathrm{TiO}_{2}$ & 0.020 \\
\hline $\mathrm{ZnO}$ & $0.17 \%$ & $\mathrm{ZnO}$ & 0.172 \\
\hline $\mathrm{ZrO}_{2}$ & $0.81 \%$ & $\mathrm{Zr}(\mathrm{OH})_{4} \cdot x \mathrm{H}_{2} \mathrm{O}$ & 2.093 \\
\hline $\mathrm{SO}_{3}$ & $0.41 \%$ & $\mathrm{Na}_{2} \mathrm{SO}_{4}$ & 0.735 \\
\hline $\mathrm{Bi}_{2} \mathrm{O}_{3}$ & $2.35 \%$ & $\mathrm{Bi}_{2} \mathrm{O}_{3}$ & 2.374 \\
\hline $\mathrm{ThO}_{2}$ & $0.37 \%$ & \multicolumn{2}{|c|}{ Omitted } \\
\hline $\mathrm{Cr}_{2} \mathrm{O}_{3}$ & $1.07 \%$ & $\mathrm{Cr}_{2} \mathrm{O}_{3} \cdot 1.5 \mathrm{H}_{2} \mathrm{O}$ & 1.273 \\
\hline $\mathrm{K}_{2} \mathrm{O}$ & $0.29 \%$ & $\mathrm{KNO}_{3}$ & 0.632 \\
\hline $\mathrm{U}_{3} \mathrm{O}_{8}$ & $7.25 \%$ & \multicolumn{2}{|c|}{ Omitted } \\
\hline $\mathrm{BaO}$ & $0.11 \%$ & $\mathrm{BaCO}_{3}$ & 0.143 \\
\hline $\mathrm{CdO}$ & $0.05 \%$ & $\mathrm{CdO}$ & 0.051 \\
\hline $\mathrm{NiO}$ & $0.82 \%$ & $\mathrm{Ni}(\mathrm{OH})_{2}$ & 1.055 \\
\hline $\mathrm{PbO}$ & $0.84 \%$ & $\mathrm{PbO}$ & 0.848 \\
\hline $\mathrm{P}_{2} \mathrm{O}_{5}$ & $2.16 \%$ & $\mathrm{FePO}_{4} \cdot x \mathrm{H}_{2} \mathrm{O}$ & 5.738 \\
\hline $\mathrm{F}$ & $1.37 \%$ & $\mathrm{NaF}$ & 3.044 \\
\hline Carbonate & $1.20^{\#}$ & $\mathrm{Na}_{2} \mathrm{CO}_{3}$ & 0.806 \\
\hline Nitrite & 0.50 & $\mathrm{NaNO}_{2}$ & 0.769 \\
\hline Nitrate & 2.00 & $\mathrm{NaNO}_{3}$ & 2.230 \\
\hline Organic Carbon & 0.05 & $\mathrm{H}_{2} \mathrm{C}_{2} \mathrm{O}_{4} \cdot 2 \mathrm{H}_{2} \mathrm{O}$ & 0.264 \\
\hline- & - & Water & 279.400 \\
\hline TOTAL & $100.0 \%$ & TOTAL & 469.478 \\
\hline
\end{tabular}

${ }^{*}$ Target weights adjusted for assay information of starting materials

${ }^{\#}$ Unit for volatile components is $\mathrm{g} / 100 \mathrm{~g}$ of waste oxide

- Empty data field 
Table 3.7. TCLP Results (ppm) for Selected HWI Glasses.

\begin{tabular}{|l|c|c|c|c|c|c|c|}
\hline Element & $\mathrm{Ba}$ & $\mathrm{Bi}$ & $\mathrm{Cd}$ & $\mathrm{Cr}$ & $\mathrm{Ni}$ & $\mathrm{Pb}$ & $\mathrm{Zn}$ \\
\hline UTS Limits & 21 & $\mathrm{~N} / \mathrm{A}$ & 0.11 & 0.6 & 11 & 0.75 & 4.3 \\
\hline Delisting Limits & 100 & $\mathrm{~N} / \mathrm{A}$ & 0.48 & 4.95 & 22.6 & 5 & 225 \\
\hline HLW-E-Al27R1 [2] & 0.12 & 0.91 & $\mathrm{NA}$ & 0.21 & 0.20 & 0.37 & 0.13 \\
\hline HWI-Al-4 & 0.14 & 0.55 & $<0.03$ & 0.03 & $<0.04$ & 0.18 & $\mathrm{NA}$ \\
\hline HWI-Al-7 & 0.17 & $\mathrm{NA}$ & $<0.03$ & 0.02 & 0.12 & 0.43 & $\mathrm{NA}$ \\
\hline HWI-Al-16 & 0.13 & $\mathrm{NA}$ & $<0.03$ & 0.17 & 0.27 & 0.50 & $\mathrm{NA}$ \\
\hline HWI-Al-18G & 0.17 & 0.74 & 0.04 & 0.08 & 0.23 & 0.31 & NA \\
\hline HWI-Al-19 & 0.17 & 0.86 & $<0.03$ & 0.23 & 0.23 & 0.45 & NA \\
\hline HWI-Al-20 & 0.16 & 0.78 & $<0.03$ & 0.13 & $<0.04$ & 0.30 & NA \\
\hline
\end{tabular}

\# For comparison only; does not apply to WTP glasses

N/A- Not Applicable

NA-Not analyzed

Table 3.8. Melt Rate Ranking of Feed Samples by VGF vs. Glass Production Rate by DM100 at $1150^{\circ} \mathrm{C}$.

\begin{tabular}{|c|c|c|c|c|}
\hline Waste Stream & Glass Name & Feed Sample & $\begin{array}{c}\text { VGF Melt Rate } \\
\text { Ranking* }\end{array}$ & $\begin{array}{l}\text { Glass Production } \\
\text { Rate }\left(\mathrm{kg} / \mathrm{m}^{2} / \text { day }\right)\end{array}$ \\
\hline Al-limited $\left(\mathrm{Al}_{2} \mathrm{O}_{3}\right)[2]$ & HLW-E-Al-27 & BLL-F-135A & 6 & 550 \\
\hline Al-limited $\left(\mathrm{Al}(\mathrm{OH})_{3}\right)$ & HLW-E-Al-27 & BLX-F-50 & 5 & 700 \\
\hline Al/Na-limited [2] & HLW-E-ANa-22 & BLN-F-21A & 3 & 400 \\
\hline Bi-limited [2] & HLW-E-Bi-6 & BLK-F-84A & 5 & 830 \\
\hline Cr-limited [2] & HLW-E-CrM & BLL-F-65A & 1 & 1150 \\
\hline Algorithm Matrix 1 [24] & Matrix 1-B1 & BLS-F-7A & 3 & 1000 \\
\hline Algorithm Matrix 2 [25] & Matrix 2-9 & BLV-F-132B & 3 & 900 \\
\hline Al-limited $\left(\mathrm{Al}_{2} \mathrm{O}_{3}\right)$ & HWI-Al-16 & F-HWI-Al-16 & 3 & 700 \\
\hline Al-limited $\left(\mathrm{Al}(\mathrm{OH})_{3}\right)$ & HWI-Al-16 & F-HWI-Al-16B & 2 & 950 \\
\hline Al-limited $\left(\mathrm{Al}(\mathrm{OH})_{3}\right)$ & HWI-Al-19 & F-HWI-Al-19B & 2 & 950 \\
\hline
\end{tabular}

*: Based on Table 3.5 


\section{Table 3.9. Crystalline Phases in the Partially Reacted Feed (VGF) Identified by SEM/EDS} and XRD.

\begin{tabular}{|c|c|c|c|c|}
\hline 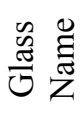 & $\begin{array}{l}\text { Feed Sample } \\
\text { (VGF test time) }\end{array}$ & $\begin{array}{l}\text { Al Form } \\
\text { in Feed } \\
\text { Recipe }\end{array}$ & $\begin{array}{l}\text { Phase identified by SEM/EDS } \\
\text { (Surface sample) }\end{array}$ & $\begin{array}{c}\text { Phase identified by } \\
\text { XRD } \\
\text { (Bulk sample) }\end{array}$ \\
\hline \multirow{2}{*}{ 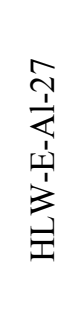 } & $\begin{array}{l}\text { BLL-F-135 } \\
\text { (60 minutes) }\end{array}$ & $\mathrm{Al}_{2} \mathrm{O}_{3}$ & $\begin{array}{l}\text { - Sodalite (wide spread) } \\
\text { - Spinel (NiFe) } \\
\text { - Ca-Phosphate } \\
\text { - NaCaFeAl-Silicate }\end{array}$ & $\begin{array}{l}\text {-Quartz } \\
\text {-Spinel } \\
\text {-Nepheline } \\
\text {-Sodalite }\end{array}$ \\
\hline & $\begin{array}{l}\text { BLX-F-50 } \\
\text { (60 minutes) }\end{array}$ & $\mathrm{Al}(\mathrm{OH})_{3}$ & $\begin{array}{l}\text { - Sodalite } \\
\text { - Zr rich oxide with } \mathrm{Na}, \mathrm{Ca}, \mathrm{A}, \mathrm{SSi} \\
\text { - Fe rich oxide with } \mathrm{Ca}, \mathrm{Al}, \mathrm{Si}\end{array}$ & $\begin{array}{l}\cdot \text { Quartz } \\
\cdot \text {-Spinel } \\
\cdot \text { Nepheline } \\
\text {-Sodalite } \\
\end{array}$ \\
\hline \multirow{2}{*}{ 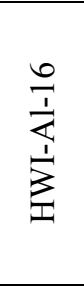 } & $\begin{array}{l}\text { F-HWI-Al-16 } \\
\text { (30 minutes) }\end{array}$ & $\mathrm{Al}_{2} \mathrm{O}_{3}$ & $\begin{array}{l}\text { - Spinel (NiCrFe) } \\
\text { - Ca-Phosphate } \\
\text { - NaCaFeAl-Silicate } \\
\text { - CaAl-Silicate with Zr } \\
\end{array}$ & $\begin{array}{l}\text {-Zircon } \\
\text {-Spinel } \\
\text { •Sodalite }\end{array}$ \\
\hline & $\begin{array}{l}\text { F-HWI-Al-16B } \\
\text { (30 minutes) }\end{array}$ & $\mathrm{Al}(\mathrm{OH})_{3}$ & $\begin{array}{l}\text { - Spinel (NiCrFe) } \\
\text { - Zr oxide with Ca, Al, Si }\end{array}$ & $\begin{array}{l}\text {-Zircon } \\
\text {-Spinel } \\
\text { •Sodalite }\end{array}$ \\
\hline \multirow{2}{*}{$\sum_{\substack{1 \\
1}}^{\frac{9}{1}}$} & $\begin{array}{l}\text { F-HWI-Al-19F } \\
\text { (30 minutes) }\end{array}$ & $\mathrm{Al}_{2} \mathrm{O}_{3}$ & $\begin{array}{l}\text { - Sodalite (wide spread) } \\
\text { - Spinel (NiCrFe) } \\
\text { - Ca-Phosphate }\end{array}$ & $\begin{array}{l}\text {-Zircon } \\
\text {-Spinel } \\
\text { •Sodalite } \\
\text {-Quartz } \\
\end{array}$ \\
\hline & $\begin{array}{l}\text { F-HWI-Al-19B } \\
\text { (30 minutes) }\end{array}$ & $\mathrm{Al}(\mathrm{OH})_{3}$ & $\begin{array}{l}\text { - NaCaAlFe-Silicate } \\
\text { - Spinel (NiCrFe) } \\
\text { - Zr oxide with Ca, Al, Si }\end{array}$ & $\begin{array}{l}\text {-Zircon } \\
\text {-Spinel } \\
\text { •Sodalite } \\
\text {-Quartz }\end{array}$ \\
\hline
\end{tabular}


Table 3.10. Target Glass Compositions for Base Feeds Used During DM10 Melter Rate Tests (wt\%).

\begin{tabular}{|c|c|c|c|c|c|c|c|c|c|c|c|c|}
\hline Base Feed & \multicolumn{3}{|c|}{$\begin{array}{l}\text { HLW-E-Al-27 with } \mathrm{Al}_{2} \mathrm{O}_{3} \\
\text { (see Table 2.2) }\end{array}$} & \multicolumn{3}{|c|}{$\begin{array}{c}\text { HLW-E-Al-27 with } \mathrm{Al}(\mathrm{OH})_{3} \\
\text { (see Table } 2.3 \text { ) }\end{array}$} & \multicolumn{3}{|c|}{$\begin{array}{c}\text { HLW-E-Al-27 with } \mathrm{Al}_{2} \mathrm{O}_{3} \text { and } \\
\text { Boric Acid/Soda Ash Replacing } \\
\text { Borax }\end{array}$} & \multicolumn{3}{|c|}{$\begin{array}{c}\text { HLW-E-Al-27 with } \mathrm{Al}_{2} \mathrm{O}_{3} \text {, and } \\
\text { Boric Acid/ } \mathrm{K}_{2} \mathrm{CO}_{3} \text { Replacing } \\
\text { Borax }\end{array}$} \\
\hline Test s & $\begin{array}{c}50,51,79 \\
105,153\end{array}$ & \multicolumn{2}{|c|}{64,65} & $\begin{array}{c}66,92 \\
118,149 \\
205 \\
\end{array}$ & \multicolumn{2}{|c|}{$86,115,147$} & 67,93 & \multicolumn{2}{|c|}{87,116} & $\begin{array}{c}68,94 \\
119,126 \\
155 \\
\end{array}$ & \multicolumn{2}{|c|}{$88,117,148$} \\
\hline Feed $(\mathrm{g})$ & 1000 & \multicolumn{2}{|c|}{950} & 1000 & \multicolumn{2}{|c|}{950} & 1000 & \multicolumn{2}{|c|}{950} & 1000 & \multicolumn{2}{|c|}{950} \\
\hline Type of Additive & None & $\mathrm{HNO}_{3}$ & Sugar & None & $\mathrm{HNO}_{3}$ & Sugar & None & $\mathrm{HNO}_{3}$ & Sugar & None & $\mathrm{HNO}_{3}$ & Sugar \\
\hline Additive & $0 \mathrm{~g}$ & $50 \mathrm{ml}$ & $17 \mathrm{~g}$ & 0 & $50 \mathrm{ml}$ & $17 \mathrm{~g}$ & $0 \mathrm{~g}$ & $50 \mathrm{ml}$ & $17 \mathrm{~g}$ & $0 \mathrm{~g}$ & $50 \mathrm{ml}$ & $17 \mathrm{~g}$ \\
\hline $\mathrm{Al}_{2} \mathrm{O}_{3}$ & 23.97 & \multicolumn{2}{|c|}{23.97} & 23.97 & \multicolumn{2}{|c|}{23.97} & 23.97 & \multicolumn{2}{|c|}{23.97} & 23.97 & \multicolumn{2}{|c|}{23.97} \\
\hline $\mathrm{B}_{2} \mathrm{O}_{3}$ & 15.19 & \multicolumn{2}{|c|}{15.19} & 15.19 & \multicolumn{2}{|c|}{15.19} & 15.19 & \multicolumn{2}{|c|}{15.19} & 15.19 & \multicolumn{2}{|c|}{15.19} \\
\hline $\mathrm{BaO}$ & 0.05 & \multicolumn{2}{|c|}{0.05} & 0.05 & \multicolumn{2}{|c|}{0.05} & 0.05 & \multicolumn{2}{|c|}{0.05} & 0.05 & \multicolumn{2}{|c|}{0.05} \\
\hline $\mathrm{Bi}_{2} \mathrm{O}_{3}$ & 1.14 & \multicolumn{2}{|c|}{1.14} & 1.14 & \multicolumn{2}{|c|}{1.14} & 1.14 & \multicolumn{2}{|c|}{1.14} & 1.14 & \multicolumn{2}{|c|}{1.14} \\
\hline $\mathrm{CaO}$ & 6.08 & \multicolumn{2}{|c|}{6.08} & 6.08 & & & 6.08 & & & 6.08 & & \\
\hline $\mathrm{CdO}$ & 0.02 & & & 0.02 & & & 0.02 & & & 0.02 & & \\
\hline $\mathrm{Cr}_{2} \mathrm{O}_{3}$ & 0.52 & & & 0.52 & & & 0.52 & & & 0.52 & & \\
\hline $\mathrm{F}$ & 0.67 & & & 0.67 & & & 0.67 & & & 0.67 & & \\
\hline $\mathrm{Fe}_{2} \mathrm{O}_{3}$ & 5.90 & & & 5.90 & & & 5.90 & & & 5.90 & & \\
\hline $\mathrm{K}_{2} \mathrm{O}$ & 0.14 & & & 0.14 & & & 0.14 & & & 6.14 & & \\
\hline $\mathrm{Li}_{2} \mathrm{O}$ & 3.57 & & & 3.57 & & & 3.57 & & & 3.57 & & \\
\hline $\mathrm{MgO}$ & 0.12 & & & 0.12 & & & 0.12 & & & 0.12 & & \\
\hline $\mathrm{Na}_{2} \mathrm{O}$ & 9.58 & & & 9.58 & & & 9.58 & & & 3.58 & & \\
\hline $\mathrm{NiO}$ & 0.40 & & & 0.40 & & & 0.40 & & & 0.40 & & \\
\hline $\mathrm{P}_{2} \mathrm{O}_{5}$ & 1.05 & & & 1.05 & & & 1.05 & & & 1.05 & & \\
\hline $\mathrm{PbO}$ & 0.41 & & & 0.41 & & & 0.41 & & & 0.41 & & \\
\hline $\mathrm{SiO}_{2}$ & 30.50 & & & 30.50 & & & 30.50 & & & 30.50 & & \\
\hline $\mathrm{SO}_{3}$ & 0.20 & & & 0.20 & & & 0.20 & & & 0.20 & & \\
\hline $\mathrm{TiO}_{2}$ & 0.01 & & & 0.01 & & & 0.01 & & & 0.01 & & \\
\hline $\mathrm{ZnO}$ & 0.08 & & & 0.08 & & & 0.08 & & & 0.08 & & \\
\hline $\mathrm{ZrO}_{2}$ & 0.39 & & & 0.39 & & & 0.39 & & & 0.39 & & \\
\hline Sum & 100.00 & & & 100.00 & & & 100.00 & & & 100.00 & & \\
\hline
\end{tabular}


Table 3.10. Target Glass Compositions for Base Feeds Used During DM10 Melter Rate Tests (wt\%) (continued).

\begin{tabular}{|c|c|c|c|c|c|c|c|c|c|c|}
\hline Feed type & \multicolumn{5}{|c|}{ HWI-Al-9Melt } & \multicolumn{5}{|c|}{ HWI-Al-9KSM } \\
\hline Test \#s & $\begin{array}{c}154,166 \\
180\end{array}$ & \multicolumn{2}{|c|}{173,202} & \multicolumn{2}{|c|}{175,204} & $\begin{array}{c}156,179 \\
181\end{array}$ & \multicolumn{2}{|c|}{174,203} & \multicolumn{2}{|c|}{176} \\
\hline Feed $(\mathrm{g})$ & 1000 & \multicolumn{2}{|c|}{950} & \multicolumn{2}{|c|}{975} & 1000 & \multicolumn{2}{|c|}{950} & \multicolumn{2}{|c|}{975} \\
\hline Type of Additive & None & HNO3 & Sugar & HNO3 & Sugar & None & HNO3 & Sugar & HNO3 & Sugar \\
\hline Additive & $0 \mathrm{~g}$ & $50 \mathrm{ml}$ & $17 \mathrm{~g}$ & $25 \mathrm{ml}$ & $8.5 \mathrm{~g}$ & $0 \mathrm{~g}$ & $50 \mathrm{ml}$ & $17 \mathrm{~g}$ & $25 \mathrm{ml}$ & $8.5 \mathrm{~g}$ \\
\hline $\mathrm{Al}_{2} \mathrm{O}_{3}$ & 21.31 & \multicolumn{2}{|c|}{21.31} & \multicolumn{2}{|c|}{21.31} & 23.97 & \multicolumn{2}{|c|}{23.97} & \multicolumn{2}{|c|}{23.97} \\
\hline $\mathrm{B}_{2} \mathrm{O}_{3}$ & 18.17 & \multicolumn{2}{|c|}{18.17} & \multicolumn{2}{|c|}{18.17} & 18.19 & \multicolumn{2}{|c|}{18.19} & \multicolumn{2}{|c|}{18.19} \\
\hline $\mathrm{BaO}$ & 0.05 & \multicolumn{2}{|c|}{0.05} & \multicolumn{2}{|c|}{0.05} & 0.05 & \multicolumn{2}{|c|}{0.05} & \multicolumn{2}{|c|}{0.05} \\
\hline $\mathrm{Bi}_{2} \mathrm{O}_{3}$ & 1.02 & \multicolumn{2}{|c|}{1.02} & \multicolumn{2}{|c|}{1.02} & 1.14 & \multicolumn{2}{|c|}{1.14} & \multicolumn{2}{|c|}{1.14} \\
\hline $\mathrm{CaO}$ & 0.96 & \multicolumn{2}{|c|}{0.96} & \multicolumn{2}{|c|}{0.96} & 1.08 & \multicolumn{2}{|c|}{1.08} & \multicolumn{2}{|c|}{1.08} \\
\hline $\mathrm{CdO}$ & 0.02 & & & & & 0.02 & & & & \\
\hline $\mathrm{Cr}_{2} \mathrm{O}_{3}$ & 0.46 & & & & & 0.52 & & & & \\
\hline $\mathrm{F}$ & 0.59 & & & & & 0.67 & & & & \\
\hline $\mathrm{Fe}_{2} \mathrm{O}_{3}$ & 5.24 & & & & & 5.90 & & & & \\
\hline $\mathrm{K}_{2} \mathrm{O}$ & 0.13 & & & & & 5.14 & & & & \\
\hline $\mathrm{Li}_{2} \mathrm{O}$ & 3.15 & & & & & 3.17 & & & & \\
\hline $\mathrm{MgO}$ & 0.10 & & & & & 0.12 & & & & \\
\hline $\mathrm{Na}_{2} \mathrm{O}$ & 13.18 & & & & & 8.58 & & & & \\
\hline $\mathrm{NiO}$ & 0.36 & & & & & 0.40 & & & & \\
\hline $\mathrm{P}_{2} \mathrm{O}_{5}$ & 0.94 & & & & & 1.05 & & & & \\
\hline $\mathrm{PbO}$ & 0.36 & & & & & 0.41 & & & & \\
\hline $\mathrm{SiO}_{2}$ & 33.35 & & & & & 28.90 & & & & \\
\hline $\mathrm{SO}_{3}$ & 0.18 & & & & & 0.20 & & & & \\
\hline $\mathrm{TiO}_{2}$ & 0.01 & & & & & 0.01 & & & & \\
\hline $\mathrm{ZnO}$ & 0.07 & & & & & 0.08 & & & & \\
\hline $\mathrm{ZrO}_{2}$ & 0.35 & & & & & 0.39 & & & & \\
\hline Sum & 100.00 & & & & & 100.00 & & & & \\
\hline
\end{tabular}


ORP-56292 Rev. 0

Table 3.11. Target Compositions for Vitrified Melter Feed with Various Additives During DM10 Melter Rate Tests (wt\%).

\begin{tabular}{|c|c|c|c|c|c|c|c|c|c|c|c|c|}
\hline \multirow{2}{*}{$\begin{array}{c}\text { Base Feed } \\
\text { Test \#s }\end{array}$} & \multicolumn{12}{|c|}{ HLW-E-Al-27 with $\mathrm{Al}_{2} \mathrm{O}_{3}$} \\
\hline & $\begin{array}{c}50,51, \\
64,65,79, \\
105,153 \\
\end{array}$ & 58,59 & 52,53 & $\begin{array}{c}75,101 \\
124\end{array}$ & 56,57 & 60,61 & 54,55 & 62,63 & 159,182 & 199 & 162,186 & 167,192 \\
\hline Feed (g) & $950-1000$ & 950 & 950 & 950 & 950 & 950 & 950 & 950 & 900 & 900 & 900 & 900 \\
\hline Type of Additive & None & Boric Acid & $\mathrm{Na} 2 \mathrm{CO} 3$ & $\mathrm{~K} 2 \mathrm{CO} 3$ & Borax & $\mathrm{Li} 2 \mathrm{CO} 3$ & $\mathrm{CaCO} 3$ & $\mathrm{SiO} 2$ & Boric Acid & $\mathrm{Na} 2 \mathrm{CO} 3$ & $\mathrm{~K} 2 \mathrm{CO} 3$ & Borax \\
\hline Additive (g) & 0 & \begin{tabular}{|l|}
50 \\
\end{tabular} & 50 & 50 & 50 & 50 & 50 & 50 & \begin{tabular}{l|l}
100 \\
\end{tabular} & 100 & 100 & 100 \\
\hline $\mathrm{Al}_{2} \mathrm{O}_{3}$ & 23.97 & 22.17 & 22.12 & 21.85 & 21.82 & 22.66 & 22.19 & 20.98 & 20.47 & 20.36 & 19.89 & 19.84 \\
\hline $\mathrm{B}_{2} \mathrm{O}_{3}$ & 15.19 & 21.55 & 14.01 & 13.84 & 20.04 & 14.36 & 14.06 & 13.29 & 27.58 & 12.90 & 12.60 & 24.50 \\
\hline $\mathrm{BaO}$ & 0.05 & 0.05 & 0.05 & 0.05 & 0.05 & 0.05 & 0.05 & 0.05 & 0.05 & 0.05 & 0.04 & 0.04 \\
\hline $\mathrm{Bi}_{2} \mathrm{O}_{3}$ & 1.14 & 1.06 & 1.06 & 1.04 & 1.04 & 1.08 & 1.06 & 1.00 & 0.98 & 0.97 & 0.95 & 0.95 \\
\hline $\mathrm{CaO}$ & 6.08 & 5.62 & 5.61 & 5.54 & 5.53 & 5.74 & 13.06 & 5.32 & 5.19 & 5.16 & 5.04 & 5.03 \\
\hline $\mathrm{CdO}$ & 0.02 & 0.02 & 0.02 & 0.02 & 0.02 & 0.02 & 0.02 & 0.02 & 0.02 & 0.02 & 0.02 & 0.02 \\
\hline $\mathrm{Cr}_{2} \mathrm{O}_{3}$ & 0.52 & 0.48 & 0.48 & 0.47 & 0.47 & 0.49 & 0.48 & 0.46 & 0.44 & 0.44 & 0.43 & 0.43 \\
\hline $\mathrm{F}$ & 0.67 & 0.62 & 0.62 & 0.61 & 0.61 & 0.63 & 0.62 & 0.58 & 0.57 & 0.57 & 0.55 & 0.55 \\
\hline $\mathrm{Fe}_{2} \mathrm{O}_{3}$ & 5.90 & 5.46 & 5.44 & 5.38 & 5.37 & 5.58 & 5.46 & 5.16 & 5.04 & 5.01 & 4.89 & 4.88 \\
\hline $\mathrm{K}_{2} \mathrm{O}$ & 0.14 & 0.13 & 0.13 & 9.00 & 0.13 & 0.13 & 0.13 & 0.12 & 0.12 & 0.12 & 17.16 & 0.12 \\
\hline $\mathrm{Li}_{2} \mathrm{O}$ & 3.57 & 3.30 & 3.29 & 3.25 & 3.25 & 8.83 & 3.30 & 3.12 & 3.05 & 3.03 & 2.96 & 2.96 \\
\hline $\mathrm{MgO}$ & 0.12 & 0.11 & 0.11 & 0.11 & 0.11 & 0.11 & 0.11 & 0.10 & 0.10 & 0.10 & 0.10 & 0.10 \\
\hline $\mathrm{Na}_{2} \mathrm{O}$ & 9.58 & 8.86 & 16.58 & 8.73 & 11.49 & 9.06 & 8.87 & 8.38 & 8.18 & 23.19 & 7.95 & 13.24 \\
\hline $\mathrm{NiO}$ & 0.40 & 0.37 & 0.37 & 0.36 & 0.36 & 0.38 & 0.37 & 0.35 & 0.34 & 0.34 & 0.33 & 0.33 \\
\hline $\mathrm{P}_{2} \mathrm{O}_{5}$ & 1.05 & 0.97 & 0.97 & 0.96 & 0.96 & 0.99 & 0.97 & 0.92 & 0.90 & 0.89 & 0.87 & 0.87 \\
\hline $\mathrm{PbO}$ & 0.41 & 0.38 & 0.38 & 0.37 & 0.37 & 0.39 & 0.38 & 0.36 & 0.35 & 0.35 & 0.34 & 0.34 \\
\hline $\mathrm{SiO}_{2}$ & 30.50 & 28.21 & 28.13 & 27.79 & 27.76 & 28.83 & 28.23 & 39.18 & 26.04 & 25.91 & 25.30 & 25.24 \\
\hline $\mathrm{SO}_{3}$ & 0.20 & 0.18 & 0.18 & 0.18 & 0.18 & 0.19 & 0.18 & 0.17 & 0.17 & 0.17 & 0.17 & 0.17 \\
\hline $\mathrm{TiO}_{2}$ & 0.01 & 0.01 & 0.01 & 0.01 & 0.01 & 0.01 & 0.01 & 0.01 & 0.01 & 0.01 & 0.01 & 0.01 \\
\hline $\mathrm{ZnO}$ & 0.08 & 0.08 & 0.08 & 0.08 & 0.08 & 0.08 & 0.08 & 0.07 & 0.07 & 0.07 & 0.07 & 0.07 \\
\hline $\mathrm{ZrO}_{2}$ & 0.39 & 0.37 & 0.36 & 0.36 & 0.36 & 0.37 & 0.37 & 0.35 & 0.34 & 0.34 & 0.33 & 0.33 \\
\hline Sum & 100.00 & 100.00 & 100.00 & 100.00 & 100.00 & 100.00 & 100.00 & 100.00 & 100.00 & 100.00 & 100.00 & 100.00 \\
\hline
\end{tabular}




\section{Table 3.11. Target Compositions for Vitrified Melter Feed with Various Additives During DM10 Melter Rate Tests (wt\%)} (continued).

\begin{tabular}{|c|c|c|c|c|c|c|c|c|c|c|c|}
\hline Base Feed & \multicolumn{11}{|c|}{ HLW-E-Al-27 with $\mathrm{Al}_{2} \mathrm{O}_{3}$} \\
\hline Test \#s & $\begin{array}{c}50,51,79 \\
105,153\end{array}$ & 160,183 & 200 & $\begin{array}{c}163,188, \\
208\end{array}$ & 168,193 & 161,184 & 164,189 & 194 & 177,185 & 190 & 196 \\
\hline Feed $(\mathrm{g})$ & 1000 & 850 & 850 & 850 & 850 & 800 & 800 & 800 & 750 & 750 & 750 \\
\hline Type of Additive & None & Boric Acid & $\mathrm{Na} 2 \mathrm{CO} 3$ & $\mathrm{~K} 2 \mathrm{CO} 3$ & Borax & Boric Acid & $\mathrm{K} 2 \mathrm{CO} 3$ & Borax & Boric Acid & $\mathrm{K} 2 \mathrm{CO} 3$ & Borax \\
\hline Additives (g) & 0 & 150 & 150 & 150 & 150 & 200 & 200 & 200 & 250 & 250 & 250 \\
\hline $\mathrm{Al}_{2} \mathrm{O}_{3}$ & 23.97 & 18.85 & 18.71 & 18.07 & 18.01 & 17.31 & 16.39 & 16.32 & 15.84 & 14.83 & 14.76 \\
\hline $\mathrm{B}_{2} \mathrm{O}_{3}$ & 15.19 & 33.31 & 11.85 & 11.45 & 28.61 & 38.76 & 10.39 & 32.42 & 43.95 & 9.40 & 35.95 \\
\hline $\mathrm{BaO}$ & 0.05 & 0.04 & 0.04 & 0.04 & 0.04 & 0.04 & 0.04 & 0.04 & 0.04 & 0.03 & 0.03 \\
\hline $\mathrm{Bi}_{2} \mathrm{O}_{3}$ & 1.14 & 0.90 & 0.89 & 0.86 & 0.86 & 0.83 & 0.78 & 0.78 & 0.76 & 0.71 & 0.70 \\
\hline $\mathrm{CaO}$ & 6.08 & 4.78 & 4.74 & 4.58 & 4.57 & 4.39 & 4.16 & 4.14 & 4.02 & 3.76 & 3.74 \\
\hline $\mathrm{CdO}$ & 0.02 & 0.02 & 0.02 & 0.02 & 0.02 & 0.02 & 0.02 & 0.02 & 0.02 & 0.02 & 0.01 \\
\hline $\mathrm{Cr}_{2} \mathrm{O}_{3}$ & 0.52 & 0.41 & 0.41 & 0.39 & 0.39 & 0.38 & 0.36 & 0.35 & 0.34 & 0.32 & 0.32 \\
\hline $\mathrm{F}$ & 0.67 & 0.52 & 0.52 & 0.50 & 0.50 & 0.48 & 0.46 & 0.45 & 0.44 & 0.41 & 0.41 \\
\hline $\mathrm{Fe}_{2} \mathrm{O}_{3}$ & 5.90 & 4.64 & 4.60 & 4.45 & 4.43 & 4.26 & 4.03 & 4.02 & 3.90 & 3.65 & 3.63 \\
\hline $\mathrm{K}_{2} \mathrm{O}$ & 0.14 & 0.11 & 0.11 & 24.70 & 0.11 & 0.10 & 31.70 & 0.10 & 0.09 & 38.21 & 0.09 \\
\hline $\mathrm{Li}_{2} \mathrm{O}$ & 3.57 & 2.81 & 2.79 & 2.69 & 2.68 & 2.58 & 2.44 & 2.43 & 2.36 & 2.21 & 2.20 \\
\hline $\mathrm{MgO}$ & 0.12 & 0.09 & 0.09 & 0.09 & 0.09 & 0.08 & 0.08 & 0.08 & 0.08 & 0.07 & 0.07 \\
\hline $\mathrm{Na}_{2} \mathrm{O}$ & 9.58 & 7.53 & 29.43 & 7.22 & 14.85 & 6.92 & 6.55 & 16.35 & 6.33 & 5.93 & 17.74 \\
\hline $\mathrm{NiO}$ & 0.40 & 0.31 & 0.31 & 0.30 & 0.30 & 0.29 & 0.27 & 0.27 & 0.26 & 0.25 & 0.25 \\
\hline $\mathrm{P}_{2} \mathrm{O}_{5}$ & 1.05 & 0.83 & 0.82 & 0.79 & 0.79 & 0.76 & 0.72 & 0.72 & 0.70 & 0.65 & 0.65 \\
\hline $\mathrm{PbO}$ & 0.41 & 0.32 & 0.32 & 0.31 & 0.31 & 0.30 & 0.28 & 0.28 & 0.27 & 0.25 & 0.25 \\
\hline $\mathrm{SiO}_{2}$ & 30.50 & 23.98 & 23.80 & 22.99 & 22.92 & 22.02 & 20.86 & 20.77 & 20.15 & 18.87 & 18.77 \\
\hline $\mathrm{SO}_{3}$ & 0.20 & 0.16 & 0.16 & 0.15 & 0.15 & 0.14 & 0.14 & 0.14 & 0.13 & 0.12 & 0.12 \\
\hline $\mathrm{TiO}_{2}$ & 0.01 & 0.01 & 0.01 & 0.01 & 0.01 & 0.01 & 0.01 & 0.01 & 0.01 & 0.01 & 0.01 \\
\hline $\mathrm{ZnO}$ & 0.08 & 0.07 & 0.06 & 0.06 & 0.06 & 0.06 & 0.06 & 0.06 & 0.05 & 0.05 & 0.05 \\
\hline $\mathrm{ZrO}_{2}$ & 0.39 & 0.31 & 0.31 & 0.30 & 0.30 & 0.28 & 0.27 & 0.27 & 0.26 & 0.24 & 0.24 \\
\hline Sum & 100.00 & 100.00 & 100.00 & 100.00 & 100.00 & 100.00 & 100.00 & 100.00 & 100.00 & 100.00 & 100.00 \\
\hline
\end{tabular}


ORP-56292 Rev. 0

\section{Table 3.11. Target Compositions for Vitrified Melter Feed with Various Additives During DM10 Melter Rate Tests (wt\%)} (continued).

\begin{tabular}{|c|c|c|c|c|c|c|c|c|c|c|}
\hline Base Feed & \multicolumn{10}{|c|}{ HLW-E-Al-27 with $\mathrm{Al}(\mathrm{OH})_{3}$} \\
\hline Test \#s & $\begin{array}{c}66,86,92,115,118 \\
147,149,205\end{array}$ & $\begin{array}{c}69,95 \\
120\end{array}$ & $72,98,122$ & $\begin{array}{c}76,102 \\
125\end{array}$ & $\begin{array}{c}80,106, \\
145\end{array}$ & 83,109 & 89,112 & 207,209 & 211,213 & 222,226 \\
\hline Feed $(\mathrm{g})$ & $950-1000$ & 950 & 950 & 950 & 950 & 950 & 950 & 900 & 900 & 900 \\
\hline Type of Additive & None & Boric Acid & $\mathrm{Na} 2 \mathrm{CO} 3$ & $\mathrm{~K} 2 \mathrm{CO} 3$ & Borax & $\mathrm{Li} 2 \mathrm{CO} 3$ & $\mathrm{CaCO} 3$ & Boric Acid & $\mathrm{K} 2 \mathrm{CO} 3$ & Borax \\
\hline Additive (g) & 0 & 50 & 50 & 50 & 50 & 50 & 50 & 100 & 100 & 100 \\
\hline $\mathrm{Al}_{2} \mathrm{O}_{3}$ & 23.97 & 22.17 & 22.12 & 21.85 & 21.82 & 22.66 & 22.19 & 20.47 & 19.89 & 19.84 \\
\hline $\mathrm{B}_{2} \mathrm{O}_{3}$ & 15.19 & 21.55 & 14.01 & 13.84 & 20.04 & 14.36 & 14.06 & 27.58 & 12.60 & 24.50 \\
\hline $\mathrm{BaO}$ & 0.05 & 0.05 & 0.05 & 0.05 & 0.05 & 0.05 & 0.05 & 0.05 & 0.04 & 0.04 \\
\hline $\mathrm{Bi}_{2} \mathrm{O}_{3}$ & 1.14 & 1.06 & 1.06 & 1.04 & 1.04 & 1.08 & 1.06 & 0.98 & 0.95 & 0.95 \\
\hline $\mathrm{CaO}$ & 6.08 & 5.62 & 5.61 & 5.54 & 5.53 & 5.74 & 13.06 & 5.19 & 5.04 & 5.03 \\
\hline $\mathrm{CdO}$ & 0.02 & 0.02 & 0.02 & 0.02 & 0.02 & 0.02 & 0.02 & 0.02 & 0.02 & 0.02 \\
\hline $\mathrm{Cr}_{2} \mathrm{O}_{3}$ & 0.52 & 0.48 & 0.48 & 0.47 & 0.47 & 0.49 & 0.48 & 0.44 & 0.43 & 0.43 \\
\hline $\mathrm{F}$ & 0.67 & 0.62 & 0.62 & 0.61 & 0.61 & 0.63 & 0.62 & 0.57 & 0.55 & 0.55 \\
\hline $\mathrm{Fe}_{2} \mathrm{O}_{3}$ & 5.90 & 5.46 & 5.44 & 5.38 & 5.37 & 5.58 & 5.46 & 5.04 & 4.89 & 4.88 \\
\hline $\mathrm{K}_{2} \mathrm{O}$ & 0.14 & 0.13 & 0.13 & 9.00 & 0.13 & 0.13 & 0.13 & 0.12 & 17.16 & 0.12 \\
\hline $\mathrm{Li}_{2} \mathrm{O}$ & 3.57 & 3.30 & 3.29 & 3.25 & 3.25 & 8.83 & 3.30 & 3.05 & 2.96 & 2.96 \\
\hline $\mathrm{MgO}$ & 0.12 & 0.11 & 0.11 & 0.11 & 0.11 & 0.11 & 0.11 & 0.10 & 0.10 & 0.10 \\
\hline $\mathrm{Na}_{2} \mathrm{O}$ & 9.58 & 8.86 & 16.58 & 8.73 & 11.49 & 9.06 & 8.87 & 8.18 & 7.95 & 13.24 \\
\hline $\mathrm{NiO}$ & 0.40 & 0.37 & 0.37 & 0.36 & 0.36 & 0.38 & 0.37 & 0.34 & 0.33 & 0.33 \\
\hline $\mathrm{P}_{2} \mathrm{O}_{5}$ & 1.05 & 0.97 & 0.97 & 0.96 & 0.96 & 0.99 & 0.97 & 0.90 & 0.87 & 0.87 \\
\hline $\mathrm{PbO}$ & 0.41 & 0.38 & 0.38 & 0.37 & 0.37 & 0.39 & 0.38 & 0.35 & 0.34 & 0.34 \\
\hline $\mathrm{SiO}_{2}$ & 30.50 & 28.21 & 28.13 & 27.79 & 27.76 & 28.83 & 28.23 & 26.04 & 25.30 & 25.24 \\
\hline $\mathrm{SO}_{3}$ & 0.20 & 0.18 & 0.18 & 0.18 & 0.18 & 0.19 & 0.18 & 0.17 & 0.17 & 0.17 \\
\hline $\mathrm{TiO}_{2}$ & 0.01 & 0.01 & 0.01 & 0.01 & 0.01 & 0.01 & 0.01 & 0.01 & 0.01 & 0.01 \\
\hline $\mathrm{ZnO}$ & 0.08 & 0.08 & 0.08 & 0.08 & 0.08 & 0.08 & 0.08 & 0.07 & 0.07 & 0.07 \\
\hline $\mathrm{ZrO}_{2}$ & 0.39 & 0.37 & 0.36 & 0.36 & 0.36 & 0.37 & 0.37 & 0.34 & 0.33 & 0.33 \\
\hline Sum & 100.00 & 100.00 & 100.00 & 100.00 & 100.00 & 100.00 & 100.00 & 100.00 & 100.00 & 100.00 \\
\hline
\end{tabular}


Table 3.11. Target Compositions for Vitrified Melter Feed with Various Additives During DM10 Melter Rate Tests (wt\%), (continued).

\begin{tabular}{|c|c|c|c|c|c|c|c|c|c|c|c|}
\hline Base Feed & \multicolumn{11}{|c|}{ HLW-E-Al-27 with $\mathrm{Al}(\mathrm{OH})_{3}$} \\
\hline Test \#s & $\begin{array}{c}66,92,118 \\
149,205\end{array}$ & 210 & 200 & 212 & 223,227 & 214,216 & 215,217 & 224,228 & 218,220 & 219,221 & 225 \\
\hline Feed $(\mathrm{g})$ & 1000 & 850 & 850 & 850 & 850 & 800 & 800 & 800 & 750 & 750 & 750 \\
\hline Type of Additive & None & Boric Acid & $\mathrm{Na} 2 \mathrm{CO} 3$ & $\mathrm{~K} 2 \mathrm{CO} 3$ & Borax & Boric Acid & $\mathrm{K} 2 \mathrm{CO} 3$ & Borax & Boric Acid & $\mathrm{K} 2 \mathrm{CO} 3$ & Borax \\
\hline Additives (g) & 0 & 150 & 150 & 150 & 150 & 200 & 200 & 200 & 250 & 250 & 250 \\
\hline $\mathrm{Al}_{2} \mathrm{O}_{3}$ & 23.97 & 18.85 & 18.71 & 18.07 & 18.01 & 17.31 & 16.39 & 16.32 & 15.84 & 14.83 & 14.76 \\
\hline $\mathrm{B}_{2} \mathrm{O}_{3}$ & 15.19 & 33.31 & 11.85 & 11.45 & 28.61 & 38.76 & 10.39 & 32.42 & 43.95 & 9.40 & 35.95 \\
\hline $\mathrm{BaO}$ & 0.05 & 0.04 & 0.04 & 0.04 & 0.04 & 0.04 & 0.04 & 0.04 & 0.04 & 0.03 & 0.03 \\
\hline $\mathrm{Bi}_{2} \mathrm{O}_{3}$ & 1.14 & 0.90 & 0.89 & 0.86 & 0.86 & 0.83 & 0.78 & 0.78 & 0.76 & 0.71 & 0.70 \\
\hline $\mathrm{CaO}$ & 6.08 & 4.78 & 4.74 & 4.58 & 4.57 & 4.39 & 4.16 & 4.14 & 4.02 & 3.76 & 3.74 \\
\hline $\mathrm{CdO}$ & 0.02 & 0.02 & 0.02 & 0.02 & 0.02 & 0.02 & 0.02 & 0.02 & 0.02 & 0.02 & 0.01 \\
\hline $\mathrm{Cr}_{2} \mathrm{O}_{3}$ & 0.52 & 0.41 & 0.41 & 0.39 & 0.39 & 0.38 & 0.36 & 0.35 & 0.34 & 0.32 & 0.32 \\
\hline $\mathrm{F}$ & 0.67 & 0.52 & 0.52 & 0.50 & 0.50 & 0.48 & 0.46 & 0.45 & 0.44 & 0.41 & 0.41 \\
\hline $\mathrm{Fe}_{2} \mathrm{O}_{3}$ & 5.90 & 4.64 & 4.60 & 4.45 & 4.43 & 4.26 & 4.03 & 4.02 & 3.90 & 3.65 & 3.63 \\
\hline $\mathrm{K}_{2} \mathrm{O}$ & 0.14 & 0.11 & 0.11 & 24.70 & 0.11 & 0.10 & 31.70 & 0.10 & 0.09 & 38.21 & 0.09 \\
\hline $\mathrm{Li}_{2} \mathrm{O}$ & 3.57 & 2.81 & 2.79 & 2.69 & 2.68 & 2.58 & 2.44 & 2.43 & 2.36 & 2.21 & 2.20 \\
\hline $\mathrm{MgO}$ & 0.12 & 0.09 & 0.09 & 0.09 & 0.09 & 0.08 & 0.08 & 0.08 & 0.08 & 0.07 & 0.07 \\
\hline $\mathrm{Na}_{2} \mathrm{O}$ & 9.58 & 7.53 & 29.43 & 7.22 & 14.85 & 6.92 & 6.55 & 16.35 & 6.33 & 5.93 & 17.74 \\
\hline $\mathrm{NiO}$ & 0.40 & 0.31 & 0.31 & 0.30 & 0.30 & 0.29 & 0.27 & 0.27 & 0.26 & 0.25 & 0.25 \\
\hline $\mathrm{P}_{2} \mathrm{O}_{5}$ & 1.05 & 0.83 & 0.82 & 0.79 & 0.79 & 0.76 & 0.72 & 0.72 & 0.70 & 0.65 & 0.65 \\
\hline $\mathrm{PbO}$ & 0.41 & 0.32 & 0.32 & 0.31 & 0.31 & 0.30 & 0.28 & 0.28 & 0.27 & 0.25 & 0.25 \\
\hline $\mathrm{SiO}_{2}$ & 30.50 & 23.98 & 23.80 & 22.99 & 22.92 & 22.02 & 20.86 & 20.77 & 20.15 & 18.87 & 18.77 \\
\hline $\mathrm{SO}_{3}$ & 0.20 & 0.16 & 0.16 & 0.15 & 0.15 & 0.14 & 0.14 & 0.14 & 0.13 & 0.12 & 0.12 \\
\hline $\mathrm{TiO}_{2}$ & 0.01 & 0.01 & 0.01 & 0.01 & 0.01 & 0.01 & 0.01 & 0.01 & 0.01 & 0.01 & 0.01 \\
\hline $\mathrm{ZnO}$ & 0.08 & 0.07 & 0.06 & 0.06 & 0.06 & 0.06 & 0.06 & 0.06 & 0.05 & 0.05 & 0.05 \\
\hline $\mathrm{ZrO}_{2}$ & 0.39 & 0.31 & 0.31 & 0.30 & 0.30 & 0.28 & 0.27 & 0.27 & 0.26 & 0.24 & 0.24 \\
\hline Sum & 100.00 & 100.00 & 100.00 & 100.00 & 100.00 & 100.00 & 100.00 & 100.00 & 100.00 & 100.00 & 100.00 \\
\hline
\end{tabular}


ORP-56292 Rev. 0

Table 3.11. Target Compositions for Vitrified Melter Feed with Various Additives During DM10 Melter Rate Tests (wt\%) (continued).

\begin{tabular}{|c|c|c|c|c|c|c|c|c|c|c|c|c|}
\hline Base Feed & \multicolumn{7}{|c|}{ HLW-E-Al-27 with $\mathrm{Al}_{2} \mathrm{O}_{3}$ and Boric Acid/Soda Ash Replacing Borax } & \multicolumn{5}{|c|}{$\begin{array}{l}\text { HLW-E-Al-27 with } \mathrm{Al}_{2} \mathrm{O}_{3} \text {, and Boric Acid/ } \mathrm{K}_{2} \mathrm{CO}_{3} \text { Replacing } \\
\text { Borax }\end{array}$} \\
\hline Test \#s & $\begin{array}{l}67,87,93 \\
116\end{array}$ & 70,96 & 73,99 & 77,103 & 81,107 & 84,110 & $\begin{array}{l}90 \\
113\end{array}$ & $\begin{array}{l}68,88,94,117 \\
119,126,148,155\end{array}$ & $71,97,121$ & $\begin{array}{l}74,100 \\
123\end{array}$ & 78,104 & 82,108 \\
\hline Feed $(\mathrm{g})$ & 950-1000 & 950 & 950 & 950 & 950 & 950 & 950 & $950-1000$ & 950 & 950 & 950 & 950 \\
\hline Type of Additive & None & Boric Acid & $\mathrm{Na} 2 \mathrm{CO} 3$ & $\mathrm{~K} 2 \mathrm{CO} 3$ & Borax & $\mathrm{Li} 2 \mathrm{CO} 3$ & $\mathrm{CaCO} 3$ & None & Boric Acid & $\mathrm{Na} 2 \mathrm{CO} 3$ & $\mathrm{~K} 2 \mathrm{CO} 3$ & Borax \\
\hline Additives (g) & 0 & 50 & 50 & 50 & 50 & 50 & 50 & 0 & 50 & 50 & 50 & 50 \\
\hline $\mathrm{Al}_{2} \mathrm{O}_{3}$ & 23.97 & 22.17 & 22.12 & 21.85 & 21.81 & 22.66 & 22.19 & 23.97 & 22.03 & 21.97 & 21.67 & 21.63 \\
\hline $\mathrm{B}_{2} \mathrm{O}_{3}$ & 15.19 & 21.55 & 14.01 & 13.84 & 20.08 & 14.36 & 14.06 & 15.19 & 22.07 & 13.92 & 13.73 & 20.47 \\
\hline $\mathrm{BaO}$ & 0.05 & 0.05 & 0.05 & 0.05 & 0.05 & 0.05 & 0.05 & 0.05 & 0.05 & 0.05 & 0.05 & 0.05 \\
\hline $\mathrm{Bi}_{2} \mathrm{O}_{3}$ & 1.14 & 1.06 & 1.06 & 1.04 & 1.04 & 1.08 & 1.06 & 1.14 & 1.05 & 1.05 & 1.04 & 1.03 \\
\hline $\mathrm{CaO}$ & 6.08 & 5.62 & 5.61 & 5.54 & 5.53 & 5.74 & 13.07 & 6.08 & 5.58 & 5.57 & 5.49 & 5.48 \\
\hline $\mathrm{CdO}$ & 0.02 & 0.02 & 0.02 & 0.02 & 0.02 & 0.02 & 0.02 & 0.02 & 0.02 & 0.02 & 0.02 & 0.02 \\
\hline $\mathrm{Cr}_{2} \mathrm{O}_{3}$ & 0.52 & 0.48 & 0.48 & 0.47 & 0.47 & 0.49 & 0.48 & 0.52 & 0.48 & 0.48 & 0.47 & 0.47 \\
\hline $\mathrm{F}$ & 0.67 & 0.62 & 0.62 & 0.61 & 0.61 & 0.63 & 0.62 & 0.67 & 0.61 & 0.61 & 0.60 & 0.60 \\
\hline $\mathrm{Fe}_{2} \mathrm{O}_{3}$ & 5.90 & 5.46 & 5.44 & 5.38 & 5.37 & 5.58 & 5.46 & 5.90 & 5.42 & 5.41 & 5.33 & 5.32 \\
\hline $\mathrm{K}_{2} \mathrm{O}$ & 0.14 & 0.13 & 0.13 & 9.00 & 0.13 & 0.13 & 0.13 & 6.14 & 5.64 & 5.63 & 15.14 & 5.54 \\
\hline $\mathrm{Li}_{2} \mathrm{O}$ & 3.57 & 3.30 & 3.29 & 3.25 & 3.25 & 8.83 & 3.30 & 3.57 & 3.28 & 3.27 & 3.23 & 3.22 \\
\hline $\mathrm{MgO}$ & 0.12 & 0.11 & 0.11 & 0.11 & 0.11 & 0.11 & 0.11 & 0.12 & 0.11 & 0.11 & 0.11 & 0.11 \\
\hline $\mathrm{Na}_{2} \mathrm{O}$ & 9.58 & 8.86 & 16.58 & 8.73 & 11.48 & 9.06 & 8.87 & 3.58 & 3.29 & 11.62 & 3.24 & 6.22 \\
\hline $\mathrm{NiO}$ & 0.40 & 0.37 & 0.37 & 0.36 & 0.36 & 0.38 & 0.37 & 0.40 & 0.37 & 0.37 & 0.36 & 0.36 \\
\hline $\mathrm{P}_{2} \mathrm{O}_{5}$ & 1.05 & 0.97 & 0.97 & 0.96 & 0.96 & 0.99 & 0.97 & 1.05 & 0.97 & 0.96 & 0.95 & 0.95 \\
\hline $\mathrm{PbO}$ & 0.41 & 0.38 & 0.38 & 0.37 & 0.37 & 0.39 & 0.38 & 0.41 & 0.38 & 0.37 & 0.37 & 0.37 \\
\hline $\mathrm{SiO}_{2}$ & 30.50 & 28.21 & 28.13 & 27.79 & 27.74 & 28.83 & 28.23 & 30.50 & 28.02 & 27.95 & 27.57 & 27.52 \\
\hline $\mathrm{SO}_{3}$ & 0.20 & 0.18 & 0.18 & 0.18 & 0.18 & 0.19 & 0.18 & 0.20 & 0.18 & 0.18 & 0.18 & 0.18 \\
\hline $\mathrm{TiO}_{2}$ & 0.01 & 0.01 & 0.01 & 0.01 & 0.01 & 0.01 & 0.01 & 0.01 & 0.01 & 0.01 & 0.01 & 0.01 \\
\hline $\mathrm{ZnO}$ & 0.08 & 0.08 & 0.08 & 0.08 & 0.08 & 0.08 & 0.08 & 0.08 & 0.08 & 0.08 & 0.07 & 0.07 \\
\hline $\mathrm{ZrO}_{2}$ & 0.39 & 0.36 & 0.36 & 0.36 & 0.36 & 0.37 & 0.37 & 0.39 & 0.36 & 0.36 & 0.36 & 0.36 \\
\hline Sum & 100.00 & 100.00 & 100.00 & 100.00 & 100.00 & 100.00 & 100.00 & 100.00 & 100.00 & 100.00 & 100.00 & 100.00 \\
\hline
\end{tabular}




\section{Table 3.11. Target Compositions for Vitrified Melter Feed with Various Additives During DM10 Melter Rate Tests (wt\%)} (continued).

\begin{tabular}{|c|c|c|c|c|c|c|c|c|c|c|c|c|c|c|}
\hline Base Feed & \multicolumn{8}{|c|}{ HLW-E-Al-27 with $\mathrm{Al}_{2} \mathrm{O}_{3}$, and Boric Acid/ $\mathrm{K}_{2} \mathrm{CO}_{3}$ Replacing Borax } & \multicolumn{3}{|c|}{ HWI-Al-9Melt } & \multicolumn{3}{|c|}{ HWI-Al-9KSM } \\
\hline Test \#s & $\begin{array}{c}68,94, \\
119,126, \\
155 \\
\end{array}$ & 85,111 & 91,114 & 178 & 165 & 169,178 & 187 & 172 & $\begin{array}{c}154,166,173, \\
175,180,202, \\
204 \\
\end{array}$ & 158 & 170 & $\begin{array}{l}156,174, \\
176,179, \\
181,203 \\
\end{array}$ & 157,206 & 171 \\
\hline Feed $(\mathrm{g})$ & 1000 & 950 & 950 & 900 & 900 & 900 & 850 & 850 & $950-1000$ & 950 & 950 & $950-1000$ & 950 & 950 \\
\hline $\begin{array}{c}\text { Type of } \\
\text { Additive } \\
\end{array}$ & None & $\mathrm{Li} 2 \mathrm{CO} 3$ & $\mathrm{CaCO} 3$ & Boric Acid & $\mathrm{K} 2 \mathrm{CO} 3$ & Borax & $\mathrm{K} 2 \mathrm{CO} 3$ & Borax & None & Boric Acid & Borax & None & $\begin{array}{l}\text { Boric } \\
\text { Acid } \\
\end{array}$ & Borax \\
\hline Additives (g) & 0 & 50 & 50 & 100 & 100 & 100 & 150 & 150 & 0 & 50 & 50 & 0 & 50 & 50 \\
\hline $\mathrm{Al}_{2} \mathrm{O}_{3}$ & 23.97 & 22.55 & 22.04 & 20.21 & 19.59 & 19.52 & 17.68 & 17.60 & 21.31 & 19.70 & 19.38 & 23.97 & 22.17 & 21.82 \\
\hline $\mathrm{B}_{2} \mathrm{O}_{3}$ & 15.19 & 14.29 & 13.97 & 28.51 & 12.41 & 25.25 & 11.21 & 29.60 & 18.17 & 24.34 & 22.78 & 18.19 & 24.32 & 22.77 \\
\hline $\mathrm{BaO}$ & 0.05 & 0.05 & 0.05 & 0.05 & 0.04 & 0.04 & 0.04 & 0.04 & 0.05 & 0.04 & 0.04 & 0.05 & 0.05 & 0.05 \\
\hline $\mathrm{Bi}_{2} \mathrm{O}_{3}$ & 1.14 & 1.08 & 1.05 & 0.96 & 0.94 & 0.93 & 0.84 & 0.84 & 1.02 & 0.94 & 0.93 & 1.14 & 1.06 & 1.04 \\
\hline $\mathrm{CaO}$ & 6.08 & 5.72 & 13.64 & 5.12 & 4.97 & 4.95 & 4.48 & 4.46 & 0.96 & 0.88 & 0.87 & 1.08 & 1.00 & 0.98 \\
\hline $\mathrm{CdO}$ & 0.02 & 0.02 & 0.02 & 0.02 & 0.02 & 0.02 & 0.02 & 0.02 & 0.02 & 0.02 & 0.02 & 0.02 & 0.02 & 0.02 \\
\hline $\mathrm{Cr}_{2} \mathrm{O}_{3}$ & 0.52 & 0.49 & 0.48 & 0.44 & 0.43 & 0.42 & 0.38 & 0.38 & 0.46 & 0.43 & 0.42 & 0.52 & 0.48 & 0.47 \\
\hline $\mathrm{F}$ & 0.67 & 0.63 & 0.61 & 0.56 & 0.55 & 0.54 & 0.49 & 0.49 & 0.59 & 0.55 & 0.54 & 0.67 & 0.62 & 0.61 \\
\hline $\mathrm{Fe}_{2} \mathrm{O}_{3}$ & 5.90 & 5.55 & 5.42 & 4.97 & 4.82 & 4.80 & 4.35 & 4.33 & 5.24 & 4.85 & 4.77 & 5.90 & 5.46 & 5.37 \\
\hline $\mathrm{K}_{2} \mathrm{O}$ & 6.14 & 5.78 & 5.65 & 5.18 & 23.31 & 5.00 & 30.75 & 4.51 & 0.13 & 0.12 & 0.11 & 5.14 & 4.76 & 4.68 \\
\hline $\mathrm{Li}_{2} \mathrm{O}$ & 3.57 & 9.28 & 3.28 & 3.01 & 2.92 & 2.91 & 2.63 & 2.62 & 3.15 & 2.91 & 2.87 & 3.17 & 2.93 & 2.89 \\
\hline $\mathrm{MgO}$ & 0.12 & 0.11 & 0.11 & 0.10 & 0.10 & 0.10 & 0.09 & 0.09 & 0.10 & 0.10 & 0.09 & 0.12 & 0.11 & 0.11 \\
\hline $\mathrm{Na}_{2} \mathrm{O}$ & 3.58 & 3.37 & 3.29 & 3.02 & 2.93 & 8.60 & 2.64 & 10.77 & 13.18 & 12.19 & 14.77 & 8.58 & 7.94 & 10.57 \\
\hline $\mathrm{NiO}$ & 0.40 & 0.38 & 0.37 & 0.34 & 0.33 & 0.33 & 0.29 & 0.29 & 0.36 & 0.33 & 0.32 & 0.40 & 0.37 & 0.36 \\
\hline $\mathrm{P}_{2} \mathrm{O}_{5}$ & 1.05 & 0.99 & 0.97 & 0.89 & 0.86 & 0.86 & 0.78 & 0.77 & 0.94 & 0.86 & 0.85 & 1.05 & 0.97 & 0.96 \\
\hline $\mathrm{PbO}$ & 0.41 & 0.38 & 0.38 & 0.34 & 0.33 & 0.33 & 0.30 & 0.30 & 0.36 & 0.34 & 0.33 & 0.41 & 0.38 & 0.37 \\
\hline $\mathrm{SiO}_{2}$ & 30.50 & 28.69 & 28.04 & 25.71 & 24.92 & 24.83 & 22.50 & 22.39 & 33.35 & 30.84 & 30.34 & 28.90 & 26.73 & 26.30 \\
\hline $\mathrm{SO} 3$ & 0.20 & 0.19 & 0.18 & 0.17 & 0.16 & 0.16 & 0.15 & 0.15 & 0.18 & 0.16 & 0.16 & 0.20 & 0.18 & 0.18 \\
\hline $\mathrm{TiO}_{2}$ & 0.01 & 0.01 & 0.01 & 0.01 & 0.01 & 0.01 & 0.01 & 0.01 & 0.01 & 0.01 & 0.01 & 0.01 & 0.01 & 0.01 \\
\hline $\mathrm{ZnO}$ & 0.08 & 0.08 & 0.08 & 0.07 & 0.07 & 0.07 & 0.06 & 0.06 & 0.07 & 0.07 & 0.07 & 0.08 & 0.08 & 0.08 \\
\hline $\mathrm{ZrO}_{2}$ & 0.39 & 0.37 & 0.36 & 0.33 & 0.32 & 0.32 & 0.29 & 0.29 & 0.35 & 0.32 & 0.32 & 0.39 & 0.36 & 0.36 \\
\hline Sum & 100.00 & 100.00 & 100.00 & 100.00 & 100.00 & 100.00 & 100.00 & 100.00 & 100.00 & 100.00 & 100.00 & 100.00 & 100.00 & 100.00 \\
\hline
\end{tabular}


The Catholic University of America Vitreous State Laboratory
ORP-56292 Rev. 0

Melt Rate Enhancement for High Aluminum HLW Glass Formulations

Final Report, VSL-08R1360-1, Rev. 0

Table 3.12. Composition and Properties of Aluminum Limited Waste and Glass Formulation HWI-Al-16 with $43.65 \%$ Waste Loading (wt \%).

\begin{tabular}{|c|c|c|c|c|}
\hline- & $\begin{array}{c}\text { Al-Limited } \\
\text { Waste }\end{array}$ & Waste in Glass & $\begin{array}{c}\text { Glass Forming } \\
\text { Additives }\end{array}$ & $\begin{array}{c}\text { Target Glass } \\
\text { HWI-Al-16 }\end{array}$ \\
\hline $\mathrm{Al}_{2} \mathrm{O}_{3}$ & 53.27 & 23.25 & - & 23.25 \\
\hline $\mathrm{B}_{2} \mathrm{O}_{3}$ & 0.42 & 0.18 & 17.55 & 17.73 \\
\hline $\mathrm{BaO}$ & 0.12 & 0.05 & - & 0.05 \\
\hline $\mathrm{Bi}_{2} \mathrm{O}_{3}$ & 2.54 & 1.11 & - & 1.11 \\
\hline $\mathrm{CaO}$ & 2.39 & 1.04 & 4.85 & 5.89 \\
\hline $\mathrm{CdO}$ & 0.05 & 0.02 & - & 0.02 \\
\hline $\mathrm{Cr}_{2} \mathrm{O}_{3}$ & 1.16 & 0.51 & & 0.51 \\
\hline $\mathrm{F}$ & 1.48 & 0.65 & - & 0.65 \\
\hline $\mathrm{Fe}_{2} \mathrm{O}_{3}$ & 13.11 & 5.72 & - & 5.72 \\
\hline $\mathrm{K}_{2} \mathrm{O}$ & 0.31 & 0.14 & - & 0.14 \\
\hline $\mathrm{Li}_{2} \mathrm{O}$ & 0.38 & 0.17 & 3.30 & 3.46 \\
\hline $\mathrm{MgO}^{\mathrm{Na}} \mathrm{O}_{2} \mathrm{O}$ & 0.26 & 0.11 & - & 0.11 \\
\hline $\mathrm{NiO}$ & 7.96 & 3.47 & 5.82 & 9.29 \\
\hline $\mathrm{P}_{2} \mathrm{O}_{5}$ & 0.89 & 0.39 & - & 0.39 \\
\hline $\mathrm{PbO}^{2}$ & 2.34 & 1.02 & - & 1.02 \\
\hline $\mathrm{SO}_{3}$ & 0.91 & 0.40 & - & 0.40 \\
\hline $\mathrm{SiO}_{2}$ & 0.44 & 0.19 & - & 0.19 \\
\hline $\mathrm{TiO}_{2}$ & 0.88 & 4.75 & 24.83 & 29.58 \\
\hline $\mathrm{ZnO}$ & 0.18 & 0.01 & - & 0.01 \\
\hline $\mathrm{ZrO}_{2}$ & 0.88 & 0.08 & - & 0.08 \\
\hline $\mathrm{Sum}$ & 100.0 & 0.38 & - & 0.38 \\
\hline
\end{tabular}

* Renormalized from Ref. [5] after removal of radioactive components.

\# The sum does not equal to 100.00 because of rounding of decimals.

\begin{tabular}{|c|c|c|c|}
\hline \multicolumn{3}{|c|}{ Viscosity @1150ㄷ, P } & 43 \\
\hline \multicolumn{3}{|c|}{ Conductivity@1150º, S/cm } & 0.24 \\
\hline \multicolumn{3}{|c|}{ Crystal Content, As Melted } & None \\
\hline \multicolumn{3}{|c|}{ Crystal Content, $72 \mathrm{hr}$ at $950^{\circ} \mathrm{C}$} & $1.6 \%$ \\
\hline \multicolumn{3}{|c|}{ Crystal Content, $\mathrm{CCC}$} & $1.9 \%$ \\
\hline \multicolumn{3}{|c|}{ TCLP } & Pass \\
\hline \multirow{4}{*}{ PCT, $g / L$} & - & DWPF-EA & HWI-Al-16 \\
\hline & $\mathrm{B}$ & 16.7 & 0.314 \\
\hline & $\mathrm{Li}$ & 9.6 & 0.394 \\
\hline & $\mathrm{Na}$ & 13.3 & 0.285 \\
\hline
\end{tabular}

- Empty data field 
Table 3.13. Composition and Properties of Aluminum Limited Waste and Glass Formulation HWI-Al-19 with $\mathbf{4 5 \%}$ Waste Loading (wt \%).

\begin{tabular}{|c|c|c|c|c|}
\hline- & $\begin{array}{c}\text { Al-Limited } \\
\text { Waste }\end{array}$ & Waste in Glass & $\begin{array}{c}\text { Glass Forming } \\
\text { Additives }\end{array}$ & $\begin{array}{c}\text { Target Glass } \\
\text { HWI-Al-19 }\end{array}$ \\
\hline $\mathrm{Al}_{2} \mathrm{O}_{3}$ & 53.27 & 23.97 & - & 23.97 \\
\hline $\mathrm{B}_{2} \mathrm{O}_{3}$ & 0.42 & 0.19 & 19.00 & 19.19 \\
\hline $\mathrm{BaO}$ & 0.12 & 0.05 & - & 0.05 \\
\hline $\mathrm{Bi}_{2} \mathrm{O}_{3}$ & 2.54 & 1.14 & - & 1.14 \\
\hline $\mathrm{CaO}$ & 2.39 & 1.08 & 4.50 & 5.58 \\
\hline $\mathrm{CdO}$ & 0.05 & 0.02 & - & 0.02 \\
\hline $\mathrm{Cr}_{2} \mathrm{O}_{3}$ & 1.16 & 0.52 & & 0.52 \\
\hline $\mathrm{F}$ & 1.48 & 0.67 & - & 0.67 \\
\hline $\mathrm{Fe}_{2} \mathrm{O}_{3}$ & 13.11 & 5.90 & - & 5.90 \\
\hline $\mathrm{K}_{2} \mathrm{O}$ & 0.31 & 0.14 & - & 0.14 \\
\hline $\mathrm{Li}_{2} \mathrm{O}$ & 0.38 & 0.17 & 3.40 & 3.57 \\
\hline $\mathrm{MgO}_{\mathrm{Na}} \mathrm{O}$ & 0.26 & 0.12 & - & 0.12 \\
\hline $\mathrm{NiO}$ & 7.96 & 3.58 & 6.00 & 9.58 \\
\hline $\mathrm{P}_{2} \mathrm{O}_{5}$ & 0.89 & 0.40 & - & 0.40 \\
\hline $\mathrm{PbO}^{\mathrm{SOO}} \mathrm{F}_{3}$ & 2.34 & 1.05 & - & 1.05 \\
\hline $\mathrm{SiO}_{2}$ & 0.91 & 0.41 & - & 0.41 \\
\hline $\mathrm{TiO}$ & 0.44 & 0.20 & - & 0.20 \\
\hline $\mathrm{ZnO}$ & 10.88 & 4.90 & 22.10 & 27.00 \\
\hline $\mathrm{ZrO}_{2}$ & 0.02 & 0.01 & - & 0.01 \\
\hline $\mathrm{Sum}$ & 0.18 & 0.08 & - & 0.08 \\
\hline
\end{tabular}

Renormalized from Ref. [5] after removal of radioactive components.

\# The sum does not equal to 100.00 because of rounding of decimals.

\begin{tabular}{|c|c|c|c|}
\hline \multicolumn{3}{|c|}{ Viscosity @1150, P } & 33 \\
\hline \multicolumn{3}{|c|}{ Conductivity@1150º, S/cm } & 0.27 \\
\hline \multicolumn{3}{|c|}{ Crystal Content, As Melted } & None \\
\hline \multicolumn{3}{|c|}{ Crystal Content, $72 \mathrm{hr}$ at $950^{\circ} \mathrm{C}$} & 1.3 \\
\hline \multicolumn{3}{|c|}{ Crystal Content, CCC } & 1.9 \\
\hline \multicolumn{3}{|c|}{ TCLP } & Pass \\
\hline \multirow{4}{*}{ PCT, g/L } & - & DWPF-EA & HWI-Al-19 \\
\hline & $\mathrm{B}$ & 16.7 & 0.654 \\
\hline & $\mathrm{Li}$ & 9.6 & 0.794 \\
\hline & $\mathrm{Na}$ & 13.3 & 0.624 \\
\hline
\end{tabular}

- Empty data field 
The Catholic University of America Vitreous State Laboratory
Melt Rate Enhancement for High Aluminum HLW Glass Formulations Final Report, VSL-08R1360-1, Rev. 0

Table 3.14. Composition of Melter Feed to Produce $100 \mathrm{~kg}$ of Target Glass HWI-Al-16 (Target Glass Yield $=500 \mathrm{~g} / \mathrm{L}$ Feed) from the Al-Limited Waste Simulant Using $\mathrm{Al}(\mathrm{OH})_{3}$ as the Aluminum Source.

\begin{tabular}{|c|c|c|c|}
\hline \multicolumn{2}{|c|}{ Al-Limited Waste Simulant } & \multicolumn{2}{|c|}{ Glass-Forming Additives } \\
\hline Starting Materials & Target Weight (kg) ${ }^{*}$ & Starting Materials & Target Weight (kg) ${ }^{*}$ \\
\hline $\mathrm{Al}(\mathrm{OH})_{3}$ & 35.935 & - & - \\
\hline $\mathrm{H}_{3} \mathrm{BO}_{3}$ & 0.331 & $\mathrm{H}_{3} \mathrm{BO}_{3}$ & 31.487 \\
\hline $\mathrm{BaCO}_{3}$ & 0.068 & - & - \\
\hline $\mathrm{Bi}_{2} \mathrm{O}_{3}$ & 1.122 & - & - \\
\hline $\mathrm{CaO}$ & 1.066 & $\mathrm{CaSiO}_{3}$ (Wollastonite) & 10.560 \\
\hline $\mathrm{CdO}$ & 0.024 & - & - \\
\hline $\mathrm{Cr}_{2} \mathrm{O}_{3}$ & 0.516 & - & - \\
\hline $\mathrm{NaF}$ & 1.438 & - & - \\
\hline $\mathrm{Fe}(\mathrm{OH})_{3}(13 \%$ Slurry $)$ & 47.083 & - & - \\
\hline $\mathrm{KNO}_{3}$ & 0.299 & - & - \\
\hline $\mathrm{Li}_{2} \mathrm{CO}_{3}$ & 0.420 & $\mathrm{Li}_{2} \mathrm{CO}_{3}$ & 8.366 \\
\hline $\mathrm{MgO}$ & 0.117 & - & - \\
\hline $\mathrm{NaOH}$ & 2.124 & $\mathrm{Na}_{2} \mathrm{CO}_{3}$ & 10.053 \\
\hline $\mathrm{Ni}(\mathrm{OH})_{2}$ & 0.498 & - & - \\
\hline $\mathrm{FePO}_{4} \cdot x \mathrm{H}_{2} \mathrm{O}$ & 2.711 & - & - \\
\hline $\mathrm{PbO}$ & 0.401 & - & - \\
\hline $\mathrm{Na}_{2} \mathrm{SO}_{4}$ & 0.347 & - & - \\
\hline $\mathrm{SiO}_{2}$ & 4.797 & $\mathrm{SiO}_{2}$ & 19.643 \\
\hline $\mathrm{TiO}_{2}$ & 0.010 & - & - \\
\hline $\mathrm{ZnO}$ & 0.081 & - & - \\
\hline $\mathrm{Zr}(\mathrm{OH})_{4} \cdot x \mathrm{H}_{2} \mathrm{O}$ & 0.989 & - & - \\
\hline $\mathrm{H}_{2} \mathrm{O}$ & 95.874 & - & - \\
\hline $\mathrm{Na}_{2} \mathrm{CO}_{3}$ & 0.304 & - & - \\
\hline $\mathrm{NaNO}_{2}$ & 0.336 & - & - \\
\hline $\mathrm{NaNO}_{3}$ & 0.954 & - & - \\
\hline $\mathrm{H}_{2} \mathrm{C}_{2} \mathrm{O}_{4} \cdot 2 \mathrm{H}_{2} \mathrm{O}$ & 0.115 & - & - \\
\hline- & - & - & - \\
\hline Simulant Total & 197.960 & Additives Total & 80.109 \\
\hline- & - & FEED TOTAL & 278.069 \\
\hline
\end{tabular}

* Target weights adjusted for assay information of starting materials

- Empty data field 
Table 3.15. Composition of Melter Feed to Produce $100 \mathrm{~kg}$ of Target Glass HWI-Al-16 (Target Glass Yield = $500 \mathrm{~g} / \mathrm{L}$ Feed) from the Al-Limited Waste Simulant Using $\mathrm{Al}_{2} \mathrm{O}_{3}$ as the Aluminum Source.

\begin{tabular}{|c|c|c|c|}
\hline \multicolumn{2}{|c|}{ Al-Limited Waste Simulant } & \multicolumn{2}{|c|}{ Glass-Forming Additives } \\
\hline Starting Materials & Target Weight (kg) $^{*}$ & Starting Materials & Target Weight (kg)* \\
\hline $\mathrm{Al}_{2} \mathrm{O}_{3}$ & 23.487 & - & - \\
\hline $\mathrm{H}_{3} \mathrm{BO}_{3}$ & 0.331 & $\mathrm{H}_{3} \mathrm{BO}_{3}$ & 31.487 \\
\hline $\mathrm{BaCO}_{3}$ & 0.068 & - & - \\
\hline $\mathrm{Bi}_{2} \mathrm{O}_{3}$ & 1.122 & - & - \\
\hline $\mathrm{CaO}$ & 1.066 & $\mathrm{CaSiO}_{3}$ (Wollastonite) & 10.560 \\
\hline $\mathrm{CdO}$ & 0.024 & - & - \\
\hline $\mathrm{Cr}_{2} \mathrm{O}_{3}$ & 0.516 & - & - \\
\hline $\mathrm{NaF}$ & 1.438 & - & - \\
\hline $\mathrm{Fe}(\mathrm{OH})_{3}(13 \%$ Slurry $)$ & 47.083 & - & - \\
\hline $\mathrm{KNO}_{3}$ & 0.299 & - & - \\
\hline $\mathrm{Li}_{2} \mathrm{CO}_{3}$ & 0.420 & $\mathrm{Li}_{2} \mathrm{CO}_{3}$ & 8.366 \\
\hline $\mathrm{MgO}$ & 0.117 & - & - \\
\hline $\mathrm{NaOH}$ & 2.124 & $\mathrm{Na}_{2} \mathrm{CO}_{3}$ & 10.053 \\
\hline $\mathrm{Ni}(\mathrm{OH})_{2}$ & 0.498 & - & - \\
\hline $\mathrm{FePO}_{4} \cdot x \mathrm{H}_{2} \mathrm{O}$ & 2.711 & - & - \\
\hline $\mathrm{PbO}$ & 0.401 & - & - \\
\hline $\mathrm{Na}_{2} \mathrm{SO}_{4}$ & 0.347 & - & - \\
\hline $\mathrm{SiO}_{2}$ & 4.797 & $\mathrm{SiO}_{2}$ & 19.643 \\
\hline $\mathrm{TiO}_{2}$ & 0.010 & - & - \\
\hline $\mathrm{ZnO}$ & 0.081 & - & - \\
\hline $\mathrm{Zr}(\mathrm{OH})_{4} \cdot x \mathrm{H}_{2} \mathrm{O}$ & 0.989 & - & - \\
\hline $\mathrm{H}_{2} \mathrm{O}$ & 105.579 & - & - \\
\hline $\mathrm{Na}_{2} \mathrm{CO}_{3}$ & 0.304 & - & - \\
\hline $\mathrm{NaNO}_{2}$ & 0.336 & - & - \\
\hline $\mathrm{NaNO}_{3}$ & 0.954 & - & - \\
\hline $\mathrm{H}_{2} \mathrm{C}_{2} \mathrm{O}_{4} \cdot 2 \mathrm{H}_{2} \mathrm{O}$ & 0.115 & - & - \\
\hline$-^{2}$ & - & - & - \\
\hline Simulant Total & 195.217 & Additives Total & 80.109 \\
\hline- & - & FEED TOTAL & 275.326 \\
\hline
\end{tabular}

* Target weights adjusted for assay information of starting materials

- Empty data field 
The Catholic University of America Vitreous State Laboratory
ORP-56292 Rev. 0

Melt Rate Enhancement for High Aluminum HLW Glass Formulations

Final Report, VSL-08R1360-1, Rev. 0

Table 3.16. Composition of Melter Feed to Produce $100 \mathrm{~kg}$ of Target Glass HWI-Al-19 (Target Glass Yield = $500 \mathrm{~g} / \mathrm{L}$ Feed) from the Al-Limited Waste Simulant Using $\mathrm{Al}(\mathrm{OH})_{3}$ as the Aluminum Source.

\begin{tabular}{|c|c|c|c|}
\hline \multicolumn{2}{|c|}{ Al-Limited Waste Simulant } & \multicolumn{2}{|c|}{ Glass-Forming Additives } \\
\hline Starting Materials & Target Weight (kg) $^{*}$ & Starting Materials & Target Weight (kg) ${ }^{*}$ \\
\hline $\mathrm{Al}(\mathrm{OH})_{3}$ & 37.047 & - & - \\
\hline $\mathrm{H}_{3} \mathrm{BO}_{3}$ & 0.341 & $\mathrm{H}_{3} \mathrm{BO}_{3}$ & 34.089 \\
\hline $\mathrm{BaCO}_{3}$ & 0.070 & - & - \\
\hline $\mathrm{Bi}_{2} \mathrm{O}_{3}$ & 1.156 & - & - \\
\hline $\mathrm{CaO}$ & 1.099 & $\mathrm{CaSiO}_{3}$ (Wollastonite) & 9.798 \\
\hline $\mathrm{CdO}$ & 0.025 & - & - \\
\hline $\mathrm{Cr}_{2} \mathrm{O}_{3}$ & 0.532 & - & - \\
\hline $\mathrm{NaF}$ & 1.483 & - & - \\
\hline $\mathrm{Fe}(\mathrm{OH})_{3}(13 \%$ Slurry $)$ & 48.539 & - & - \\
\hline $\mathrm{KNO}_{3}$ & 0.308 & - & - \\
\hline $\mathrm{Li}_{2} \mathrm{CO}_{3}$ & 0.432 & $\mathrm{Li}_{2} \mathrm{CO}_{3}$ & 8.625 \\
\hline $\mathrm{MgO}$ & 0.121 & - & - \\
\hline $\mathrm{NaOH}$ & 2.190 & $\mathrm{Na}_{2} \mathrm{CO}_{3}$ & 10.364 \\
\hline $\mathrm{Ni}(\mathrm{OH})_{2}$ & 0.514 & - & - \\
\hline $\mathrm{FePO}_{4} \cdot x \mathrm{H}_{2} \mathrm{O}$ & 2.795 & - & - \\
\hline $\mathrm{PbO}$ & 0.413 & - & - \\
\hline $\mathrm{Na}_{2} \mathrm{SO}_{4}$ & 0.358 & - & - \\
\hline $\mathrm{SiO}_{2}$ & 4.945 & $\mathrm{SiO}_{2}$ & 17.276 \\
\hline $\mathrm{TiO}_{2}$ & 0.010 & - & - \\
\hline $\mathrm{ZnO}$ & 0.084 & - & - \\
\hline $\mathrm{Zr}(\mathrm{OH})_{4} \cdot x \mathrm{H}_{2} \mathrm{O}$ & 1.020 & - & - \\
\hline $\mathrm{H}_{2} \mathrm{O}$ & 91.903 & - & - \\
\hline $\mathrm{Na}_{2} \mathrm{CO}_{3}$ & 0.314 & - & - \\
\hline $\mathrm{NaNO}_{2}$ & 0.346 & - & - \\
\hline $\mathrm{NaNO}_{3}$ & 0.984 & - & - \\
\hline $\mathrm{H}_{2} \mathrm{C}_{2} \mathrm{O}_{4} \cdot 2 \mathrm{H}_{2} \mathrm{O}$ & 0.119 & - & - \\
\hline$-^{2}$ & - & - & - \\
\hline Simulant Total & 197.148 & Additives Total & 80.152 \\
\hline- & - & FEED TOTAL & 277.300 \\
\hline
\end{tabular}

* Target weights adjusted for assay information of starting materials

- Empty data field 
Table 4.1. Summary of Results from DM100 Tests.

\begin{tabular}{|c|c|c|c|c|c|}
\hline & Test & 1 & 2 & 3 & 4 \\
\hline & Feed Start & 2/4/08 8:26 & 2/6/08 12:15 & 5/5/08 9:32 & $5 / 7 / 0814: 32$ \\
\hline$\Xi$ & Feed End & 2/6/08 11:30 & 2/8/08 23:00 & 5/7/08 13:30 & 5/9/08 16:32 \\
\hline & Interval & $51.1 \mathrm{hr}$ & $58.75 \mathrm{hr}$ & $52.0 \mathrm{hr}$ & 50.0 \\
\hline Wate & eeding for Cold Cap & $34 \min$ & NA & $58 \mathrm{~min}$ & NA \\
\hline & Slurry Feeding & $50.5 \mathrm{hr}$ & $58.75 \mathrm{hr}$ & $51.0 \mathrm{hr}$ & $50.0 \mathrm{hr}$ \\
\hline & ding Interruptions & $39 \min$ & $50 \mathrm{~min}$ & $62 \min$ & $5 \mathrm{~min}$ \\
\hline Targ & Glass Temperature & $1200^{\circ} \mathrm{C}$ & $1150^{\circ} \mathrm{C}$ & $1200^{\circ} \mathrm{C}$ & $1150^{\circ} \mathrm{C}$ \\
\hline Av & age Bubbling Rate & $9.3 \mathrm{lpm}$ & $9.2 \mathrm{lpm}$ & $9.1 \mathrm{lpm}$ & $9.0 \mathrm{lpm}$ \\
\hline & Aluminum Source & Hydroxide & Hydroxide & Hydroxide & Hydroxide \\
\hline & Target Glass & HLW-E-Al-27 & HLW-E-Al-27 & HWI-Al-16 & HWI-Al-16 \\
\hline & Waste Loading & $45 \%$ & $45 \%$ & $43.6 \%$ & $43.6 \%$ \\
\hline 选 & Used & $854 \mathrm{~kg}$ & $527 \mathrm{~kg}$ & $879 \mathrm{~kg}$ & $617 \mathrm{~kg}$ \\
\hline & & $500 \mathrm{~g} / 1$ & $500 \mathrm{~g} / 1$ & $500 \mathrm{~g} / 1$ & $500 \mathrm{~g} / 1$ \\
\hline & & $0.3596 \mathrm{~kg} / \mathrm{kg}$ & $0.3596 \mathrm{~kg} / \mathrm{kg}$ & $0.358 \mathrm{~kg} / \mathrm{kg}$ & $0.358 \mathrm{~kg} / \mathrm{kg}$ \\
\hline & Average Feed Rate & $16.9 \mathrm{~kg} / \mathrm{hr}$ & $9.0 \mathrm{~kg} / \mathrm{hr}$ & $16.9 \mathrm{~kg} / \mathrm{hr}$ & $12.3 \mathrm{~kg} / \mathrm{hr}$ \\
\hline & Poured & $239 \mathrm{~kg}$ & $251 \mathrm{~kg}$ & $225 \mathrm{~kg}$ & $281 \mathrm{~kg}$ \\
\hline$\stackrel{0}{E}$ & Average Rate & $1351 \mathrm{~kg} / \mathrm{m}^{2} /$ day & $717 \mathrm{~kg} / \mathrm{m}^{2} /$ day & $1371 \mathrm{~kg} / \mathrm{m}^{2} /$ day & $982 \mathrm{~kg} / \mathrm{m}^{2} /$ day \\
\hline$\stackrel{0}{2}$ & Steady State Rate ${ }^{*}$ & $1200 \mathrm{~kg} / \mathrm{m}^{2} /$ day & $700 \mathrm{~kg} / \mathrm{m}^{2} /$ day & $1400 \mathrm{~kg} / \mathrm{m}^{2} /$ day & $950 \mathrm{~kg} / \mathrm{m}^{2} /$ day \\
\hline$\tilde{U}$ & Average Power Use & $\begin{array}{c}4.1 \mathrm{~kW} \mathrm{hr} / \mathrm{kg} \\
\text { glass }\end{array}$ & $\begin{array}{c}5.4 \mathrm{~kW} \mathrm{hr} / \mathrm{kg} \\
\text { glass }\end{array}$ & $\begin{array}{c}4.2 \mathrm{~kW} \mathrm{hr} / \mathrm{kg} \\
\text { glass }\end{array}$ & $\begin{array}{c}4.4 \mathrm{~kW} \mathrm{hr} / \mathrm{kg} \\
\text { glass }\end{array}$ \\
\hline
\end{tabular}

*- Rates calculated from feed data.

Note: Rates do not take into account the time for water feeding and cold cap burn-off. 
Table 4.1. Summary of Results from DM100 Tests (continued).

\begin{tabular}{|c|c|c|c|c|c|}
\hline & Test & 5 & 6 & 7 & 8 \\
\hline & Feed Start & 6/2/08 12:52 & $6 / 4 / 0817: 30$ & $6 / 23 / 087: 56$ & 6/25/08 12:15 \\
\hline$\Xi$ & Feed End & 6/4/08 15:30 & 6/7/08 00:30 & $6 / 25 / 0811: 30$ & 6/27/08 23:30 \\
\hline & Interval & $50.6 \mathrm{hr}$ & $55.0 \mathrm{hr}$ & $51.6 \mathrm{hr}$ & 59.25 \\
\hline Wate & eeding for Cold Cap & $38 \mathrm{~min}$ & NA & $64 \min$ & NA \\
\hline & lurry Feeding & $50.0 \mathrm{hr}$ & $55.0 \mathrm{hr}$ & $50.5 \mathrm{hr}$ & $59.25 \mathrm{hr}$ \\
\hline & ling Interruptions & $13 \mathrm{~min}$ & $42 \mathrm{~min}$ & $38 \mathrm{~min}$ & $13 \mathrm{~min}$ \\
\hline Targ & Glass Temperature & $1200^{\circ} \mathrm{C}$ & $1150^{\circ} \mathrm{C}$ & $1200^{\circ} \mathrm{C}$ & $1150^{\circ} \mathrm{C}$ \\
\hline Av & age Bubbling Rate & $8.6 \mathrm{lpm}$ & $8.8 \mathrm{lpm}$ & $9.0 \mathrm{lpm}$ & $9.0 \mathrm{lpm}$ \\
\hline & Aluminum Source & Oxide & Oxide & Hydroxide & Hydroxide \\
\hline & Target Glass & HWI-Al-16 & HWI-Al-16 & HWI-Al-19 & HWI-Al-19 \\
\hline & Waste Loading & $43.6 \%$ & $43.6 \%$ & $45 \%$ & $45 \%$ \\
\hline 造 & Used & $806 \mathrm{~kg}$ & $510 \mathrm{~kg}$ & $902 \mathrm{~kg}$ & $693 \mathrm{~kg}$ \\
\hline & & $500 \mathrm{~g} / 1$ & $500 \mathrm{~g} / 1$ & $500 \mathrm{~g} / 1$ & $500 \mathrm{~g} / \mathrm{l}$ \\
\hline & & $0.363 \mathrm{~kg} / \mathrm{kg}$ & $0.363 \mathrm{~kg} / \mathrm{kg}$ & $0.361 \mathrm{~kg} / \mathrm{kg}$ & $0.361 \mathrm{~kg} / \mathrm{kg}$ \\
\hline & Average Feed Rate & $16.1 \mathrm{~kg} / \mathrm{hr}$ & $9.3 \mathrm{~kg} / \mathrm{hr}$ & $17.9 \mathrm{~kg} / \mathrm{hr}$ & $11.7 \mathrm{~kg} / \mathrm{hr}$ \\
\hline & Poured & $214 \mathrm{~kg}$ & $254 \mathrm{~kg}$ & $245 \mathrm{~kg}$ & $239 \mathrm{~kg}$ \\
\hline$\stackrel{\circlearrowright}{\Xi}$ & Average Rate ${ }^{*}$ & $1291 \mathrm{~kg} / \mathrm{m}^{2} /$ day & $748 \mathrm{~kg} / \mathrm{m}^{2} /$ day & $1434 \mathrm{~kg} / \mathrm{m}^{2} /$ day & $938 \mathrm{~kg} / \mathrm{m}^{2} /$ day \\
\hline$D_{n}^{2}$ & Steady State Rate ${ }^{*}$ & $1300 \mathrm{~kg} / \mathrm{m}^{2} /$ day & $700 \mathrm{~kg} / \mathrm{m}^{2} /$ day & $1500 \mathrm{~kg} / \mathrm{m}^{2} /$ day & $950 \mathrm{~kg} / \mathrm{m}^{2} /$ day \\
\hline$\tilde{U}$ & Average Power Use & $\begin{array}{l}4.1 \mathrm{~kW} \mathrm{hr} / \mathrm{kg} \\
\text { glass }\end{array}$ & $\begin{array}{c}4.8 \mathrm{~kW} \mathrm{hr} / \mathrm{kg} \\
\text { glass }\end{array}$ & $\begin{array}{c}4.1 \mathrm{~kW} \mathrm{hr} / \mathrm{kg} \\
\text { glass }\end{array}$ & $\begin{array}{c}4.6 \mathrm{~kW} \mathrm{hr} / \mathrm{kg} \\
\text { glass }\end{array}$ \\
\hline
\end{tabular}

*- Rates calculated from feed data.

Note: Rates do not take into account the time for water feeding and cold cap burn-off. 
Table 4.2. Steady-State Production Rates Achieved with HLW Compositions on the DM100 at Melt Pool Bubbling of $9 \mathrm{lpm}$ and Solids content near 500 g glass/liter.

\begin{tabular}{|c|c|c|c|}
\hline HLW Waste & Glass Yield (g/L) & $\begin{array}{l}\text { Glass Temperature } \\
\left({ }^{\circ} \mathrm{C}\right)\end{array}$ & $\begin{array}{l}\text { Production Rate } \\
\mathrm{kg} / \mathrm{m}^{2} / \text { day }\end{array}$ \\
\hline \multirow{2}{*}{$\begin{array}{c}\text { Aluminum Limited } \\
\text { (HLW-E-Al-27, Al hydroxide) }\end{array}$} & 500 & 1200 & 1200 \\
\hline & 500 & 1150 & 700 \\
\hline \multirow{2}{*}{$\begin{array}{c}\text { Aluminum Limited } \\
\text { (HWI-Al-16, Al hydroxide) }\end{array}$} & 500 & 1200 & 1400 \\
\hline & 500 & 1150 & 950 \\
\hline \multirow{2}{*}{$\begin{array}{c}\text { Aluminum Limited } \\
\text { (HWI-Al-16, Al oxide) }\end{array}$} & 500 & 1200 & 1300 \\
\hline & 500 & 1150 & 700 \\
\hline \multirow{2}{*}{$\begin{array}{c}\text { Aluminum Limited } \\
\text { (HWI-Al-19, Al hydroxide) }\end{array}$} & 500 & 1200 & 1500 \\
\hline & 500 & 1150 & 950 \\
\hline \multirow{2}{*}{$\begin{array}{c}\text { Aluminum Limited } \\
\text { (HLW-E-Al-27, Al oxide) }\end{array}$} & 500 & 1175 & 550 \\
\hline & 500 & 1150 & 550 \\
\hline \multirow{2}{*}{ Aluminum and Sodium Limited [2] } & 500 & 1175 & 900 \\
\hline & 500 & 1150 & 400 \\
\hline \multirow{2}{*}{ Bismuth Limited [2] } & 500 & 1175 & 1000 \\
\hline & 500 & 1150 & 830 \\
\hline \multirow{2}{*}{ Chromium Limited [2] } & 500 & 1175 & 1300 \\
\hline & 500 & 1150 & 1150 \\
\hline AZ-101 [14] & 530 & 1150 & 1300 \\
\hline AZ-102, Nominal Rheology [23] & 550 & 1150 & 1200 \\
\hline AZ-102, Adjusted Rheology [23] & 550 & 1150 & 1400 \\
\hline C-106/AY-102, SIPP [15] & 470 & 1150 & 1180 \\
\hline HLW02-24, High Viscosity [24] & 500 & 1150 & 900 \\
\hline HLW-ALG-17, Low Viscosity [24] & 500 & 1150 & 1600 \\
\hline HLW-ALG-16, High Conductivity [24] & 500 & 1150 & 1200 \\
\hline HLW02-46, Low Conductivity [24] & 500 & 1150 & 900 \\
\hline $\mathrm{C}-106 / \mathrm{AY}-102[24]$ & 500 & 1150 & 1000 \\
\hline C-106/AY-102+15\% GFCs [24] & 500 & 1150 & 1000 \\
\hline C-106/AY-102- 15\% GFCs [24] & 500 & 1150 & 1050 \\
\hline $\begin{array}{l}\text { C-106/AY-102 replacing borax with boric acid } \\
\text { and soda ash [20] }\end{array}$ & 500 & 1150 & 1050 \\
\hline $\mathrm{C}-106 / \mathrm{AY}-102, \mathrm{SiO}_{2}=33 \%[25]$ & 500 & 1150 & 2000 \\
\hline $\mathrm{C}-106 / \mathrm{AY}-102, \mathrm{SiO}_{2}=53.1 \%[25]$ & 500 & 1150 & 700 \\
\hline $\mathrm{C}-106 / \mathrm{AY}-102, \mathrm{MnO}=8 \%[25]$ & 500 & 1150 & 750 \\
\hline $\mathrm{C}-106 / \mathrm{AY}-102, \mathrm{Na}_{2} \mathrm{O}=20.0 \%[25]$ & 500 & 1150 & 2150 \\
\hline $\begin{aligned} \mathrm{C}-106 / \mathrm{AY}-102, \mathrm{~K}_{2} \mathrm{O} & =2.5 \%, \mathrm{Cr}_{2} \mathrm{O}_{3}=0.6 \%, \\
\mathrm{La}_{2} \mathrm{O}_{3}=1.2 \%, \mathrm{TiO}_{2} & =1 \%, \mathrm{ZnO}=4 \%[25]\end{aligned}$ & 500 & 1150 & 1700 \\
\hline $\mathrm{C}-106 / \mathrm{AY}-102, \mathrm{~B}_{2} \mathrm{O}_{3}=4.3 \%[25]$ & 500 & 1150 & 900 \\
\hline $\mathrm{C}-106 / \mathrm{AY}-102, \mathrm{~B}_{2} \mathrm{O}_{3}=15 \%[25]$ & 500 & 1150 & 1550 \\
\hline $\mathrm{C}-106 / \mathrm{AY}-102, \mathrm{Al}_{2} \mathrm{O}_{3}=13 \%[25]$ & 500 & 1150 & 900 \\
\hline $\mathrm{C}-106 / \mathrm{AY}-102, \mathrm{Li}_{2} \mathrm{O}=0 \%[25]$ & 500 & 1150 & 450 \\
\hline Algorithm Generated, $\mathrm{ZrO}_{2}=10.65 \%[25]$ & 500 & 1150 & 850 \\
\hline Algorithm Generated, $\mathrm{SrO}=9.27 \%[25]$ & 500 & 1150 & 650 \\
\hline
\end{tabular}


ORP-56292 Rev. 0

Table 4.3. Summary of Measured DM100 Parameters.

\begin{tabular}{|c|c|c|c|c|c|c|c|c|c|c|c|c|c|c|}
\hline \multirow{2}{*}{\multicolumn{3}{|c|}{ Test }} & \multicolumn{3}{|c|}{1} & \multicolumn{3}{|c|}{2} & \multicolumn{3}{|c|}{3} & \multicolumn{3}{|c|}{4} \\
\hline & & & AVG & MIN & MAX & AVG & MIN & MAX & AVG & MIN & MAX & $\mathrm{AVG}$ & MIN & MAX \\
\hline \multirow{14}{*}{$\begin{array}{c}\mathrm{T} \\
\mathrm{E} \\
\mathrm{M} \\
\mathrm{P} \\
\mathrm{E} \\
\mathrm{R} \\
\mathrm{A} \\
\mathrm{T} \\
\mathrm{U} \\
\mathrm{R} \\
\mathrm{E} \\
\left({ }^{\circ} \mathrm{C}\right)\end{array}$} & \multirow{4}{*}{ Electrode } & East Upper & 1076 & 677 & 1155 & 1096 & 1073 & 1113 & 988 & 335 & 1156 & 1089 & 1059 & 1112 \\
\hline & & West Upper & 1138 & 773 & 1186 & 1095 & 1073 & 1127 & 1088 & 695 & 1178 & 1111 & 1089 & 1140 \\
\hline & & West Lower & 1125 & 1104 & 1167 & 1063 & 1051 & 1093 & 1119 & 1089 & 1139 & 1072 & 1056 & 1100 \\
\hline & & Bottom & 804 & 794 & 841 & 759 & 748 & 794 & 726 & 718 & 753 & 705 & 694 & 729 \\
\hline & \multirow{4}{*}{ Glass } & 27" from bottom & 1076 & 192 & 1195 & 1131 & 1055 & 1156 & 1014 & 118 & 1207 & 1139 & 1099 & 1160 \\
\hline & & 16 " from bottom & 1159 & 773 & 1216 & 1141 & 1115 & 1167 & 1126 & 309 & 1213 & 1149 & 1125 & 1166 \\
\hline & & 10 " from bottom & 1203 & 1179 & 1242 & 1153 & 1132 & 1178 & 1201 & 1162 & 1223 & 1155 & 1135 & 1176 \\
\hline & & $5 "$ from bottom & 1192 & 1137 & 1229 & 1147 & 1126 & 1169 & 1191 & 1155 & 1219 & 1140 & 1122 & 1163 \\
\hline & \multirow{2}{*}{ Plenum } & Exposed & 468 & 246 & 664 & 449 & 383 & 573 & 437 & 302 & 607 & 406 & 314 & 602 \\
\hline & & Thermowell & 442 & 356 & 656 & 415 & 370 & 516 & 395 & 272 & 588 & 392 & 313 & 625 \\
\hline & \multirow{2}{*}{ Discharge } & Chamber & 1022 & 806 & 1075 & 1038 & 1023 & 1060 & 1056 & 1008 & 1095 & 1060 & 1022 & 1080 \\
\hline & & Air Lift & 1023 & 913 & 1109 & 1029 & 1009 & 1069 & 1049 & 927 & 1130 & 1054 & 1036 & 1101 \\
\hline & \multicolumn{2}{|c|}{ Film Cooler Outlet } & 285 & 260 & 301 & 283 & 277 & 287 & 287 & 262 & 306 & 283 & 266 & 296 \\
\hline & \multicolumn{2}{|c|}{ Transition Line Outlet } & 271 & 219 & 288 & 269 & 265 & 276 & 270 & 218 & 287 & 268 & 211 & 278 \\
\hline \multicolumn{3}{|c|}{ Lance Bubbling (lpm) } & 9.3 & 1.6 & 9.4 & 9.2 & 9.0 & 9.4 & 9.1 & 8.6 & 9.3 & 9.0 & 9.0 & 9.2 \\
\hline \multicolumn{3}{|c|}{ Melter Pressure (inches water) } & -1.05 & -3.38 & 0.44 & -1.17 & -3.44 & 0.62 & -1.03 & -4.34 & 0.27 & -0.99 & -1.62 & 0.50 \\
\hline \multicolumn{3}{|c|}{ Total Electrode Voltage (V) } & 46.0 & 1.8 & 57.3 & 42.5 & 38.3 & 50.0 & 49.2 & 1.9 & 56.7 & 46.3 & 35.8 & 48.9 \\
\hline \multicolumn{3}{|c|}{ Total Power $(\mathrm{kW})$} & 24.9 & 0.3 & 32.6 & 17.4 & 13.9 & 22.0 & 25.4 & 0.3 & 29.9 & 19.3 & 12.8 & 21.4 \\
\hline \multicolumn{3}{|c|}{ Glass Resistance (ohms) } & 0.085 & 0.011 & 0.105 & 0.104 & 0.095 & 0.117 & 0.096 & 0.012 & 0.134 & 0.111 & 0.100 & 0.121 \\
\hline
\end{tabular}


ORP-56292 Rev. 0

Table 4.3. Summary of Measured DM100 Parameters (continued).

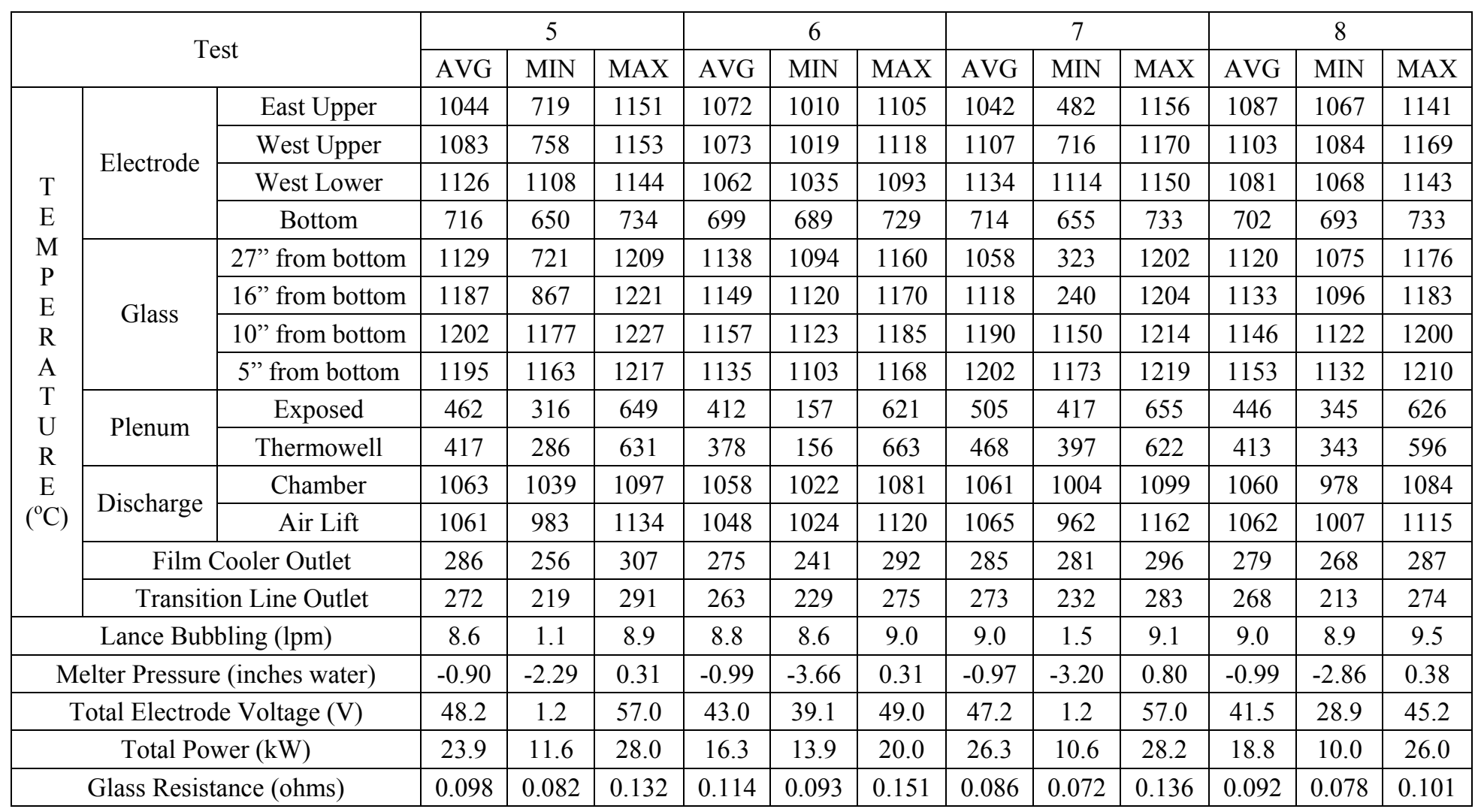


Table 5.1. Summary of DM1200 Test Conditions and Results.

\begin{tabular}{|c|c|c|c|c|}
\hline \multicolumn{2}{|r|}{-} & 1 & 2 & 3 \\
\hline \multirow{3}{*}{$\stackrel{\mathscr{\Xi}}{\Xi}$} & Feed Start & $8 / 6 / 089: 21$ & $8 / 11 / 0814: 45$ & 8/13/08 16:05 \\
\hline & Feed End & 8/8/08 10:21 & 8/13/04 16:00 & $8 / 15 / 0819: 30$ \\
\hline & Interval & $49.0 \mathrm{hr}$ & $49.25 \mathrm{hr}$ & $51.4 \mathrm{hr}$ \\
\hline \multicolumn{2}{|c|}{ Water Feeding for Cold Cap } & $1.0 \mathrm{hr}$ & $1.0 \mathrm{hr}$ & NA \\
\hline \multicolumn{2}{|c|}{ Slurry Feeding } & $48.0 \mathrm{hr}$ & $48.25 \mathrm{hr}$ & $51.4 \mathrm{hr}$ \\
\hline \multicolumn{2}{|c|}{ Cold cap burn } & $3.2 \mathrm{hr}$ & NA & $4.0 \mathrm{hr}$ \\
\hline \multicolumn{2}{|c|}{ Average Total Bubbling } & $125 \mathrm{lpm}$ & $65 \mathrm{lpm}$ & 54 lpm \\
\hline \multicolumn{2}{|c|}{ Steady State Bubbling } & $124 \mathrm{lpm}$ & $71 \mathrm{lpm}$ & $48 \mathrm{lpm}$ \\
\hline \multicolumn{2}{|c|}{$\begin{array}{l}\text { Average Glass } \\
\text { Temperature, East }\end{array}$} & $1150^{\circ} \mathrm{C}$ & $1154^{\circ} \mathrm{C}$ & $1178^{\circ} \mathrm{C}$ \\
\hline \multicolumn{2}{|c|}{$\begin{array}{c}\text { Average Glass } \\
\text { Temperature, West }\end{array}$} & $1148^{\circ} \mathrm{C}$ & $1146^{\circ} \mathrm{C}$ & $1170^{\circ} \mathrm{C}$ \\
\hline \multicolumn{2}{|c|}{$\begin{array}{l}\text { Average Plenum } \\
\text { Temperature }\end{array}$} & $653^{\circ} \mathrm{C}$ & $571^{\circ} \mathrm{C}$ & $595^{\circ} \mathrm{C}$ \\
\hline \multicolumn{2}{|c|}{ Average Electrode Power } & $225 \mathrm{~kW}$ & $170 \mathrm{~kW}$ & $181 \mathrm{~kW}$ \\
\hline \multirow{2}{*}{ Feed } & Used & $9942 \mathrm{~kg}$ & $6932 \mathrm{~kg}$ & $7498 \mathrm{~kg}$ \\
\hline & Average Rate & $207.1 \mathrm{~kg} / \mathrm{hr}$ & $143.7 \mathrm{~kg} / \mathrm{hr}$ & $145.9 \mathrm{~kg} / \mathrm{hr}$ \\
\hline \multirow{4}{*}{ 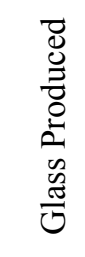 } & Poured & $3737 \mathrm{~kg}$ & $2404 \mathrm{~kg}$ & $2732 \mathrm{~kg}$ \\
\hline & Average Rate & $1557 \mathrm{~kg} / \mathrm{m}^{2} /$ day & $996 \mathrm{~kg} / \mathrm{m}^{2} /$ day & $1063 \mathrm{~kg} / \mathrm{m}^{2} /$ day \\
\hline & Average Rate ${ }^{*}$ & $1495 \mathrm{~kg} / \mathrm{m}^{2} /$ day & $1038 \mathrm{~kg} / \mathrm{m}^{2} /$ day & $1053 \mathrm{~kg} / \mathrm{m}^{2} /$ day \\
\hline & Steady State Rate & $1500 \mathrm{~kg} / \mathrm{m}^{2} /$ day & $1050 \mathrm{~kg} / \mathrm{m}^{2} /$ day & $1050 \mathrm{~kg} / \mathrm{m}^{2} /$ day \\
\hline
\end{tabular}

$\$$ - Rates calculated from glass poured.

*- Rates calculated from feed data.

Note: Rates do not take into account the time for water feeding and cold cap burn-off.

NA: Not applicable. 
Table 5.2. Summary of Operational Events.

\begin{tabular}{|c|c|c|}
\hline \multirow[b]{2}{*}{ Test } & \multicolumn{2}{|r|}{ Operational notes } \\
\hline & $\begin{array}{l}\text { Run time } \\
\text { (hours) }\end{array}$ & Run time note \\
\hline \multirow{22}{*}{1} & 0.0 & Start water feeding at 8/6/2008 9:21 \\
\hline & 1.0 & Started slurry feeding \\
\hline & 5.3 & Paused feeding for 5 minutes to collect feed sample. \\
\hline & 7.5 & During the SBS blowdown, Y-strainer clogged and was cleaned out. \\
\hline & 10.5 & Transferred feed from mixing tank to feed tank. \\
\hline & 10.9 & Film cooler rinse was performed. \\
\hline & 11.0 & $\begin{array}{l}\text { During film cooler rinse, it was discerned the film cooler was } \sim 90 \% \text { clogged. } \\
\text { Paused feeding for } 8 \text { minutes to manually clear film cooler. }\end{array}$ \\
\hline & 20.2 & Transferred feed from mixing tank to feed tank. \\
\hline & 23.4 & Film cooler rinse was performed. \\
\hline & 26.7 & Took picture of cold cap through melter view port. (see Figure 5.1) \\
\hline & $27.4-27.5$ & Performed WESP deluge, pre-blowdown and post blow down. \\
\hline & 30.4 & Transferred feed from mixing tank to feed tank. \\
\hline & 33.4 & Paused feeding for 4 minutes to collect feed sample. \\
\hline & 35.0 & $\begin{array}{l}\text { Melter tripped into Emergency Off Gas line because port was opened to } \\
\text { remove exhaust sampling probe. Exhaust immediately returned to main line. }\end{array}$ \\
\hline & 35.6 & $\begin{array}{l}\text { Film cooler rinse was performed. Film cooler blockage was } \sim 40-50 \% \text {. Film } \\
\text { cooler rinse opened up the blockage. Below the film cooler there was still } \\
\text { residual blockage of about } 10 \% \text { after rinsing. }\end{array}$ \\
\hline & 40.7 & Transferred feed from mixing tank to feed tank. \\
\hline & 49.00 & Feed stopped at the end of Test 1. \\
\hline & 49.6 & $\begin{array}{l}\text { Opened port C-1 (see Figure 1.6) to retrieve a cold cap sample. The gasket } \\
\text { ring was replaced. }\end{array}$ \\
\hline & 49.9 & Film cooler rinse was performed. \\
\hline & 51.0 & Feed transferred to mixing tank for Test 2 . \\
\hline & $51.9-60.0$ & Performed WESP deluge, pre-blow down and post blow down. \\
\hline & 52.2 & Off gas shut down is completed. \\
\hline
\end{tabular}


Table 5.2. Summary of Operational Events (continued).

\begin{tabular}{|c|c|c|}
\hline \multirow[b]{2}{*}{ Test } & \multicolumn{2}{|r|}{ Operational notes } \\
\hline & $\begin{array}{l}\text { Run time } \\
\text { (hours) }\end{array}$ & Run time note \\
\hline \multirow{21}{*}{2} & - & Transferred feed from mixing tank to feed tank. \\
\hline & 0.0 & Start water feeding at 8/11/2008 14:45 \\
\hline & 1.0 & Slurry feed started \\
\hline & 7.4 & Paused feeding for 6 minutes to collect feed sample. \\
\hline & 10.6 & Film cooler rinse was performed. \\
\hline & 14.9 & Transferred feed from mixing tank to feed tank. \\
\hline & 18.1 & Transferred feed to mixing tank. \\
\hline & 22.3 & Paused feeding for 6 minutes to collect feed sample. \\
\hline & $23.1-23.3$ & Blower 701 failed. Paused feeding for 13 minutes to switch to Blower 702 . \\
\hline & 23.5 & $\begin{array}{l}\text { Melter tripped into Emergency Off Gas line because port was opened for } \\
\text { removal of exhaust sampling probe. Exhaust immediately returned to main } \\
\text { line. }\end{array}$ \\
\hline & $23.6-23.9$ & Performed WESP deluge, pre-blow down and post blow down. \\
\hline & 23.8 & Film cooler rinse was performed. \\
\hline & 25.3 & $\begin{array}{l}\text { Melter tripped into Emergency Off Gas line due to port opened to remove } \\
\text { exhaust sampling probe. Exhaust immediately returned to main line. }\end{array}$ \\
\hline & 29.6 & Transferred feed from mixing tank to feed tank. \\
\hline & 34.9 & Film cooler rinse was performed. \\
\hline & 41.2 & $\begin{array}{l}\text { Replaced Blower- } 701 \text { head for back-up. Observed that Blower- } 702 \text { outlet } \\
\text { temperature is } 90^{\circ} \mathrm{C} \text {. This could cause premature failure. Reduced Blower } \\
\text { setting from } 46 \text { to } 45 \mathrm{~Hz} \text { and increased Blower } 801 \text { setting from } 21 \text { to } 23 \mathrm{~Hz} \text {. }\end{array}$ \\
\hline & 44.3 & Transferred feed from mixing tank to feed tank. \\
\hline & 47.3 & Film cooler rinse was performed. \\
\hline & $48.1-48.2$ & Performing WESP deluge, pre-blow down and post blow down. \\
\hline & 49.2 & Film cooler rinse was performed. \\
\hline & 49.3 & Feed stopped at end of Test 2 . Feed sample was also collected. \\
\hline
\end{tabular}


ORP-56292 Rev. 0

The Catholic University of America

Table 5.2. Summary of Operational Events (continued).

\begin{tabular}{|c|c|c|}
\hline \multirow[b]{2}{*}{ Test } & \multicolumn{2}{|r|}{ Operational notes } \\
\hline & $\begin{array}{c}\text { Run time } \\
\text { (hours) }\end{array}$ & Run time note \\
\hline \multirow{22}{*}{3} & 49.3 & Changed test conditions at 8/13/2008 16.05 \\
\hline & $56.5-56.6$ & Film cooler differential pressure was up, 9.5 "WC, film cooler was cleared. \\
\hline & 58.3 & Transferred feed from mixing tank to feed tank. \\
\hline & $63.9-64.1$ & $\begin{array}{l}\text { Feed tube was partially clogged. Tapped with hammer to dislodge the } \\
\text { blockage. Feed was paused for } 13 \text { minutes. Feed sample was collected. }\end{array}$ \\
\hline & 64.6 & $\begin{array}{l}\text { Electric high temperature alarm sounded (East Electrode thermocouple } \\
\text { reading, TR-2 } 21=1172^{\circ} \mathrm{C} \text { ). Reduced power from } 150 \text { to } 145 \mathrm{~kW} \text {, later electric } \\
\text { was shut down. Increased lance bubbler } 2 \text { flow rate from } 20 \text { to } 22 \mathrm{lpm} \text {. }\end{array}$ \\
\hline & 64.9 & $\begin{array}{l}\text { Electric alarm was cleared. Sounded. East Electrode thermocouple reading } \\
\text { was } 1164{ }^{\circ} \mathrm{C} \text {. }\end{array}$ \\
\hline & 66.0 & Transferred feed from mixing tank to feed tank. \\
\hline & 66.2 & $\begin{array}{l}\text { Cold cap ridge or cone collapsed, causing pressure surge. Emergency Off Gas } \\
\text { was activated. Exhaust immediately returned to main line. }\end{array}$ \\
\hline & $71.6-71.8$ & Performed WESP deluge, pre-blow down and post blow down. \\
\hline & 73.1 & Transferred feed from mixing tank to feed tank. \\
\hline & 73.2 & Film cooler rinse was performed. \\
\hline & 77.10 & $\begin{array}{l}\text { High Temperature alarm and power shut off set points attached to the East } \\
\text { Electrode thermocouple were increased to } 1175^{\circ} \mathrm{C} \text { and } 1180^{\circ} \mathrm{C} \text { respectively. }\end{array}$ \\
\hline & 84.8 & Film cooler rinse was performed. \\
\hline & 86.3 & Transferred feed from mixing tank to feed tank. \\
\hline & 88.4 & Feed tube was manually flushed. \\
\hline & 92.5 & Paused feeding for 7 minutes to collect feed sample. \\
\hline & 96.7 & Film cooler rinse was performed. \\
\hline & $\begin{array}{c}99.7 \text { and } \\
100.7\end{array}$ & $\begin{array}{l}\text { Tapped on the feed tube to clear the stalactite which was growing under the } \\
\text { feed tube. }\end{array}$ \\
\hline & 100.8 & Feed stopped at the end of Test 3. \\
\hline & 102.0 & Removed feed from feed tank. \\
\hline & $106.0-106.4$ & Performed WESP deluge, pre-blow down and post blow down. \\
\hline & 107.6 & Started melter and off-gas shut down. \\
\hline
\end{tabular}


Table 5.3. Operator Observations of Cold Cap (CC).

\begin{tabular}{|c|c|c|c|c|}
\hline Test & Date & Time & $\begin{array}{l}\text { Run } \\
\text { Time } \\
\text { (hours) }\end{array}$ & Cold Cap Observations \\
\hline \multirow{29}{*}{1} & \multirow{29}{*}{$8 / 6 / 2008$} & $9: 21$ & 0.0 & Started feeding water at $500 \mathrm{~mL} / \mathrm{min}$. \\
\hline & & $11: 03$ & 1.7 & $\begin{array}{l}\mathrm{CC} \sim 80 \% \text { is flat with boiling on top and feed flowing into opening in S- } \\
\mathrm{E} \& \mathrm{~N}-\mathrm{W} \text { corners. }\end{array}$ \\
\hline & & $11: 15$ & 1.9 & $\begin{array}{l}\text { CC } 75-80 \% \text { with liquid boiling profusely and flowing into openings in } \\
\text { between feed shots. }\end{array}$ \\
\hline & & $11: 34$ & 2.2 & $\mathrm{CC} \sim 75-80 \%$ with liquid boiling profusely. \\
\hline & & $11: 50$ & 2.5 & CC opening on east side of melter is larger than west. \\
\hline & & 12:05 & 2.7 & $\mathrm{CC} \sim 80 \%$ with liquid boiling. \\
\hline & & $12: 11$ & 2.8 & $\mathrm{CC}$ is $\sim 85 \%$ with liquid flowing to openings in between feed shots. \\
\hline & & $12: 33$ & 3.2 & $\begin{array}{l}\mathrm{CC} \sim 85 \% \text {. Flat } \sim 6 " \text { thick with feed boiling on surface. Opening on S-E and } \\
\text { N-W corners with feed flowing into the openings. }\end{array}$ \\
\hline & & 13:05 & 3.7 & $\begin{array}{l}\mathrm{CC} \sim 85 \% \sim 6 " \text { thick with small ridge around openings on } \mathrm{S}-\mathrm{E} \& \mathrm{~N}-\mathrm{W} \\
\text { corners. Feed boiling on the surface and flowing into openings. }\end{array}$ \\
\hline & & $13: 12$ & 3.9 & CC unchanged. \\
\hline & & $13: 40$ & 4.3 & $\begin{array}{l}\text { Increase bubbling from } 60 \text { to } 80 \mathrm{lpm}, \mathrm{CC} \sim 85 \% \text { with more aggressive liquid } \\
\text { boiling observed. }\end{array}$ \\
\hline & & $13: 53$ & 4.5 & $\mathrm{CC}$ is still $\sim 80-85 \%$ with liquid boiling and flowing into openings. \\
\hline & & 14:07 & 4.8 & CC $\sim 85 \%$ with liquid mildly boiling and flowing into openings. \\
\hline & & $14: 19$ & 5.0 & $\begin{array}{l}\mathrm{CC} \sim 80 \% \text { with opening slightly larger and center island bridge } \sim 8 " \text { thick } \\
\text { liquid on each side. }\end{array}$ \\
\hline & & $14: 43$ & 5.4 & $\mathrm{CC} \sim 80-85$ and $6-8 "$ thick boiling liquid pool and center ridge. \\
\hline & & $15: 05$ & 5.7 & $\mathrm{CC} \sim 80-\%$ couple of high ridges around openings. \\
\hline & & $15: 35$ & 6.2 & $\mathrm{CC} \sim 80 \%$ and $6-8 "$ thick. \\
\hline & & $15: 56$ & 6.6 & CC $\sim 90 \%$. Can not see east opening due to center ridge. \\
\hline & & $16: 13$ & 6.9 & $\begin{array}{l}\text { CC } \sim 90 \% \text {, No visible changes other than larger amount of liquid is flowing } \\
\text { into melt pool. }\end{array}$ \\
\hline & & $16: 35$ & 7.2 & $\mathrm{CC} \sim 85 \%$. Feed is slow to boil but is boiling in between each feed shot. \\
\hline & & $16: 49$ & 7.5 & $\mathrm{CC} \sim 85 \%$, Not able to see east side anymore due to ridge on that side. \\
\hline & & $17: 10$ & 7.8 & $\begin{array}{l}\mathrm{CC} \sim 80 \% \text {, large ridge appears to be near center of melter, can not see east } \\
\text { side. }\end{array}$ \\
\hline & & $17: 26$ & 8.1 & $\mathrm{CC} \sim 75 \%$, large ridge is still present as well as build up on the west wall. \\
\hline & & $17: 38$ & 8.3 & $\begin{array}{l}\mathrm{CC} \sim 75 \% \text {, ridge seems smaller and vigorously boiling feed can be seen on } \\
\text { the east side of the melter. }\end{array}$ \\
\hline & & $17: 53$ & 8.5 & $\mathrm{CC} \sim 75 \%$, appears to be the same as last observation. \\
\hline & & 18:08 & 8.8 & $\begin{array}{l}\mathrm{CC} \sim 75 \% \text {, appears as before but build up on the west wall which is just south } \\
\text { of middle view port extends out past but does not yet touch } \mathrm{T} / \mathrm{W} 2 \text {. }\end{array}$ \\
\hline & & $18: 22$ & 9.0 & $\mathrm{CC} \sim 75 \%$ \\
\hline & & $18: 37$ & 9.3 & $\begin{array}{l}\mathrm{CC} \sim 75 \% \text {, build up has now surrounded } \mathrm{T} / \mathrm{W} \# 2 \text {, otherwise conditions appear } \\
\text { unchanged. }\end{array}$ \\
\hline & & 18:40 & 9.3 & $\begin{array}{l}\text { Increased bubbling on Lance } 1 \text { from } 55 \text { to } 85 \mathrm{lpm} \text {, try to shift the cap around } \\
\text { to break the ridges. }\end{array}$ \\
\hline
\end{tabular}


ORP-56292 Rev. 0

The Catholic University of America

Table 5.3. Operator Observations of Cold Cap (CC) (continued).

\begin{tabular}{|c|c|c|c|c|}
\hline Test & Date & Time & $\begin{array}{l}\text { Run } \\
\text { Time } \\
\text { (hours) }\end{array}$ & Cold Cap Observations \\
\hline \multirow{26}{*}{1} & \multirow{12}{*}{$8 / 6 / 2008$} & $18: 50$ & 9.5 & $\begin{array}{l}\text { Increased Lance } 2 \text { from } 65 \text { to } 85 \mathrm{lpm} \text { and at Lance } 1 \text { reduced bubbling from } \\
85 \text { to } 55 \mathrm{lpm} \text {. Trying to shift cap/ridges around. }\end{array}$ \\
\hline & & $18: 55$ & 9.6 & $\begin{array}{l}\mathrm{CC} \sim 80 \% \text {. The opening on west side has closed up some. Feed is boiling over } \\
\text { the ridge. Not able to see east side at this time. }\end{array}$ \\
\hline & & 19:09 & 9.8 & $\begin{array}{l}\mathrm{CC} \sim 80 \% \text {, Since discharge cap has not moved ridge looks bigger, still not } \\
\text { able to see east side other than the light that is emitting from that side. } \\
\text { Reduced Lance } 2 \text { from } 85 \text { to } 55 \mathrm{lpm} \text {, and increased Lance } 1 \text { from } 55 \text { to } 65 \\
\text { lpm. }\end{array}$ \\
\hline & & $20: 12$ & 10.9 & $\begin{array}{l}\mathrm{CC} \sim 80 \% \text {, large ridge on the west side is high not allowing to see east side. } \\
\text { Increased bubbling on Lance } 2 \text { from } 65 \text { to } 90 \mathrm{lpm} \text { to see if this will break it } \\
\text { down.. }\end{array}$ \\
\hline & & $20: 41$ & 11.3 & $\begin{array}{l}\mathrm{CC} \sim 75 \% \text {, Glass level is low. Increased bubbling on Lance } 1 \text { to } 85 \text { from } 65 \\
\mathrm{lpm} \text { and reduced bubbling on Lance } 2 \text { from } 90 \text { to } 65 \mathrm{lpm} .\end{array}$ \\
\hline & & 21:08 & 11.8 & $\mathrm{CC} \sim 75 \%$ very little or no change. \\
\hline & & $22: 13$ & 12.9 & $\begin{array}{l}\mathrm{CC} \sim 85 \% \text {, ridge still divides east and west. East side opening can not be seen. } \\
\text { Nothing can be seen through middle view port. }\end{array}$ \\
\hline & & $22: 28$ & 13.1 & $\mathrm{CC} \sim 85 \%$ as before. \\
\hline & & $22: 55$ & 13.6 & $\begin{array}{l}\mathrm{CC} \sim 80-85 \% \text {, opening visible around Lance } 2 \text { with slight ridge around. Light } \\
\text { is visible on east wall. }\end{array}$ \\
\hline & & $23: 10$ & 13.8 & $\mathrm{CC} \sim 80-85 \%$, basically unchanged. \\
\hline & & $23: 32$ & 14.2 & $\mathrm{CC} \sim 75-80 \%$ \\
\hline & & $23: 40$ & 14.3 & CC $\sim 80 \%$. Ridge on the west side seems lower. \\
\hline & \multirow{14}{*}{$8 / 7 / 2008$} & 0:08 & 14.8 & $\begin{array}{l}\text { CC is at } 85 \% \text {, ridge is much smaller around Lance } \# 2 \text {, light is still visible on } \\
\text { east. }\end{array}$ \\
\hline & & $0: 53$ & 15.5 & $\mathrm{CC} \sim 85 \%$, large ridge in center of melter. \\
\hline & & $1: 42$ & 16.4 & $\mathrm{CC} \sim 85 \%$, ridge has grown larger near Lance $\# 2$. \\
\hline & & $2: 23$ & 17.0 & $\mathrm{CC} \sim 85 \%$, but ridge in center/ seems to be growing with increased bubbling. \\
\hline & & $2: 37$ & 17.3 & $\mathrm{CC} \sim 85 \%$, only opening on the west wall partially visible. \\
\hline & & $2: 59$ & 17.6 & $\begin{array}{l}\text { From the south view port, "existing wall like" portion of cold cap, positioned } \\
\text { just below the feed tube and stands }<\text { or=12". }\end{array}$ \\
\hline & & $3: 39$ & 18.3 & $\mathrm{CC} \sim 85 \%$, and no visible change. \\
\hline & & $3: 58$ & 18.6 & $\begin{array}{l}\text { Larger mound growing in melter seen via south view port, also large glazed } \\
\text { ridge near Lance } \# 2 \text {. }\end{array}$ \\
\hline & & $4: 25$ & 19.1 & $\begin{array}{l}\text { Raised and lowered bubbling on both Lance's in an effort to break down large } \\
\text { mound in south view port with no success. }\end{array}$ \\
\hline & & $4: 51$ & 19.5 & Large mound is still in place around Lance $\# 2$. \\
\hline & & $5: 04$ & 19.7 & Mound is still in place. \\
\hline & & $5: 17$ & 19.9 & $\begin{array}{l}\mathrm{CC} \sim 75-80 \% \text {, mound is still in place but starting to see more liquid feed } \\
\text { trickling off of ridge by Lance } \# 2 \text { and flowing into melt pool. }\end{array}$ \\
\hline & & $5: 34$ & 20.2 & $\begin{array}{l}\mathrm{CC} \sim 80 \% \text {, mound still in place, however, ridge around Lance } \# 2 \text { has broken } \\
\text { down some. }\end{array}$ \\
\hline & & $5: 49$ & 20.5 & $\mathrm{CC} \sim 80-85 \%$ \\
\hline
\end{tabular}


Table 5.3. Operator Observations of Cold Cap (CC) (continued).

\begin{tabular}{|c|c|c|c|c|}
\hline Test & Date & Time & $\begin{array}{l}\text { Run } \\
\text { Time } \\
\text { (hours) }\end{array}$ & Cold Cap Observations \\
\hline \multirow{27}{*}{1} & \multirow{27}{*}{$8 / 7 / 2008$} & $6: 02$ & 20.7 & $\mathrm{CC} \sim 80-85 \%$. \\
\hline & & $7: 05$ & 21.7 & $\begin{array}{l}\mathrm{CC} \sim 85 \% \text {, Large ridge in center of melter. Openings on S-E and } \mathrm{N}-\mathrm{W} \\
\text { corners. Large mound has formed around feed tube. }\end{array}$ \\
\hline & & $7: 14$ & 21.9 & $\begin{array}{l}\mathrm{CC} \sim 95 \% \text {, large ridge and funnel below feed tube. Openings on S-E and N-W } \\
\text { corners. }\end{array}$ \\
\hline & & $7: 25$ & 22.1 & $\begin{array}{l}\text { CC } \sim 90-95 \% \text {, with large ridge in center with funnel below feed tube. } \\
\text { Openings at S-E and N-W corners. }\end{array}$ \\
\hline & & $7: 50$ & 22.5 & $\begin{array}{l}\text { CC } \sim 90 \% \text {, with high center. Light visible on east side. Liquid visibly flowing } \\
\text { into L2 bubbler. Opening on west side. }\end{array}$ \\
\hline & & $8: 10$ & 22.8 & CC conditions are stable $\sim 90-95 \%$ with liquid flowing. \\
\hline & & $8: 22$ & 23.0 & $\mathrm{CC} \sim 95 \%$, liquid flowing into openings. Light visible on east side. \\
\hline & & $8: 37$ & 23.3 & No visible change in $\mathrm{CC}$ conditions. \\
\hline & & $9: 15$ & 23.9 & $\mathrm{CC} \sim 95 \%$ with large ridge in center with openings on S-E and N-W corners. \\
\hline & & $9: 40$ & 24.3 & $\begin{array}{l}\text { CC } \sim 90-95 \% \text { with large ridge in center with openings in S-E and N-W } \\
\text { corners. Feed visibly flowing into N-W opening. Funnel below feed tube has } \\
\text { not changed. }\end{array}$ \\
\hline & & 10:10 & 24.8 & $\begin{array}{l}\mathrm{CC} \sim 90-95 \% \text {, large ridge in center with openings in S-E and N-W corners. } \\
\text { Feed is flowing into N-W corner. }\end{array}$ \\
\hline & & $10: 45$ & 25.4 & $\mathrm{CC}$ is at $90-95 \%$ with same conditions as before. \\
\hline & & $11: 10$ & 25.8 & CC conditions unchanged (90-95\%) \\
\hline & & $11: 50$ & 26.5 & $\begin{array}{l}\mathrm{CC} \sim 90-95 \% \text { with large ridge in center with openings on S-E and N-W } \\
\text { corners. Feed flowing into N-W corner opening. }\end{array}$ \\
\hline & & 12:00 & 26.7 & $\begin{array}{l}\text { Collected picture of the cold cap thru. N. viewport showing part of cap } \\
\text { thickness. }\end{array}$ \\
\hline & & $12: 20$ & 27.0 & $\begin{array}{l}\mathrm{CC} \sim 90 \% \text {, Large ridge in center with openings in S-E and N-W corners feed } \\
\text { is flowing into N-W corner. }\end{array}$ \\
\hline & & $12: 40$ & 27.3 & Unchanged from previous observation ( $\mathrm{CC} \sim 90-95)$. \\
\hline & & $13: 14$ & 27.9 & $\begin{array}{l}\mathrm{CC} \sim 95 \% \text {, Opening at Lance } 2 \text { has a "glazed" face. Cone below feed tube has } \\
\text { grown, it is now almost out of view at top.. }\end{array}$ \\
\hline & & 13:20 & 28.0 & Dislodging cone below feed tube manually. Minor pressure spike. \\
\hline & & 13:29 & 28.1 & CC $\sim 95 \%$. \\
\hline & & 13:44 & 28.4 & $\begin{array}{l}\mathrm{CC} \sim 95 \% \text {, can't see liquid flow to Lance } 2 \text { opening. Observed splash from } \\
\text { boiling liquid through south viewport prior to feed shot. }\end{array}$ \\
\hline & & 14:00 & 28.7 & CC $\sim 95 \%$.Some liquid now flowing into Lance 2 opening. \\
\hline & & 14:17 & 28.9 & $\mathrm{CC} \sim 86 \%$, liquid boiling in center and flowing to Lance 2 opening. \\
\hline & & $14: 34$ & 29.2 & $\begin{array}{l}\text { CC } \sim 90 \% \text {, large mound seen in the south view port. North view port able to } \\
\text { see the melt pool with a large ridge blocking the east side. }\end{array}$ \\
\hline & & 14:50 & 29.5 & CC $\sim 90 \%$, No visible changes at this time. \\
\hline & & 15:02 & 29.7 & $\begin{array}{l}\text { Increased Lance } 1 \text { from } 60 \text { to } 80 \mathrm{lpm} \text {, trying to collapse the large mound } \\
\text { underneath feed tube. }\end{array}$ \\
\hline & & 15:08 & 29.8 & CC $\sim 90 \%$, starting to see more glow from east side. No change on west side. \\
\hline
\end{tabular}


ORP-56292 Rev. 0

The Catholic University of America

Table 5.3. Operator Observations of Cold Cap (CC) (continued).

\begin{tabular}{|c|c|c|c|c|}
\hline Test & Date & Time & $\begin{array}{c}\text { Run } \\
\text { Time } \\
\text { (hours) }\end{array}$ & Cold Cap Observations \\
\hline \multirow{28}{*}{1} & \multirow{28}{*}{$8 / 7 / 2008$} & $15: 20$ & 30.0 & $\begin{array}{l}\text { CC } \sim 90 \% \text {. The cap dropped when glass was discharged. The mound looks } \\
\text { smaller due to this. }\end{array}$ \\
\hline & & 15:39 & 30.3 & CC $\sim 90 \%$, west side cap/mound is starting to melt down. \\
\hline & & $15: 54$ & 30.6 & $\mathrm{CC} \sim 85 \%$, mound on west side continues to melt. \\
\hline & & 16:09 & 30.8 & $\mathrm{CC} \sim 90 \%$, more liquid is flowing into the west opening. \\
\hline & & $16: 16$ & 30.9 & Not much has melted down from the mound on the west side. $\mathrm{CC} \sim 90 \%$. \\
\hline & & $16: 39$ & 31.3 & $\begin{array}{l}\text { CC } \sim 90 \% \text {. Not much light seen emitting from east side through the south } \\
\text { view port. West side mound has built up some over the opening. }\end{array}$ \\
\hline & & $16: 48$ & 31.5 & CC $\sim 90 \%$ \\
\hline & & $17: 13$ & 31.9 & $\mathrm{CC} \sim 90 \%$. \\
\hline & & $17: 26$ & 32.1 & $\begin{array}{l}\text { CC } \sim 90 \% \text {, able to see feed boiling between shots. Mounds and shots have not } \\
\text { grown any. }\end{array}$ \\
\hline & & $17: 42$ & 32.4 & $\begin{array}{l}\text { CC } \sim 90 \% \text {, some melting of mound on west side. Very little changes } \\
\text { elsewhere. }\end{array}$ \\
\hline & & $17: 55$ & 32.6 & $\begin{array}{l}\text { CC } \sim 90 \% \text {, The face of the west side mound looks glazed now. East side } \\
\text { unchanged. }\end{array}$ \\
\hline & & 18:11 & 32.8 & CC $\sim 90 \%$ same as before. \\
\hline & & 18:26 & 33.1 & $\begin{array}{l}\mathrm{CC} \sim 90 \% \text {, large glazed ridge can be seen in north port, moderate size circular } \\
\text { ridge visible in south port. }\end{array}$ \\
\hline & & $18: 52$ & 33.5 & CC $\sim 90 \%$, no visible changes at this time. \\
\hline & & 19:10 & 33.8 & $\begin{array}{l}\mathrm{CC} \sim 90 \% \text {. There is large cone shaped mound underneath the feed tube. It has } \\
\text { gotten larger and taller. }\end{array}$ \\
\hline & & 19:17 & 33.9 & Melter pressure spiked almost positive due to off-gas sampling. \\
\hline & & 19:37 & 34.3 & CC $\sim 90 \%$, conditions have not changed. \\
\hline & & 19:54 & 34.6 & $\begin{array}{l}\mathrm{CC} \sim 90 \% \text {, North side mound is melting. It does not look as glazed from } \\
\text { previous observation. }\end{array}$ \\
\hline & & 20:11 & 34.8 & CC $\sim 95 \%$, Not much light coming from east side. \\
\hline & & $20: 20$ & 35.0 & $\mathrm{CC} \sim 90 \%$ \\
\hline & & $20: 38$ & 35.3 & $\begin{array}{l}\text { CC } \sim 90, \text { Able to see more light on the east side. West side mound is glazed } \\
\text { over melt pool is smaller with a secondary cap forming. }\end{array}$ \\
\hline & & $20: 55$ & 35.6 & $\begin{array}{l}\text { CC } \sim 90 \% \text {, a visible dome of hardened feed in west end of melter. Melt pool } \\
\text { is visible from east not much cap. }\end{array}$ \\
\hline & & $21: 29$ & 36.1 & $\begin{array}{l}\mathrm{CC} \sim 85 \% \text {, a very large glazed wall of glass is visible through north view port. } \\
\text { Cylinder like mound which is large can be seen from south port. }\end{array}$ \\
\hline & & $21: 43$ & 36.4 & $\mathrm{CC} \sim 85 \%$, conditions are same as previously noted. \\
\hline & & 22:06 & 36.8 & $\mathrm{CC} \sim 85 \%$, appears unchanged. \\
\hline & & 22:56 & 37.6 & $\begin{array}{l}\mathrm{CC} \sim 80-85 \%, \text { mound is still in place when viewed from south port and glazed } \\
\text { ridge near Lance \#2 although feed is now flowing into opening. }\end{array}$ \\
\hline & & 23:13 & 37.9 & CC $\sim 80 \%$, large opening still present near Lance \#2. Mound unchanged. \\
\hline & & 23:39 & 38.3 & $\mathrm{CC}$ unchanged since previous observation. \\
\hline
\end{tabular}


Table 5.3. Operator Observations of Cold Cap (CC) (continued).

\begin{tabular}{|c|c|c|c|c|}
\hline Test & Date & Time & $\begin{array}{l}\text { Run } \\
\text { Time } \\
\text { (hours) }\end{array}$ & Cold Cap Observations \\
\hline \multirow{25}{*}{1} & $8 / 7 / 2008$ & $23: 58$ & 38.6 & $\mathrm{CC} \sim 80-85 \%$ unchanged. \\
\hline & \multirow{24}{*}{$8 / 8 / 2008$} & $0: 33$ & 39.2 & $\mathrm{CC} \sim 80 \%$ unchanged. \\
\hline & & 1:09 & 39.8 & $\mathrm{CC} \sim 80 \%$ unchanged. \\
\hline & & $1: 27$ & 40.1 & $\begin{array}{l}\mathrm{CC} \sim 80-85 \% \text { seem like mound has grown taller while ridge has broken down } \\
\text { somewhat. }\end{array}$ \\
\hline & & 2:12 & 40.9 & Mound still growing, $\mathrm{CC}$ at $85 \%$. \\
\hline & & $2: 55$ & 41.6 & $\mathrm{CC} \sim 80-85 \%$, unchanged. \\
\hline & & $3: 17$ & 41.9 & $\mathrm{CC} \sim 80 \%$. \\
\hline & & $3: 25$ & 42.1 & $\begin{array}{l}\text { Increasing Lance from } 80 \text { to } 120 \mathrm{lpm} \text { did not have any effect on mound. } \\
\text { Mound is growing close to melter ceiling. }\end{array}$ \\
\hline & & $3: 39$ & 42.3 & Mound is large near ceiling \\
\hline & & 4:08 & 42.8 & $\begin{array}{l}\text { Manually dislodged top of mound allowing feed to flow to melt pool. A } \\
\text { byproduct of this seems that glass temps have come back. }\end{array}$ \\
\hline & & $4: 23$ & 43.0 & $\begin{array}{l}\text { Attempted once again to dislodge some of the mound but unable to make } \\
\text { contact with it. } \mathrm{CC} \sim 85 \% \text { ridges has broken down some. }\end{array}$ \\
\hline & & $5: 43$ & 44.4 & $\begin{array}{l}\mathrm{CC} \sim 85 \% \text {, ridge near Lance } 2 \text {, has some feed flowing over it into melt pool. } \\
\text { Majority of mound still evident via south view port. }\end{array}$ \\
\hline & & $6: 27$ & 45.1 & No light visible. \\
\hline & & $6: 35$ & 45.2 & $\begin{array}{l}\mathrm{CC} \sim 85 \% \text {, ridge near Lance } 2 \text { shows some glazing but liquid flowing into } \\
\text { opening. Part of mound still evident via south viewport. }\end{array}$ \\
\hline & & $6: 55$ & 45.6 & $\begin{array}{l}\mathrm{CC} \sim 85 \% \text {, some liquid flowing to L2 opening. A small amount of light is } \\
\text { visible from east side. }\end{array}$ \\
\hline & & $7: 10$ & 45.8 & Cold cap unchanged (95\%). \\
\hline & & $7: 25$ & 46.1 & $\begin{array}{l}\mathrm{CC} \sim 95 \% \text { with liquid flowing to } \mathrm{L} 2 \text { opening. East side shows some light } \\
\text { reflection on wall. }\end{array}$ \\
\hline & & $7: 40$ & 46.3 & Cold cap unchanged. \\
\hline & & $7: 51$ & 46.5 & $\begin{array}{l}\text { Observing liquid in center "cone" area is boiling more vigorously prior to } \\
\text { shot the shot with bubbling increased. }\end{array}$ \\
\hline & & 8:06 & 46.8 & $\begin{array}{l}\text { Opening around L2 shows a more glazed surface to cap material with no } \\
\text { liquid flow. Center area still boils vigorously, covered still } \sim 95 \% \text {. }\end{array}$ \\
\hline & & $8: 27$ & 47.1 & $\begin{array}{l}\text { CC } \sim 95 \% \text {, L2 bubbling appear to be undercutting the cap, leaving an } \\
\text { overhang. No liquid appears to be flowing to opening. Center cone liquid still } \\
\text { reaching vigorous boil prior to shot. Some light visible on east side. }\end{array}$ \\
\hline & & $8: 43$ & 47.4 & $\mathrm{CC} \sim 90-95 \%$, unchanged visually. $10-12$ "thick with boiling liquid in center. \\
\hline & & 9:52 & 48.5 & Some light on east side. \\
\hline & & 10:06 & 48.8 & CC unchanged. 90-95\%, 10-12" thick. \\
\hline & & 10:21 & 49.0 & End of Test 1. \\
\hline
\end{tabular}


Table 5.3. Operator Observations of Cold Cap (CC) (continued).

\begin{tabular}{|c|c|c|c|c|}
\hline Test & Date & Time & $\begin{array}{l}\text { Run } \\
\text { Time } \\
\text { (hours) }\end{array}$ & Cold Cap Observations \\
\hline \multirow{18}{*}{1} & \multirow{18}{*}{$8 / 8 / 2008$} & 10:55 & 49.6 & $\begin{array}{l}\text { Removed port C-1 to retrieve cold cap sample, Very little material on } \\
\text { surface. Scraped collector along hard shell material for sample. O- } 12 \mathrm{~J}- \\
106 \mathrm{~A} \text {, mass }=268 \mathrm{~g} \text {. Port } \mathrm{C}-1 \text { gasket needs a new gasket ring and ring was } \\
\text { replaced. }\end{array}$ \\
\hline & & 11:05 & 49.7 & Shelf/CC still $\sim 80 \%$, and $10-12 "$ thick. \\
\hline & & $11: 18$ & 50.0 & $\begin{array}{l}\text { Shelf beginning to dissolve and expose cavities within. Still thick at center } \\
\text { with cone still in place } \sim 12 " \text { at thickest point. }\end{array}$ \\
\hline & & $11: 26$ & 50.1 & $\begin{array}{l}\text { Shelf has dropped from bottom side and provided a partial }(\sim 30 \%) \text { cold cap } \\
\text { with } 2-3 " \text { separation to a shelf/bridge. }\end{array}$ \\
\hline & & 11:45 & 50.4 & Shelf dissolving from bottom but still bridged over melt pool. \\
\hline & & 12:05 & 50.7 & $\begin{array}{l}\text { Large clumps of cold cap/bridge pieces in S-W and N-E corners. Openings } \\
\text { in middle and S-E and N-W corners. Observed } 2 \text { mounds on south side of } \\
\text { pool } \sim 8-10 " \text { thick, no mound or bridge observed through N. viewport. } \\
\text { About } 5 \% \text { feed material dissolving on glass surface. }\end{array}$ \\
\hline & & $12: 25$ & 51.1 & $\begin{array}{l}\text { Mound in south area diminished. But still visible through S. viewport. } \\
\text { Suggesting 6-8" thick. }\end{array}$ \\
\hline & & $12: 37$ & 38.7 & $\begin{array}{l}\text { Mounds of material have dropped to melt surface. Mounds are } \sim 1-12 " \text { in } \\
\text { diameter and } \sim 4-6 " \text { thick. }\end{array}$ \\
\hline & & 11:05 & 49.7 & Shelf/CC still $\sim 80 \%$, and $10-12 "$ thick. \\
\hline & & 11:18 & 50.0 & $\begin{array}{l}\text { Shelf beginning to dissolve and expose cavities within. Still thick at center } \\
\text { with cone still in place } \sim 12 " \text { at thickest point. }\end{array}$ \\
\hline & & 11:26 & 50.1 & $\begin{array}{l}\text { Shelf has dropped from bottom side and provided a partial }(\sim 30 \%) \text { cold cap } \\
\text { with } 2-3 " \text { separation to a shelf/bridge. }\end{array}$ \\
\hline & & $11: 45$ & 50.4 & Shelf dissolving from bottom but still bridged over melt pool. \\
\hline & & 12:05 & 50.7 & $\begin{array}{l}\text { Large clumps of cold cap/bridge pieces in S-W and N-E corners. Openings } \\
\text { in middle and S-E and N-W corners. Observed } 2 \text { mounds on south side of } \\
\text { pool } \sim 8-10 " \text { thick, no mound or bridge observed through N. viewport. } \\
\text { About } 5 \% \text { feed material dissolving on glass surface. }\end{array}$ \\
\hline & & $12: 25$ & 51.1 & $\begin{array}{l}\text { Mound in south area diminished. But still visible through S. viewport. } \\
\text { Suggesting } 6-8 \text { " thick. }\end{array}$ \\
\hline & & $12: 37$ & 38.7 & $\begin{array}{l}\text { Mounds of material have dropped to melt surface. Mounds are } \sim 1-12 " \text { in } \\
\text { diameter and } \sim 4-6 " \text { thick. }\end{array}$ \\
\hline & & $12: 58$ & 51.6 & Cold cap log of feed material floating on surface. \\
\hline & & 13:04 & 38.7 & $\begin{array}{l}\text { Cold cap material dissolved down to } 3 \text { "x } 10 " \text { logs. Two chunks of feed } \\
\text { material still floating on surface. One is about the size of a football the } \\
\text { other one is about the size of a softball. }\end{array}$ \\
\hline & & 13:17 & 52.0 & $\begin{array}{l}\text { Only a small area of darker material on melt surface remains. No feed } \\
\text { material solids visible. Cold cap is gone. }\end{array}$ \\
\hline \multirow{5}{*}{2} & \multirow{5}{*}{$8 / 11 / 2008$} & $14: 45$ & 0.0 & Started feeding water for test 2 . \\
\hline & & $15: 55$ & 1.2 & $\mathrm{CC} \sim 80 \%$. Cold cap is very thin with liquid boiling on surface. \\
\hline & & 16:10 & 1.4 & $\begin{array}{l}\text { CC } \sim 75 \%, 2 \text { openings on both sides. East side opening is larger than west } \\
\text { side's. Cold cap is flat at this time. }\end{array}$ \\
\hline & & $16: 23$ & 1.6 & $\mathrm{CC} \sim 80$, Starting to get thicker. \\
\hline & & $16: 37$ & 1.9 & $\mathrm{CC} \sim 80 \%$, it is a little thicker than last observation. \\
\hline
\end{tabular}


Table 5.3. Operator Observations of Cold Cap (CC) (continued).

\begin{tabular}{|c|c|c|c|c|}
\hline Test & Date & Time & $\begin{array}{c}\text { Run } \\
\text { Time } \\
\text { (hours) }\end{array}$ & Cold Cap Observations \\
\hline \multirow{27}{*}{2} & \multirow{27}{*}{$8 / 11 / 2008$} & $16: 45$ & 2.0 & CC $\sim 80 \%$, cap hot along the walls. Heavy boiling on the center observed. \\
\hline & & 17:01 & 2.3 & $\begin{array}{l}\mathrm{CC} \sim 75 \% \text {, it is starting to stiffen up. Larger amount of feed boiling on the } \\
\text { surface. }\end{array}$ \\
\hline & & $17: 15$ & 2.5 & $\begin{array}{l}\mathrm{CC} \sim 80 \% \text {, Starting to close up some. There are small ridges around the } \\
\text { openings but feed is flowing into the melt pools. }\end{array}$ \\
\hline & & $17: 30$ & 2.8 & $\begin{array}{l}\mathrm{CC} \sim 80 \% \text {. The ridges are getting larger. The openings are staying the same } \\
\text { size. }\end{array}$ \\
\hline & & $17: 45$ & 3.0 & CC $\sim 80 \%$, Hot cap around Thermowell \#2. No other changes at this time. \\
\hline & & 18:01 & 3.3 & $\begin{array}{l}\text { CC } \sim 85 \% \text {. Cap has closed up some on east side. On west side no visible } \\
\text { changes. }\end{array}$ \\
\hline & & $18: 17$ & 3.5 & $\begin{array}{l}\mathrm{CC} \sim 90-95 \% \text { with small ridges around openings. Cap is } 2-3 " \text { thick with } \\
\text { liquid boiling vigorously. }\end{array}$ \\
\hline & & $18: 32$ & 3.8 & $\begin{array}{l}\text { There is more liquid rushing into the melt pools at this time. The ridges are } \\
\text { the same as last entry. }\end{array}$ \\
\hline & & 18:39 & 3.9 & Cold cap has opened up some on the west side. \\
\hline & & $18: 53$ & 4.1 & $\begin{array}{l}\text { Cold cap } ~ 90 \% \text {, Ridge around the openings have grown some 3-4" high. } \\
\text { Moderate amount of liquid boiling all the time. }\end{array}$ \\
\hline & & 19:10 & 4.4 & $\mathrm{CC} \sim 85 \%$. Cap is floating on the melt pool. \\
\hline & & 19:27 & 4.7 & CC $\sim 90 \%$, Not able to see the east side. \\
\hline & & 19:42 & 5.0 & $\begin{array}{l}\text { CC } \sim 90 \% \text {. More liquid flowing into the west side melt pool. Only see light } \\
\text { emitting from the east side through the south view port. }\end{array}$ \\
\hline & & 20:05 & 5.3 & $\begin{array}{l}\mathrm{CC} \sim 90 \% \text {. Able to see a small opening on the east side. West side cap } \\
\text { around Thermowell } \# 2 \text { has darkened up. }\end{array}$ \\
\hline & & $20: 22$ & 5.6 & CC $\sim 95 \%$. West side has closed up more. \\
\hline & & $20: 36$ & 5.9 & $\begin{array}{l}\mathrm{CC} \sim 90 \% \text {. Not able to see east side. West side has a ridge that curls back to } \\
\text { the center. Feed is boiling over it }\end{array}$ \\
\hline & & $20: 53$ & 6.1 & CC $\sim 90 \%$. Conditions unchanged. \\
\hline & & 21:06 & 6.4 & $\begin{array}{l}\text { CC } \sim 90 \% \text {, Conditions are unchanged except that it looks like more feed is } \\
\text { pooling on the west side. }\end{array}$ \\
\hline & & $21: 24$ & 6.7 & $\begin{array}{l}\mathrm{CC} \sim 90 \% \text {, Ridge is larger now on the west side but there is no ridge close } \\
\text { to the wall. Feed is boiling over. Not able to see east side. }\end{array}$ \\
\hline & & $21: 39$ & 6.9 & $\mathrm{CC} \sim 90$, There is more liquid feed flowing into the west melt pool. \\
\hline & & $21: 47$ & 7.0 & $\mathrm{CC} \sim 90$, west side is starting to melt down due to the higher bubbling. \\
\hline & & 22:17 & 7.5 & CC $\sim 85 \%$, West side opened up some. \\
\hline & & $22: 32$ & 7.8 & CC $\sim 90 \%$, West side closed up some. \\
\hline & & $22: 46$ & 8.0 & $\mathrm{CC}$ at $85-90 \%$ fairly flat on west side, light is visible on east side. \\
\hline & & 23:07 & 8.4 & $\mathrm{CC} \sim 85 \%$, with liquid spilling into opening on west side. \\
\hline & & $23: 34$ & 8.8 & CC $\sim 85-90 \%$ unchanged. \\
\hline & & 23:56 & 9.2 & $\mathrm{CC} \sim 85 \%$ opening on west side appears larger. \\
\hline
\end{tabular}


Table 5.3. Operator Observations of Cold Cap (CC) (continued).

\begin{tabular}{|c|c|c|c|c|}
\hline Test & Date & Time & $\begin{array}{l}\text { Run } \\
\text { Time } \\
\text { (hours) }\end{array}$ & Cold Cap Observations \\
\hline \multirow{26}{*}{2} & \multirow{26}{*}{$8 / 12 / 2008$} & $0: 10$ & 9.4 & $\begin{array}{l}\mathrm{CC} \sim 80-85 \% \text { opening on west side is starting to glaze up, not much liquid } \\
\text { trickling into opening. }\end{array}$ \\
\hline & & $0: 25$ & 9.7 & $\begin{array}{l}\mathrm{CC} \sim 80-85 \% \text {, more feed starting to flow into west opening. Light is visible } \\
\text { on east side. }\end{array}$ \\
\hline & & $0: 40$ & 9.9 & $\begin{array}{l}\mathrm{CC} \sim 85 \% \text {, West side opening still has a thick ridge around it. But glazing } \\
\text { is reduced. Light still on east side. }\end{array}$ \\
\hline & & $0: 55$ & 10.2 & CC $\sim 90 \%$, opening on west side closed considerably. \\
\hline & & $1: 33$ & 10.8 & $\begin{array}{l}\text { CC } \sim 85 \%, \text { Ridge appears larger on west side, small amount of feed rushing } \\
\text { into opening. }\end{array}$ \\
\hline & & $1: 51$ & 11.1 & $\begin{array}{l}\mathrm{CC} \sim 90 \% \text {, Opening on west side is almost closed, but also has about } 5 " \text { or - } \\
6 " \text { ridge around it. Light still on east. }\end{array}$ \\
\hline & & $2: 10$ & 11.4 & $\mathrm{CC} \sim 90 \%$, unchanged since previous observation. \\
\hline & & $2: 30$ & 11.8 & $\mathrm{CC} \sim 85 \%$ same as previous observation. \\
\hline & & $2: 50$ & 12.1 & $\mathrm{CC} \sim 85 \%$ unchanged since previous. \\
\hline & & 3:05 & 12.3 & $\mathrm{CC} \sim 85 \%$, same as previous. \\
\hline & & $3: 48$ & 13.1 & $\begin{array}{l}\text { Not seeing any feed flowing over ridge currently has a large opening along } \\
\text { west wall. } \mathrm{CC} \sim 80 \% \text {. }\end{array}$ \\
\hline & & 4:06 & 13.4 & $\begin{array}{l}\text { CC } 90-95 \% \text {, finally big rush of feed along west wall completely dark on } \\
\text { that side. }\end{array}$ \\
\hline & & $4: 32$ & 13.8 & CC $\sim 90-95 \%$, slight amount of light visible. \\
\hline & & $4: 58$ & 14.2 & $\begin{array}{l}\mathrm{CC} \sim 90 \% \text {, visible light evidence of opening on east, partial opening on the } \\
\text { west. Portion of the cold cap surface shows some liquid and boiling. }\end{array}$ \\
\hline & & $5: 48$ & 15.1 & $\mathrm{CC} \sim 80-85 \%$ \\
\hline & & $6: 06$ & 15.4 & $\begin{array}{l}\text { North Port: Cold cap portion with liquid boiling about } 10 \text { " towards the } \\
\text { center is a thicker portion limiting further view. South Port: Light from the } \\
\text { east wall, no mounds at the center could be seen. }\end{array}$ \\
\hline & & $6: 26$ & 15.7 & $\begin{array}{l}\mathrm{CC} \sim 90 \% \text {, opening visible on west side with lower ridge in center. Light is } \\
\text { visible on east side. }\end{array}$ \\
\hline & & $6: 40$ & 15.9 & $\begin{array}{l}\text { CC } \sim 90 \% \text {, large mound in center, blocking view to east side through North } \\
\text { view port. }\end{array}$ \\
\hline & & $7: 11$ & 16.4 & CC unchanged in appearance, still 90-95\%. \\
\hline & & $7: 23$ & 16.6 & $\begin{array}{l}\mathrm{CC} \sim 90 \% \text {, liquid observed flowing into Lance } 2 \text { opening and splashing } \\
\text { from boiling in center area via south view port. }\end{array}$ \\
\hline & & $7: 45$ & 17.0 & $\begin{array}{l}\text { Cold cap thickness appears to be } \sim 12-14 " \text { in center are, currently it } \\
\text { appears most of the feed is flowing to Lance } 2 \text { opening. }\end{array}$ \\
\hline & & $8: 14$ & 17.5 & $\begin{array}{l}\text { No change in cold cap appearance, still 90-95\% coverage and 10-14" thick } \\
\text { at the center. }\end{array}$ \\
\hline & & $8: 33$ & 17.8 & CC unchanged. \\
\hline & & $9: 13$ & 18.5 & $\begin{array}{l}\text { CC unchanged except the surface of opening in Lance } 2 \text { area has a more } \\
\text { "glazed" glass coating. }\end{array}$ \\
\hline & & $9: 37$ & 18.9 & CC appearance unchanged at $90-95 \%, 10-14 "$ thick. \\
\hline & & 10:12 & 19.5 & CC $\sim 90-95 \%$ with feed flowing predominantly into Lance 2 opening \\
\hline
\end{tabular}


ORP-56292 Rev. 0

The Catholic University of America

Table 5.3. Operator Observations of Cold Cap (CC) (continued).

\begin{tabular}{|c|c|c|c|c|}
\hline Test & Date & Time & $\begin{array}{l}\text { Run } \\
\text { Time } \\
\text { (hours) }\end{array}$ & Cold Cap Observations \\
\hline \multirow{26}{*}{2} & \multirow{26}{*}{$8 / 12 / 2008$} & $10: 38$ & 19.9 & $\mathrm{CC} \sim 90-95 \%$. \\
\hline & & 11:13 & 20.5 & CC $90-95 \%, 10-14 "$ thick. \\
\hline & & 12:10 & 21.4 & CC conditions are unchanged. \\
\hline & & $12: 15$ & 21.5 & $\mathrm{CC}$ has softened around thermowell \#2. \\
\hline & & $12: 37$ & 21.9 & $\begin{array}{l}\mathrm{CC} \sim 90-95 \% \text {, openings are on S-E and N-W corners. Ridge } \sim 14 " \text { thick as } \\
\text { seen from N-W view port. Light is visible in S-E corner via } \mathrm{S}-\mathrm{W} \text { view port. }\end{array}$ \\
\hline & & 13:21 & 22.6 & $\mathrm{CC} \sim 90 \%$. \\
\hline & & $13: 36$ & 22.9 & $\mathrm{CC} \sim 80-85 \%$ \\
\hline & & $13: 44$ & 23.0 & $\mathrm{CC} \sim 80$ with no feed flowing to Lance 2 area. \\
\hline & & $14: 23$ & 23.6 & $\begin{array}{l}\mathrm{CC} \sim 85 \% \text {. Feed is starting to flow into the west side of the melt pool. Only } \\
\text { see light emitting from the east side. }\end{array}$ \\
\hline & & $14: 39$ & 23.9 & $\begin{array}{l}\text { CC } \sim 90 \% \text {, very little light on east side, slightly more on west side. Nothing } \\
\text { can be seen in center view port. Large glazed wall has surface that looks } \\
\text { crumbly. }\end{array}$ \\
\hline & & $14: 48$ & 24.1 & CC $\sim 95 \%$. East side has some light emitting from the south view port. \\
\hline & & 15:04 & 24.3 & $\begin{array}{l}\text { CC 95\% still power limited, set point is } 155 \mathrm{~kW} \text {, output is } 141 \mathrm{~kW} \text {. West } \\
\text { side has large amount of feed flowing toward the west wall. }\end{array}$ \\
\hline & & $15: 17$ & 24.5 & $\begin{array}{l}\mathrm{CC} \sim 95 \% \text {, there are } 2 \text { pools of feed that can be seen. The lower pool along } \\
\text { the west wall. A ridge is holding it back until it boils over. Not able to see } \\
\text { east side. }\end{array}$ \\
\hline & & 15:38 & 24.9 & $\mathrm{CC} \sim 95 \%$ \\
\hline & & 15:52 & 25.1 & $\mathrm{CC} \sim 95 \%$, no visible changes since last observation. \\
\hline & & $16: 17$ & 25.5 & CC $\sim 95 \%$, not able to see east side. West side glass is being splashed up. \\
\hline & & $16: 35$ & 25.8 & $\mathrm{CC} \sim 95 \%$ \\
\hline & & $17: 10$ & 26.4 & $\begin{array}{l}\mathrm{CC} \sim 95 \% \text {, there is a hole in the side of the ridge allowing feed to flow } \\
\text { through into the melt pool. }\end{array}$ \\
\hline & & $17: 25$ & 26.7 & $\begin{array}{l}\text { CC } \sim 95 \% \text {, Able to see a cone mound rising underneath the feed tube. No } \\
\text { other visible changes. }\end{array}$ \\
\hline & & $17: 39$ & 26.9 & CC $\sim 95 \%$, No changes from last observation. \\
\hline & & $17: 48$ & 27.1 & $\begin{array}{l}\mathrm{CC} \sim 90 \% \text {, cap opened up a little on west side. Not much light is coming } \\
\text { from east. }\end{array}$ \\
\hline & & $17: 53$ & 27.1 & CC opened up on west side. \\
\hline & & 18:16 & 27.5 & $\begin{array}{l}\mathrm{CC} \sim 85 \% \text {, west side opened up some more. There is a hole in the side of } \\
\text { the ridge. Feed is flowing into the opening. }\end{array}$ \\
\hline & & $18: 34$ & 27.8 & $\begin{array}{l}\mathrm{CC} \sim 85 \% \text {, the several holes in the ridge visible through north view port are } \\
\text { getting larger., feed is boiling on the surface and flowing into the glass pool } \\
\text { through the south view port of top part of an inverted cone can be seen. }\end{array}$ \\
\hline & & $18: 50$ & 28.1 & $\begin{array}{l}\mathrm{CC} \sim 85 \% \text {, holes in the ridge are getting larger, some areas of the cap near } \\
\text { the middle view part are floating }\end{array}$ \\
\hline & & 19:15 & 28.5 & $\mathrm{CC} \sim 85 \%$, The west side ridge is melting. \\
\hline
\end{tabular}


ORP-56292 Rev. 0

The Catholic University of America

Table 5.3. Operator Observations of Cold Cap (CC) (continued).

\begin{tabular}{|c|c|c|c|c|}
\hline Test & Date & Time & $\begin{array}{c}\text { Run } \\
\text { Time } \\
\text { (hours) }\end{array}$ & Cold Cap Observations \\
\hline \multirow{22}{*}{2} & \multirow{12}{*}{$8 / 12 / 2008$} & 19:35 & 28.8 & $\begin{array}{l}\mathrm{CC} \sim 85 \% \text {, Starting to close up. There is large amount of liquid feed on cold } \\
\text { capthat boils over into the melt pool right before each shot. }\end{array}$ \\
\hline & & 19:51 & 29.1 & $\begin{array}{l}\text { CC } \sim 90 \% \text {, the opening on west side is closing. Around thermowell \#2 cold } \\
\text { cap stiffening up. }\end{array}$ \\
\hline & & $20: 08$ & 29.4 & CC $\sim 90 \%$, no visible changes. \\
\hline & & $20: 43$ & 30.0 & $\begin{array}{l}\mathrm{CC} \sim 85 \% \text {, ridge on the west side has stopped melting. It looks dry. Cap is } \\
\text { hot around thermowell \#2.. }\end{array}$ \\
\hline & & $21: 10$ & 30.4 & $\mathrm{CC} \sim 90 \%$, more liquid feed is flowing into west melt pool. \\
\hline & & $21: 24$ & 30.7 & $\begin{array}{l}\text { CC } \sim 90 \% \text {, east side able to see light emitting from the south view port. } \\
\text { The cone shape mound underneath feed tube has collapsed just around the } \\
\text { top. There is a ridge forming over the west side melt pool. Feed is still } \\
\text { flowing over it. }\end{array}$ \\
\hline & & $21: 41$ & 30.9 & $\begin{array}{l}\mathrm{CC} \sim 90 \% \text {, the lower part of the ridge is visible from north port is thin and } \\
\text { has lots of holes and looks like there is a thicker section above it. A mound } \\
\text { is growing in front of middle view port. Cone and east side look mostly the } \\
\text { same. }\end{array}$ \\
\hline & & $21: 57$ & 31.2 & $\mathrm{CC} \sim 90 \%$, appears unchanged. \\
\hline & & $22: 42$ & 32.0 & $\begin{array}{l}\mathrm{CC} \sim 85-90 \% \text { with feed flowing into opening on west side of melter mound } \\
\text { is visible via south view port. }\end{array}$ \\
\hline & & $22: 58$ & 32.2 & $\begin{array}{l}\mathrm{CC} \sim 80-85 \% \text {, there is large opening on the west side, mound growing in } \\
\text { the south view port. }\end{array}$ \\
\hline & & 23:14 & 32.5 & $\mathrm{CC} \sim 80-85 \%$ \\
\hline & & $23: 34$ & 32.8 & $\begin{array}{l}\mathrm{CC} \sim 80-85 \% \text { and } \sim 10 \text { inches high ridge on Lance } 2 \text { opening has a hole } \\
\text { revealing heavy liquid accumulation on the cap surface. Feed flows to the } \\
\text { melt pool between shots. Lance } 2 \text { opening is also visible through the } \\
\text { middle port. From the south port observable mound is present. Light along } \\
\text { the mound L1 exists. }\end{array}$ \\
\hline & \multirow{10}{*}{$8 / 13 / 2008$} & 0:02 & 33.3 & $\begin{array}{l}\mathrm{CC} \sim 85 \% \text {, observed heavy liquid flow from the surface through the hole } \\
\text { around Lance } 2 \text { opening. }\end{array}$ \\
\hline & & $0: 23$ & 33.6 & $\begin{array}{l}\mathrm{CC} \sim 85 \% \text {, partial Lance } 2 \text { opening visible from the mid-view port is } \\
\text { slightly reduced. Others are the same. }\end{array}$ \\
\hline & & $0: 40$ & 33.9 & $\begin{array}{l}\mathrm{CC} \sim 90 \% \text {, still large amount of feed flowing through hole in center ridge to } \\
\text { west side of melter. Large mound still growing. }\end{array}$ \\
\hline & & $1: 00$ & 34.3 & $\mathrm{CC} \sim 90 \%$ is same as before. \\
\hline & & $1: 12$ & 34.5 & $\mathrm{CC} \sim 90 \%$, opening on west wall is closing up. \\
\hline & & $1: 26$ & 34.7 & $\mathrm{CC}$ at $85 \%$, opening on west side appears larger. \\
\hline & & $1: 55$ & 35.2 & $\mathrm{CC} \sim 85 \%$ unchanged. \\
\hline & & $2: 15$ & 35.5 & $\begin{array}{l}\mathrm{CC} \sim 85-90 \text {, west opening unchanged, mound growing taller to south with a } \\
\text { stalactite. Growing near feed tube. }\end{array}$ \\
\hline & & $2: 22$ & 35.6 & Removed top section of mound and stalactite by rodding. \\
\hline & & $2: 45$ & 36.0 & $\begin{array}{l}\mathrm{CC} \sim 85 \% \text {, liquid coming from center of cap formed through-like portion of } \\
\text { cap where it flows freely to melt pool }\end{array}$ \\
\hline
\end{tabular}


Table 5.3. Operator Observations of Cold Cap (CC) (continued).

\begin{tabular}{|c|c|c|c|c|}
\hline Test & Date & Time & $\begin{array}{l}\text { Run } \\
\text { Time } \\
\text { (hours) }\end{array}$ & Cold Cap Observations \\
\hline \multirow{23}{*}{2} & \multirow{23}{*}{$8 / 13 / 2008$} & $3: 36$ & 36.9 & $\begin{array}{l}\text { CC } \sim 85-90 \% \text {, opening near west wall appears to have a second small ridge } \\
\text { growing near it. Mound is still in place. }\end{array}$ \\
\hline & & 4:05 & 37.3 & $\mathrm{CC} \sim 85 \%$ \\
\hline & & $4: 26$ & 37.7 & CC $\sim 85-90 \%$, ridge seems slightly larger. \\
\hline & & $4: 47$ & 38.0 & $\begin{array}{l}\mathrm{CC} \sim 85-90 \% \text {, sizable opening on west side but thermowell } \# 2 \text { heavily } \\
\text { encased in cold cap. }\end{array}$ \\
\hline & & $5: 14$ & 38.5 & CC $\sim 85$ unchanged. \\
\hline & & $5: 25$ & 38.7 & $\begin{array}{l}\text { Still large opening on west side but ridge appears somewhat bigger. CC } \\
\sim 85-90 \% \text {. }\end{array}$ \\
\hline & & $5: 41$ & 38.9 & $\begin{array}{l}\mathrm{CC} \sim 85 \% \text {, from the north viewport cap has thickened but an opening on } \\
\text { the ridge remains letting liquid from the surface out. Lance } 2 \text { opening not } \\
\text { visible from the middle view port. South viewport shows the existing } \\
\text { mound only now appears smaller than previously observed. Light from the } \\
\text { east side also observed. }\end{array}$ \\
\hline & & $6: 23$ & 39.6 & $\begin{array}{l}\text { CC } \sim 85-90 \% \text {, large ridge in center of melter also large cone shape growth } \\
\text { via south view port. }\end{array}$ \\
\hline & & $6: 50$ & 40.1 & $\begin{array}{l}\mathrm{CC} \sim 90 \%, \text { large ridge in center opening on S-E and N-W corners. } \\
\text { Manually removed cone from below feed tube. }\end{array}$ \\
\hline & & $7: 21$ & 40.6 & Very thick hard cold cap in Thermowell 2 area. CC $\sim 95 \%$. \\
\hline & & $7: 27$ & 40.7 & Now observing liquid flow into Lance 2 opening, CC $\sim 90$. \\
\hline & & $7: 42$ & 41.0 & $\mathrm{CC} \sim 90 \%$, with liquid flowing to Lance 2 opening. \\
\hline & & 8:00 & 41.3 & $\begin{array}{l}\text { Lance } 2 \text { area slightly more open than previously observed, feed still } \\
\text { flowing to opening. }\end{array}$ \\
\hline & & $8: 19$ & 41.6 & $\begin{array}{l}\text { CC } \sim 90 \% \text { with liquid still boiling over into Lance } 2 \text { area in between the } \\
\text { feed shots. }\end{array}$ \\
\hline & & $8: 45$ & 42.0 & $\begin{array}{l}\text { CC } \sim 90 \% \text { with liquid still boiling over into Lance area in between the feed } \\
\text { shots. }\end{array}$ \\
\hline & & $8: 53$ & 42.1 & Very little liquid flowing into Lance 2 area. \\
\hline & & 9:07 & 42.4 & $\begin{array}{l}\mathrm{CC} \sim 85 \% \text {, liquid flowing to Lance } 2 \text { area better now. Some light can be } \\
\text { seen thru center view port. }\end{array}$ \\
\hline & & $9: 55$ & 43.2 & $\begin{array}{l}\text { CC } \sim 85 \% \text {, feed flowing into opening on N-W corner opening visible on S- } \\
\text { E corner via S-W view port. }\end{array}$ \\
\hline & & $10: 10$ & 43.4 & $\begin{array}{l}\mathrm{CC} \sim 80-85 \% \text {, large ridge in center. Feed flowing into N-W corner. } \\
\text { Opening on S-E and N-W corners. }\end{array}$ \\
\hline & & $10: 35$ & 43.8 & $\begin{array}{l}\text { CC } \sim 85 \% \text {, with large ridge in center. Feed flowing into center of ridge and } \\
\text { into melt pool thru openings in ridge. Openings in cold cap on S-E and N- } \\
\text { W corners. }\end{array}$ \\
\hline & & 11:15 & 44.5 & $\begin{array}{l}\mathrm{CC} \sim 85 \% \text {, with ridge in center. Openings in S-E and NW corners with feed } \\
\text { flowing into openings. }\end{array}$ \\
\hline & & $11: 52$ & 45.1 & $\begin{array}{l}\mathrm{CC} \sim 80-85 \% \text {, more light visible reflecting on east side. Liquid flowing to } \\
\text { Lance } 2 \text { area. }\end{array}$ \\
\hline & & 12:06 & 45.4 & CC $\sim 80-85 \%$ with feed primarily flowing to Lance 2 area. \\
\hline
\end{tabular}


Table 5.3. Operator Observations of Cold Cap (CC) (continued).

\begin{tabular}{|c|c|c|c|c|}
\hline Test & Date & Time & $\begin{array}{c}\text { Run } \\
\text { Time } \\
\text { (hours) }\end{array}$ & Cold Cap Observations \\
\hline \multirow{6}{*}{2} & \multirow{6}{*}{$8 / 13 / 2008$} & $12: 36$ & 45.9 & $\begin{array}{l}\text { CC } \sim 90 \% \text {, with Lance } 2 \text { area is closing up slightly. Thermowell } 2 \text { partially } \\
\text { encased in cap now. Cone in center area is taller. }\end{array}$ \\
\hline & & $12: 50$ & 46.1 & $\begin{array}{l}\mathrm{CC} \sim 85 \% \text { with large ridge in center cone below feed tube. On S-E and N- } \\
\mathrm{W} \text { corners. Feed flowing into NW opening. }\end{array}$ \\
\hline & & $14: 32$ & 47.8 & CC $\sim 90 \%$, west side has closed up around thermowell 2 . No other changes. \\
\hline & & $14: 48$ & 48.1 & $\mathrm{CC} \sim 90 \%$ \\
\hline & & 15:04 & 48.3 & $\begin{array}{l}\mathrm{CC} \sim 90 \% \text {, through south view port there is a large cone shape mound } \\
\text { underneath the feed tube. West side ridge has a couple of openings } \\
\text { allowing liquid to flow through. The ridge is dry looking. }\end{array}$ \\
\hline & & $15: 49$ & 49.1 & $\mathrm{CC} \sim 95 \%$. \\
\hline \multirow{21}{*}{3} & \multirow{21}{*}{$8 / 13 / 2008$} & $16: 10$ & 49.4 & $\begin{array}{l}\mathrm{CC} \sim 90 \% \text {, part of the cone has collapsed about } 4-5 " \text { off the top. The west } \\
\text { ridge is melting. Feed is flowing into the melt pool. }\end{array}$ \\
\hline & & $16: 25$ & 49.7 & $\mathrm{CC} \sim 85 \%$, west side has opened up some but only along the west wall. \\
\hline & & $16: 38$ & 49.9 & $\mathrm{CC} \sim 85 \%$, No visible changes at this time. \\
\hline & & $17: 17$ & 50.5 & $\mathrm{CC} \sim 85 \%$, ridge is melting on west side. The cone has grown some. \\
\hline & & $17: 34$ & 50.8 & $\mathrm{CC} \sim 85 \%$, the west side ridge has a bigger hole in it from melting. \\
\hline & & $17: 50$ & 51.1 & CC $\% 85 \%$, unchanged. \\
\hline & & $18: 12$ & 51.5 & $\begin{array}{l}\mathrm{CC} \sim 85 \% \text {, west side is melting a lot. It looks like the ridge is about to } \\
\text { collapse. Large amount of liquid that can be seen through the ridge. }\end{array}$ \\
\hline & & $18: 36$ & 51.9 & $\begin{array}{l}\text { Cold cap } \sim 85 \% \text {, ridge continues to melt, boiling feed flows into melter. } \\
\text { Cone is larger. }\end{array}$ \\
\hline & & 18:54 & 52.2 & $\mathrm{CC} \sim 85 \%$ \\
\hline & & 19:12 & 52.5 & $\mathrm{CC} \sim 80$, ridge is no longer melting down. \\
\hline & & 19:31 & 52.8 & $\mathrm{CC} \sim 85 \%$, west side ridge is not melting as fast as previous. \\
\hline & & 19:47 & 53.0 & $\mathrm{CC} \sim 85 \%$, no visible changes. \\
\hline & & 20:05 & 53.3 & $\mathrm{CC} \sim 80 \%$, east side has opened up. \\
\hline & & $20: 23$ & 53.6 & $\mathrm{CC} \sim 85 \%$, west side is closing up. \\
\hline & & $20: 42$ & 54.0 & $\begin{array}{l}\mathrm{CC} \sim 85 \% \text {, ridge appears slightly larger feed can still be seen boiling and } \\
\text { flowing into glass pool. }\end{array}$ \\
\hline & & 20:59 & 54.2 & $\mathrm{CC} \sim 80 \%$, cap is mostly the same. \\
\hline & & $21: 17$ & 54.5 & $\begin{array}{l}\mathrm{CC} \sim 80 \% \text {, opening on west side a little larger, feed is boiling on surface } \\
\text { and flowing into glass pool. }\end{array}$ \\
\hline & & $21: 40$ & 54.9 & $\begin{array}{l}\mathrm{CC} \sim 85 \% \text {, part of both the ridge and the cone have collapsed. Large } \\
\text { quantity of feed flows into glass pool with each shot. }\end{array}$ \\
\hline & & $21: 57$ & 55.2 & $\mathrm{CC} \sim 80 \%$, conditions unchanged. \\
\hline & & $22: 15$ & 55.5 & $\mathrm{CC} \sim 85 \%$, unchanged. \\
\hline & & $22: 52$ & 56.1 & $\begin{array}{l}\mathrm{CC} \sim 70 \% \text {, large opening on west side of melter and very bright glow on } \\
\text { west side of melter. }\end{array}$ \\
\hline
\end{tabular}


ORP-56292 Rev. 0

The Catholic University of America

Vitreous State Laboratory

Table 5.3. Operator Observations of Cold Cap (CC) (continued).

\begin{tabular}{|c|c|c|c|c|}
\hline Test & Date & Time & $\begin{array}{l}\text { Run } \\
\text { Time } \\
\text { (hours) }\end{array}$ & Cold Cap Observations \\
\hline \multirow{20}{*}{3} & \multirow{3}{*}{$8 / 13 / 2008$} & 23:11 & 56.4 & $\mathrm{CC} \sim 70 \%$, appearance unchanged. \\
\hline & & 23:23 & 56.6 & $\mathrm{CC} \sim 75 \%$. \\
\hline & & 23:43 & 57.0 & CC 75\%, basically unchanged. \\
\hline & \multirow{17}{*}{$8 / 14 / 2008$} & 0:05 & 57.3 & $\begin{array}{l}\mathrm{CC} \sim 75 \% \text {, opening on west side has closed up somewhat. Still lots of light } \\
\text { on east side. }\end{array}$ \\
\hline & & $0: 20$ & 57.6 & $\mathrm{CC} \sim 75 \%$ \\
\hline & & $0: 35$ & 57.8 & CC $\sim 75-80 \%$, lots of feed rushing into opening on west side of melter. \\
\hline & & $0: 55$ & 58.2 & CC $\sim 75-80 \%$ basically unchanged. \\
\hline & & $1: 34$ & 58.8 & $\begin{array}{l}\text { CC } \sim 75-80 \% \text {, large opening on west side of surface, but feed is constantly } \\
\text { flowing into it. Large mound is visible on south side but it does not have } \\
\text { pocket at the top to collect liquid. }\end{array}$ \\
\hline & & $1: 58$ & 59.2 & $\begin{array}{l}\mathrm{CC} \sim 80 \% \text {, heavy liquid flowing from the surface, mound at the center and } \\
\text { light from Lance } 1 \text { opening. }\end{array}$ \\
\hline & & $2: 35$ & 59.8 & CC $\sim 70-80 \%$, no significant change. \\
\hline & & 3:02 & 60.3 & $\begin{array}{l}\text { CC } \sim 75-80 \% \text {, still have large amount of feed flowing into opening on west } \\
\text { side. }\end{array}$ \\
\hline & & $3: 12$ & 60.5 & $\mathrm{CC} \sim 75-80 \%$ \\
\hline & & 3:25 & 60.7 & $\begin{array}{l}\text { CC } \sim 80-85 \% \text {, feed rushing into opening on west side. Mound is still in } \\
\text { place with lots of light on east wall. }\end{array}$ \\
\hline & & $3: 40$ & 60.9 & $\begin{array}{l}\text { CC } \sim 80-85 \% \text {, opening on west has feed flowing directly into it, no ridge in } \\
\text { view. Large amount of still on east side. }\end{array}$ \\
\hline & & $3: 55$ & 61.2 & $\begin{array}{l}\text { CC } \sim 80 \% \text {, large opening on west side cap around it is very rigid. Large } \\
\text { mound on the west side with lots of light on east wall. }\end{array}$ \\
\hline & & $4: 15$ & 61.5 & $\begin{array}{l}\text { CC } \sim 80 \% \text {, west opening has a glazed ridge around it, visible after } \\
\text { discharge. Large amount of feed spilling over ridge and into opening } \\
\text { however. East side has mound and great deal of light along the wall. }\end{array}$ \\
\hline & & $5: 20$ & 62.6 & $\begin{array}{l}\text { CC } \sim 80 \% \text {, observed heavy liquid overflow from the ridge on the west, light } \\
\text { from the east exist. Mound on the center appears higher and heavy boiling } \\
\text { around could be seen at times. }\end{array}$ \\
\hline & & $5: 40$ & 62.9 & Mound is still in place and ridge in center of melter \\
\hline & & $5: 54$ & 63.2 & $\begin{array}{l}\mathrm{CC} \sim 80 \% \text {, observed large influx of feed into west opening, so feed is still } \\
\text { flowing over ridge. }\end{array}$ \\
\hline & & $7: 10$ & 64.4 & $\begin{array}{l}\mathrm{CC} \sim 90 \% \text {, west opening is much smaller than previous with liquid still } \\
\text { flowing into opening. East area appears larger based on reflected light. }\end{array}$ \\
\hline
\end{tabular}


Table 5.3. Operator Observations of Cold Cap (CC) (continued).

\begin{tabular}{|c|c|c|c|c|}
\hline Test & Date & Time & $\begin{array}{c}\text { Run } \\
\text { Time } \\
\text { (hours) }\end{array}$ & Cold Cap Observations \\
\hline \multirow{27}{*}{3} & \multirow{27}{*}{$8 / 14 / 2008$} & $7: 20$ & 64.6 & $\begin{array}{l}\text { CC } \sim 95 \% \text {, west opening reduced to } \sim 6 " \text { diameter with still flowing into } \\
\text { opening. East side. Reflected light is reduced from previous observation. }\end{array}$ \\
\hline & & $7: 46$ & 65.0 & $\begin{array}{l}\text { CC } \sim 95 \% \text {, with only small holes open on west, Lance } 2 \text { side. East appears } \\
\text { about the same. }\end{array}$ \\
\hline & & 8:05 & 65.3 & CC $\sim 95 \%$, conditions of cap has not changed. \\
\hline & & $8: 50$ & 66.1 & $\begin{array}{l}\text { Opening is large and not observing liquid flow. East side light is } \\
\text { diminished. }\end{array}$ \\
\hline & & $8: 59$ & 66.2 & Ridge is collapsed causing pressure surge. \\
\hline & & $9: 19$ & 66.6 & $\mathrm{CC} \sim 90 \%$ \\
\hline & & 9:47 & 67.0 & CC $\sim 90-95 \%$. Feed flowing to Lance 2 area freely. \\
\hline & & 9:54 & 67.2 & A shift on cap coverage on east is not visible. \\
\hline & & 10:36 & 67.9 & $\begin{array}{l}\text { CC } \sim 90 \% \text {, mainly unchanged in appearance. Liquid boils over "cone" ridge } \\
\text { between the shots. }\end{array}$ \\
\hline & & $11: 28$ & 68.7 & Cold cap $\sim 85-90 \%$ \\
\hline & & $11: 45$ & 69.0 & $\begin{array}{l}\mathrm{CC} \sim 90 \% \text { with liquid moving into Lance } 2 \text { area again.Liquid in "cone" } \\
\text { under feet tube boils vigorously in between the shots. }\end{array}$ \\
\hline & & $12: 35$ & 69.8 & CC $\sim 90 \%$, observations unchanged from previous observation. \\
\hline & & 13:07 & 70.4 & $\begin{array}{l}\mathrm{CC} \sim 85 \% \text {, Lance } 2 \text { area slightly opened up with undercut into shelf. Liquid } \\
\text { boiling over into opening. }\end{array}$ \\
\hline & & $13: 24$ & 70.7 & $\begin{array}{l}\mathrm{CC} \sim 85 \% \text {, and } 12-18 " \text { thick. Liquid flow is predominantly into Lance } 2 \\
\text { opening. }\end{array}$ \\
\hline & & $13: 41$ & 70.9 & $\begin{array}{l}\text { Light indicates a good opening on east side. Due to liquid flow } \\
\text { predominantly to Lance } 2 \text { area. }\end{array}$ \\
\hline & & $14: 14$ & 71.5 & CC still the same as previous. \\
\hline & & $14: 38$ & 71.9 & $\begin{array}{l}\mathrm{CC} \sim 85 \% \text {. Cone like shape is large. West side ridge/dome has feed boiling } \\
\text { over it. It looks like thermowell } 2 \text { is encased in feed (dry). }\end{array}$ \\
\hline & & $14: 50$ & 72.1 & $\mathrm{CC} \sim 85 \%$, no visible changes. \\
\hline & & 15:05 & 72.3 & $\begin{array}{l}\mathrm{CC} \sim 85 \% \text {, very little to no change from the east. West side is able to see } \\
\text { the top of the dome. }\end{array}$ \\
\hline & & 16:10 & 73.4 & $\begin{array}{l}\text { CC } \sim 85 \% \text {, perforated ridge on west allows feed top flow into melt pool in } \\
\text { between the shots. Moderate size cone is seen trough south view port. }\end{array}$ \\
\hline & & $16: 31$ & 73.8 & $\mathrm{CC} \sim 85 \%$, cone appears slightly larger, other conditions are not changed. \\
\hline & & $16: 49$ & 74.1 & $\mathrm{CC} \sim 85 \%$, conditions mostly unchanged. \\
\hline & & 17:05 & 74.3 & $\begin{array}{l}\mathrm{CC} \sim 85 \% \text {, ridge on west side looks like it is fillings in, feed is still boiling } \\
\text { and flowing into the melter. Cone appears unchanged. }\end{array}$ \\
\hline & & 17:29 & 74.7 & $\begin{array}{l}\text { CC } \sim 90 \% \text {, both sides look slightly darker, also a ceiling like growth can be } \\
\text { seen in the upper part of the north view port. }\end{array}$ \\
\hline & & 17:45 & 75.0 & CC $\sim 90 \%$, unchanged. \\
\hline & & 18:13 & 75.5 & $\begin{array}{l}\mathrm{CC} \sim 85 \% \text {, west side ridge seems smaller; slightly more light can be seen on } \\
\text { the east side. }\end{array}$ \\
\hline & & $18: 32$ & 75.8 & $\begin{array}{l}\mathrm{CC} \sim 85 \% \text {, west ridge appears to be melting. Feed is boiling and flowing } \\
\text { into melt pool, cone looks the same. }\end{array}$ \\
\hline
\end{tabular}


Table 5.3. Operator Observations of Cold Cap (CC) (continued).

\begin{tabular}{|c|c|c|c|c|}
\hline Test & Date & Time & $\begin{array}{l}\text { Run } \\
\text { Time } \\
\text { (hours) }\end{array}$ & Cold Cap Observations \\
\hline \multirow{25}{*}{3} & \multirow{15}{*}{$8 / 14 / 2008$} & 18:50 & 76.1 & CC $\sim 90 \%$, west side has closed up some. Large cone underneath feed tube. \\
\hline & & 19:18 & 76.6 & CC $\sim 90 \%$, west side closing up. \\
\hline & & 19:51 & 77.1 & $\mathrm{CC} \sim 90 \%$. \\
\hline & & 20:20 & 77.6 & $\mathrm{CC} \sim 85 \%$. Slightly darker on east side, otherwise unchanged. \\
\hline & & $20: 36$ & 77.9 & CC $\sim 90 \%$, both sides slightly darker. \\
\hline & & 20:54 & 78.2 & CC $\sim 90 \%$, mostly the same. \\
\hline & & $21: 13$ & 78.5 & $\mathrm{CC} \sim 90 \%$, slight darker on sides of the melter. \\
\hline & & $21: 27$ & 78.7 & $\mathrm{CC} \sim 90 \%$, very little change, maybe a little darker on both sides. \\
\hline & & $21: 47$ & 79.0 & CC $\sim 90 \%$, east side looks a little lighter. \\
\hline & & $22: 15$ & 79.5 & CC $\sim 90-95 \%$, west side darker and east side unchanged. \\
\hline & & 22:47 & 80.0 & $\begin{array}{l}\mathrm{CC} \sim 80 \% \text { very little light visible on west side. Large mound still visible in } \\
\text { south view port. }\end{array}$ \\
\hline & & 23:12 & 80.5 & $\mathrm{CC} \sim 80$, with a large mound on south east side of the melter. \\
\hline & & $23: 35$ & 80.8 & Attempt to break down mound manually. \\
\hline & & 23:43 & 81.0 & $\begin{array}{l}\mathrm{CC} \sim 90 \% \text {, light on the east exists. Previous attempts were able to break } \\
\text { away part of the volcano releasing liquid accumulation. }\end{array}$ \\
\hline & & 23:54 & 81.2 & $\begin{array}{l}\text { West side of the melter is completely dark with no molten glass visible, } \\
\text { there appears to be a hard dark crusty shell over melt surface. That is } \\
\text { building quicker than its melting. }\end{array}$ \\
\hline & \multirow{10}{*}{$8 / 15 / 2008$} & $0: 23$ & 81.6 & $\begin{array}{l}\mathrm{CC} \sim 90-95 \% \text {. Some light now visible on west side but with crusty ridge } \\
\text { above it. Almost no light visible on east side. }\end{array}$ \\
\hline & & $0: 33$ & 81.8 & No light on the east side. \\
\hline & & $0: 54$ & 82.2 & $\begin{array}{l}\text { CC } \sim 85-90 \% \text {, West side has opened up considerably. Slight amount of } \\
\text { light on the east side. }\end{array}$ \\
\hline & & $1: 17$ & 82.5 & $\begin{array}{l}\text { Large opening on the west side with glazed ridge overhanging it. Slight } \\
\text { amount of light on east side. }\end{array}$ \\
\hline & & $1: 36$ & 82.9 & $\begin{array}{l}\mathrm{CC} \sim 85 \% \text {, large opening on west side unchanged, small amount of light on } \\
\text { east side. }\end{array}$ \\
\hline & & $1: 56$ & 83.2 & CC $\sim 85 \%$ unchanged. \\
\hline & & 2:06 & 83.4 & $\begin{array}{l}\mathrm{CC} \sim 85 \% \text {, cold cap wall at the Lance } 2 \text { opening is glazed. Observed no } \\
\text { liquid flowing. To this opening in between shots. Lance } 1 \text { opening exists } \\
\text { with some light reflection; partial mound at south view port is visible. }\end{array}$ \\
\hline & & $2: 25$ & 83.7 & $\begin{array}{l}\mathrm{CC} \sim 85 \% \text {, opening at Lance } 2 \mathrm{n} \text { slightly larger. Thin layer of cap floating on } \\
\text { the glass, glazed wall with no change. }\end{array}$ \\
\hline & & $2: 44$ & 84.0 & $\begin{array}{l}\mathrm{CC} \sim 85 \% \text {, glazed wall on the west still no liquid overflow. Light reflection } \\
\text { on the east slightly brighter. }\end{array}$ \\
\hline & & 3:02 & 84.3 & $\mathrm{CC} \sim 85 \%$, west section observed slowly dissolving. \\
\hline
\end{tabular}


Table 5.3. Operator Observations of Cold Cap (CC) (continued).

\begin{tabular}{|c|c|c|c|c|}
\hline Test & Date & Time & $\begin{array}{l}\text { Run } \\
\text { Time } \\
\text { (hours) }\end{array}$ & Cold Cap Observations \\
\hline \multirow{22}{*}{3} & \multirow{22}{*}{$8 / 15 / 2008$} & 3:07 & 84.4 & Liquid starting to overflow from the cap to the opening on the west. \\
\hline & & $3: 43$ & 85.0 & $\begin{array}{l}\mathrm{CC} \sim 85 \% \text {, west has a thin cap on the glass have now solidified about 2-3", } \\
\text { glazed wall is still present }\end{array}$ \\
\hline & & $4: 20$ & 85.6 & $\mathrm{CC} \sim 85 \%$, unchanged. \\
\hline & & $5: 25$ & 86.7 & $\mathrm{CC} \sim 80-85 \%$, mound starting to build up again. \\
\hline & & $6: 05$ & 87.3 & CC $\sim 80-85 \%$ unchanged. \\
\hline & & 7:08 & 88.4 & $\begin{array}{l}\mathrm{CC} \sim 95 \% \text {, cone is fairly high and limiting liquid dispersion. Dislodged top } \\
\text { portion of cone. Suspected partial full line clog, But subsequent shots were } \\
\text { fine. Performed manual line flush. }\end{array}$ \\
\hline & & $7: 25$ & 88.7 & $\begin{array}{l}\mathrm{CC} \sim 90-95 \% \text {, liquid flowing to Lance } 2 \text { opening. An area with } \sim 8-10 " \\
\text { diameter is open now. }\end{array}$ \\
\hline & & $7: 50$ & 89.1 & $\begin{array}{l}\mathrm{CC} \sim 95 \% \text {, east opening appears to be closing, observe only a small amount } \\
\text { of light. }\end{array}$ \\
\hline & & $7: 54$ & 89.2 & $\begin{array}{l}\text { Believed most if not all feed is flowing to east side. No liquid flow to } \\
\text { Lance } 2 \text { area is observable. }\end{array}$ \\
\hline & & 8:00 & 89.3 & Observed liquid flowing to Lance 2 area now. East side appears unchanged. \\
\hline & & 8:07 & 89.4 & Observed large influx of liquid to Lance 2 area. \\
\hline & & $8: 20$ & 89.6 & $\mathrm{CC} \sim 90 \%$ \\
\hline & & $9: 10$ & 90.4 & $\begin{array}{l}\mathrm{CC} \sim 85-90 \% \text {, light is visible from SE corner. Opening on NW corner has } \\
\text { been flowing into melt pool. }\end{array}$ \\
\hline & & 9:50 & 91.1 & $\begin{array}{l}\mathrm{CC} \sim 90 \% \text {, light visible on SE corner. Mound in center below feed tube. } \\
\text { NW Corner is pen with feed flowing surface. }\end{array}$ \\
\hline & & 10:10 & 91.4 & CC unchanged. \\
\hline & & $10: 25$ & 91.7 & $\begin{array}{l}\mathrm{CC} \sim 90 \% \text {, Light is visible on } \mathrm{S}-\mathrm{W} \text { corner. Cone below feed tube is larger. } \\
\text { Opening on NW corner has feed flowing through cold cap/into melt } \\
\text { surface. }\end{array}$ \\
\hline & & $11: 22$ & 92.6 & $\begin{array}{l}\text { Cold cap } \sim 85 \% \text {. Lance } 2 \text { area is opened up. Liquid is flowing into opening. } \\
\text { East side appears unchanged. }\end{array}$ \\
\hline & & $11: 46$ & 93.0 & $\begin{array}{l}\mathrm{CC} \sim 85-90 \% \text { with flowing strongly into Lance } 2 \text { opening. Light visible on } \\
\text { east appears about the same as previous. }\end{array}$ \\
\hline & & $12: 20$ & 93.6 & $\begin{array}{l}\mathrm{CC} \sim 90 \% \text {, light visible on S-E corner. Cone is still below feed tube. N-W } \\
\text { opening has been flowing thru cold cap. }\end{array}$ \\
\hline & & $12: 38$ & 93.9 & CC unchanged. \\
\hline & & $12: 55$ & 94.2 & $\mathrm{CC} \sim 90 \%$, little changed since last full description. \\
\hline & & $13: 15$ & 94.5 & $\mathrm{CC}$ still very stable. \\
\hline
\end{tabular}


Table 5.3. Operator Observations of Cold Cap (CC) (continued).

\begin{tabular}{|c|c|c|c|c|}
\hline Test & Date & Time & $\begin{array}{l}\text { Run } \\
\text { Time } \\
\text { (hours) }\end{array}$ & Cold Cap Observations \\
\hline \multirow{23}{*}{3} & \multirow{21}{*}{$8 / 15 / 2008$} & 13:39 & 94.9 & Dislodged cone during discharge. \\
\hline & & $14: 32$ & 95.8 & $\begin{array}{l}\text { CC } \sim 90 \% \text {, west side has a large ridge that has a couple of holes in it, which is } \\
\text { allowing liquid feed to flow into the melt pool. The cone shaped mound is the } \\
\text { same height as the south view port. }\end{array}$ \\
\hline & & 14:48 & 96.1 & CC $\sim 90 \%$, No visible changes. \\
\hline & & 15:10 & 96.4 & CC $\sim 90 \%$, west side ridge looks dry in spots and glazed in other places. \\
\hline & & 15:23 & 96.6 & CC $\sim 90 \%$, cone shaped mound has grown some. No other changes. \\
\hline & & 15:42 & 97.0 & $\mathrm{CC} \sim 90 \%$, it seems to be stable at this point. \\
\hline & & 10:04 & 91.3 & $\begin{array}{l}\text { CC } \sim 90 \% \text {, large ridge on the west side. Looks more like a double wall than a } \\
\text { cone under feed tube area.. }\end{array}$ \\
\hline & & $16: 26$ & 97.7 & $\begin{array}{l}\mathrm{CC} \sim 90 \%, \text { most of the west side is glazed. The cone shape mound looks } \\
\text { higher now. }\end{array}$ \\
\hline & & $16: 40$ & 97.9 & $\begin{array}{l}\mathrm{CC} \sim 90 \% \text {, the hole in west ridge is a little larger allowing liquid to flow onto } \\
\text { the melt pool. }\end{array}$ \\
\hline & & $16: 55$ & 98.2 & CC $\sim 90-95 \%$. West side is closing up. \\
\hline & & $17: 15$ & 98.5 & $\begin{array}{l}\mathrm{CC} \sim 90 \% \text {, west side opened up some since discharge. Able to see more light } \\
\text { from the east side. Cone shaped mound does not look any bigger. }\end{array}$ \\
\hline & & $17: 36$ & 98.9 & $\begin{array}{l}\text { CC } \sim 90 \% \text {. Feed is not flowing into the melt pool on the east side like it was } \\
\text { earlier. }\end{array}$ \\
\hline & & $17: 52$ & 99.1 & $\begin{array}{l}\mathrm{CC} \sim 90 \% \text {, west side ridge is glazed and extends toward the south and can be } \\
\text { seen in the south view port. Under the feed tube the mound looks the same. }\end{array}$ \\
\hline & & 18:11 & 99.4 & $\begin{array}{l}\text { CC } \sim 90 \% \text {, a small hole has opened at the bottom center of the west ridge and } \\
\text { is allowing feed to flow into the west side of the melt pool. }\end{array}$ \\
\hline & & 18:27 & 99.7 & $\begin{array}{l}\mathrm{CC} \sim 90 \% \text {, hole in ridge is slightly larger; a stalactite has grown under feed } \\
\text { tube causing shots to spray slightly to the south. Moderate tapping on feed } \\
\text { tube including during shot dislodged about half of it. The shot is not spraying } \\
\text { now. }\end{array}$ \\
\hline & & 18:44 & 100.0 & $\mathrm{CC} \sim 90 \%$, little to no change in conditions. \\
\hline & & 19:05 & 100.3 & $\begin{array}{l}\mathrm{CC} \sim 90 \%, \text { most of the liquid is flowing into east side of melt pool. West side } \\
\text { ridge is mostly glazed. }\end{array}$ \\
\hline & & 19:20 & 100.6 & $\begin{array}{l}\text { CC } \sim 90 \% \text {, West side ridge melting. The stalactite has grown to top of the } \\
\text { cone. }\end{array}$ \\
\hline & & 19:30 & 100.8 & End of Test 3. \\
\hline & & 22:00 & 103.3 & $\begin{array}{l}\text { Most of the cap is gone but the cone shaped mound is still present in the south } \\
\text { view port which looks like it is being held up between the thermowells and } \\
\text { the bubblers. }\end{array}$ \\
\hline & & 23:23 & 104.6 & $\begin{array}{l}\text { Majority of cold cap is gone but still a lot of build up on melter walls. Middle } \\
\text { view port is still entirely blocked. }\end{array}$ \\
\hline & \multirow{2}{*}{$8 / 16 / 2008$} & $0: 37$ & 105.9 & CC material still melting off walls, almost nothing on melter surface. \\
\hline & & $1: 20$ & 106.6 & Cold cap is gone. \\
\hline
\end{tabular}


ORP-56292 Rev. 0

The Catholic University of America

Vitreous State Laboratory

Table 5.4. DM1200 Tests Performed with Final HLW Bubbler Configuration and Glass Temperature of $1150^{\circ} \mathrm{C}$.

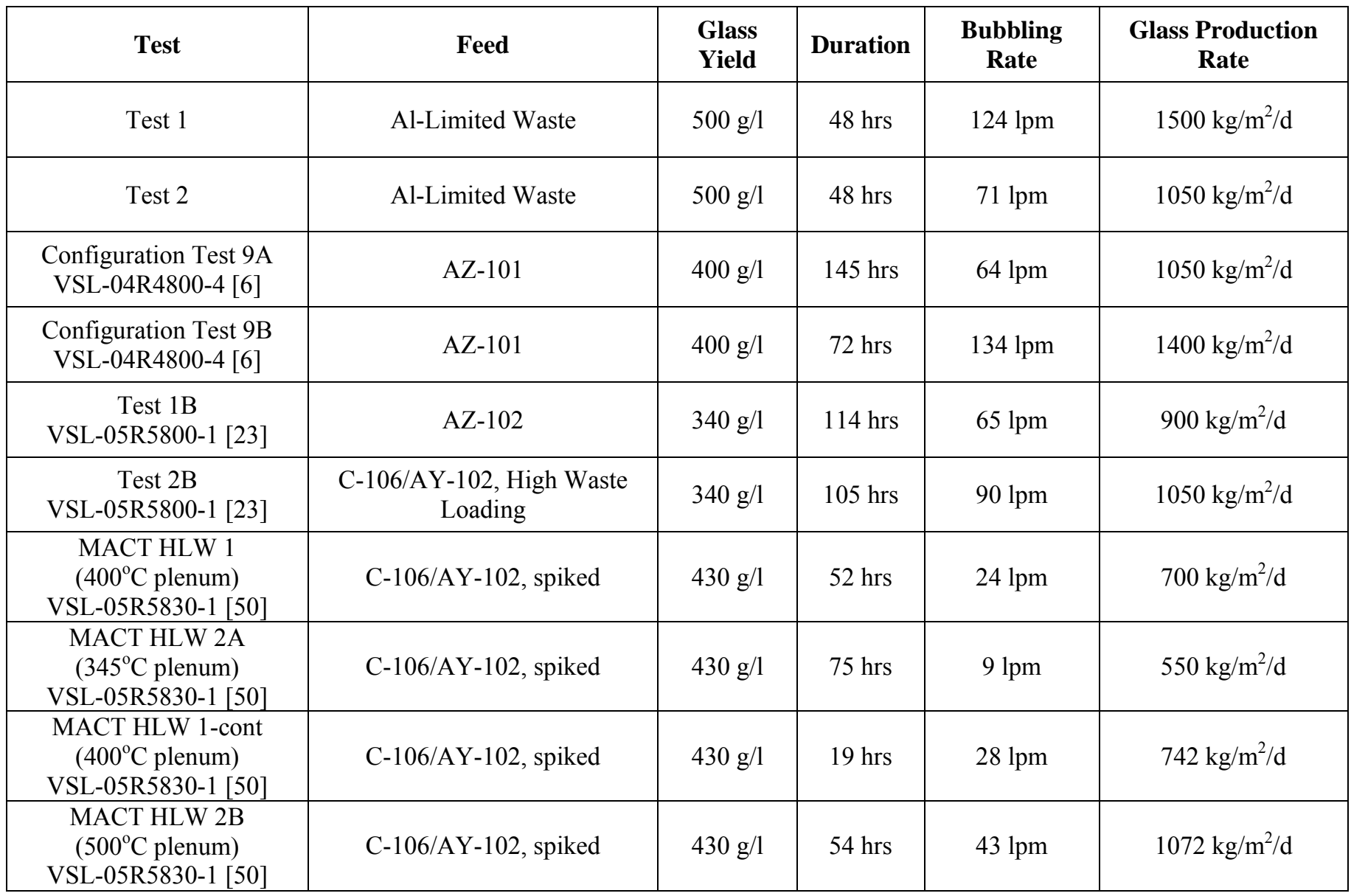


ORP-56292 Rev. 0

The Catholic University of America

Table 5.5. Measured DM1200 Melter System Parameters (8/6/2008 - 8/16/2008).

\begin{tabular}{|c|c|c|c|c|c|c|c|c|c|c|c|c|c|c|}
\hline & \multicolumn{6}{|c|}{1} & \multicolumn{6}{|c|}{2} \\
\hline & & & \multicolumn{3}{|c|}{ Total } & \multicolumn{3}{|c|}{ Steady State } & \multicolumn{3}{|c|}{ Total } & \multicolumn{3}{|c|}{ Steady State } \\
\hline & & & avg & $\min$ & $\max$ & avg & $\min$ & $\max$ & avg & $\min$ & $\max$ & avg & $\min$ & $\max$ \\
\hline \multirow{20}{*}{ 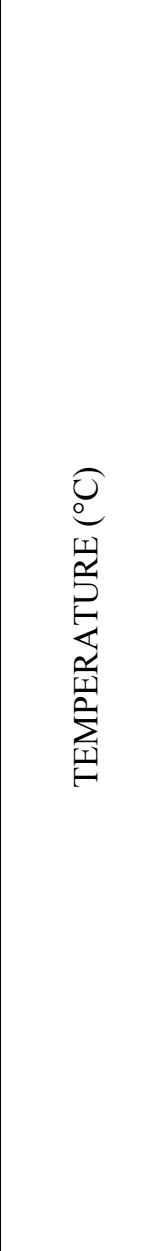 } & \multirow{8}{*}{ Glass } & $\begin{array}{c}13 " \text { from } \\
\text { floor } E\end{array}$ & 1152 & 1113 & 1207 & 1149 & 1113 & 1177 & 1157 & 1131 & 1177 & 1156 & 1131 & 1174 \\
\hline & & $\begin{array}{c}15.5 " \text { from } \\
\text { floor } \mathrm{E}\end{array}$ & 1148 & 1110 & 1203 & 1146 & 1110 & 1173 & 1153 & 1127 & 1174 & 1153 & 1127 & 1170 \\
\hline & & \begin{tabular}{|c|}
$18 "$ from \\
floor $\mathrm{E}$
\end{tabular} & 1149 & 1113 & 1203 & 1147 & 1113 & 1171 & 1153 & 1126 & 1173 & 1153 & 1126 & 1171 \\
\hline & & $\begin{array}{c}27 " \text { from } \\
\text { floor E }\end{array}$ & 1122 & 965 & 1188 & 1117 & 965 & 1158 & 1140 & 1076 & 1165 & 1141 & 1090 & 1165 \\
\hline & & \begin{tabular}{|c|}
$13 "$ from \\
floor $\mathrm{W}$
\end{tabular} & 1146 & 1102 & 1194 & 1145 & 1102 & 1166 & 1145 & 1103 & 1166 & 1144 & 1103 & 1165 \\
\hline & & $\begin{array}{c}15.5 " \text { from } \\
\text { floor } W\end{array}$ & 1149 & 1106 & 1193 & 1148 & 1106 & 1175 & 1147 & 1106 & 1168 & 1147 & 1106 & 1167 \\
\hline & & $\begin{array}{l}18 \text { " from } \\
\text { floor } \mathrm{W}\end{array}$ & 1149 & 1101 & 1193 & 1149 & 1101 & 1179 & 1147 & 1104 & 1170 & 1146 & 1104 & 1170 \\
\hline & & $\begin{array}{l}27 " \text { from } \\
\text { floor } \mathrm{W}\end{array}$ & 1129 & 738 & 1190 & 1127 & 738 & 1187 & 1136 & 1035 & 1169 & 1137 & 1035 & 1169 \\
\hline & \multirow{3}{*}{ Plenum } & $\begin{array}{l}8 " \text { below } \\
\text { ceiling }\end{array}$ & 591 & 452 & 862 & 559 & 452 & 763 & 580 & 482 & 820 & 572 & 482 & 664 \\
\hline & & $\begin{array}{c}17 " \text { below } \\
\text { ceiling }\end{array}$ & 659 & 518 & 835 & 647 & 518 & 782 & 570 & 382 & 792 & 556 & 382 & 778 \\
\hline & & Exposed & 710 & 516 & 986 & 714 & 516 & 986 & 563 & 404 & 772 & 560 & 404 & 726 \\
\hline & \multirow{4}{*}{ Discharge } & TC 1 & 1018 & 942 & 1063 & 1023 & 946 & 1063 & 1024 & 921 & 1085 & 1035 & 1003 & 1085 \\
\hline & & TC 2 & 1050 & 976 & 1080 & 1057 & 1021 & 1080 & 1053 & 968 & 1106 & 1062 & 1029 & 1106 \\
\hline & & Air Flow & 316 & 251 & 342 & 319 & 251 & 342 & 316 & 239 & 345 & 323 & 259 & 345 \\
\hline & & Riser & 1119 & 986 & 1156 & 1128 & 1098 & 1156 & 1109 & 973 & 1162 & 1122 & 1081 & 1162 \\
\hline & \multirow{3}{*}{ Electrode } & East & 1141 & 1113 & 1163 & 1141 & 1113 & 1163 & 1142 & 1097 & 1169 & 1145 & 1116 & 1169 \\
\hline & & West & 1131 & 1098 & 1146 & 1134 & 1117 & 1146 & 1118 & 1062 & 1134 & 1117 & 1093 & 1130 \\
\hline & & Bottom & 1068 & 1054 & 1082 & 1069 & 1059 & 1082 & 1056 & 1018 & 1069 & 1057 & 1039 & 1069 \\
\hline & Film & Added Air & 219 & 125 & 428 & 194 & 125 & 357 & 210 & 128 & 416 & 197 & 128 & 362 \\
\hline & Cooler & \begin{tabular}{|l|} 
Outlet \\
\end{tabular} & 454 & 295 & 630 & 439 & 295 & 510 & 410 & 188 & 610 & 400 & 188 & 491 \\
\hline \multirow{3}{*}{ Glass } & \multicolumn{2}{|c|}{ Density $(\mathrm{g} / \mathrm{cc})$} & 2.24 & 2.00 & 2.46 & 2.22 & 2.00 & 2.33 & 2.30 & 2.19 & 2.44 & 2.29 & 2.19 & 2.38 \\
\hline & \multicolumn{2}{|c|}{ Level (" from floor) } & 31.64 & 28.04 & 34.82 & 31.63 & 28.04 & 34.82 & 31.63 & 29.01 & 33.70 & 31.69 & 30.20 & 33.70 \\
\hline & \multicolumn{2}{|c|}{ Resistance (ohms) } & 0.098 & 0.073 & 0.110 & 0.099 & 0.089 & 0.110 & 0.092 & 0.080 & 0.102 & 0.093 & 0.087 & 0.102 \\
\hline \multirow{3}{*}{ Electrodes } & \multicolumn{2}{|c|}{ Current (A) } & 661 & 627 & 734 & 663 & 627 & 734 & 739 & 676 & 855 & 732 & 676 & 855 \\
\hline & \multirow{2}{*}{\multicolumn{2}{|c|}{$\begin{array}{l}\text { Voltage }(\mathrm{V}) \\
\text { Power }(\mathrm{kW})\end{array}$}} & 148 & 112 & 155 & 149 & 139 & 155 & 125 & 103 & 141 & 128 & 113 & 141 \\
\hline & & & 224 & 170 & 243 & 225 & 205 & 241 & 170 & 129 & 201 & 175 & 140 & 201 \\
\hline \multirow{2}{*}{$\begin{array}{c}\text { Lance } \\
\text { Bubblers }\end{array}$} & 1 & Rate (lpm) & 67.1 & 6.4 & 121.1 & 68.0 & 40.7 & 121.1 & 32.4 & 6.1 & 75.7 & 35.3 & 20.8 & 75.7 \\
\hline & 2 & Rate (lpm) & 56.8 & 6.1 & 121.1 & 54.5 & 35.2 & 121.1 & 31.4 & 6.0 & 71.0 & 34.4 & 11.9 & 71.0 \\
\hline \multicolumn{3}{|c|}{ Total Lance Bubbling (lpm) } & 125.1 & 13.7 & 183.7 & 123.7 & 92.9 & 183.7 & 65.0 & 13.2 & 113.1 & 70.9 & 42.2 & 113.1 \\
\hline
\end{tabular}


Table 5.5. Measured DM1200 Melter System Parameters (8/6/2008 - 8/16/2008) (continued).

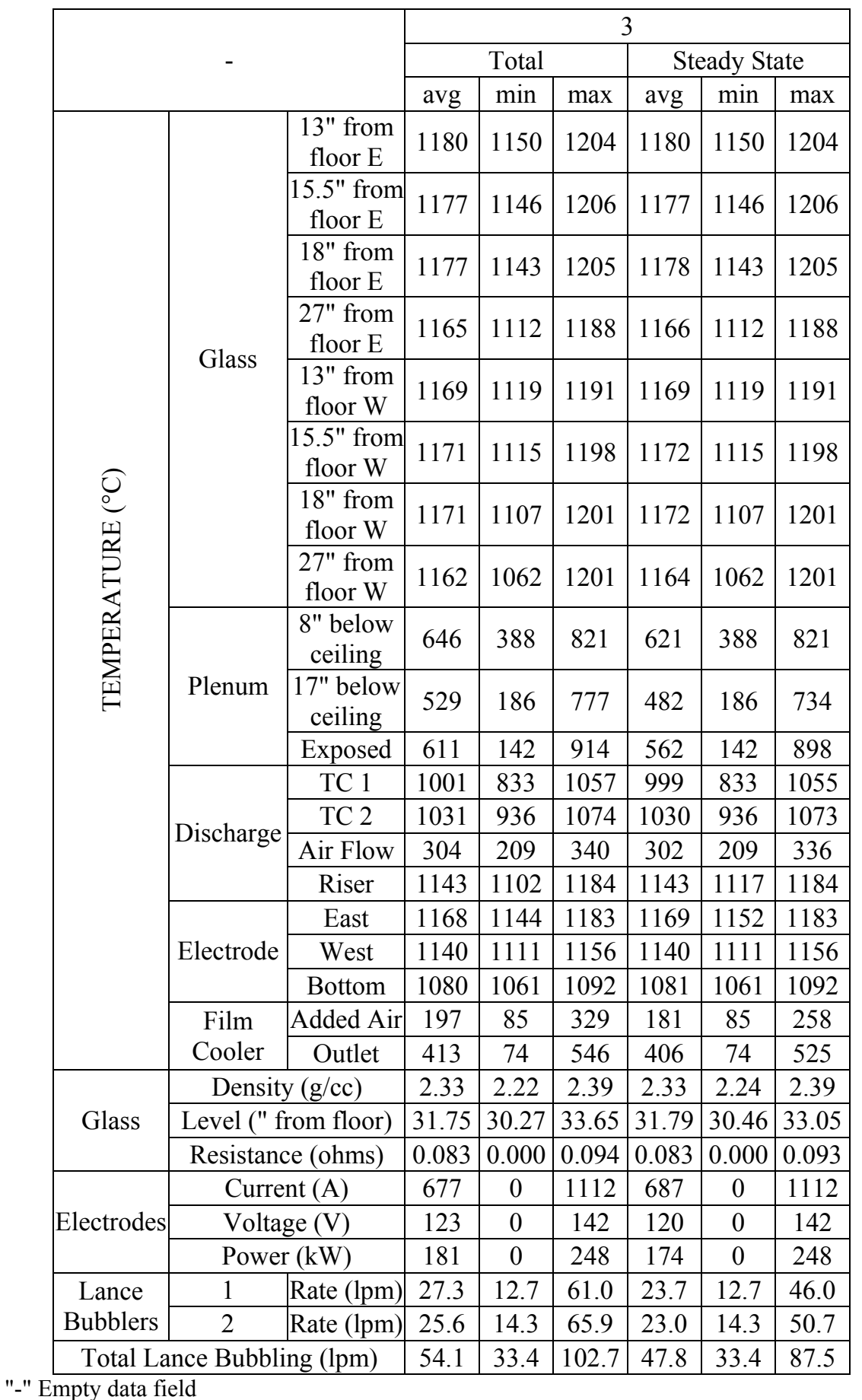


ORP-56292 Rev. 0

The Catholic University of America

Table 5.6. Measured DM1200 Off-Gas System Parameters.

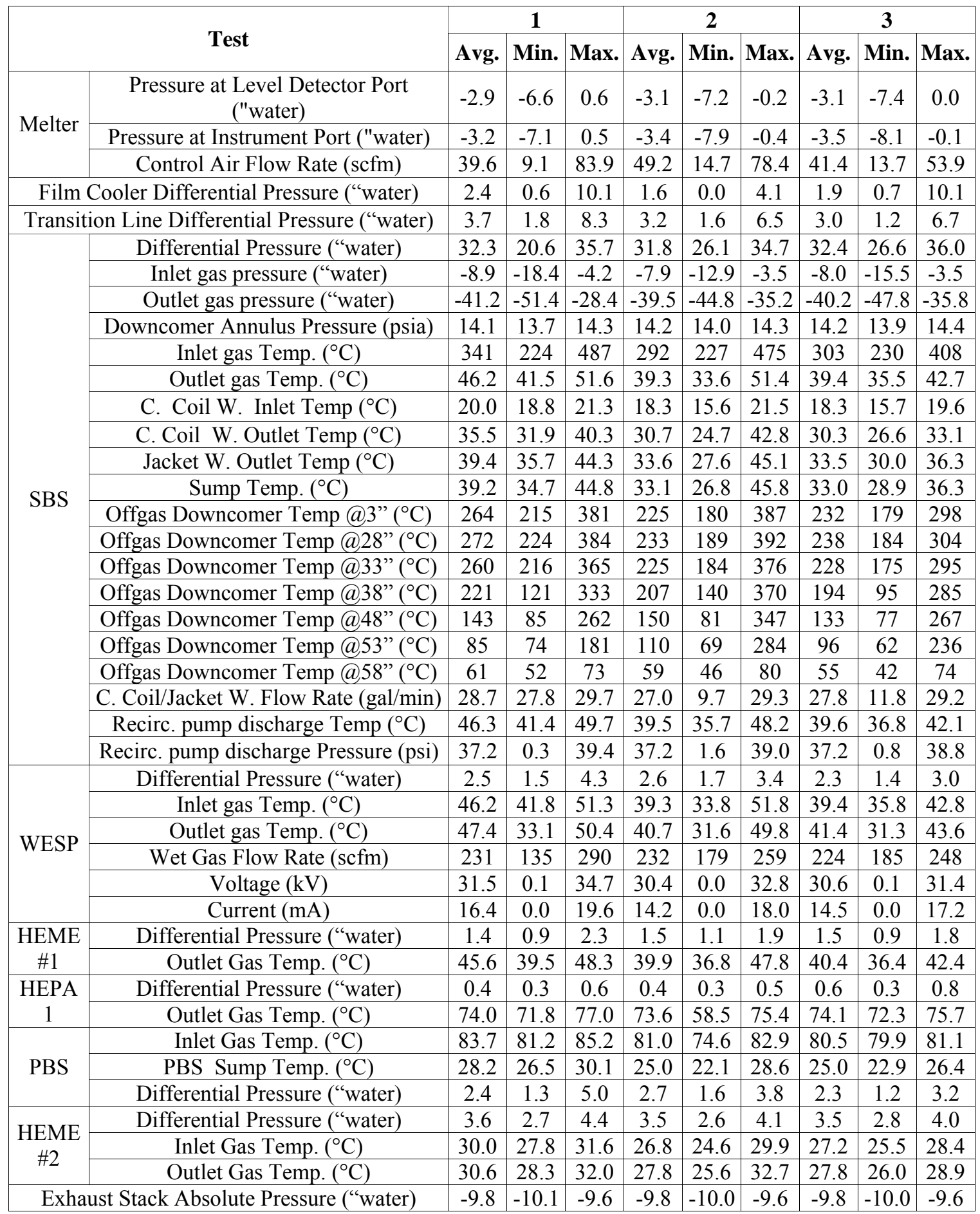


Table 5.7. Off-Gas Solution Volumes.

\begin{tabular}{|c|c|c|c|c|c|c|}
\hline $\begin{array}{l}\text { Type of } \\
\text { Sample }\end{array}$ & Test & Date & $\begin{array}{l}\text { Sample ID for last } \\
\text { Blow-down }\end{array}$ & $\begin{array}{c}\text { Measured } \\
\text { pH }\end{array}$ & $\begin{array}{l}\text { Number of } \\
\text { Blow-downs } \\
\text { per test }\end{array}$ & $\begin{array}{c}\text { Blow-down per } \\
\text { Test (gal) }\end{array}$ \\
\hline \multirow{3}{*}{ SBS } & 1 & $8 / 8 / 2008$ & S-12J-106A & 2.20 & 29 & 1176.49 \\
\hline & 2 & $8 / 13 / 2008$ & S-12K-46A & 2.13 & 21 & 853.84 \\
\hline & 3 & $8 / 15 / 2008$ & S-12K-129A & 1.97 & 24 & 952.51 \\
\hline \multirow{6}{*}{ WESP } & \multirow{2}{*}{1} & \multirow{2}{*}{$8 / 8 / 2008$} & W-12J-110A & 2.67 & \multirow{2}{*}{4} & \multirow{2}{*}{186.51} \\
\hline & & & W-12J-110B & 3.17 & & \\
\hline & \multirow{2}{*}{2} & \multirow{2}{*}{$9 / 12 / 2008$} & W-12K-46A & 2.86 & \multirow{2}{*}{4} & \multirow{2}{*}{209.83} \\
\hline & & & $\mathrm{W}-12 \mathrm{~K}-46 \mathrm{~B}$ & 3.46 & & \\
\hline & \multirow{2}{*}{3} & \multirow{2}{*}{$8 / 16 / 2008$} & $\mathrm{~W}-12 \mathrm{~K}-138 \mathrm{~A}$ & 2.71 & \multirow{2}{*}{4} & \multirow{2}{*}{213.83} \\
\hline & & & $\mathrm{W}-12 \mathrm{~K}-138 \mathrm{~B}$ & 4.37 & & \\
\hline \multirow{3}{*}{ PBS } & 1 & $8 / 8 / 2008$ & P-12J-110A & 8.70 & 8 & 266.62 \\
\hline & 2 & $8 / 13 / 2008$ & P-12K-47A & 8.89 & 5 & 159.23 \\
\hline & 3 & $8 / 15 / 2008$ & $\mathrm{P}-12 \mathrm{~K}-138 \mathrm{~A}$ & 8.94 & 4 & 155.08 \\
\hline \multirow{3}{*}{ HEME 1} & 1 & $8 / 8 / 2008$ & H1-12J-108A & 2.63 & 1 & 16.16 \\
\hline & 2 & $8 / 13 / 2008$ & H1-12K-46A & 2.68 & 1 & 20.10 \\
\hline & 3 & $8 / 16 / 08$ & H1-12K-138A & 2.68 & 1 & 14.63 \\
\hline \multirow{3}{*}{ HEME 2} & 1 & $8 / 8 / 2008$ & H2-12J-108A & 7.56 & 2 & 16.97 \\
\hline & 2 & $8 / 13 / 2008$ & $\mathrm{H} 2-12 \mathrm{~K}-46 \mathrm{~A}$ & 7.46 & 1 & 4.75 \\
\hline & 3 & $8 / 16 / 08$ & H2-12K-138A & 8.13 & 2 & 32.36 \\
\hline
\end{tabular}


Table 5.8. Analytical Results for Solutions from the DM1200 Off-gas System Sampled at End of Testing $(\mathrm{mg} / \mathrm{L})$.

\begin{tabular}{|c|c|c|c|c|c|c|c|c|c|}
\hline Sample Type & \multicolumn{3}{|c|}{ SBS } & \multicolumn{6}{|c|}{ WESP } \\
\hline Sample I.D. & \multicolumn{3}{|c|}{ S-12K-129A } & \multicolumn{3}{|c|}{ W-12K-138A } & \multicolumn{3}{|c|}{$\mathrm{W}-12 \mathrm{~K}-138 \mathrm{~B}$} \\
\hline Deluge & \multicolumn{3}{|c|}{ No } & \multicolumn{3}{|c|}{ Before Deluge } & \multicolumn{3}{|c|}{ After Deluge } \\
\hline Fraction & Sus. & Dis. & Total & Sus. & Dis. & Total & Sus. & Dis. & Total \\
\hline Solids & 280 & 3122 & 3402 & 6 & 1491 & 1497 & 96 & 498 & 594 \\
\hline $\mathrm{Al}$ & 8.86 & 191.78 & 200.64 & $<0.01$ & 1.70 & 1.70 & 0.18 & 0.34 & 0.52 \\
\hline $\mathrm{B}$ & 0.33 & 571.46 & 571.79 & 0.01 & 104.8 & 104.81 & 0.55 & 13.42 & 13.97 \\
\hline$\overline{\mathrm{Ba}}$ & $<0.01$ & 1.44 & 1.44 & $<0.01$ & 0.07 & 0.07 & $<0.01$ & 0.04 & 0.04 \\
\hline $\mathrm{Bi}$ & 7.69 & 13.99 & 21.68 & 0.05 & 2.44 & 2.49 & 17.92 & $<0.01$ & 17.92 \\
\hline $\mathrm{Ca}$ & 2.01 & 53.72 & 55.74 & $<0.01$ & 48.83 & 48.83 & 0.09 & 44.05 & 44.14 \\
\hline $\mathrm{Cd}$ & $<0.01$ & 2.08 & 2.08 & $<0.01$ & 1.68 & 1.68 & 0.46 & 0.51 & 0.97 \\
\hline$\overline{\mathrm{Cu}}$ & 2.76 & 11.25 & 14.01 & 0.03 & 25.35 & 25.38 & 11.70 & 1.20 & 12.90 \\
\hline $\mathrm{Fe}$ & 47.64 & 58.08 & 105.72 & 0.03 & 3.25 & 3.28 & 5.67 & $<0.01$ & 5.67 \\
\hline $\mathrm{K}$ & 0.17 & 13.91 & 14.08 & 0.01 & 20.9 & 20.91 & 0.27 & 7.28 & 7.55 \\
\hline $\mathrm{Li}$ & 0.33 & 34.45 & 34.78 & 0.01 & 32.66 & 32.67 & 0.09 & 8.57 & 8.66 \\
\hline $\mathrm{Mg}$ & 0.08 & 7.83 & 7.91 & $<0.01$ & 11.99 & 11.99 & $<0.01$ & 12.25 & 12.25 \\
\hline $\mathrm{Mn}$ & 0.33 & 2.53 & 2.86 & $<0.01$ & 0.08 & 0.08 & $<0.01$ & $<0.01$ & $<0.01$ \\
\hline $\mathrm{Na}$ & 0.25 & 236.14 & 236.39 & $<0.01$ & 214.35 & 214.35 & $<0.01$ & 59.02 & 59.02 \\
\hline $\mathrm{Ni}$ & 2.26 & 4.65 & 6.91 & 0.01 & 0.34 & 0.35 & 0.46 & 0.09 & 0.55 \\
\hline $\mathrm{P}$ & 1.17 & 8.82 & 9.99 & $<0.01$ & 1.24 & 1.24 & $<0.01$ & $<0.01$ & $<0.01$ \\
\hline $\mathrm{Pb}$ & 1.50 & 16.23 & 17.73 & 0.04 & 4.67 & 4.71 & 12.43 & 0.77 & 13.20 \\
\hline $\mathrm{Si}$ & 54.16 & 80.97 & 135.13 & 0.02 & 7.1 & 7.10 & 1.28 & 3.25 & 4.53 \\
\hline $\mathrm{Sr}$ & $<0.01$ & 1.94 & 1.94 & $<0.01$ & 0.43 & 0.43 & $<0.01$ & 0.32 & 0.32 \\
\hline $\mathrm{Zn}$ & 0.50 & 5.82 & 6.32 & $<0.01$ & 0.54 & 0.54 & 0.46 & 0.06 & 0.52 \\
\hline $\mathrm{Zr}$ & 2.09 & 6.10 & 8.19 & $<0.01$ & 0.19 & 0.19 & $<0.01$ & $<0.01$ & $<0.01$ \\
\hline $\mathrm{Cl}$ & NA & 1284.9 & $\mathrm{NC}$ & NA & 194.88 & $\mathrm{NC}$ & NA & 25.39 & $\mathrm{NC}$ \\
\hline $\mathrm{F}$ & NA & 92.52 & $\mathrm{NC}$ & NA & 45.19 & $\mathrm{NC}$ & NA & 34.05 & $\mathrm{NC}$ \\
\hline Nitrate & NA & 199.49 & $\mathrm{NC}$ & NA & 76.98 & $\mathrm{NC}$ & NA & 18.16 & $\mathrm{NC}$ \\
\hline Nitrite & NA & $<0.1$ & $\mathrm{NC}$ & NA & 0.17 & $\mathrm{NC}$ & NA & $<0.1$ & $\mathrm{NC}$ \\
\hline Sulfate & NA & 647.95 & $\mathrm{NC}$ & NA & 314.98 & $\mathrm{NC}$ & NA & 71.49 & $\mathrm{NC}$ \\
\hline
\end{tabular}


Table 5.8. Analytical Results for Solutions from the DM1200 Off-gas System Sampled at end of Testing (mg/L) (continued).

\begin{tabular}{|c|c|c|c|c|c|c|}
\hline Sample Type & \multicolumn{2}{|c|}{ PBS } & \multicolumn{4}{c|}{ HEME } \\
\hline Sample I.D. & P-12K-138A & \multicolumn{2}{|c|}{ H1-12K-138A } & \multicolumn{2}{l|}{ H2-12K-138A } \\
\hline Fraction & Sus. & Dis. & Sus. & Dis. & Sus. & Dis. \\
\hline Solids & 40 & 9859 & $<1$ & 406 & $<1$ & 1252 \\
\hline $\mathrm{Al}$ & NA & 2.64 & NA & 1.36 & NA & 0.23 \\
\hline $\mathrm{B}$ & NA & 5.12 & NA & 14.52 & NA & 1.17 \\
\hline $\mathrm{Ba}$ & NA & $<0.01$ & NA & 0.06 & NA & 0.06 \\
\hline $\mathrm{Bi}$ & NA & $<0.25$ & NA & $<0.25$ & NA & $<0.25$ \\
\hline $\mathrm{Ca}$ & NA & 2.45 & NA & 46.87 & NA & 63.36 \\
\hline $\mathrm{Cd}$ & NA & $<0.03$ & NA & 0.14 & NA & $<0.03$ \\
\hline $\mathrm{Cu}$ & NA & $<0.01$ & NA & 0.65 & NA & 0.01 \\
\hline $\mathrm{Fe}$ & NA & $<0.05$ & NA & 2.18 & NA & 0.06 \\
\hline $\mathrm{K}$ & NA & 12.39 & NA & 4.21 & NA & 14.34 \\
\hline $\mathrm{Li}$ & NA & 0.08 & NA & 0.54 & NA & 0.64 \\
\hline $\mathrm{Mg}$ & NA & 0.91 & NA & 11.85 & NA & 15.76 \\
\hline $\mathrm{Mn}$ & NA & $<0.04$ & NA & 0.09 & NA & 0.06 \\
\hline $\mathrm{Na}$ & NA & 3305.8 & NA & 18.98 & NA & 226.13 \\
\hline $\mathrm{Ni}$ & NA & $<0.04$ & NA & 0.18 & NA & 0.23 \\
\hline $\mathrm{P}$ & NA & $<0.6$ & NA & 0.96 & NA & 0.92 \\
\hline $\mathrm{Pb}$ & NA & $<0.1$ & NA & 0.69 & NA & $<0.1$ \\
\hline $\mathrm{Si}$ & NA & 1.05 & NA & 3.85 & NA & 2.82 \\
\hline $\mathrm{Sr}$ & NA & 0.04 & NA & 0.38 & NA & 0.50 \\
\hline $\mathrm{Zn}$ & NA & 0.09 & NA & 0.59 & NA & 0.61 \\
\hline $\mathrm{Zr}$ & NA & $<0.02$ & NA & 0.11 & NA & $<0.02$ \\
\hline $\mathrm{Cl}$ & NA & 15.56 & NA & 33.81 & NA & 2.17 \\
\hline $\mathrm{F}$ & NA & 91.06 & NA & 37.37 & NA & 44.58 \\
\hline $\mathrm{Nitrate}$ & NA & 84.73 & NA & 200.26 & NA & 506.85 \\
\hline $\mathrm{Nitrite}$ & NA & 2839.77 & NA & 1.91 & NA & 227.94 \\
\hline $\mathrm{Sulfate}$ & NA & 313.97 & NA & 136.81 & NA & 100.23 \\
\hline NA - Not analyzed & & & & \\
\hline
\end{tabular}


Table 6.1. Characteristics of Melter Feed Samples.

\begin{tabular}{|c|c|c|c|c|c|c|c|c|c|c|c|c|}
\hline \multirow{2}{*}{ Formulation } & \multirow{2}{*}{$\begin{array}{c}\text { Melter } \\
\text { Type }\end{array}$} & \multirow{2}{*}{ Test } & \multirow{2}{*}{ Al Source } & \multirow{2}{*}{ Date } & \multirow{2}{*}{ Name } & \multirow{2}{*}{$\begin{array}{c}\% \\
\text { Water } \\
\end{array}$} & \multirow{2}{*}{$\begin{array}{c}\text { Density } \\
(\mathrm{g} / \mathrm{ml})\end{array}$} & \multirow{2}{*}{$\mathrm{pH}$} & \multirow{2}{*}{$\begin{array}{c}\text { Glass Yield } \\
(\mathrm{g} / \mathrm{l})\end{array}$} & \multicolumn{2}{|c|}{ Glass Yield (kg/kg) } & \multirow{2}{*}{$\begin{array}{c}\% \text { Dev. From } \\
\text { Target }\end{array}$} \\
\hline & & & & & & & & & & Target & Measured & \\
\hline \multirow{6}{*}{$\begin{array}{c}\text { HLW-E-Al- } \\
27\end{array}$} & \multirow{18}{*}{$\begin{array}{l}\mathrm{DM} \\
100\end{array}$} & \multirow{4}{*}{1} & \multirow{6}{*}{$\mathrm{Al}(\mathrm{OH})_{3}$} & $1 / 29 / 08$ & BLX-F-50B & 55.81 & 1.41 & 10.36 & 507 & 0.358 & 0.360 & 0.53 \\
\hline & & & & $2 / 4 / 08$ & BLX-F-62A & NA & 1.38 & 10.41 & NA & 0.358 & NA & $\mathrm{NC}$ \\
\hline & & & & \multirow{2}{*}{$2 / 5 / 08$} & BLX-F-71A & NA & 1.37 & 10.46 & NA & 0.358 & NA & $\mathrm{NC}$ \\
\hline & & & & & BLX-F-79A & NA & 1.38 & 10.17 & NA & 0.358 & NA & $\mathrm{NC}$ \\
\hline & & \multirow{2}{*}{2} & & \multirow{2}{*}{$2 / 6 / 08$} & BLX-F-91A & NA & 1.38 & 10.18 & NA & 0.358 & NA & $\mathrm{NC}$ \\
\hline & & & & & BLX-F-104A & NA & 1.38 & 10.20 & NA & 0.358 & NA & $\mathrm{NC}$ \\
\hline \multirow{12}{*}{ HWI-Al -16 } & & \multirow{4}{*}{3} & \multirow{6}{*}{$\mathrm{Al}(\mathrm{OH})_{3}$} & \multirow{3}{*}{$5 / 5 / 08$} & BLX-F-125A & 58.43 & 1.37 & 8.12 & 487 & 0.360 & 0.356 & -1.11 \\
\hline & & & & & BLX-F-138A & NA & 1.37 & 8.18 & NA & 0.360 & NA & $\mathrm{NC}$ \\
\hline & & & & & BLX-F-145A & NA & 1.39 & 8.12 & NA & 0.360 & NA & $\mathrm{NC}$ \\
\hline & & & & $5 / 6 / 08$ & BLX-F-153A & NA & 1.38 & 8.13 & NA & 0.360 & NA & $\mathrm{NC}$ \\
\hline & & \multirow{2}{*}{4} & & $5 / 7 / 08$ & BLY-F-15A & NA & 1.38 & 8.28 & NA & 0.360 & NA & $\mathrm{NC}$ \\
\hline & & & & $5 / 8 / 08$ & BLY-F-22A & NA & 1.37 & 8.24 & NA & 0.360 & NA & $\mathrm{NC}$ \\
\hline & & \multirow{4}{*}{5} & \multirow{6}{*}{$\mathrm{Al}_{2} \mathrm{O}_{3}$} & \multirow{2}{*}{$6 / 2 / 08$} & BLY-F-57A & 60.00 & 1.36 & 8.34 & 487 & 0.363 & 0.358 & -1.32 \\
\hline & & & & & BLY-F-59A & NA & 1.38 & 8.33 & NA & 0.363 & NA & $\mathrm{NC}$ \\
\hline & & & & $6 / 3 / 08$ & BLY-F-66A & NA & 1.38 & 8.39 & NA & 0.363 & NA & $\mathrm{NC}$ \\
\hline & & & & \multirow{2}{*}{$6 / 4 / 08$} & BLY-F-74A & NA & 1.37 & 8.42 & NA & 0.363 & NA & $\mathrm{NC}$ \\
\hline & & \multirow{2}{*}{6} & & & BLY-F-84A & NA & 1.37 & 8.61 & NA & 0.363 & NA & $\mathrm{NC}$ \\
\hline & & & & $6 / 5 / 08$ & BLY-F-99A & NA & 1.37 & 8.44 & NA & 0.363 & NA & $\mathrm{NC}$ \\
\hline \multirow{5}{*}{ HWI-Al-19 } & & & & $6 / 23 / 08$ & BLY-F-132A & 57.60 & 1.38 & 8.10 & 479 & 0.361 & 0.347 & -3.93 \\
\hline & & & & $0 / 23 / 08$ & BLY-F-133A & NA & 1.37 & 8.16 & NA & 0.361 & NA & $\mathrm{NC}$ \\
\hline & & 7 & $\mathrm{Al}(\mathrm{OH})_{3}$ & $6 / 24 / 08$ & BLY-F-141A & 56.44 & 1.39 & 8.06 & 491 & 0.361 & 0.353 & -2.22 \\
\hline & & & & $0 / 24 / 08$ & BLY-F-147A & NA & 1.38 & 8.15 & NA & 0.361 & NA & $\mathrm{NC}$ \\
\hline & & & & $6 / 25 / 08$ & BLZ-F-10A & NA & 1.40 & 8.21 & NA & 0.361 & NA & $\mathrm{NC}$ \\
\hline
\end{tabular}

NA - Not analyzed; NC - Not calculated 
Table 6.1. Characteristics of Melter Feed Samples (continued).

\begin{tabular}{|c|c|c|c|c|c|c|c|c|c|c|c|c|}
\hline \multirow{2}{*}{ Formulation } & \multirow{2}{*}{$\begin{array}{c}\text { Melter } \\
\text { Type }\end{array}$} & \multirow{2}{*}{ Test } & \multirow{2}{*}{ Al Source } & \multirow{2}{*}{ Date } & \multirow{2}{*}{ Name } & \multirow{2}{*}{$\begin{array}{c}\% \\
\text { Water } \\
\end{array}$} & \multirow{2}{*}{$\begin{array}{c}\text { Density } \\
(\mathrm{g} / \mathrm{ml})\end{array}$} & \multirow{2}{*}{$\mathrm{pH}$} & \multirow{2}{*}{$\begin{array}{c}\text { Glass Yield } \\
(\mathrm{g} / \mathrm{l})\end{array}$} & \multicolumn{2}{|c|}{ Glass Yield (kg/kg) } & \multirow{2}{*}{$\begin{array}{c}\text { \%Dev. From } \\
\text { Target }\end{array}$} \\
\hline & & & & & & & & & & Target & Measured & \\
\hline \multirow{10}{*}{ HWI-Al-19 } & \multirow[b]{2}{*}{ DM100 } & \multirow{2}{*}{8} & \multirow{10}{*}{$\mathrm{Al}(\mathrm{OH})_{3}$} & $6 / 26 / 08$ & BLZ-F-18A & NA & 1.39 & 8.04 & NA & 0.361 & NA & $\mathrm{NC}$ \\
\hline & & & & $6 / 27 / 08$ & BLZ-F-28A & $\mathrm{NA}$ & 1.40 & 8.11 & NA & 0.361 & NA & $\mathrm{NC}$ \\
\hline & \multirow{8}{*}{$\begin{array}{c}\text { DM } \\
1200\end{array}$} & \multirow{3}{*}{1} & & $8 / 6 / 08$ & F-12J-44A & 55.40 & 1.38 & 8.17 & 497 & 0.361 & 0.360 & -0.17 \\
\hline & & & & $8 / 7 / 08$ & F-12J-79A & 56.02 & 1.39 & 8.10 & 480 & 0.361 & 0.345 & -4.32 \\
\hline & & & & $8 / 8 / 08$ & F-12J-106A & 58.90 & 1.36 & 8.46 & 446 & 0.361 & 0.328 & -9.09 \\
\hline & & \multirow{2}{*}{2} & & $8 / 11 / 08$ & F-12J-135A & 56.97 & 1.38 & 8.42 & 469 & 0.361 & 0.340 & -5.84 \\
\hline & & & & $8 / 12 / 08$ & $\mathrm{~F}-12 \mathrm{~K}-7 \mathrm{~A}$ & 56.50 & 1.39 & 8.12 & 477 & 0.361 & 0.343 & -4.93 \\
\hline & & \multirow{3}{*}{3} & & $8 / 13 / 08$ & F-12K-47A & 58.82 & 1.35 & 8.12 & 432 & 0.361 & 0.320 & -11.36 \\
\hline & & & & $8 / 14 / 08$ & F-12K-69A & 55.88 & 1.39 & 8.17 & 468 & 0.361 & 0.337 & -6.65 \\
\hline & & & & $8 / 15 / 08$ & F-12K-113A & 58.78 & 1.37 & 8.45 & 454 & 0.361 & 0.331 & -8.28 \\
\hline
\end{tabular}

NA - Not analyzed; NC - Not calculated 
Table 6.2. Rheological Properties of Melter Feed Samples.

\begin{tabular}{|c|c|c|c|c|c|c|c|c|c|c|c|}
\hline \multirow{2}{*}{ Test } & \multirow{2}{*}{ Formulation } & \multirow{2}{*}{ Al Source } & \multirow{2}{*}{ Date } & \multirow{2}{*}{ Name } & \multirow{2}{*}{$\begin{array}{c}\% \\
\text { Water }\end{array}$} & \multirow{2}{*}{$\begin{array}{c}\text { Density } \\
(\mathrm{g} / \mathrm{ml})\end{array}$} & \multirow{2}{*}{$\mathbf{p H}$} & \multirow{2}{*}{$\begin{array}{c}\text { Yield Stress } \\
\text { (Pa) }\end{array}$} & \multicolumn{3}{|c|}{ Viscosity (Poise) } \\
\hline & & & & & & & & & (a) $1 / \mathrm{s}$ & (a) $10 / \mathrm{s}$ & (a) $100 / \mathrm{s}$ \\
\hline$[2]$ & HLW-E-Al-27 & $\mathrm{Al}_{2} \mathrm{O}_{3}$ & $10 / 2 / 06$ & BLN-F-9A & 61.23 & 1.37 & 10.90 & 0.1 & 1.39 & 0.27 & 0.06 \\
\hline 3 & HWI-Al -16 & $\mathrm{Al}(\mathrm{OH})_{3}$ & $5 / 5 / 08$ & BLX-F-125A & 58.43 & 1.37 & 8.12 & 2.5 & 3.04 & 0.58 & 0.27 \\
\hline 5 & HWI-Al -16 & $\mathrm{Al}_{2} \mathrm{O}_{3}$ & $6 / 2 / 08$ & BLY-F-57A & 60.00 & 1.36 & 8.34 & 1.9 & 5.36 & 0.66 & 0.16 \\
\hline 7 & HWI-Al-19 & $\mathrm{Al}(\mathrm{OH})_{3}$ & $6 / 24 / 08$ & BLY-F-141A & 56.44 & 1.39 & 8.06 & 1.1 & 2.72 & 0.39 & 0.14 \\
\hline
\end{tabular}


Table 6.3. XRF Analyzed Compositions of Vitrified Melter Feed Samples (wt\%).

\begin{tabular}{|c|c|c|c|c|c|c|c|c|}
\hline Melter Type & \multicolumn{8}{|c|}{ DM100 } \\
\hline Formulation & \multicolumn{3}{|c|}{ HLW-E-Al-27 } & \multicolumn{5}{|c|}{ HWI-Al -16 } \\
\hline Al Source & \multicolumn{3}{|c|}{ Aluminum Hydroxide } & \multirow{4}{*}{ Target } & \multirow{2}{*}{\multicolumn{2}{|c|}{\begin{tabular}{|c|} 
Aluminum Hydroxide \\
3
\end{tabular}}} & \multirow{2}{*}{\multicolumn{2}{|c|}{$\begin{array}{c}\text { Aluminum Oxide } \\
5\end{array}$}} \\
\hline Test & \multirow{3}{*}{ Target } & \multirow{2}{*}{\multicolumn{2}{|c|}{$\frac{1}{\text { BLX-F-50B }}$}} & & & & & \\
\hline Sample I.D. & & & & & \multicolumn{2}{|c|}{ BLX-F-125A } & \multicolumn{2}{|c|}{ BLY-F-57A } \\
\hline Constituent & & XRF & $\%$ Dev. & & XRF & \%Dev. & XRF & \%Dev. \\
\hline $\mathrm{Al}_{2} \mathrm{O}_{3}$ & 23.97 & 23.01 & -4.01 & 23.25 & 22.04 & -5.22 & 22.11 & -4.91 \\
\hline $\mathrm{B}_{2} \mathrm{O}_{3} *$ & 15.19 & 15.19 & $\mathrm{NC}$ & 17.73 & 17.73 & $\mathrm{NC}$ & 17.73 & $\mathrm{NC}$ \\
\hline $\mathrm{BaO}$ & 0.05 & 0.07 & $\mathrm{NC}$ & 0.05 & 0.05 & $\mathrm{NC}$ & 0.05 & $\mathrm{NC}$ \\
\hline $\mathrm{Bi}_{2} \mathrm{O}_{3}$ & 1.14 & 1.20 & 4.88 & 1.11 & 1.16 & 4.87 & 1.26 & 13.56 \\
\hline $\mathrm{CaO}$ & 6.08 & 6.03 & -0.71 & 5.89 & 6.04 & 2.53 & 5.85 & -0.71 \\
\hline $\mathrm{CdO}$ & 0.02 & 0.03 & $\mathrm{NC}$ & 0.02 & 0.03 & $\mathrm{NC}$ & 0.02 & $\mathrm{NC}$ \\
\hline $\mathrm{Cr}_{2} \mathrm{O}_{3}$ & 0.52 & 0.60 & $\mathrm{NC}$ & 0.51 & 0.60 & $\mathrm{NC}$ & 0.59 & $\mathrm{NC}$ \\
\hline $\mathrm{F}^{*}$ & 0.67 & 0.67 & $\mathrm{NC}$ & 0.65 & 0.65 & $\mathrm{NC}$ & 0.65 & $\mathrm{NC}$ \\
\hline $\mathrm{Fe}_{2} \mathrm{O}_{3}$ & 5.90 & 5.90 & 0.08 & 5.72 & 6.17 & 7.80 & 6.83 & 19.44 \\
\hline $\mathrm{K}_{2} \mathrm{O}$ & 0.14 & 0.18 & $\mathrm{NC}$ & 0.14 & 0.17 & $\mathrm{NC}$ & 0.16 & $\mathrm{NC}$ \\
\hline $\mathrm{Li}_{2} \mathrm{O} *$ & 3.57 & 3.57 & $\mathrm{NC}$ & 3.46 & 3.46 & $\mathrm{NC}$ & 3.46 & $\mathrm{NC}$ \\
\hline $\mathrm{MgO}$ & 0.12 & 0.26 & $\mathrm{NC}$ & 0.11 & 0.35 & $\mathrm{NC}$ & 0.26 & $\mathrm{NC}$ \\
\hline $\mathrm{MnO}$ & $\S$ & 0.02 & $\mathrm{NC}$ & $\S$ & 0.04 & $\mathrm{NC}$ & 0.03 & $\mathrm{NC}$ \\
\hline $\mathrm{Na}_{2} \mathrm{O}$ & 9.58 & 9.21 & -3.88 & 9.29 & 8.96 & -3.59 & 9.06 & -2.53 \\
\hline $\mathrm{Nd}_{2} \mathrm{O}_{3}$ & $\S$ & $<0.01$ & $\mathrm{NC}$ & $\S$ & $<0.01$ & $\mathrm{NC}$ & $<0.01$ & $\mathrm{NC}$ \\
\hline $\mathrm{NiO}$ & 0.40 & 0.39 & $\mathrm{NC}$ & 0.39 & 0.40 & $\mathrm{NC}$ & 0.37 & $\mathrm{NC}$ \\
\hline $\mathrm{P}_{2} \mathrm{O} 5$ & 1.05 & 1.22 & 16.01 & 1.02 & 1.13 & 10.32 & 1.10 & 7.52 \\
\hline $\mathrm{PbO}$ & 0.41 & 0.37 & $\mathrm{NC}$ & 0.40 & 0.37 & $\mathrm{NC}$ & 0.34 & $\mathrm{NC}$ \\
\hline $\mathrm{SiO}_{2}$ & 30.50 & 31.28 & 2.56 & 29.58 & 29.86 & 0.95 & 28.98 & -2.02 \\
\hline $\mathrm{SO}_{3}$ & 0.20 & 0.23 & $\mathrm{NC}$ & 0.19 & 0.15 & $\mathrm{NC}$ & 0.16 & $\mathrm{NC}$ \\
\hline $\mathrm{SrO}$ & $\S$ & 0.05 & $\mathrm{NC}$ & $\S$ & 0.02 & $\mathrm{NC}$ & 0.01 & $\mathrm{NC}$ \\
\hline $\mathrm{TiO}_{2}$ & 0.01 & 0.04 & $\mathrm{NC}$ & 0.01 & 0.05 & $\mathrm{NC}$ & 0.04 & $\mathrm{NC}$ \\
\hline $\mathrm{ZnO}$ & 0.08 & 0.08 & $\mathrm{NC}$ & 0.08 & 0.09 & $\mathrm{NC}$ & 0.08 & $\mathrm{NC}$ \\
\hline $\mathrm{ZrO}_{2}$ & 0.39 & 0.39 & $\mathrm{NC}$ & 0.38 & 0.49 & $\mathrm{NC}$ & 0.83 & $\mathrm{NC}$ \\
\hline Sum & 100.00 & 100.00 & $\mathrm{NC}$ & 100.00 & 100.00 & $\mathrm{NC}$ & 100.00 & $\mathrm{NC}$ \\
\hline
\end{tabular}


The Catholic University of America Vitreous State Laboratory
ORP-56292 Rev. 0

Melt Rate Enhancement for High Aluminum HLW Glass Formulations

Final Report, VSL-08R1360-1, Rev. 0

Table 6.3. XRF Analyzed Compositions of Vitrified Melter Feed Samples (wt\%) (continued).

\begin{tabular}{|c|c|c|c|c|c|c|c|c|c|}
\hline Melter Type & \multicolumn{5}{|c|}{ DM100 } & \multicolumn{4}{|c|}{ DM1200 } \\
\hline Formulation & \multicolumn{5}{|c|}{ HWI-Al-19 } & \multicolumn{4}{|c|}{ HWI-Al-19 } \\
\hline Al Source & \multicolumn{5}{|c|}{ Aluminum Hydroxide } & \multicolumn{4}{|c|}{ Aluminum Hydroxide } \\
\hline Test & \multirow{3}{*}{ Target } & \multicolumn{4}{|c|}{7} & \multicolumn{3}{|c|}{1} & 2 \\
\hline Sample I.D. & & \multicolumn{2}{|c|}{ BLY-F-132A } & \multicolumn{2}{|c|}{ BLY-F-141A } & $\begin{array}{c}\text { F-12J- } \\
44 \mathrm{~A}\end{array}$ & $\begin{array}{c}\text { F-12J- } \\
79 \mathrm{~A}\end{array}$ & $\begin{array}{c}\text { F-12J- } \\
106 \mathrm{~A}\end{array}$ & $\begin{array}{c}\mathrm{F}-12 \mathrm{~J}- \\
135 \mathrm{~A}\end{array}$ \\
\hline Constituent & & XRF & $\%$ Dev. & XRF & \%Dev. & XRF & XRF & XRF & XRF \\
\hline $\mathrm{Al}_{2} \mathrm{O}_{3}$ & 23.97 & 22.88 & -4.56 & 22.73 & -5.18 & 22.61 & 22.74 & 22.69 & 23.18 \\
\hline $\mathrm{B}_{2} \mathrm{O}_{3} *$ & 19.19 & 19.19 & $\mathrm{NC}$ & 19.19 & $\mathrm{NC}$ & 19.19 & 19.19 & 19.19 & 19.19 \\
\hline $\mathrm{BaO}$ & 0.05 & 0.06 & $\mathrm{NC}$ & 0.06 & $\mathrm{NC}$ & 0.05 & 0.05 & 0.06 & 0.06 \\
\hline $\mathrm{Bi}_{2} \mathrm{O}_{3}$ & 1.14 & 1.31 & 14.50 & 1.29 & 12.81 & 1.23 & 1.19 & 1.10 & 1.23 \\
\hline $\mathrm{CaO}$ & 5.58 & 5.81 & 4.17 & 5.97 & 7.01 & 5.61 & 5.62 & 5.56 & 5.80 \\
\hline $\mathrm{CdO}$ & 0.02 & 0.02 & $\mathrm{NC}$ & 0.02 & $\mathrm{NC}$ & 0.02 & 0.02 & 0.02 & 0.03 \\
\hline $\mathrm{Cr}_{2} \mathrm{O}_{3}$ & 0.52 & 0.68 & $\mathrm{NC}$ & 0.67 & $\mathrm{NC}$ & 0.65 & 0.64 & 0.64 & 0.67 \\
\hline $\mathrm{F}^{*}$ & 0.67 & 0.67 & $\mathrm{NC}$ & 0.67 & $\mathrm{NC}$ & 0.67 & 0.67 & 0.67 & 0.67 \\
\hline $\mathrm{Fe}_{2} \mathrm{O}_{3}$ & 5.90 & 6.41 & 8.71 & 6.50 & 10.11 & 6.26 & 6.22 & 6.19 & 6.49 \\
\hline $\mathrm{K}_{2} \mathrm{O}$ & 0.14 & 0.19 & $\mathrm{NC}$ & 0.20 & $\mathrm{NC}$ & 0.19 & 0.19 & 0.20 & 0.20 \\
\hline $\mathrm{Li}_{2} \mathrm{O}^{*}$ & 3.57 & 3.57 & $\mathrm{NC}$ & 3.57 & $\mathrm{NC}$ & 3.57 & 3.57 & 3.57 & 3.57 \\
\hline $\mathrm{MgO}$ & 0.12 & 0.27 & $\mathrm{NC}$ & 0.27 & $\mathrm{NC}$ & 0.30 & 0.27 & 0.29 & 0.27 \\
\hline $\mathrm{MnO}$ & $\S$ & 0.02 & $\mathrm{NC}$ & 0.02 & $\mathrm{NC}$ & 0.05 & 0.02 & 0.02 & 0.02 \\
\hline $\mathrm{Na}_{2} \mathrm{O}$ & 9.58 & 9.01 & -5.99 & 9.20 & -3.96 & 9.68 & 9.64 & 10.48 & 9.31 \\
\hline $\mathrm{Nd}_{2} \mathrm{O}_{3}$ & $\S$ & 0.01 & $\mathrm{NC}$ & $<0.01$ & $\mathrm{NC}$ & $<0.01$ & $<0.01$ & $<0.01$ & $<0.01$ \\
\hline $\mathrm{NiO}$ & 0.40 & 0.44 & $\mathrm{NC}$ & 0.45 & $\mathrm{NC}$ & 0.40 & 0.40 & 0.39 & 0.41 \\
\hline $\mathrm{P}_{2} \mathrm{O} 5$ & 1.05 & 0.90 & -14.67 & 0.90 & -14.88 & 1.06 & 1.11 & 1.01 & 1.03 \\
\hline $\mathrm{PbO}$ & 0.41 & 0.37 & $\mathrm{NC}$ & 0.37 & $\mathrm{NC}$ & 0.35 & 0.34 & 0.31 & 0.34 \\
\hline $\mathrm{SiO}_{2}$ & 27.00 & 27.27 & 1.03 & 27.06 & 0.26 & 27.24 & 27.30 & 26.84 & 26.69 \\
\hline $\mathrm{SO} 3$ & 0.20 & 0.17 & $\mathrm{NC}$ & 0.16 & $\mathrm{NC}$ & 0.22 & 0.19 & 0.19 & 0.20 \\
\hline $\mathrm{SrO}$ & $\S$ & 0.01 & $\mathrm{NC}$ & 0.01 & $\mathrm{NC}$ & 0.01 & $<0.01$ & $<0.01$ & $<0.01$ \\
\hline $\mathrm{TiO}_{2}$ & 0.01 & 0.04 & $\mathrm{NC}$ & 0.05 & $\mathrm{NC}$ & 0.05 & 0.04 & 0.04 & 0.05 \\
\hline $\mathrm{ZnO}$ & 0.08 & 0.09 & $\mathrm{NC}$ & 0.10 & $\mathrm{NC}$ & 0.09 & 0.09 & 0.08 & 0.09 \\
\hline $\mathrm{ZrO}_{2}$ & 0.39 & 0.60 & $\mathrm{NC}$ & 0.56 & $\mathrm{NC}$ & 0.52 & 0.48 & 0.46 & 0.52 \\
\hline Sum & 100.00 & 100.00 & $\mathrm{NC}$ & 100.00 & $\mathrm{NC}$ & 100.00 & 100.00 & 100.00 & 100.00 \\
\hline
\end{tabular}


Table 6.3. XRF Analyzed Compositions of Vitrified Melter Feed Samples (wt\%) (continued).

\begin{tabular}{|c|c|c|c|c|c|c|c|}
\hline Melter Type & \multicolumn{7}{|c|}{ DM1200 } \\
\hline Formulation & \multicolumn{7}{|c|}{ HWI-Al-19 } \\
\hline Al Source & \multicolumn{7}{|c|}{ Aluminum Hydroxide } \\
\hline Test & \multirow{3}{*}{ Target } & \begin{tabular}{l|}
2 \\
\end{tabular} & & 3 & & \multirow{3}{*}{$\begin{array}{l}\text { Avg. for } \\
\text { DM1200 }\end{array}$} & \multirow{3}{*}{$\%$ Dev. } \\
\hline Sample I.D. & & F-12K-7A & F-12K-47A & F-12K-69A & F-12K-113A & & \\
\hline Constituent & & XRF & \begin{tabular}{l|} 
XRF \\
\end{tabular} & XRF & XRF & & \\
\hline $\mathrm{Al}_{2} \mathrm{O}_{3}$ & 23.97 & 23.04 & 23.38 & 24.06 & 23.84 & 23.19 & -3.25 \\
\hline $\mathrm{B}_{2} \mathrm{O}_{3} *$ & 19.19 & 19.19 & 19.19 & 19.19 & 19.19 & 19.19 & $\mathrm{NC}$ \\
\hline $\mathrm{BaO}$ & 0.05 & 0.07 & 0.07 & 0.07 & 0.06 & 0.06 & $\mathrm{NC}$ \\
\hline $\mathrm{Bi}_{2} \mathrm{O}_{3}$ & 1.14 & 1.28 & 1.22 & 1.18 & 1.16 & 1.20 & 4.46 \\
\hline $\mathrm{CaO}$ & 5.58 & 5.82 & 5.63 & 5.50 & 5.48 & 5.63 & 0.93 \\
\hline $\mathrm{CdO}$ & 0.02 & 0.03 & 0.03 & $<0.01$ & 0.02 & 0.02 & $\mathrm{NC}$ \\
\hline $\mathrm{Cr}_{2} \mathrm{O}_{3}$ & 0.52 & 0.66 & 0.69 & 0.62 & 0.67 & 0.66 & $\mathrm{NC}$ \\
\hline $\mathrm{F}^{*}$ & 0.67 & 0.67 & 0.67 & 0.67 & 0.67 & 0.67 & $\mathrm{NC}$ \\
\hline $\mathrm{Fe}_{2} \mathrm{O}_{3}$ & 5.90 & 6.56 & 6.54 & 6.20 & 6.57 & 6.38 & 8.12 \\
\hline $\mathrm{K}_{2} \mathrm{O}$ & 0.14 & 0.20 & 0.22 & 0.19 & 0.20 & 0.20 & $\mathrm{NC}$ \\
\hline $\mathrm{Li}_{2} \mathrm{O}^{*}$ & 3.57 & 3.57 & 3.57 & 3.57 & 3.57 & 3.57 & $\mathrm{NC}$ \\
\hline $\mathrm{MgO}$ & 0.12 & 0.25 & 0.31 & 0.26 & 0.29 & 0.28 & $\mathrm{NC}$ \\
\hline $\mathrm{MnO}$ & $\S$ & 0.02 & 0.02 & 0.02 & 0.03 & 0.03 & $\mathrm{NC}$ \\
\hline $\mathrm{Na}_{2} \mathrm{O}$ & 9.58 & 9.08 & 9.35 & 9.31 & 9.86 & 9.59 & 0.08 \\
\hline $\mathrm{Nd}_{2} \mathrm{O}_{3}$ & $\S$ & $<0.01$ & $<0.01$ & $<0.01$ & $<0.01$ & $<0.01$ & $\mathrm{NC}$ \\
\hline $\mathrm{NiO}$ & 0.40 & 0.43 & 0.42 & 0.39 & 0.42 & 0.41 & $\mathrm{NC}$ \\
\hline $\mathrm{P}_{2} \mathrm{O} 5$ & 1.05 & 1.10 & 1.20 & 1.12 & 1.13 & 1.09 & 3.80 \\
\hline $\mathrm{PbO}$ & 0.41 & 0.35 & 0.31 & 0.33 & 0.33 & 0.33 & $\mathrm{NC}$ \\
\hline $\mathrm{SiO}_{2}$ & 27.00 & 26.80 & 26.38 & 26.51 & 25.70 & 26.68 & -1.16 \\
\hline $\mathrm{SO}_{3}$ & 0.20 & 0.19 & 0.22 & 0.21 & 0.21 & 0.21 & $\mathrm{NC}$ \\
\hline $\mathrm{SrO}$ & $\S$ & $<0.01$ & $<0.01$ & $<0.01$ & $<0.01$ & $<0.01$ & $\mathrm{NC}$ \\
\hline $\mathrm{TiO}_{2}$ & 0.01 & 0.05 & 0.05 & 0.04 & 0.04 & 0.05 & $\mathrm{NC}$ \\
\hline $\mathrm{ZnO}$ & 0.08 & 0.09 & 0.08 & 0.08 & 0.08 & 0.08 & $\mathrm{NC}$ \\
\hline $\mathrm{ZrO}_{2}$ & 0.39 & 0.54 & 0.47 & 0.49 & 0.47 & 0.49 & $\mathrm{NC}$ \\
\hline Sum & 100.00 & 100.00 & 100.00 & 100.00 & 100.00 & 100.00 & $\mathrm{NC}$ \\
\hline
\end{tabular}


The Catholic University of America Vitreous State Laboratory
ORP-56292 Rev. 0

Melt Rate Enhancement for High Aluminum HLW Glass Formulations

Final Report, VSL-08R1360-1, Rev. 0

Table 6.4. Listing of Glass Discharged, Masses, and Analysis Performed During DM100

Tests.

\begin{tabular}{|c|c|c|c|c|c|c|}
\hline Test & $\mathrm{T}\left({ }^{\circ} \mathrm{C}\right)$ & Date & Name & Analysis & Mass (kg) & Cumulative Mass (kg) \\
\hline \multirow{17}{*}{1} & \multirow{17}{*}{1200} & \multirow{2}{*}{$2 / 4 / 08$} & BLX-G-65A & - & - & - \\
\hline & & & BLX-G-67A & $\mathrm{XRF}, \mathrm{F}$ & 28.72 & 28.72 \\
\hline & & \multirow{10}{*}{$2 / 5 / 08$} & BLX-G-67B & - & - & - \\
\hline & & & BLX-G-71A & XRF & 33.80 & 62.52 \\
\hline & & & BLX-G-71B & - & - & - \\
\hline & & & BLX-G-71C & $\mathrm{XRF}$ & 31.34 & 93.86 \\
\hline & & & BLX-G-76A & - & - & - \\
\hline & & & BLX-G-76B & $\mathrm{XRF}$ & 23.34 & 117.20 \\
\hline & & & BLX-G-77A & - & - & - \\
\hline & & & BLX-G-79A & $\mathrm{XRF}, \mathrm{F}$ & 26.06 & 143.26 \\
\hline & & & BLX-G-79B & - & - & - \\
\hline & & & BLX-G-82A & $\mathrm{XRF}$ & 26.12 & 169.38 \\
\hline & & \multirow{8}{*}{$2 / 6 / 08$} & BLX-G-82B & - & - & - \\
\hline & & & BLX-G-84A & XRF & 27.32 & 196.70 \\
\hline & & & BLX-G-84B & - & - & - \\
\hline & & & BLX-G-84C & XRF, PCT, TCLP & 25.48 & 222.18 \\
\hline & & & BLX-G-89A & - & - & - \\
\hline \multirow{17}{*}{2} & \multirow{17}{*}{1150} & & BLX-G-91A & XRF, F & 33.50 & 255.68 \\
\hline & & & BLX-G-93A & - & - & - \\
\hline & & & BLX-G-96A & XRF & 21.40 & 277.08 \\
\hline & & \multirow{5}{*}{$2 / 7 / 08$} & BLX-G-98A & - & - & - \\
\hline & & & BLX-G-99A & XRF & 23.10 & 300.18 \\
\hline & & & BLX-G-102A & - & - & - \\
\hline & & & BLX-G-102B & XRF & 23.76 & 323.94 \\
\hline & & & BLX-G-104A & - & - & - \\
\hline & & \multirow{7}{*}{$2 / 8 / 08$} & BLX-G-108A & $\mathrm{XRF}, \mathrm{F}$ & 20.62 & 344.56 \\
\hline & & & BLX-G-109A & - & - & - \\
\hline & & & BLX-G-113A & XRF & 31.96 & 376.52 \\
\hline & & & BLX-G-114A & - & - & - \\
\hline & & & BLX-G-114B & XRF & 24.24 & 400.76 \\
\hline & & & BLX-G-114C & - & - & - \\
\hline & & & BLX-G-115A & XRF,PCT, TCLP & 21.00 & 421.76 \\
\hline & & \multirow{2}{*}{$2 / 9 / 08$} & BLX-G-119A & XRF & 35.78 & 457.54 \\
\hline & & & BLX-G-119B & $\mathrm{XRF}, \mathrm{F}$ & 32.56 & 490.10 \\
\hline \multirow{10}{*}{3} & \multirow{10}{*}{1200} & $5 / 5 / 08$ & BLX-G-143A & - & - & - \\
\hline & & \multirow{9}{*}{$5 / 6 / 08$} & BLX-G-144A & XRF, F & 20.16 & 510.26 \\
\hline & & & BLX-G-144B & - & - & - \\
\hline & & & BLX-G-145A & XRF & 24.26 & 534.52 \\
\hline & & & BLX-G-145B & - & - & - \\
\hline & & & BLX-G-147A & $\mathrm{XRF}$ & 24.72 & 559.24 \\
\hline & & & BLX-G-151A & - & - & - \\
\hline & & & BLX-G-151B & XRF & 28.90 & 588.14 \\
\hline & & & BLX-G-152A & - & - & - \\
\hline & & & BLX-G-153A & XRF, F & 25.02 & 613.16 \\
\hline
\end{tabular}

- Empty data field 
Table 6.4. List of Glass Discharged, Masses, and Analysis Performed During DM100 Tests (continued).

\begin{tabular}{|c|c|c|c|c|c|c|}
\hline Test & $\mathbf{T}\left({ }^{\circ} \mathbf{C}\right)$ & Date & Name & Analysis & Mass (kg) & $\begin{array}{l}\text { Cumulative } \\
\text { Mass (kg) }\end{array}$ \\
\hline \multirow{8}{*}{3} & \multirow{8}{*}{1200} & \multirow{2}{*}{$5 / 6 / 08$} & BLX-G-154A & - & - & - \\
\hline & & & BLY-G-8A & XRF & 22.98 & 636.14 \\
\hline & & \multirow{10}{*}{$5 / 7 / 08$} & BLY-G-8B & - & - & - \\
\hline & & & BLY-G-10A & XRF & 23.50 & 659.64 \\
\hline & & & BLY-G-10B & - & - & - \\
\hline & & & BLY-G-10C & XRF & 23.50 & 683.14 \\
\hline & & & BLY-G-14A & - & - & - \\
\hline & & & BLY-G-14B & XRF,PCT,TCLP,DCP,F & 31.88 & 715.02 \\
\hline \multirow{23}{*}{4} & \multirow{23}{*}{1150} & & BLY-G-15A & - & - & - \\
\hline & & & BLY-G-16A & XRF & 21.78 & 736.80 \\
\hline & & & BLY-G-16B & - & - & - \\
\hline & & & BLY-G-17A & XRF & 19.68 & 756.48 \\
\hline & & \multirow{10}{*}{$5 / 8 / 08$} & BLY-G-17B & - & - & - \\
\hline & & & BLY-G-22A & XRF & 21.20 & 777.68 \\
\hline & & & BLY-G-22B & - & - & - \\
\hline & & & BLY-G-25A & XRF, F & 18.66 & 796.34 \\
\hline & & & BLY-G-25B & - & - & - \\
\hline & & & BLY-G-26A & XRF & 23.14 & 819.48 \\
\hline & & & BLY-G-26B & - & - & - \\
\hline & & & BLY-G-26C & XRF & 18.84 & 838.32 \\
\hline & & & BLY-G-28A & - & - & - \\
\hline & & & BLY-G-28B & XRF & 18.64 & 856.96 \\
\hline & & \multirow{9}{*}{$5 / 9 / 08$} & BLY-G-32A & - & - & - \\
\hline & & & BLY-G-34A & XRF, F & 18.64 & 875.60 \\
\hline & & & BLY-G-34B & - & - & - \\
\hline & & & BLY-G-35A & XRF & 20.78 & 896.38 \\
\hline & & & BLY-G-36A & - & - & - \\
\hline & & & BLY-G-36B & XRF,PCT,TCLP,DCP & 24.28 & 920.66 \\
\hline & & & BLY-G-40A & XRF & 28.42 & 949.08 \\
\hline & & & BLY-G-40B & XRF, F & 29.14 & 978.22 \\
\hline & & & BLY-G-40C & XRF & 17.72 & 995.94 \\
\hline \multirow{12}{*}{5} & \multirow{12}{*}{1200} & \multirow{9}{*}{$6 / 3 / 08$} & BLY-G-62A & - & - & - \\
\hline & & & BLY-G-63A & XRF, F & 28.70 & 1024.64 \\
\hline & & & BLY-G-66A & - & - & - \\
\hline & & & BLY-G-66B & XRF & 32.86 & 1057.50 \\
\hline & & & BLY-G-68A & - & - & - \\
\hline & & & BLY-G-69A & XRF & 26.66 & 1084.16 \\
\hline & & & BLY-G-69B & - & - & - \\
\hline & & & BLY-G-73A & XRF & 26.26 & 1110.42 \\
\hline & & & BLY-G-74A & - & - & - \\
\hline & & \multirow{3}{*}{$6 / 4 / 08$} & BLY-G-75A & XRF, F & 28.64 & 1139.06 \\
\hline & & & BLY-G-79A & - & - & - \\
\hline & & & BLY-G-80A & XRF & 27.14 & 1166.20 \\
\hline
\end{tabular}

- Empty data field 
Table 6.4. List of Glass Discharged, Masses, and Analysis Performed During DM100 Tests (continued).

\begin{tabular}{|c|c|c|c|c|c|c|}
\hline Test & $\mathbf{T}\left({ }^{\circ} \mathrm{C}\right)$ & Date & Name & Analysis & Mass (kg) & $\begin{array}{c}\text { Cumulative } \\
\text { Mass (kg) }\end{array}$ \\
\hline \multirow{3}{*}{5} & \multirow{3}{*}{1200} & \multirow{5}{*}{$6 / 4 / 08$} & BLY-G-80B & - & - & - \\
\hline & & & BLY-G-80C & XRF,PCT,TCLP,DCP & 27.40 & 1193.60 \\
\hline & & & BLY-G-84A & - & - & - \\
\hline \multirow{20}{*}{6} & \multirow{20}{*}{1150} & & BLY-G-85A & XRF & 33.64 & 1227.24 \\
\hline & & & BLY-G-87A & - & - & - \\
\hline & & \multirow{9}{*}{$6 / 5 / 08$} & BLY-G-91A & XRF, F & 22.68 & 1249.92 \\
\hline & & & BLY-G-92A & - & - & - \\
\hline & & & BLY-G-93A & XRF & 20.42 & 1270.34 \\
\hline & & & BLY-G-93B & - & - & - \\
\hline & & & BLY-G-93C & XRF & 15.78 & 1286.12 \\
\hline & & & BLY-G-94A & - & - & - \\
\hline & & & BLY-G-98A & - & - & - \\
\hline & & & BLY-G-98B & XRF & 20.34 & 1306.46 \\
\hline & & & BLY-G-99A & - & - & - \\
\hline & & \multirow{6}{*}{$6 / 6 / 08$} & BLY-G-101A & XRF & 15.56 & 1322.02 \\
\hline & & & BLY-G-106A & - & - & - \\
\hline & & & BLY-G-107A & XRF, F & 28.62 & 1350.64 \\
\hline & & & BLY-G-111A & - & - & - \\
\hline & & & BLY-G-111B & XRF & 23.54 & 1374.18 \\
\hline & & & BLY-G-112A & - & - & - \\
\hline & & $6 / 7 / 08$ & BLY-G-114A & XRF,PCT,TCLP,DCP & 21.76 & 1395.94 \\
\hline & & \multirow{2}{*}{$6 / 19 / 08$} & BLY-G-120A & XRF & 27.16 & 1423.10 \\
\hline & & & BLY-G-120B & XRF & 41.04 & 1464.14 \\
\hline \multirow{16}{*}{7} & \multirow{16}{*}{1200} & $6 / 23 / 08$ & BLY-G-135A & - & - & - \\
\hline & & \multirow{9}{*}{$6 / 24 / 08$} & BLY-G-139A & XRF, F & 32.24 & 1496.38 \\
\hline & & & BLY-G-141A & - & - & - \\
\hline & & & BLY-G-141B & XRF & 33.58 & 1529.96 \\
\hline & & & BLY-G-144A & - & - & - \\
\hline & & & BLY-G-144B & XRF & 30.16 & 1560.12 \\
\hline & & & BLY-G-145A & - & - & - \\
\hline & & & BLY-G-145B & XRF & 31.38 & 1591.50 \\
\hline & & & BLY-G-147A & - & - & - \\
\hline & & & BLY-G-151A & XRF, F & 33.98 & 1625.48 \\
\hline & & \multirow{8}{*}{$6 / 25 / 00$} & BLY-G-151B & - & - & - \\
\hline & & & BLY-G-152A & XRF & 30.34 & 1655.82 \\
\hline & & & BLY-G-153A & - & - & - \\
\hline & & & BLY-G-153B & XRF & 26.16 & 1681.98 \\
\hline & & & BLZ-G-5A & - & - & - \\
\hline & & & BLZ-G-5B & XRF,PCT,TCLP,DCP & 27.36 & 1709.34 \\
\hline \multirow{4}{*}{8} & \multirow{4}{*}{1150} & & BLZ-G-11A & - & - & - \\
\hline & & & BLZ-G-13A & XRF, F & 31.96 & 1741.30 \\
\hline & & \multirow{2}{*}{$6 / 26 / 08$} & BLZ-G-13B & - & - & - \\
\hline & & & BLZ-G-16A & XRF & 25.74 & 1767.04 \\
\hline
\end{tabular}

- Empty data field 
The Catholic University of America Vitreous State Laboratory
ORP-56292 Rev. 0

Melt Rate Enhancement for High Aluminum HLW Glass Formulations

Final Report, VSL-08R1360-1, Rev. 0

Table 6.4. List of Glass Discharged, Masses, and Analysis Performed During DM100 Tests (continued).

\begin{tabular}{|c|c|c|c|c|c|c|}
\hline Test & $\mathbf{T}\left({ }^{\circ} \mathbf{C}\right)$ & Date & Name & Analysis & Mass (kg) & $\begin{array}{c}\text { Cumulative } \\
\text { Mass (kg) }\end{array}$ \\
\hline \multirow{15}{*}{8} & \multirow{15}{*}{1150} & \multirow{6}{*}{$6 / 26 / 08$} & BLZ-G-18A & - & - & - \\
\hline & & & BLZ-G-21A & XRF & 24.62 & 1791.66 \\
\hline & & & BLZ-G-21B & - & - & - \\
\hline & & & BLZ-G-23A & XRF & 24.32 & 1815.98 \\
\hline & & & BLZ-G-23B & - & - & - \\
\hline & & & BLZ-G-27A & XRF, F & 25.28 & 1841.26 \\
\hline & & \multirow{9}{*}{$6 / 27 / 08$} & BLZ-G-27B & - & - & - \\
\hline & & & BLZ-G-28A & $\mathrm{XRF}$ & 25.70 & 1866.96 \\
\hline & & & BLZ-G-29A & - & - & - \\
\hline & & & BLZ-G-29B & XRF & 22.60 & 1889.56 \\
\hline & & & BLZ-G-33A & - & - & - \\
\hline & & & BLZ-G-33B & $\mathrm{XRF}$ & 23.06 & 1912.62 \\
\hline & & & BLZ-G-35A & - & - & - \\
\hline & & & BLZ-G-35B & XRF, $F$ & 24.14 & 1936.76 \\
\hline & & & BLZ-G-37A & XRF, PCT, TCLP, DCP & 11.64 & 1948.40 \\
\hline
\end{tabular}

- Empty data field 
ORP-56292 Rev. 0

The Catholic University of America Vitreous State Laboratory

Table 6.5. List of Glass Discharged, Masses, and Analysis Performed during DM1200 Test.

\begin{tabular}{|c|c|c|c|c|c|}
\hline Test & Date & Name & Analysis & Mass (kg) & $\begin{array}{c}\text { Cumulative } \\
\text { Mass (kg) }\end{array}$ \\
\hline \multirow{43}{*}{1} & \multirow{12}{*}{$8 / 6 / 08$} & G-12J-41A & - & - & - \\
\hline & & G-12J-42A & - & - & - \\
\hline & & G-12J-42B & - & - & - \\
\hline & & G-12J-43A & - & - & - \\
\hline & & G-12J-43B & - & - & - \\
\hline & & G-12J-44A & - & - & - \\
\hline & & G-12J-45A & XRF, DCP, F & 478.5 & 478.5 \\
\hline & & G-12J-45B & - & - & - \\
\hline & & G-12J-46A & - & - & - \\
\hline & & G-12J-48A & - & - & - \\
\hline & & G-12J-48B & - & - & - \\
\hline & & G-12J-60A & & 502.0 & 980.5 \\
\hline & \multirow{26}{*}{$8 / 7 / 08$} & G-12J-60B & - & - & - \\
\hline & & G-12J-61A & - & - & - \\
\hline & & G-12J-61B & - & - & - \\
\hline & & G-12J-62A & - & - & - \\
\hline & & $\mathrm{G}-12 \mathrm{~J}-62 \mathrm{~B}$ & - & - & - \\
\hline & & G-12J-64A & XRF & 481.5 & 1462.0 \\
\hline & & G-12J-65A & - & - & - \\
\hline & & G-12J-69A & - & - & - \\
\hline & & G-12J-69B & - & - & - \\
\hline & & G-12J-70A & - & - & - \\
\hline & & G-12J-71A & - & - & - \\
\hline & & G-12J-71B & - & - & - \\
\hline & & G-12J-71C & - & - & - \\
\hline & & G-12J-72A & XRF, F & 499.0 & 1961.0 \\
\hline & & G-12J-72B & - & - & - \\
\hline & & G-12J-73A & - & - & - \\
\hline & & G-12J-75A & - & - & - \\
\hline & & G-12J-75B & - & - & - \\
\hline & & G-12J-77A & - & - & - \\
\hline & & G-12J-79A & - & - & - \\
\hline & & G-12J-79B & $\mathrm{XRF}$ & 485.0 & 2446.0 \\
\hline & & G-12J-88A & - & - & - \\
\hline & & G-12J-89A & - & - & - \\
\hline & & G-12J-89B & - & - & - \\
\hline & & G-12J-90A & - & - & - \\
\hline & & G-12J-90B & - & - & - \\
\hline & \multirow{5}{*}{$8 / 8 / 08$} & G-12J-100A & $\mathrm{XRF}$ & 446.5 & 2892.5 \\
\hline & & G-12J-100B & - & - & - \\
\hline & & G-12J-101A & - & - & - \\
\hline & & G-12J-102A & - & - & - \\
\hline & & G-12J-104A & - & - & - \\
\hline
\end{tabular}

- Empty data field 
Table 6.5. List of Glass Discharged, Masses, and Analysis Performed during DM1200 Test (continued).

\begin{tabular}{|c|c|c|c|c|c|}
\hline Test & Date & Name & Analysis & Mass (kg) & $\begin{array}{l}\text { Cumulative } \\
\text { Mass (kg) }\end{array}$ \\
\hline \multirow{5}{*}{1} & \multirow{5}{*}{$8 / 8 / 08$} & G-12J-105A & - & - & - \\
\hline & & G-12J-105B & XRF, DCP, F & 480.5 & 3373.0 \\
\hline & & G-12J-106A & - & - & - \\
\hline & & G-12J-110A & - & - & - \\
\hline & & G-12J-110B & - & - & - \\
\hline \multirow{28}{*}{2} & \multirow{4}{*}{$8 / 11 / 08$} & G-12J-133A & - & - & - \\
\hline & & G-12J-135A & XRF & 492.5 & 3865.5 \\
\hline & & G-12J-135B & - & - & - \\
\hline & & G-12J-136A & - & - & - \\
\hline & \multirow{18}{*}{$8 / 12 / 08$} & G-12J-137A & - & - & - \\
\hline & & G-12J-139A & - & - & - \\
\hline & & G-12J-139B & - & - & - \\
\hline & & G-12J-148A & - & - & - \\
\hline & & G-12J-149A & - & - & - \\
\hline & & G-12J-149B & XRF, DCP & 498.5 & 4364.0 \\
\hline & & G-12J-152A & - & - & - \\
\hline & & G-12J-152B & - & - & - \\
\hline & & G-12J-154A & - & - & - \\
\hline & & G-12J-155A & - & - & - \\
\hline & & G-12K-7A & - & - & - \\
\hline & & G-12K-11A & - & - & - \\
\hline & & G-12K-11B & - & - & - \\
\hline & & G-12K-21A & XRF & 495.5 & 4859.5 \\
\hline & & $\mathrm{G}-12 \mathrm{~K}-22 \mathrm{~A}$ & - & - & - \\
\hline & & G-12K-23A & - & - & - \\
\hline & & G-12K-24A & - & - & - \\
\hline & & G-12K-24B & - & - & - \\
\hline & \multirow{15}{*}{$8 / 13 / 08$} & G-12K-26A & - & - & - \\
\hline & & $\mathrm{G}-12 \mathrm{~K}-26 \mathrm{~B}$ & - & - & - \\
\hline & & G-12K-28A & - & - & - \\
\hline & & G-12K-28B & - & - & - \\
\hline & & $\mathrm{G}-12 \mathrm{~K}-28 \mathrm{C}$ & XRF, F & 498.0 & 5357.5 \\
\hline & & G-12K-37A & - & - & - \\
\hline \multirow{9}{*}{3} & & $\mathrm{G}-12 \mathrm{~K}-37 \mathrm{~B}$ & - & - & - \\
\hline & & G-12K-38A & - & - & - \\
\hline & & G-12K-38B & - & - & - \\
\hline & & $\mathrm{G}-12 \mathrm{~K}-42 \mathrm{~A}$ & - & - & - \\
\hline & & G-12K-43A & - & - & - \\
\hline & & G-12K-43B & - & - & - \\
\hline & & G-12K-44A & XRF & 475.0 & 5832.5 \\
\hline & & G-12K-46A & - & - & - \\
\hline & & G-12K-47A & - & - & - \\
\hline
\end{tabular}

- Empty data field 
The Catholic University of America Vitreous State Laboratory
ORP-56292 Rev. 0

Melt Rate Enhancement for High Aluminum HLW Glass Formulations

Final Report, VSL-08R1360-1, Rev. 0

Table 6.5. List of Glass Discharged, Masses, and Analysis Performed during DM1200 Test (continued).

\begin{tabular}{|c|c|c|c|c|c|}
\hline Test & Date & Name & Analysis & Mass (kg) & $\begin{array}{c}\text { Cumulative } \\
\text { Mass (kg) }\end{array}$ \\
\hline \multirow{43}{*}{3} & \multirow{6}{*}{$8 / 13 / 08$} & G-12K-57A & - & - & - \\
\hline & & G-12K-58A & - & - & - \\
\hline & & G-12K-58B & - & - & - \\
\hline & & G-12K-59A & XRF & 462.5 & 6295.0 \\
\hline & & G-12K-61A & - & - & - \\
\hline & & G-12K-63A & - & - & - \\
\hline & \multirow{16}{*}{$8 / 14 / 08$} & G-12K-64A & - & - & - \\
\hline & & G-12K-66A & - & - & - \\
\hline & & G-12K-67A & - & - & - \\
\hline & & G-12K-68A & - & - & - \\
\hline & & G-12K-81A & - & - & - \\
\hline & & G-12K-81B & XRF & 513.0 & 6808.0 \\
\hline & & G-12K-84A & - & - & - \\
\hline & & G-12K-85A & - & - & - \\
\hline & & G-12K-86A & - & - & - \\
\hline & & G-12K-87A & - & - & - \\
\hline & & G-12K-87B & - & - & - \\
\hline & & G-12K-89A & - & - & - \\
\hline & & G-12K-91A & XRF, F & 502.0 & 7310.0 \\
\hline & & G-12K-92A & - & - & - \\
\hline & & G-12K-92B & - & - & - \\
\hline & & G-12K-102A & - & - & - \\
\hline & \multirow{20}{*}{$8 / 15 / 08$} & G-12K-104A & - & - & - \\
\hline & & G-12K-105A & - & - & - \\
\hline & & G-12K-105B & - & - & - \\
\hline & & G-12K-107A & - & - & - \\
\hline & & G-12K-107B & - & - & - \\
\hline & & G-12K-109A & XRF & 483.5 & 7793.5 \\
\hline & & G-12K-109B & - & - & - \\
\hline & & G-12K-111A & - & - & - \\
\hline & & G-12K-112A & - & - & - \\
\hline & & G-12K-112B & - & - & - \\
\hline & & G-12K-113A & - & - & - \\
\hline & & G-12K-114A & - & - & - \\
\hline & & G-12K-114B & - & - & - \\
\hline & & G-12K-114C & - & - & - \\
\hline & & G-12K-115A & XRF & 494.5 & 8288.0 \\
\hline & & G-12K-117A & - & - & - \\
\hline & & G-12K-117B & - & - & - \\
\hline & & G-12K-127A & - & - & - \\
\hline & & G-12K-129A & - & - & - \\
\hline & & G-12K-138A & XRF, DCP, F & 472.5 & 8760.5 \\
\hline & $8 / 16 / 08$ & G-12K-139A & $\mathrm{XRF}$ & 112.5 & 8873.0 \\
\hline
\end{tabular}

- Empty data field 
The Catholic University of America Vitreous State Laboratory
ORP-56292 Rev. 0

Melt Rate Enhancement for High Aluminum HLW Glass Formulations

Final Report, VSL-08R1360-1, Rev. 0

Table 6.6. XRF Analyzed Composition for Glass Discharged During DM100 Melter Test (wt\%).

\begin{tabular}{|c|c|c|c|c|c|c|c|c|c|c|c|}
\hline Formulation & \multicolumn{11}{|c|}{ HLW-E-Al-27 } \\
\hline Al Sources & \multicolumn{11}{|c|}{ Aluminum Hydroxide } \\
\hline Temperature & \multirow{4}{*}{ Target } & \multicolumn{8}{|c|}{$1200{ }^{\circ} \mathrm{C}$} & \multicolumn{2}{|c|}{$1150^{\circ} \mathrm{C}$} \\
\hline Test & & \multicolumn{8}{|c|}{1} & \multicolumn{2}{|c|}{2} \\
\hline Glass (kg) & & 28.72 & 62.52 & 93.86 & 117.20 & 143.26 & 169.38 & 196.70 & 222.18 & 255.68 & 277.08 \\
\hline Constituent & & $\begin{array}{l}\text { BLX- } \\
\text { G-67A }\end{array}$ & $\begin{array}{l}\text { BLX- } \\
\text { G-71A }\end{array}$ & $\begin{array}{l}\text { BLX- } \\
\text { G-71C }\end{array}$ & \begin{tabular}{|c|} 
BLX- \\
G-76B
\end{tabular} & $\begin{array}{r}\text { BLX- } \\
\text { G-79A }\end{array}$ & $\begin{array}{l}\text { BLX- } \\
\text { G-82A }\end{array}$ & \begin{tabular}{|c} 
BLX- \\
G-84A
\end{tabular} & $\begin{array}{c}\text { BLX- } \\
\text { G-84C }\end{array}$ & $\begin{array}{r}\text { BLX- } \\
\text { G-91A }\end{array}$ & $\begin{array}{l}\text { BLX- } \\
\text { G-96A }\end{array}$ \\
\hline $\mathrm{Al}_{2} \mathrm{O}_{3}$ & 23.97 & 12.36 & 13.93 & 15.26 & 16.75 & 17.40 & 17.96 & 18.65 & 19.33 & 19.77 & 20.25 \\
\hline $\mathrm{B}_{2} \mathrm{O}_{3} *$ & 15.19 & 13.98 & 14.19 & 14.35 & 14.45 & 14.55 & 14.64 & 14.71 & 14.78 & 14.85 & 14.89 \\
\hline $\mathrm{BaO}$ & 0.05 & $<0.01$ & $<0.01$ & $<0.01$ & $<0.01$ & $<0.01$ & $<0.01$ & $<0.01$ & $<0.01$ & $<0.01$ & $<0.01$ \\
\hline $\mathrm{Bi}_{2} \mathrm{O}_{3}$ & 1.14 & 0.79 & 0.90 & 0.95 & 0.90 & 0.99 & 1.09 & 1.10 & 1.06 & 1.05 & 1.12 \\
\hline $\mathrm{CaO}$ & 6.08 & 2.67 & 3.35 & 3.74 & 3.89 & 4.34 & 4.69 & 4.86 & 4.98 & 5.05 & 5.25 \\
\hline $\mathrm{CdO}$ & 0.02 & 0.04 & 0.04 & 0.04 & 0.03 & 0.03 & 0.03 & 0.03 & 0.03 & 0.03 & 0.03 \\
\hline $\mathrm{Ce}_{2} \mathrm{O}_{3}$ & $\S$ & 0.04 & 0.04 & 0.03 & 0.02 & 0.02 & 0.01 & 0.02 & 0.02 & 0.02 & 0.02 \\
\hline $\mathrm{Cr}_{2} \mathrm{O}_{3}$ & 0.52 & 0.52 & 0.54 & 0.53 & 0.50 & 0.51 & 0.56 & 0.56 & 0.55 & 0.56 & 0.56 \\
\hline $\mathrm{F}$ & 0.67 & $0.22^{\#}$ & 0.26 & 0.29 & 0.32 & $0.35^{\#}$ & 0.36 & 0.36 & 0.37 & $0.38^{\#}$ & 0.39 \\
\hline $\mathrm{Fe}_{2} \mathrm{O}_{3}$ & 5.90 & 7.24 & 7.18 & 6.97 & 6.32 & 6.52 & 6.78 & 6.63 & 6.38 & 6.16 & 6.27 \\
\hline $\mathrm{K}_{2} \mathrm{O}$ & 0.14 & 0.29 & 0.28 & 0.27 & 0.24 & 0.24 & 0.24 & 0.24 & 0.23 & 0.21 & 0.21 \\
\hline $\mathrm{La}_{2} \mathrm{O}_{3}$ & $\S$ & 0.07 & $<0.01$ & $<0.01$ & 0.04 & 0.04 & 0.03 & 0.02 & 0.02 & $<0.01$ & $<0.01$ \\
\hline $\mathrm{Li}_{2} \mathrm{O}^{*}$ & 3.57 & 2.60 & 2.76 & 2.89 & 2.97 & 3.05 & 3.12 & 3.19 & 3.24 & 3.29 & 3.33 \\
\hline $\mathrm{MgO}$ & 0.12 & 0.35 & 0.30 & 0.31 & 0.31 & 0.29 & 0.26 & 0.30 & 0.30 & 0.27 & 0.26 \\
\hline $\mathrm{MnO}$ & 0.00 & 0.72 & 0.61 & 0.53 & 0.41 & 0.39 & 0.36 & 0.32 & 0.28 & 0.24 & 0.22 \\
\hline $\mathrm{Na}_{2} \mathrm{O}$ & 9.58 & 11.07 & 10.63 & 10.47 & 11.28 & 10.51 & 9.75 & 10.01 & 10.18 & 10.53 & 9.97 \\
\hline $\mathrm{Nd}_{2} \mathrm{O}_{3}$ & $\S$ & 0.06 & 0.05 & 0.04 & 0.03 & 0.03 & 0.03 & 0.02 & 0.02 & 0.02 & 0.02 \\
\hline $\mathrm{NiO}$ & 0.40 & 0.51 & 0.51 & 0.49 & 0.42 & 0.43 & 0.45 & 0.42 & 0.41 & 0.37 & 0.39 \\
\hline $\mathrm{P}_{2} \mathrm{O}_{5}$ & 1.05 & 0.74 & 0.81 & 0.85 & 0.91 & 0.93 & 0.99 & 1.00 & 1.05 & 1.04 & 1.06 \\
\hline $\mathrm{PbO}$ & 0.41 & 0.27 & 0.31 & 0.31 & 0.30 & 0.32 & 0.35 & 0.35 & 0.33 & 0.33 & 0.36 \\
\hline $\mathrm{SiO}_{2}$ & 30.50 & 36.56 & 35.40 & 34.79 & 34.50 & 33.95 & 33.45 & 33.00 & 32.97 & 32.71 & 32.54 \\
\hline $\mathrm{SO}_{3}$ & 0.20 & 0.12 & 0.12 & 0.13 & 0.12 & 0.13 & 0.12 & 0.12 & 0.11 & 0.11 & 0.13 \\
\hline $\mathrm{SrO}$ & $\S$ & 4.04 & 3.58 & 3.06 & 2.35 & 2.20 & 2.08 & 1.76 & 1.45 & 1.25 & 1.12 \\
\hline $\mathrm{TiO}_{2}$ & 0.01 & 0.05 & 0.03 & 0.03 & 0.04 & 0.04 & 0.04 & 0.04 & 0.04 & 0.04 & 0.04 \\
\hline $\mathrm{ZnO}$ & 0.08 & 0.60 & 0.52 & 0.46 & 0.36 & 0.34 & 0.34 & 0.30 & 0.27 & 0.23 & 0.22 \\
\hline $\mathrm{ZrO}_{2}$ & 0.39 & 4.09 & 3.67 & 3.20 & 2.51 & 2.40 & 2.28 & 1.98 & 1.65 & 1.47 & 1.37 \\
\hline Sum & 100.00 & 100.00 & 100.00 & 100.00 & 100.00 & 100.00 & 100.00 & 100.00 & 100.00 & 100.00 & 100.00 \\
\hline
\end{tabular}

$\S$ - Not a target constituent

* - for XRF-analyzed compositions, values for $\mathrm{B}_{2} \mathrm{O}_{3}$ and $\mathrm{Li}_{2} \mathrm{O}$ were calculated based on simple well-stirred tank model and target values.

\# - Fluorine was measured by XRF on polished samples, values for other samples calculated by interpolation 
ORP-56292 Rev. 0

The Catholic University of America

Table 6.6. XRF Analyzed Composition for Glass Discharged During DM100 Melter Test (wt\%) (continued).

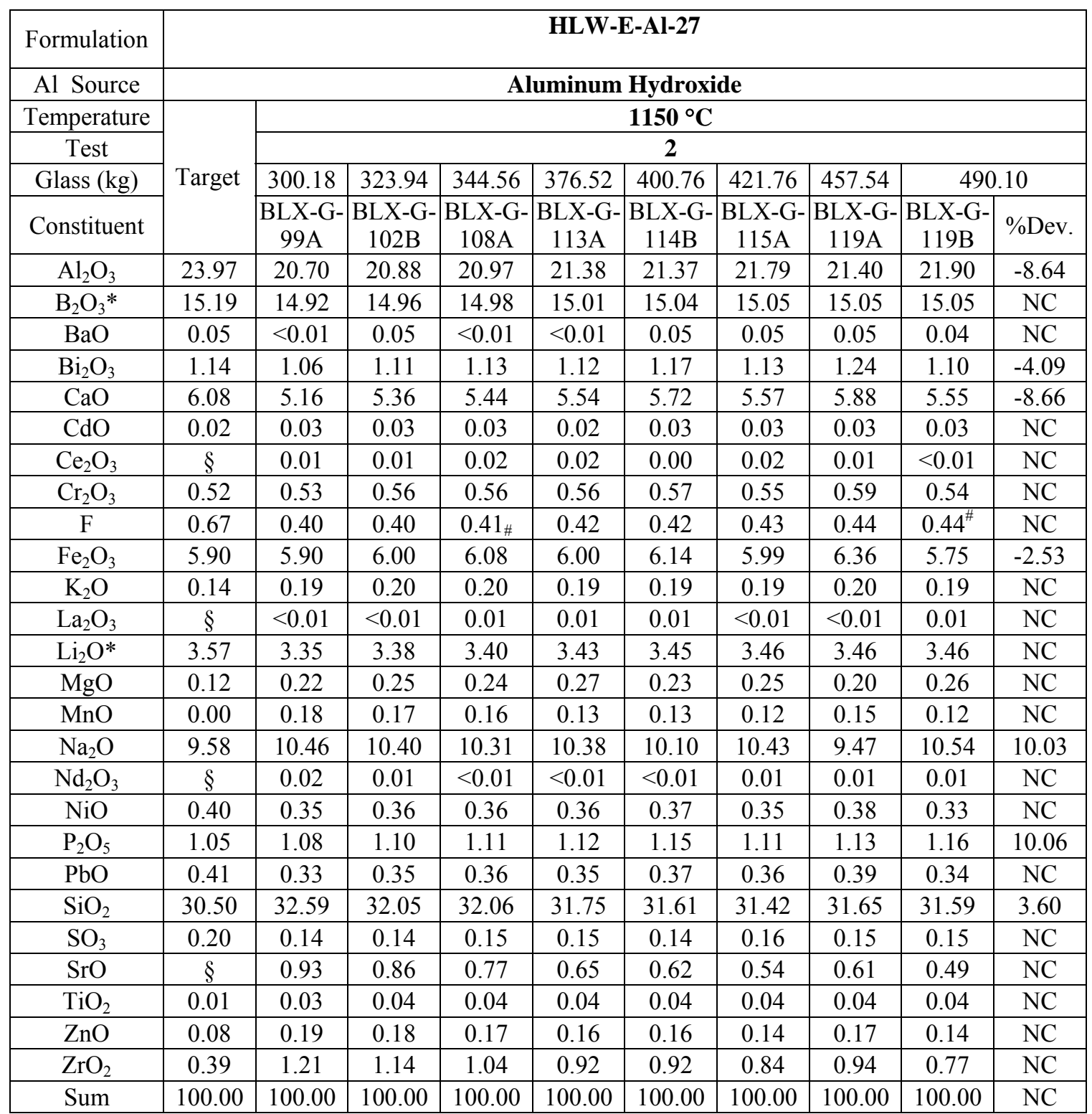

$\S$ - Not a target constituent

* - for XRF-analyzed compositions, values for $\mathrm{B}_{2} \mathrm{O}_{3}$ and $\mathrm{Li}_{2} \mathrm{O}$ were calculated based on simple well-stirred tank model and target values.

\# - Fluorine was measured by XRF on polished samples, values for other samples calculated by interpolation $\mathrm{NC}-$ Not calculated 
ORP-56292 Rev. 0

The Catholic University of America

Table 6.6. XRF Analyzed Composition for Glass Discharged During DM100BL Melter Test (wt \%) (continued).

\begin{tabular}{|c|c|c|c|c|c|c|c|c|c|c|}
\hline Formulation & \multicolumn{10}{|c|}{ HWI-Al-16 } \\
\hline Al Source & \multicolumn{10}{|c|}{ Aluminum Hydroxide } \\
\hline Temperature & \multirow{5}{*}{ Target } & \multicolumn{9}{|c|}{$1200{ }^{\circ} \mathrm{C}$} \\
\hline Test & & \multicolumn{9}{|c|}{3} \\
\hline Glass (kg) & & 510.26 & 534.52 & 559.24 & 588.14 & 613.16 & 636.14 & 659.64 & 683.14 & 715.02 \\
\hline & & BLX-G & BLX-G & BLX-G- & BLX-G- & BLX-G & BLY-G & BLY-G- & BLY-G- & BLY-G \\
\hline Constituent & & $144 \mathrm{~A}$ & $145 \mathrm{~A}$ & $147 \mathrm{~A}$ & 151B & $153 \mathrm{~A}$ & $8 \mathrm{~A}$ & $10 \mathrm{~A}$ & $10 \mathrm{C}$ & $14 \mathrm{~B}$ \\
\hline $\mathrm{Al}_{2} \mathrm{O}_{3}$ & 23.25 & 21.54 & 21.85 & 21.79 & 22.00 & 21.89 & 21.81 & 21.87 & 22.03 & 22.12 \\
\hline $\mathrm{B}_{2} \mathrm{O}_{3} *$ & 17.73 & 15.34 & 15.64 & 15.91 & 16.18 & 16.38 & 16.54 & 16.69 & 16.82 & 16.97 \\
\hline $\mathrm{BaO}$ & 0.05 & 0.04 & 0.04 & 0.05 & 0.05 & 0.06 & 0.05 & 0.05 & 0.04 & 0.06 \\
\hline $\mathrm{Bi}_{2} \mathrm{O}_{3}$ & 1.11 & 1.22 & 1.17 & 1.14 & 1.13 & 1.18 & 1.22 & 1.16 & 1.15 & 1.13 \\
\hline $\mathrm{CaO}$ & 5.89 & 5.97 & 5.85 & 5.72 & 5.74 & 5.84 & 5.98 & 5.91 & 5.82 & 5.77 \\
\hline $\mathrm{CdO}$ & 0.02 & 0.03 & 0.03 & 0.03 & 0.03 & 0.03 & 0.03 & 0.03 & 0.02 & 0.03 \\
\hline $\mathrm{Ce}_{2} \mathrm{O}_{3}$ & $\S$ & $<0.01$ & $<0.01$ & 0.01 & 0.01 & $<0.01$ & 0.01 & 0.01 & 0.01 & $<0.01$ \\
\hline $\mathrm{Cr}_{2} \mathrm{O}_{3}$ & 0.51 & 0.46 & 0.46 & 0.46 & 0.46 & 0.48 & 0.50 & 0.52 & 0.51 & 0.50 \\
\hline $\mathrm{F}$ & 0.65 & $0.36^{\#}$ & 0.37 & 0.38 & 0.39 & $0.40^{\#}$ & 0.39 & 0.38 & 0.37 & $0.36^{\#}$ \\
\hline $\mathrm{Fe}_{2} \mathrm{O}_{3}$ & 5.72 & 6.15 & 5.93 & 5.80 & 5.76 & 5.83 & 6.09 & 5.99 & 5.89 & 5.75 \\
\hline $\mathrm{K}_{2} \mathrm{O}$ & 0.14 & 0.21 & 0.18 & 0.17 & 0.18 & 0.17 & 0.18 & 0.18 & 0.17 & 0.16 \\
\hline $\mathrm{La}_{2} \mathrm{O}_{3}$ & $\S$ & $<0.01$ & 0.02 & $<0.01$ & $<0.01$ & $<0.01$ & $<0.01$ & $<0.01$ & $<0.01$ & 0.01 \\
\hline $\mathrm{Li}_{2} \mathrm{O}^{*}$ & 3.46 & 3.46 & 3.46 & 3.46 & 3.46 & 3.46 & 3.46 & 3.46 & 3.46 & 3.46 \\
\hline $\mathrm{MgO}$ & 0.11 & 0.30 & 0.32 & 0.29 & 0.34 & 0.29 & 0.27 & 0.32 & 0.30 & 0.30 \\
\hline $\mathrm{MnO}$ & $\S$ & 0.20 & 0.18 & 0.15 & 0.14 & 0.13 & 0.12 & 0.11 & 0.10 & 0.09 \\
\hline $\mathrm{Na}_{2} \mathrm{O}$ & 9.29 & 9.60 & 9.71 & 10.17 & 9.76 & 9.57 & 9.53 & 9.67 & 9.45 & 9.48 \\
\hline $\mathrm{Nd}_{2} \mathrm{O}_{3}$ & $\S$ & 0.01 & 0.01 & 0.01 & $<0.01$ & $<0.01$ & 0.01 & 0.01 & $<0.01$ & $<0.01$ \\
\hline $\mathrm{NiO}$ & 0.39 & 0.31 & 0.32 & 0.32 & 0.29 & 0.31 & 0.34 & 0.35 & 0.34 & 0.32 \\
\hline $\mathrm{P}_{2} \mathrm{O}_{5}$ & 1.02 & 1.11 & 1.12 & 1.12 & 1.15 & 1.11 & 1.11 & 1.13 & 1.12 & 1.16 \\
\hline $\mathrm{PbO}$ & 0.40 & 0.40 & 0.37 & 0.37 & 0.36 & 0.38 & 0.39 & 0.37 & 0.36 & 0.36 \\
\hline $\mathrm{SiO}_{2}$ & 29.58 & 31.60 & 31.45 & 31.28 & 31.31 & 31.20 & 30.75 & 30.71 & 30.94 & 30.97 \\
\hline $\mathrm{SO}_{3}$ & 0.19 & 0.13 & 0.12 & 0.11 & 0.12 & 0.12 & 0.11 & 0.10 & 0.10 & 0.11 \\
\hline $\mathrm{SrO}$ & $\S$ & 0.47 & 0.39 & 0.32 & 0.28 & 0.27 & 0.24 & 0.19 & 0.18 & 0.15 \\
\hline $\mathrm{TiO}_{2}$ & 0.01 & 0.05 & 0.05 & 0.04 & 0.04 & 0.04 & 0.04 & 0.04 & 0.05 & 0.04 \\
\hline $\mathrm{ZnO}$ & 0.08 & 0.18 & 0.16 & 0.14 & 0.13 & 0.13 & 0.13 & 0.13 & 0.12 & 0.10 \\
\hline $\mathrm{ZrO}_{2}$ & 0.38 & 0.86 & 0.80 & 0.75 & 0.69 & 0.72 & 0.71 & 0.63 & 0.62 & 0.59 \\
\hline Sum & 100.00 & 100.00 & 100.00 & 100.00 & 100.00 & 100.00 & 100.00 & 100.00 & 100.00 & 100.00 \\
\hline
\end{tabular}

$\S$ - Not a target constituent

* - for XRF-analyzed compositions, values for $\mathrm{B}_{2} \mathrm{O}_{3}$ and $\mathrm{Li}_{2} \mathrm{O}$ were calculated based on simple well-stirred tank model and target values.

\# - Fluorine was measured by XRF on polished samples, values for other samples calculated by interpolation 
The Catholic University of America Vitreous State Laboratory
ORP-56292 Rev. 0

Melt Rate Enhancement for High Aluminum HLW Glass Formulations

Final Report, VSL-08R1360-1, Rev. 0

Table 6.6. XRF Analyzed Composition for Glass Discharged During DM100 Melter Test (wt\%) (continued).

\begin{tabular}{|c|c|c|c|c|c|c|c|c|c|c|c|}
\hline Formulation & \multicolumn{11}{|c|}{ HWI-Al-16 } \\
\hline Al Source & \multicolumn{11}{|c|}{ Aluminum Hydroxide } \\
\hline Temperature & \multirow{5}{*}{ Target } & \multicolumn{10}{|c|}{$1150{ }^{\circ} \mathrm{C}$} \\
\hline Test & & \multicolumn{10}{|c|}{4} \\
\hline Glass (kg) & & 736.80 & 756.48 & 777.68 & 796.34 & 819.48 & 838.32 & 856.96 & 875.60 & 896.38 & 920.66 \\
\hline \multirow{2}{*}{ Constituent } & & BLY-G- & BLY-G & BLY-G- & BLY-G & BLY-G & BLY-G & BLY-G & $-B L Y-G-$ & BLY-G & BLY-G \\
\hline & & $16 \mathrm{~A}$ & $17 \mathrm{~A}$ & $22 \mathrm{~A}$ & $25 \mathrm{~A}$ & $26 \mathrm{~A}$ & $26 \mathrm{C}$ & $28 \mathrm{~B}$ & $34 \mathrm{~A}$ & $35 \mathrm{~A}$ & $36 \mathrm{~B}$ \\
\hline $\mathrm{Al}_{2} \mathrm{O}_{3}$ & 23.25 & 22.23 & 22.03 & 21.96 & 21.91 & 22.26 & 22.01 & 22.28 & 21.99 & 22.04 & 22.09 \\
\hline $\mathrm{B}_{2} \mathrm{O}_{3} *$ & 17.73 & 17.05 & 17.12 & 17.19 & 17.25 & 17.30 & 17.35 & 17.39 & 17.42 & 17.45 & 17.49 \\
\hline $\mathrm{BaO}$ & 0.05 & 0.06 & 0.05 & 0.07 & 0.06 & 0.06 & 0.06 & 0.06 & 0.06 & 0.06 & 0.06 \\
\hline $\mathrm{Bi}_{2} \mathrm{O}_{3}$ & 1.11 & 1.08 & 1.17 & 1.15 & 1.21 & 1.15 & 1.16 & 1.12 & 1.19 & 1.19 & 1.22 \\
\hline $\mathrm{CaO}$ & 5.89 & 5.64 & 5.90 & 5.90 & 6.07 & 5.85 & 5.86 & 5.76 & 6.00 & 5.98 & 6.14 \\
\hline $\mathrm{CdO}$ & 0.02 & 0.03 & 0.03 & 0.03 & 0.03 & 0.03 & 0.03 & 0.03 & 0.03 & 0.03 & 0.03 \\
\hline $\mathrm{Ce}_{2} \mathrm{O}_{3}$ & $\S$ & 0.01 & 0.01 & $<0.01$ & $<0.01$ & 0.01 & 0.01 & 0.01 & 0.01 & 0.01 & 0.01 \\
\hline $\mathrm{Cr}_{2} \mathrm{O}_{3}$ & 0.51 & 0.47 & 0.50 & 0.52 & 0.53 & 0.52 & 0.53 & 0.52 & 0.55 & 0.55 & 0.56 \\
\hline $\mathrm{F}$ & 0.65 & 0.37 & 0.38 & 0.39 & $0.40^{\#}$ & 0.40 & 0.41 & 0.41 & $0.41^{\#}$ & 0.42 & 0.44 \\
\hline $\mathrm{Fe}_{2} \mathrm{O}_{3}$ & 5.72 & 5.55 & 5.84 & 5.88 & 6.06 & 5.83 & 5.88 & 5.71 & 6.04 & 6.03 & 6.10 \\
\hline $\mathrm{K}_{2} \mathrm{O}$ & 0.14 & 0.16 & 0.17 & 0.17 & 0.17 & 0.16 & 0.16 & 0.16 & 0.16 & 0.17 & 0.17 \\
\hline $\mathrm{La}_{2} \mathrm{O}_{3}$ & $\S$ & 0.02 & $<0.01$ & $<0.01$ & $<0.01$ & $<0.01$ & 0.01 & $<0.01$ & $<0.01$ & 0.01 & $<0.01$ \\
\hline $\mathrm{Li}_{2} \mathrm{O}^{*}$ & 3.46 & 3.46 & 3.46 & 3.46 & 3.46 & 3.46 & 3.46 & 3.46 & 3.46 & 3.46 & 3.46 \\
\hline $\mathrm{MgO}$ & 0.11 & 0.33 & 0.26 & 0.32 & 0.32 & 0.30 & 0.32 & 0.30 & 0.31 & 0.33 & 0.28 \\
\hline $\mathrm{MnO}$ & $\S$ & 0.08 & 0.08 & 0.08 & 0.08 & 0.07 & 0.07 & 0.06 & 0.06 & 0.07 & 0.06 \\
\hline $\mathrm{Na}_{2} \mathrm{O}$ & 9.29 & 9.88 & 9.69 & 9.59 & 9.07 & 9.23 & 9.61 & 9.77 & 9.33 & 9.18 & 8.71 \\
\hline $\mathrm{Nd}_{2} \mathrm{O}_{3}$ & $\S$ & $<0.01$ & $<0.01$ & 0.01 & $<0.01$ & $<0.01$ & $<0.01$ & $<0.01$ & $<0.01$ & 0.01 & $<0.01$ \\
\hline $\mathrm{NiO}$ & 0.39 & 0.30 & 0.32 & 0.33 & 0.34 & 0.33 & 0.32 & 0.33 & 0.35 & 0.34 & 0.33 \\
\hline $\mathrm{P}_{2} \mathrm{O}_{5}$ & 1.02 & 1.13 & 1.15 & 1.12 & 1.16 & 1.15 & 1.13 & 1.14 & 1.12 & 1.13 & 1.16 \\
\hline $\mathrm{PbO}$ & 0.40 & 0.35 & 0.37 & 0.38 & 0.40 & 0.37 & 0.37 & 0.35 & 0.39 & 0.39 & 0.39 \\
\hline $\mathrm{SiO}_{2}$ & 29.58 & 30.85 & 30.52 & 30.50 & 30.54 & 30.60 & 30.30 & 30.27 & 30.19 & 30.24 & 30.39 \\
\hline $\mathrm{SO}_{3}$ & 0.19 & 0.10 & 0.11 & 0.11 & 0.11 & 0.12 & 0.12 & 0.13 & 0.14 & 0.13 & 0.13 \\
\hline $\mathrm{SrO}$ & $\S$ & 0.13 & 0.12 & 0.11 & 0.11 & 0.09 & 0.10 & 0.08 & 0.08 & 0.07 & 0.07 \\
\hline $\mathrm{TiO}_{2}$ & 0.01 & 0.05 & 0.04 & 0.05 & 0.04 & 0.04 & 0.04 & 0.04 & 0.04 & 0.05 & 0.04 \\
\hline $\mathrm{ZnO}$ & 0.08 & 0.11 & 0.10 & 0.11 & 0.10 & 0.10 & 0.10 & 0.09 & 0.10 & 0.10 & 0.10 \\
\hline $\mathrm{ZrO}_{2}$ & 0.38 & 0.55 & 0.58 & 0.58 & 0.60 & 0.55 & 0.58 & 0.53 & 0.56 & 0.56 & 0.56 \\
\hline Sum & 100.00 & 100.00 & 100.00 & 100.00 & 100.00 & 100.00 & 100.00 & 100.00 & 100.00 & 100.00 & 100.00 \\
\hline
\end{tabular}

$\S$ - Not a target constituent

* - for XRF-analyzed compositions, values for $\mathrm{B}_{2} \mathrm{O}_{3}$ and $\mathrm{Li}_{2} \mathrm{O}$ were calculated based on simple well-stirred tank model and target values.

\# - Fluorine was measured by XRF on polished samples, values for other samples calculated by interpolation 
ORP-56292 Rev. 0

The Catholic University of America

Table 6.6. XRF Analyzed Composition for Glass Discharged During DM100 Melter Test (wt\%) (continued).

\begin{tabular}{|c|c|c|c|c|c|c|c|c|c|c|c|}
\hline Formulation & \multicolumn{11}{|c|}{ HWI-Al-16 } \\
\hline \multirow{4}{*}{$\begin{array}{c}\text { Al Source } \\
\text { Temperature } \\
\text { Test } \\
\text { Glass }(\mathrm{kg})\end{array}$} & \multirow{5}{*}{ Target } & \multirow{2}{*}{\multicolumn{4}{|c|}{$\frac{\text { Aluminum Hydroxide }}{1150^{\circ} \mathrm{C}}$}} & \multicolumn{6}{|c|}{ Aluminum Oxide } \\
\hline & & & & & & & & 120 & $0^{\circ} \mathrm{C}$ & & \\
\hline & & & 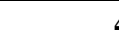 & 4 & & & & & 5 & & \\
\hline & & 949.08 & 978.22 & 99 & 5.94 & 1024.64 & 1057.50 & 1084.16 & 1110.42 & 1139.06 & 1166.20 \\
\hline Constituent & & $\begin{array}{l}\text { BLY- } \\
\text { G-40A }\end{array}$ & $\begin{array}{l}\text { BLY- } \\
\text { G-40B }\end{array}$ & $\begin{array}{l}\text { BLY- } \\
\text { G-40C }\end{array}$ & $\%$ Dev. & $\begin{array}{l}\text { BLY- } \\
\text { G-63A }\end{array}$ & $\begin{array}{l}\text { BLY- } \\
\text { G-66B }\end{array}$ & $\begin{array}{l}\text { BLY- } \\
\text { G-69A }\end{array}$ & $\begin{array}{l}\text { BLY- } \\
\text { G-73A }\end{array}$ & $\begin{array}{l}\text { BLY- } \\
\text { G-75A }\end{array}$ & $\begin{array}{l}\text { BLY- } \\
\text { G-80A }\end{array}$ \\
\hline $\mathrm{Al}_{2} \mathrm{O}_{3}$ & 23.25 & 22.07 & 21.96 & 21.78 & -6.33 & 22.18 & 22.18 & 22.18 & 22.13 & 22.13 & 22.58 \\
\hline $\mathrm{B}_{2} \mathrm{O}_{3} *$ & 17.73 & 17.52 & 17.52 & 17.52 & $\mathrm{NC}$ & 17.56 & 17.59 & 17.61 & 17.62 & 17.64 & 17.65 \\
\hline $\mathrm{BaO}$ & 0.05 & 0.06 & 0.05 & 0.06 & $\mathrm{NC}$ & 0.05 & 0.05 & 0.05 & 0.05 & 0.06 & 0.06 \\
\hline $\mathrm{Bi}_{2} \mathrm{O}_{3}$ & 1.11 & 1.14 & 1.17 & 1.22 & 9.70 & 1.11 & 1.16 & 1.16 & 1.19 & 1.19 & 1.07 \\
\hline $\mathrm{CaO}$ & 5.89 & 5.93 & 5.98 & 6.19 & 4.97 & 5.74 & 5.88 & 5.90 & 5.90 & 5.99 & 5.56 \\
\hline $\mathrm{CdO}$ & 0.02 & 0.03 & 0.03 & 0.03 & $\mathrm{NC}$ & 0.02 & 0.02 & 0.02 & 0.03 & 0.03 & 0.02 \\
\hline $\mathrm{Ce}_{2} \mathrm{O}_{3}$ & $\S$ & $<0.01$ & $<0.01$ & 0.01 & $\mathrm{NC}$ & $<0.01$ & 0.01 & 0.01 & 0.01 & $<0.01$ & $<0.01$ \\
\hline $\mathrm{Cr}_{2} \mathrm{O}_{3}$ & 0.51 & 0.53 & 0.53 & 0.54 & $\mathrm{NC}$ & 0.44 & 0.46 & 0.49 & 0.50 & 0.50 & 0.46 \\
\hline $\mathrm{F}$ & 0.65 & 0.46 & $0.48^{\#}$ & 0.48 & $\mathrm{NC}$ & $0.39^{\#}$ & 0.39 & 0.39 & 0.39 & $0.39^{\#}$ & 0.40 \\
\hline $\mathrm{Fe}_{2} \mathrm{O}_{3}$ & 5.72 & 5.84 & 5.94 & 6.16 & 7.62 & 6.00 & 6.25 & 6.29 & 6.41 & 6.54 & 5.99 \\
\hline $\mathrm{K}_{2} \mathrm{O}$ & 0.14 & 0.17 & 0.17 & 0.18 & $\mathrm{NC}$ & 0.17 & 0.17 & 0.17 & 0.17 & 0.17 & 0.16 \\
\hline $\mathrm{La}_{2} \mathrm{O}_{3}$ & $\S$ & $<0.01$ & $<0.01$ & $<0.01$ & $\mathrm{NC}$ & $<0.01$ & $<0.01$ & $<0.01$ & $<0.01$ & 0.01 & 0.01 \\
\hline $\mathrm{Li}_{2} \mathrm{O}^{*}$ & 3.46 & 3.46 & 3.46 & 3.46 & $\mathrm{NC}$ & 3.46 & 3.46 & 3.46 & 3.46 & 3.46 & 3.46 \\
\hline $\mathrm{MgO}$ & 0.11 & 0.38 & 0.35 & 0.30 & $\mathrm{NC}$ & 0.29 & 0.28 & 0.26 & 0.25 & 0.21 & 0.26 \\
\hline $\mathrm{MnO}$ & $\S$ & 0.06 & 0.07 & 0.08 & $\mathrm{NC}$ & 0.09 & 0.08 & 0.07 & 0.07 & 0.07 & 0.06 \\
\hline $\mathrm{Na}_{2} \mathrm{O}$ & 9.29 & 9.56 & 9.37 & 8.66 & -6.79 & 9.89 & 9.12 & 9.32 & 9.40 & 9.03 & 9.56 \\
\hline $\mathrm{Nd}_{2} \mathrm{O}_{3}$ & $\S$ & 0.01 & $<0.01$ & $<0.01$ & $\mathrm{NC}$ & $<0.01$ & $<0.01$ & $<0.01$ & $<0.01$ & $<0.01$ & $<0.01$ \\
\hline $\mathrm{NiO}$ & 0.39 & 0.33 & 0.34 & 0.34 & $\mathrm{NC}$ & 0.30 & 0.30 & 0.32 & 0.32 & 0.32 & 0.29 \\
\hline $\mathrm{P}_{2} \mathrm{O}_{5}$ & 1.02 & 1.13 & 1.12 & 1.15 & 12.72 & 1.10 & 1.13 & 1.11 & 1.10 & 1.13 & 1.14 \\
\hline $\mathrm{PbO}$ & 0.40 & 0.38 & 0.38 & 0.41 & $\mathrm{NC}$ & 0.35 & 0.35 & 0.35 & 0.36 & 0.35 & 0.32 \\
\hline $\mathrm{SiO}_{2}$ & 29.58 & 30.09 & 30.19 & 30.44 & 2.92 & 29.89 & 30.11 & 29.82 & 29.58 & 29.72 & 29.96 \\
\hline $\mathrm{SO}_{3}$ & 0.19 & 0.13 & 0.13 & 0.13 & $\mathrm{NC}$ & 0.11 & 0.11 & 0.11 & 0.10 & 0.11 & 0.11 \\
\hline $\mathrm{SrO}$ & $\S$ & 0.06 & 0.07 & 0.09 & $\mathrm{NC}$ & 0.07 & 0.06 & 0.05 & 0.05 & 0.04 & 0.03 \\
\hline $\mathrm{TiO}_{2}$ & 0.01 & 0.04 & 0.05 & 0.05 & $\mathrm{NC}$ & 0.04 & 0.04 & 0.05 & 0.04 & 0.05 & 0.04 \\
\hline $\mathrm{ZnO}$ & 0.08 & 0.09 & 0.10 & 0.11 & $\mathrm{NC}$ & 0.10 & 0.10 & 0.10 & 0.10 & 0.10 & 0.08 \\
\hline $\mathrm{ZrO}_{2}$ & 0.38 & 0.53 & 0.55 & 0.61 & $\mathrm{NC}$ & 0.65 & 0.69 & 0.71 & 0.76 & 0.75 & 0.70 \\
\hline Sum & 100.00 & 100.00 & 100.00 & 100.00 & $\mathrm{NC}$ & 100.00 & 100.00 & 100.00 & 100.00 & 100.00 & 100.00 \\
\hline
\end{tabular}

$\S$ - Not a target constituent

* - for XRF-analyzed compositions, values for $\mathrm{B}_{2} \mathrm{O}_{3}$ and $\mathrm{Li}_{2} \mathrm{O}$ were calculated based on simple well-stirred tank model and target values.

\# - Fluorine was measured by XRF on polished samples, values for other samples calculated by interpolation $\mathrm{NC}-$ Not calculated 
Table 6.6. XRF Analyzed Composition for Glass Discharged During DM100 Melter Test (wt\%) (continued).

\begin{tabular}{|c|c|c|c|c|c|c|c|c|c|c|}
\hline Formulation & \multicolumn{10}{|c|}{ HWI-Al-16 } \\
\hline Al Source & \multicolumn{10}{|c|}{ Aluminum Oxide } \\
\hline Temperature & \multirow{5}{*}{ Target } & $1200{ }^{\circ} \mathrm{C}$ & \multicolumn{8}{|c|}{$1150{ }^{\circ} \mathrm{C}$} \\
\hline Test & & 5 & \multicolumn{8}{|c|}{$\begin{array}{c} \\
\end{array}$} \\
\hline Glass (kg) & & 1193.60 & 1227.24 & 1249.92 & 1270.34 & 1286.12 & 1306.46 & 1322.02 & 1350.64 & 1374.18 \\
\hline & & BLY-G- & BLY-G- & BLY-G- & BLY-G- & BLY-G- & BLY-G- & BLY-G- & BLY-G- & BLY-G- \\
\hline Constituent & & $80 \mathrm{C}$ & $85 \mathrm{~A}$ & $91 \mathrm{~A}$ & $93 \mathrm{~A}$ & $93 \mathrm{C}$ & $98 \mathrm{~B}$ & $101 \mathrm{~A}$ & $107 \mathrm{~A}$ & $111 \mathrm{~B}$ \\
\hline $\mathrm{Al}_{2} \mathrm{O}_{3}$ & 23.25 & 22.38 & 22.25 & 22.37 & 22.36 & 22.53 & 22.43 & 22.49 & 22.67 & 22.23 \\
\hline $\mathrm{B}_{2} \mathrm{O}_{3} *$ & 17.73 & 17.66 & 17.68 & 17.68 & 17.69 & 17.69 & 17.70 & 17.70 & 17.71 & 17.71 \\
\hline $\mathrm{BaO}$ & 0.05 & 0.05 & 0.05 & 0.07 & 0.06 & 0.06 & 0.05 & 0.05 & 0.05 & 0.05 \\
\hline $\mathrm{Bi}_{2} \mathrm{O}_{3}$ & 1.11 & 1.16 & 1.18 & 1.16 & 1.13 & 1.10 & 1.12 & 1.11 & 1.08 & 1.22 \\
\hline $\mathrm{CaO}$ & 5.89 & 5.91 & 5.83 & 5.79 & 5.70 & 5.69 & 5.76 & 5.73 & 5.63 & 5.98 \\
\hline $\mathrm{CdO}$ & 0.02 & 0.03 & 0.03 & 0.03 & 0.03 & 0.03 & 0.02 & 0.03 & 0.02 & 0.02 \\
\hline $\mathrm{Ce}_{2} \mathrm{O}_{3}$ & $\S$ & $<0.01$ & 0.01 & 0.01 & $<0.01$ & 0.01 & $<0.01$ & 0.01 & $<0.01$ & 0.01 \\
\hline $\mathrm{Cr}_{2} \mathrm{O}_{3}$ & 0.51 & 0.50 & 0.50 & 0.49 & 0.50 & 0.50 & 0.50 & 0.48 & 0.49 & 0.54 \\
\hline $\mathrm{F}$ & 0.65 & 0.41 & 0.43 & $0.44^{\#}$ & 0.45 & 0.45 & 0.46 & 0.46 & $0.47^{\#}$ & 0.47 \\
\hline $\mathrm{Fe}_{2} \mathrm{O}_{3}$ & 5.72 & 6.44 & 6.47 & 6.37 & 6.30 & 6.22 & 6.31 & 6.24 & 6.12 & 6.82 \\
\hline $\mathrm{K}_{2} \mathrm{O}$ & 0.14 & 0.17 & 0.17 & 0.17 & 0.16 & 0.17 & 0.17 & 0.16 & 0.17 & 0.17 \\
\hline $\mathrm{La}_{2} \mathrm{O}_{3}$ & $\S$ & $<0.01$ & $<0.01$ & $<0.01$ & $<0.01$ & $<0.01$ & $<0.01$ & $<0.01$ & $<0.01$ & $<0.01$ \\
\hline $\mathrm{Li}_{2} \mathrm{O}^{*}$ & 3.46 & 3.46 & 3.46 & 3.46 & 3.46 & 3.46 & 3.46 & 3.46 & 3.46 & 3.46 \\
\hline $\mathrm{MgO}$ & 0.11 & 0.23 & 0.23 & 0.22 & 0.26 & 0.21 & 0.27 & 0.20 & 0.23 & 0.22 \\
\hline $\mathrm{MnO}$ & $\S$ & 0.06 & 0.05 & 0.05 & 0.05 & 0.05 & 0.05 & 0.04 & 0.04 & 0.04 \\
\hline $\mathrm{Na}_{2} \mathrm{O}$ & 9.29 & 8.93 & 9.30 & 9.28 & 9.58 & 9.33 & 9.20 & 9.26 & 9.34 & 9.13 \\
\hline $\mathrm{Nd}_{2} \mathrm{O}_{3}$ & $\S$ & $<0.01$ & $<0.01$ & $<0.01$ & $<0.01$ & $<0.01$ & $<0.01$ & $<0.01$ & $<0.01$ & $<0.01$ \\
\hline $\mathrm{NiO}$ & 0.39 & 0.33 & & 0.30 & 0.29 & 0.30 & 0.30 & 0.30 & 0.28 & 0.34 \\
\hline $\mathrm{P}_{2} \mathrm{O}_{5}$ & 1.02 & 1.15 & 1.20 & 1.17 & 1.16 & 1.18 & 1.17 & 1.18 & 1.18 & 1.12 \\
\hline $\mathrm{PbO}$ & 0.40 & 0.34 & 0.34 & 0.35 & 0.34 & 0.32 & 0.32 & 0.33 & 0.31 & 0.36 \\
\hline $\mathrm{SiO}_{2}$ & 29.58 & 29.75 & 29.47 & 29.55 & 29.48 & 29.69 & 29.71 & 29.73 & 29.78 & 29.00 \\
\hline $\mathrm{SO}_{3}$ & 0.19 & 0.11 & 0.10 & 0.11 & 0.10 & 0.11 & 0.12 & 0.12 & 0.13 & 0.12 \\
\hline $\mathrm{SrO}$ & $\S$ & 0.03 & 0.03 & 0.03 & 0.02 & 0.02 & 0.02 & 0.02 & 0.02 & 0.02 \\
\hline $\mathrm{TiO}_{2}$ & 0.01 & 0.05 & 0.05 & 0.04 & 0.04 & 0.04 & 0.04 & 0.04 & 0.05 & 0.05 \\
\hline $\mathrm{ZnO}$ & 0.08 & 0.09 & 0.09 & 0.08 & 0.08 & 0.08 & 0.08 & 0.08 & 0.08 & 0.08 \\
\hline $\mathrm{ZrO}_{2}$ & 0.38 & 0.75 & 0.76 & 0.77 & 0.76 & 0.75 & 0.75 & 0.76 & 0.71 & 0.83 \\
\hline Sum & 100.00 & 100.00 & 100.00 & 100.00 & \begin{tabular}{l|l}
100.00 \\
\end{tabular} & 100.00 & 100.00 & 100.00 & 100.00 & 100.00 \\
\hline
\end{tabular}

$\S$ - Not a target constituent

* - for XRF-analyzed compositions, values for $\mathrm{B}_{2} \mathrm{O}_{3}$ and $\mathrm{Li}_{2} \mathrm{O}$ were calculated based on simple well-stirred tank model and target values.

\# - Fluorine was measured by XRF on polished samples, values for other samples calculated by interpolation 
The Catholic University of America Vitreous State Laboratory
Melt Rate Enhancement for High Aluminum HLW Glass Formulations

Final Report, VSL-08R1360-1, Rev. 0

Table 6.6. XRF Analyzed Composition for Glass Discharged During DM100 Melter Test (wt \%) (continued)

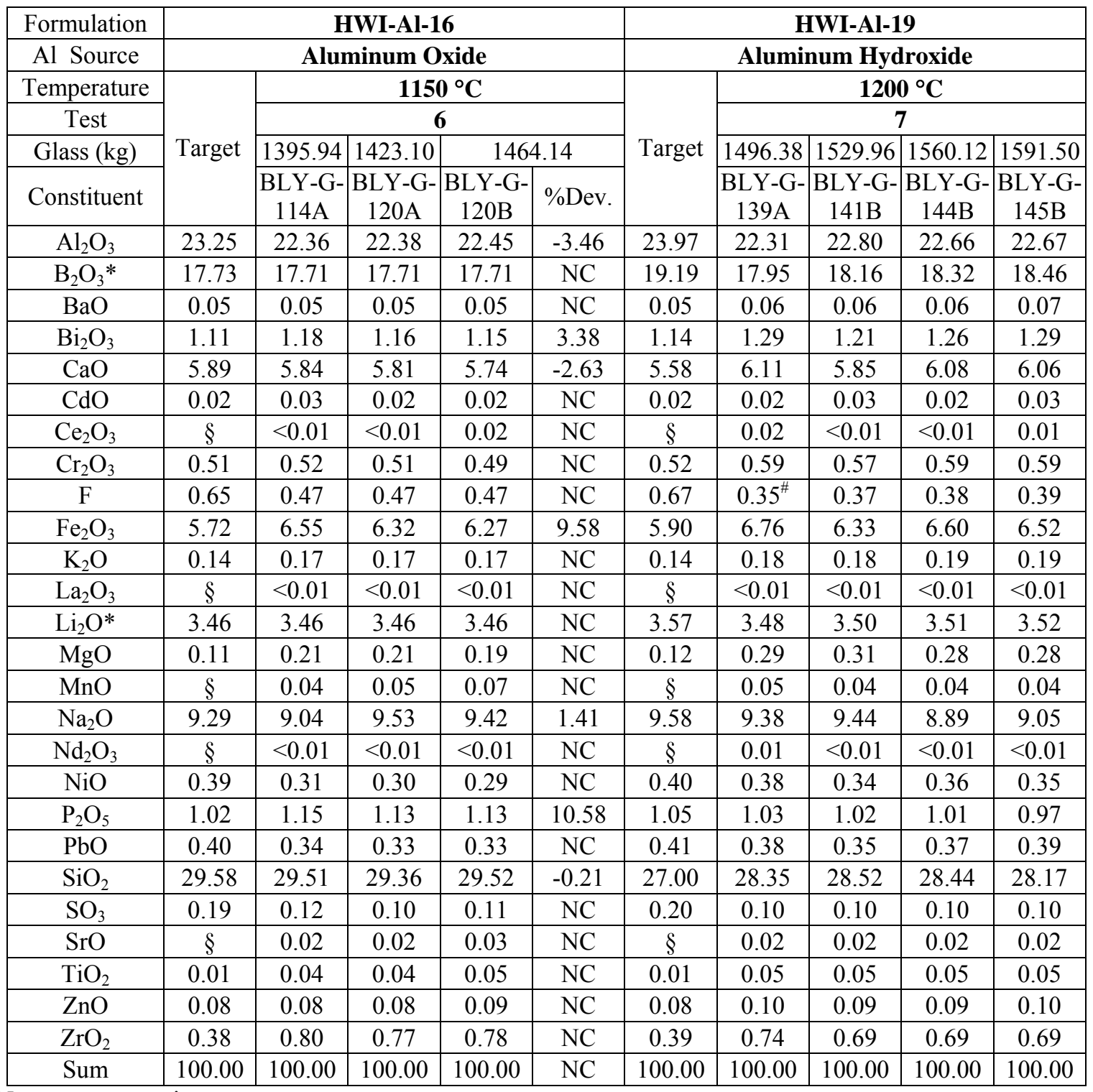

$\S$ - Not a target constituent

* - for XRF-analyzed compositions, values for $\mathrm{B}_{2} \mathrm{O}_{3}$ and $\mathrm{Li}_{2} \mathrm{O}$ were calculated based on simple well-stirred tank model and target values.

\# - Fluorine was measured by XRF on polished samples, values for other samples calculated by interpolation $\mathrm{NC}-$ Not calculated 
The Catholic University of America Vitreous State Laboratory
ORP-56292 Rev. 0

Melt Rate Enhancement for High Aluminum HLW Glass Formulations

Final Report, VSL-08R1360-1, Rev. 0

Table 6.6. XRF Analyzed Composition for Glass Discharged During DM100 Melter Test (wt\%) (continued).

\begin{tabular}{|c|c|c|c|c|c|c|c|c|c|c|}
\hline Formulation & \multicolumn{10}{|c|}{ HWI-Al-19 } \\
\hline Al Source & \multicolumn{10}{|c|}{ Aluminum Hydroxide } \\
\hline Temperature & \multirow{5}{*}{ Target } & \multicolumn{4}{|c|}{$1200^{\circ} \mathrm{C}$} & \multicolumn{5}{|c|}{$1150{ }^{\circ} \mathrm{C}$} \\
\hline Test & & \multicolumn{4}{|c|}{7} & \multicolumn{5}{|c|}{8} \\
\hline Glass $(\mathrm{kg})$ & & 1625.48 & 1655.82 & 1681.98 & 1709.34 & 1741.30 & 1767.04 & 1791.66 & 1815.98 & 1841.26 \\
\hline & & BLY-G- & BLY-G- & BLY-G & BLZ-G- & BLZ-G- & BLZ-G- & BLZ-G- & BLZ-G & BLZ-G- \\
\hline Constituent & & $151 \mathrm{~A}$ & $152 \mathrm{~A}$ & 153B & $5 \mathrm{~B}$ & $13 \mathrm{~A}$ & $16 \mathrm{~A}$ & $21 \mathrm{~A}$ & $23 \mathrm{~A}$ & $27 \mathrm{~A}$ \\
\hline $\mathrm{Al}_{2} \mathrm{O}_{3}$ & 23.97 & 22.53 & 22.52 & 22.82 & 22.73 & 22.77 & 22.65 & 22.72 & 22.85 & 22.82 \\
\hline $\mathrm{B}_{2} \mathrm{O}_{3} *$ & 19.19 & 18.59 & 18.68 & 18.75 & 18.81 & 18.87 & 18.92 & 18.95 & 18.98 & 19.01 \\
\hline $\mathrm{BaO}$ & 0.05 & 0.06 & 0.06 & 0.05 & 0.05 & 0.07 & 0.07 & 0.06 & 0.06 & 0.06 \\
\hline $\mathrm{Bi}_{2} \mathrm{O}_{3}$ & 1.14 & 1.28 & 1.23 & 1.21 & 1.25 & 1.26 & 1.31 & 1.27 & 1.26 & 1.27 \\
\hline $\mathrm{CaO}$ & 5.58 & 6.00 & 5.93 & 5.77 & 5.86 & 5.88 & 5.98 & 5.91 & 5.85 & 5.81 \\
\hline $\mathrm{CdO}$ & 0.02 & 0.03 & 0.03 & 0.02 & 0.02 & 0.03 & 0.03 & 0.03 & 0.03 & 0.03 \\
\hline $\mathrm{Ce}_{2} \mathrm{O}_{3}$ & $\S$ & $<0.01$ & $<0.01$ & 0.01 & 0.01 & 0.01 & $<0.01$ & 0.01 & 0.01 & $<0.01$ \\
\hline $\mathrm{Cr}_{2} \mathrm{O}_{3}$ & 0.52 & 0.61 & 0.58 & 0.57 & 0.60 & 0.58 & 0.59 & 0.59 & 0.58 & 0.58 \\
\hline $\mathrm{F}$ & 0.67 & $0.41^{\#}$ & 0.41 & 0.41 & 0.40 & $0.40^{\#}$ & 0.41 & 0.42 & 0.43 & $0.44^{\#}$ \\
\hline $\mathrm{Fe}_{2} \mathrm{O}_{3}$ & 5.90 & 6.50 & 6.32 & 5.97 & 6.22 & 6.26 & 6.38 & 6.17 & 6.18 & 6.07 \\
\hline $\mathrm{K}_{2} \mathrm{O}$ & 0.14 & 0.19 & 0.18 & 0.18 & 0.18 & 0.19 & 0.19 & 0.19 & 0.19 & 0.19 \\
\hline $\mathrm{La}_{2} \mathrm{O}_{3}$ & $\S$ & $<0.01$ & $<0.01$ & $<0.01$ & $<0.01$ & $<0.01$ & $<0.01$ & $<0.01$ & $<0.01$ & $<0.01$ \\
\hline $\mathrm{Li}_{2} \mathrm{O}^{*}$ & 3.57 & 3.53 & 3.53 & 3.54 & 3.54 & 3.55 & 3.55 & 3.55 & 3.56 & 3.56 \\
\hline $\mathrm{MgO}$ & 0.12 & 0.28 & 0.34 & 0.35 & 0.33 & 0.32 & 0.28 & 0.30 & 0.35 & 0.28 \\
\hline $\mathrm{MnO}$ & $\S$ & 0.03 & 0.04 & 0.03 & 0.03 & 0.03 & 0.03 & 0.03 & 0.03 & 0.03 \\
\hline $\mathrm{Na}_{2} \mathrm{O}$ & 9.58 & 9.40 & 9.50 & 9.41 & 9.78 & 9.37 & 9.29 & 9.43 & 9.56 & 9.59 \\
\hline $\mathrm{Nd}_{2} \mathrm{O}_{3}$ & $\S$ & $<0.01$ & $<0.01$ & $<0.01$ & $<0.01$ & $<0.01$ & $<0.01$ & $<0.01$ & $<0.01$ & $<0.01$ \\
\hline $\mathrm{NiO}$ & 0.40 & 0.37 & 0.37 & 0.32 & 0.35 & 0.35 & 0.36 & 0.34 & 0.36 & 0.34 \\
\hline $\mathrm{P}_{2} \mathrm{O}_{5}$ & 1.05 & 0.96 & 0.96 & 1.02 & 0.97 & 0.98 & 0.99 & 0.97 & 0.96 & 0.97 \\
\hline $\mathrm{PbO}$ & 0.41 & 0.37 & 0.38 & 0.36 & 0.38 & 0.39 & 0.39 & 0.39 & 0.37 & 0.37 \\
\hline $\mathrm{SiO}_{2}$ & 27.00 & 27.96 & 28.06 & 28.40 & 27.65 & 27.83 & 27.71 & 27.80 & 27.56 & 27.73 \\
\hline $\mathrm{SO}_{3}$ & 0.20 & 0.11 & 0.10 & 0.11 & 0.11 & 0.11 & 0.13 & 0.13 & 0.13 & 0.13 \\
\hline $\mathrm{SrO}$ & $\S$ & 0.02 & 0.02 & 0.01 & 0.01 & 0.01 & 0.01 & 0.01 & 0.01 & 0.01 \\
\hline $\mathrm{TiO}_{2}$ & 0.01 & 0.05 & 0.05 & 0.04 & 0.05 & 0.05 & 0.05 & 0.04 & 0.05 & 0.04 \\
\hline $\mathrm{ZnO}$ & 0.08 & 0.09 & 0.09 & 0.09 & 0.09 & 0.09 & 0.09 & 0.08 & 0.09 & 0.08 \\
\hline $\mathrm{ZrO}_{2}$ & 0.39 & 0.64 & 0.64 & 0.57 & 0.58 & 0.61 & 0.61 & 0.60 & 0.58 & 0.59 \\
\hline Sum & 100.00 & 100.00 & 100.00 & 100.00 & 100.00 & 100.00 & 100.00 & 100.00 & 100.00 & 100.00 \\
\hline
\end{tabular}

$\S$ - Not a target constituent

* - for XRF-analyzed compositions, values for $\mathrm{B}_{2} \mathrm{O}_{3}$ and $\mathrm{Li}_{2} \mathrm{O}$ were calculated based on simple well-stirred tank model and target values.

\# - Fluorine was measured by XRF on polished samples, values for other samples calculated by interpolation 
The Catholic University of America Vitreous State Laboratory
ORP-56292 Rev. 0

Melt Rate Enhancement for High Aluminum HLW Glass Formulations

Final Report, VSL-08R1360-1, Rev. 0

Table 6.6. XRF Analyzed Composition for Glass Discharged During DM100 Melter Test (wt\%) (continued).

\begin{tabular}{|c|c|c|c|c|c|c|c|}
\hline Formulation & \multicolumn{7}{|c|}{ HWI-Al-19 } \\
\hline Al Source & \multicolumn{7}{|c|}{ Aluminum Hydroxide } \\
\hline Temperature & \multirow{4}{*}{ Target } & \multicolumn{6}{|c|}{$1150{ }^{\circ} \mathrm{C}$} \\
\hline Test & & \multicolumn{6}{|c|}{8} \\
\hline Glass (kg) & & 1866.96 & 1889.56 & 1912.62 & 1936.76 & \multicolumn{2}{|c|}{1948.40} \\
\hline Constituent & & BLZ-G-28A & BLZ-G-29B & BLZ-G-33B & BLZ-G-35B & BLZ-G-37A & \% Dev. \\
\hline $\mathrm{Al}_{2} \mathrm{O}_{3}$ & 23.97 & 22.88 & 23.11 & 23.03 & 23.01 & 22.94 & -4.30 \\
\hline $\mathrm{B}_{2} \mathrm{O}_{3}{ }^{*}$ & 19.19 & 19.03 & 19.05 & 19.07 & 19.08 & 19.09 & $\mathrm{NC}$ \\
\hline $\mathrm{BaO}$ & 0.05 & 0.06 & 0.05 & 0.06 & 0.06 & 0.05 & $\mathrm{NC}$ \\
\hline $\mathrm{Bi}_{2} \mathrm{O}_{3}$ & 1.14 & 1.25 & 1.20 & 1.28 & 1.27 & 1.26 & 9.96 \\
\hline $\mathrm{CaO}$ & 5.58 & 5.87 & 5.64 & 5.80 & 5.80 & 5.74 & 2.89 \\
\hline $\mathrm{CdO}$ & 0.02 & 0.02 & 0.02 & 0.03 & 0.03 & 0.02 & $\mathrm{NC}$ \\
\hline $\mathrm{Ce}_{2} \mathrm{O}_{3}$ & $\S$ & $<0.01$ & 0.01 & $<0.01$ & $<0.01$ & $<0.01$ & $\mathrm{NC}$ \\
\hline $\mathrm{Cr}_{2} \mathrm{O}_{3}$ & 0.52 & 0.60 & 0.56 & 0.59 & 0.60 & 0.60 & $\mathrm{NC}$ \\
\hline $\mathrm{F}$ & 0.67 & 0.45 & 0.46 & 0.47 & $0.48^{\#}$ & 0.48 & $\mathrm{NC}$ \\
\hline $\mathrm{Fe}_{2} \mathrm{O}_{3}$ & 5.90 & 6.17 & 5.74 & 6.18 & 6.11 & 6.15 & 4.21 \\
\hline $\mathrm{K}_{2} \mathrm{O}$ & 0.14 & 0.19 & 0.19 & 0.19 & 0.19 & 0.18 & $\mathrm{NC}$ \\
\hline $\mathrm{La}_{2} \mathrm{O}_{3}$ & $\S$ & $<0.01$ & $<0.01$ & $<0.01$ & $<0.01$ & $<0.01$ & $\mathrm{NC}$ \\
\hline $\mathrm{Li}_{2} \mathrm{O}^{*}$ & 3.57 & 3.56 & 3.56 & 3.56 & 3.56 & 3.56 & $\mathrm{NC}$ \\
\hline $\mathrm{MgO}$ & 0.12 & 0.31 & 0.31 & 0.32 & 0.29 & 0.31 & $\mathrm{NC}$ \\
\hline $\mathrm{MnO}$ & $\S$ & 0.03 & 0.03 & 0.03 & 0.03 & 0.03 & $\mathrm{NC}$ \\
\hline $\mathrm{Na}_{2} \mathrm{O}$ & 9.58 & 9.25 & 9.88 & 9.23 & 8.81 & 9.54 & -0.38 \\
\hline $\mathrm{Nd}_{2} \mathrm{O}_{3}$ & $\S$ & $<0.01$ & $<0.01$ & $<0.01$ & $<0.01$ & $<0.01$ & $\mathrm{NC}$ \\
\hline $\mathrm{NiO}$ & 0.40 & 0.36 & 0.31 & 0.35 & 0.34 & 0.35 & $\mathrm{NC}$ \\
\hline $\mathrm{P}_{2} \mathrm{O}_{5}$ & 1.05 & 0.97 & 0.99 & 0.95 & 0.99 & 0.94 & -10.22 \\
\hline $\mathrm{PbO}$ & 0.41 & 0.38 & 0.35 & 0.37 & 0.37 & 0.36 & $\mathrm{NC}$ \\
\hline $\mathrm{SiO}_{2}$ & 27.00 & 27.77 & 27.74 & 27.65 & 28.14 & 27.55 & 2.04 \\
\hline $\mathrm{SO}_{3}$ & 0.20 & 0.13 & 0.13 & 0.14 & 0.14 & 0.14 & $\mathrm{NC}$ \\
\hline $\mathrm{SrO}$ & $\S$ & 0.01 & 0.01 & 0.01 & 0.01 & 0.01 & $\mathrm{NC}$ \\
\hline $\mathrm{TiO}_{2}$ & 0.01 & 0.05 & 0.04 & 0.04 & 0.04 & 0.04 & $\mathrm{NC}$ \\
\hline $\mathrm{ZnO}$ & 0.08 & 0.08 & 0.08 & 0.08 & 0.08 & 0.08 & $\mathrm{NC}$ \\
\hline $\mathrm{ZrO}_{2}$ & 0.39 & 0.57 & 0.52 & 0.56 & 0.57 & 0.57 & $\mathrm{NC}$ \\
\hline Sum & 100.00 & 100.00 & 100.00 & 100.00 & 100.00 & 100.00 & $\mathrm{NC}$ \\
\hline
\end{tabular}

$\S$ - Not a target constituent

* - for XRF-analyzed compositions, values for $\mathrm{B}_{2} \mathrm{O}_{3}$ and $\mathrm{Li}_{2} \mathrm{O}$ were calculated based on simple well-stirred tank model and target values.

\# - Fluorine was measured by XRF on polished samples, values for other samples calculated by interpolation $\mathrm{NC}$ - Not calculated 
The Catholic University of America Vitreous State Laboratory
ORP-56292 Rev. 0

Melt Rate Enhancement for High Aluminum HLW Glass Formulations

Final Report, VSL-08R1360-1, Rev. 0

Table 6.7. XRF Analyzed Composition for Glass Discharged During DM1200 Melter Test (wt\%).

\begin{tabular}{|c|c|c|c|c|c|c|c|c|c|c|c|}
\hline Test & \multirow{3}{*}{ Target } & \multicolumn{7}{|c|}{1} & \multicolumn{3}{|c|}{2} \\
\hline Glass (kg) & & 478.5 & 980.5 & 1462.0 & 1961.0 & 2446.0 & 2892.5 & 3373.0 & 3865.5 & 4364.0 & 4859.5 \\
\hline Constituent & & $\begin{array}{c}\text { G-12J- } \\
45 \mathrm{~A}\end{array}$ & $\begin{array}{c}\text { G-12J- } \\
60 \mathrm{~A}\end{array}$ & $\begin{array}{c}\text { G-12J- } \\
64 \mathrm{~A}\end{array}$ & $\begin{array}{c}\text { G-12J- } \\
72 \mathrm{~A}\end{array}$ & $\begin{array}{c}\text { G-12J- } \\
79 \mathrm{~B}\end{array}$ & $\begin{array}{c}\text { G-12J- } \\
100 \mathrm{~A}\end{array}$ & $\begin{array}{c}\text { G-12J- } \\
105 \mathrm{~B}\end{array}$ & $\begin{array}{c}\text { G-12J- } \\
135 \mathrm{~A}\end{array}$ & $\begin{array}{c}\text { G-12J- } \\
149 B\end{array}$ & $\begin{array}{c}\mathrm{G}-12 \mathrm{~K} \\
21 \mathrm{~A}\end{array}$ \\
\hline $\mathrm{Al}_{2} \mathrm{O}_{3}$ & 23.97 & 13.80 & 16.12 & 17.29 & 18.51 & 19.35 & 20.23 & 20.82 & 21.07 & 21.71 & 22.08 \\
\hline $\mathrm{B}_{2} \mathrm{O}_{3} *$ & 19.19 & 13.58 & 15.81 & 16.56 & 17.16 & 17.61 & 17.94 & 18.21 & 18.43 & 18.61 & 18.74 \\
\hline $\mathrm{BaO}$ & 0.05 & 0.04 & 0.05 & 0.04 & 0.04 & 0.04 & 0.04 & 0.05 & 0.06 & 0.05 & 0.06 \\
\hline $\mathrm{Bi}_{2} \mathrm{O}_{3}$ & 1.14 & 0.44 & 0.61 & 0.70 & 0.80 & 0.94 & 0.96 & 1.06 & 1.09 & 1.10 & 1.12 \\
\hline $\mathrm{CaO}$ & 5.58 & 2.44 & 3.18 & 3.60 & 3.97 & 4.44 & 4.66 & 4.92 & 5.16 & 5.12 & 5.24 \\
\hline $\mathrm{CdO}$ & 0.02 & 0.06 & 0.05 & 0.05 & 0.04 & 0.04 & 0.03 & 0.04 & 0.04 & 0.03 & 0.03 \\
\hline $\mathrm{Cr}_{2} \mathrm{O}_{3}$ & 0.52 & 0.32 & 0.39 & 0.41 & 0.43 & 0.48 & 0.48 & 0.51 & 0.53 & 0.51 & 0.54 \\
\hline $\mathrm{F}$ & 0.67 & $0.14^{\#}$ & 0.19 & 0.23 & $0.28^{\#}$ & 0.31 & 0.31 & $0.30^{\#}$ & 0.32 & 0.33 & 0.35 \\
\hline $\mathrm{Fe}_{2} \mathrm{O}_{3}$ & 5.90 & 8.94 & 8.21 & 7.78 & 7.26 & 7.24 & 6.96 & 6.87 & 6.93 & 6.49 & 6.43 \\
\hline $\mathrm{K}_{2} \mathrm{O}$ & 0.14 & 0.24 & 0.22 & 0.23 & 0.21 & 0.22 & 0.21 & 0.20 & 0.20 & 0.20 & 0.19 \\
\hline $\mathrm{La}_{2} \mathrm{O}_{3}$ & $\S$ & 0.18 & 0.14 & 0.13 & 0.09 & 0.08 & 0.07 & 0.05 & 0.04 & 0.03 & 0.03 \\
\hline $\mathrm{Li}_{2} \mathrm{O}^{*}$ & 3.57 & 3.46 & 2.90 & 3.05 & 3.17 & 3.26 & 3.32 & 3.38 & 3.42 & 3.45 & 3.48 \\
\hline $\mathrm{MgO}$ & 0.12 & 0.48 & 0.40 & 0.37 & 0.41 & 0.38 & 0.33 & 0.33 & 0.34 & 0.36 & 0.30 \\
\hline $\mathrm{MnO}$ & 0.00 & 0.72 & 0.56 & 0.47 & 0.36 & 0.31 & 0.25 & 0.20 & 0.17 & 0.14 & 0.11 \\
\hline $\mathrm{Na}_{2} \mathrm{O}$ & 9.58 & 11.03 & 10.18 & 10.04 & 10.37 & 10.00 & 9.94 & 9.84 & 9.48 & 9.62 & 9.74 \\
\hline $\mathrm{Nd}_{2} \mathrm{O}_{3}$ & $\S$ & 0.12 & 0.09 & 0.07 & 0.06 & 0.05 & 0.04 & 0.03 & 0.03 & 0.02 & 0.01 \\
\hline $\mathrm{NiO}$ & 0.40 & 0.32 & 0.33 & 0.33 & 0.32 & 0.32 & 0.32 & 0.34 & 0.35 & 0.31 & 0.33 \\
\hline $\mathrm{P}_{2} \mathrm{O} 5$ & 1.05 & 0.52 & 0.69 & 0.75 & 0.86 & 0.90 & 0.94 & 1.00 & 1.07 & 1.07 & 1.12 \\
\hline $\mathrm{PbO}$ & 0.41 & 0.16 & 0.20 & 0.22 & 0.25 & 0.28 & 0.29 & 0.32 & 0.32 & 0.31 & 0.33 \\
\hline $\mathrm{Sb}_{2} \mathrm{O}_{3}$ & $\S$ & 0.04 & 0.04 & 0.02 & 0.02 & 0.02 & 0.01 & 0.01 & 0.01 & 0.01 & $<0.01$ \\
\hline $\mathrm{SiO}_{2}$ & 27.00 & 39.68 & 36.98 & 35.31 & 33.38 & 31.92 & 31.09 & 30.10 & 29.61 & 29.36 & 28.65 \\
\hline SO3 & 0.20 & 0.08 & 0.10 & 0.11 & 0.11 & 0.12 & 0.13 & 0.14 & 0.12 & 0.12 & 0.13 \\
\hline $\mathrm{SrO}$ & $\S$ & 0.21 & 0.16 & 0.14 & 0.11 & 0.09 & 0.07 & 0.06 & 0.05 & 0.04 & 0.03 \\
\hline $\mathrm{TiO}_{2}$ & 0.01 & 0.15 & 0.12 & 0.11 & 0.10 & 0.09 & 0.08 & 0.07 & 0.07 & 0.07 & 0.06 \\
\hline $\mathrm{ZnO}$ & 0.08 & 1.10 & 0.86 & 0.72 & 0.57 & 0.49 & 0.41 & 0.34 & 0.30 & 0.25 & 0.21 \\
\hline $\mathrm{ZrO}_{2}$ & 0.39 & 1.74 & 1.42 & 1.27 & 1.11 & 1.03 & 0.89 & 0.83 & 0.78 & 0.70 & 0.68 \\
\hline Sum & 100.00 & 100.00 & 100.00 & 100.00 & 100.00 & 100.00 & 100.00 & 100.00 & 100.00 & 100.00 & 100.00 \\
\hline
\end{tabular}

$\S$ - Not a target constituent

* - Target values calculated by simple well-stirred tank model using the DCP analyzed values for the first discharge of the whole test.

\# - Fluorine was measured by XRF on polished samples, values for other samples calculated by interpolation 
ORP-56292 Rev. 0

The Catholic University of America

Table 6.7. XRF Analyzed Composition for Glass Discharged During DM1200 Melter Test (wt\%) (continued).

\begin{tabular}{|c|c|c|c|c|c|c|c|c|c|c|c|c|}
\hline \multirow{2}{*}{$\begin{array}{c}\text { Test } \\
\text { Glass }(\mathrm{kg}) \\
\end{array}$} & \multirow{4}{*}{ Target } & 2 & \multicolumn{8}{|c|}{3} & \multirow{2}{*}{\multicolumn{2}{|c|}{$5832-8873$}} \\
\hline & & \multirow{2}{*}{$\frac{5357.5}{G-12 K-}$} & 5832.5 & 6295.0 & 6808.0 & 7310.0 & 7793.5 & 8288.0 & 8760.5 & 8873.0 & & \\
\hline & & & $\mathrm{G}-12 \mathrm{~K}$ & $\mathrm{G}-12 \mathrm{~K}$ & $\mathrm{G}-12 \mathrm{~K}$ & G-12K- & $\mathrm{G}-12 \mathrm{~K}$ & $\mathrm{G}-12 \mathrm{~K}$ & $\mathrm{G}-12 \mathrm{~K}$ & $\mathrm{G}-12 \mathrm{~K}$ & & \\
\hline Constituent & & $28 \mathrm{C}$ & $44 \mathrm{~A}$ & 59A & $81 \mathrm{~B}$ & 91A & 109A & $115 \mathrm{~A}$ & 138A & 139A & Avg. & \%De \\
\hline $\mathrm{Al}_{2} \mathrm{O}_{3}$ & 23.97 & 22.45 & 22.80 & 23.00 & 22.99 & 23.43 & 23.67 & 23.83 & 23.71 & 23.64 & 23.38 & -2.51 \\
\hline $\mathrm{B}_{2} \mathrm{O}_{3}$ & \begin{tabular}{|l|}
19.19 \\
\end{tabular} & 18.84 & 18.92 & 18.97 & 19.03 & 19.06 & 19.09 & 19.11 & 19.13 & 19.13 & 19.06 & $\mathrm{NC}$ \\
\hline $\mathrm{BaO}$ & 0.05 & 0.06 & 0.06 & 0.07 & 0.06 & 0.06 & 0.05 & 0.07 & 0.06 & 0.07 & 0.06 & $\mathrm{NC}$ \\
\hline $\mathrm{Bi}_{2} \mathrm{O}_{3}$ & 1.14 & 1.12 & 1.07 & 1.12 & 1.19 & 1.13 & 1.14 & 1.17 & 1.16 & 1.15 & 1.14 & -0.22 \\
\hline $\mathrm{CaO}$ & 5.58 & 5.31 & 5.16 & 5.33 & 5.55 & 5.52 & 5.50 & 5.47 & 5.44 & 5.45 & 5.43 & -2.74 \\
\hline $\mathrm{CdO}$ & 0.02 & 0.03 & 0.03 & 0.03 & 0.03 & 0.03 & 0.02 & 0.03 & 0.03 & 0.03 & 0.03 & $\mathrm{NC}$ \\
\hline $\mathrm{Cr}_{2} \mathrm{O}_{3}$ & 0.52 & 0.53 & 0.52 & 0.51 & 0.55 & 0.54 & 0.55 & 0.54 & 0.51 & 0.53 & 0.53 & $\mathrm{NC}$ \\
\hline $\mathrm{F}$ & 0.67 & $0.37^{\#}$ & 0.36 & 0.35 & 0.34 & $0.33^{\#}$ & 0.34 & 0.36 & $0.37^{\#}$ & 0.37 & 0.35 & $\mathrm{NC}$ \\
\hline $\mathrm{Fe}_{2} \mathrm{O}_{3}$ & 5.90 & 6.17 & 5.84 & 5.92 & 6.20 & 6.07 & 6.08 & 5.99 & 6.00 & 6.07 & 6.02 & 2.02 \\
\hline $\mathrm{K}_{2} \mathrm{O}$ & 0.14 & 0.19 & 0.19 & 0.19 & 0.20 & 0.19 & 0.19 & 0.18 & 0.18 & 0.19 & 0.19 & $\mathrm{NC}$ \\
\hline $\mathrm{La}_{2} \mathrm{O}_{3}$ & $\S$ & 0.02 & 0.02 & 0.02 & 0.01 & $<0.01$ & $<0.01$ & $<0.01$ & $<0.01$ & $<0.01$ & 0.01 & $\mathrm{NC}$ \\
\hline $\mathrm{Li}_{2} \mathrm{O}$ & 3.57 & 3.50 & 3.52 & 3.53 & 3.54 & 3.55 & 3.55 & 3.56 & 3.56 & 3.56 & 3.54 & $\mathrm{NC}$ \\
\hline $\mathrm{MgO}$ & 0.12 & 0.30 & 0.31 & 0.29 & 0.28 & 0.33 & 0.30 & 0.28 & 0.33 & 0.31 & 0.30 & $\mathrm{NC}$ \\
\hline $\mathrm{MnO}$ & 0.00 & 0.09 & 0.07 & 0.07 & 0.06 & 0.05 & 0.05 & 0.04 & 0.04 & 0.04 & 0.05 & $\mathrm{NC}$ \\
\hline $\mathrm{Na}_{2} \mathrm{O}$ & 9.58 & 9.76 & 10.39 & 9.91 & 9.40 & 9.31 & 9.54 & 9.50 & 9.87 & 9.84 & 9.72 & 1.44 \\
\hline $\mathrm{Nd}_{2} \mathrm{O}_{3}$ & $\S$ & 0.01 & $<0.01$ & 0.01 & 0.01 & $<0.01$ & $<0.01$ & $<0.01$ & $<0.01$ & $<0.01$ & $<0.01$ & $\mathrm{NC}$ \\
\hline $\mathrm{NiO}$ & 0.40 & 0.31 & 0.30 & 0.31 & 0.34 & 0.33 & 0.33 & 0.31 & 0.32 & 0.33 & 0.32 & $\mathrm{NC}$ \\
\hline $\mathrm{P}_{2} \mathrm{O} 5$ & 1.05 & 1.11 & 1.13 & 1.13 & 1.14 & 1.13 & 1.12 & 1.14 & 1.15 & 1.16 & 1.14 & 7.59 \\
\hline $\mathrm{PbO}$ & 0.41 & 0.33 & 0.31 & 0.32 & 0.34 & 0.32 & 0.31 & 0.33 & 0.33 & 0.34 & 0.32 & $\mathrm{NC}$ \\
\hline $\mathrm{Sb}_{2} \mathrm{O}_{3}$ & $\S$ & $<0.01$ & $<0.01$ & $<0.01$ & $<0.01$ & $<0.01$ & $<0.01$ & $<0.01$ & $<0.01$ & $<0.01$ & $<0.01$ & $\mathrm{NC}$ \\
\hline $\mathrm{SiO}_{2}$ & 27.00 & 28.48 & 28.10 & 28.04 & 27.85 & 27.74 & 27.37 & 27.28 & 27.01 & 26.99 & 27.55 & 2.00 \\
\hline $\mathrm{SO} 3$ & 0.20 & 0.14 & 0.13 & 0.15 & 0.14 & 0.16 & 0.14 & 0.13 & 0.13 & 0.14 & 0.14 & $\mathrm{NC}$ \\
\hline $\mathrm{SrO}$ & $\S$ & 0.02 & 0.02 & 0.02 & 0.01 & 0.01 & $<0.01$ & $<0.01$ & 0.01 & $<0.01$ & 0.01 & $\mathrm{NC}$ \\
\hline $\mathrm{TiO}_{2}$ & 0.01 & 0.06 & 0.05 & 0.05 & 0.05 & 0.05 & 0.04 & 0.05 & 0.05 & 0.04 & 0.05 & $\mathrm{NC}$ \\
\hline $\mathrm{ZnO}$ & 0.08 & 0.18 & 0.15 & 0.14 & 0.14 & 0.12 & 0.11 & 0.11 & 0.10 & 0.11 & 0.12 & $\mathrm{NC}$ \\
\hline $\mathrm{ZrO}_{2}$ & 0.39 & 0.62 & 0.55 & 0.56 & 0.56 & 0.53 & 0.49 & 0.52 & 0.50 & 0.50 & 0.53 & $\mathrm{NC}$ \\
\hline Sum & 100.00 & 100.00 & 100.00 & 100.00 & 100.00 & 100.00 & 100.00 & 100.00 & 100.00 & 100.00 & 100.00 & $\mathrm{NC}$ \\
\hline
\end{tabular}

$\S$ - Not a target constituent

* - Target values calculated by simple well-stirred tank model using the DCP analyzed values for the first discharge of the whole test.

\# - Fluorine was measured by XRF on polished samples, values for other samples calculated by interpolation $\mathrm{NC}-$ Not calculated 
Table 6.8. XRF and DCP Analyzed Compositions of Selected Glass Samples Discharged during DM100 and DM1200 Melter Tests (wt\%).

\begin{tabular}{|c|c|c|c|c|c|c|c|c|c|c|}
\hline Melter Type & \multicolumn{10}{|c|}{ DM100BL } \\
\hline Formulation & \multicolumn{5}{|c|}{ HLW-E-Al-27 } & \multicolumn{5}{|c|}{ HWI-Al -16 } \\
\hline Test & \multirow{3}{*}{ Target } & \multirow{2}{*}{\multicolumn{2}{|c|}{$\begin{array}{c}\mathbf{1} \\
\text { BLX-G-84C }\end{array}$}} & \multirow{2}{*}{\multicolumn{2}{|c|}{$\begin{array}{c}\mathbf{2} \\
\text { BLX-G-115A }\end{array}$}} & \multirow{3}{*}{ Target } & \multicolumn{2}{|c|}{3} & \multicolumn{2}{|c|}{4} \\
\hline \multirow{2}{*}{ Constituent } & & & & & & & BLY & $\mathrm{J}-14 \mathrm{~B}$ & BLY- & $\mathrm{J}-36 \mathrm{~B}$ \\
\hline & & XRF & DCP & XRF & DCP & & XRF & DCP & XRF & DCP \\
\hline $\mathrm{Al}_{2} \mathrm{O}_{3}$ & 23.97 & 19.33 & 17.06 & 21.79 & 18.76 & 23.25 & 22.12 & 19.65 & 22.09 & 19.52 \\
\hline $\mathrm{B}_{2} \mathrm{O}_{3}$ & 15.19 & $14.78^{*}$ & 13.70 & $15.05^{*}$ & 15.29 & 17.73 & $16.97 *$ & 17.16 & $17.49^{*}$ & 17.66 \\
\hline $\mathrm{BaO}$ & 0.05 & $<0.01$ & 0.06 & 0.05 & 0.06 & 0.05 & 0.06 & 0.06 & 0.06 & 0.06 \\
\hline $\mathrm{Bi}_{2} \mathrm{O}_{3}$ & 1.14 & 1.06 & 1.02 & 1.13 & 1.11 & 1.11 & 1.13 & 1.11 & 1.22 & 1.08 \\
\hline $\mathrm{CaO}$ & 6.08 & 4.98 & 4.50 & 5.57 & 5.07 & 5.89 & 5.77 & 5.27 & 6.14 & 5.35 \\
\hline $\mathrm{CdO}$ & 0.02 & 0.03 & NA & 0.03 & NA & 0.02 & 0.03 & NA & 0.03 & NA \\
\hline $\mathrm{Ce}_{2} \mathrm{O}_{3}$ & $\S$ & 0.02 & NA & 0.02 & $\mathrm{NA}$ & $\S$ & $<0.01$ & NA & 0.01 & NA \\
\hline $\mathrm{Cr}_{2} \mathrm{O}_{3}$ & 0.52 & 0.55 & 0.22 & 0.55 & 0.22 & 0.51 & 0.50 & 0.21 & 0.56 & 0.19 \\
\hline $\mathrm{F}$ & 0.67 & $0.37^{\$}$ & NA & $0.43^{\$}$ & NA & 0.65 & $0.36^{\#}$ & NA & $0.44^{\$}$ & NA \\
\hline $\mathrm{Fe}_{2} \mathrm{O}_{3}$ & 5.90 & 6.38 & 5.90 & 5.99 & 5.38 & 5.72 & 5.75 & 5.33 & 6.10 & 5.21 \\
\hline $\mathrm{K}_{2} \mathrm{O}$ & 0.14 & 0.23 & 0.26 & 0.19 & 0.23 & 0.14 & 0.16 & 0.20 & 0.17 & 0.19 \\
\hline $\mathrm{La}_{2} \mathrm{O}_{3}$ & $\S$ & 0.02 & NA & $<0.01$ & NA & $\S$ & 0.01 & NA & $<0.01$ & NA \\
\hline $\mathrm{Li}_{2} \mathrm{O}$ & 3.57 & $3.24 *$ & 3.47 & $3.46^{*}$ & 3.52 & 3.46 & $3.46^{*}$ & 3.19 & $3.46^{*}$ & 3.19 \\
\hline $\mathrm{MgO}$ & 0.12 & 0.30 & 0.34 & 0.25 & 0.31 & 0.11 & 0.30 & 0.38 & 0.28 & 0.38 \\
\hline $\mathrm{MnO}$ & $\S$ & 0.28 & 0.31 & 0.12 & 0.13 & $\S$ & 0.09 & 0.10 & 0.06 & 0.06 \\
\hline $\mathrm{Na}_{2} \mathrm{O}$ & 9.58 & 10.18 & 8.81 & 10.43 & 8.71 & 9.29 & 9.48 & 8.40 & 8.71 & 8.24 \\
\hline $\mathrm{Nd}_{2} \mathrm{O}_{3}$ & $\S$ & 0.02 & NA & 0.01 & NA & $\S$ & $<0.01$ & NA & $<0.01$ & NA \\
\hline $\mathrm{NiO}$ & 0.40 & 0.41 & 0.32 & 0.35 & 0.26 & 0.39 & 0.32 & 0.27 & 0.33 & 0.24 \\
\hline $\mathrm{P}_{2} \mathrm{O} 5$ & 1.05 & 1.05 & 0.92 & 1.11 & 0.97 & 1.02 & 1.16 & 0.99 & 1.16 & 1.03 \\
\hline $\mathrm{PbO}$ & 0.41 & 0.33 & 0.36 & 0.36 & 0.39 & 0.40 & 0.36 & 0.39 & 0.39 & 0.38 \\
\hline $\mathrm{SiO}_{2}$ & 30.50 & 32.97 & 31.92 & 31.42 & 29.87 & 29.58 & 30.97 & 29.96 & 30.39 & 29.32 \\
\hline $\mathrm{SO}_{3}$ & 0.20 & 0.11 & NA & 0.16 & NA & 0.19 & 0.11 & NA & 0.13 & NA \\
\hline $\mathrm{SrO}$ & $\S$ & 1.45 & 1.62 & 0.54 & 0.65 & $\S$ & 0.15 & 0.19 & 0.07 & 0.08 \\
\hline $\mathrm{TiO}_{2}$ & 0.01 & 0.04 & 0.05 & 0.04 & 0.05 & 0.01 & 0.04 & 0.05 & 0.04 & 0.05 \\
\hline $\mathrm{ZnO}$ & 0.08 & 0.27 & 0.23 & 0.14 & 0.13 & 0.08 & 0.10 & 0.10 & 0.10 & 0.08 \\
\hline $\mathrm{ZrO}_{2}$ & 0.39 & 1.65 & 1.91 & 0.84 & 0.99 & 0.38 & 0.59 & 0.71 & 0.56 & 0.65 \\
\hline Sum & 100.00 & 100.00 & 92.98 & 100.00 & 92.10 & 100.00 & 100.00 & 93.72 & 100.00 & 92.96 \\
\hline
\end{tabular}

$\S$ - Not a target constituent;

NA - Not analyzed

* - for XRF-analyzed compositions, values for $\mathrm{B}_{2} \mathrm{O}_{3}$ and $\mathrm{Li}_{2} \mathrm{O}$ were calculated based on simple well-stirred tank model with target values

\# - Fluorine measured by XRF on polished samples

$\$$ - Fluorine values calculated by interpolation 
ORP-56292 Rev. 0

The Catholic University of America

Table 6.8. XRF and DCP Analyzed Compositions of Selected Glass Samples Discharged during DM100 and DM1200 Melter Tests (wt\%) (continued).

\begin{tabular}{|c|c|c|c|c|c|c|c|c|c|c|}
\hline Meter Type & \multicolumn{10}{|c|}{ DM100BL } \\
\hline Formulation & \multicolumn{5}{|c|}{ HWI-Al -16 } & \multicolumn{5}{|c|}{ HWI-Al-19 } \\
\hline Test & \multirow{3}{*}{ Target } & \multicolumn{2}{|c|}{5} & \multicolumn{2}{|c|}{6} & \multirow{3}{*}{ Target } & \multicolumn{2}{|c|}{7} & \multicolumn{2}{|c|}{8} \\
\hline \multirow{2}{*}{ Constituent } & & \multicolumn{2}{|c|}{ BLY-G-80C } & \multicolumn{2}{|c|}{ BLY-G-114A } & & \multicolumn{2}{|c|}{ BLZ-G-5B } & \multicolumn{2}{|c|}{ BLZ-G-37A } \\
\hline & & XRF & DCP & XRF & DCP & & XRF & DCP & XRF & DCP \\
\hline $\mathrm{Al}_{2} \mathrm{O}_{3}$ & 23.25 & 22.38 & 20.17 & 22.36 & 19.85 & 23.97 & 22.73 & 20.09 & 22.94 & 19.89 \\
\hline $\mathrm{B}_{2} \mathrm{O}_{3}$ & 17.73 & $17.66^{*}$ & 17.35 & $17.71^{*}$ & 17.31 & 19.19 & $18.81^{*}$ & 19.13 & $19.09^{*}$ & 19.17 \\
\hline $\mathrm{BaO}$ & 0.05 & 0.05 & 0.06 & 0.05 & 0.05 & 0.05 & 0.05 & 0.06 & 0.05 & 0.06 \\
\hline $\mathrm{Bi}_{2} \mathrm{O}_{3}$ & 1.11 & 1.16 & 1.10 & 1.18 & 1.09 & 1.14 & 1.25 & 1.12 & 1.26 & 1.16 \\
\hline $\mathrm{CaO}$ & 5.89 & 5.91 & 5.27 & 5.84 & 5.15 & 5.58 & 5.86 & 5.32 & 5.74 & 5.10 \\
\hline $\mathrm{CdO}$ & 0.02 & 0.03 & NA & 0.03 & NA & 0.02 & 0.02 & $<0.01$ & 0.02 & $<0.01$ \\
\hline $\mathrm{Ce}_{2} \mathrm{O}_{3}$ & $\S$ & $<0.01$ & NA & $<0.01$ & NA & $\S$ & 0.01 & NA & $<0.01$ & NA \\
\hline $\mathrm{Cr}_{2} \mathrm{O}_{3}$ & 0.51 & 0.50 & 0.23 & 0.52 & 0.22 & 0.52 & 0.60 & 0.24 & 0.60 & 0.24 \\
\hline $\mathrm{F}$ & 0.65 & $0.41^{\$}$ & NA & $0.47^{\$}$ & NA & 0.67 & $0.40^{\$}$ & NA & $0.48^{\$}$ & NA \\
\hline $\mathrm{Fe}_{2} \mathrm{O}_{3}$ & 5.72 & 6.44 & 5.90 & 6.55 & 5.72 & 5.90 & 6.22 & 5.50 & 6.15 & 5.32 \\
\hline $\mathrm{K}_{2} \mathrm{O}$ & 0.14 & 0.17 & 0.20 & 0.17 & 0.20 & 0.14 & 0.18 & 0.23 & 0.18 & 0.22 \\
\hline $\mathrm{La}_{2} \mathrm{O}_{3}$ & $\S$ & $<0.01$ & NA & $<0.01$ & NA & $\S$ & $<0.01$ & NA & $<0.01$ & NA \\
\hline $\mathrm{Li}_{2} \mathrm{O}$ & 3.46 & $3.46^{*}$ & 3.57 & $3.46^{*}$ & 3.42 & 3.57 & $3.54^{*}$ & 3.68 & $3.56^{*}$ & 3.57 \\
\hline $\mathrm{MgO}$ & 0.11 & 0.23 & 0.29 & 0.21 & 0.29 & 0.12 & 0.33 & 0.45 & 0.31 & 0.41 \\
\hline $\mathrm{MnO}$ & $\S$ & 0.06 & 0.06 & 0.04 & 0.05 & $\S$ & 0.03 & 0.03 & 0.03 & 0.03 \\
\hline $\mathrm{Na}_{2} \mathrm{O}$ & 9.29 & 8.93 & 8.19 & 9.04 & 8.01 & 9.58 & 9.78 & 9.01 & 9.54 & 8.90 \\
\hline $\mathrm{Nd}_{2} \mathrm{O}_{3}$ & $\S$ & $<0.01$ & NA & $<0.01$ & NA & $\S$ & $<0.01$ & NA & $<0.01$ & NA \\
\hline $\mathrm{NiO}$ & 0.39 & 0.33 & 0.27 & 0.31 & 0.23 & 0.40 & 0.35 & 0.26 & 0.35 & 0.25 \\
\hline $\mathrm{P}_{2} \mathrm{O} 5$ & 1.02 & 1.15 & 1.05 & 1.15 & 0.93 & 1.05 & 0.97 & 0.81 & 0.94 & 0.88 \\
\hline $\mathrm{PbO}$ & 0.40 & 0.34 & 0.35 & 0.34 & 0.33 & 0.41 & 0.38 & 0.47 & 0.36 & 0.46 \\
\hline $\mathrm{SiO}_{2}$ & 29.58 & 29.75 & 28.66 & 29.51 & 28.08 & 27.00 & 27.65 & 28.81 & 27.55 & 28.11 \\
\hline $\mathrm{SO}_{3}$ & 0.19 & 0.11 & NA & 0.12 & NA & 0.20 & 0.11 & NA & 0.14 & NA \\
\hline $\mathrm{SrO}$ & $\S$ & 0.03 & 0.04 & 0.02 & 0.02 & $\S$ & 0.01 & 0.01 & 0.01 & $<0.01$ \\
\hline $\mathrm{TiO}_{2}$ & 0.01 & 0.05 & 0.05 & 0.04 & 0.05 & 0.01 & 0.05 & 0.04 & 0.04 & 0.04 \\
\hline $\mathrm{ZnO}$ & 0.08 & 0.09 & 0.08 & 0.08 & 0.07 & 0.08 & 0.09 & 0.06 & 0.08 & 0.06 \\
\hline $\mathrm{ZrO}_{2}$ & 0.38 & 0.75 & 0.90 & 0.80 & 0.92 & 0.39 & 0.58 & 0.57 & 0.57 & 0.57 \\
\hline Sum & 100.00 & 100.00 & 93.79 & 100.00 & 91.99 & 100.00 & 100.00 & 95.89 & 100.00 & 94.44 \\
\hline
\end{tabular}

$\S$ - Not a target constituent;

NA - Not analyzed

* - for XRF-analyzed compositions, values for $\mathrm{B}_{2} \mathrm{O}_{3}$ and $\mathrm{Li}_{2} \mathrm{O}$ were calculated based on simple well-stirred tank model with target values

\# - Fluorine measured by XRF on polished samples

$\$$ - Fluorine values calculated by interpolation 
ORP-56292 Rev. 0

The Catholic University of America

Table 6.8. XRF and DCP Analyzed Compositions of Selected Glass Samples Discharged during DM100 and DM1200 Melter Tests (wt\%) (continued).

\begin{tabular}{|c|c|c|c|c|c|c|c|c|c|}
\hline Melter Type & \multicolumn{9}{|c|}{ DM1200 } \\
\hline Formulation & \multicolumn{9}{|c|}{ HWI-Al-19 } \\
\hline Test & \multirow{3}{*}{ Target } & \multicolumn{4}{|c|}{1} & \multirow{2}{*}{\multicolumn{2}{|c|}{\begin{tabular}{|c|}
$\mathbf{2}$ \\
G-12J-149B
\end{tabular}}} & \multirow{2}{*}{\multicolumn{2}{|c|}{$\begin{array}{c}3 \\
\text { G-12K-138A }\end{array}$}} \\
\hline \multirow{2}{*}{ Constituent } & & \multicolumn{2}{|c|}{ G-12J-45A } & \multicolumn{2}{|c|}{ G-12J-105B } & & & & \\
\hline & & XRF & DCP & XRF & DCP & XRF & DCP & XRF & DCP \\
\hline $\mathrm{Al}_{2} \mathrm{O}_{3}$ & 23.97 & 13.81 & 12.46 & 20.83 & 18.47 & 21.71 & 18.8 & 23.71 & 21.44 \\
\hline $\mathrm{B}_{2} \mathrm{O}_{3}$ & 19.19 & $13.58^{* *}$ & 13.58 & $18.21 * *$ & 17.75 & $18.61^{* *}$ & 18.07 & $19.13^{* *}$ & 18.86 \\
\hline $\mathrm{BaO}$ & 0.05 & 0.04 & 0.06 & 0.05 & 0.06 & 0.05 & 0.06 & 0.06 & 0.06 \\
\hline $\mathrm{Bi}_{2} \mathrm{O}_{3}$ & 1.14 & 0.44 & 0.47 & 1.06 & 0.99 & 1.10 & 1.06 & 1.16 & 1.17 \\
\hline $\mathrm{CaO}$ & 5.58 & 2.44 & 2.54 & 4.92 & 4.36 & 5.12 & 4.60 & 5.44 & 4.95 \\
\hline $\mathrm{CdO}$ & 0.02 & 0.06 & $<0.01$ & 0.04 & $<0.01$ & 0.03 & NA & 0.03 & $<0.01$ \\
\hline $\mathrm{Ce}_{2} \mathrm{O}_{3}$ & $\S$ & 0.01 & NA & $<0.01$ & NA & 0.01 & NA & $<0.01$ & NA \\
\hline $\mathrm{Cr}_{2} \mathrm{O}_{3}$ & 0.52 & 0.32 & 0.20 & 0.51 & 0.19 & 0.51 & 0.20 & 0.51 & 0.20 \\
\hline $\mathrm{F}$ & 0.67 & $0.14^{\#}$ & NA & $0.30^{\#}$ & NA & $0.33^{\$}$ & NA & $0.37^{\#}$ & NA \\
\hline $\mathrm{Fe}_{2} \mathrm{O}_{3}$ & 5.90 & 8.94 & 8.97 & 6.87 & 6.21 & 6.49 & 5.96 & 6.00 & 5.6 \\
\hline $\mathrm{K}_{2} \mathrm{O}$ & 0.14 & 0.24 & 0.24 & 0.20 & 0.24 & 0.20 & 0.24 & 0.18 & 0.23 \\
\hline $\mathrm{La}_{2} \mathrm{O}_{3}$ & $\S$ & 0.18 & NA & 0.05 & NA & 0.03 & NA & $<0.01$ & NA \\
\hline $\mathrm{Li}_{2} \mathrm{O}$ & 3.57 & $3.46^{* *}$ & 3.46 & $3.38 * *$ & 3.69 & $3.45 * *$ & 3.73 & $3.56^{* *}$ & 3.85 \\
\hline $\mathrm{MgO}$ & 0.12 & 0.48 & 0.43 & 0.33 & 0.43 & 0.36 & 0.43 & 0.33 & 0.43 \\
\hline $\mathrm{MnO}$ & $\S$ & 0.72 & 0.21 & 0.20 & 0.21 & 0.14 & 0.16 & 0.04 & 0.05 \\
\hline $\mathrm{Na}_{2} \mathrm{O}$ & 9.58 & 11.04 & 9.95 & 9.84 & 9.06 & 9.62 & 8.96 & 9.87 & 8.64 \\
\hline $\mathrm{Nd}_{2} \mathrm{O}_{3}$ & $\S$ & 0.12 & NA & 0.03 & NA & 0.02 & NA & $<0.01$ & NA \\
\hline $\mathrm{NiO}$ & 0.40 & 0.32 & 0.26 & 0.34 & 0.26 & 0.31 & 0.25 & 0.32 & 0.26 \\
\hline $\mathrm{P}_{2} \mathrm{O} 5$ & 1.05 & 0.52 & 0.90 & 1.00 & 0.89 & 1.07 & 0.98 & 1.15 & 1.01 \\
\hline $\mathrm{PbO}$ & 0.41 & 0.16 & 0.24 & 0.32 & 0.40 & 0.31 & 0.42 & 0.33 & 0.44 \\
\hline $\mathrm{SiO}_{2}$ & 27.00 & 39.69 & 40.59 & 30.10 & 31.24 & 29.35 & 30.01 & 27.01 & 28.77 \\
\hline $\mathrm{SO}_{3}$ & 0.20 & 0.08 & NA & 0.14 & NA & 0.12 & NA & 0.13 & NA \\
\hline $\mathrm{SrO}$ & $\S$ & 0.21 & 0.27 & 0.06 & 0.07 & 0.04 & 0.04 & 0.01 & $<0.01$ \\
\hline $\mathrm{TiO}_{2}$ & 0.01 & 0.15 & 0.08 & 0.07 & 0.08 & 0.07 & 0.07 & 0.05 & 0.05 \\
\hline $\mathrm{ZnO}$ & 0.08 & 1.10 & 1.14 & 0.34 & 0.28 & 0.25 & 0.21 & 0.10 & 0.08 \\
\hline $\mathrm{ZrO}_{2}$ & 0.39 & 1.74 & 2.06 & 0.83 & 0.93 & 0.70 & 0.81 & 0.50 & 0.58 \\
\hline Sum & 100.00 & 100.00 & 98.11 & 100.00 & 95.81 & 100.00 & 95.06 & 100.00 & 96.67 \\
\hline $\begin{array}{l}\$ \text { - Not a targe } \\
\text { NA - Not anal } \\
\text { **- for XRF-a } \\
\text { tank model } \\
\text { - Fluorine m } \\
\$ \text { - Fluorine va }\end{array}$ & $\begin{array}{l}\text { constitu } \\
\text { zed } \\
\text { alyzed c }\end{array}$ & $\begin{array}{l}\text { ent; } \\
\text { ompositio } \\
\text { analyzed } \\
\text { y XRF on } \\
\text { ulated by }\end{array}$ & $\begin{array}{l}\text { ns, valu } \\
\text { values f } \\
\text { polishe } \\
\text { nterpol }\end{array}$ & $\begin{array}{l}\text { the first } \\
\text { samples } \\
\text { on }\end{array}$ & discharg & $\begin{array}{l}\text { O were c } \\
\text { e. }\end{array}$ & ulate & conds & molo \\
\hline
\end{tabular}


Table 6.9. PCT Results for Melter Glasses (ASTM C1285, 7-days at $90^{\circ} \mathrm{C}$, Stainless Steel Vessel; S/V=2000 ${ }^{-1}$ ).

\begin{tabular}{|c|c|c|c|c|c|c|c|c|c|c|}
\hline \multicolumn{2}{|l|}{ Test } & 1 & 2 & 3 & 4 & 5 & 6 & 7 & 8 & \multirow[b]{2}{*}{ DWPF-EA } \\
\hline \multicolumn{2}{|c|}{ Glass Samples } & $\begin{array}{l}\text { BLX- } \\
\text { G-84C }\end{array}$ & $\begin{array}{c}\text { BLX-G- } \\
115 \mathrm{~A}\end{array}$ & BLY-G-14B & $\begin{array}{l}\text { BLY- } \\
\text { G-36B }\end{array}$ & $\begin{array}{c}\text { BLY-G- } \\
80 \mathrm{C}\end{array}$ & $\begin{array}{c}\text { BLY-G- } \\
114 \mathrm{~A}\end{array}$ & BLZ-G-5B & $\begin{array}{c}\text { BLZ-G- } \\
\text { 37A }\end{array}$ & \\
\hline \multirow{4}{*}{$\begin{array}{c}\text { 7-Day PCT } \\
\text { Concentration in } \\
\mathrm{mg} / \mathrm{L}\end{array}$} & $\mathrm{B}$ & 10.15 & 13.18 & 13.95 & 12.96 & 16.92 & 17.89 & 29.58 & 36.86 & 16695 \\
\hline & $\mathrm{Li}$ & 6.53 & 6.79 & 5.71 & 5.34 & 7.32 & 7.56 & 9.14 & 10.45 & 9565 \\
\hline & $\mathrm{Na}$ & 21.89 & 20.70 & 17.74 & 16.56 & 19.68 & 20.25 & 31.04 & 35.97 & 13346 \\
\hline & $\mathrm{Si}$ & 23.49 & 21.28 & 24.33 & 21.56 & 23.11 & 24.31 & 26.46 & 27.56 & 3920 \\
\hline \multirow{5}{*}{$\begin{array}{c}\text { 7-Day PCT } \\
\text { Normalized } \\
\text { Concentrations, } \\
\text { g/L }\end{array}$} & $\mathrm{B}$ & 0.22 & 0.28 & 0.26 & 0.24 & 0.31 & 0.33 & 0.51 & 0.62 & \\
\hline & $\mathrm{Li}$ & 0.43 & 0.42 & 0.35 & 0.33 & 0.46 & 0.47 & 0.56 & 0.63 & \\
\hline & $\mathrm{Na}$ & 0.29 & 0.27 & 0.25 & 0.26 & 0.30 & 0.30 & 0.43 & 0.51 & \\
\hline & $\mathrm{Si}$ & 0.15 & 0.14 & 0.17 & 0.15 & 0.17 & 0.18 & 0.20 & 0.21 & \\
\hline & $\mathrm{pH}$ & 9.92 & 9.68 & 9.41 & 9.33 & 9.45 & 9.42 & 9.40 & 9.37 & \\
\hline \multirow{4}{*}{$\begin{array}{c}\text { 7-Day PCT } \\
\text { Normalized Mass } \\
\text { Loss }\left(\mathrm{g} / \mathrm{m}^{2}\right)\end{array}$} & $\mathrm{B}$ & 0.11 & 0.14 & 0.13 & 0.12 & 0.15 & 0.16 & 0.25 & 0.31 & \\
\hline & $\mathrm{Li}$ & 0.22 & 0.21 & 0.18 & 0.17 & 0.23 & 0.24 & 0.28 & 0.32 & \\
\hline & $\mathrm{Na}$ & 0.14 & 0.13 & 0.13 & 0.13 & 0.15 & 0.15 & 0.21 & 0.25 & \\
\hline & $\mathrm{Si}$ & 0.08 & 0.07 & 0.08 & 0.08 & 0.08 & 0.09 & 0.10 & 0.11 & \\
\hline \multirow{4}{*}{$\begin{array}{c}\text { 7-Day PCT } \\
\text { Normalized Loss } \\
\text { Rate, } \mathrm{g} / \mathrm{d} / \mathrm{m}^{2}\end{array}$} & $\mathrm{~B}$ & 0.02 & 0.02 & 0.02 & 0.02 & 0.02 & 0.02 & 0.04 & 0.04 & \\
\hline & $\mathrm{Li}$ & 0.03 & 0.03 & 0.03 & 0.02 & 0.03 & 0.03 & 0.04 & 0.05 & \\
\hline & $\mathrm{Na}$ & 0.02 & 0.02 & 0.02 & 0.02 & 0.02 & 0.02 & 0.03 & 0.04 & \\
\hline & $\mathrm{Si}$ & 0.01 & 0.01 & 0.01 & 0.01 & 0.01 & 0.01 & 0.01 & 0.02 & \\
\hline
\end{tabular}


The Catholic University of America Vitreous State Laboratory
ORP-56292 Rev. 0

Melt Rate Enhancement for High Aluminum HLW Glass Formulations

Final Report, VSL-08R1360-1, Rev. 0

Table 6.10. TCLP Results for Melter Glasses (mg/L).

\begin{tabular}{|c|c|c|c|c|c|c|c|}
\hline \multirow{2}{*}{ Test } & Sample I.D. & $\mathrm{Ba}$ & $\mathrm{Cd}$ & $\mathrm{Cr}$ & $\mathrm{Ni}$ & $\mathrm{Pb}$ & $\mathrm{Zn}$ \\
\cline { 2 - 8 } & UTS Limits \# & 21 & 0.11 & 0.60 & 11.00 & 0.75 & 4.3 \\
\cline { 2 - 8 } & Delisting Limits & 100 & 0.48 & 4.95 & 22.6 & 5.00 & 225 \\
\hline 1 & BLX-G-84C & 0.15 & 0.04 & 0.04 & 0.10 & 0.11 & 0.17 \\
\hline 2 & BLX-G-115A & 0.15 & 0.04 & 0.05 & 0.11 & 0.21 & 0.14 \\
\hline 3 & BLY-G-14B & 0.18 & 0.05 & 0.05 & 0.08 & 0.21 & 0.12 \\
\hline 4 & BLY-G-36B & 0.18 & 0.05 & 0.04 & 0.09 & 0.27 & 0.11 \\
\hline 5 & BLY-G-80C & 0.18 & 0.04 & 0.10 & 0.05 & 0.27 & 0.12 \\
\hline 6 & BLY-G-114A & 0.17 & 0.04 & 0.05 & 0.12 & 0.11 & 0.10 \\
\hline 7 & BLZ-G-5B & 0.26 & $<0.03$ & 0.07 & 0.10 & 0.55 & 0.11 \\
\hline 8 & BLZ-G-37A & 0.20 & 0.03 & 0.08 & 0.13 & 0.39 & 0.08 \\
\hline
\end{tabular}

\# For comparison only; does not apply to WTP glasses 
Table 6.11. Glass Pool Samples and Secondary Phase Observations.

\begin{tabular}{|c|l|c|c|c|c|}
\hline \multicolumn{2}{|c|}{ Test } & \multirow{2}{*}{$\left({ }^{\circ}\right.$ C) } & $\begin{array}{c}\text { Sampling } \\
\text { Date }\end{array}$ & Sample I.D. & $\begin{array}{c}\text { Visual Observations Upon } \\
\text { Sampling }\end{array}$ \\
\hline \multirow{2}{*}{1} & Before Test & \multirow{2}{*}{1200} & $2 / 4 / 08$ & BLX-D-50B & No Secondary Phase \\
\cline { 2 - 5 } & End of Test & & $2 / 6 / 08$ & BLX-D-88A & No Secondary Phase \\
\hline 2 & End of Test & 1150 & $2 / 9 / 08$ & BLX-D-119A & No Secondary Phase \\
\hline \multirow{2}{*}{3} & Before Test & \multirow{2}{*}{1200} & $5 / 3 / 08$ & BLX-D-125A & No Secondary Phase \\
\cline { 2 - 5 } & End of Test & & $5 / 7 / 08$ & BLY-D-14A & No Secondary Phase \\
\hline 4 & End of Test & 1150 & $5 / 9 / 08$ & BLY-D-36A & No Secondary Phase \\
\hline \multirow{2}{*}{5} & Before Test & \multirow{2}{*}{1200} & $6 / 2 / 08$ & BLY-D-46A & No Secondary Phase \\
\cline { 2 - 5 } & End of Test & & $6 / 4 / 08$ & BLY-D-84A & No Secondary Phase \\
\hline 6 & End of Test & 1150 & $6 / 7 / 08$ & BLY-D-114A & No Secondary Phase \\
\hline 7 & End of Test & 1200 & $6 / 25 / 08$ & BLZ-D-5A & No Secondary Phase \\
\hline 8 & End of Test & 1150 & $6 / 28 / 08$ & BLZ-D-40A & No Secondary Phase \\
\hline
\end{tabular}


The Catholic University of America Vitreous State Laboratory
ORP-56292 Rev. 0

Melt Rate Enhancement for High Aluminum HLW Glass Formulations

Final Report, VSL-08R1360-1, Rev. 0

Table 7.1. Results from DM100 Off-Gas Emission Samples.

\begin{tabular}{|c|c|c|c|c|c|c|c|c|c|}
\hline & \multicolumn{4}{|c|}{ Test 1} & \multicolumn{4}{|c|}{ Test 2} \\
\hline & & \multicolumn{4}{|c|}{$\begin{array}{c}02 / 06 / 0809: 29-10: 29 \\
105.0 \% \text { Isokinetic, } 13.1 \% \text { Moisture }\end{array}$} & \multicolumn{4}{|c|}{$\begin{array}{c}02 / 08 / 0812: 22-13: 22 \\
102.2 \% \text { Isokinetic, } 8.5 \% \text { Moisture }\end{array}$} \\
\hline & & $\begin{array}{c}\text { Feed } \\
\text { Rate }^{\#} \\
(\mathrm{mg} / \mathrm{min})\end{array}$ & $\begin{array}{c}\text { Emissions } \\
\text { Rate } \\
\text { (mg/min) }\end{array}$ & $\%$ Feed & $\mathrm{DF}$ & $\begin{array}{c}\text { Feed } \\
\text { Rate }^{\#} \\
(\mathrm{mg} / \mathrm{min})\end{array}$ & $\begin{array}{c}\text { Emissions } \\
\text { Rate } \\
\text { (mg/min) }\end{array}$ & $\%$ Feed & DF \\
\hline \multirow{22}{*}{ 童 } & Total $^{\$}$ & 110500 & 318 & 0.29 & 348 & 64440 & 64.7 & 0.10 & 995 \\
\hline & $\mathrm{Al}$ & 11413 & 16.5 & 0.14 & 692 & 6657 & 2.06 & 0.03 & 3235 \\
\hline & B & 4243 & 17.6 & 0.41 & 242 & 2475 & 2.60 & 0.11 & 951 \\
\hline & $\mathrm{Ba}$ & 40 & 0.25 & 0.63 & 158 & 24 & 0.27 & 1.15 & 86.8 \\
\hline & $\mathrm{Bi}$ & 460 & 3.51 & 0.76 & 131 & 268 & 0.58 & 0.21 & 467 \\
\hline & $\mathrm{Ca}$ & 3911 & 8.50 & 0.22 & 460 & 2282 & 1.35 & 0.06 & 1691 \\
\hline & $\mathrm{Cd}$ & 16 & 0.39 & 2.39 & 41.9 & 9 & $<0.10$ & $<1.06$ & $>94$ \\
\hline & $\mathrm{Cl}^{*}$ & 0 & 0.46 & $\mathrm{NC}$ & $\mathrm{NC}$ & 0 & $<0.10$ & $\mathrm{NC}$ & $\mathrm{NC}$ \\
\hline & $\mathrm{Cr}$ & 320 & 3.25 & 1.01 & 98.6 & 187 & 0.98 & 0.52 & 191 \\
\hline & $\mathrm{F}^{*}$ & 603 & 29.1 & 4.82 & 20.8 & 352 & 6.87 & 1.95 & 51.2 \\
\hline & $\mathrm{Fe}$ & 3713 & 14.5 & 0.39 & 256 & 2166 & 2.23 & 0.10 & 972 \\
\hline & $\mathrm{K}$ & 105 & 2.30 & 2.20 & 45.4 & 61 & 0.52 & 0.86 & 117 \\
\hline & $\mathrm{Li}$ & 1493 & 6.91 & 0.46 & 216 & 871 & 1.44 & 0.17 & 603 \\
\hline & $\mathrm{Mg}$ & 65 & 0.64 & 0.99 & 101 & 38 & 0.11 & 0.30 & 336 \\
\hline & $\mathrm{Na}$ & 6397 & 38.5 & 0.60 & 166 & 3732 & 9.08 & 0.24 & 411 \\
\hline & $\mathrm{Ni}$ & 283 & 0.86 & 0.30 & 330 & 165 & $<0.10$ & $<0.06$ & $>1650$ \\
\hline & $\mathrm{P}$ & 413 & 0.85 & 0.21 & 487 & 241 & 0.12 & 0.05 & 2008 \\
\hline & $\mathrm{Pb}$ & 343 & 2.38 & 0.69 & 144 & 200 & 0.55 & 0.28 & 361 \\
\hline & $\mathrm{S}^{*}$ & 72 & 4.74 & 6.58 & 15.2 & 42 & 2.36 & 5.62 & 17.8 \\
\hline & $\mathrm{Si}$ & 12832 & 19.3 & 0.15 & 664 & 7485 & 3.89 & 0.05 & 1926 \\
\hline & $\mathrm{Zn}$ & 58 & 0.48 & 0.83 & 121 & 34 & 0.22 & 0.66 & 152 \\
\hline & $\mathrm{Zr}$ & 260 & 0.52 & 0.20 & 497 & 152 & $<0.10$ & $<0.07$ & $>1516$ \\
\hline \multirow{4}{*}{ శ్ } & B & 4243 & 53.9 & 1.27 & 78.8 & 2475 & 26.8 & 1.08 & 92.2 \\
\hline & $\mathrm{Cl}$ & 0 & 8.83 & $\mathrm{NC}$ & $\mathrm{NC}$ & 0 & 3.76 & $\mathrm{NC}$ & $\mathrm{NC}$ \\
\hline & $\mathrm{F}$ & 603 & 151 & 25.0 & 4.0 & 352 & 117 & 33.4 & 3.0 \\
\hline & $\mathrm{S}$ & 72 & 25.4 & 35.3 & 2.8 & 42 & 9.80 & 23.3 & 4.3 \\
\hline
\end{tabular}

$\$$ - From gravimetric analysis of filters and particulate nitric acid rinses

\# - Feed rate calculated from target composition and steady state production rate

* - Calculated from direct analysis of nitric acid rinses

NA - Not Available

$\mathrm{NC}-$ Not Calculated 
The Catholic University of America Vitreous State Laboratory
ORP-56292 Rev. 0

Melt Rate Enhancement for High Aluminum HLW Glass Formulations

Final Report, VSL-08R1360-1, Rev. 0

Table 7.1. Results from DM100 Off-Gas Emission Samples (continued).

\begin{tabular}{|c|c|c|c|c|c|c|c|c|c|}
\hline & \multicolumn{4}{|c|}{ Test 3} & \multicolumn{4}{|c|}{ Test 4} \\
\hline & & \multicolumn{4}{|c|}{$\begin{array}{c}05 / 07 / 0809: 40-10: 40 \\
105.8 \% \text { Isokinetic, } 13.6 \% \text { Moisture }\end{array}$} & \multicolumn{4}{|c|}{$\begin{array}{c}05 / 09 / 0810: 43-11: 43 \\
100.6 \% \text { Isokinetic, } 10.3 \% \text { Moisture }\end{array}$} \\
\hline & & $\begin{array}{c}\text { Feed } \\
\text { Rate }^{\#} \\
(\mathrm{mg} / \mathrm{min})\end{array}$ & $\begin{array}{c}\text { Emissions } \\
\text { Rate } \\
\text { (mg/min) }\end{array}$ & $\%$ Feed & DF & $\begin{array}{c}\text { Feed } \\
\text { Rate }^{\#} \\
(\mathrm{mg} / \mathrm{min})\end{array}$ & $\begin{array}{c}\text { Emissions } \\
\text { Rate } \\
\text { (mg/min) }\end{array}$ & $\%$ Feed & DF \\
\hline \multirow{22}{*}{$\frac{\frac{3}{5}}{30}$} & Total $^{\$}$ & 122600 & 172 & 0.14 & 712 & 83200 & 32.6 & 0.04 & 2550 \\
\hline & $\mathrm{Al}$ & 12915 & 7.88 & 0.06 & 1638 & 8764 & 0.73 & 0.01 & 12037 \\
\hline & $\mathrm{B}$ & 5778 & 8.40 & 0.15 & 688 & 3920 & 0.54 & 0.01 & 7197 \\
\hline & $\mathrm{Ba}$ & 47 & 0.16 & 0.34 & 296 & 32 & 0.11 & 0.36 & 279 \\
\hline & $\mathrm{Bi}$ & 523 & 3.35 & 0.64 & 156 & 355 & 0.35 & 0.10 & 1005 \\
\hline & $\mathrm{Ca}$ & 4421 & 2.09 & 0.05 & 2116 & 3000 & 0.31 & 0.01 & 9773 \\
\hline & $\mathrm{Cd}$ & 19 & 0.36 & 1.90 & 52.7 & 13 & $<0.10$ & $<0.78$ & $>128$ \\
\hline & $\mathrm{Cl}^{*}$ & 0 & 19.0 & $\mathrm{NC}$ & $\mathrm{NC}$ & 0 & 12.5 & $\mathrm{NC}$ & $\mathrm{NC}$ \\
\hline & $\mathrm{Cr}$ & 366 & 3.11 & 0.85 & 118 & 249 & 0.54 & 0.22 & 462 \\
\hline & $\mathrm{F}^{*}$ & 683 & 18.6 & 2.72 & 36.8 & 463 & 7.33 & 1.58 & 63.2 \\
\hline & $\mathrm{Fe}$ & 4200 & 4.03 & 0.10 & 1042 & 2850 & 0.67 & 0.02 & 4243 \\
\hline & $\mathrm{K}$ & 122 & 1.23 & 1.00 & 99.6 & 83 & 0.25 & 0.31 & 328 \\
\hline & $\mathrm{Li}$ & 1688 & 3.74 & 0.22 & 451 & 1145 & 0.69 & 0.06 & 1651 \\
\hline & $\mathrm{Mg}$ & 70 & 0.24 & 0.34 & 293 & 47 & $<0.10$ & $<0.21$ & $>473$ \\
\hline & $\mathrm{Na}$ & 7237 & 21.7 & 0.30 & 334 & 4911 & 5.02 & 0.10 & 978 \\
\hline & $\mathrm{Ni}$ & 322 & 0.12 & 0.04 & 2791 & 218 & $<0.10$ & $<0.05$ & $>2184$ \\
\hline & $\mathrm{P}$ & 468 & 0.15 & 0.03 & 3202 & 317 & $<0.10$ & $<0.03$ & $>3173$ \\
\hline & $\mathrm{Pb}$ & 390 & 2.15 & 0.55 & 181 & 265 & 0.37 & 0.14 & 712 \\
\hline & S* & 80 & 6.23 & 7.79 & 12.8 & 54 & 2.00 & 3.70 & 27 \\
\hline & $\mathrm{Si}$ & 14519 & 6.27 & 0.04 & 2317 & 9852 & 1.10 & 0.01 & 8970 \\
\hline & $\mathrm{Zn}$ & 67 & 0.31 & 0.46 & 218 & 46 & 0.27 & 0.58 & 171 \\
\hline & $\mathrm{Zr}$ & 295 & 0.24 & 0.08 & 1221 & 200 & $<0.10$ & $<0.05$ & $>2004$ \\
\hline \multirow{4}{*}{$\mathscr{\mathscr { D }}$} & $\mathrm{B}$ & 5778 & 82.3 & 1.42 & 70.2 & 3920 & 19.1 & 0.49 & 205 \\
\hline & $\mathrm{Cl}$ & 0 & 8.37 & $\mathrm{NC}$ & $\mathrm{NC}$ & 0 & 6.26 & $\mathrm{NC}$ & $\mathrm{NC}$ \\
\hline & $\mathrm{F}$ & 683 & 206 & 30.2 & 3.3 & 463 & 88.4 & 19.1 & 5.2 \\
\hline & $\mathrm{S}$ & 80 & 38.6 & 48.3 & 2.1 & 54 & 16.6 & 30.6 & 3.3 \\
\hline
\end{tabular}


The Catholic University of America Vitreous State Laboratory
ORP-56292 Rev. 0

Melt Rate Enhancement for High Aluminum HLW Glass Formulations

Final Report, VSL-08R1360-1, Rev. 0

Table 7.1. Results from DM100 Off-Gas Emission Samples (continued).

\begin{tabular}{|c|c|c|c|c|c|c|c|c|c|}
\hline & \multicolumn{4}{|c|}{ Test 5} & \multicolumn{4}{|c|}{ Test 6} \\
\hline & & \multicolumn{4}{|c|}{$\begin{array}{c}06 / 04 / 0811: 25-12: 25 \\
102.8 \% \text { Isokinetic, } 14.3 \% \text { Moisture }\end{array}$} & \multicolumn{4}{|c|}{$\begin{array}{c}06 / 06 / 0812: 50-13: 50 \\
96.9 \% \text { Isokinetic, } 8.6 \% \text { Moisture }\end{array}$} \\
\hline & & $\begin{array}{c}\text { Feed } \\
\text { Rate }^{\#} \\
(\mathrm{mg} / \mathrm{min})\end{array}$ & $\begin{array}{c}\text { Emissions } \\
\text { Rate } \\
\text { (mg/min) }\end{array}$ & $\%$ Feed & $\mathrm{DF}$ & $\begin{array}{c}\text { Feed } \\
\text { Rate }^{\#} \\
(\mathrm{mg} / \mathrm{min})\end{array}$ & $\begin{array}{c}\text { Emissions } \\
\text { Rate } \\
\text { (mg/min) }\end{array}$ & $\%$ Feed & $\mathrm{DF}$ \\
\hline \multirow{22}{*}{$\frac{\frac{9}{a}}{3}$} & Total $^{\$}$ & 108900 & 144 & 0.13 & 756 & 58700 & 40.3 & 0.07 & 1457 \\
\hline & $\mathrm{Al}$ & 11992 & 3.11 & 0.03 & 3853 & 6457 & 0.74 & 0.01 & 8715 \\
\hline & $\mathrm{B}$ & 5365 & 7.37 & 0.14 & 728 & 2889 & 1.65 & 0.06 & 1751 \\
\hline & $\mathrm{Ba}$ & 44 & $<0.10$ & $<0.23$ & $>437$ & 24 & $<0.10$ & $<0.43$ & $>235$ \\
\hline & $\mathrm{Bi}$ & 485 & 2.37 & 0.49 & 204 & 261 & 0.35 & 0.13 & 742 \\
\hline & $\mathrm{Ca}$ & 4105 & 2.02 & 0.05 & 2037 & 2210 & 0.49 & 0.02 & 4481 \\
\hline & $\mathrm{Cd}$ & 17 & 0.20 & 1.12 & 89.1 & 9 & $<0.10$ & $<1.06$ & $>94$ \\
\hline & $\mathrm{Cl}^{*}$ & 0 & 13.8 & $\mathrm{NC}$ & $\mathrm{NC}$ & 0 & 9.37 & $\mathrm{NC}$ & $\mathrm{NC}$ \\
\hline & $\mathrm{Cr}$ & 340 & 2.47 & 0.73 & 138 & 183 & 0.68 & 0.37 & 269 \\
\hline & $\mathrm{F}^{*}$ & 634 & 19.9 & 3.14 & 31.9 & 341 & 5.53 & 1.62 & 61.7 \\
\hline & $\mathrm{Fe}$ & 3900 & 4.47 & 0.11 & 873 & 2100 & 1.16 & 0.06 & 1818 \\
\hline & $\mathrm{K}$ & 113 & 0.95 & 0.84 & 119 & 61 & 0.24 & 0.39 & 258 \\
\hline & $\mathrm{Li}$ & 1567 & 3.57 & 0.23 & 439 & 844 & 0.94 & 0.11 & 899 \\
\hline & $\mathrm{Mg}$ & 65 & 0.16 & 0.25 & 398 & 35 & $<0.10$ & $<0.29$ & $>348$ \\
\hline & $\mathrm{Na}$ & 6720 & 18.8 & 0.28 & 357 & 3619 & 5.45 & 0.15 & 664 \\
\hline & $\mathrm{Ni}$ & 299 & $<0.10$ & $<0.03$ & $>2988$ & 161 & $<0.10$ & $<0.06$ & $>1609$ \\
\hline & $\mathrm{P}$ & 434 & 0.10 & 0.02 & 4190 & 234 & $<0.10$ & $<0.04$ & $>2338$ \\
\hline & $\mathrm{Pb}$ & 362 & 1.48 & 0.41 & 245 & 195 & 0.33 & 0.17 & 591 \\
\hline & S* & 74 & 6.08 & 8.22 & 12.2 & 40 & 1.84 & 4.60 & 21.7 \\
\hline & $\mathrm{Si}$ & 13482 & 4.07 & 0.03 & 3316 & 7260 & 1.01 & 0.01 & 7173 \\
\hline & $\mathrm{Zn}$ & 63 & 0.20 & 0.31 & 320 & 34 & 0.12 & 0.36 & 280 \\
\hline & $\mathrm{Zr}$ & 274 & 0.24 & 0.09 & 1136 & 148 & $<0.10$ & $<0.07$ & $>1477$ \\
\hline \multirow{4}{*}{ రే } & $\mathrm{B}$ & 5365 & 65.3 & 1.22 & 82.1 & 2889 & 19.7 & 0.68 & 147 \\
\hline & $\mathrm{Cl}$ & 0 & 7.94 & $\mathrm{NC}$ & $\mathrm{NC}$ & 0 & 5.95 & $\mathrm{NC}$ & $\mathrm{NC}$ \\
\hline & $\mathrm{F}$ & 634 & 206 & 32.6 & 3.1 & 341 & 81.0 & 23.7 & 4.2 \\
\hline & $\mathrm{S}$ & 74 & 26.1 & 35.2 & 2.8 & 40 & 14.0 & 35.1 & 2.8 \\
\hline
\end{tabular}

$\$$ - From gravimetric analysis of filters and particulate nitric acid rinses

\# - Feed rate calculated from target composition and steady state production rate

* - Calculated from direct analysis of nitric acid rinses

$\mathrm{NC}-$ Not Calculated 
Table 7.1. Results from DM100 Off-Gas Emission Samples (continued).

\begin{tabular}{|c|c|c|c|c|c|c|c|c|c|}
\hline & \multicolumn{4}{|c|}{ Test 7} & \multicolumn{4}{|c|}{ Test 8} \\
\hline & & \multicolumn{4}{|c|}{$\begin{array}{c}\text { 6/24/08 19:44-20:44 } \\
98.5 \% \text { Isokinetic, } 14.6 \% \text { Moisture }\end{array}$} & \multicolumn{4}{|c|}{$\begin{array}{c}06 / 27 / 08 / 0817: 26-18: 26 \\
103.5 \% \text { Isokinetic, } 10.4 \% \text { Moisture }\end{array}$} \\
\hline & & $\begin{array}{c}\text { Feed } \\
\text { Rate }^{\#} \\
(\mathrm{mg} / \mathrm{min})\end{array}$ & $\begin{array}{c}\text { Emissions } \\
\text { Rate } \\
(\mathrm{mg} / \mathrm{min})\end{array}$ & $\%$ Feed & $\mathrm{DF}$ & $\begin{array}{c}\text { Feed } \\
\text { Rate }^{\#} \\
(\mathrm{mg} / \mathrm{min})\end{array}$ & \begin{tabular}{|c} 
Emissions \\
Rate \\
(mg/min)
\end{tabular} & $\%$ Feed & $\mathrm{DF}$ \\
\hline \multirow{22}{*}{$\frac{\frac{3}{5}}{3}$} & Total $^{\$}$ & 138200 & 171 & 0.12 & 806 & 87500 & 45.2 & 0.05 & 1938 \\
\hline & $\mathrm{Al}$ & 14266 & 13.8 & 0.10 & 1038 & 9035 & 2.77 & 0.03 & 3261 \\
\hline & B & 6700 & 8.58 & 0.13 & 781 & 4243 & 1.99 & 0.05 & 2127 \\
\hline & $\mathrm{Ba}$ & 50 & $<0.10$ & $<0.20$ & $>504$ & 32 & $<0.10$ & $<0.31$ & $>319$ \\
\hline & $\mathrm{Bi}$ & 575 & 2.56 & 0.44 & 225 & 364 & 0.50 & 0.14 & 726 \\
\hline & $\mathrm{Ca}$ & 4487 & 2.42 & 0.05 & 1852 & 2842 & 0.47 & 0.02 & 6086 \\
\hline & $\mathrm{Cd}$ & 20 & 0.14 & 0.71 & 141 & 13 & $<0.10$ & $<0.78$ & $>128$ \\
\hline & $\mathrm{Cl}^{*}$ & 0 & 0.21 & $\mathrm{NC}$ & $\mathrm{NC}$ & 0 & 8.79 & $\mathrm{NC}$ & $\mathrm{NC}$ \\
\hline & $\mathrm{Cr}$ & 400 & 1.94 & 0.48 & 207 & 254 & 0.77 & 0.30 & 329 \\
\hline & $\mathrm{F}^{*}$ & 754 & 19.3 & 2.56 & 39.1 & 477 & 5.53 & 1.16 & 86.3 \\
\hline & $\mathrm{Fe}$ & 4641 & 4.09 & 0.09 & 1136 & 2939 & 0.91 & 0.03 & 3235 \\
\hline & $\mathrm{K}$ & 131 & 1.19 & 0.91 & 110 & 83 & 0.40 & 0.48 & 208 \\
\hline & $\mathrm{Li}$ & 1866 & 3.48 & 0.19 & 537 & 1182 & 1.11 & 0.09 & 1065 \\
\hline & $\mathrm{Mg}$ & 81 & 0.22 & 0.27 & 369 & 52 & $<0.10$ & $<0.19$ & $>516$ \\
\hline & $\mathrm{Na}$ & 7996 & 20.1 & 0.25 & 399 & 5064 & 7.38 & 0.15 & 686 \\
\hline & $\mathrm{Ni}$ & 354 & 0.29 & 0.08 & 1219 & 224 & $<0.10$ & $<0.04$ & $>2240$ \\
\hline & $\mathrm{P}$ & 516 & 0.41 & 0.08 & 1258 & 327 & 0.38 & 0.12 & 857 \\
\hline & $\mathrm{Pb}$ & 428 & 1.08 & 0.25 & 395 & 271 & 0.39 & 0.14 & 701 \\
\hline & $\mathrm{S}^{*}$ & 90 & 4.41 & 4.90 & 20.4 & 57 & 1.60 & 2.81 & 35.6 \\
\hline & $\mathrm{Si}$ & 14199 & 6.42 & 0.05 & 2211 & 8993 & 1.56 & 0.02 & 5776 \\
\hline & $\mathrm{Zn}$ & 72 & 0.10 & 0.14 & 700 & 46 & $<0.10$ & $<0.22$ & $>458$ \\
\hline & $\mathrm{Zr}$ & 325 & 0.15 & 0.05 & 2209 & 206 & $<0.10$ & $<0.05$ & $>2057$ \\
\hline \multirow{4}{*}{$\mathscr{\mathscr { J }}$} & B & 6700 & 55.2 & 0.82 & 121 & 4243 & 24.1 & 0.57 & 176 \\
\hline & $\mathrm{Cl}$ & 0 & 14.8 & $\mathrm{NC}$ & $\mathrm{NC}$ & 0 & 8.76 & $\mathrm{NC}$ & $\mathrm{NC}$ \\
\hline & $\mathrm{F}$ & 754 & 175 & 23.2 & 4.3 & 477 & 99.9 & 20.9 & 4.8 \\
\hline & $\mathrm{S}$ & 90 & 40.9 & 45.4 & 2.2 & 57 & 15.4 & 27.0 & 3.7 \\
\hline
\end{tabular}

$\$$ - From gravimetric analysis of filters and particulate nitric acid rinses

\# - Feed rate calculated from target composition and steady state production rate

* - Calculated from direct analysis of nitric acid rinses

$\mathrm{NC}-$ Not Calculated 
The Catholic University of America Vitreous State Laboratory
ORP-56292 Rev. 0

Melt Rate Enhancement for High Aluminum HLW Glass Formulations

Final Report, VSL-08R1360-1, Rev. 0

Table 7.2. Results from DM1200 Off-Gas Emission Samples.

\begin{tabular}{|c|c|c|c|c|c|c|c|c|c|}
\hline & \multicolumn{4}{|c|}{ Test 1} & \multicolumn{4}{|c|}{ Test 2} \\
\hline & & \multicolumn{4}{|c|}{$\begin{array}{c}08 / 07 / 0819: 18-20: 18 \\
108.4 \% \text { Isokinetic, } 39.4 \% \text { Moisture }\end{array}$} & \multicolumn{4}{|c|}{$\begin{array}{c}08 / 12 / 0813: 10-14: 10 \\
96.9 \% \text { Isokinetic, } 29.2 \% \text { Moisture }\end{array}$} \\
\hline & & $\begin{array}{c}\text { Feed } \\
\text { Rate }^{\#} \\
(\mathrm{mg} / \mathrm{min})\end{array}$ & $\begin{array}{c}\text { Emissions } \\
\text { Rate } \\
\text { (mg/min) }\end{array}$ & $\%$ Feed & DF & $\begin{array}{c}\text { Feed } \\
\text { Rate }^{\#} \\
(\mathrm{mg} / \mathrm{min})\end{array}$ & $\begin{array}{c}\text { Emissions } \\
\text { Rate } \\
\text { (mg/min) }\end{array}$ & $\%$ Feed & DF \\
\hline \multirow{22}{*}{ 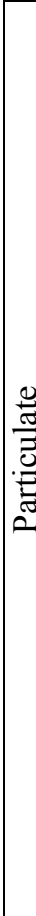 } & Total $^{\$}$ & 1569000 & 2453 & 0.16 & 640 & 1109000 & 1114 & 0.10 & 995 \\
\hline & $\mathrm{Al}$ & 158508 & 116 & 0.07 & 1367 & 110955 & 50.5 & 0.05 & 2194 \\
\hline & $\mathrm{B}$ & 58927 & 137 & 0.23 & 430 & 41249 & 59.9 & 0.15 & 689 \\
\hline & $\mathrm{Ba}$ & 560 & 2.65 & 0.47 & 211 & 392 & 0.69 & 0.18 & 564 \\
\hline & $\mathrm{Bi}$ & 6391 & 26.6 & 0.42 & 240 & 4474 & 13.1 & 0.29 & 341 \\
\hline & $\mathrm{Ca}$ & 54324 & 53.5 & 0.10 & 1016 & 38027 & 22.7 & 0.06 & 1675 \\
\hline & $\mathrm{Cd}$ & 224 & 2.19 & 0.98 & 102 & 157 & 0.70 & 0.44 & 225 \\
\hline & $\mathrm{Cl}^{*}$ & 0 & 14.1 & $\mathrm{NC}$ & $\mathrm{NC}$ & 0 & 9.50 & $\mathrm{NC}$ & $\mathrm{NC}$ \\
\hline & $\mathrm{Cr}$ & 4447 & 24.7 & 0.55 & 180 & 3113 & 15.1 & 0.48 & 207 \\
\hline & $\mathrm{F}^{*}$ & 8375 & 332 & 3.97 & 25.2 & 5863 & 211 & 3.60 & 27.8 \\
\hline & $\mathrm{Fe}$ & 51570 & 111 & 0.21 & 466 & 36099 & 49.0 & 0.14 & 737 \\
\hline & $\mathrm{K}$ & 1453 & 16.2 & 1.11 & 89.7 & 1017 & 8.47 & 0.83 & 120 \\
\hline & $\mathrm{Li}$ & 20729 & 46.3 & 0.22 & 448 & 14511 & 21.8 & 0.15 & 667 \\
\hline & $\mathrm{Mg}$ & 904 & 5.61 & 0.62 & 161 & 633 & 2.27 & 0.36 & 278.4 \\
\hline & $\mathrm{Na}$ & 88847 & 310 & 0.35 & 287 & 62193 & 141 & 0.23 & 441 \\
\hline & $\mathrm{Ni}$ & 3929 & 4.45 & 0.11 & 883 & 2750 & 2.14 & 0.08 & 1285 \\
\hline & $\mathrm{P}$ & 5731 & 7.41 & 0.13 & 773 & 4011 & 3.27 & 0.08 & 1226 \\
\hline & $\mathrm{Pb}$ & 4758 & 15.4 & 0.32 & 308 & 3330 & 8.91 & 0.27 & 374 \\
\hline & S* & 1002 & 79.5 & 7.93 & 12.6 & 701 & 27.3 & 3.89 & 25.7 \\
\hline & $\mathrm{Si}$ & 178221 & 130 & 0.07 & 1368 & 124755 & 60.1 & 0.05 & 2074 \\
\hline & $\mathrm{Zn}$ & 803 & 3.01 & 0.37 & 267 & 562 & 1.15 & 0.20 & 489 \\
\hline & $\mathrm{Zr}$ & 3609 & 2.79 & 0.08 & 1294 & 2526 & 1.12 & 0.04 & 2263 \\
\hline \multirow{4}{*}{ : } & $\mathrm{B}$ & 58927 & 846 & 1.44 & 69.7 & 41249 & 441.8 & 1.07 & 93.4 \\
\hline & $\mathrm{Cl}$ & 0 & 168 & $\mathrm{NC}$ & $\mathrm{NC}$ & 0 & 83.6 & $\mathrm{NC}$ & $\mathrm{NC}$ \\
\hline & $\mathrm{F}$ & 8375 & 1914 & 22.9 & 4.4 & 5863 & 1091 & 18.6 & 5.4 \\
\hline & $\mathrm{S}$ & 1002 & 241 & 24.1 & 4.2 & 701 & 181 & 25.8 & 3.9 \\
\hline
\end{tabular}

$\$$ - From gravimetric analysis of filters and particulate nitric acid rinses

\# - Feed rate calculated from target composition and steady state production rate

* - Calculated from direct analysis of nitric acid rinses

$\mathrm{NC}-$ Not Calculated 
The Catholic University of America Vitreous State Laboratory
ORP-56292 Rev. 0

Melt Rate Enhancement for High Aluminum HLW Glass Formulations

Final Report, VSL-08R1360-1, Rev. 0

Table 7.2. Results from DM1200 Off-Gas Emission Samples (continued).

\begin{tabular}{|c|c|c|c|c|c|}
\hline & \multicolumn{4}{|c|}{$\begin{array}{c}08 / 14 / 0813: 18-13: 50 \\
69.6 \% \text { Isokinetic, } 26.9 \% \text { Moisture }\end{array}$} \\
\hline & & $\begin{array}{c}\text { Feed } \\
\text { Rate }^{\#} \\
(\mathrm{mg} / \mathrm{min})\end{array}$ & $\begin{array}{c}\text { Emissions } \\
\text { Rate } \\
\text { (mg/min) }\end{array}$ & $\%$ Feed & DF \\
\hline \multirow{22}{*}{ 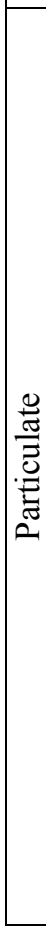 } & Total $^{\$}$ & 1120500 & 2351 & 0.21 & 477 \\
\hline & $\mathrm{Al}$ & 110955 & 126 & 0.11 & 881 \\
\hline & B & 41249 & 152 & 0.37 & 271 \\
\hline & $\mathrm{Ba}$ & 392 & 1.55 & 0.40 & 253 \\
\hline & $\mathrm{Bi}$ & 4474 & 27.9 & 0.62 & 160 \\
\hline & $\mathrm{Ca}$ & 38027 & 59.7 & 0.16 & 637 \\
\hline & $\mathrm{Cd}$ & 157 & 1.09 & 0.69 & 144 \\
\hline & $\mathrm{Cl}^{*}$ & 0 & 5.23 & $\mathrm{NC}$ & $\mathrm{NC}$ \\
\hline & $\mathrm{Cr}$ & 3113 & 19.2 & 0.62 & 162 \\
\hline & $\mathrm{F}^{*}$ & 5863 & 351 & 5.99 & 16.7 \\
\hline & $\mathrm{Fe}$ & 36099 & 109 & 0.30 & 330 \\
\hline & $\mathrm{K}$ & 1017 & 14.6 & 1.43 & 69.9 \\
\hline & $\mathrm{Li}$ & 14511 & 38.3 & 0.26 & 379 \\
\hline & $\mathrm{Mg}$ & 633 & 4.82 & 0.76 & 131 \\
\hline & $\mathrm{Na}$ & 62193 & 302 & 0.49 & 206 \\
\hline & $\mathrm{Ni}$ & 2750 & 4.92 & 0.18 & 559 \\
\hline & $\mathrm{P}$ & 4011 & 7.12 & 0.18 & 564 \\
\hline & $\mathrm{Pb}$ & 3330 & 12.7 & 0.38 & 262 \\
\hline & $\mathrm{S}^{*}$ & 701 & 50.7 & 7.24 & 13.8 \\
\hline & $\mathrm{Si}$ & 124755 & 146 & 0.12 & 852 \\
\hline & $\mathrm{Zn}$ & 562 & 2.20 & 0.39 & 255 \\
\hline & $\mathrm{Zr}$ & 2526 & 2.47 & 0.10 & 1023 \\
\hline \multirow{4}{*}{$\stackrel{\mathscr{ే}}{0}$} & B & 41249 & 539 & 1.31 & 76.5 \\
\hline & $\mathrm{Cl}$ & 0 & 107 & $\mathrm{NC}$ & $\mathrm{NC}$ \\
\hline & $\mathrm{F}$ & 5863 & 1459 & 24.9 & 4.0 \\
\hline & $\mathrm{S}$ & 701 & 229 & 32.6 & 3.1 \\
\hline
\end{tabular}

$\$$ - From gravimetric analysis of filters and particulate nitric acid rinses

\# - Feed rate calculated from target composition and steady state production rate

* - Calculated from direct analysis of nitric acid rinses

$\mathrm{NC}$ - Not Calculated 
The Catholic University of America Vitreous State Laboratory
ORP-56292 Rev. 0

Melt Rate Enhancement for High Aluminum HLW Glass Formulations

Final Report, VSL-08R1360-1, Rev. 0

Table 7.3. Concentrations (ppmv) of Selected Species in DM100 Exhaust Measured by FTIR Spectroscopy.

\begin{tabular}{|c|c|c|c|c|c|c|c|c|}
\hline & \multicolumn{2}{|c|}{$\mathbf{1}$} & \multicolumn{2}{|c|}{$\mathbf{2}$} & \multicolumn{2}{|c|}{3} & \multicolumn{2}{|c|}{4} \\
\cline { 2 - 9 } & Avg. & Range & Avg. & Range & Avg. & Range & Avg. & Range \\
\hline $\mathrm{N}_{2} \mathrm{O}$ & $<1.0$ & $<1.0-1.5$ & $<1.0$ & $<1.0-1.2$ & $<1.0$ & $<1.0-1.5$ & $<1.0$ & $<1.0-1.9$ \\
\hline $\mathrm{NO}$ & 88.0 & $<1.0-410$ & 51.3 & $5.2-232$ & 84.0 & $<1.0-248$ & 59.9 & $1.1-250$ \\
\hline $\mathrm{NO}_{2}$ & 5.0 & $<1.0-53.5$ & 4.1 & $<1.0-37.3$ & 6.3 & $<1.0-46.4$ & 8.9 & $<1.0-71.0$ \\
\hline $\mathrm{NH}_{3}$ & $<1.0$ & NA & $<1.0$ & NA & $<1.0$ & NA & $<1.0$ & NA \\
\hline $\mathrm{H}_{2} \mathrm{O}[\%]$ & 7.0 & $0.8-22.2$ & 4.3 & $1.3-14.5$ & 7.4 & $2.3-19.1$ & 6.3 & $0.9-17.8$ \\
\hline $\mathrm{CO}_{2}$ & 1337 & $352-4952$ & 1078 & $382-3803$ & 1629 & $92-3690$ & 1340 & $56-4179$ \\
\hline $\begin{array}{c}\mathrm{Nitrous} \\
\text { Acid }\end{array}$ & $<1.0$ & NA & $<1.0$ & NA & $<1.0$ & NA & $<1.0$ & NA \\
\hline $\begin{array}{c}\mathrm{Nitric} \\
\mathrm{Acid}\end{array}$ & $<1.0$ & NA & $<1.0$ & NA & $<1.0$ & NA & $<1.0$ & NA \\
\hline $\mathrm{HCN}$ & $<1.0$ & NA & $<1.0$ & NA & $<1.0$ & NA & $<1.0$ & NA \\
\hline $\mathrm{SO} \mathrm{O}_{2}$ & 4.1 & $<1.0-8.8$ & 1.9 & $<1.0-7.9$ & 3.4 & $<1.0-9.7$ & 2.3 & $<1.0-6.1$ \\
\hline $\mathrm{CO}$ & $<1.0$ & $<1.0-2.9$ & $<1.0$ & $<1.0-70.1$ & $<1.0$ & $<1.0-3.4$ & $<1.0$ & $<1.0-2.8$ \\
\hline $\mathrm{HCl}$ & $<1.0$ & $<1.0-2.1$ & $<1.0$ & $<1.0-1.2$ & 1.0 & $<1.0-2.5$ & $<1.0$ & $<1.0-2.4$ \\
\hline $\mathrm{HF}$ & 13.5 & $<1.0-41.4$ & 17.2 & $9.6-38.4$ & 15.5 & $1.3-30.6$ & 22.1 & $7.8-37.3$ \\
\hline
\end{tabular}

NA : Not applicable. 
The Catholic University of America Vitreous State Laboratory
ORP-56292 Rev. 0

Melt Rate Enhancement for High Aluminum HLW Glass Formulations

Final Report, VSL-08R1360-1, Rev. 0

Table 7.3. Concentrations (ppmv) of Selected Species in DM100 Exhaust Measured by FTIR Spectroscopy (continued).

\begin{tabular}{|c|c|c|c|c|c|c|c|c|}
\hline & \multicolumn{3}{|c|}{$\mathbf{5}$} & \multicolumn{2}{|c|}{$\mathbf{6}$} & \multicolumn{2}{c|}{$\mathbf{7}$} & \multicolumn{2}{c|}{$\mathbf{8}$} \\
\cline { 2 - 9 } & Avg. & Range & Avg. & Range & Avg. & Range & Avg. & Range \\
\hline $\mathrm{N}_{2} \mathrm{O}$ & $<1.0$ & $<1.0-1.0$ & $<1.0$ & $<1.0-1.2$ & $<1.0$ & $<1.0-2.8$ & $<1.0$ & $<1.0-2.9$ \\
\hline $\mathrm{NO}$ & 50.4 & $<1.0-270$ & 31.8 & $<1.0-254$ & 86.8 & $36.7-307$ & 55.4 & $2.2-282$ \\
\hline $\mathrm{NO}_{2}$ & 3.2 & $<1.0-54.9$ & 2.5 & $<1.0-73.0$ & 6.9 & $<1.0-51.7$ & 5.4 & $<1.0-52.5$ \\
\hline $\mathrm{NH}_{3}$ & $<1.0$ & NA & $<1.0$ & $<1.0-9.2$ & $<1.0$ & NA & $<1.0$ & NA \\
\hline $\mathrm{H}_{2} \mathrm{O}[\%]$ & 4.6 & $2.0-10.2$ & 4.0 & $1.8-11.0$ & 7.5 & $3.6-16.9$ & 5.6 & $1.5-14.6$ \\
\hline $\mathrm{CO}_{2}$ & 1073 & $<1.0-3402$ & 790 & $<1.0-3860$ & 1836 & $922-5169$ & 1336 & $369-5208$ \\
\hline Nitrous Acid & $<1.0$ & NA & $<1.0$ & NA & $<1.0$ & NA & $<1.0$ & NA \\
\hline Nitric Acid & $<1.0$ & NA & $<1.0$ & $<1.0-3.9$ & $<1.0$ & NA & $<1.0$ & NA \\
\hline $\mathrm{HCN}$ & $<1.0$ & NA & $<1.0$ & NA & $<1.0$ & NA & $<1.0$ & NA \\
\hline $\mathrm{SO}$ & 2.2 & $<1.0-9.0$ & 1.2 & $<1.0-20.2$ & 6.0 & $1.1-14.2$ & 3.6 & $<1.0-16.5$ \\
\hline $\mathrm{CO}$ & $<1.0$ & $<1.0-1.0$ & $<1.0$ & $<1.0-1.6$ & $<1.0$ & $<1.0-3.2$ & $<1.0$ & $<1.0-3.1$ \\
\hline $\mathrm{HCl}$ & $<1.0$ & $<1.0-1.2$ & $<1.0$ & $<1.0-2.0$ & 1.5 & $1.5-3.0$ & $<1.0$ & $<1.0-1.4$ \\
\hline $\mathrm{HF}$ & 8.6 & $2.2-15.7$ & 11.9 & $8.1-25.4$ & 29.3 & $9.5-41.9$ & 23.9 & $17.9-34.0$ \\
\hline
\end{tabular}

NA : Not applicable. 
The Catholic University of America Vitreous State Laboratory
ORP-56292 Rev. 0

Melt Rate Enhancement for High Aluminum HLW Glass Formulations

Final Report, VSL-08R1360-1, Rev. 0

Table 7.4 Concentrations [ppmv] of Selected Species in DM1200 Test 1 Exhaust Measured by FTIR Spectroscopy.

\begin{tabular}{|c|c|c|c|c|c|c|c|c|c|}
\hline & \multicolumn{3}{|c|}{ Melter outlet } & \multicolumn{3}{c|}{ WESP outlet } & \multicolumn{3}{c|}{ PBS outlet } \\
\cline { 2 - 11 } & Aver. & Min. & Max. & Aver. & Min. & Max. & Aver. & Min. & Max. \\
\hline $\mathrm{N}_{2} \mathrm{O}$ & 1.3 & 0.7 & 2.0 & 1.6 & $<1.0$ & 10.9 & 1.4 & $<1.0$ & 1.7 \\
\hline $\mathrm{NO}$ & 594 & 361 & 751 & 611 & 12.3 & 1303 & 520 & 260 & 626 \\
\hline $\mathrm{NO}_{2}$ & 68.6 & 44.1 & 78.9 & 120 & $<1.0$ & 424 & 106 & 54.8 & 136 \\
\hline $\mathrm{NH}_{3}$ & $<1.0$ & $<1.0$ & $<1.0$ & $<1.0$ & $<1.0$ & $<1.0$ & $<1.0$ & $<1.0$ & $<1.0$ \\
\hline $\mathrm{H}_{2} \mathrm{O} \%$ & 32.9 & 27.2 & 35.2 & 8.5 & 1.6 & 16.1 & 3.6 & 3.1 & 3.8 \\
\hline $\mathrm{CO}_{2} \%$ & 0.73 & 0.47 & 0.78 & 0.75 & 0.01 & 1.89 & 0.79 & 0.42 & 0.95 \\
\hline $\mathrm{Nitrous} \mathrm{Acid}^{2}$ & 1.7 & 1.2 & 2.0 & 2.4 & $<1.0$ & 7.2 & $<1.0$ & $<1.0$ & $<1.0$ \\
\hline Nitric Acid & 1.4 & 0.2 & 2.0 & 1.5 & $<1.0$ & 5.1 & $<1.0$ & $<1.0$ & $<1.0$ \\
\hline $\mathrm{HCN}$ & $<1.0$ & $<1.0$ & $<1.0$ & $<1.0$ & $<1.0$ & 3.2 & $<1.0$ & $<1.0$ & $<1.0$ \\
\hline $\mathrm{SO}$ & 5.1 & 3.3 & 7.3 & $<1.0$ & $<1.0$ & 7.0 & $<1.0$ & $<1.0$ & $<1.0$ \\
\hline $\mathrm{CO}$ & 2.5 & 2.0 & 3.0 & 2.9 & $<1.0$ & 15.4 & 2.0 & 1.0 & 3.0 \\
\hline $\mathrm{HCl}$ & $<1.0$ & $<1.0$ & $<1.0$ & $<1.0$ & $<1.0$ & $<1.0$ & $<1.0$ & $<1.0$ & $<1.0$ \\
\hline $\mathrm{HF}$ & 14.6 & 10.9 & 16.3 & 4.5 & 1.0 & 7.8 & 2.5 & 2.3 & 2.8 \\
\hline
\end{tabular}


Table 7.5. Concentrations [ppmv] of Selected Species in DM1200 Test 2 Exhaust Measured by FTIR Spectroscopy.

\begin{tabular}{|c|c|c|c|c|c|c|c|c|c|c|c|c|}
\hline & \multicolumn{3}{|c|}{ Melter outlet } & \multicolumn{3}{|c|}{ SBS outlet } & \multicolumn{3}{c|}{ WESP outlet } & \multicolumn{3}{c|}{ PBS outlet } \\
\cline { 2 - 16 } & Aver. & Min. & Max. & Aver. & Min. & Max. & Aver. & Min. & Max. & Aver. & Min. & Max. \\
\hline $\mathrm{N}_{2} \mathrm{O}$ & 1.0 & $<1.0$ & 1.8 & 2.3 & 1.6 & 5.5 & 1.5 & $<1.0$ & 4.9 & 2.0 & $<1.0$ & 4.3 \\
\hline $\mathrm{NO}$ & 459 & 75 & 659 & 561 & 364 & 926 & 397 & 85 & 927 & 399 & 243 & 704 \\
\hline $\mathrm{NO}_{2}$ & 73.6 & 28.6 & 130 & 107 & 65.9 & 264 & 92.7 & 22.9 & 321 & 90.2 & 36.3 & 186 \\
\hline $\mathrm{NH}_{3}$ & $<1.0$ & $<1.0$ & 1.6 & $<1.0$ & $<1.0$ & $<1.0$ & $<1.0$ & $<1.0$ & $<1.0$ & $<1.0$ & $<1.0$ & $<1.0$ \\
\hline $\mathrm{H}_{2} \mathrm{O} \%$ & 32.3 & 26.9 & 53.5 & 7.9 & 7.5 & 8.3 & 6.9 & 5.5 & 11.0 & 3.2 & 3.0 & 4.6 \\
\hline $\mathrm{CO}_{2} \%$ & 0.83 & 0.62 & 1.15 & 0.77 & 0.56 & 1.27 & 0.59 & 0.23 & 1.23 & 0.60 & 0.39 & 1.06 \\
\hline $\mathrm{Nitrous}$ Acid & $<1.0$ & $<1.0$ & 2.0 & 1.3 & 1.0 & 2.7 & 1.4 & $<1.0$ & 4.4 & $<1.0$ & $<1.0$ & $<1.0$ \\
\hline $\mathrm{Nitric} \mathrm{Acid}$ & $<1.0$ & $<1.0$ & 1.3 & $<1.0$ & $<1.0$ & 1.8 & $<1.0$ & $<1.0$ & 2.4 & $<1.0$ & $<1.0$ & 9.3 \\
\hline $\mathrm{HCN}$ & $<1.0$ & $<1.0$ & $<1.0$ & $<1.0$ & $<1.0$ & $<1.0$ & $<1.0$ & $<1.0$ & $<1.0$ & $<1.0$ & $<1.0$ & $<1.0$ \\
\hline $\mathrm{SO}$ & 18.3 & 10.6 & 23.3 & 7.8 & 4.4 & 11.0 & 4.5 & $<1.0$ & 9.5 & 2.6 & $<1.0$ & 5.9 \\
\hline $\mathrm{CO}$ & 5.9 & 1.5 & 98.7 & 5.8 & 2.4 & 83.7 & 3.3 & $<1.0$ & 22.3 & 5.0 & 1.0 & 140 \\
\hline $\mathrm{HCl}$ & $<1.0$ & $<1.0$ & 5.2 & $<1.0$ & $<1.0$ & $<1.0$ & $<1.0$ & $<1.0$ & 1.2 & $<1.0$ & $<1.0$ & 15.4 \\
\hline $\mathrm{HF}$ & 20.8 & 9.7 & 54.8 & 9.9 & 9.3 & 10.3 & 5.8 & 2.8 & 12.2 & 6.1 & 4.5 & 28.4 \\
\hline
\end{tabular}


The Catholic University of America Vitreous State Laboratory
ORP-56292 Rev. 0

Melt Rate Enhancement for High Aluminum HLW Glass Formulations

Final Report, VSL-08R1360-1, Rev. 0

Table 7.6. Concentrations [ppmv] of Selected Species in DM1200 Test 3 Exhaust Measured by FTIR Spectroscopy.

\begin{tabular}{|c|c|c|c|c|c|c|c|c|c|c|c|c|}
\hline & \multicolumn{3}{|c|}{ Melter outlet } & \multicolumn{3}{c|}{ SBS outlet } & \multicolumn{3}{c|}{ WESP outlet } & \multicolumn{3}{c|}{ PBS outlet } \\
\cline { 2 - 15 } & Aver. & Min. & Max. & Aver. & Min. & Max. & Aver. & Min. & Max. & Aver. & Min. & Max. \\
\hline $\mathrm{N}_{2} \mathrm{O}$ & 1.5 & 1.2 & 1.7 & 2.6 & 1.3 & 4.2 & 2.1 & $<1.0$ & 11.9 & 2.3 & $<1.0$ & 6.2 \\
\hline $\mathrm{NO}$ & 423 & 276 & 673 & 550 & 235 & 778 & 415 & 118 & 631 & 375 & $<1.0$ & 725 \\
\hline $\mathrm{NO}_{2}$ & 69.0 & 54.5 & 77.6 & 105 & 41.9 & 206 & 94.8 & 22.8 & 178 & 74.8 & $<1.0$ & 220 \\
\hline $\mathrm{NH}_{3}$ & $<1.0$ & $<1.0$ & $<1.0$ & $<1.0$ & $<1.0$ & $<1.0$ & $<1.0$ & $<1.0$ & $<1.0$ & $<1.0$ & $<1.0$ & 1.4 \\
\hline $\mathrm{H}_{2} \mathrm{O} \%$ & 29.9 & 26.1 & 35.6 & 8.1 & 7.0 & 8.9 & 7.2 & 6.5 & 18.4 & 3.1 & 2.4 & 4.4 \\
\hline $\mathrm{CO}_{2} \%$ & 0.67 & 0.46 & 0.86 & 0.75 & 0.38 & 1.16 & 0.58 & $<1.0$ & 0.94 & 0.50 & $<1.0$ & 1.20 \\
\hline Nitrous Acid & $<1.0$ & $<1.0$ & 1.7 & 1.2 & $<1.0$ & 2.3 & 1.4 & $<1.0$ & 2.6 & 0.4 & $<1.0$ & 1.2 \\
\hline Nitric Acid & $<1.0$ & $<1.0$ & 1.2 & 0.8 & $<1.0$ & 1.6 & $<1.0$ & $<1.0$ & 1.8 & $<1.0$ & $<1.0$ & $<1.0$ \\
\hline $\mathrm{HCN}$ & $<1.0$ & $<1.0$ & $<1.0$ & $<1.0$ & $<1.0$ & $<1.0$ & $<1.0$ & $<1.0$ & $<1.0$ & $<1.0$ & $<1.0$ & $<1.0$ \\
\hline $\mathrm{SO}$ & 17.1 & 11.7 & 22.8 & 7.5 & 3.3 & 11.8 & 5.9 & 1.3 & 11.6 & 2.1 & $<1.0$ & 7.0 \\
\hline $\mathrm{CO}$ & 3.6 & 2.4 & 4.6 & 3.8 & 1.1 & 10.3 & 4.0 & $<1.0$ & 96.8 & 3.1 & $<1.0$ & 32.7 \\
\hline $\mathrm{HCl}$ & $<1.0$ & $<1.0$ & 1.4 & $<1.0$ & $<1.0$ & 1.6 & $<1.0$ & $<1.0$ & 4.9 & $<1.0$ & $<1.0$ & 4.1 \\
\hline $\mathrm{HF}$ & 19.9 & 11.6 & 33.9 & 10.7 & 9.3 & 13.8 & 9.1 & 1.1 & 17.7 & 3.9 & 2.1 & 6.7 \\
\hline
\end{tabular}




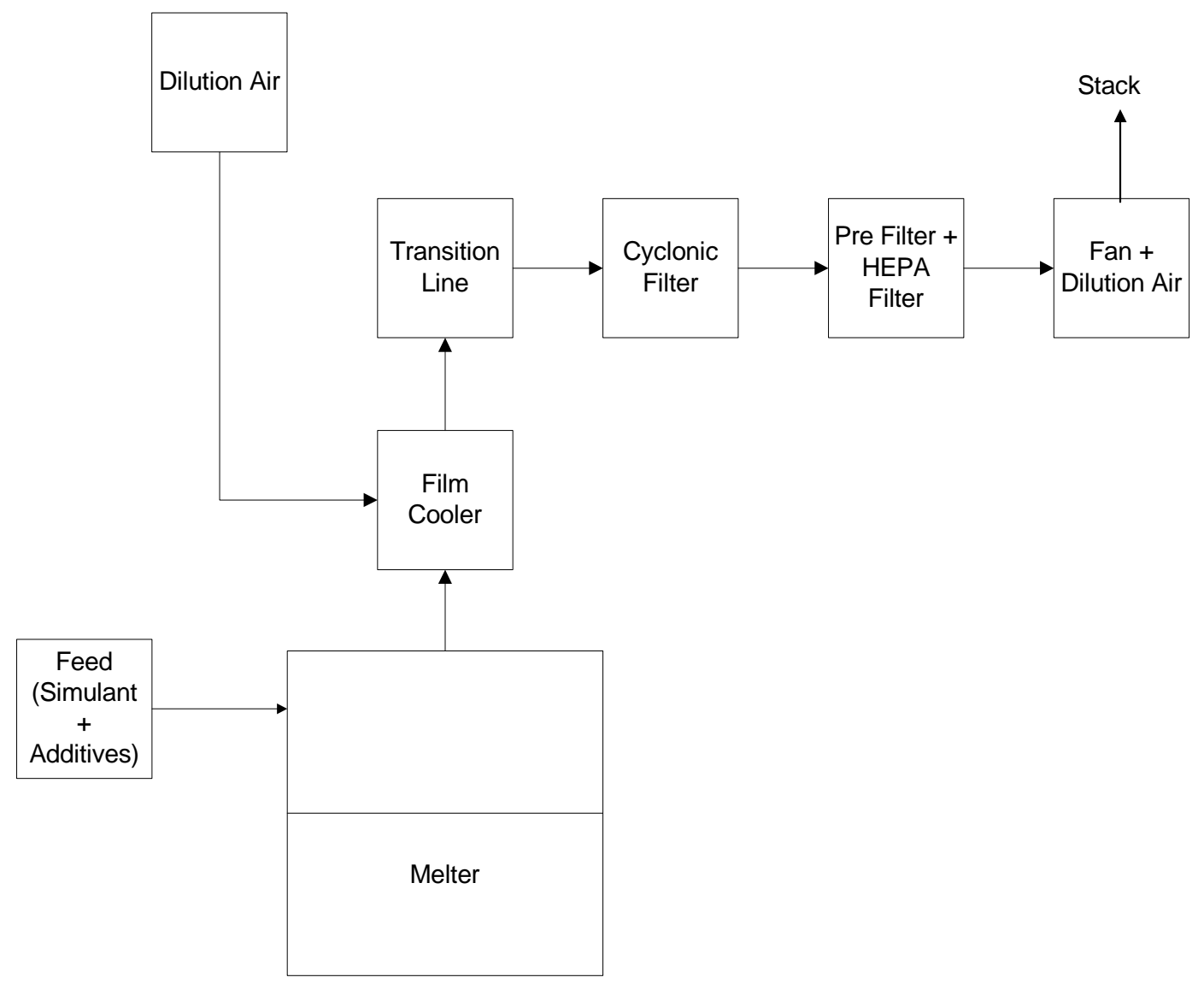

Figure 1.1. Schematic diagram of DuraMelter 100 vitrification system. 
ORP-56292 Rev. 0

The Catholic University of America Vitreous State Laboratory

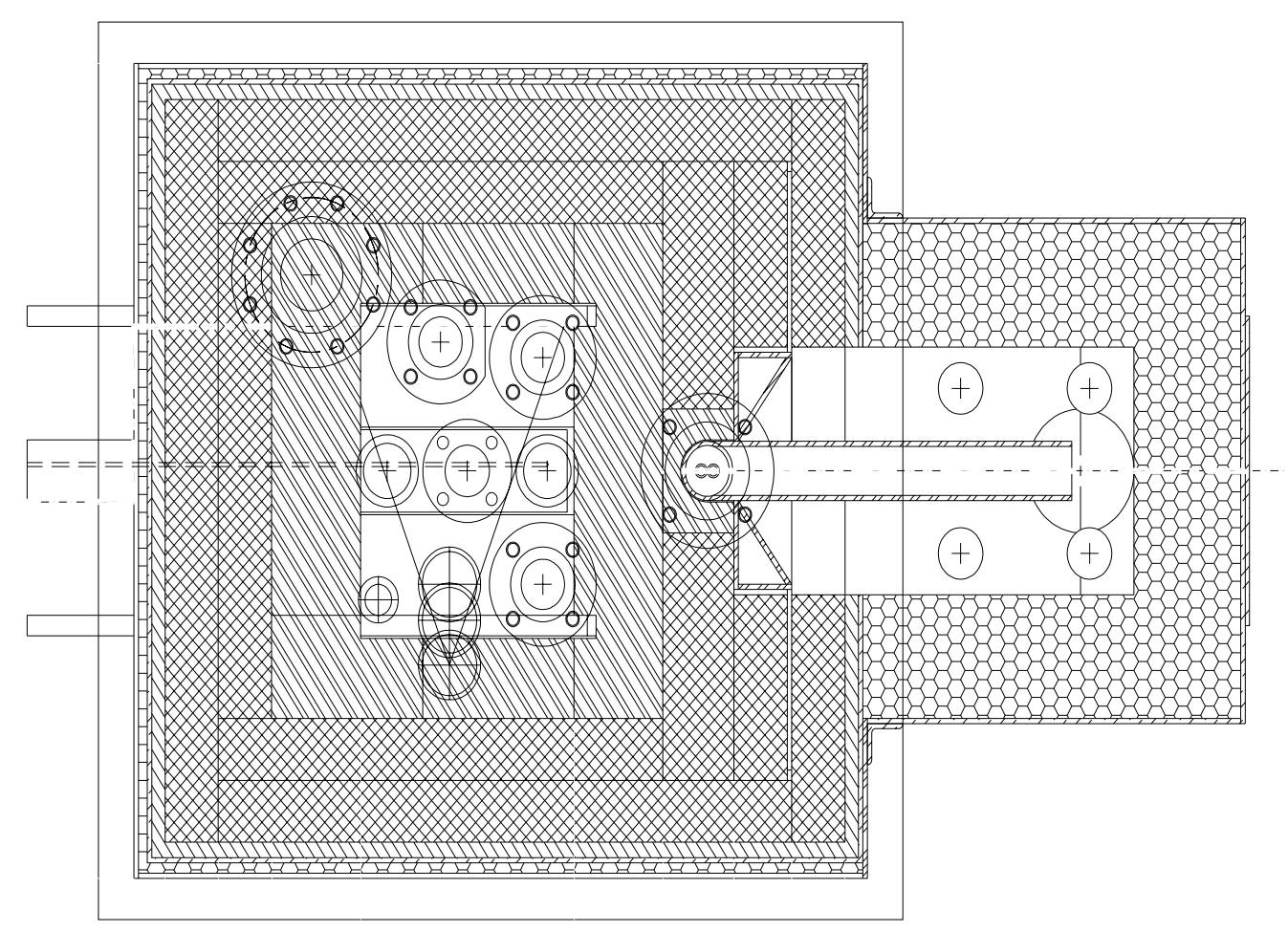

Figure 1.2.a. Schematic diagram showing cross-section through the DM100-BL-melter. Plan view showing locations of lid ports. 


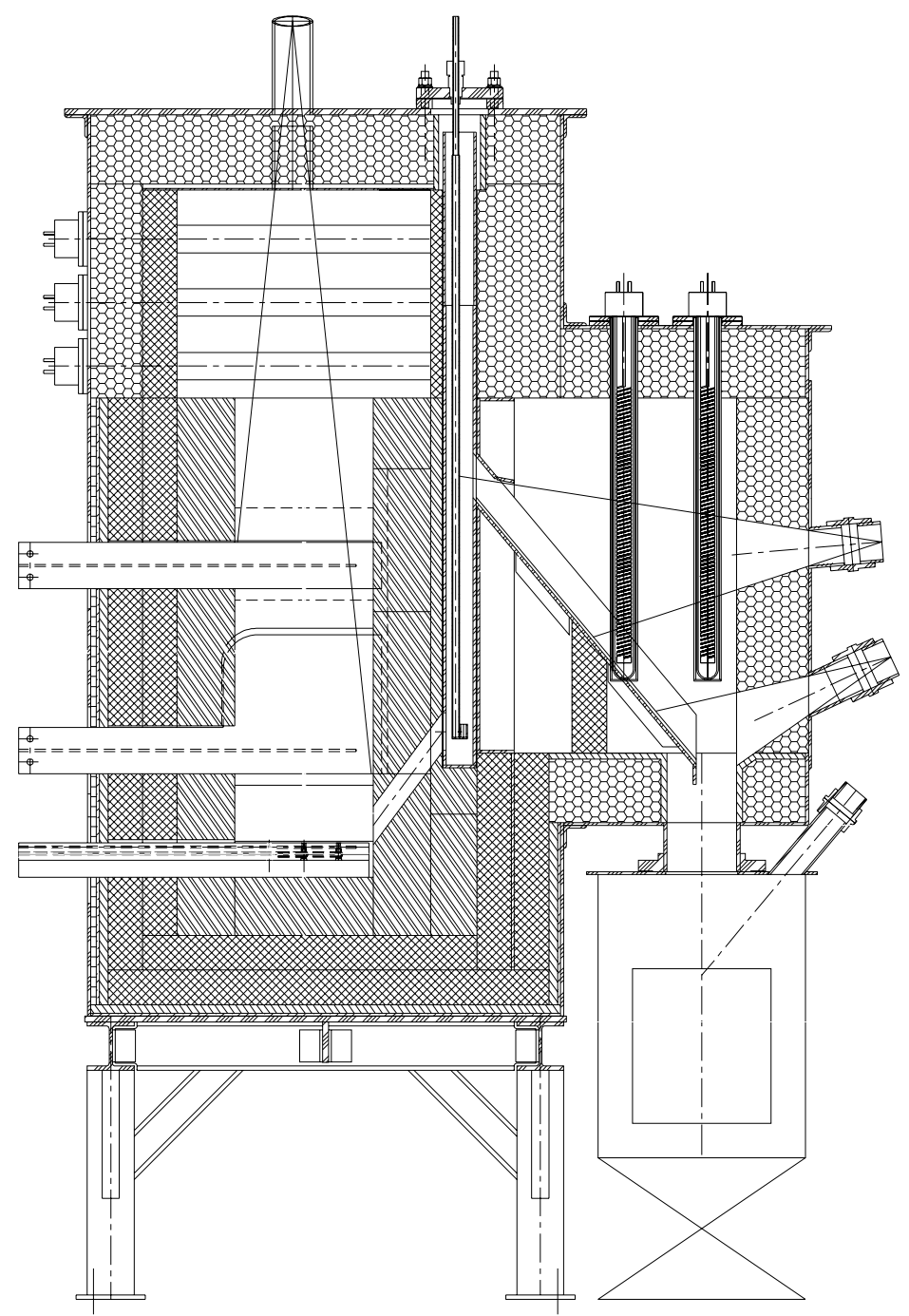

Figure 1.2.b. Schematic diagram showing cross-section through the DM100-BL melter. 


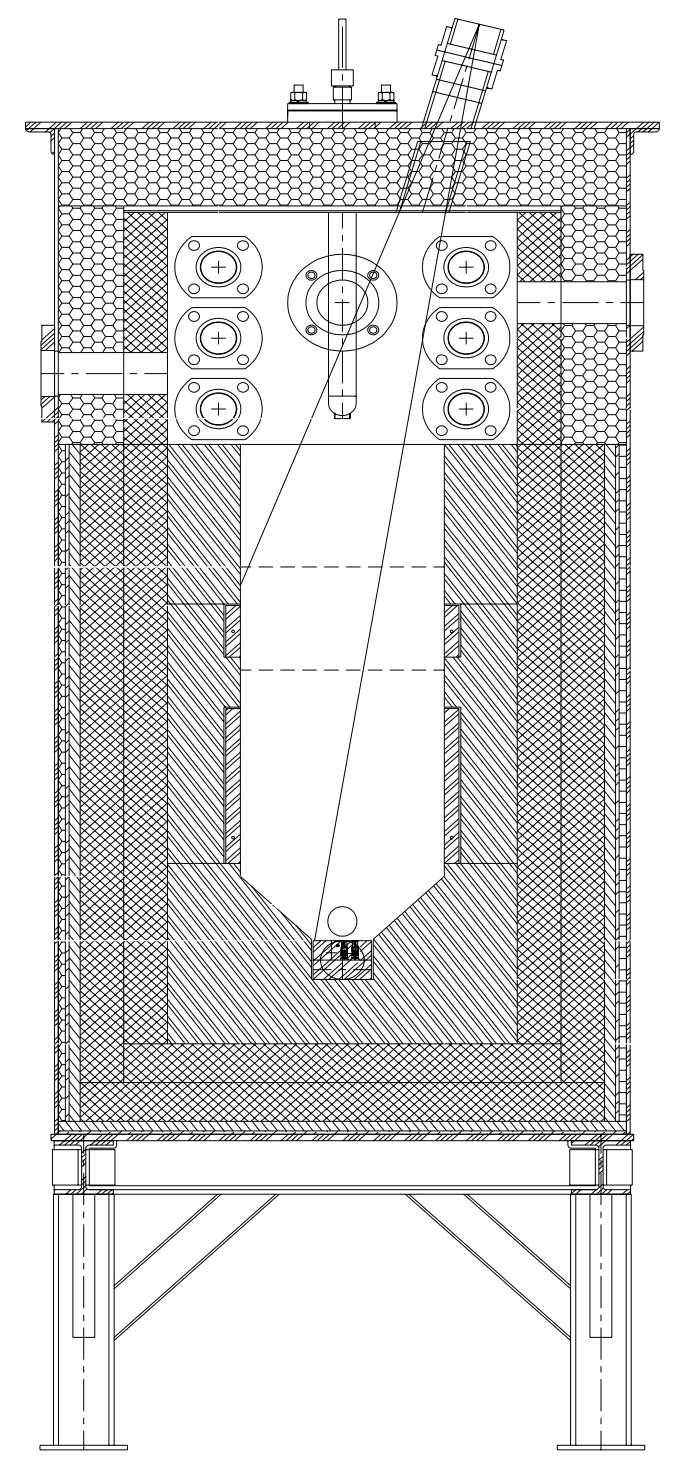

Figure 1.2.c. Schematic diagram showing cross-section through the DM100-BL melter. 
The Catholic University of America Vitreous State Laboratory
Melt Rate Enhancement for High Aluminum HLW Glass Formulations

Final Report, VSL-08R1360-1, Rev. 0

\section{Lid Refractory}

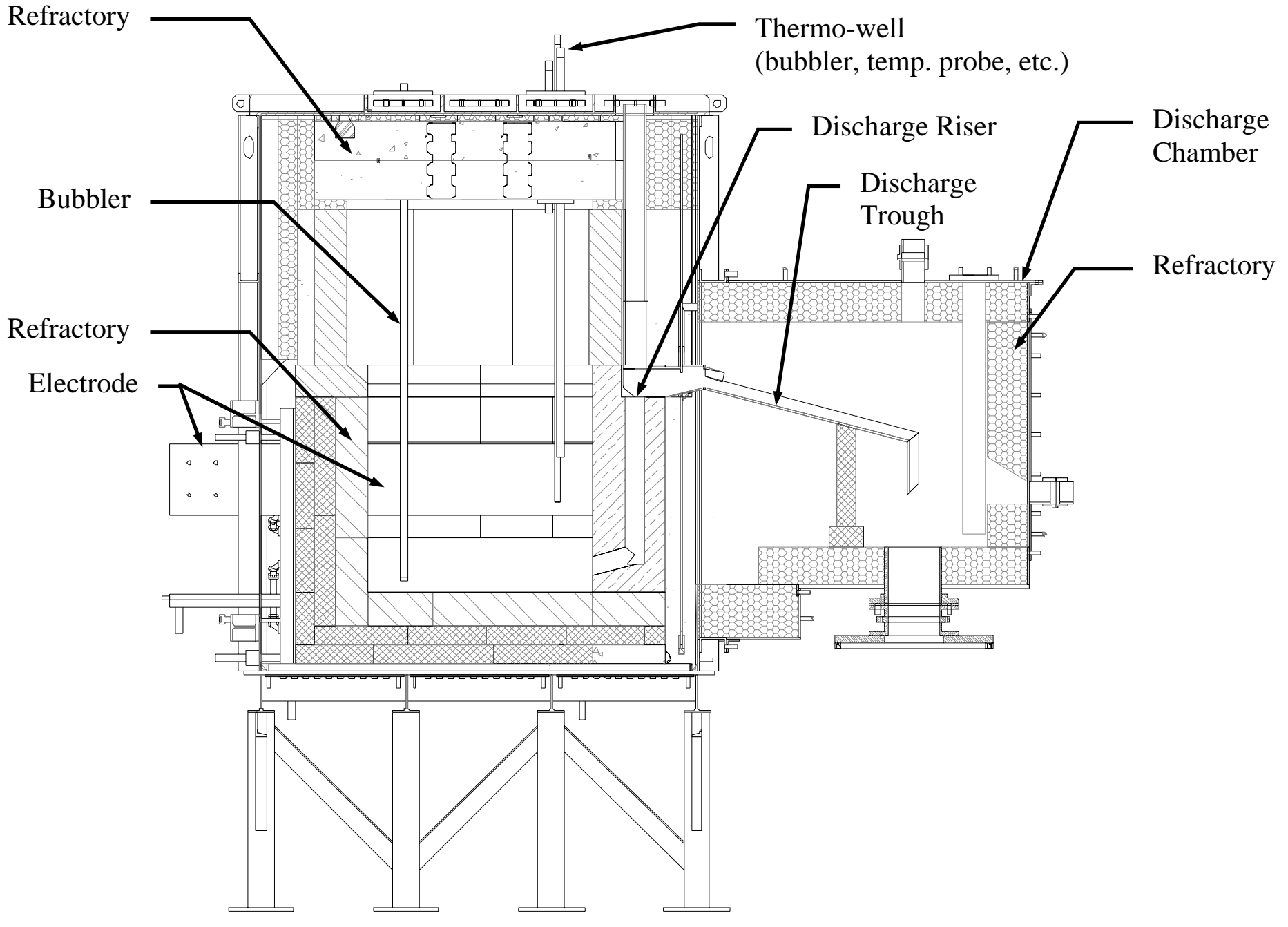

Figure 1.3. Cross-section of the DM1200 melter through the discharge chamber. 


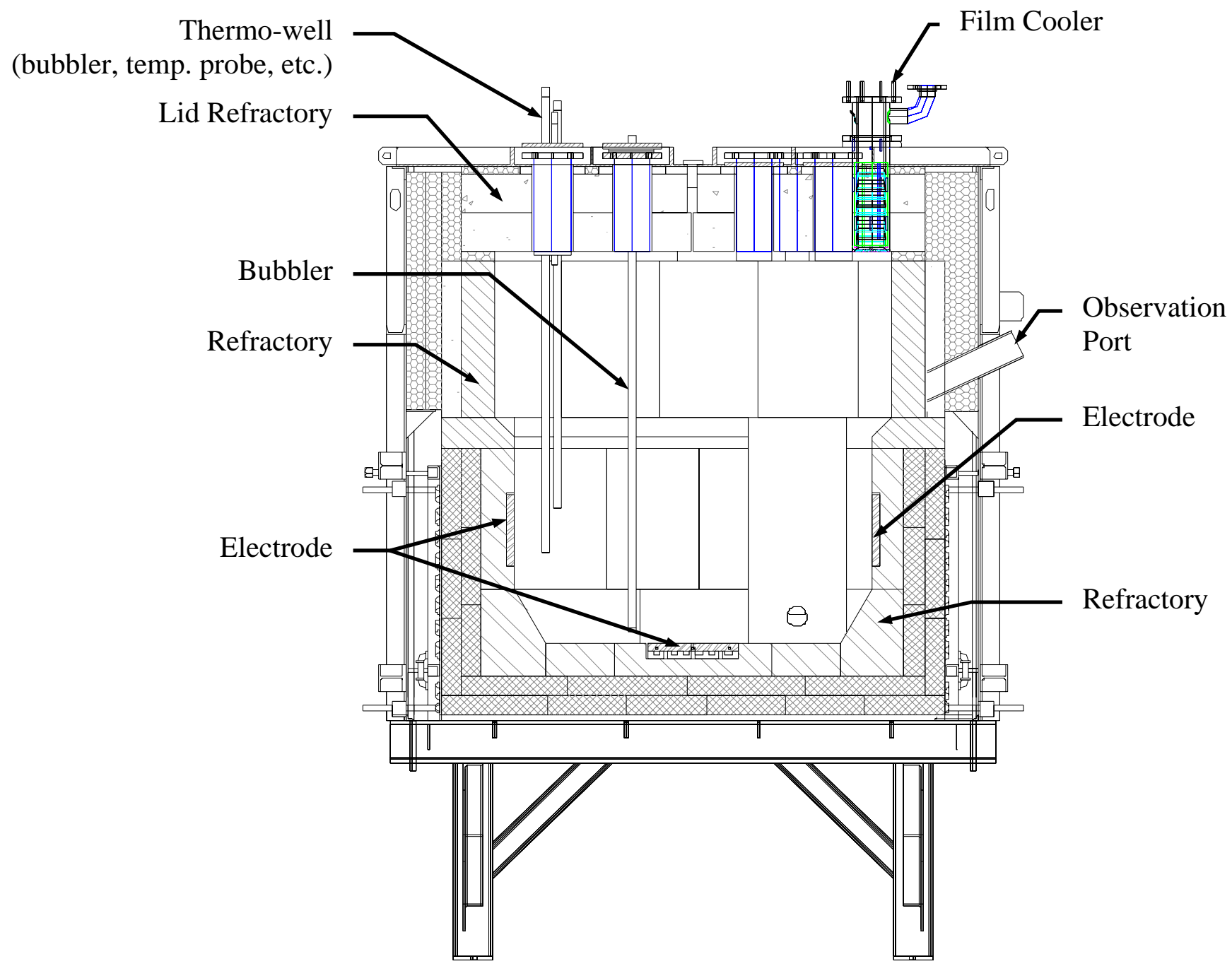

Figure 1.4. Cross-section through the DM1200 melter showing electrodes. 
The Catholic University of America Vitreous State Laboratory
ORP-56292 Rev. 0

Melt Rate Enhancement for High Aluminum HLW Glass Formulations

Final Report, VSL-08R1360-1, Rev. 0

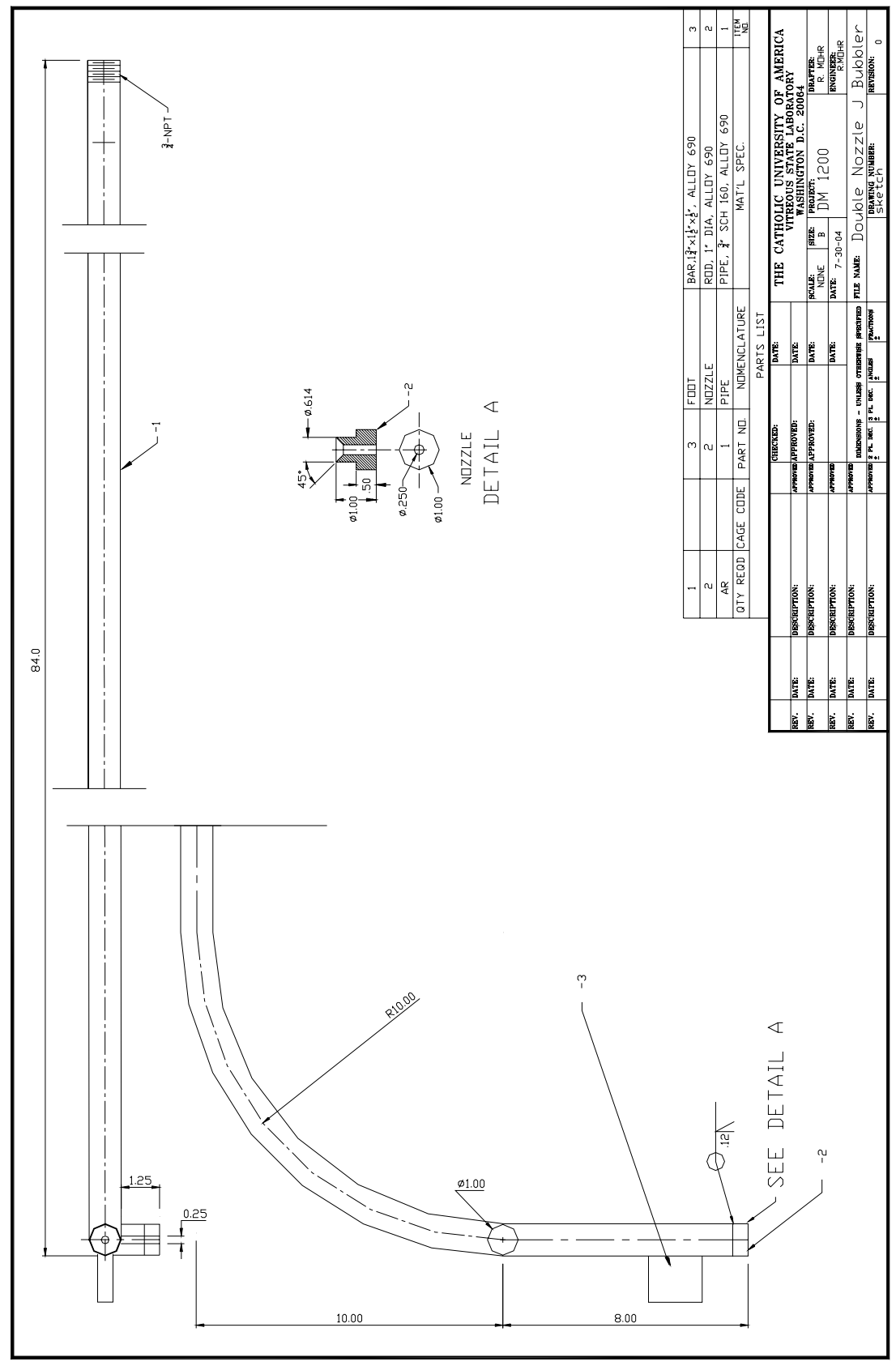

Figure 1.5. Specifications of Double Outlet “J” Bubbler. 


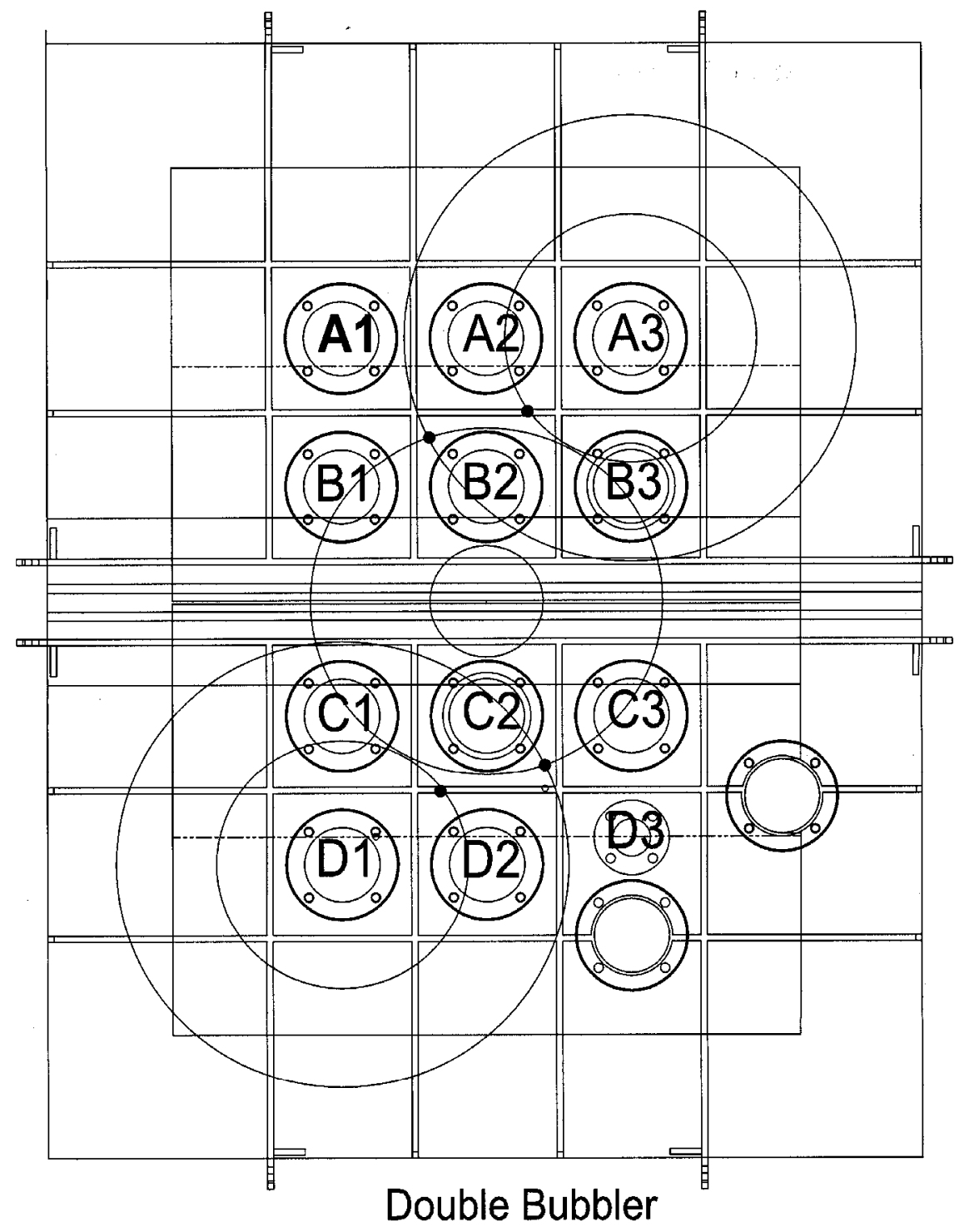

Figure 1.6. Placement of double outlet bubblers. Note: solid circles represent location of bubbler outlet. 
The Catholic University of America Vitreous State Laboratory
ORP-56292 Rev. 0

Melt Rate Enhancement for High Aluminum HLW Glass Formulations Final Report, VSL-08R1360-1, Rev. 0

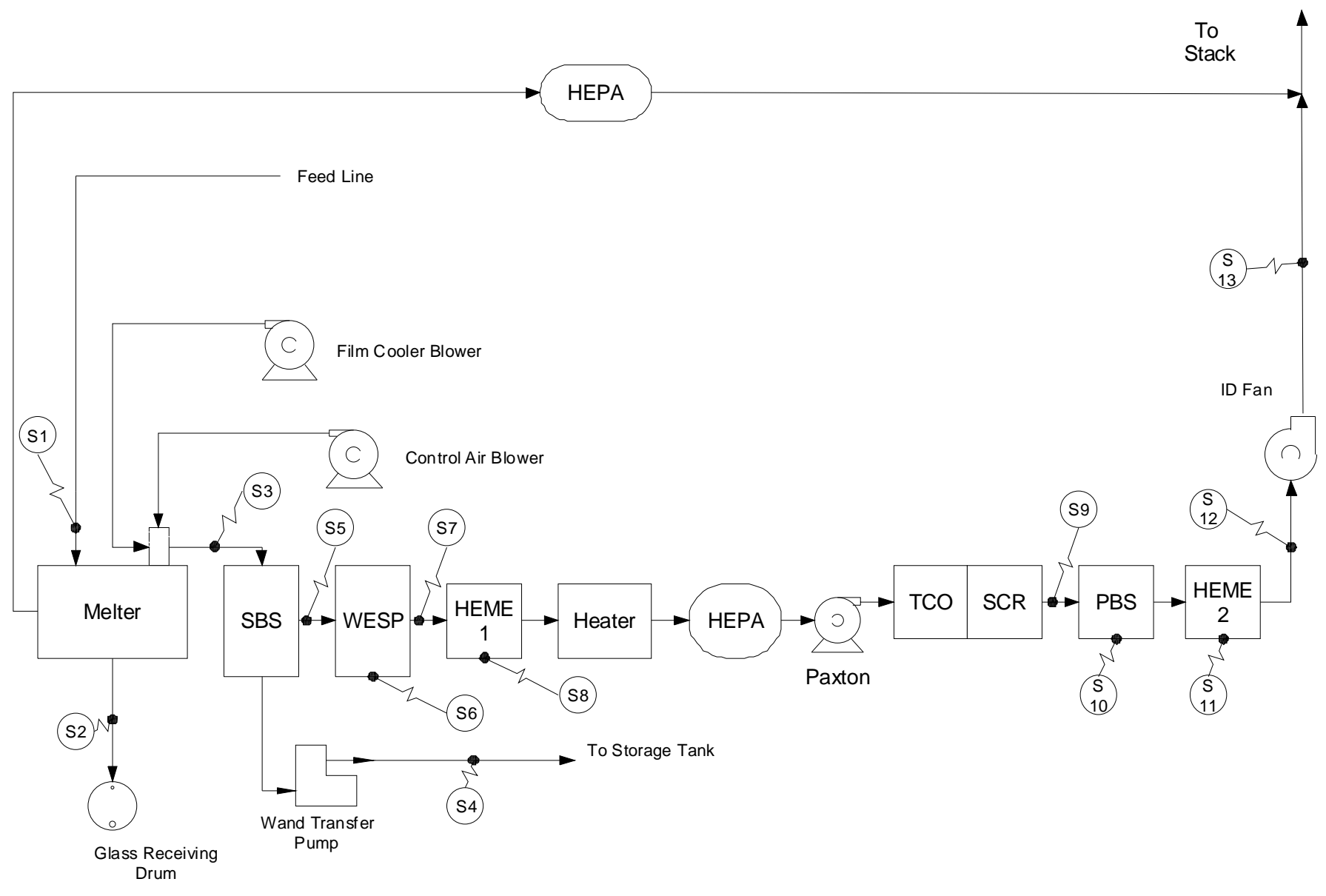

Figure 1.7. Schematic diagram of DM1200 off-gas system. "Sx" indicates sampling point. 


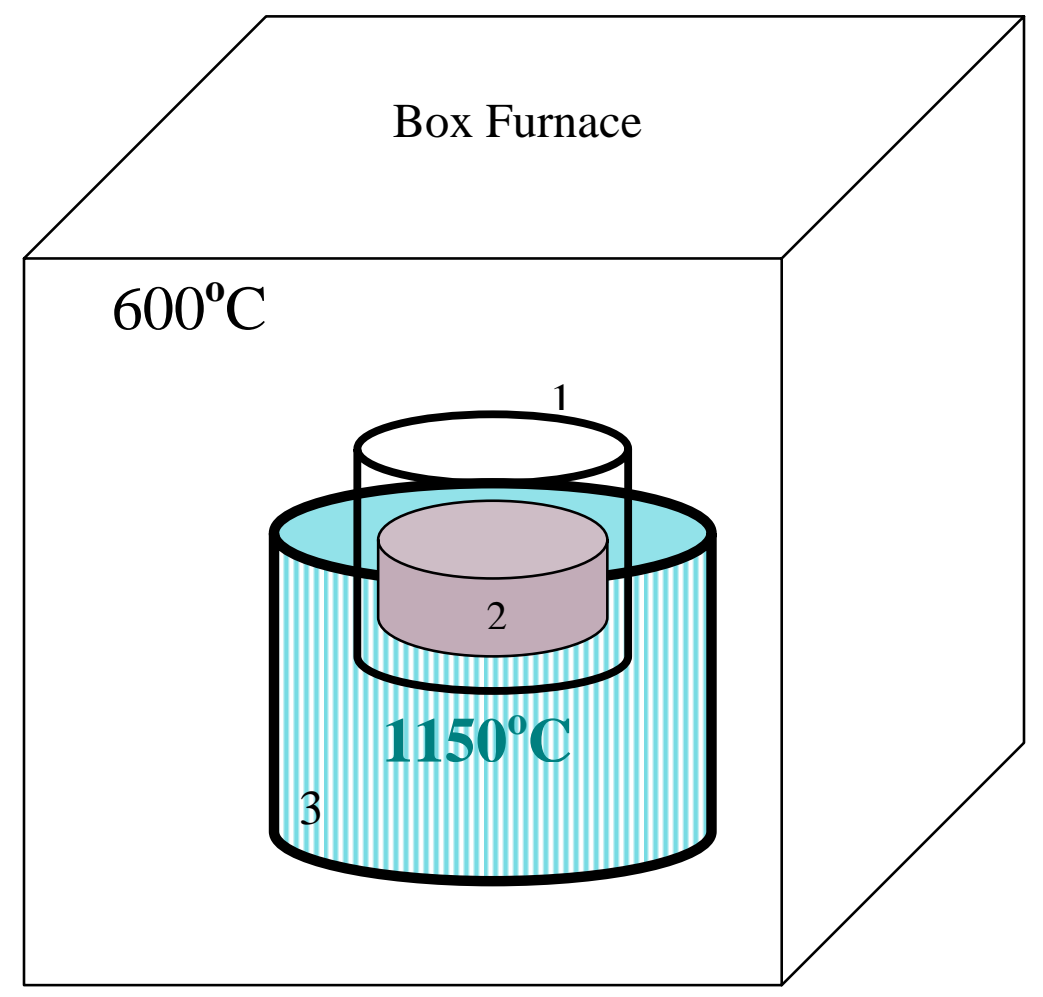

Figure 3.1. Schematic drawing of vertical gradient furnace (VGF) for feed conversion test $(1=$ ceramic crucible half inside the local heater; $2=$ feed for 20 gram glass; $3=$ local heater at $1150^{\circ} \mathrm{C}$ ). 


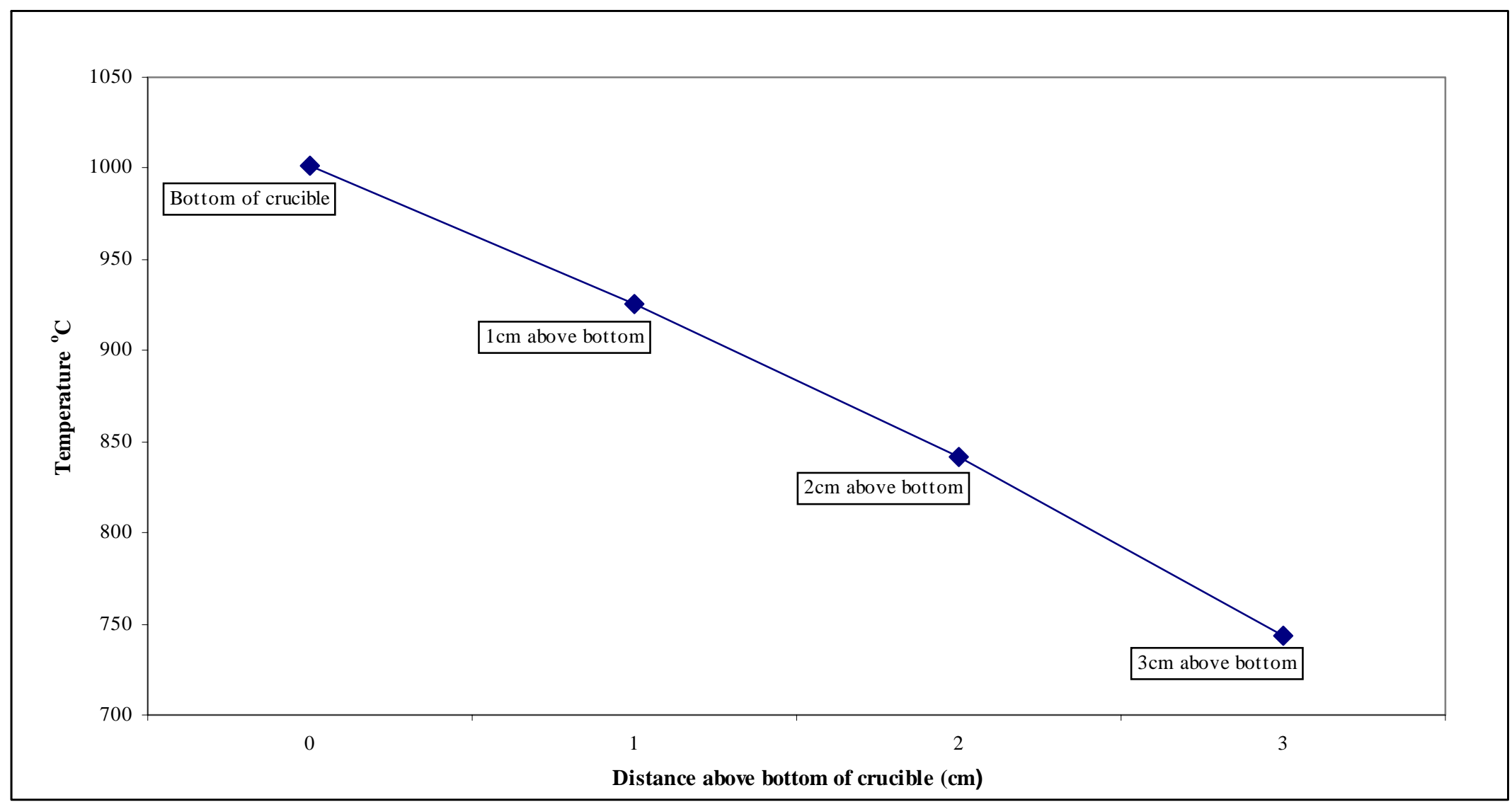

Figure 3.2. Temperature gradient (inside the loaded ceramic crucible) of the Vertical Gradient Furnace (VGF). 
(a)
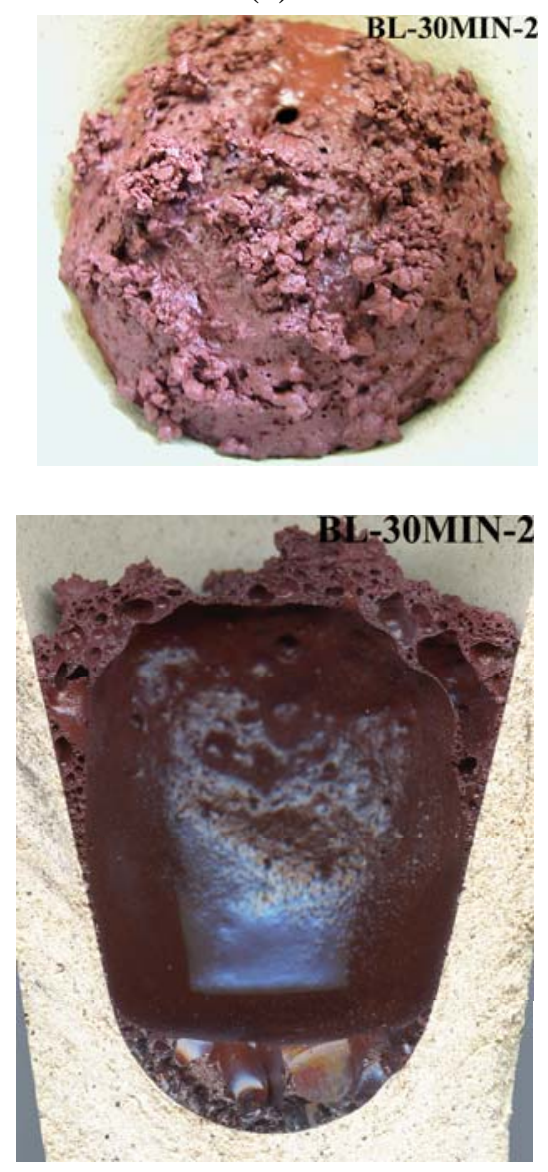

(b)
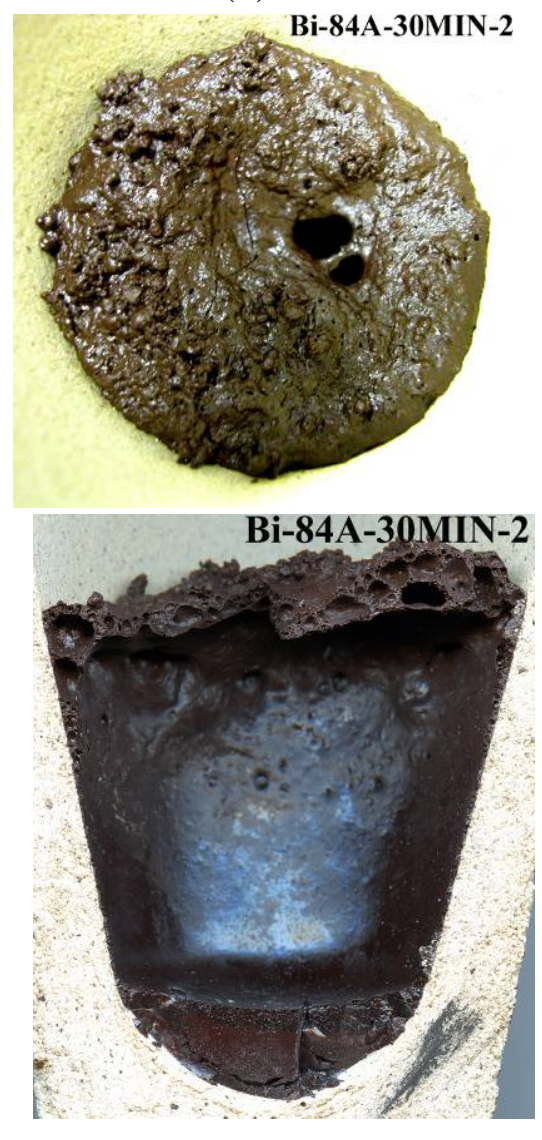

(c)
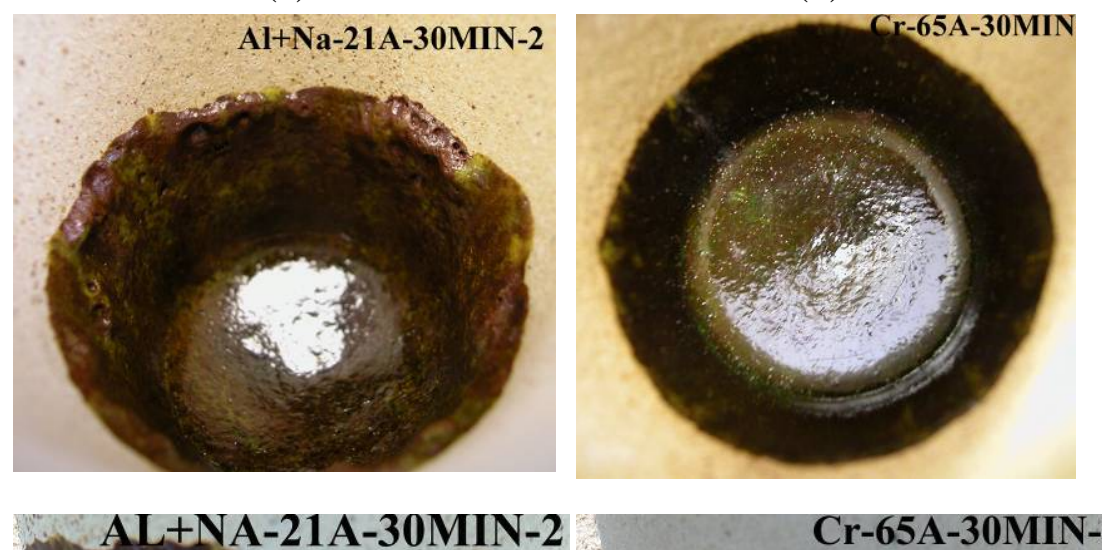

(d)

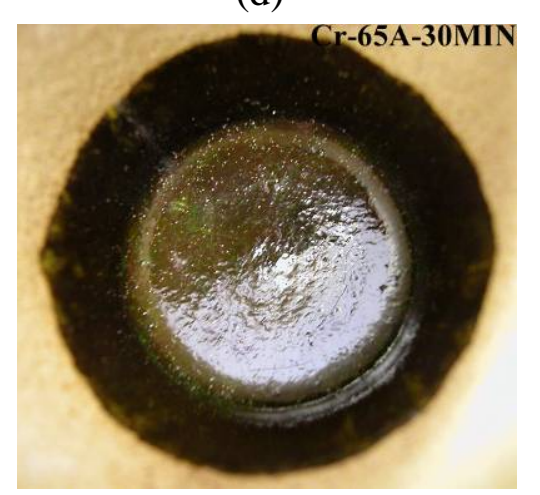

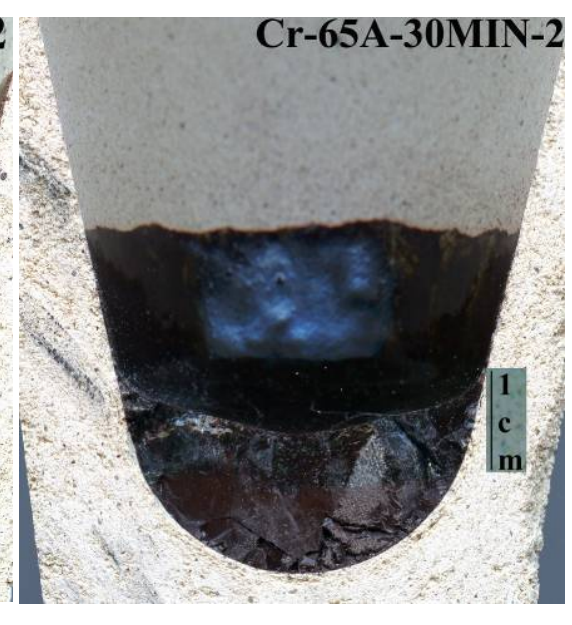

Figure 3.3. Top views and cross sections of six existing melter feeds after VGF tests (30 minutes) (a) HLW-E-Al-27, (b) HLW-E-Bi-6; (c) HLW-E-ANa-22, (d) HLW-E-CrM, (e) Matrix 1-B1, and (f) Matrix 2-9. 
(e)
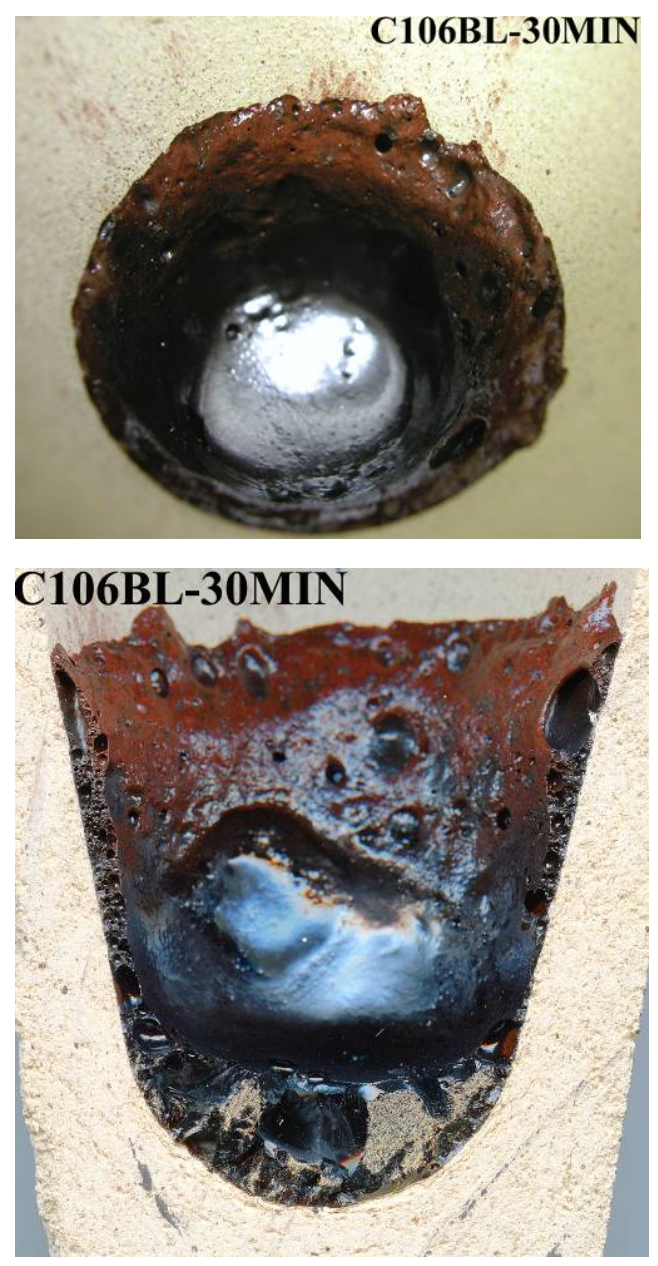

(f)
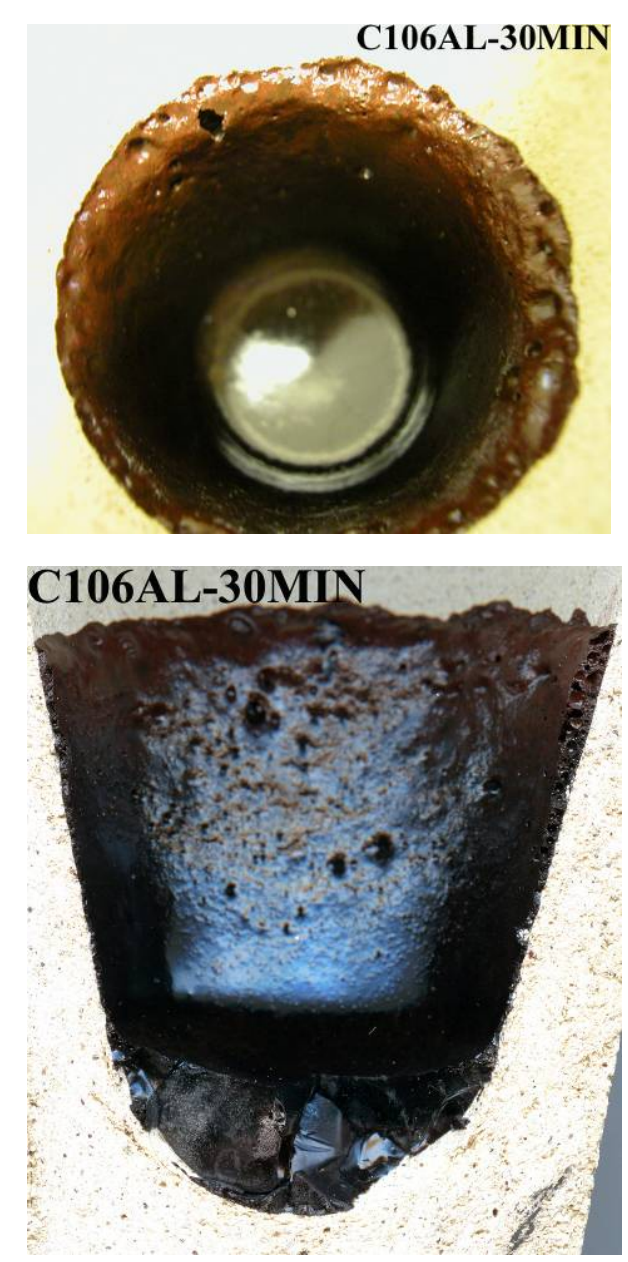

Figure 3.3. Top views and cross sections of six existing melter feeds after VGF tests (30 minutes) (a) HLW-E-Al-27, (b) HLW-E-Bi-6; (c) HLW-E-ANa-22, (d) HLW-E-CrM, (e) Matrix 1-B1, and (f) Matrix 2-9 (continued). 


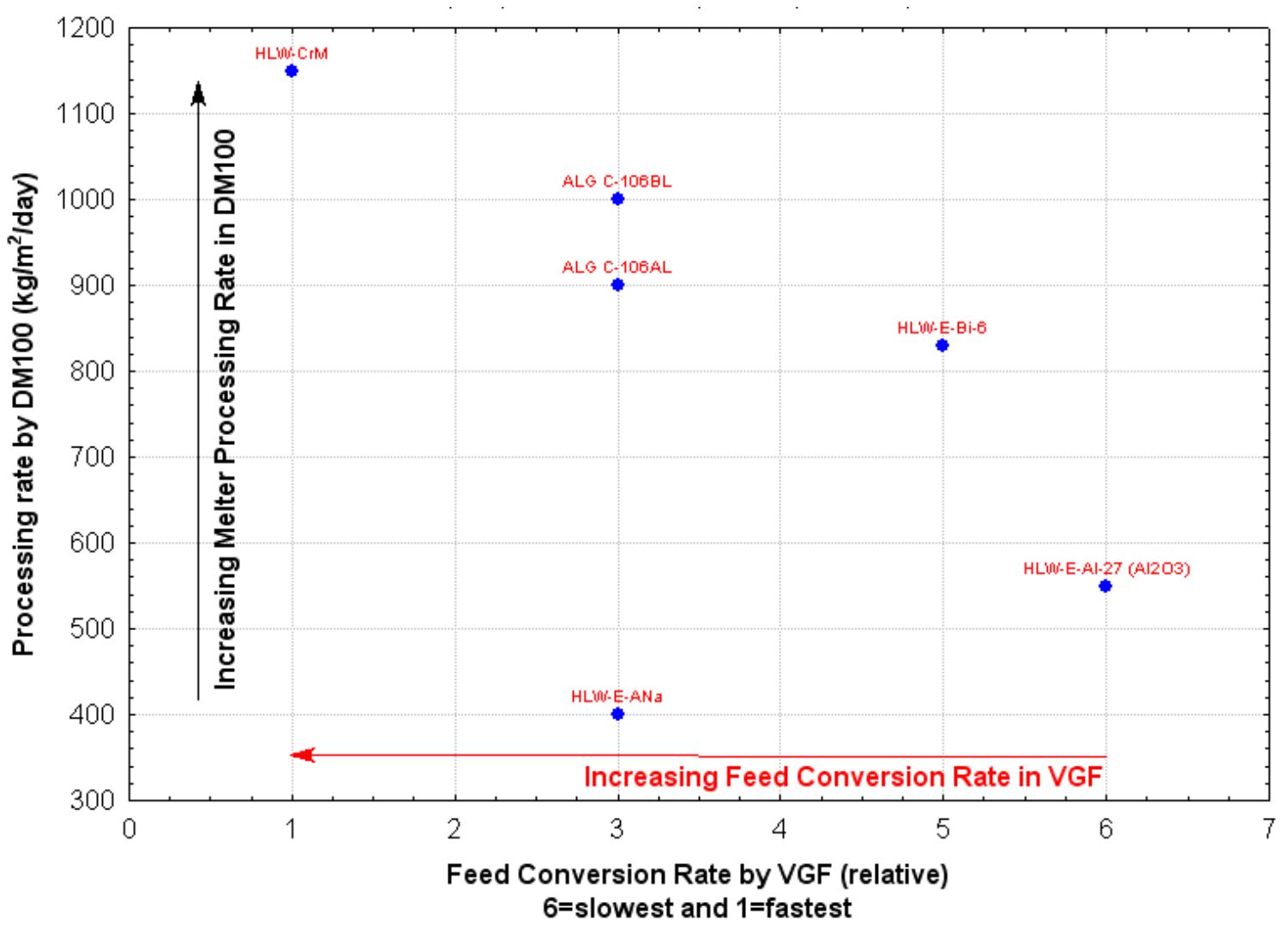

Figure 3.4. Preliminary evaluation of melt rate ranking by VGF as compared to the glass production rate determined by DM100 melter test using the same melter feed.

The definition of the VGF melt rate estimation is given in Table 3.5. 
(a)
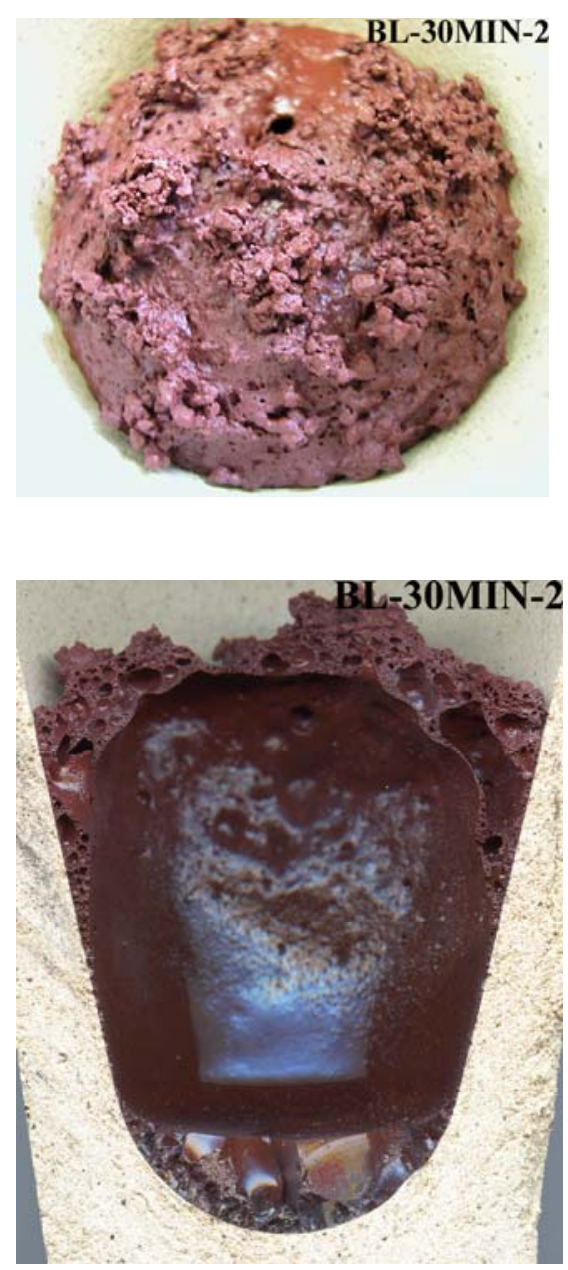

(b)
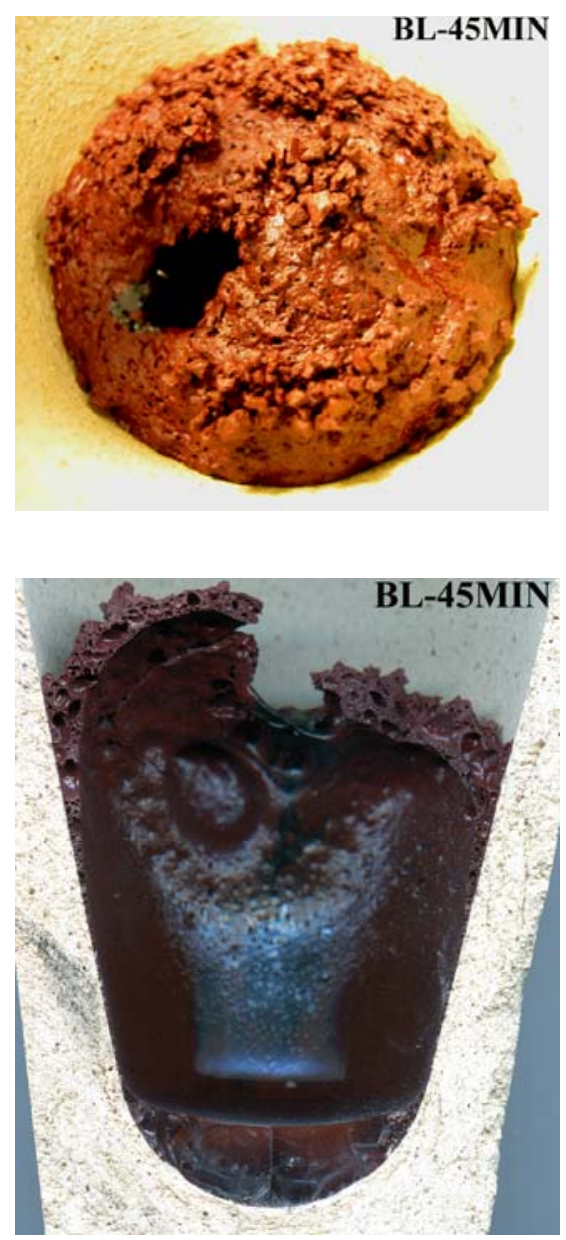

(c)
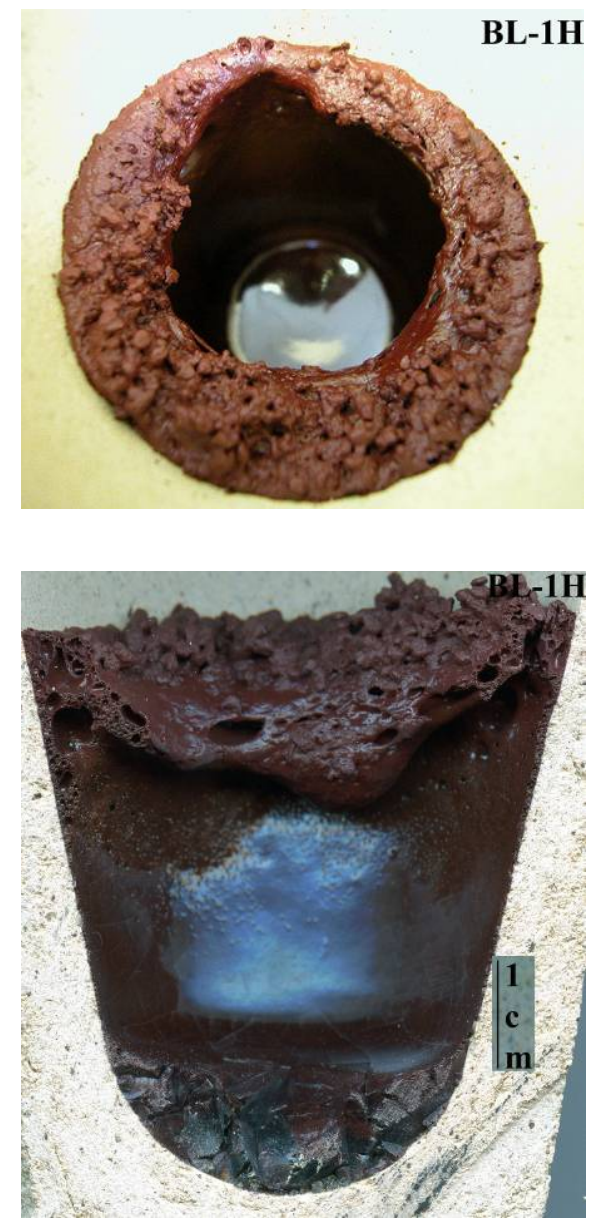

Figure 3.5. Time evolution of the baseline Al-limited melter feed (HLW-E-Al-27) after VGF tests: (a) 30 minutes, (b) 45 minutes and (c) 60 minutes. 
(a)

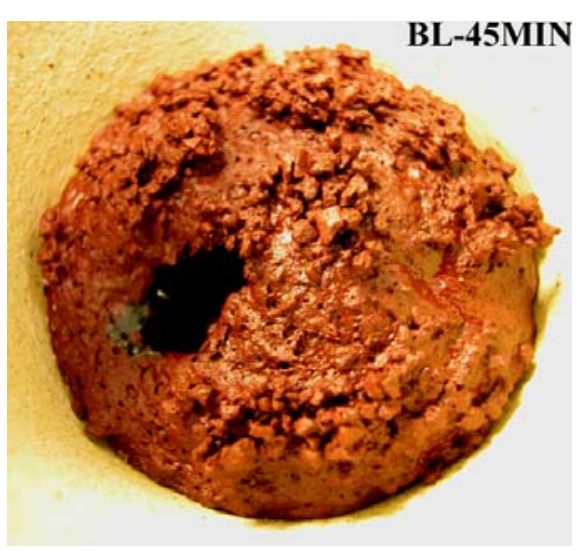

(b)

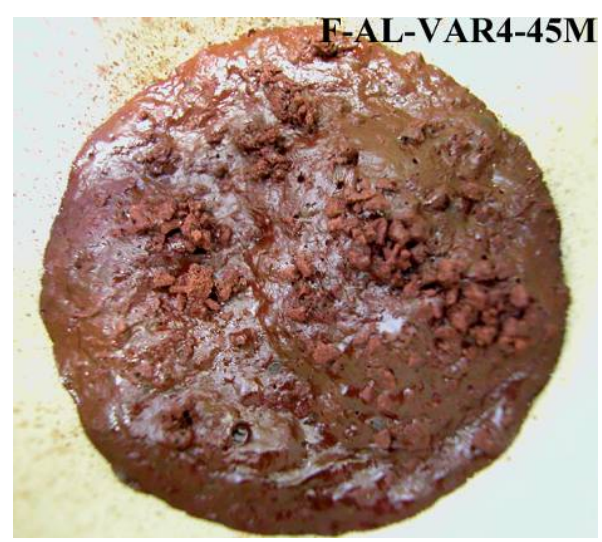

(c)
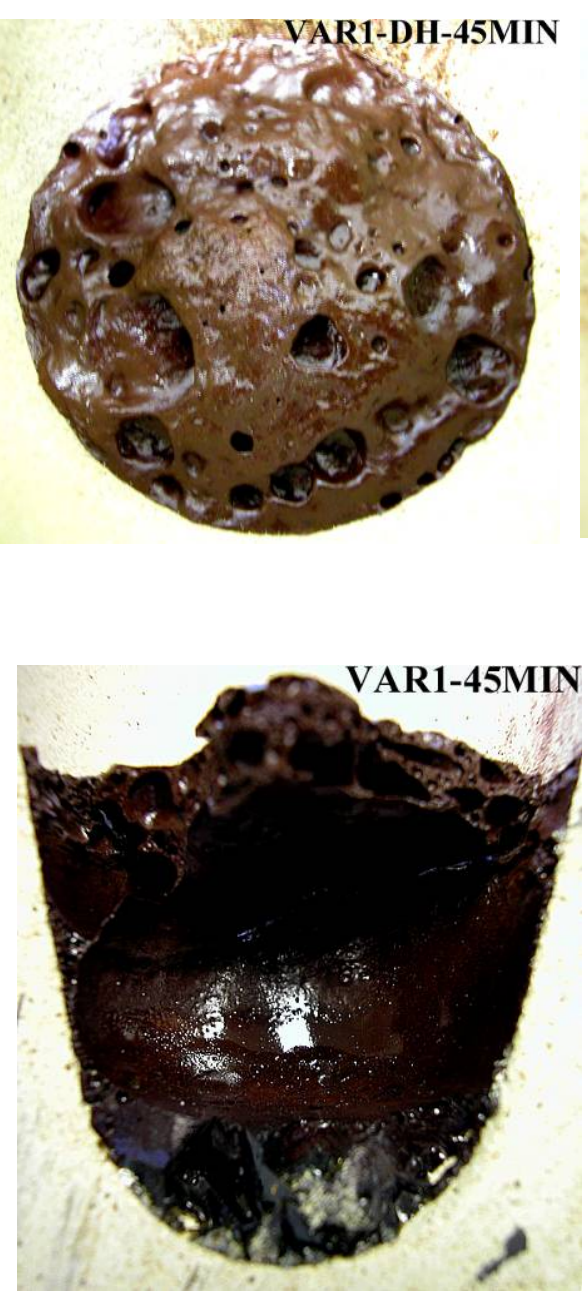

(d)
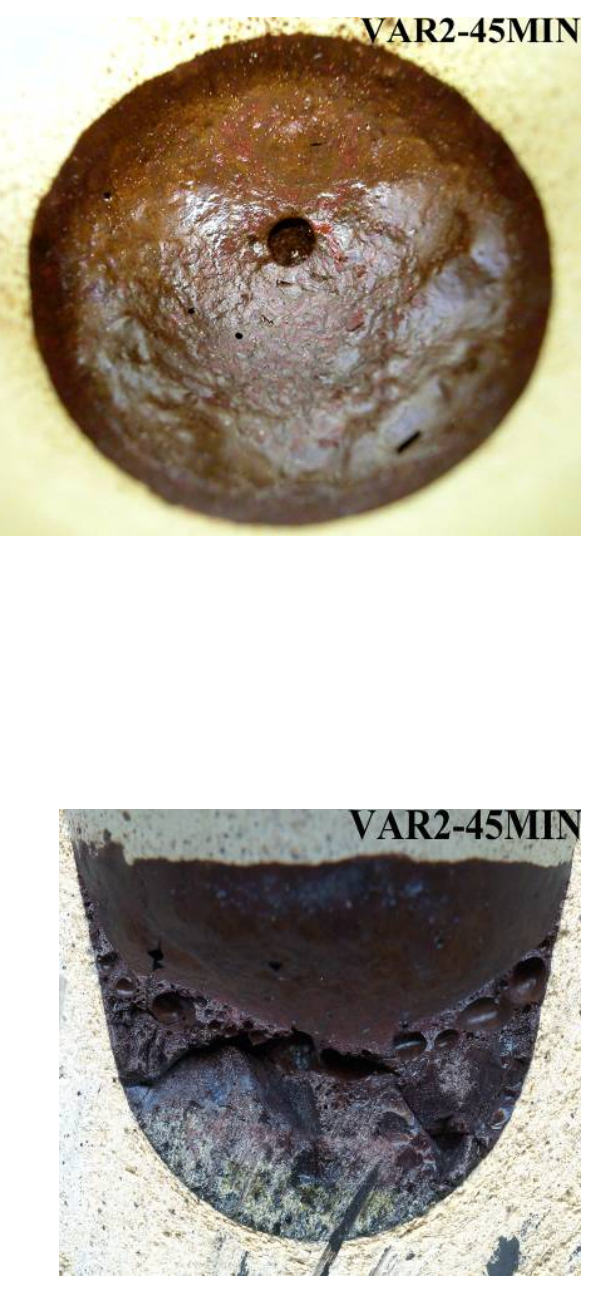

Figure 3.6. Impacts of boron and aluminum sources on melt rate in VGF experiments (45 minutes). (a) $\mathrm{Al}_{2} \mathrm{O}_{3}$ and borax, (b) $\mathrm{Al}(\mathrm{OH})_{3}$ and borax, (c) $\mathrm{Al}_{2} \mathrm{O}_{3}$ and boric acid, and (d) $\mathrm{Al}(\mathrm{OH})_{3}$ and boric acid 
(a)
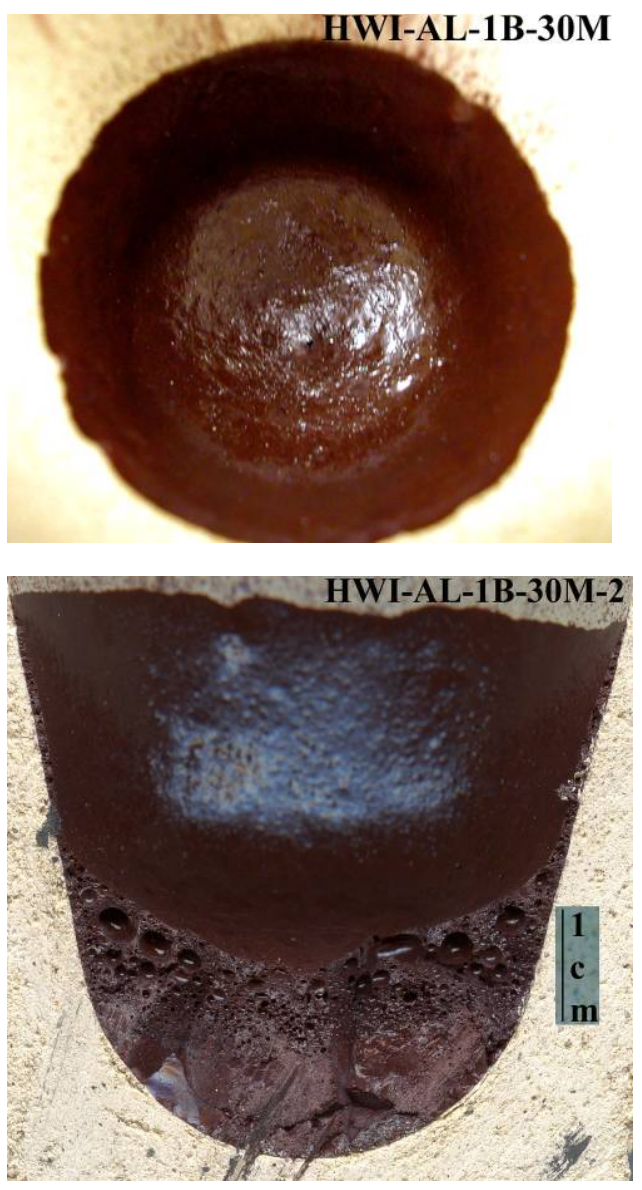

(b)
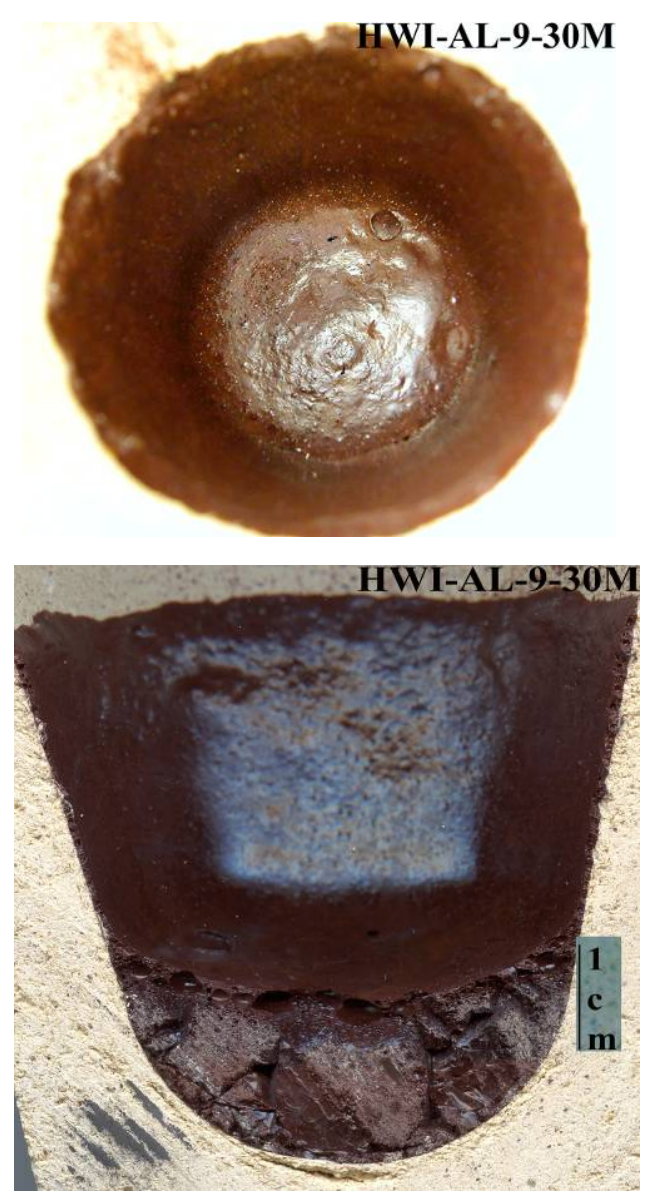

Figure 3.7. Top views and cross sections of Group 1 formulations after 30 minute test in VGF. (a) HWI-Al-1, and (b) HWI-Al-9 
(a)
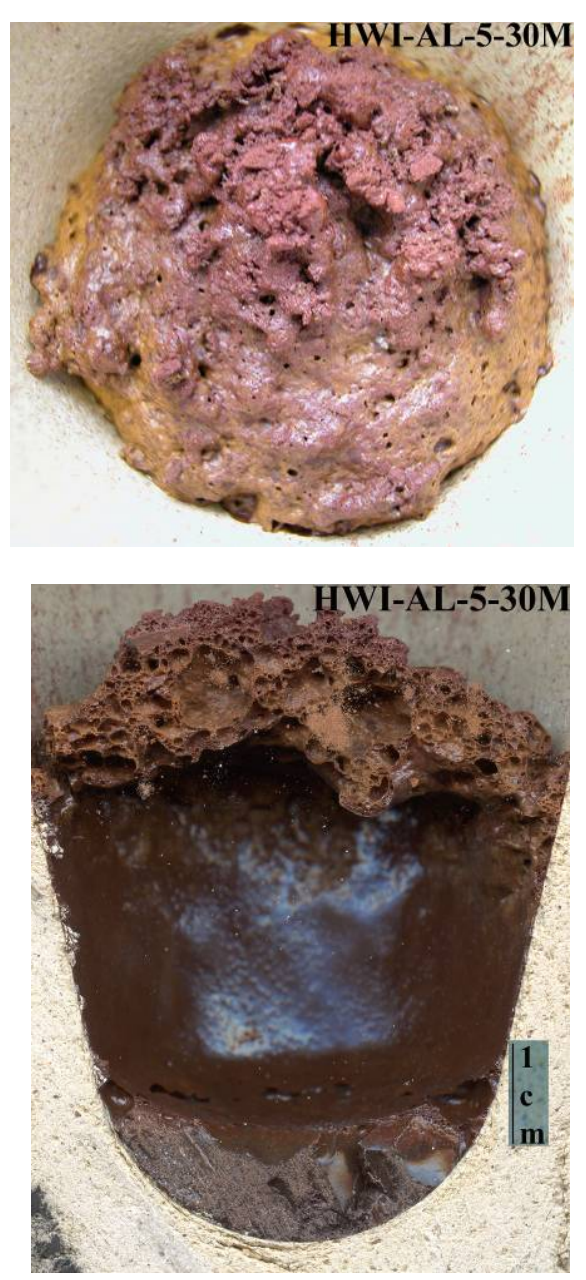

(b)
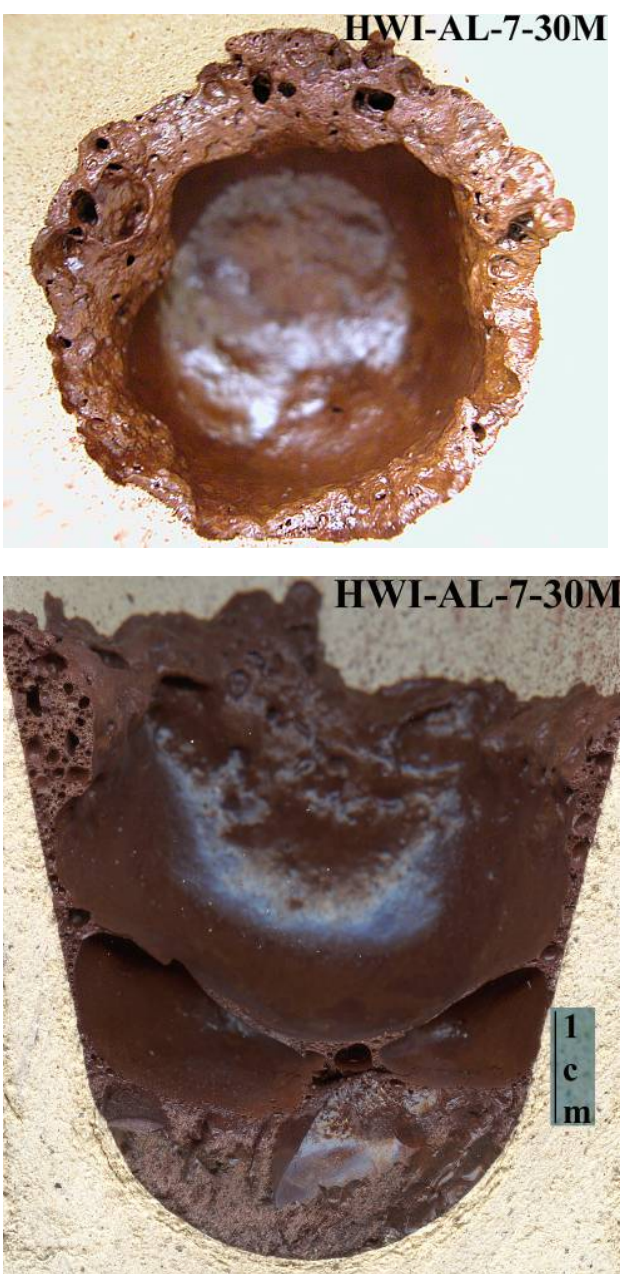

Figure 3.8. Top views and cross sections of Group $\mathbf{3}$ formulations after $\mathbf{3 0}$ minute test in VGF. (a) HWI-Al-5, and (b) HWI-Al-7. 
(a)
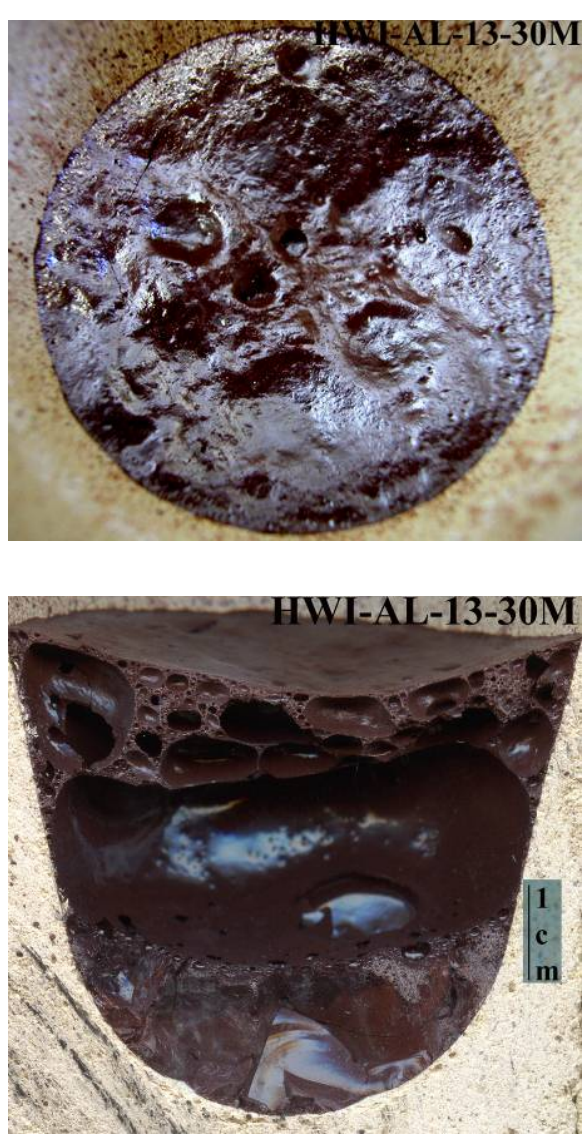

(b)
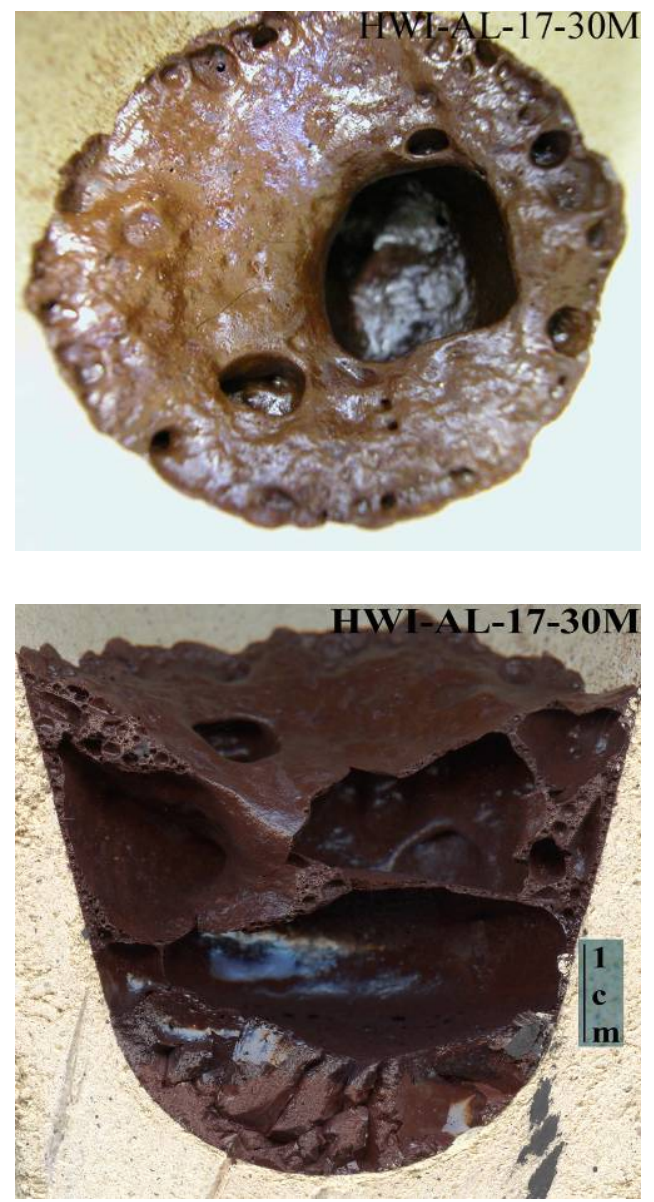

(c)
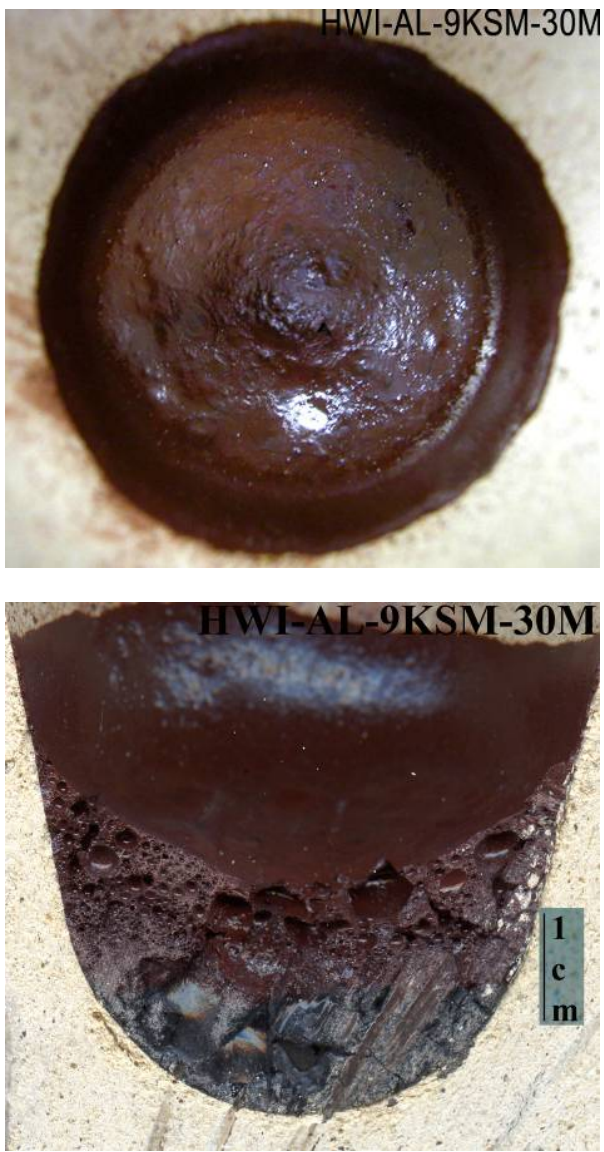

Figure 3.9. Top views and cross sections of Group 4 formulations after 30 minute test in VGF. (a) HWI-Al-13, (b) HWI-Al-17 and (b) HWI-Al-20. 
(a)
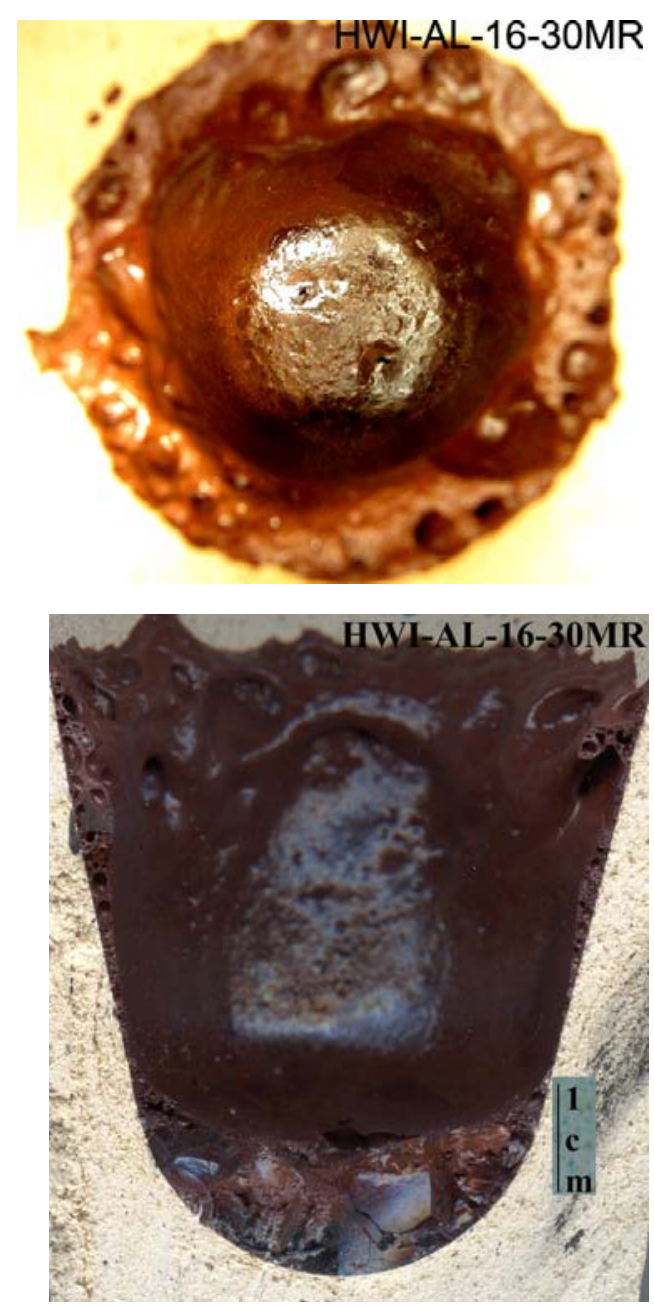

(b)
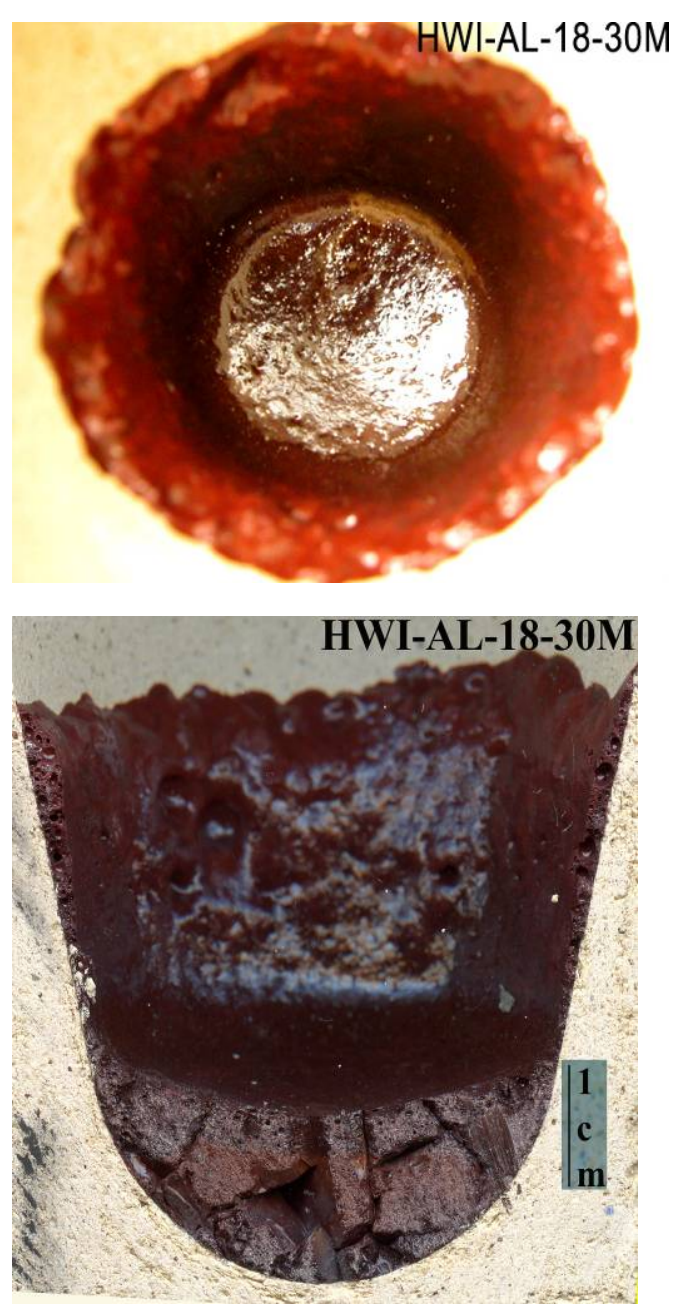

(c)
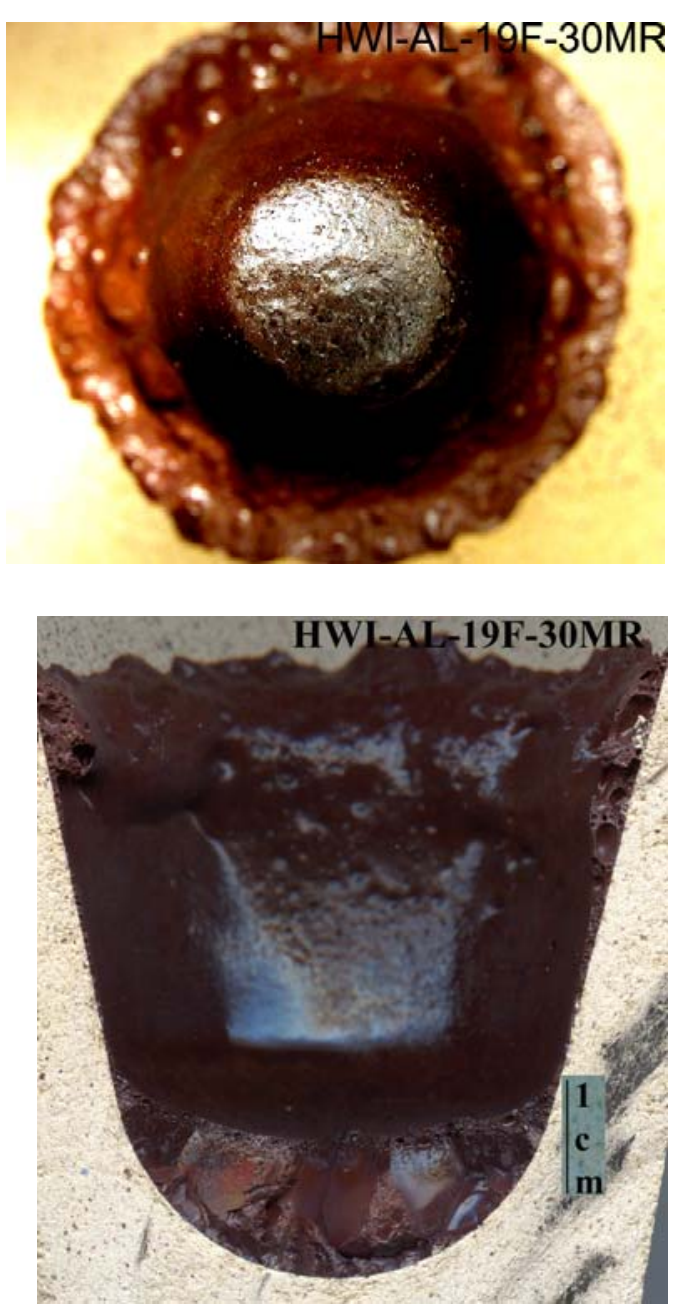

Figure 3.10. Top views and cross sections of Group 5 formulations after 30 minute test in VGF. (a) HWI-Al-16, (b) HWI-Al-18 and (c) HWI-Al-19. 
(a)
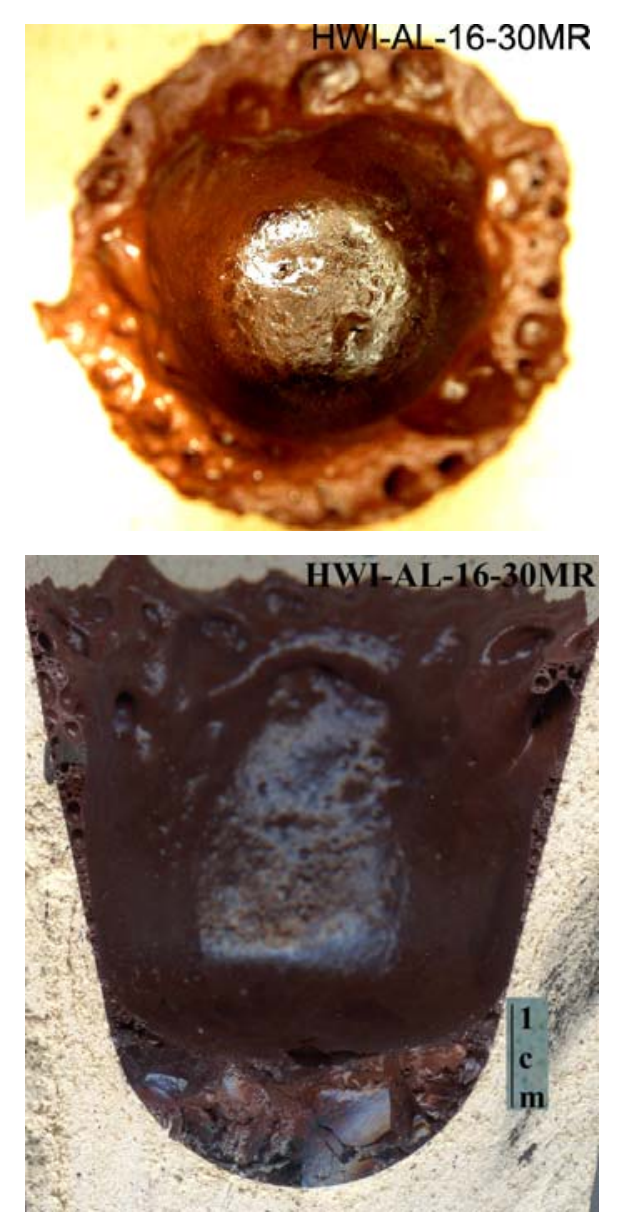

(b)
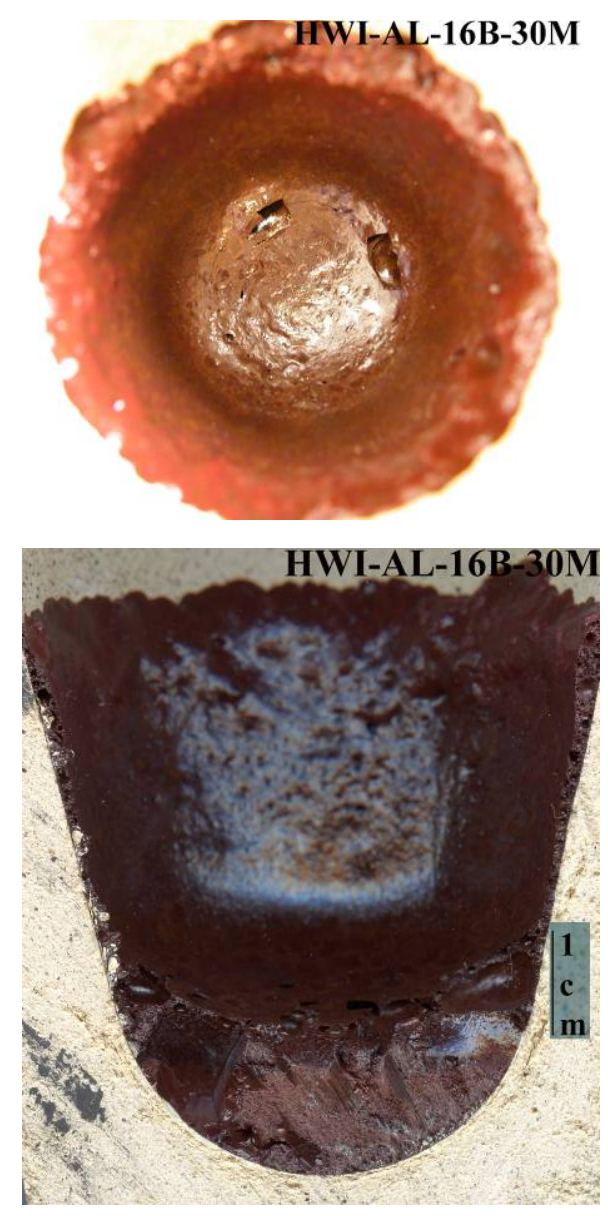

(c)
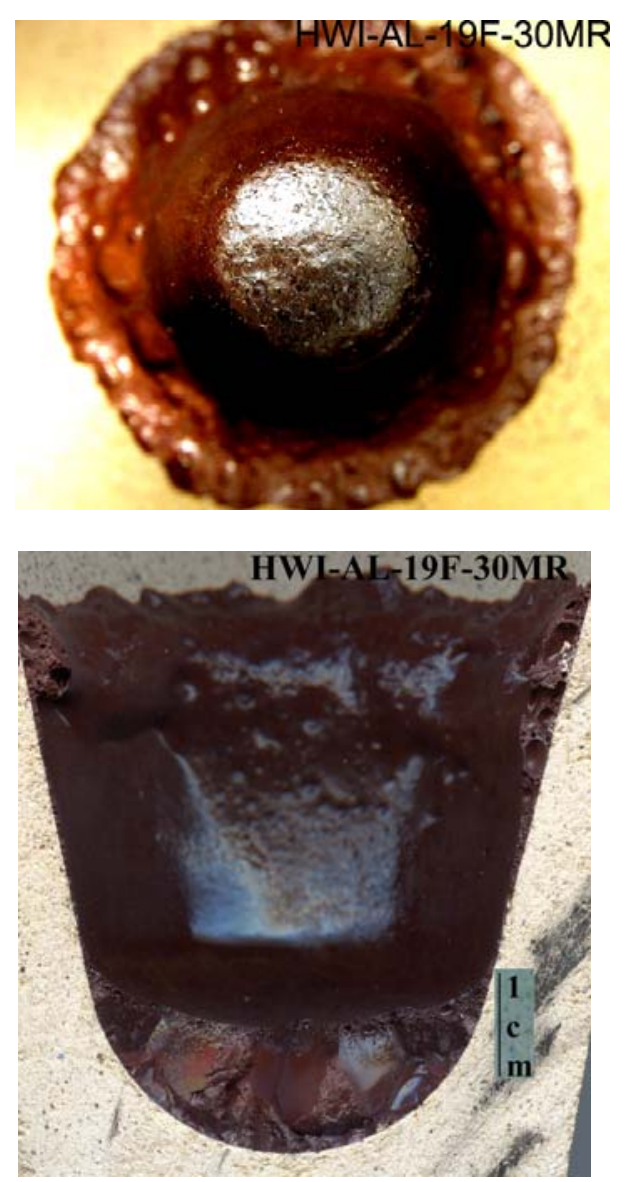

(d)
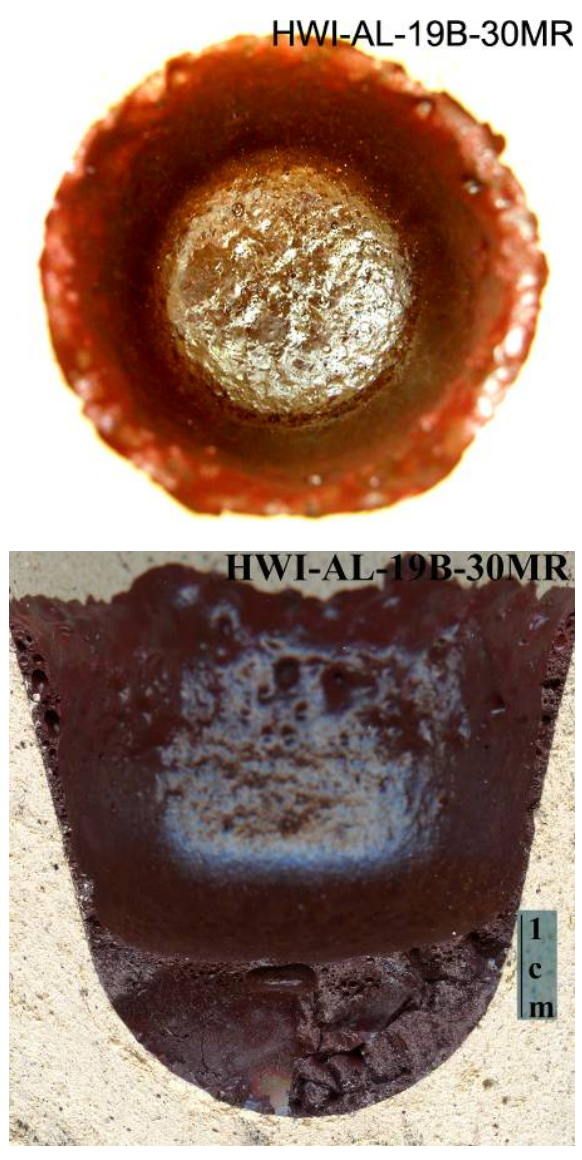

Figure 3.11. Top views and cross sections of feed samples after 30 minute test in VGF. (a) Feed $\mathrm{F}-\mathrm{HWI}-\mathrm{Al}-16$ (Al $\left.\mathrm{O}_{3}\right)$, (b) Feed F-HWI-Al-16B $\left(\mathrm{Al}(\mathrm{OH})_{3}\right)$, (c) Feed F-HWI-Al-19F $\left(\mathrm{Al}_{2} \mathrm{O}_{3}\right)$, and (d) Feed F-HWI-Al-19B (Al(OH) $)_{3}$. 

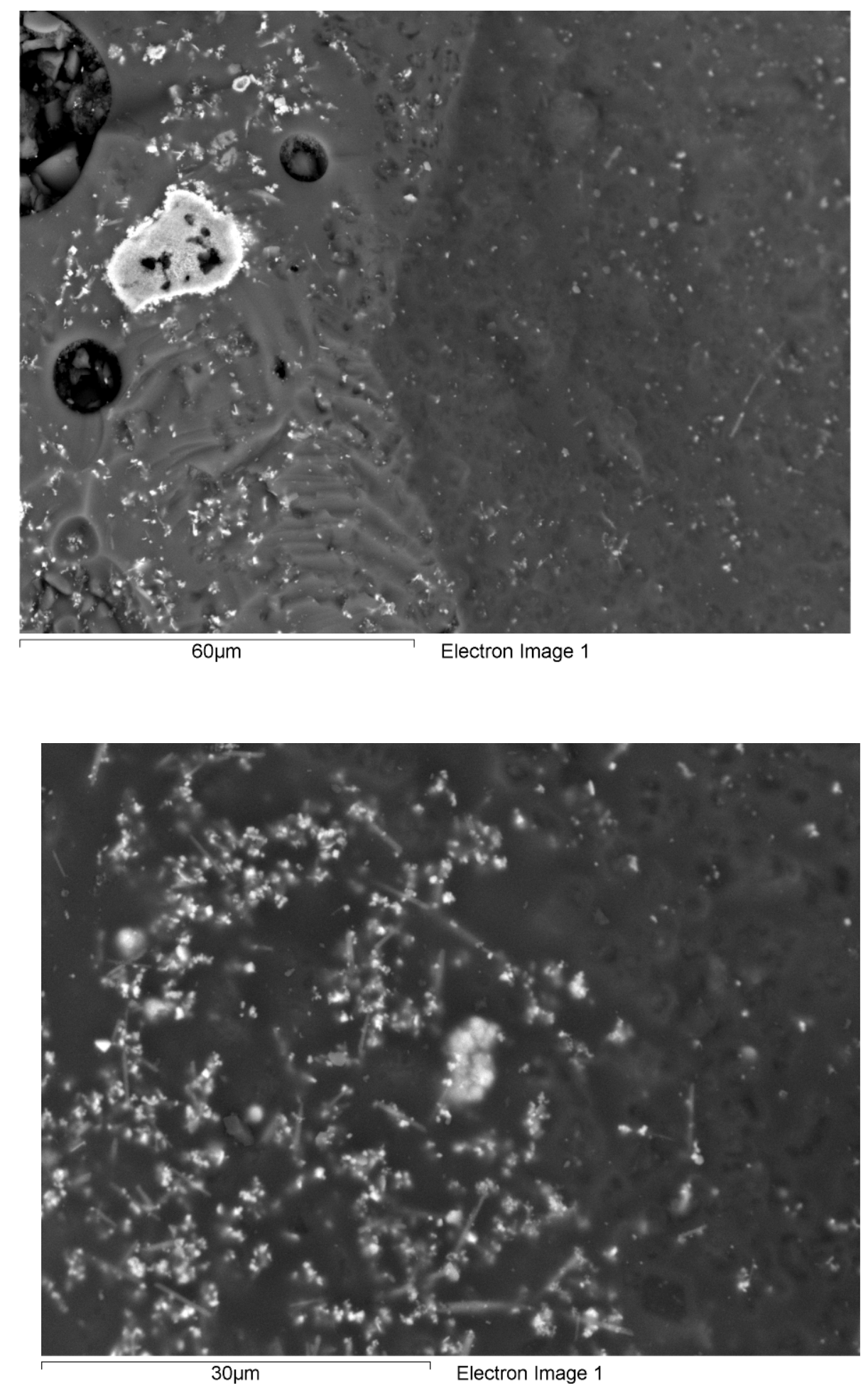

(a) Baseline feed for formulation HLW-E-Al-27 $\left(\mathrm{Al}_{2} \mathrm{O}_{3}\right)$

Figure 3.12. SEM images of partially reacted feed after 30 minute VGF tests. 


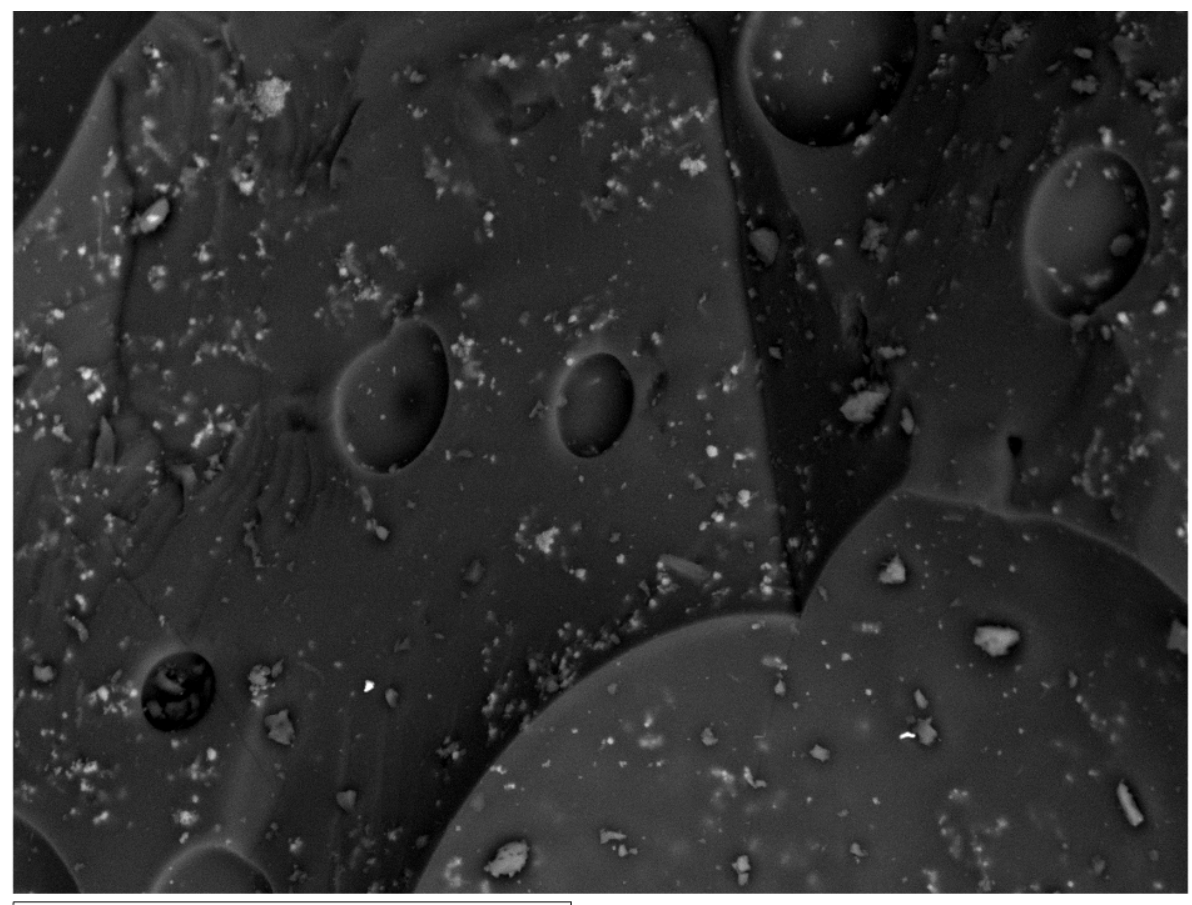

$60 \mu \mathrm{m}$

Electron Image 1

(b) Feed for formulation HWI-Al-16 $\left(\mathrm{Al}_{2} \mathrm{O}_{3}\right)$

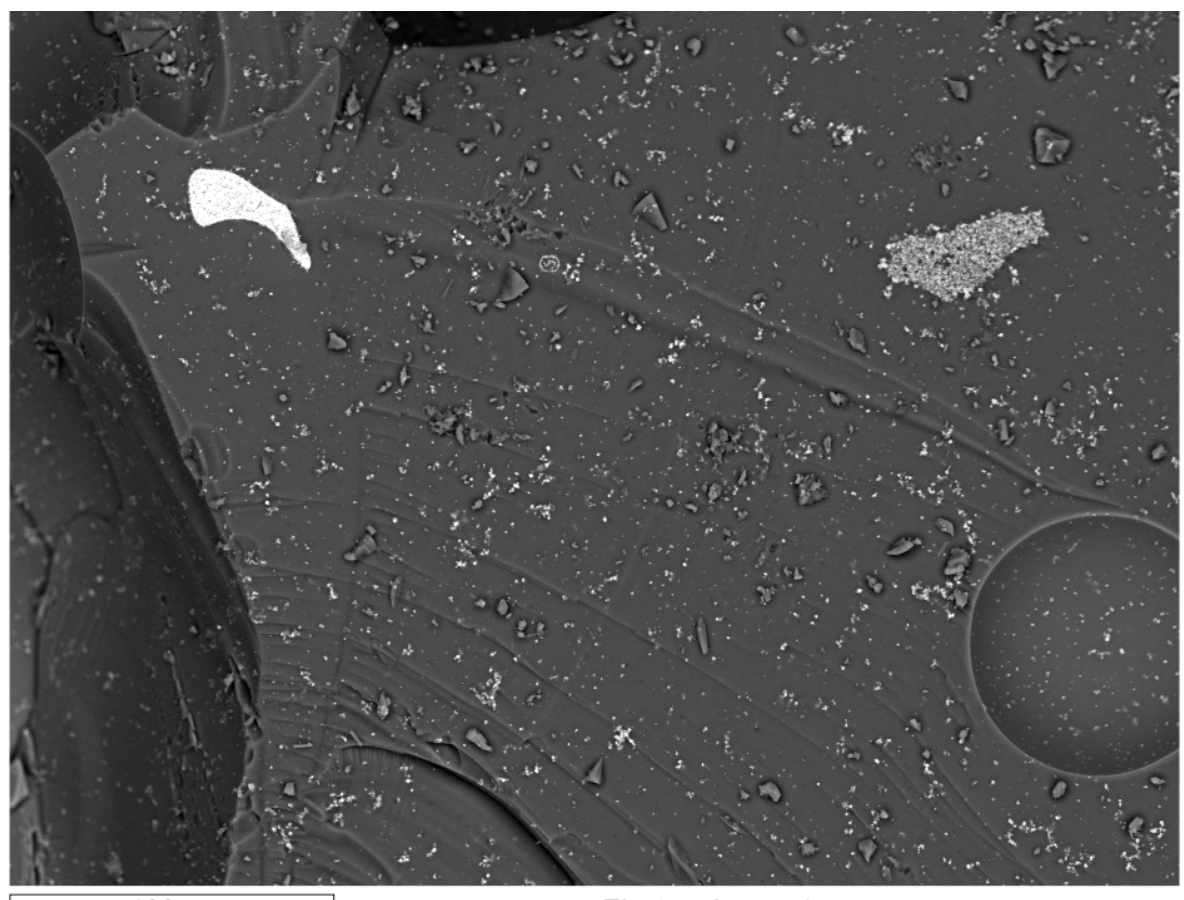

$100 \mu \mathrm{m}$

Electron Image 1

(c) Feed for formulation HWI-Al-16 $\left(\mathrm{Al}(\mathrm{OH})_{3}\right)$

Figure 3.12. SEM images of partially reacted feed after 30 minute VGF tests (continued). 
The Catholic University of America Vitreous State Laboratory
Melt Rate Enhancement for High Aluminum HLW Glass Formulations Final Report, VSL-08R1360-1, Rev. 0

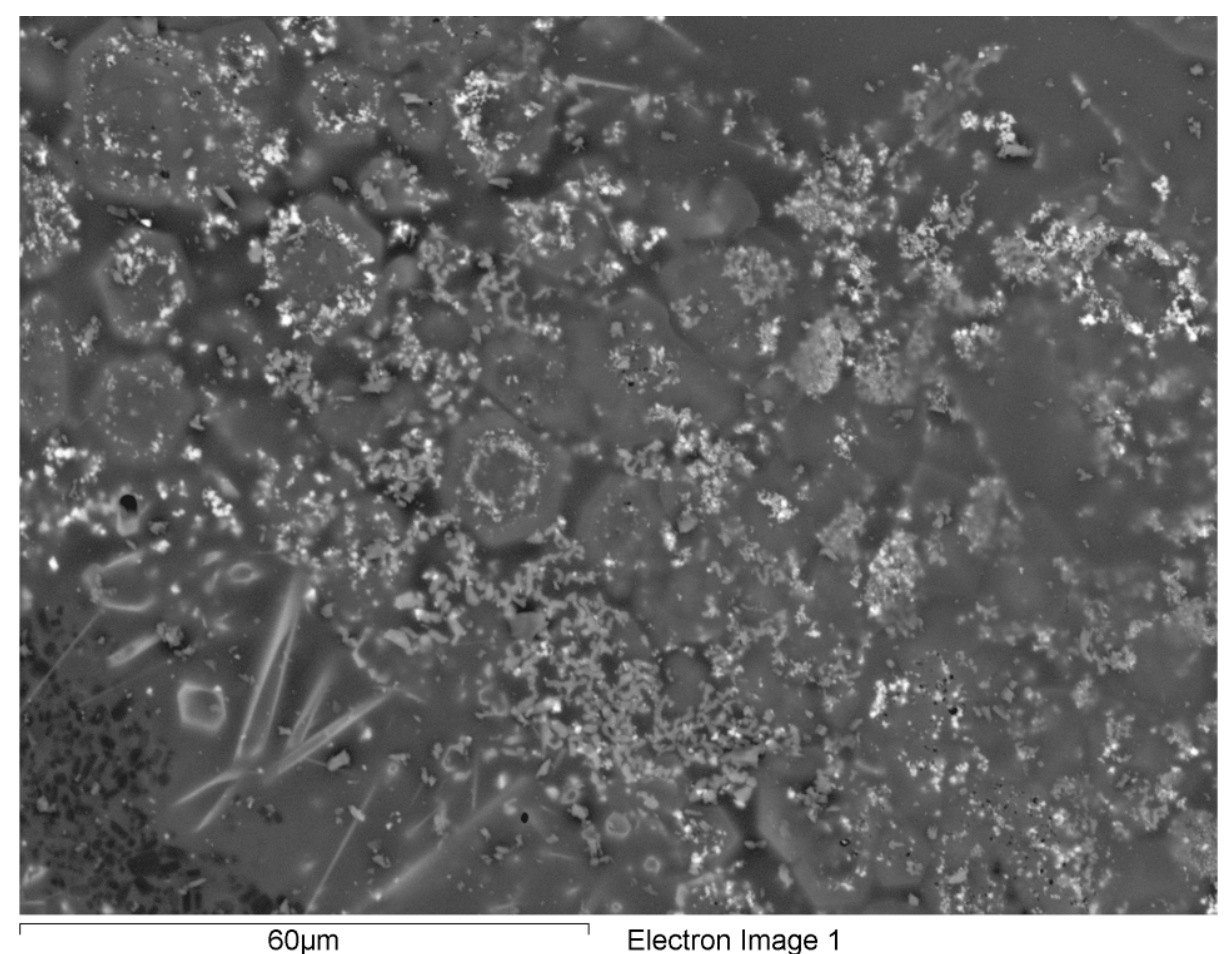

(d) Feed for formulation HWI-Al-19 $\left(\mathrm{Al}_{2} \mathrm{O}_{3}\right)$

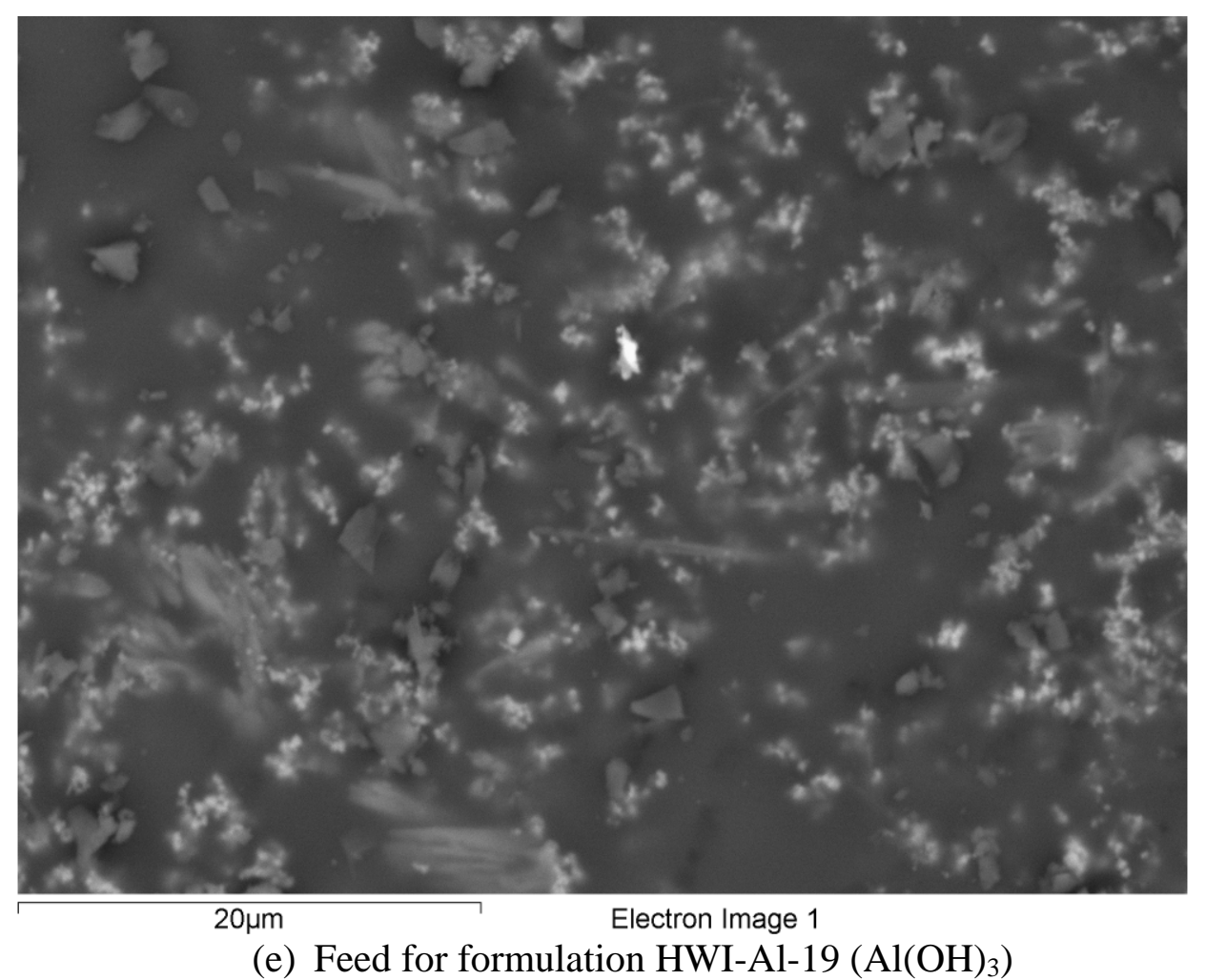

Figure 3.12. SEM images of partially reacted feed after 30 minute VGF tests (continued). 


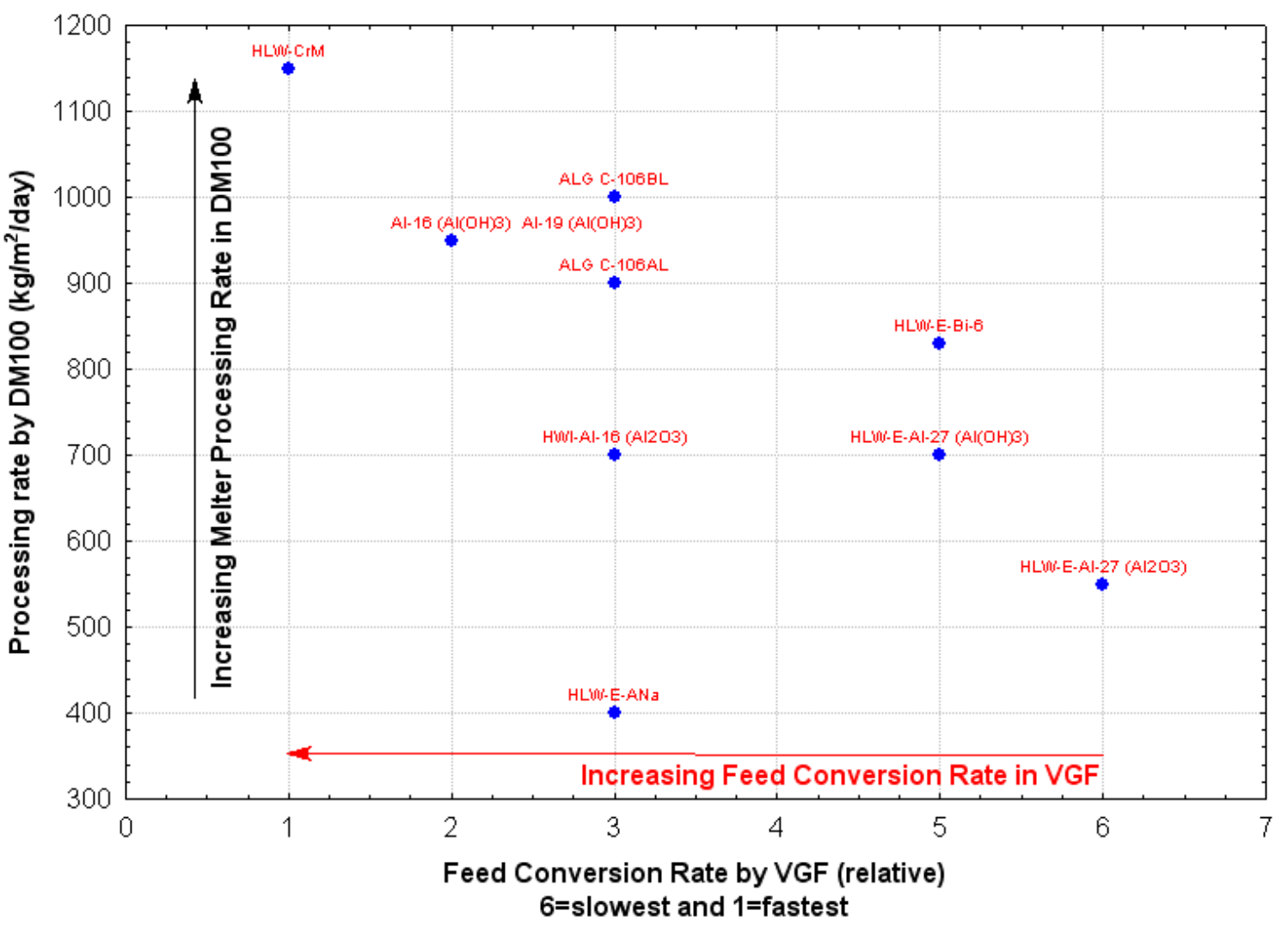

Figure 3.13. Comparison of melt rate ranking by VGF to the glass production rate determined by DM100 melter test. The definition of the VGF melt rate estimation is given in Table 3.5 . 


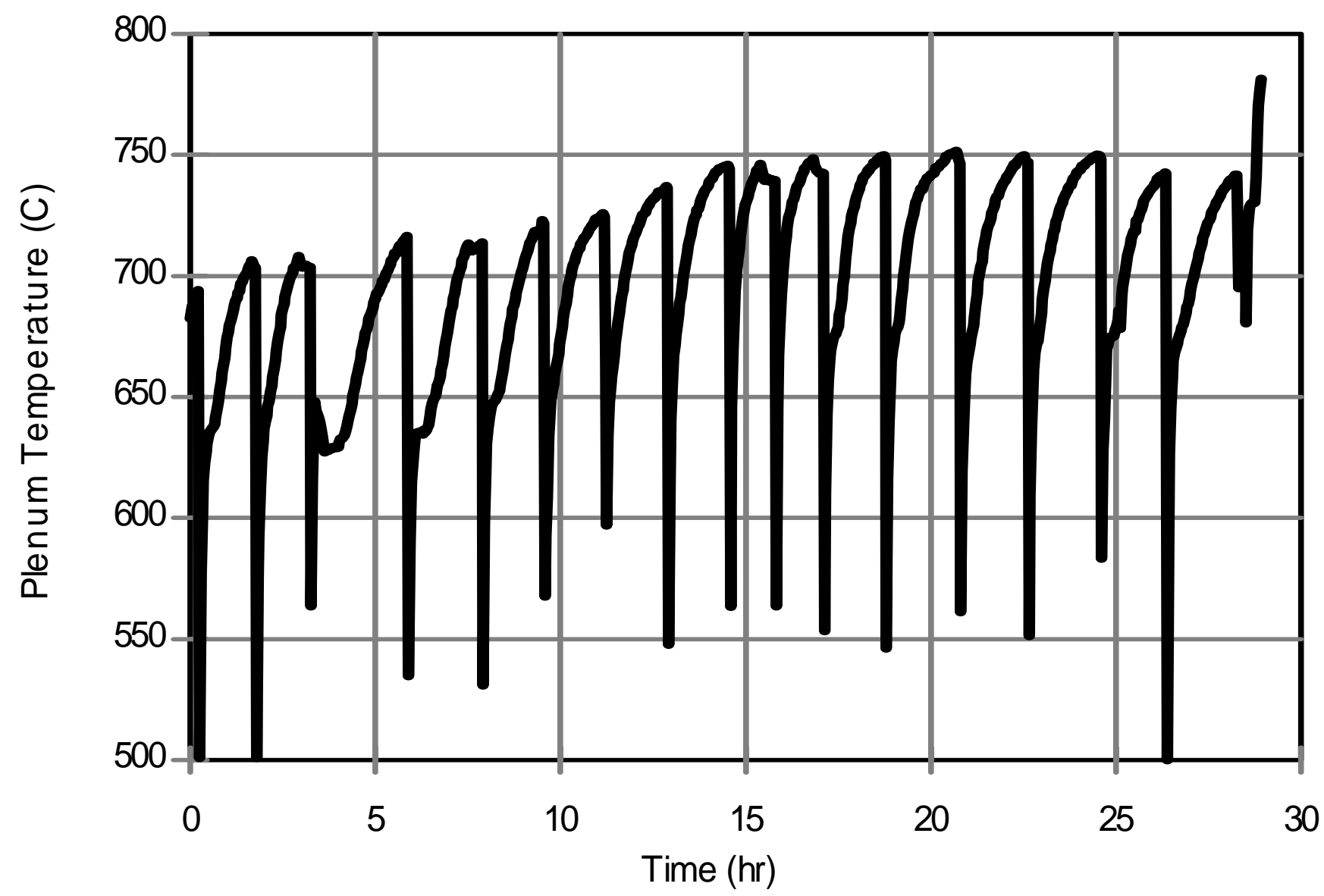

Figure 3.14. Changes in average plenum temperature over a series of DM10 feed consumption tests. 


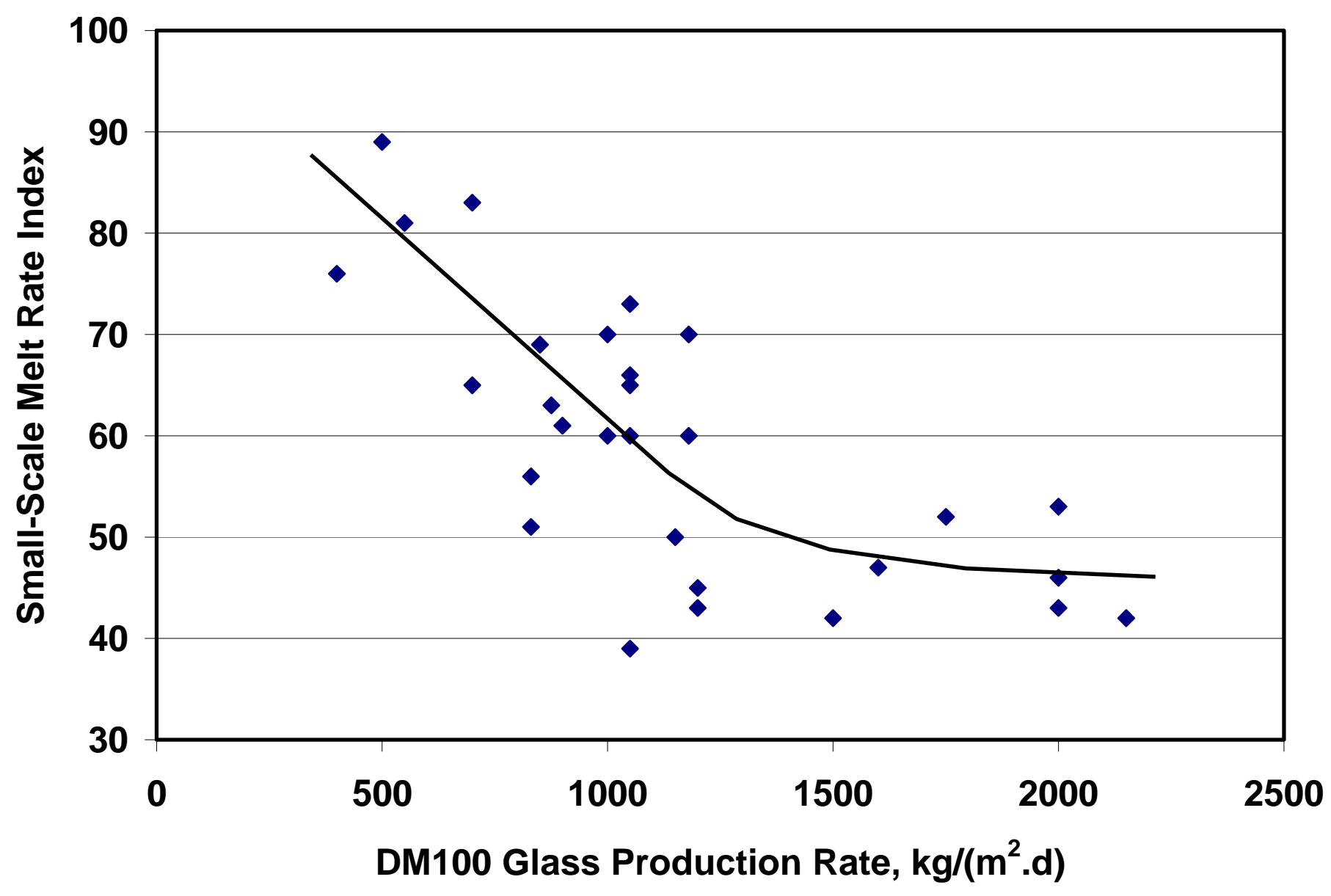

Figure 3.15. Correlation of DFC melt rate screening test data and DM100 production rates for a wide variety of feed compositions. 
HLW-E-Al-27 with Al2O3, Boric Acid/ K2CO3

HLW-E-AI-27 with Al2O3, Boric Acid/Soda Ash

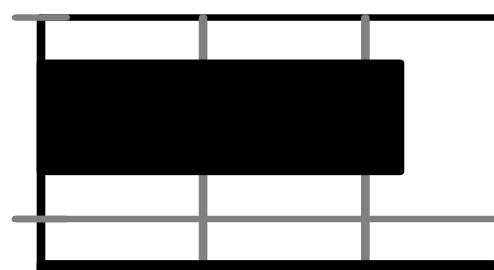

HWI-AI-9

HWI-AI-9KSM

HWIAI-9
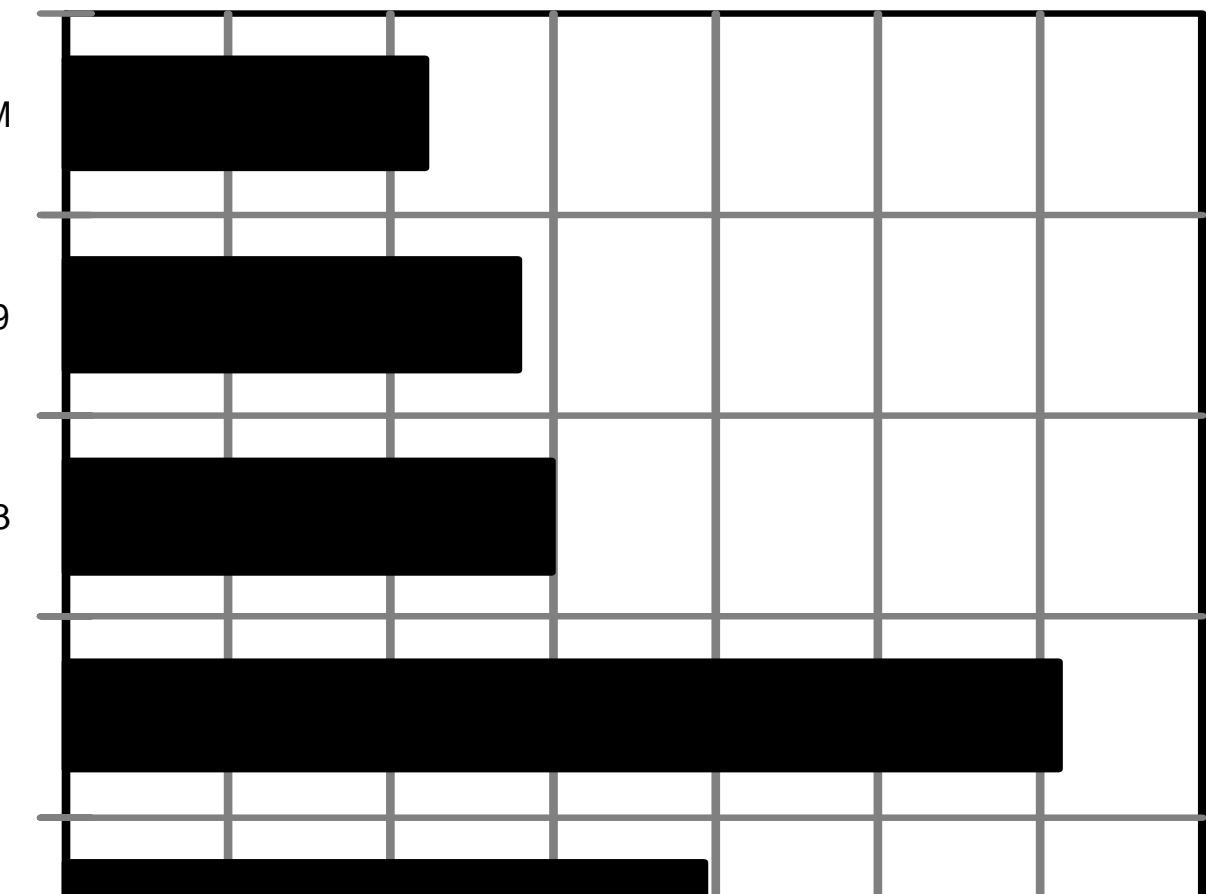

HLW-E-Al-27 with $\mathrm{Al}(\mathrm{OH}) 3$

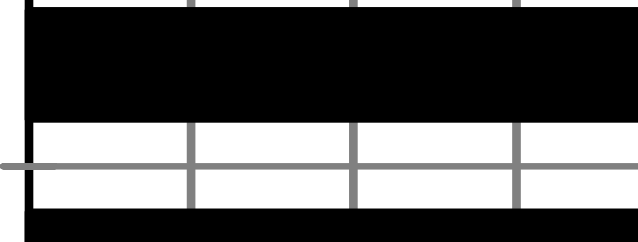

HLW-E-Al-27 with Al2O3
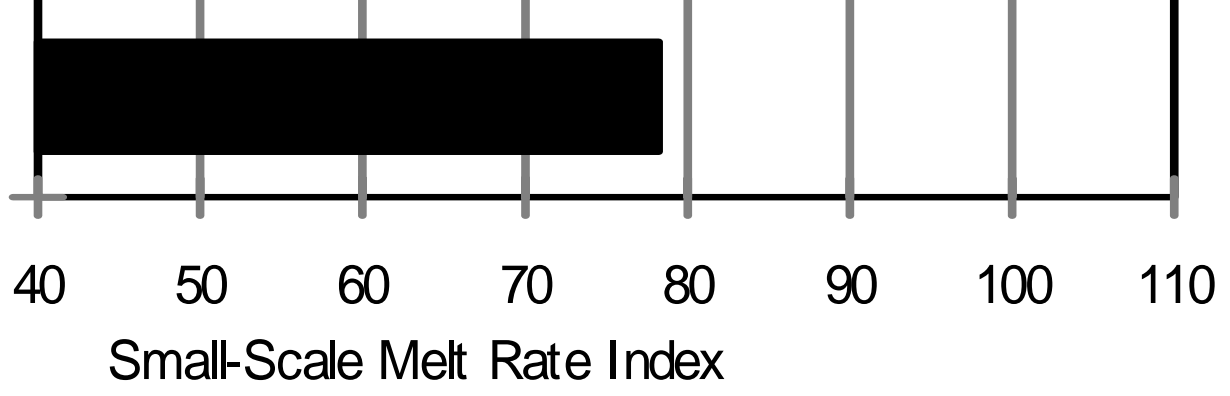

Figure 3.16. Comparison of base feeds from DFCmelt rate screening tests. 


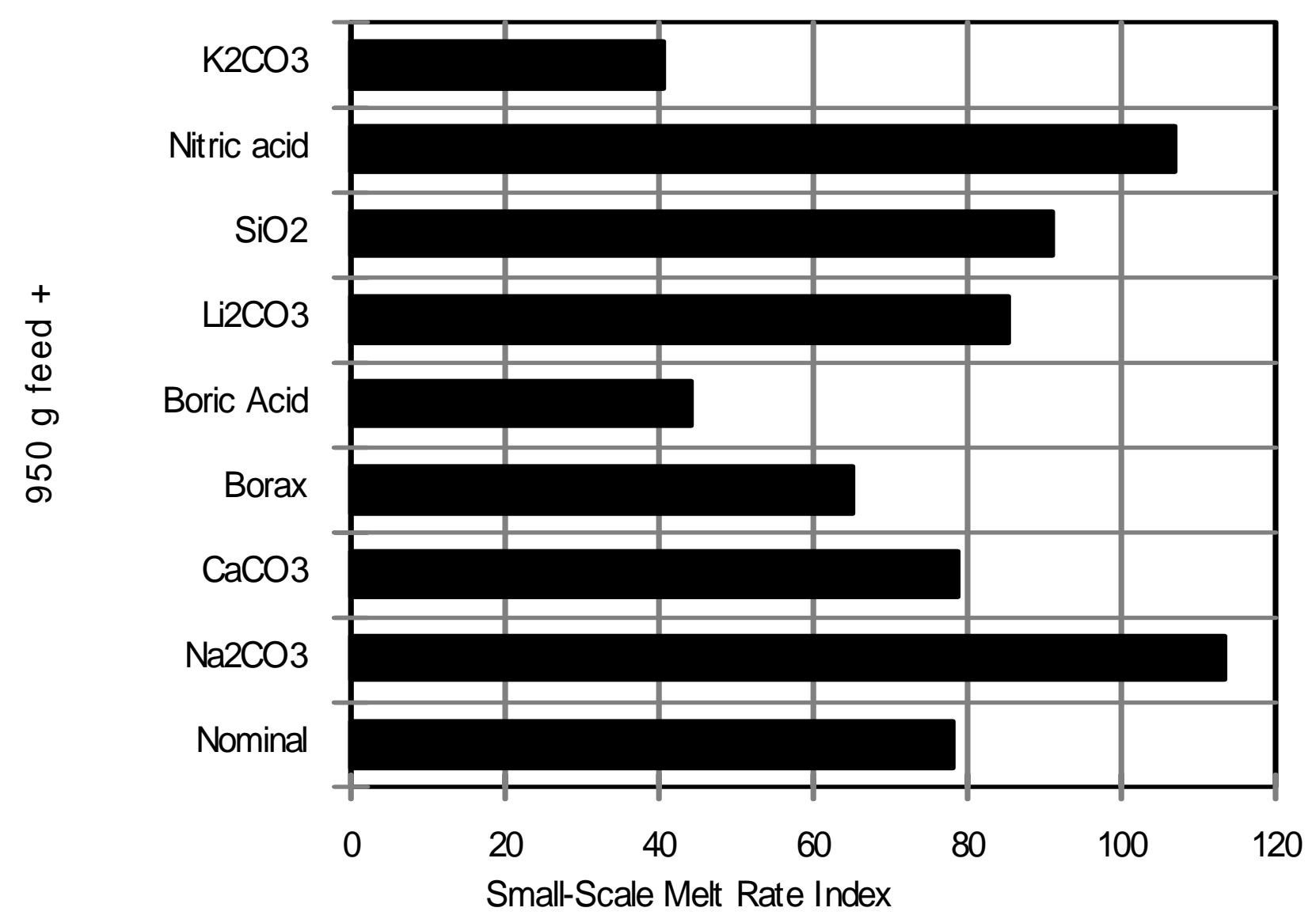

Figure 3.17. Comparison of additives combined with $\mathrm{HLW}-\mathrm{E}-\mathrm{AL}-27\left(\mathrm{Al}_{2} \mathrm{O}_{3}\right)$ from DFC melt rate screening tests. 


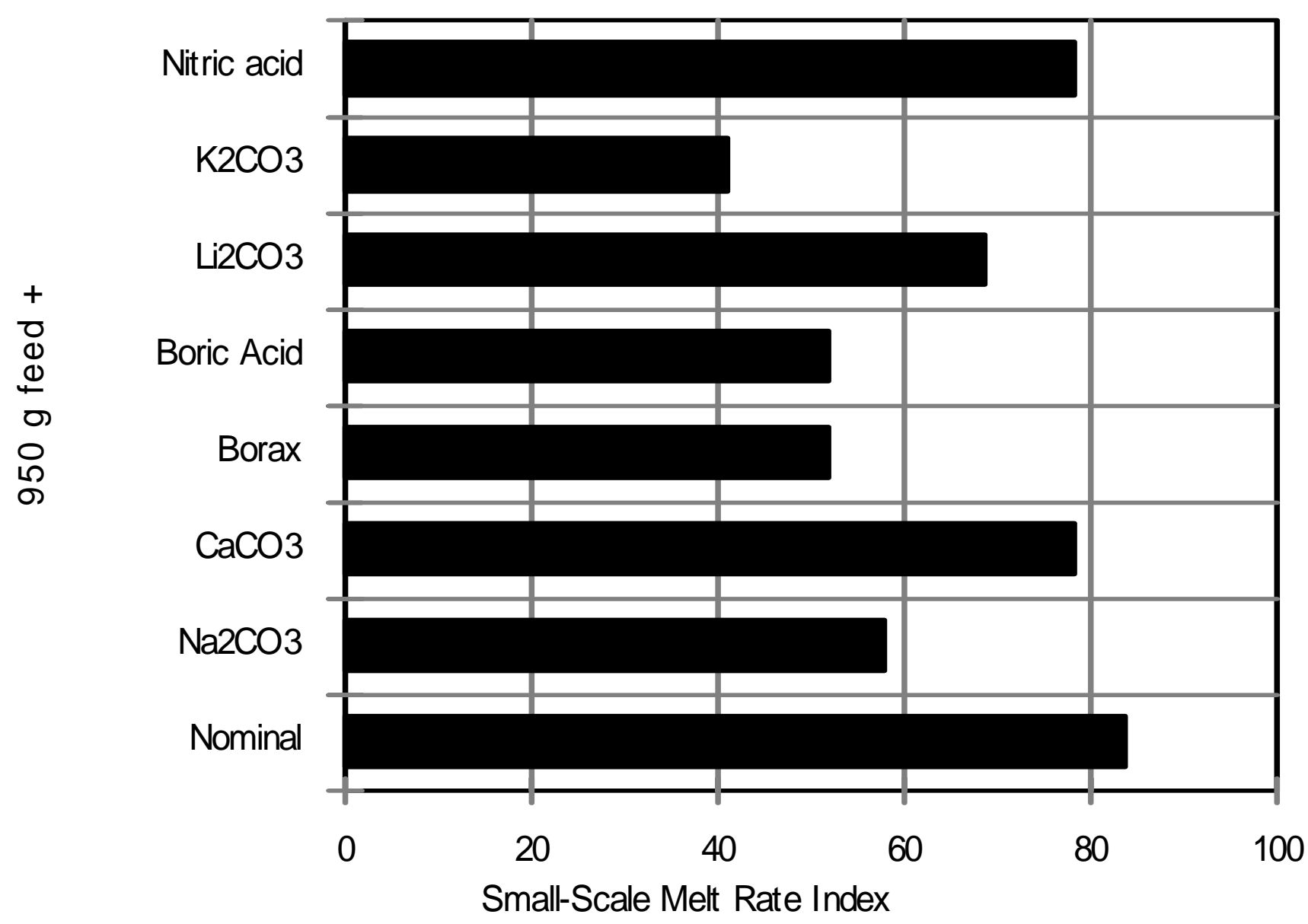

Figure 3.18. Comparison of additives combined with HLW-E-AL-27 $\left(\mathrm{Al}(\mathrm{OH})_{3}\right)$ from DFC melt rate screening tests. 


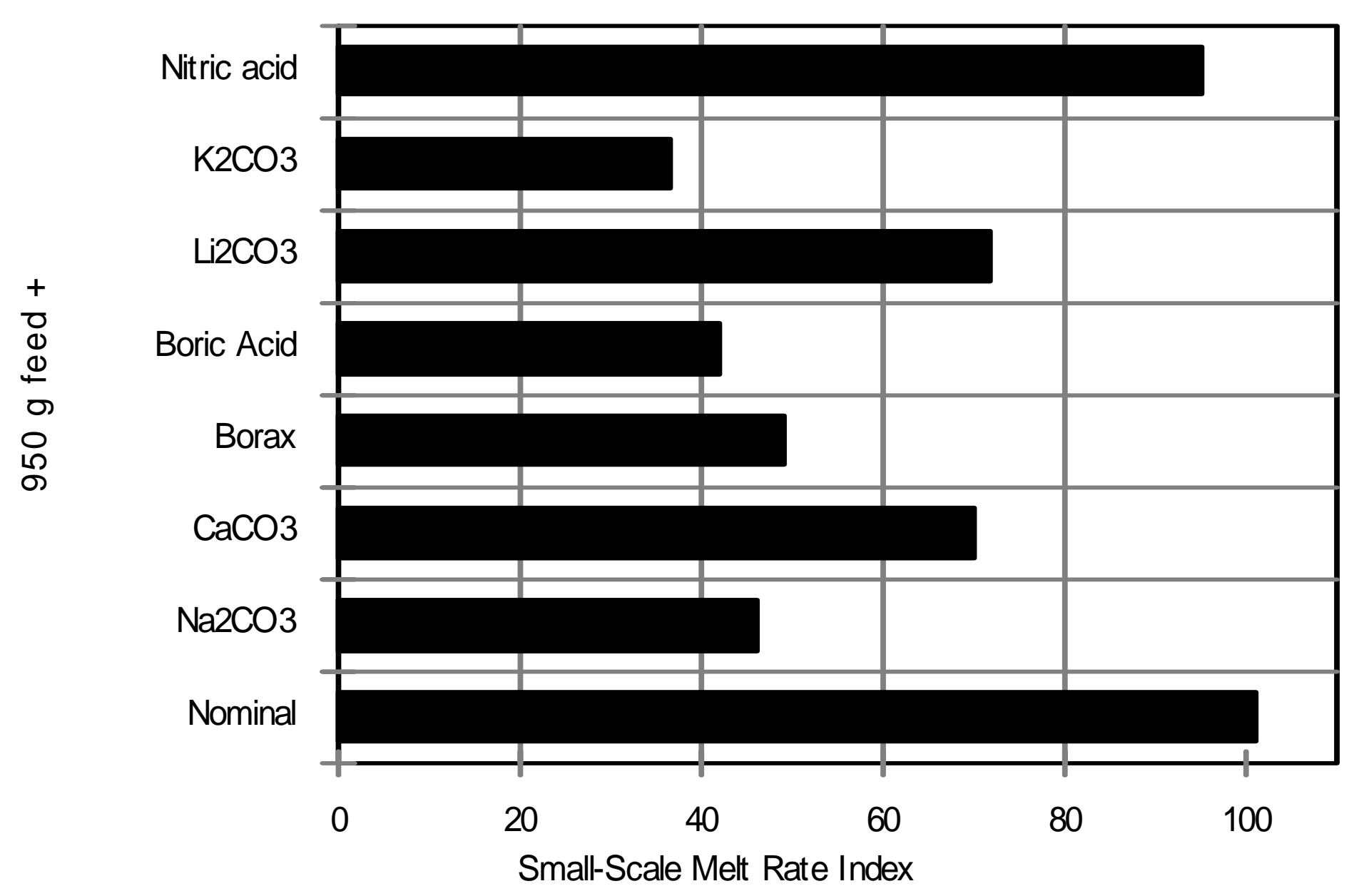

Figure 3.19. Comparison of additives combined with $\mathrm{HLW}-\mathrm{E}-\mathrm{AL}-27\left(\mathrm{Al}_{2} \mathrm{O}_{3}+\right.$ boric $\mathrm{acid} /$ soda ash replacing borax) from DFC melt rate screening tests. 


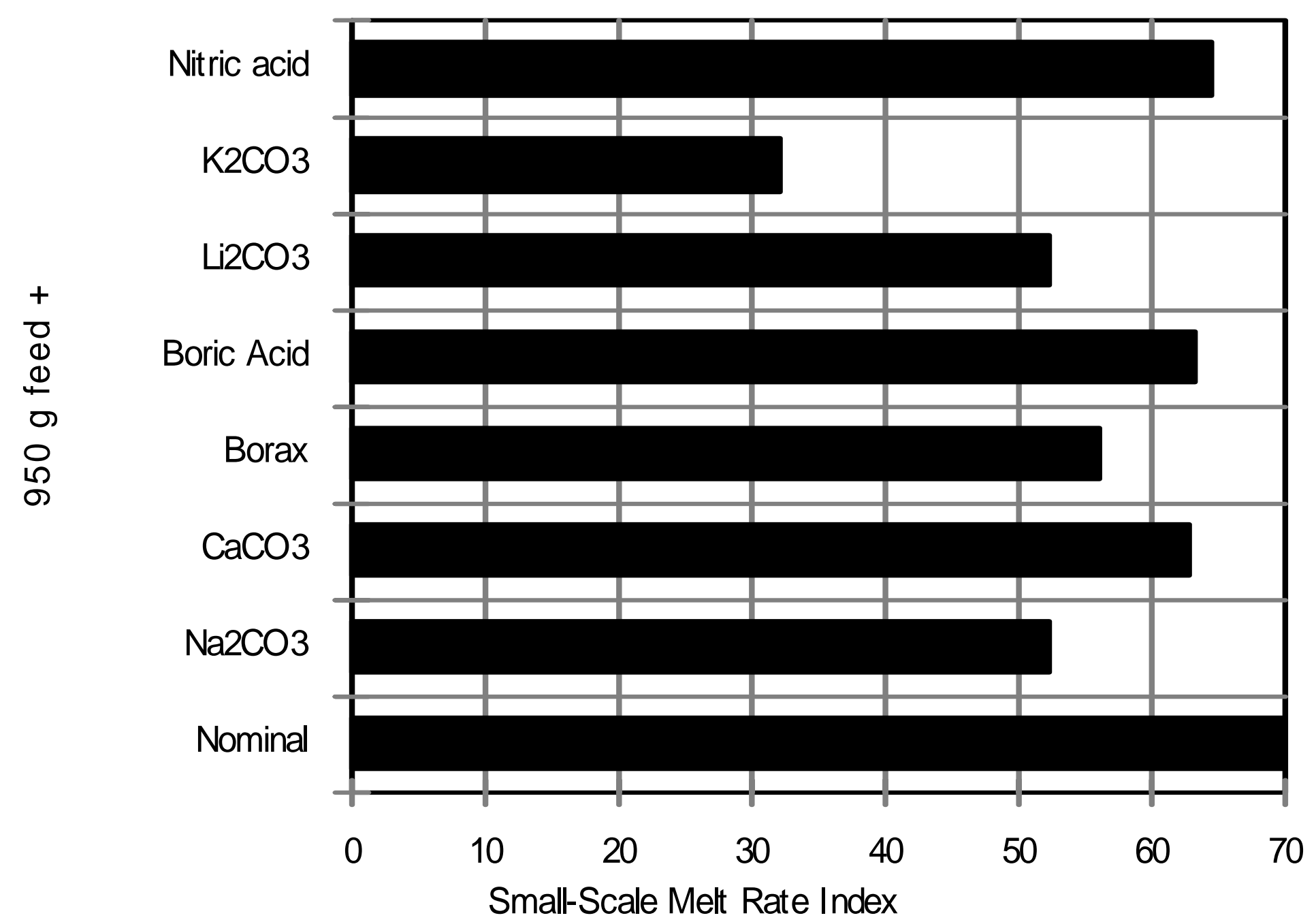

Figure 3.20. Comparison of additives combined with HLW-E-AL-27 $\left(\mathrm{Al}_{2} \mathrm{O}_{3}+\right.$ boric acid/potassium carbonate replacing borax) from DFC melt rate screening tests. 

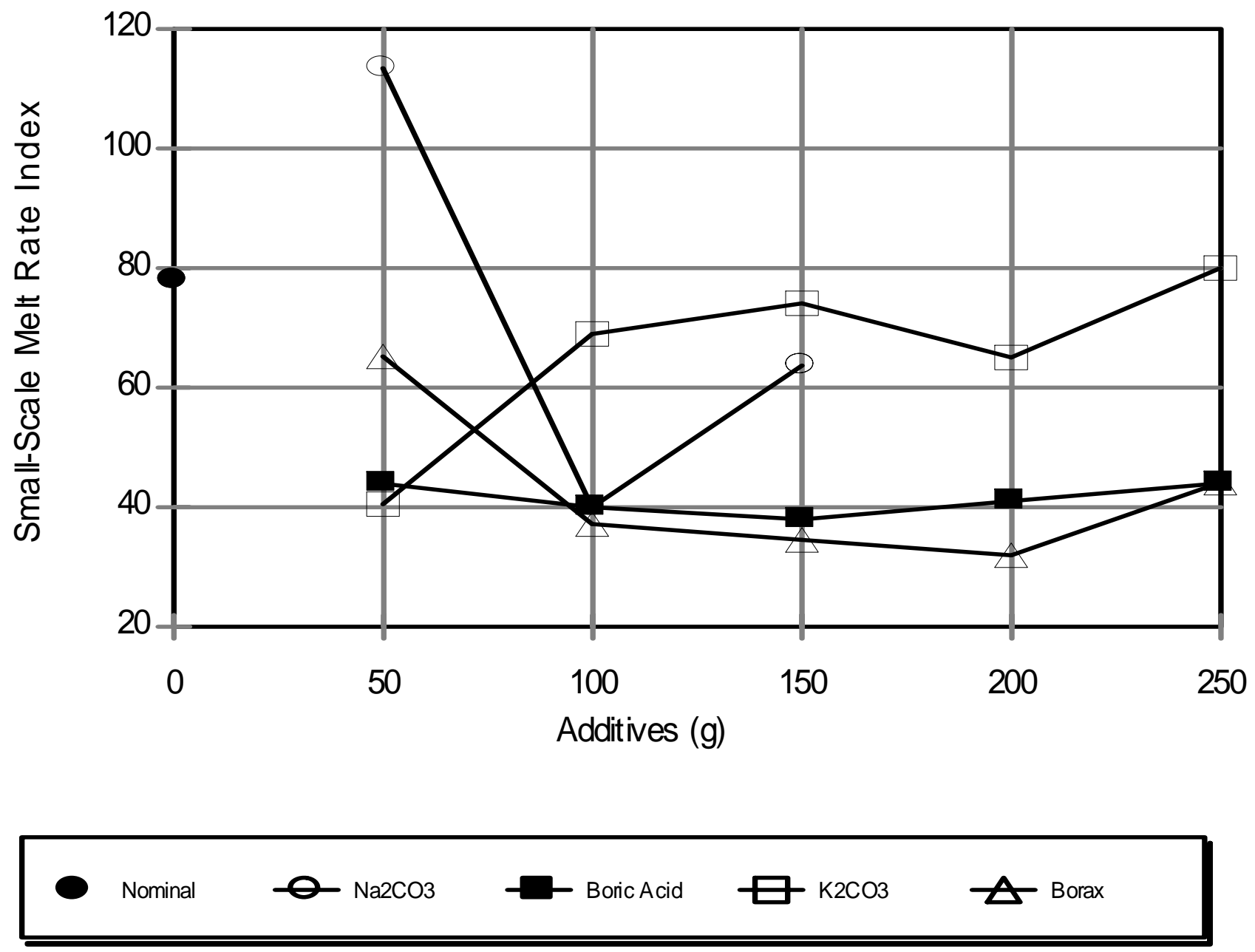

Figure 3.21. Comparison of additives and amounts combined with HLW-E-AL-27 $\left(\mathrm{Al}_{2} \mathrm{O}_{3}\right)$ from DFC melt rate screening tests. 


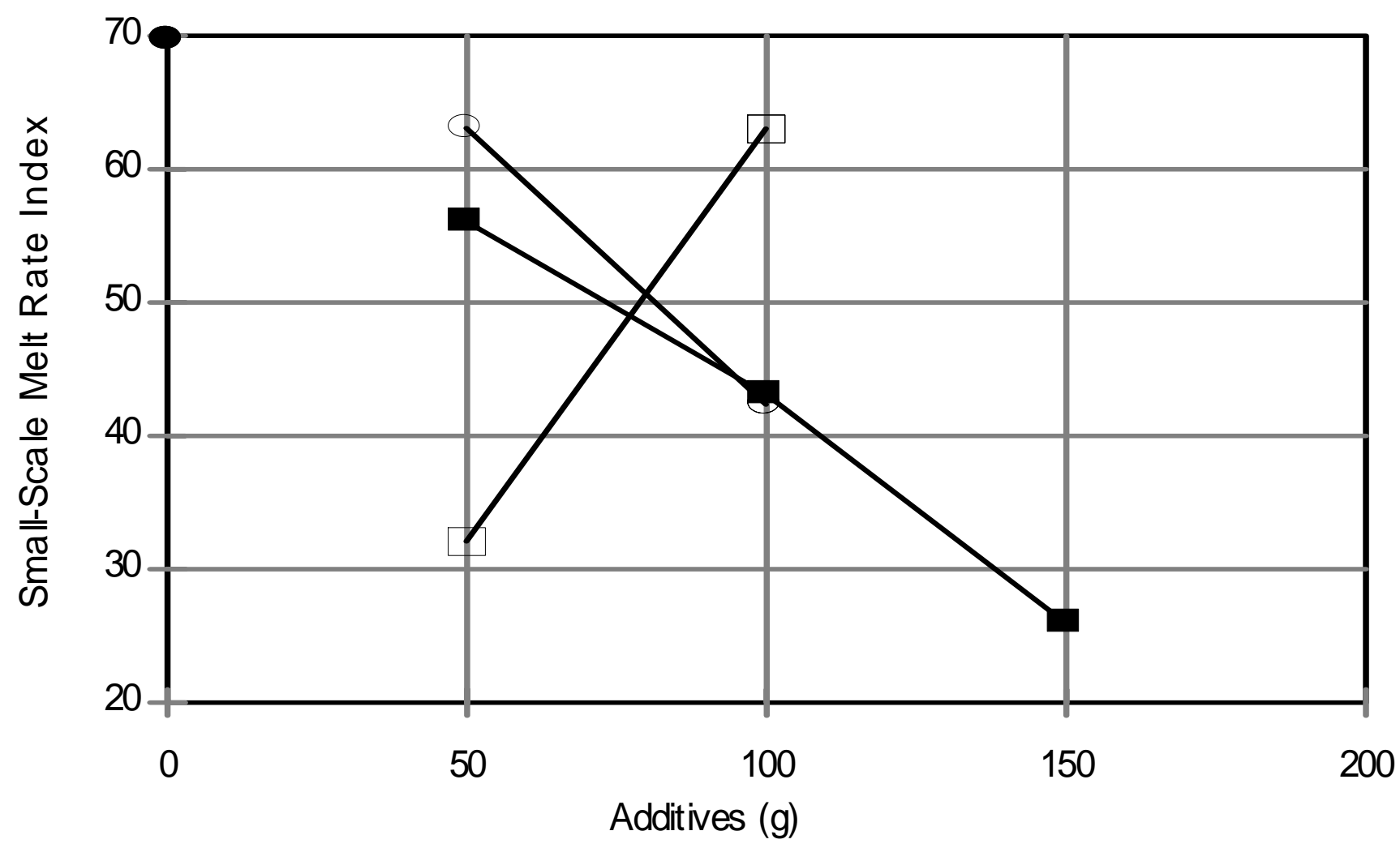

Figure 3.22. Comparison of additives and amounts combined with $\mathrm{HLW}-\mathrm{E}-\mathrm{AL}-27\left(\mathrm{Al}_{2} \mathrm{O}_{3}+\right.$ boric acid/potassium carbonate replacing borax) from DFC melt rate screening tests. 

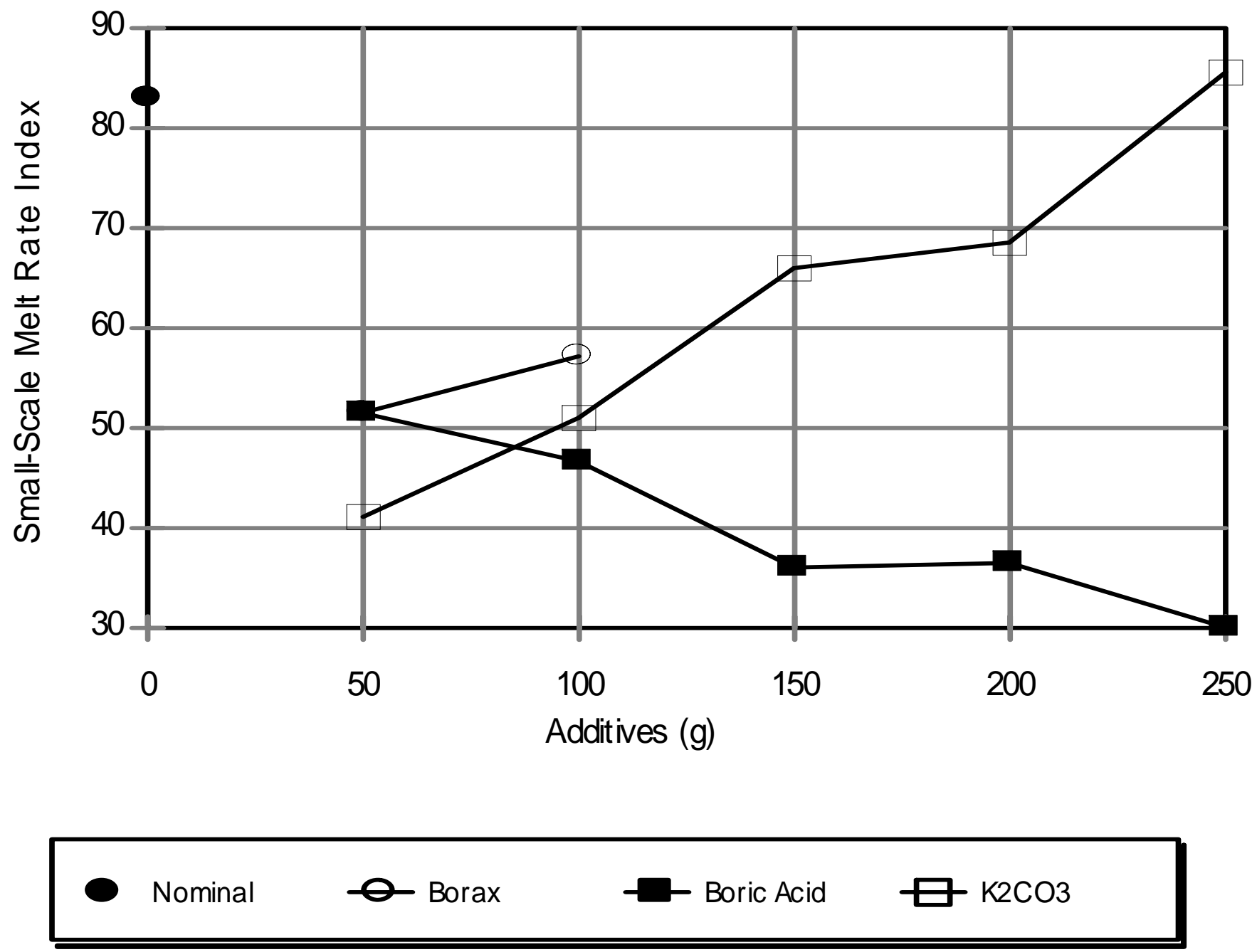

Figure 3.23. Comparison of additives and amounts combined with HLW-E-AL-27 $\left(\mathrm{Al}(\mathrm{OH})_{3}\right)$ from DFC melt rate screening tests. 


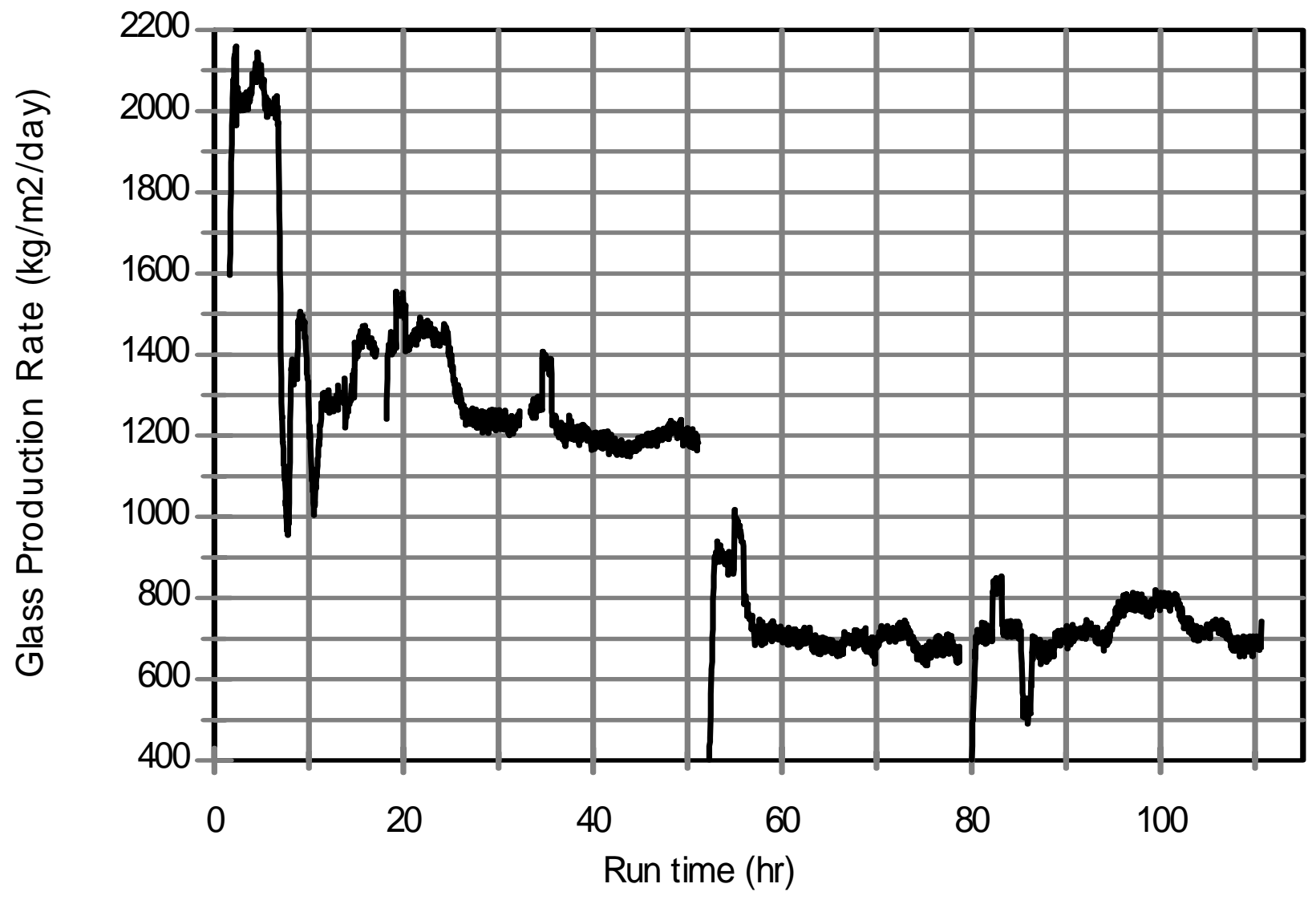

Figure 4.1.a. Glass production rates (hourly moving averages) for DM100 Tests 1 and 2. 


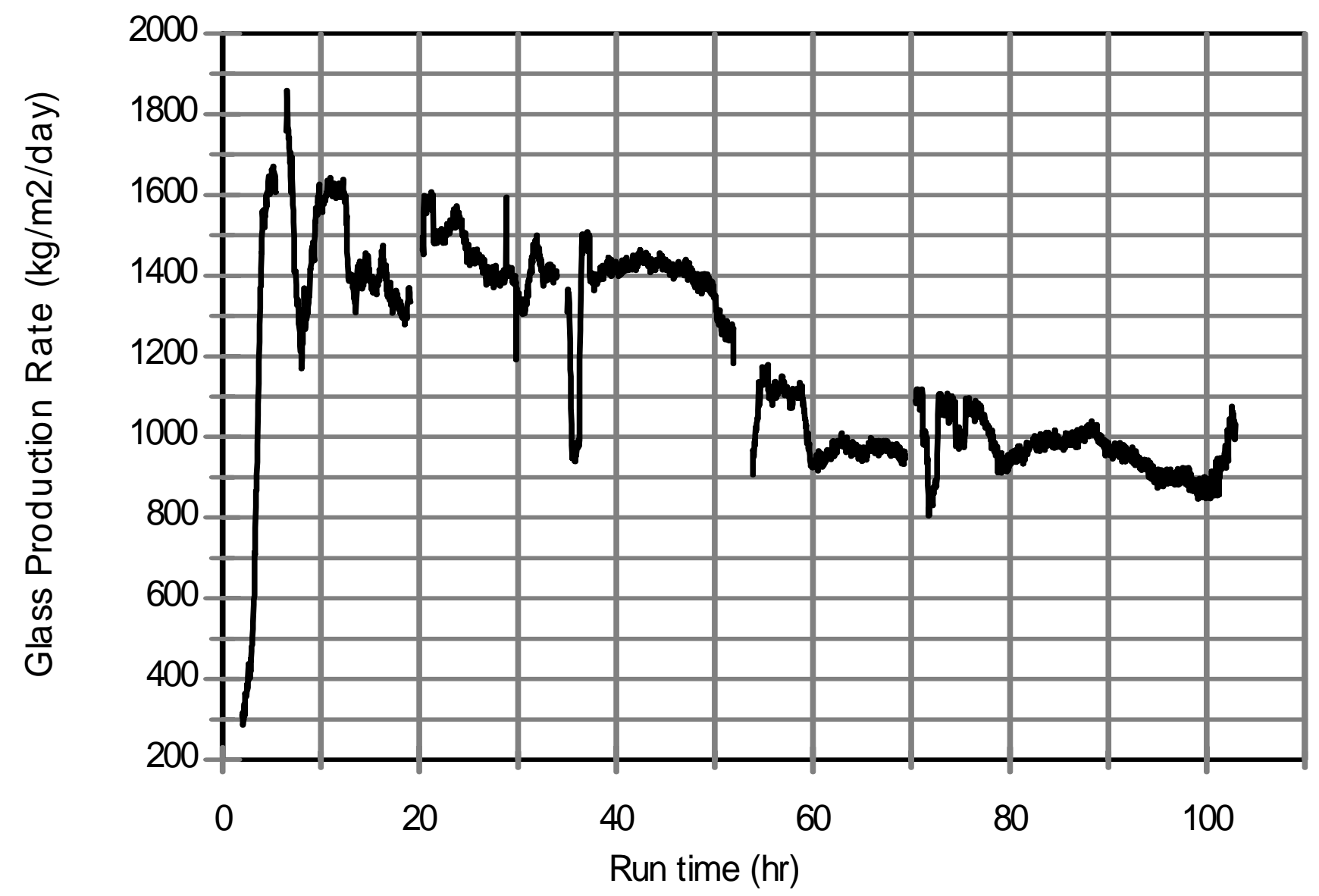

Figure 4.1.b. Glass production rates (hourly moving averages) for DM100 Tests 3 and 4. 


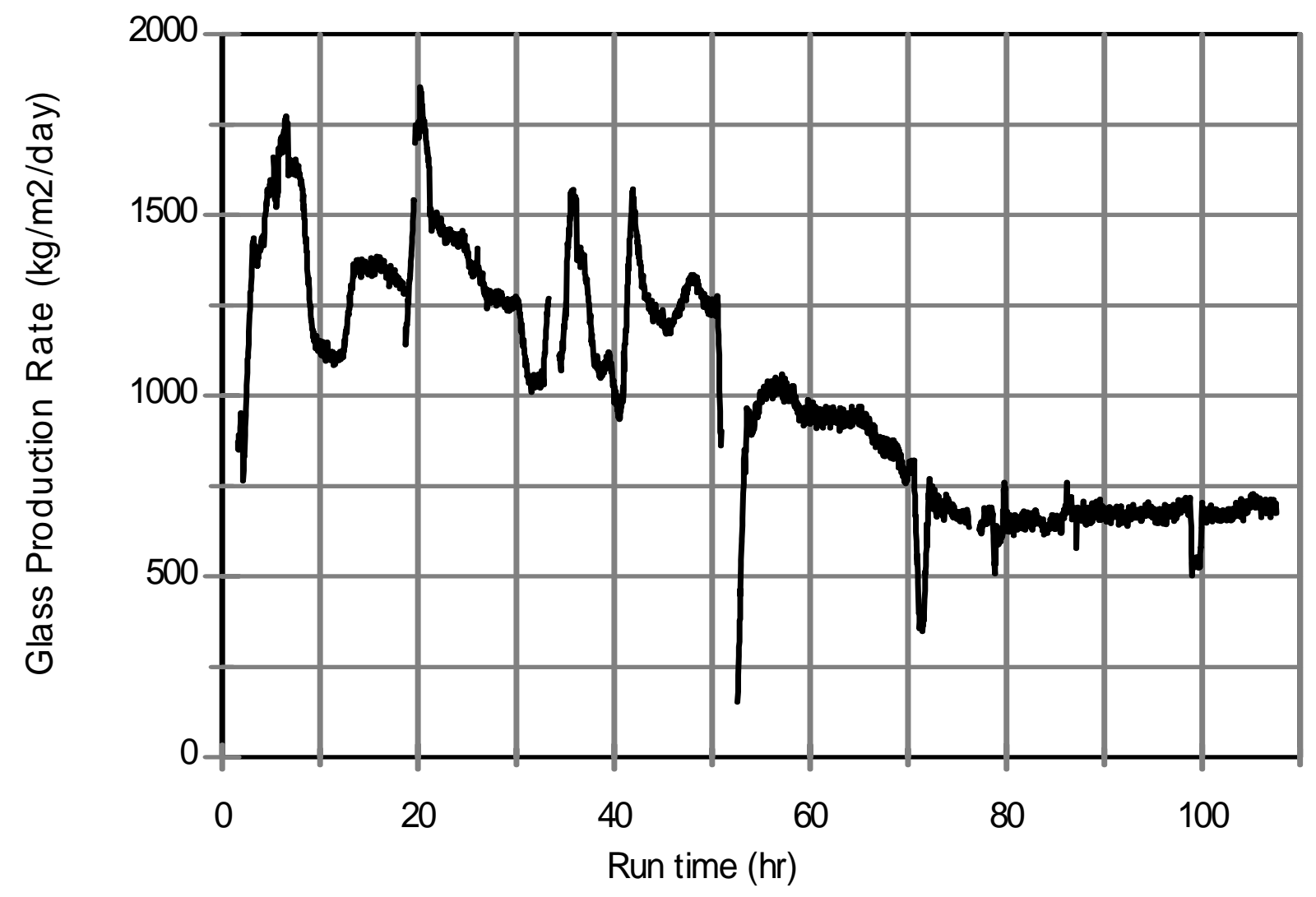

Figure 4.1.c. Glass production rates (hourly moving averages) for DM100 Tests 5 and 6. 


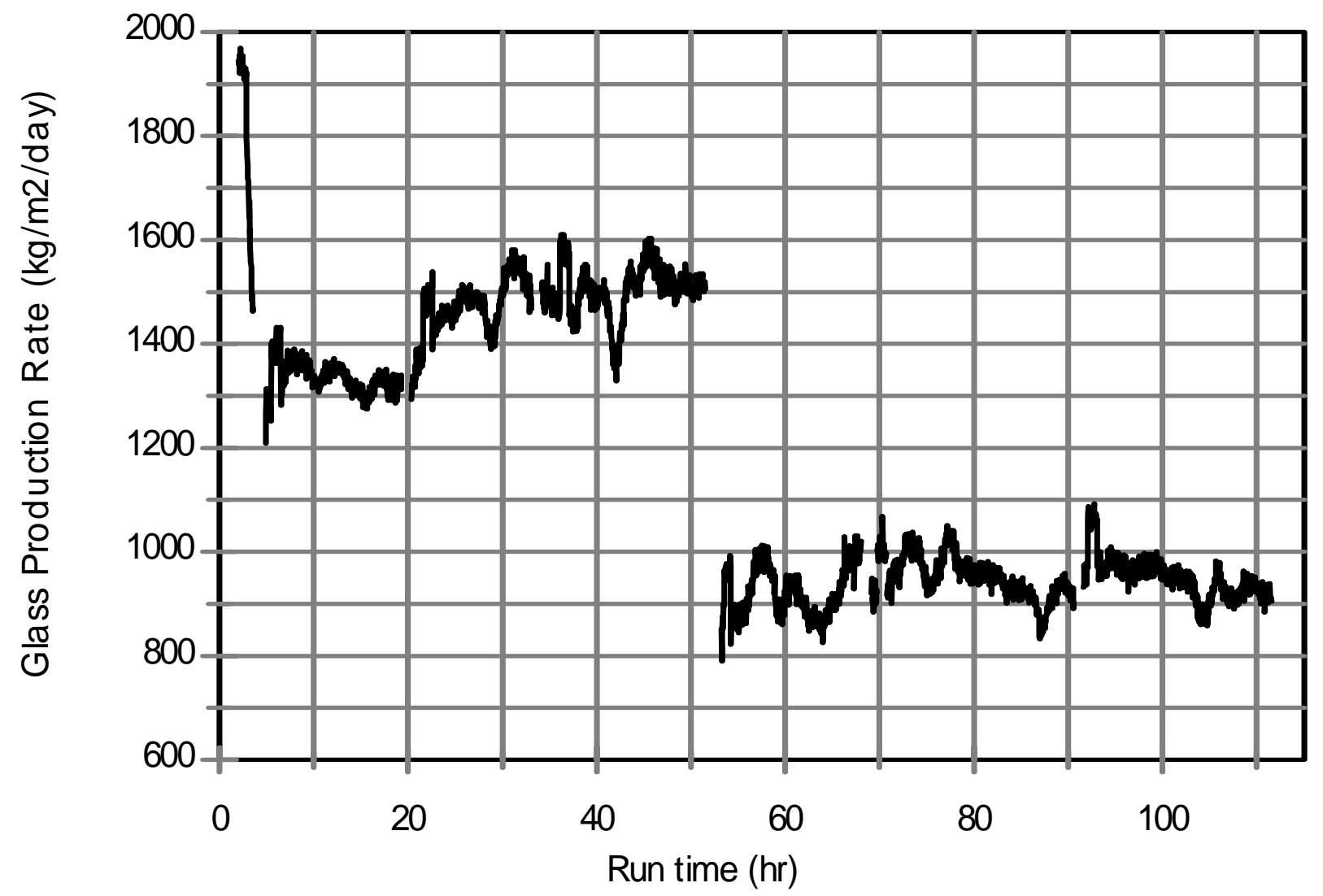

Figure 4.1.d. Glass production rates (hourly moving averages) for DM100 Tests 7 and 8. 


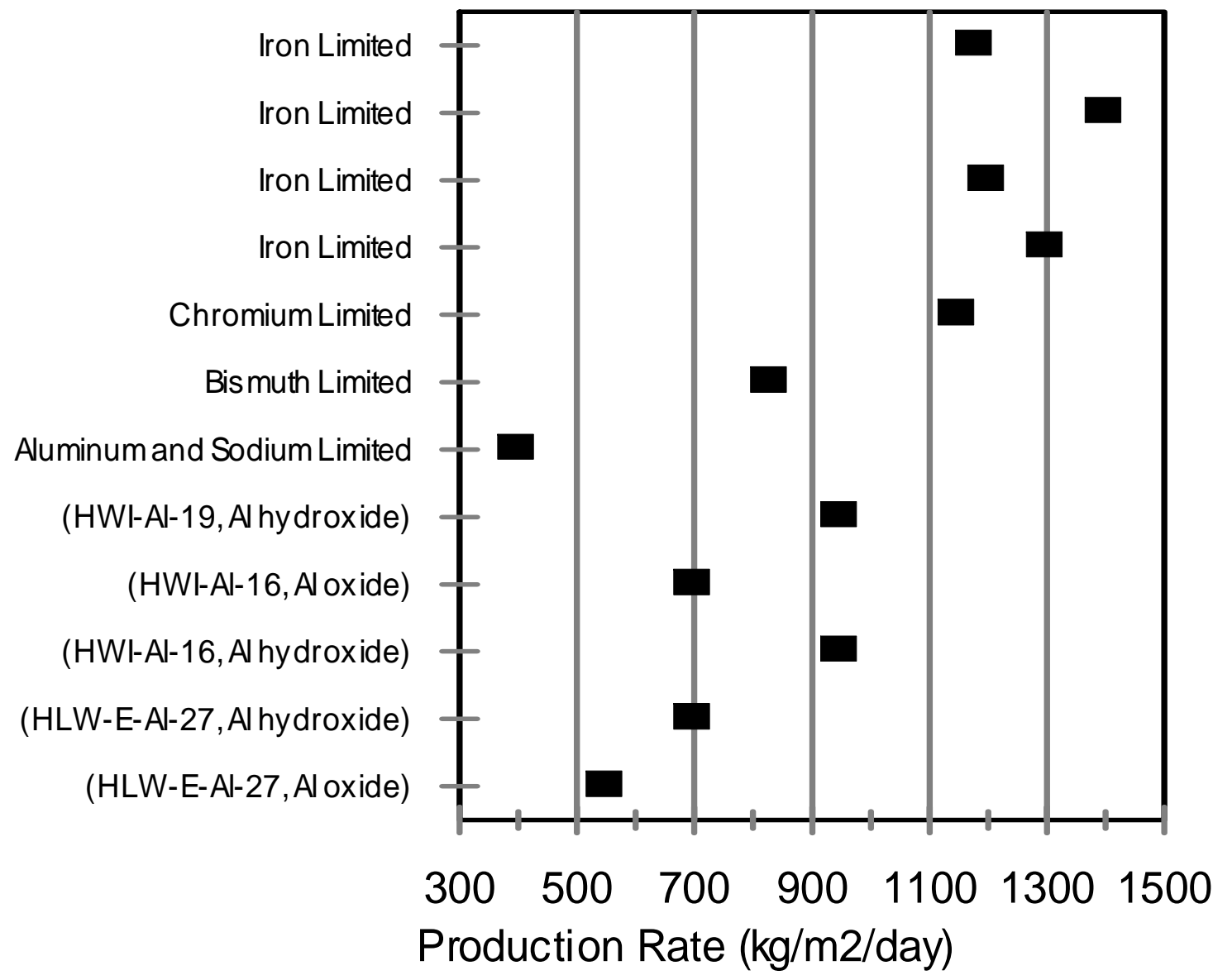

Figure 4.2. Steady-state glass production rates during DM100 tests at constant bubbling rate, glass temperature $\left(1150^{\circ} \mathrm{C}\right)$, and feed solids content $500( \pm 50)$ g glass per liter feed. 


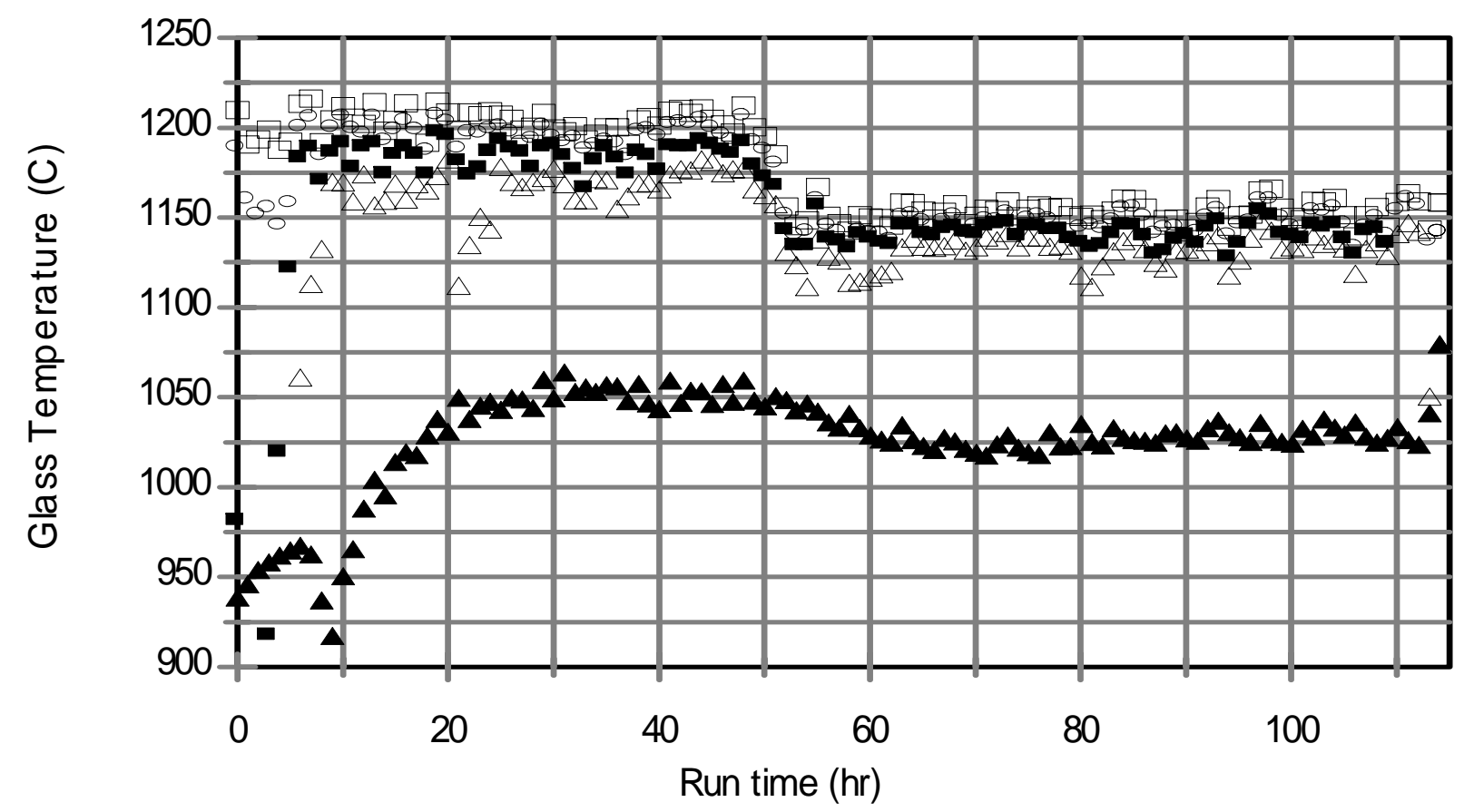

\begin{tabular}{|c|c|c|c|c|c|}
\hline$\Delta$ & 27 " from bottom & - & $16 "$ from bottom & 口 & 10 " from bottom \\
\hline 0 & 5" from bottom & $\Delta$ & Airlift & & \\
\hline
\end{tabular}

Figure 4.3.a. Glass temperatures (hourly averages) during DM100 Tests 1 and 2. 


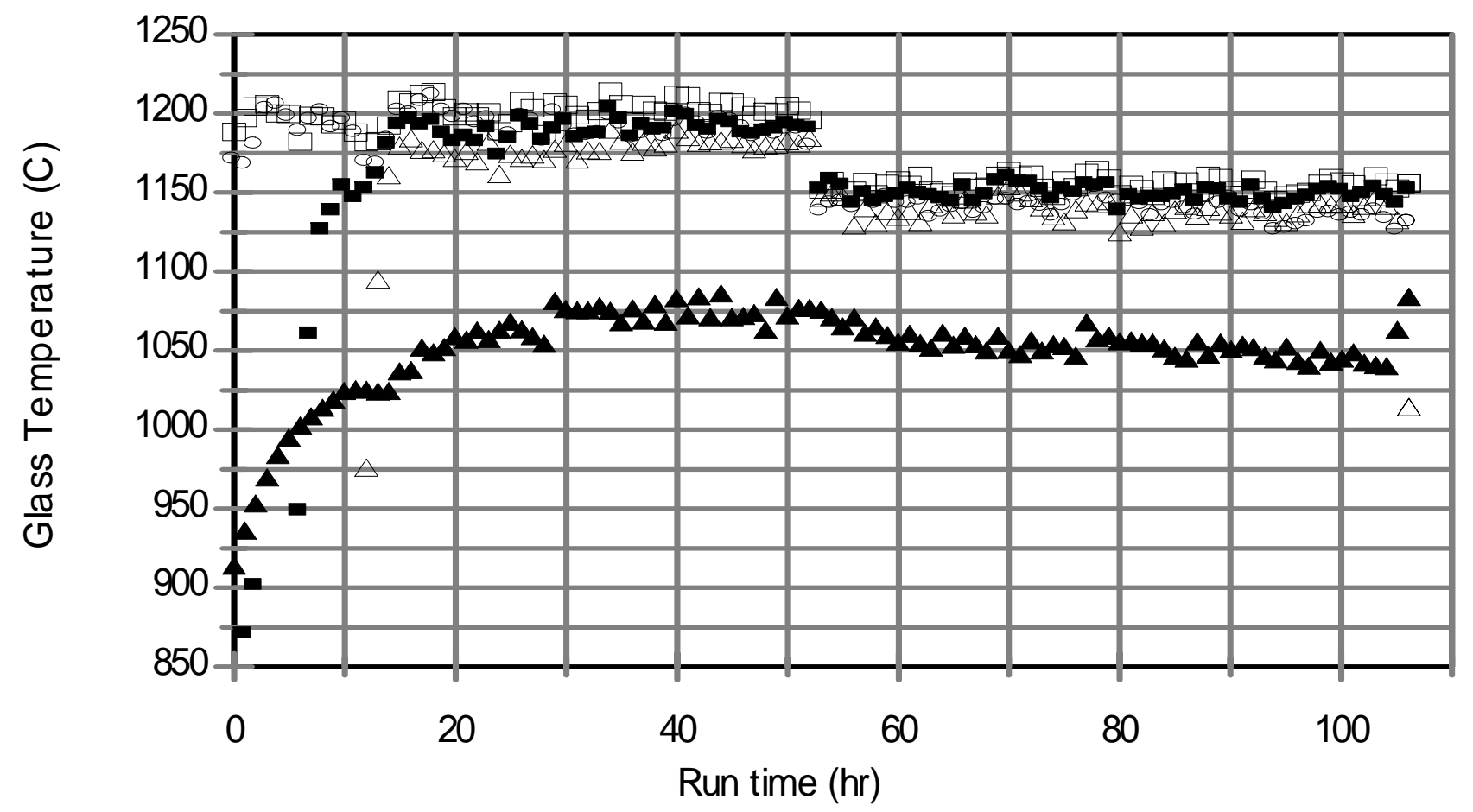
$\Delta \quad 27$ " from bottom
- 16 " from bottom
ㅁ 10" from bottom
- 5" from bottom
$\Delta \quad$ Airlift

Figure 4.3.b. Glass temperatures (hourly averages) during DM100 Tests 3 and 4. 


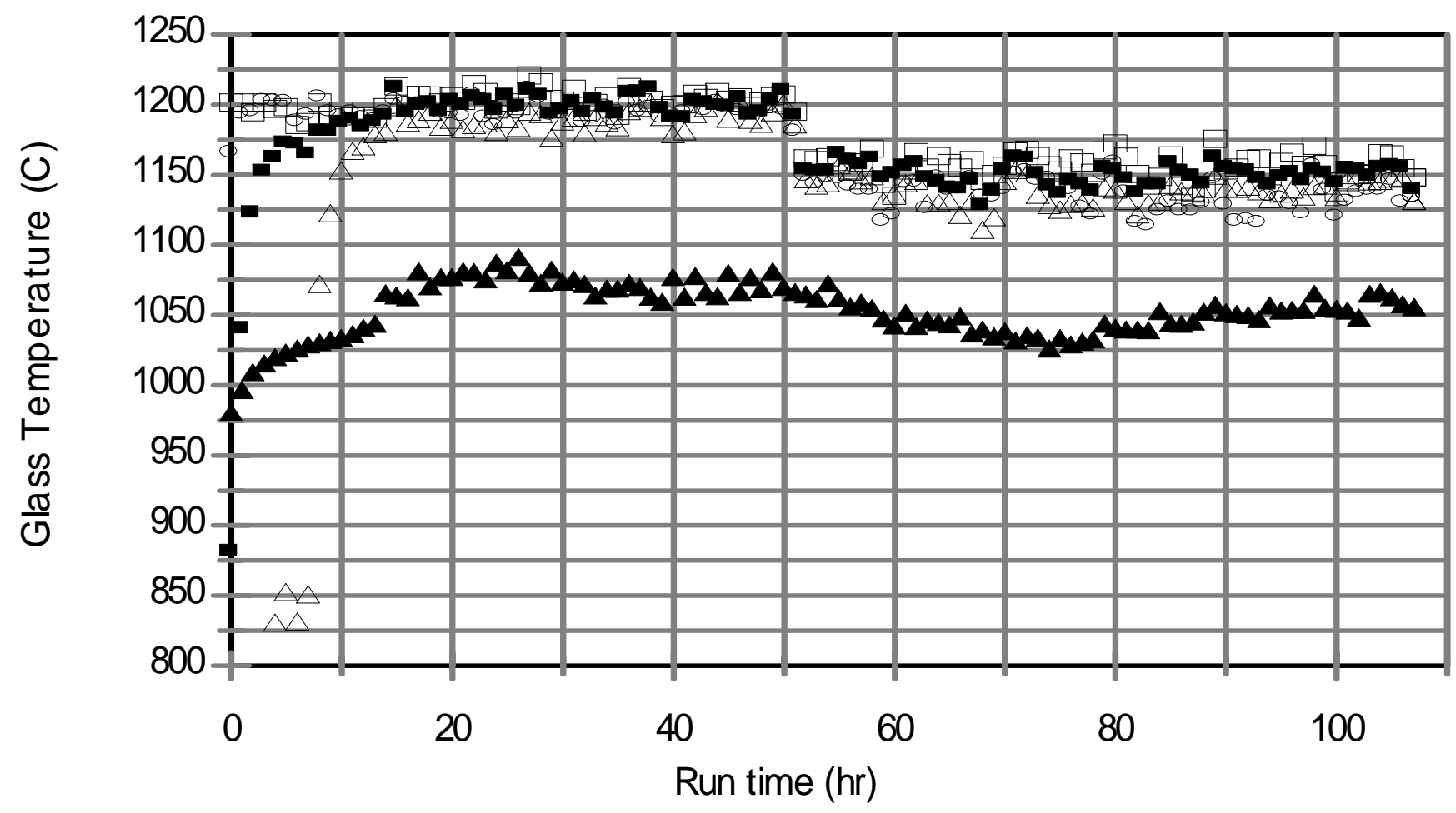

$\Delta \quad 27$ " from bottom

- 16 " from bottom

- Airlift

- 5" from bottom

口 10" from bottom

Figure 4.3.c. Glass temperatures (hourly averages) during DM100 Tests 5 and 6. 


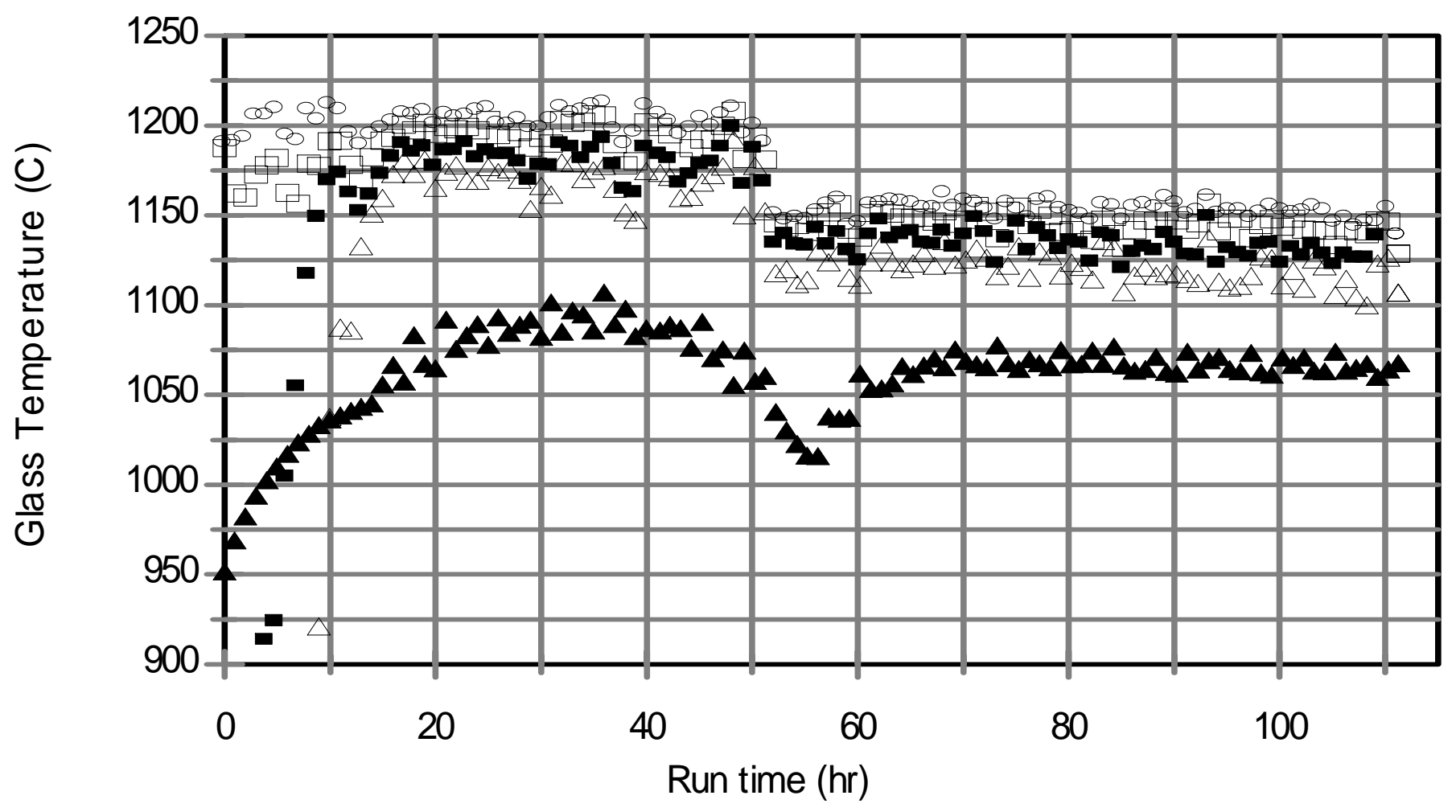

$\Delta \quad 27$ " from bottom

- 16 " from bottom

口 10 " from bottom

- 5 " from bottom

$\Delta$ Airlift

Figure 4.3.d. Glass temperatures (hourly averages) during DM100 Tests 7 and 8. 


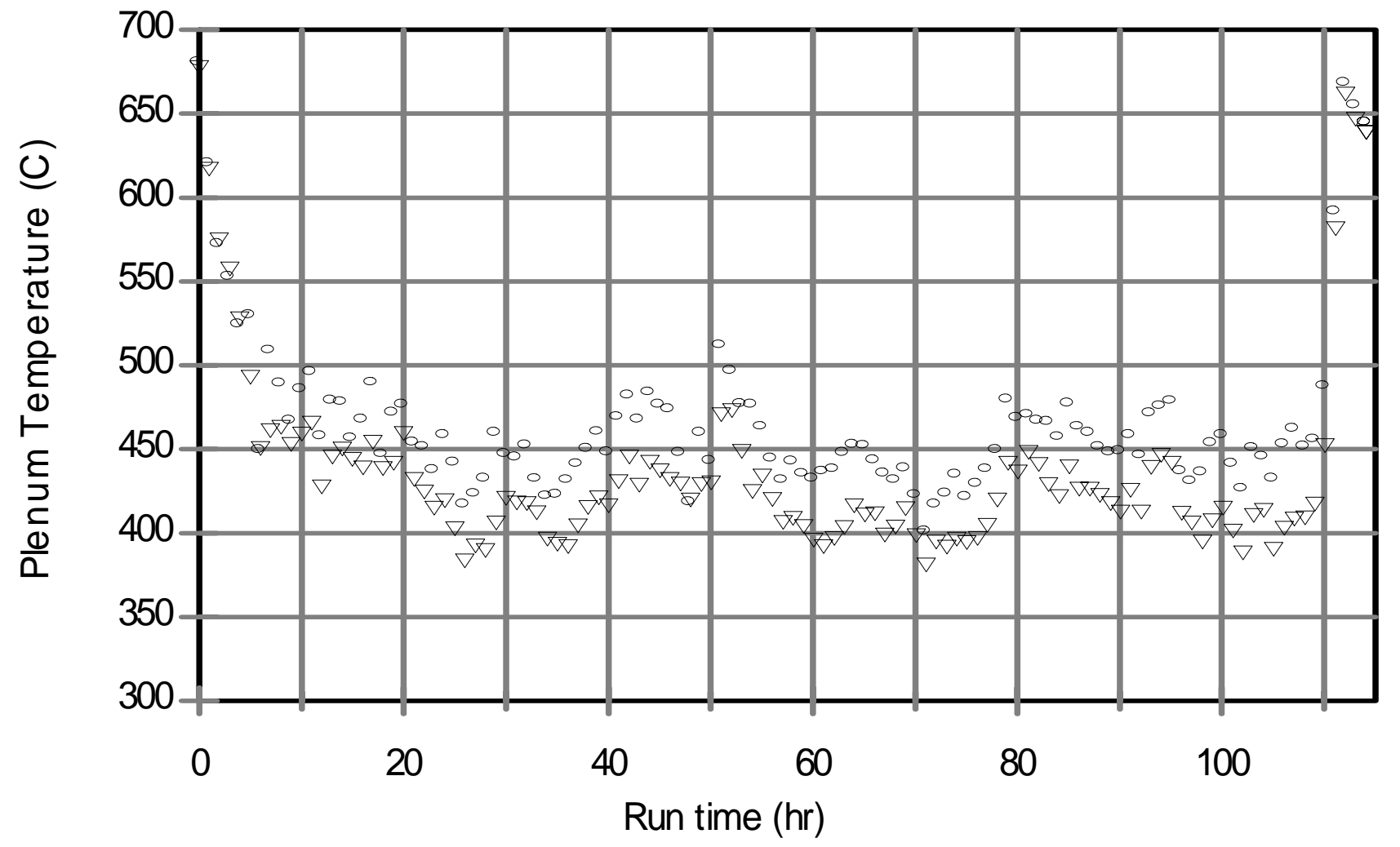

$\boldsymbol{\nabla}$ 17" from top, Thermowell

- $\quad 17^{\prime \prime}$ from top, Exposed

Figure 4.4.a. Plenum temperatures (hourly averages) during DM100 Tests 1 and 2. 


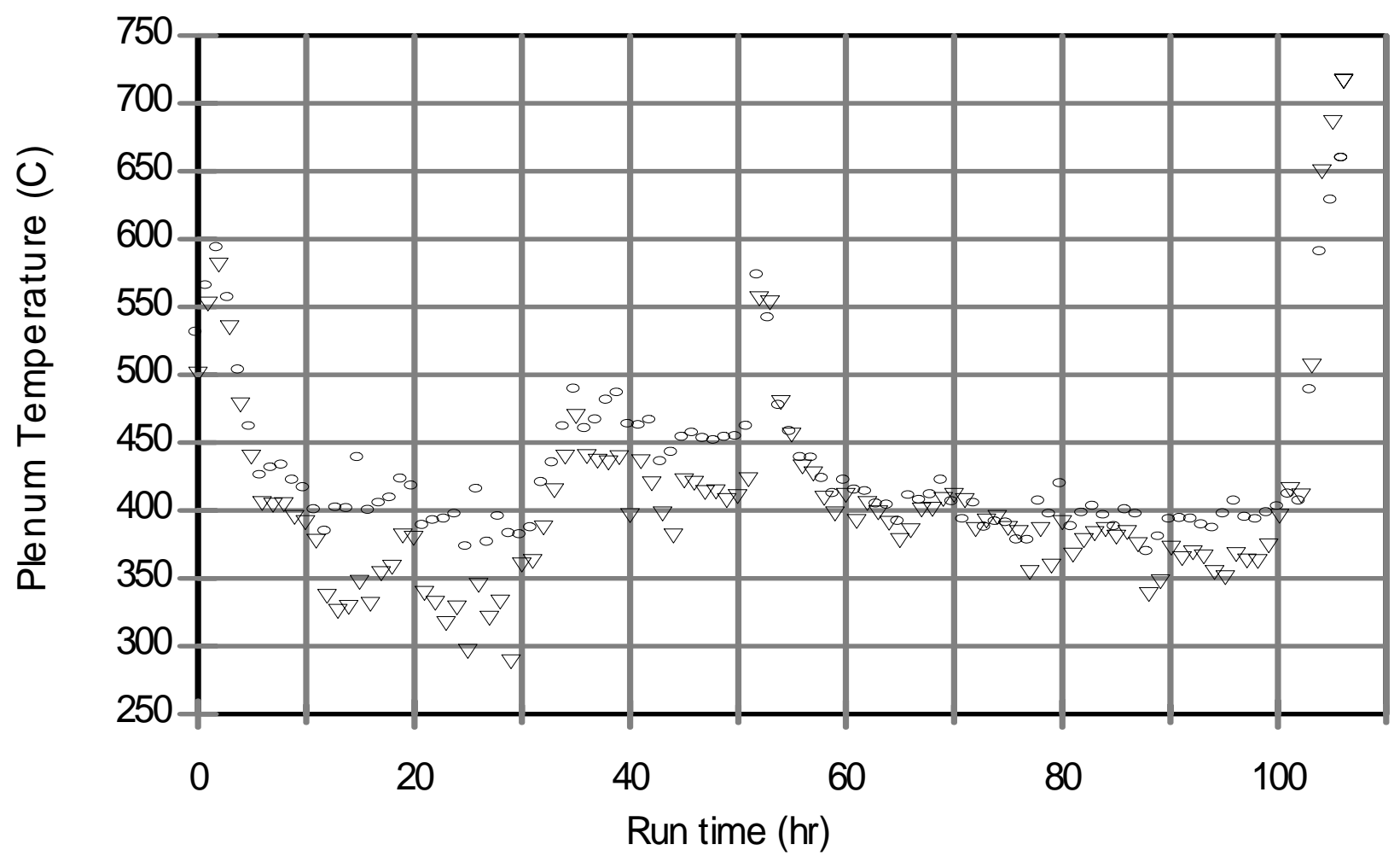

$\nabla$ 17" from top, Thermowell

- $\quad 17$ " from top, Exposed

Figure 4.4.b. Plenum temperatures (hourly averages) during DM100 Tests 3 and 4. 


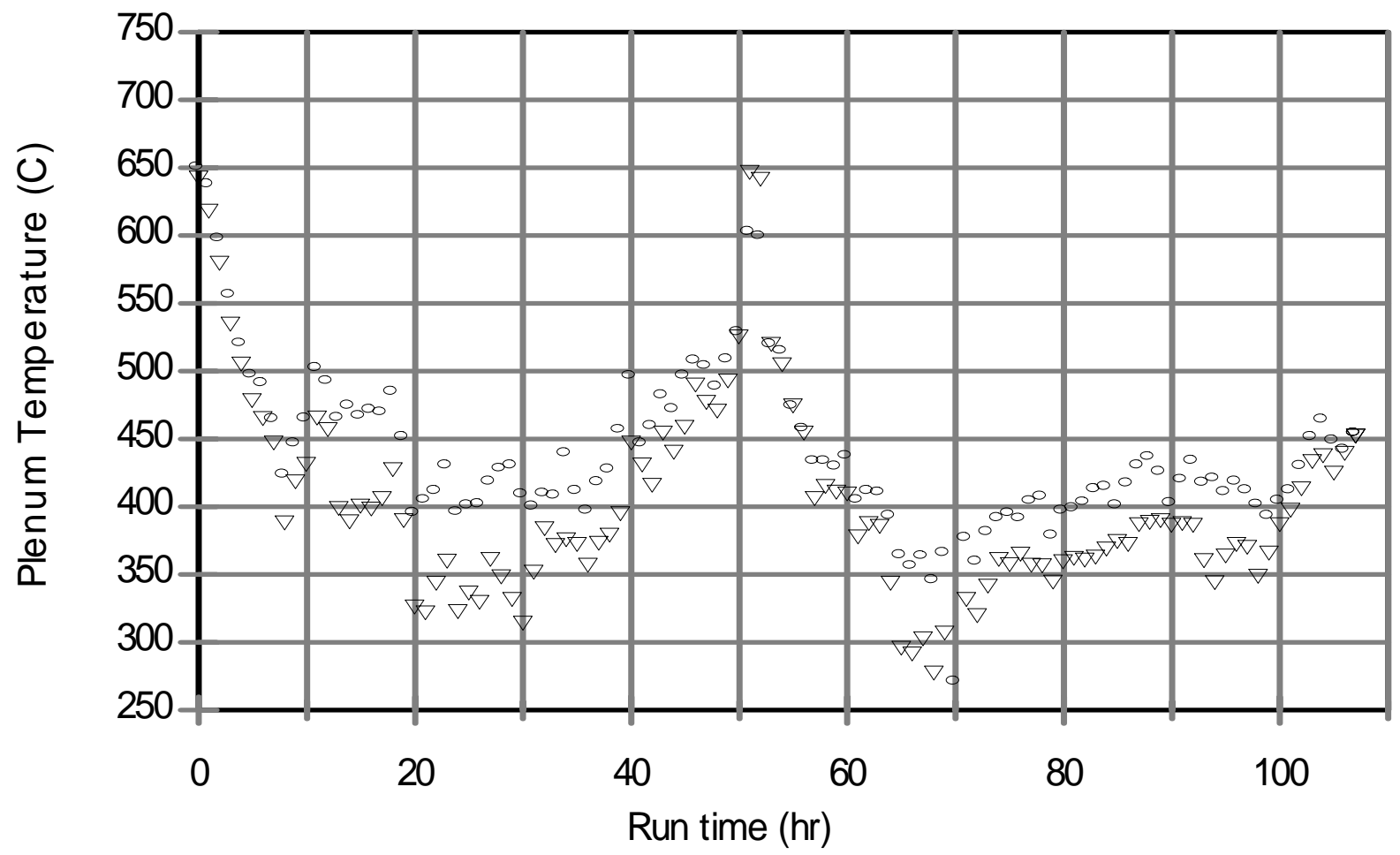

$\nabla$ 17" from top, Thermowell

- 17 " from top, Exposed

Figure 4.4.c. Plenum temperatures (hourly averages) during DM100 Tests 5 and 6. 


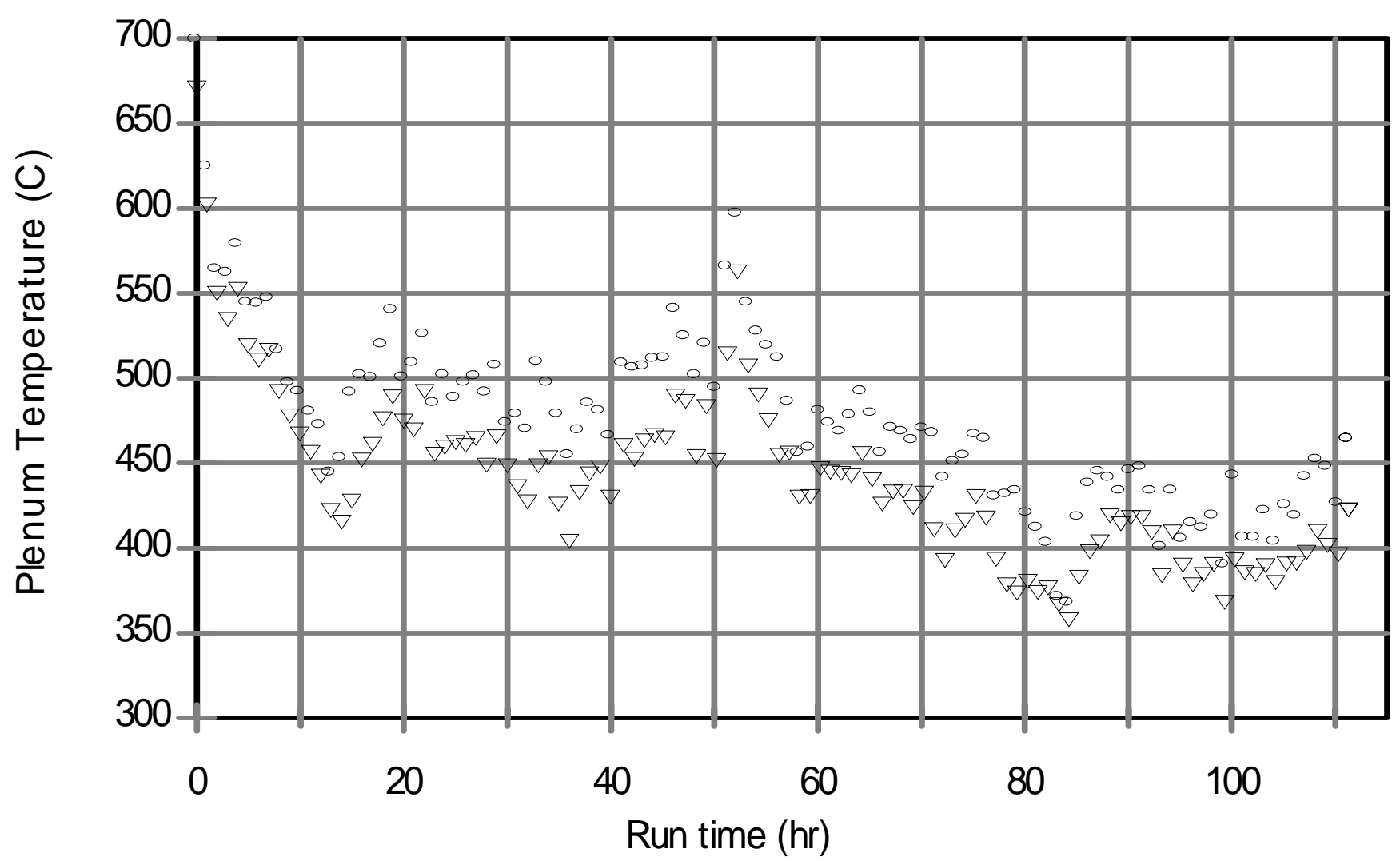

$\boldsymbol{\nabla}$ 17" from top, Thermowell

- $\quad 17^{\prime \prime}$ from top, Exposed

Figure 4.4.d. Plenum temperatures (hourly averages) during DM100 Tests 7 and 8. 


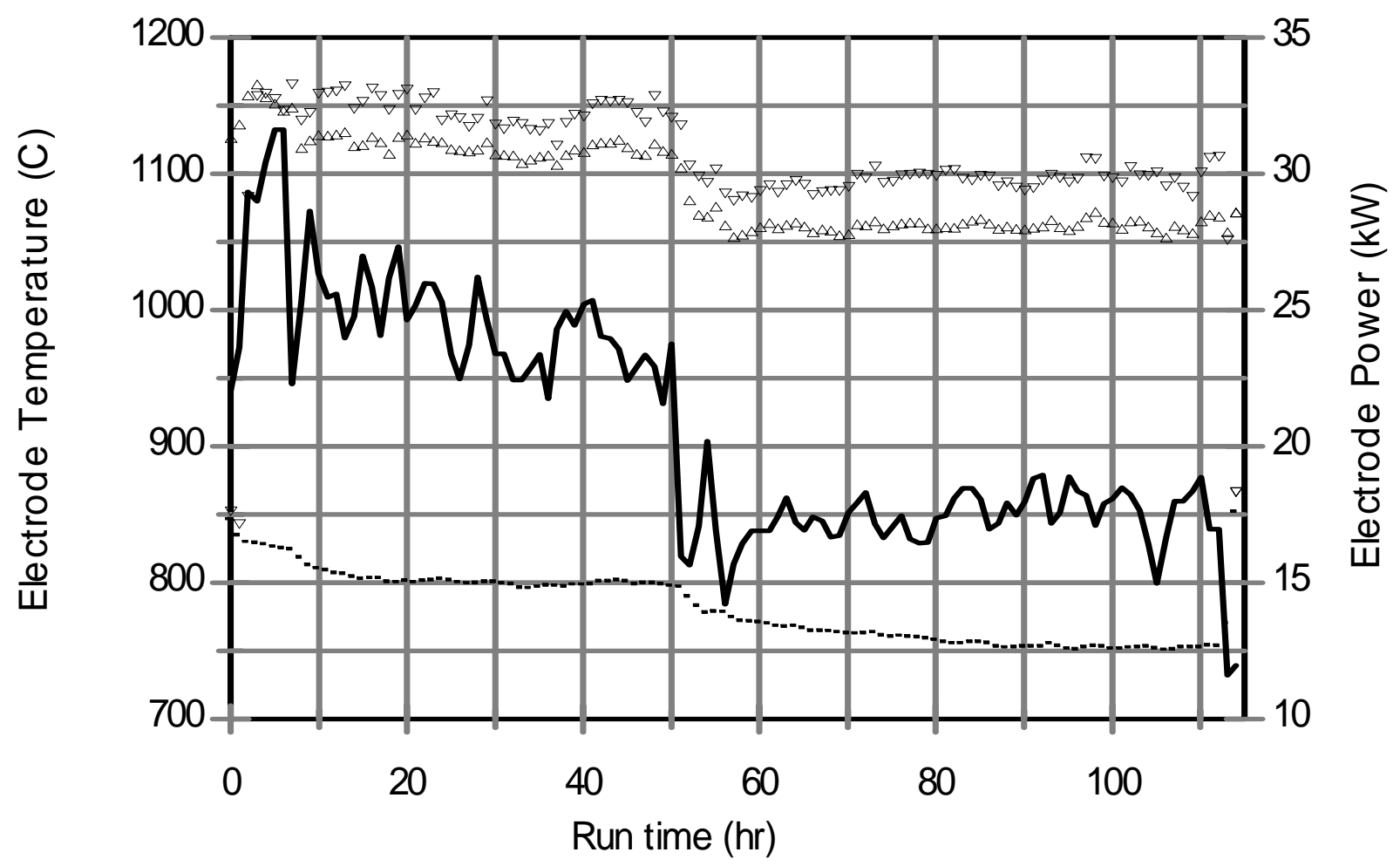
- Upper
- Lower
- Bottom
Power

Figure 4.5.a. Electrode temperatures and power (hourly averages) during DM100 Tests 1 and 2. 

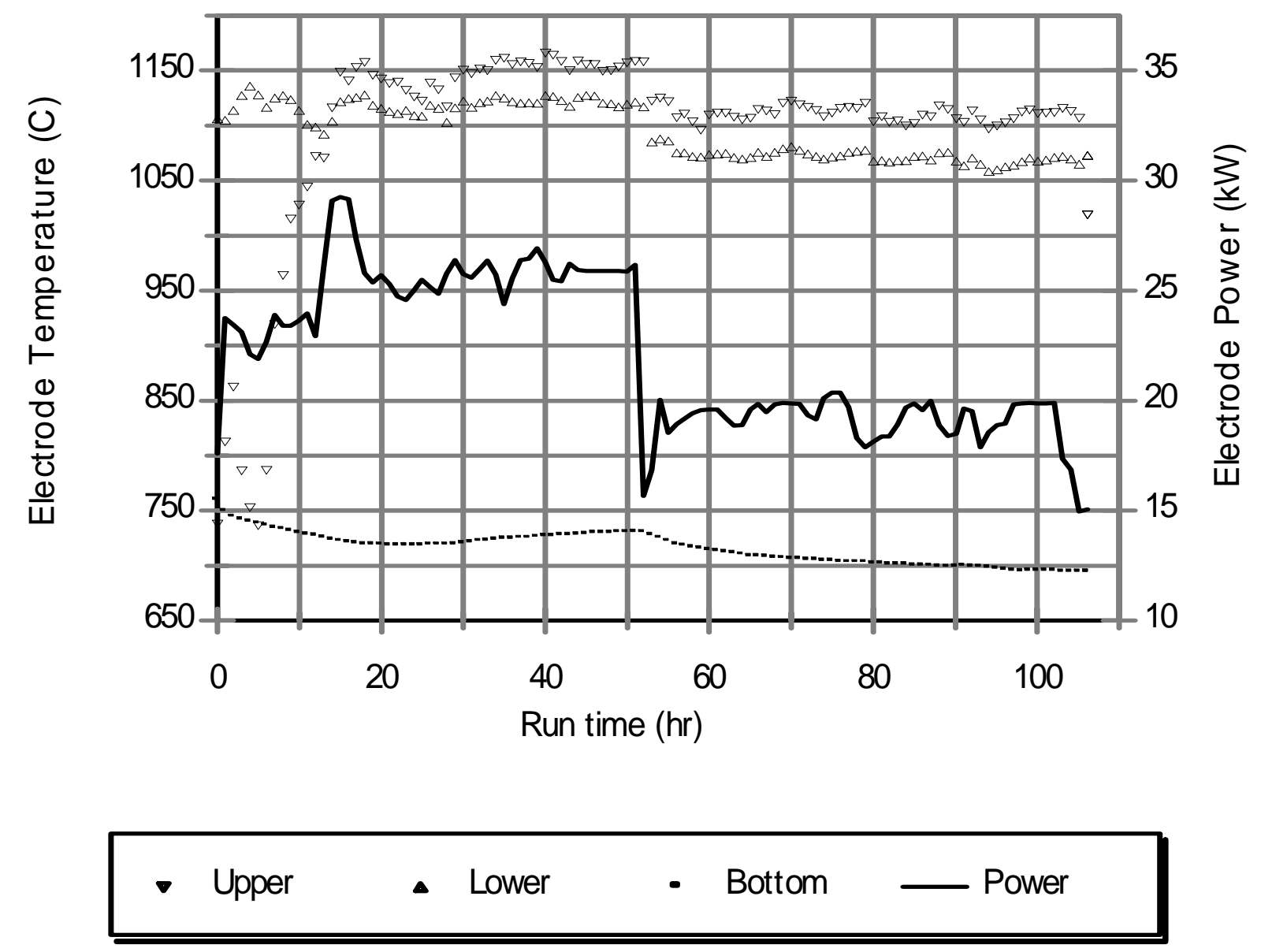

Figure 4.5.b. Electrode temperatures and power (hourly averages) during DM100 Tests 3 and 4. 


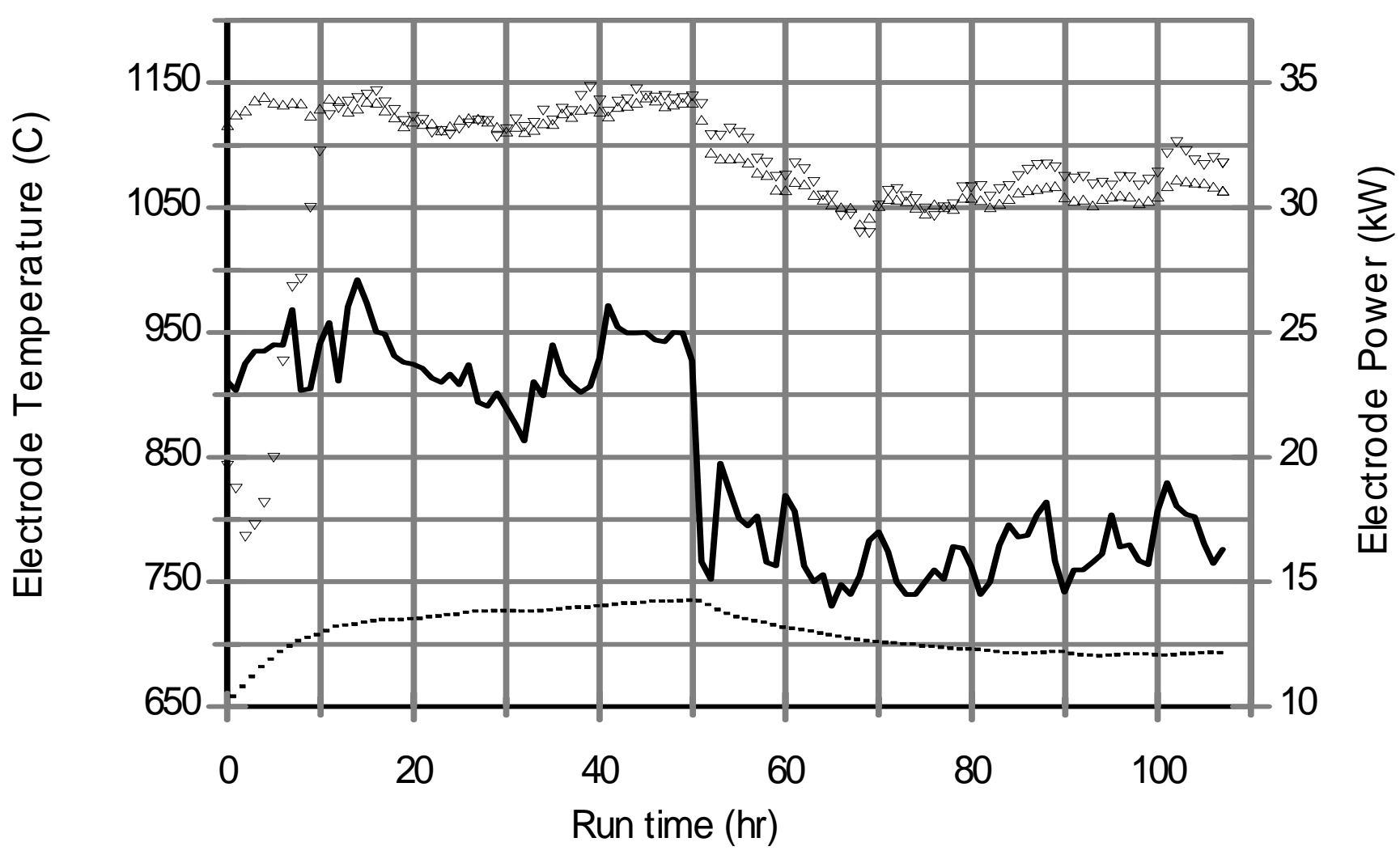

- Upper

- Lower

- Bottom

Power

Figure 4.5.c. Electrode temperatures and power (hourly averages) during DM100 Tests 5 and 6. 


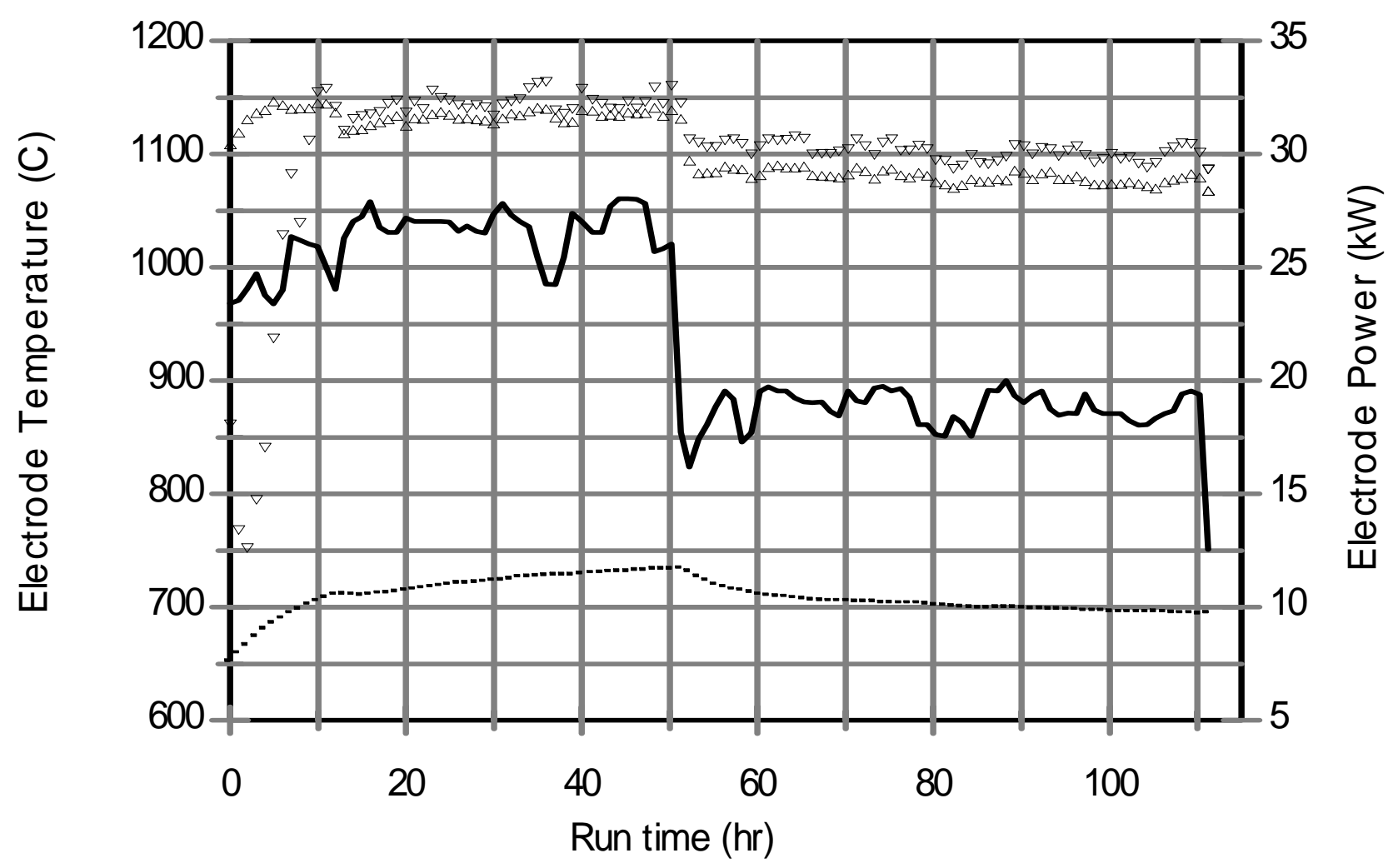
- Upper
- Lower
- Bottom
Power

Figure 4.5.d. Electrode temperatures and power (hourly averages) during DM100 Tests 7 and 8. 


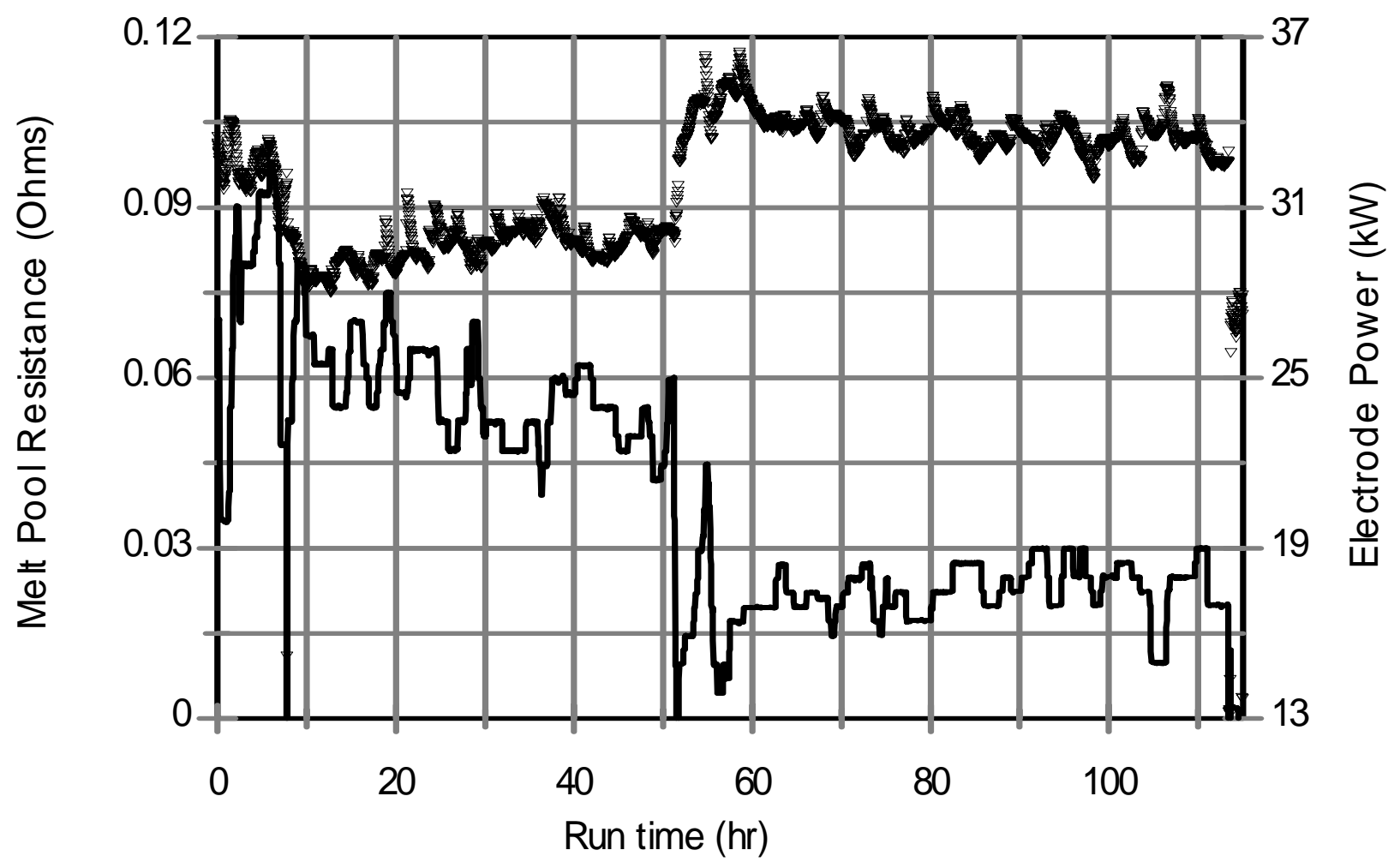

- Resistance - Power

Figure 4.6.a. Melt pool resistance and total electrode power during DM100 Tests 1 and 2. 


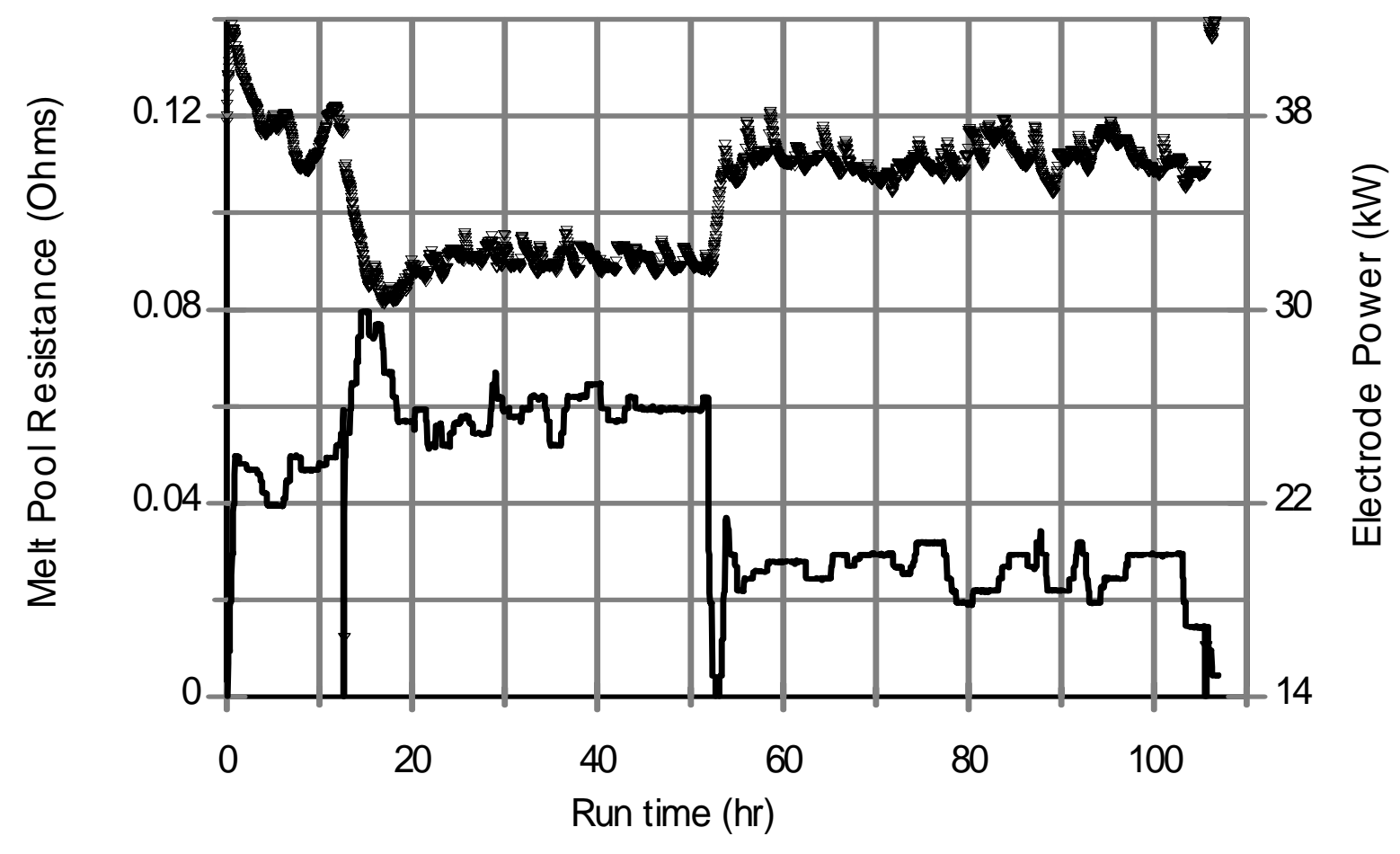

- Resistance Power

Figure 4.6.b. Melt pool resistance and total electrode power during DM100 Tests 3 and 4. 


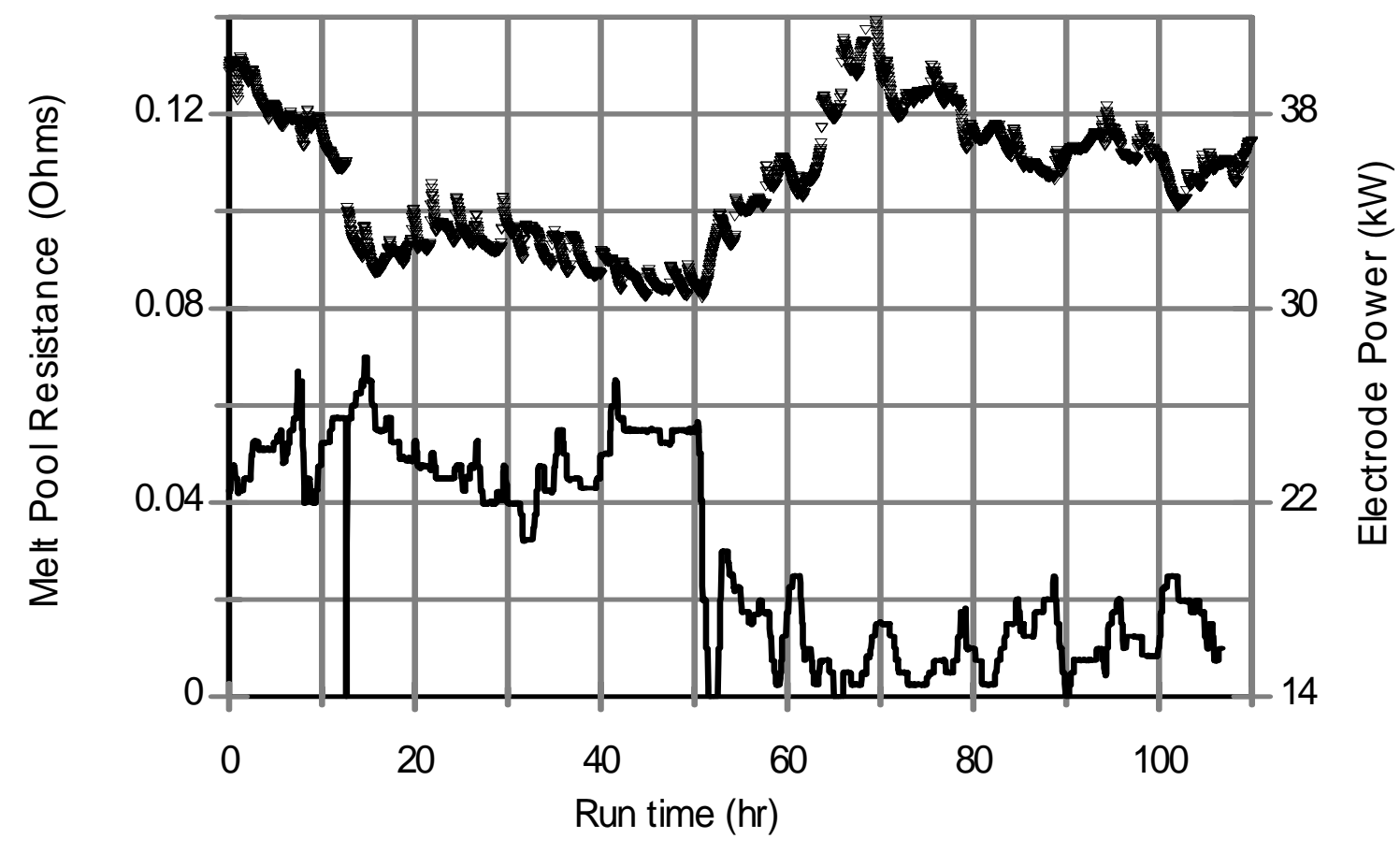

- Resistance Power

Figure 4.6.c. Melt pool resistance and total electrode power during DM100 Tests 5 and 6. 


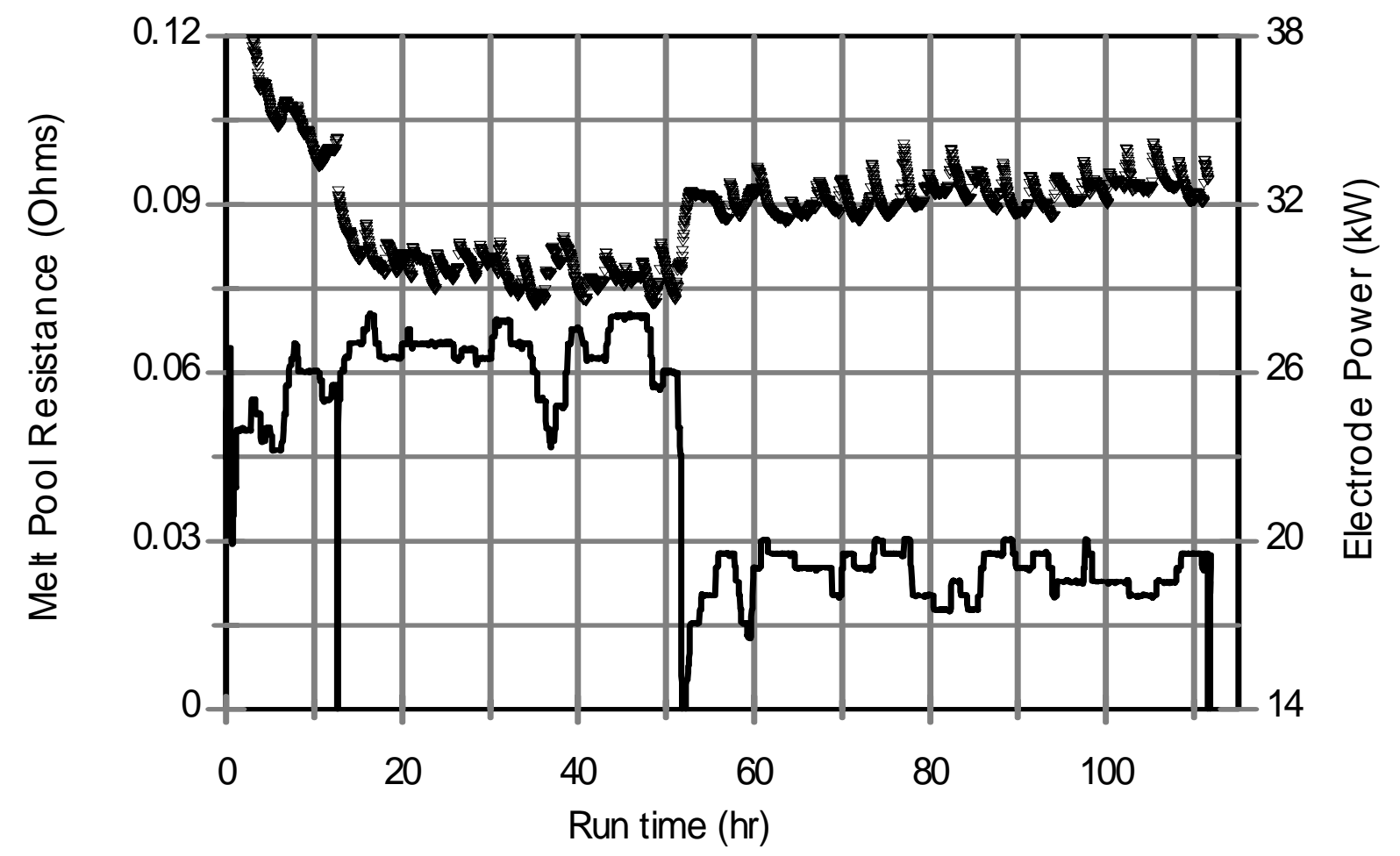

- Resistance Power

Figure 4.6.d. Melt pool resistance and total electrode power during DM100 Tests 7 and 8. 


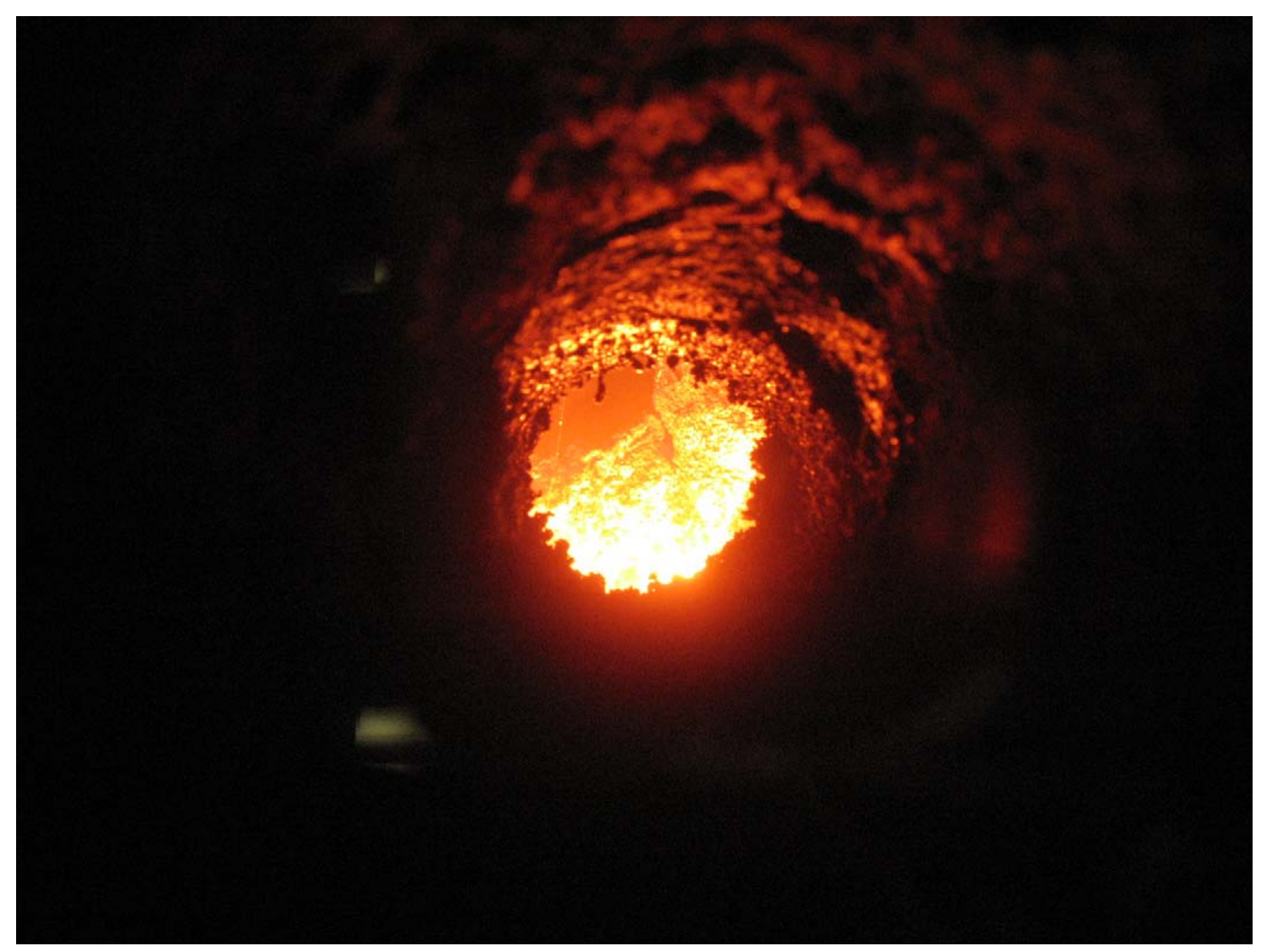

Figure 5.1. Picture of cold cap through north view port showing the thickness of the cold cap. 


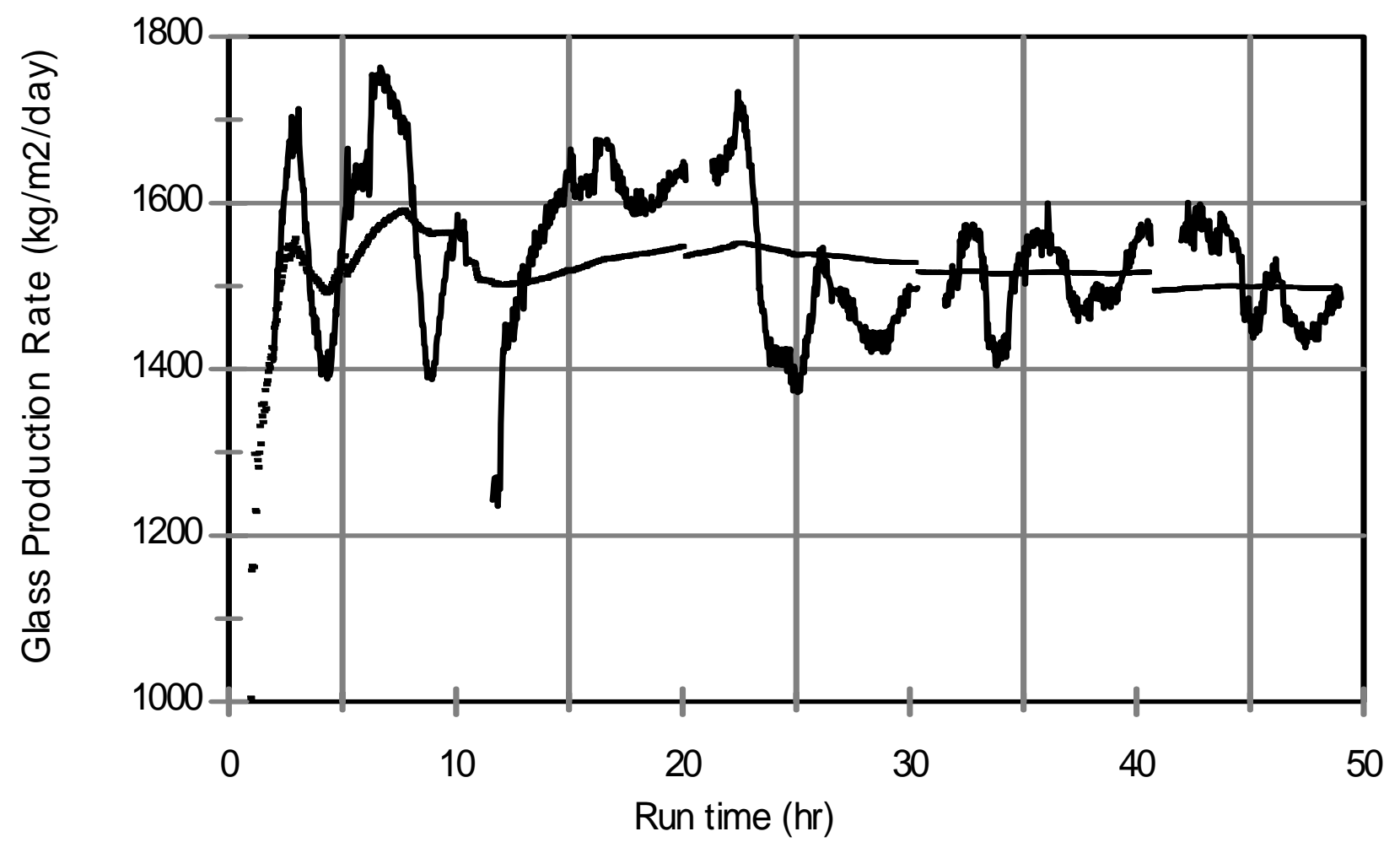

Figure 5.2.a. Production rates for DM1200 Test 1. 


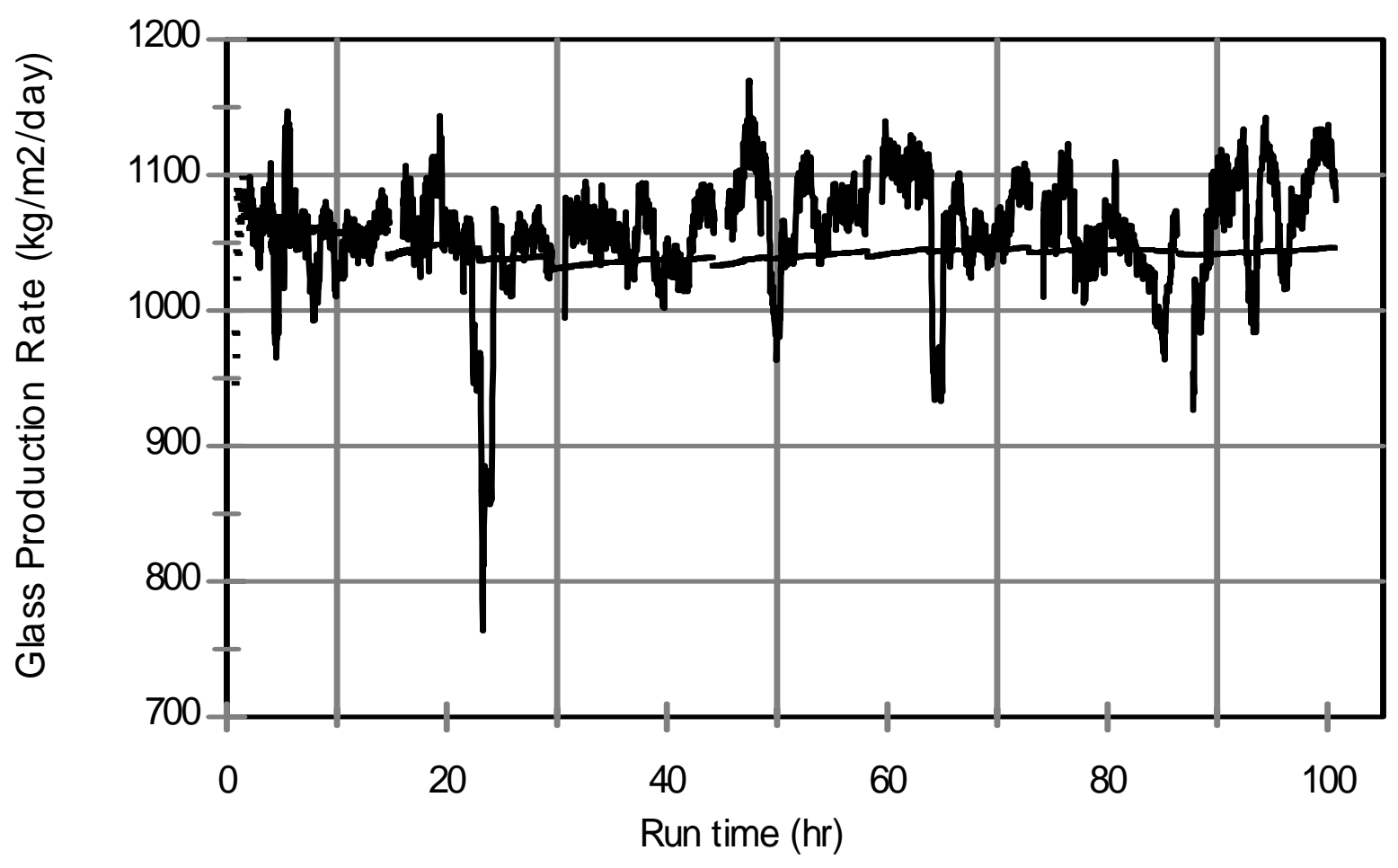

- Cumulative

Figure 5.2.b. Production rates for DM1200 Tests 2 and 3. 


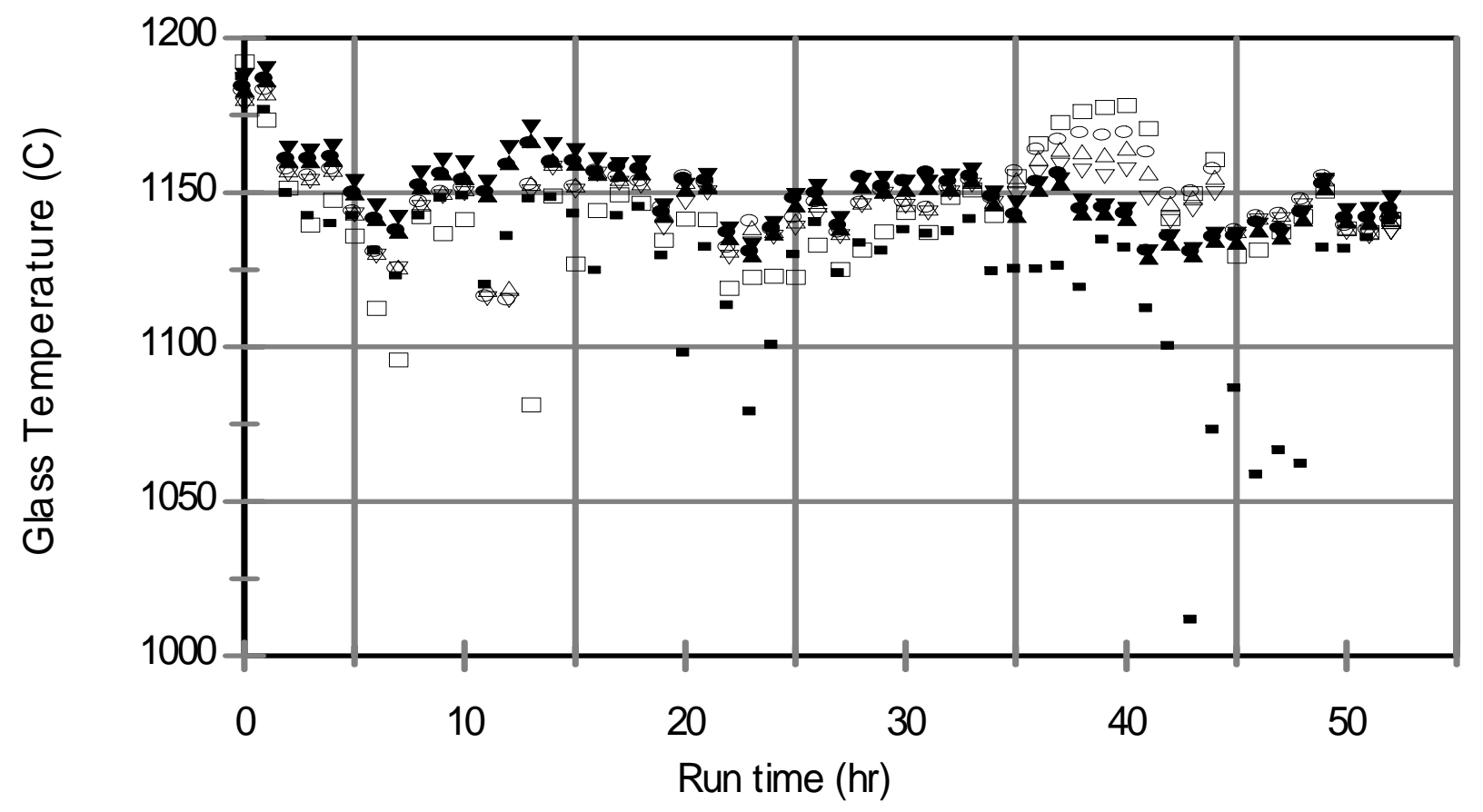

- 13" from floor

$\boldsymbol{\nabla}$ 13" from floor
- 15.5" from floor

$\Delta \quad 15.5$ " from floor
- 18 " from floor

- 18 " from floor
- 27 "from floor

- 27"from floor

Figure 5.3.a. Glass temperatures (hourly averages) for DM1200 Test 1. 


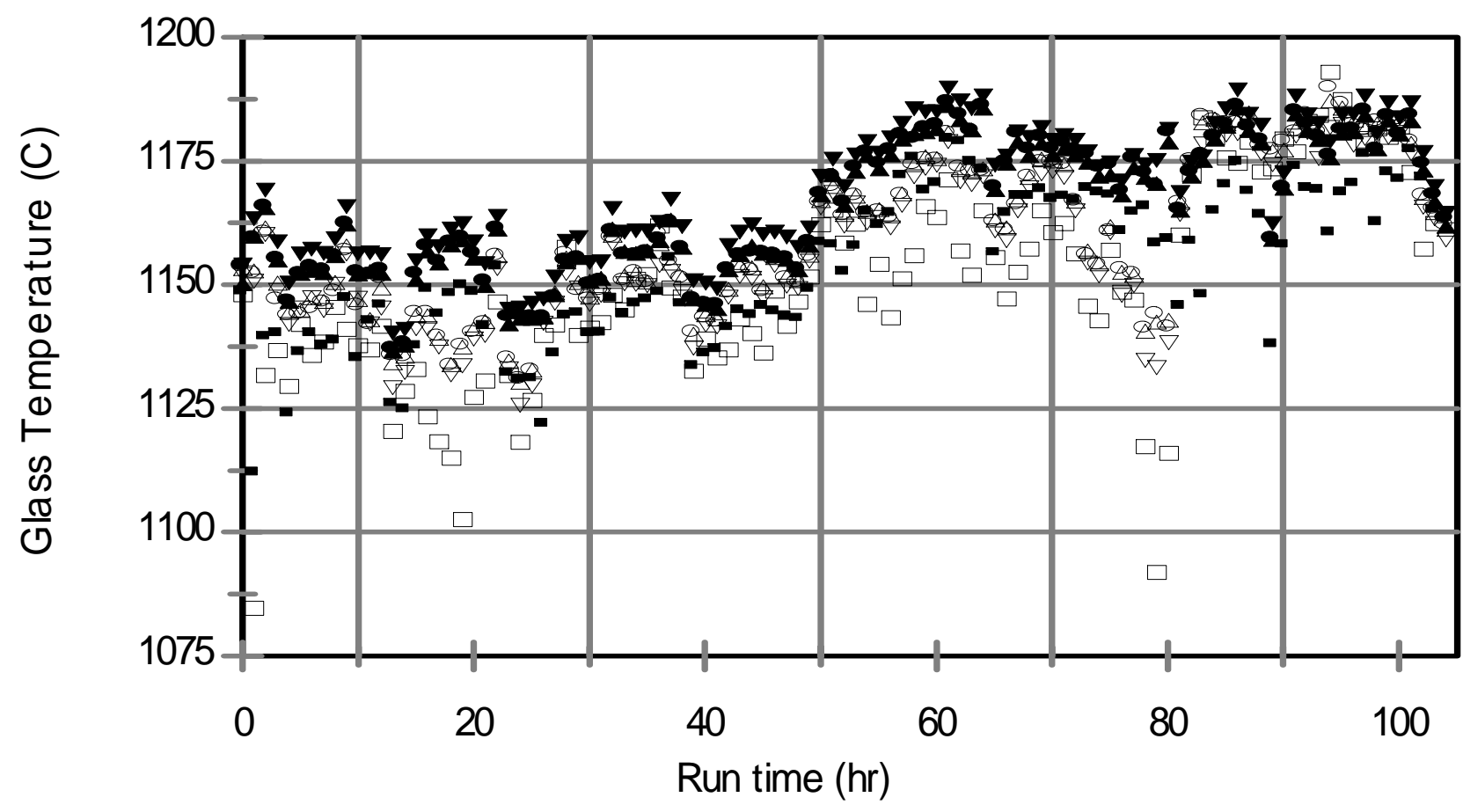

- 13" from floor

$\boldsymbol{\nabla} 13$ " from floor
- 15.5" from floor

$\Delta \quad 15.5 "$ from floor
- 18 " from floor

- 18 " from floor
- 27 " from floor

- 27 " from floor

Figure 5.3.b. Glass temperatures (hourly averages) for DM1200 Tests 2 and 3. 


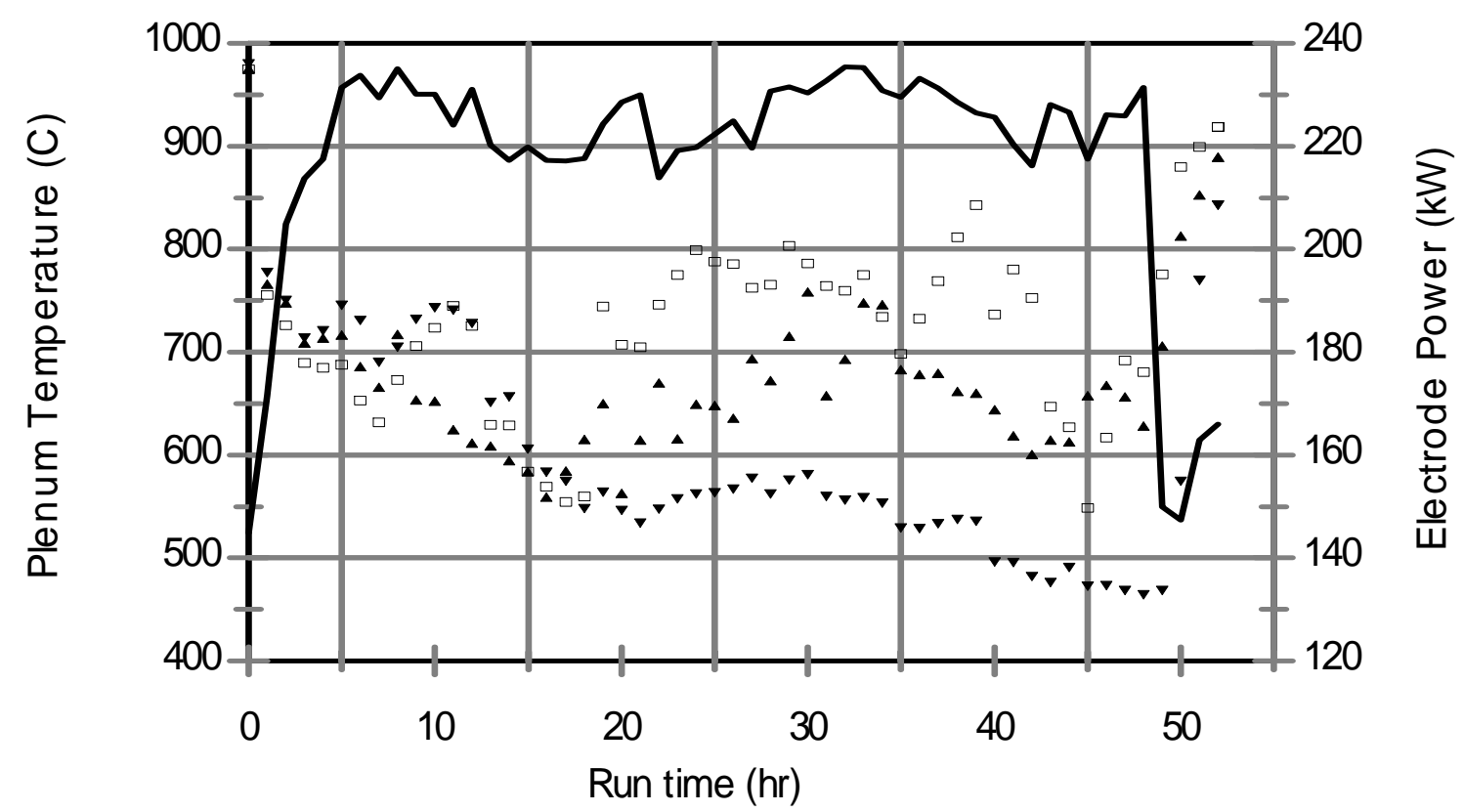

- 8" below ceiling

- 17 " below ceiling, exposed
- $\quad 17$ " below ceiling

Electrode power

Figure 5.4.a. Plenum temperatures and electrode power (hourly averages) for DM1200 Test 1. 


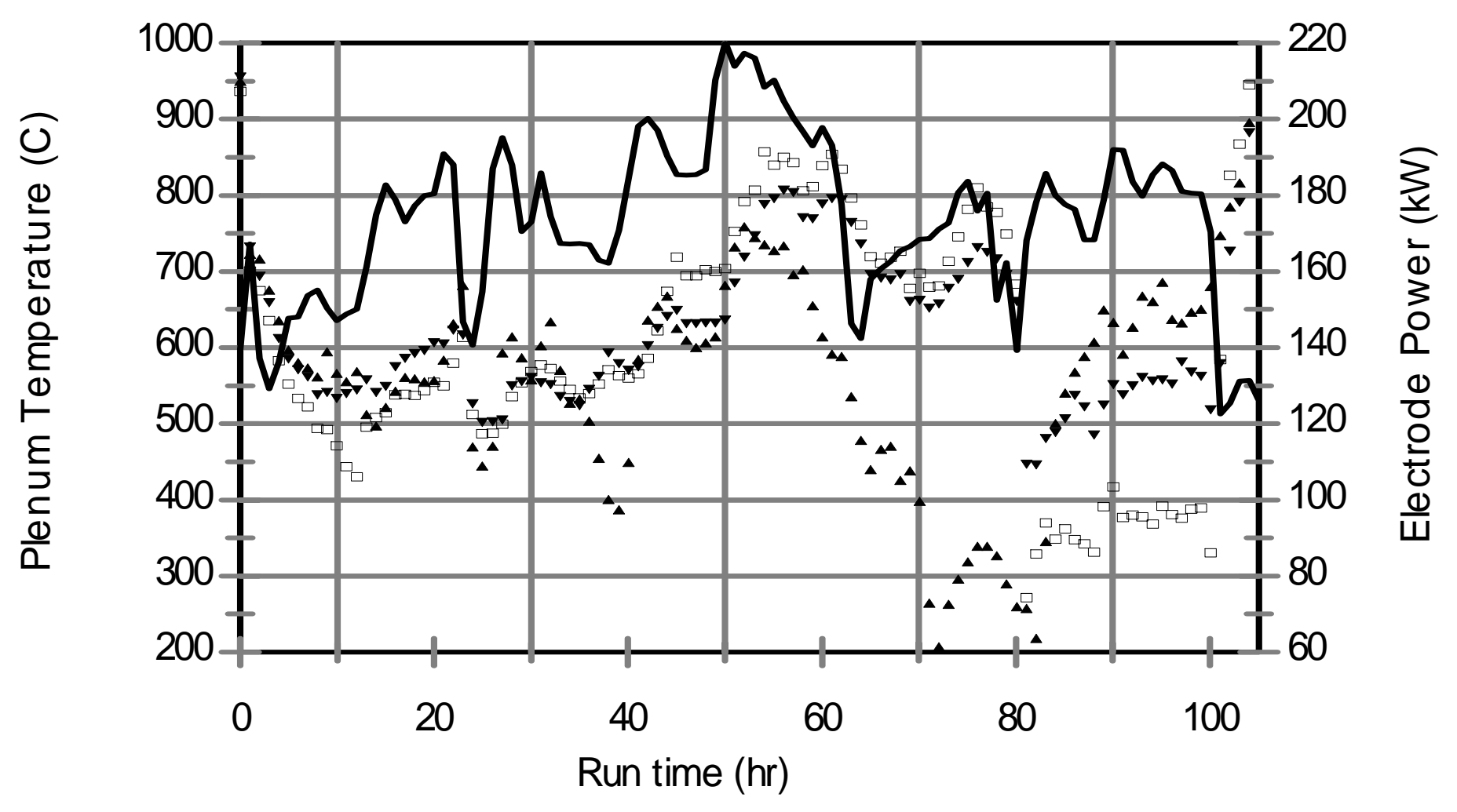

- 8" below ceiling

- 17 " below ceiling, exposed
- $\quad 17$ " below ceiling

Electrode power

Figure 5.4.b. Plenum temperatures and electrode power (hourly averages) for DM1200 Tests 2 and 3. 


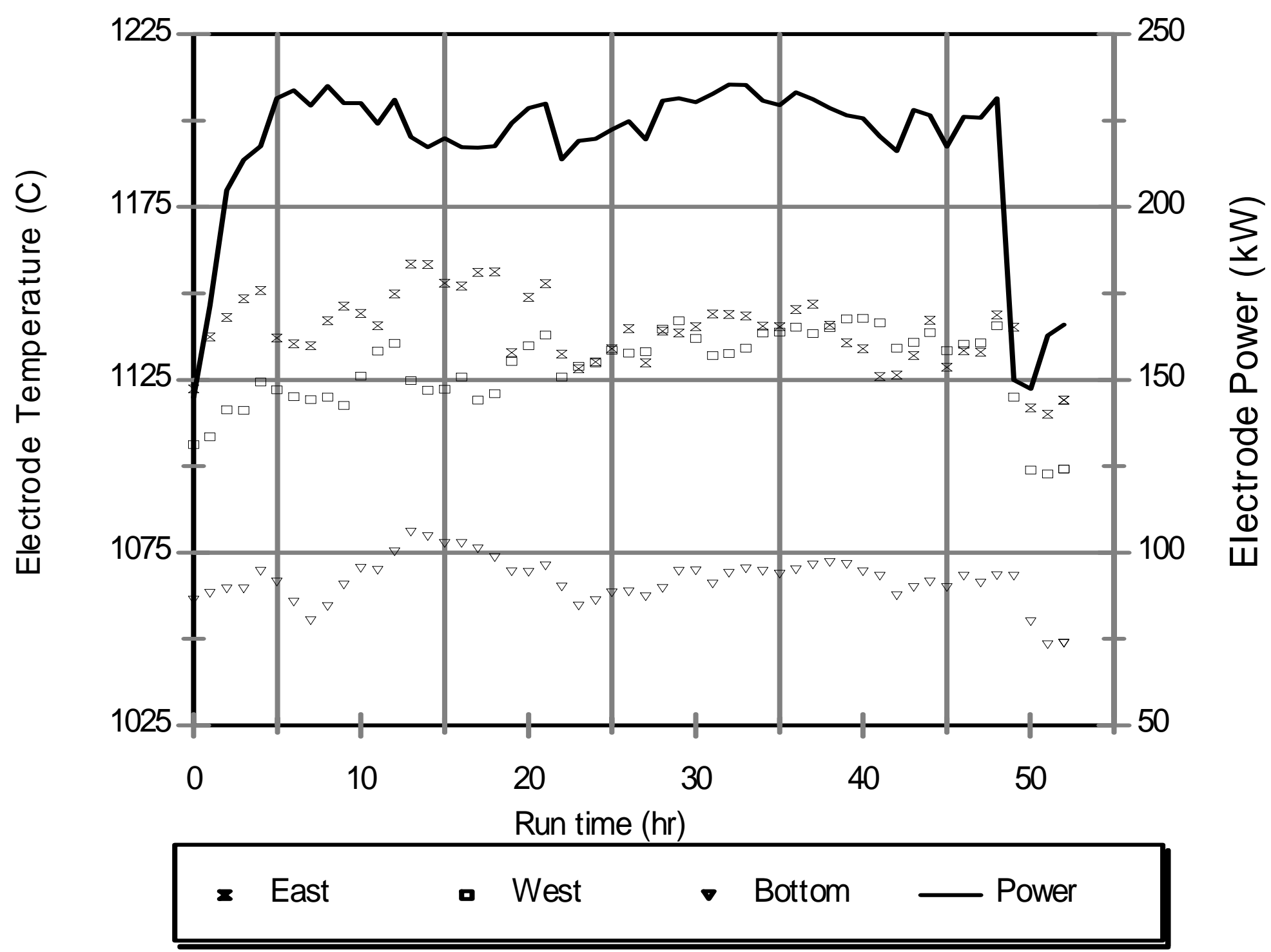

Figure 5.5.a. Electrode temperatures and power (hourly averages) for DM1200 Test 1. 


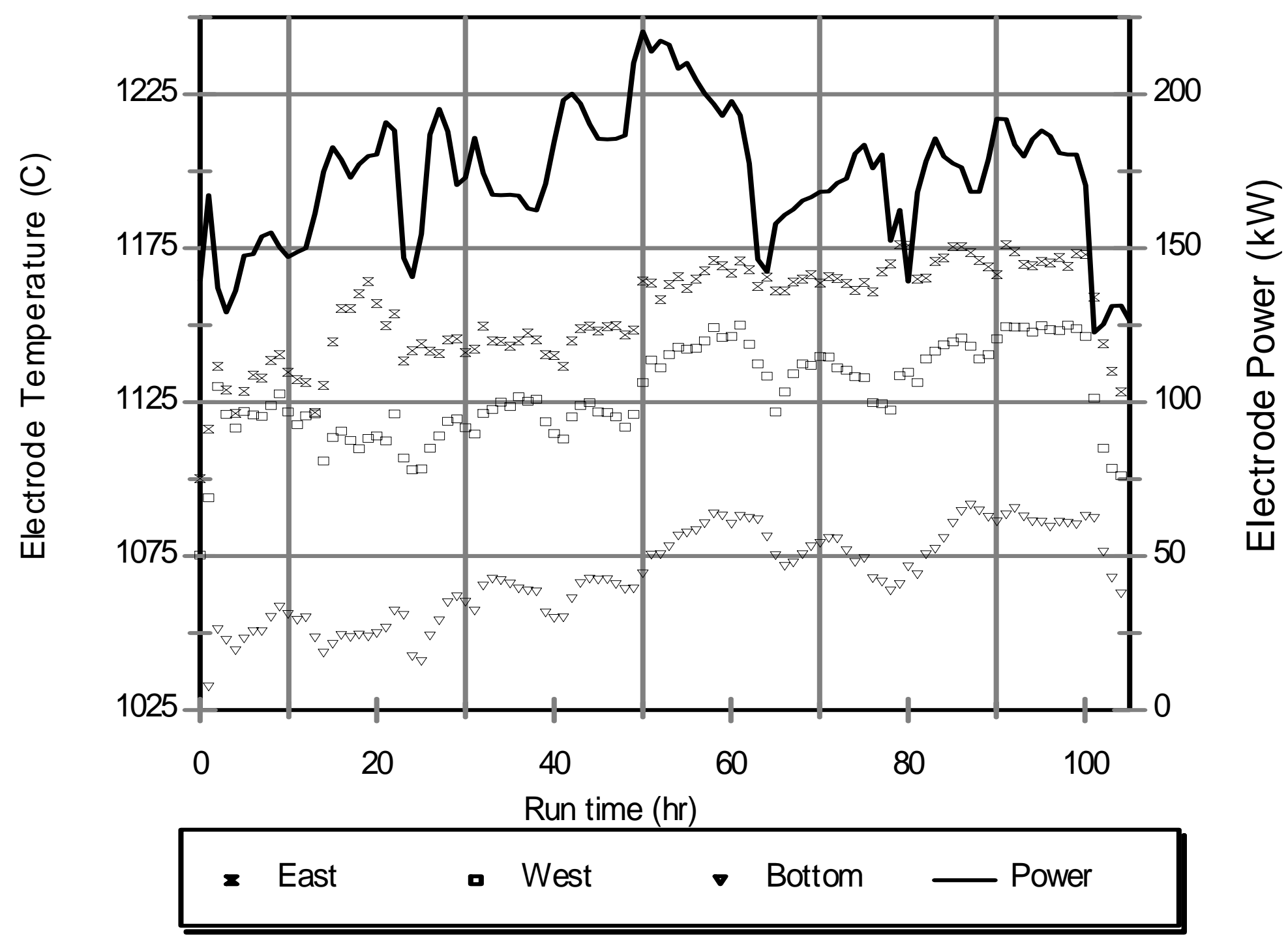

Figure 5.5.b. Electrode temperatures and power (hourly averages) for DM1200 Tests 2 and 3. 


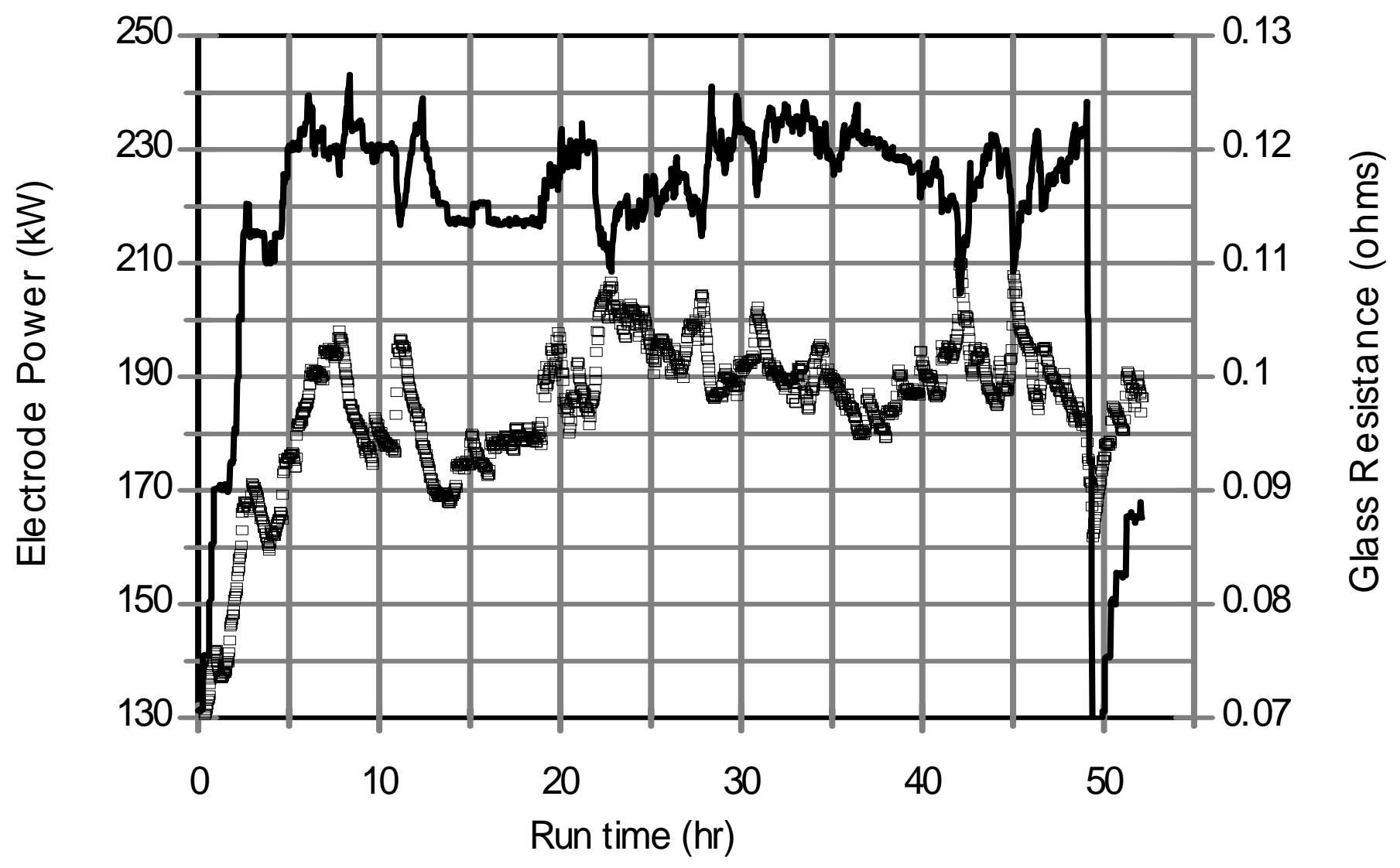

Power

- Resistance

Figure 5.6.a. Electrode power and glass resistance for DM1200 Test 1. 


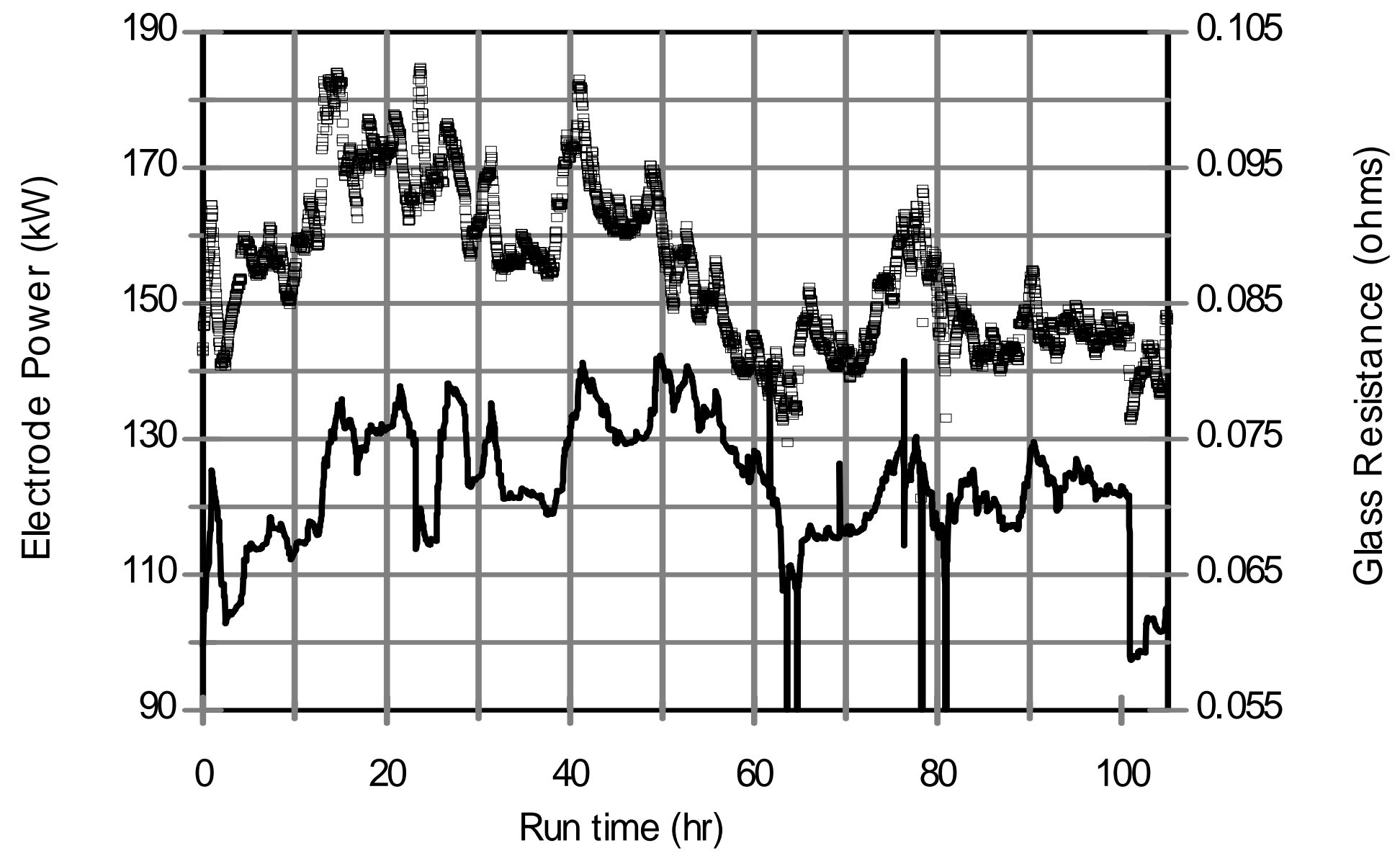

Figure 5.6.b. Electrode power and glass resistance for DM1200 Tests 2 and 3. 


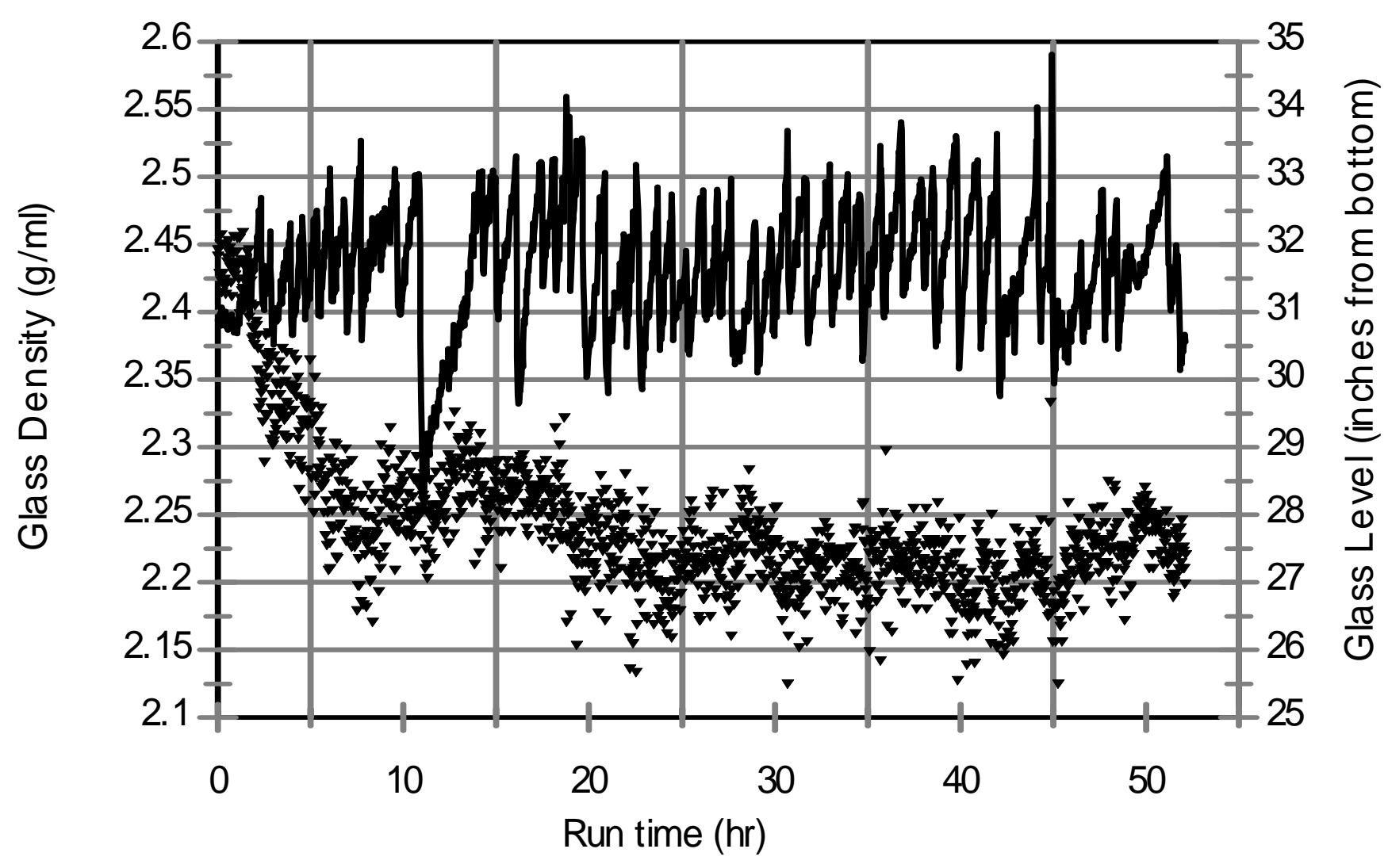

Figure 5.7.a. Glass density and level for DM1200 Test 1. 


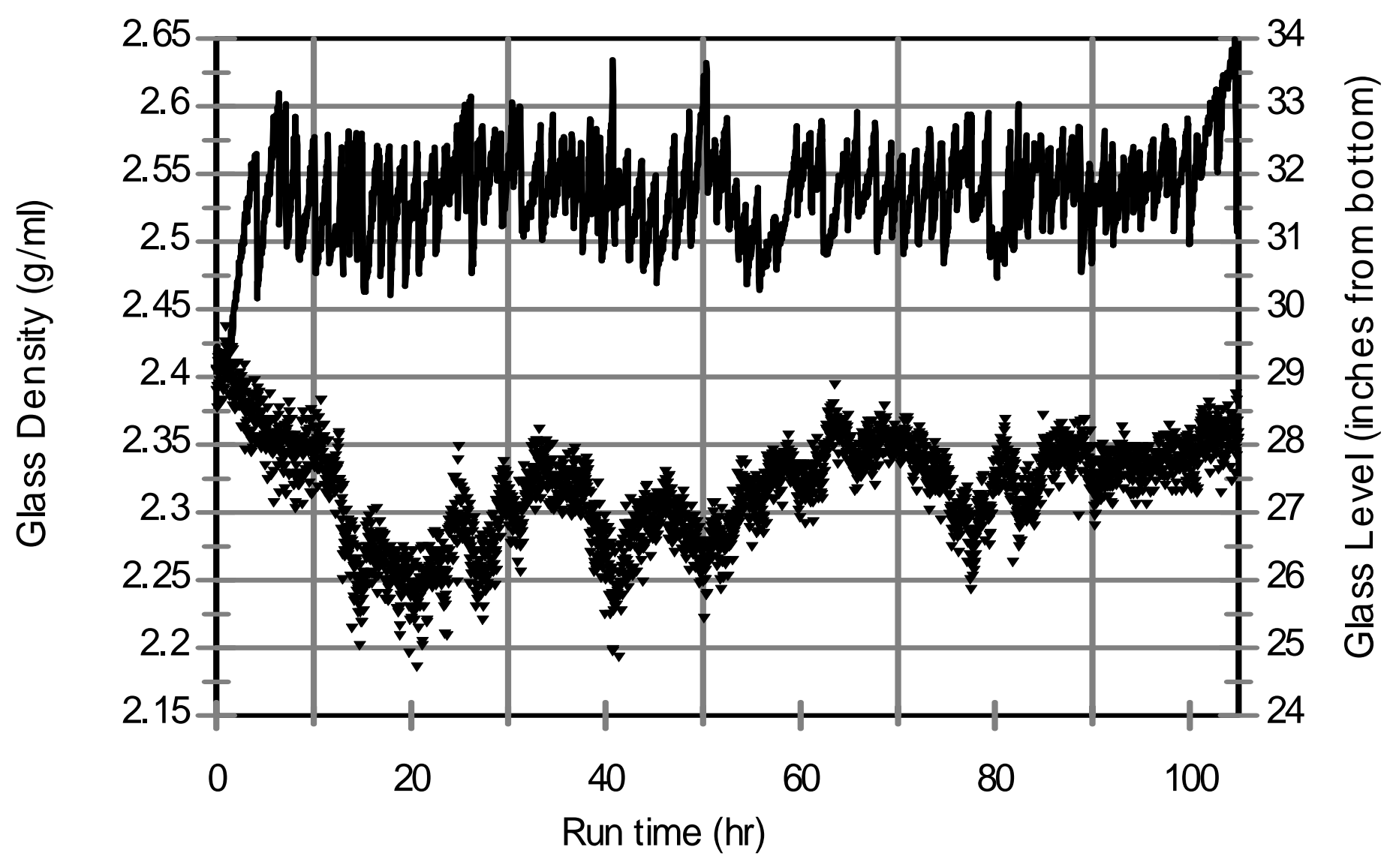

Figure 5.7.b. Glass density and level for DM1200 Tests 2 and 3. 


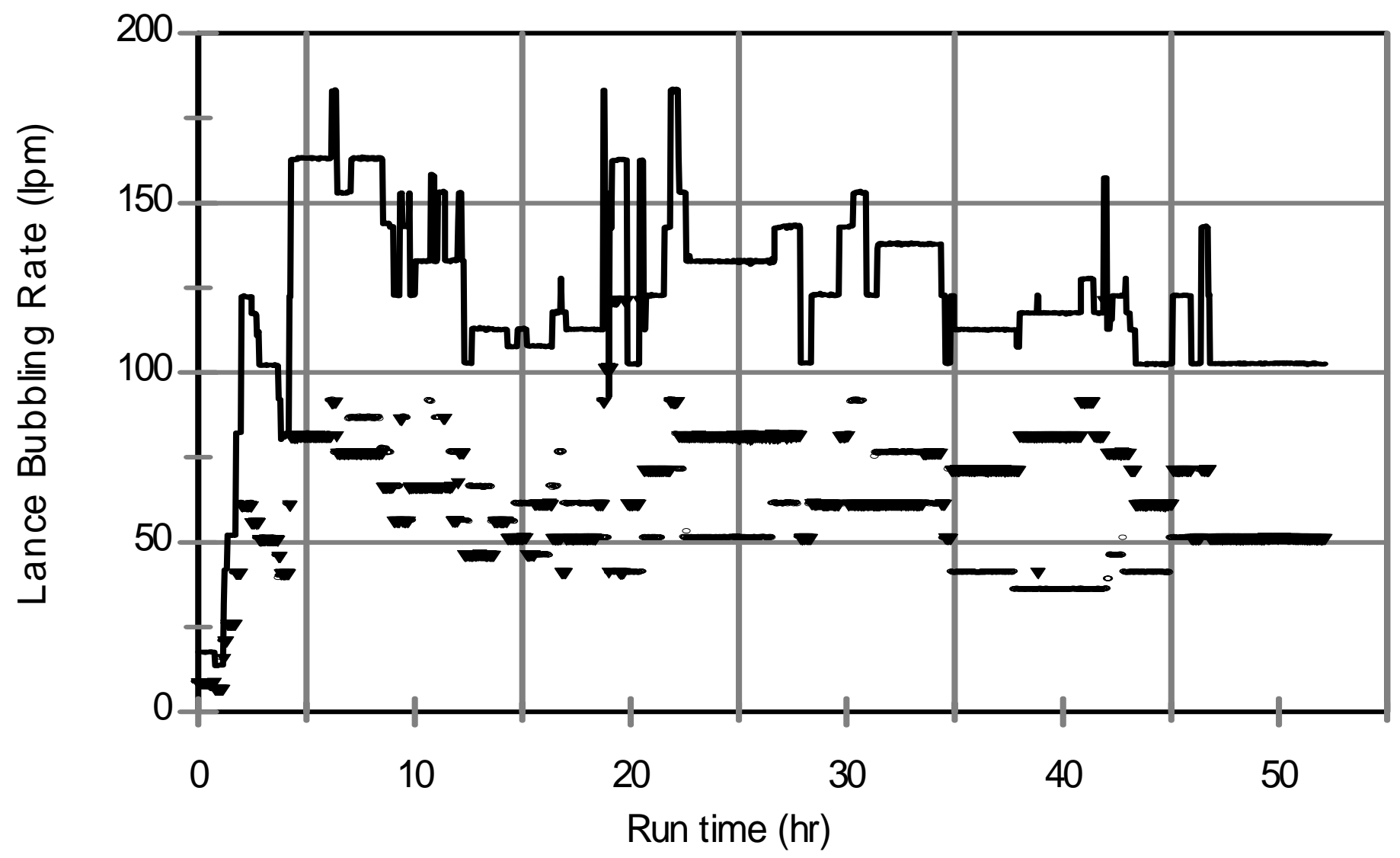

Figure 5.8.a. Glass pool bubbling for DM1200 Test 1. 


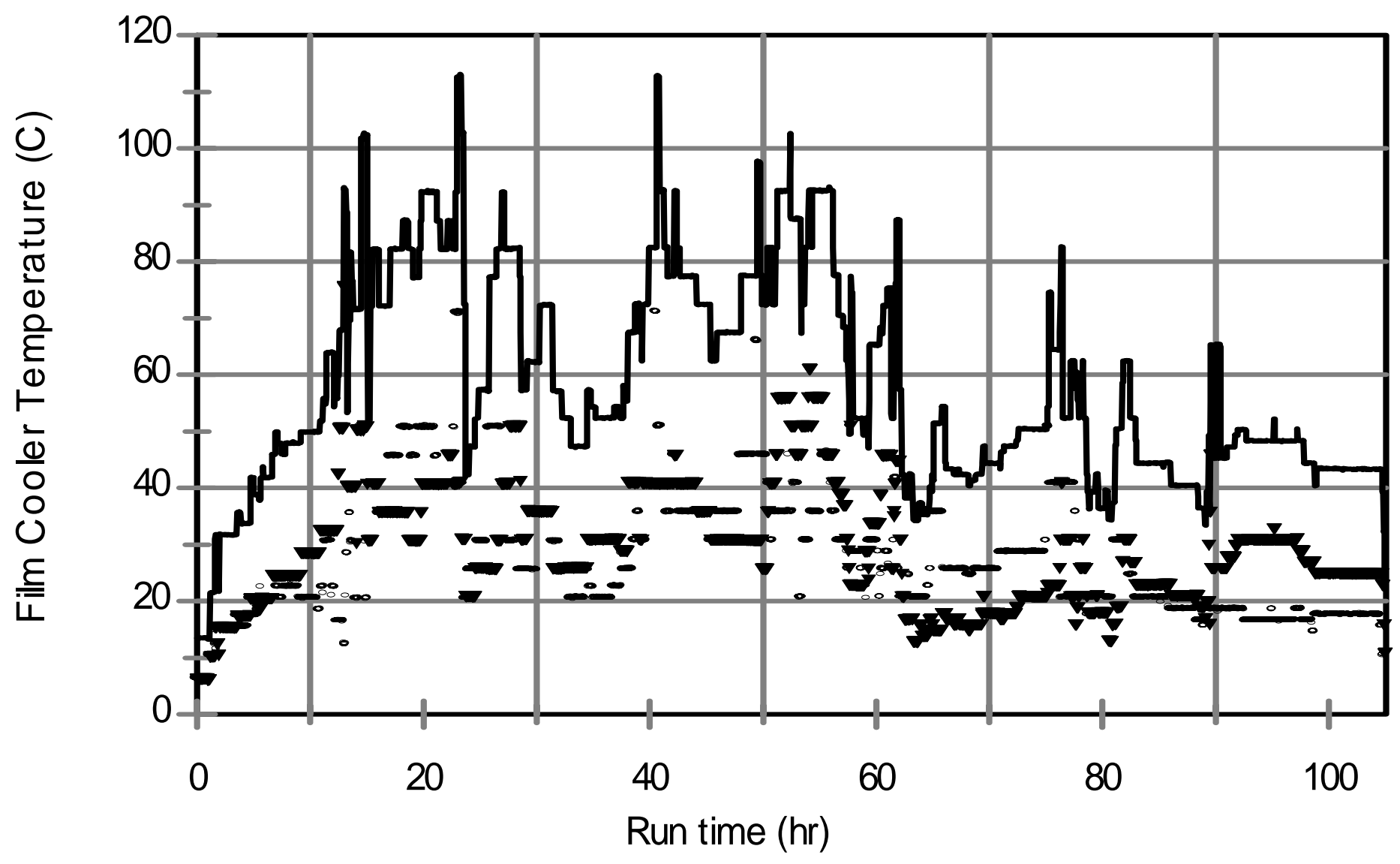

- Lance 1 - Lance $2 \longrightarrow$ Total

Figure 5.8.b. Glass pool bubbling for DM1200 Tests 2 and 3. 


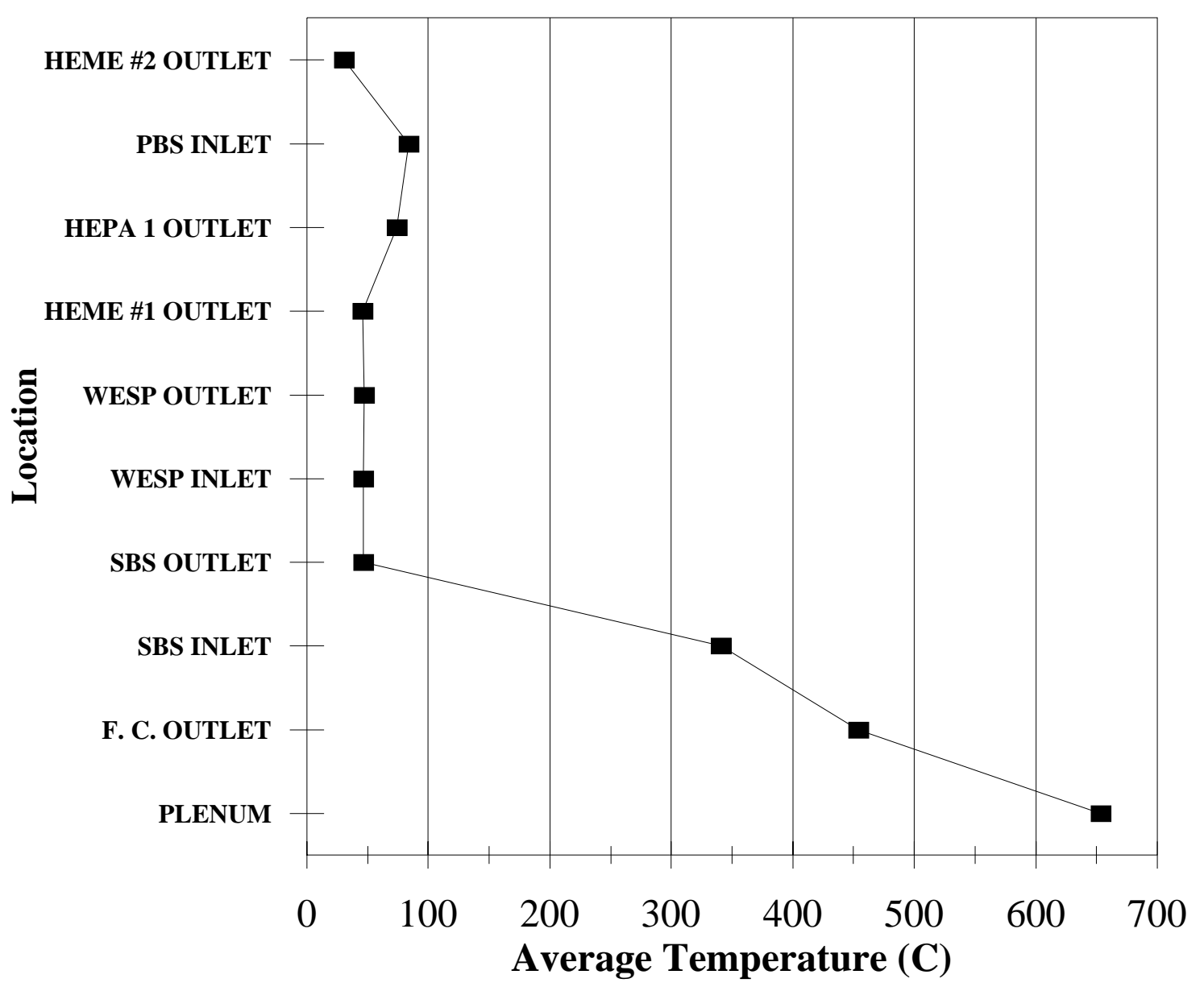

Figure 5.9.a. Average gas temperatures along the DM1200 off-gas train during Test 1. 


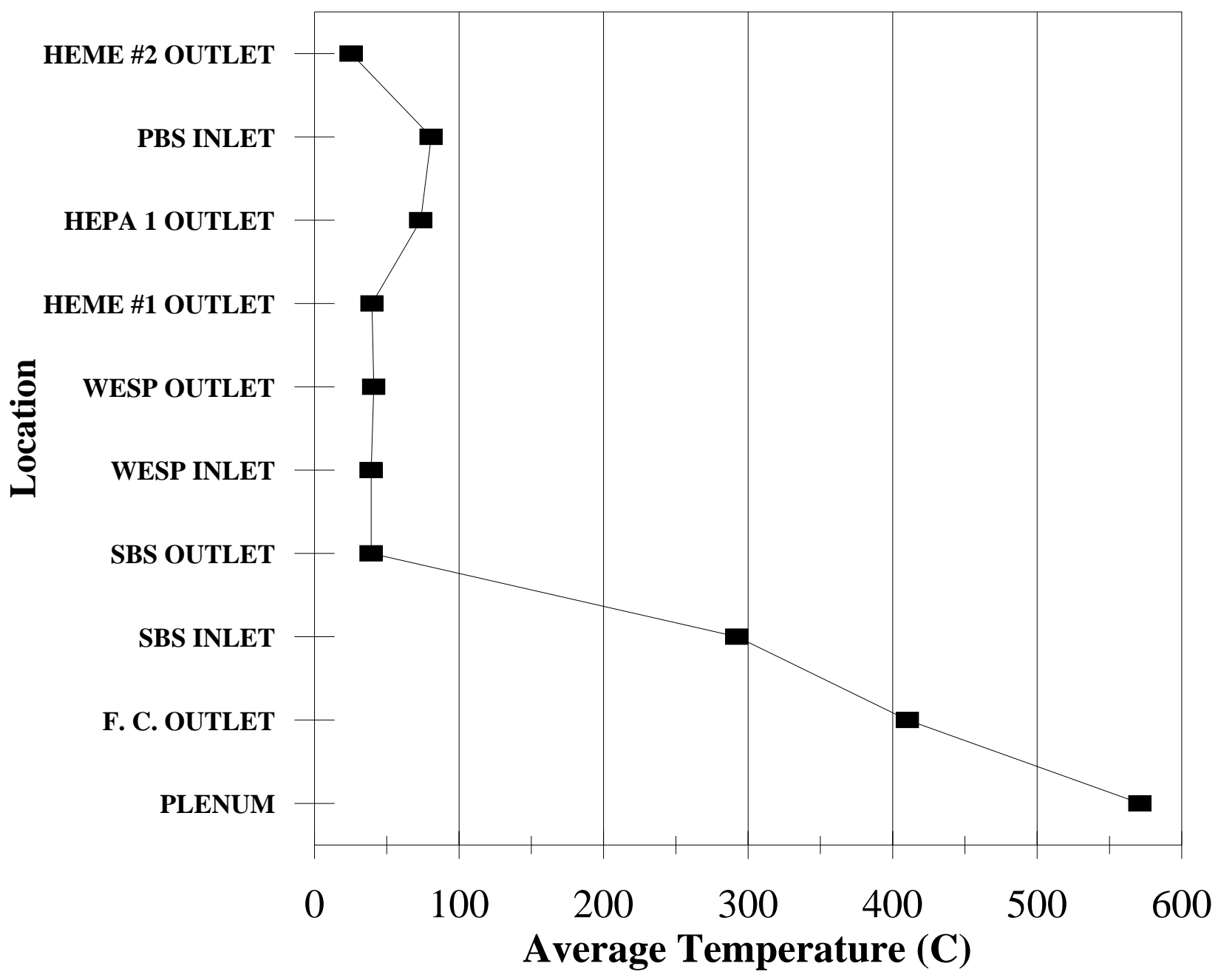

Figure 5.9.b. Average gas temperatures along the DM1200 off-gas train during Test 2. 


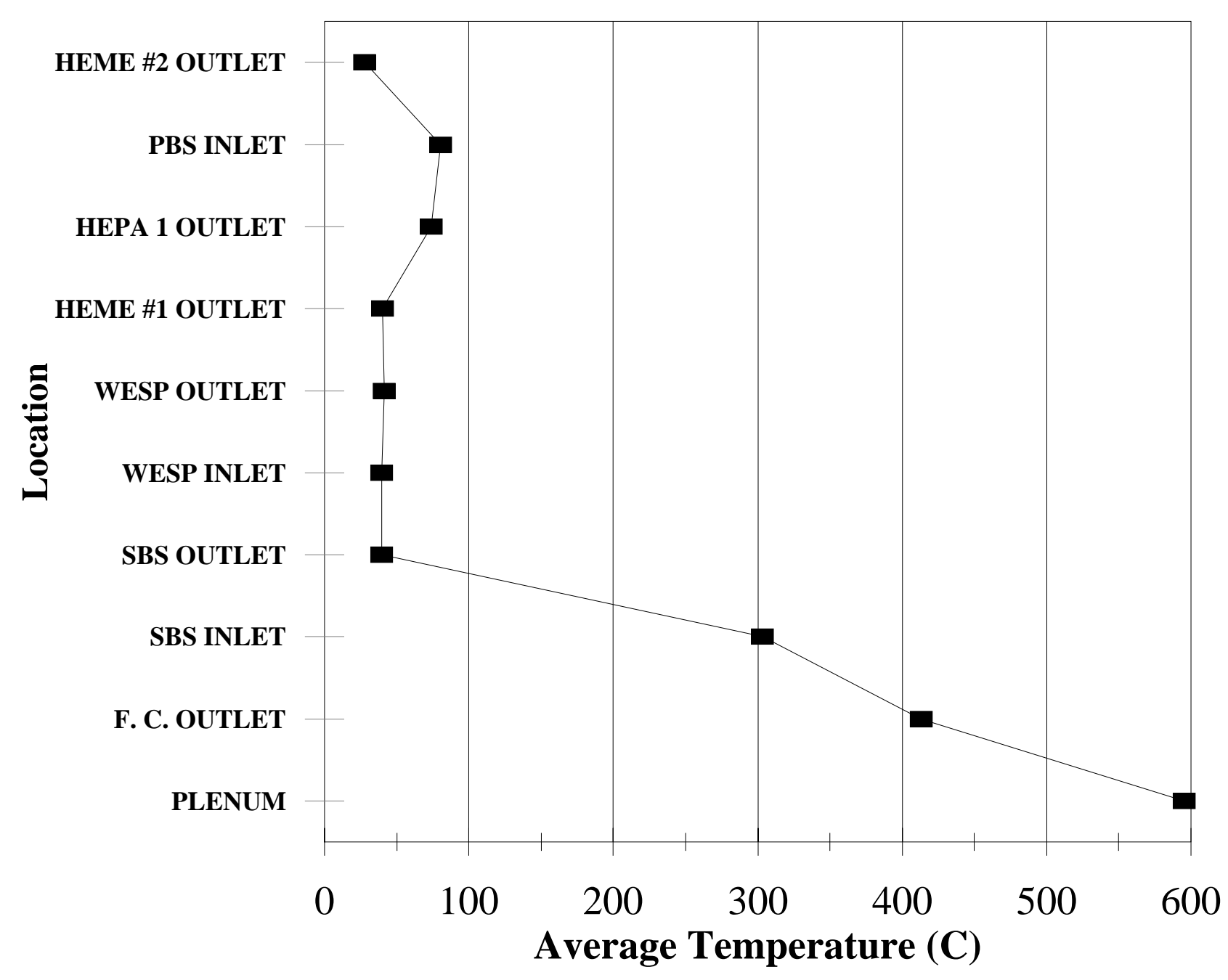

Figure 5.9.c. Average gas temperatures along the DM1200 off-gas train during Test 3. 


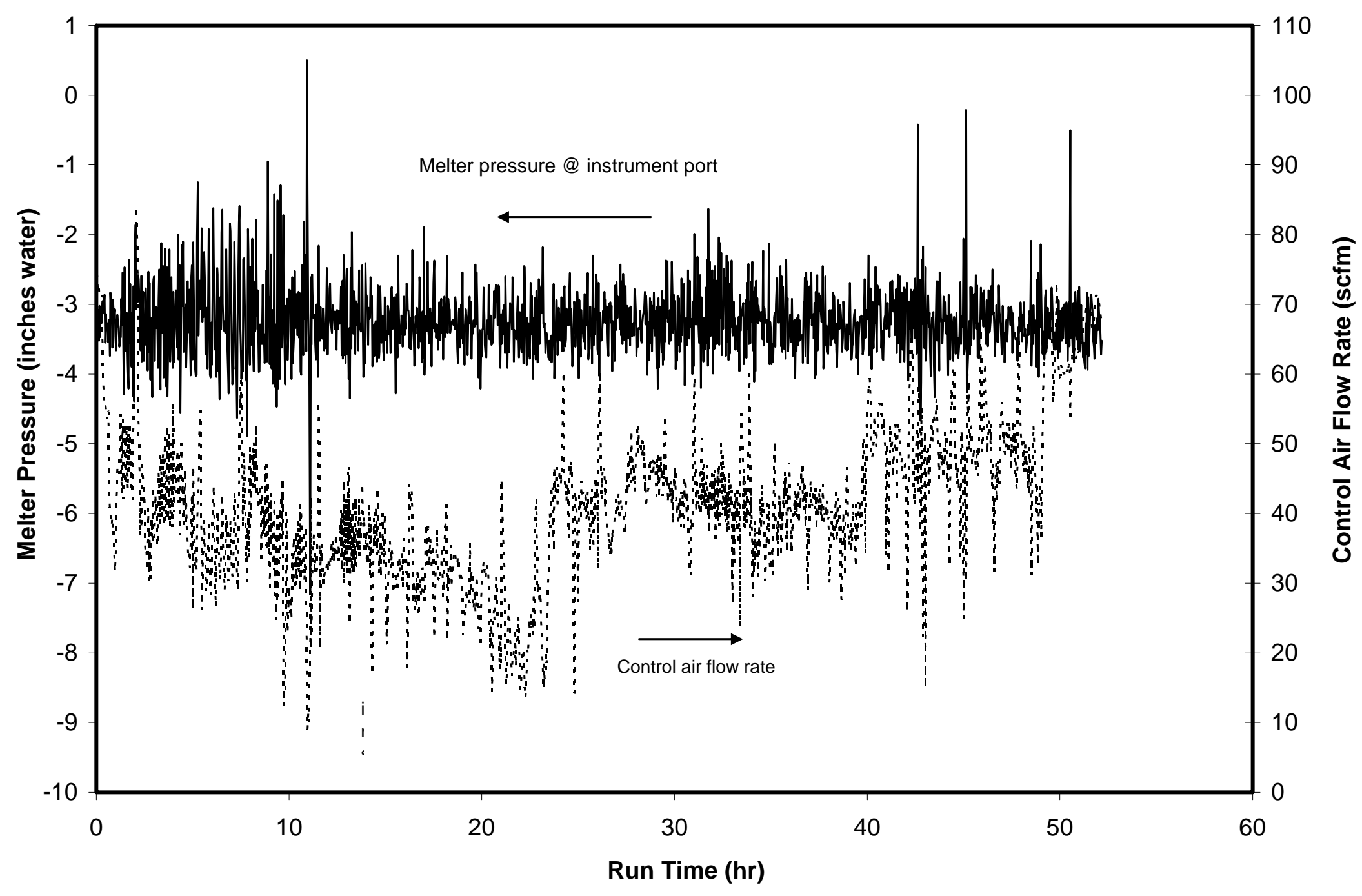

Figure 5.10.a. Melter pressure at instrument port and control air flow rate during Test 1. 


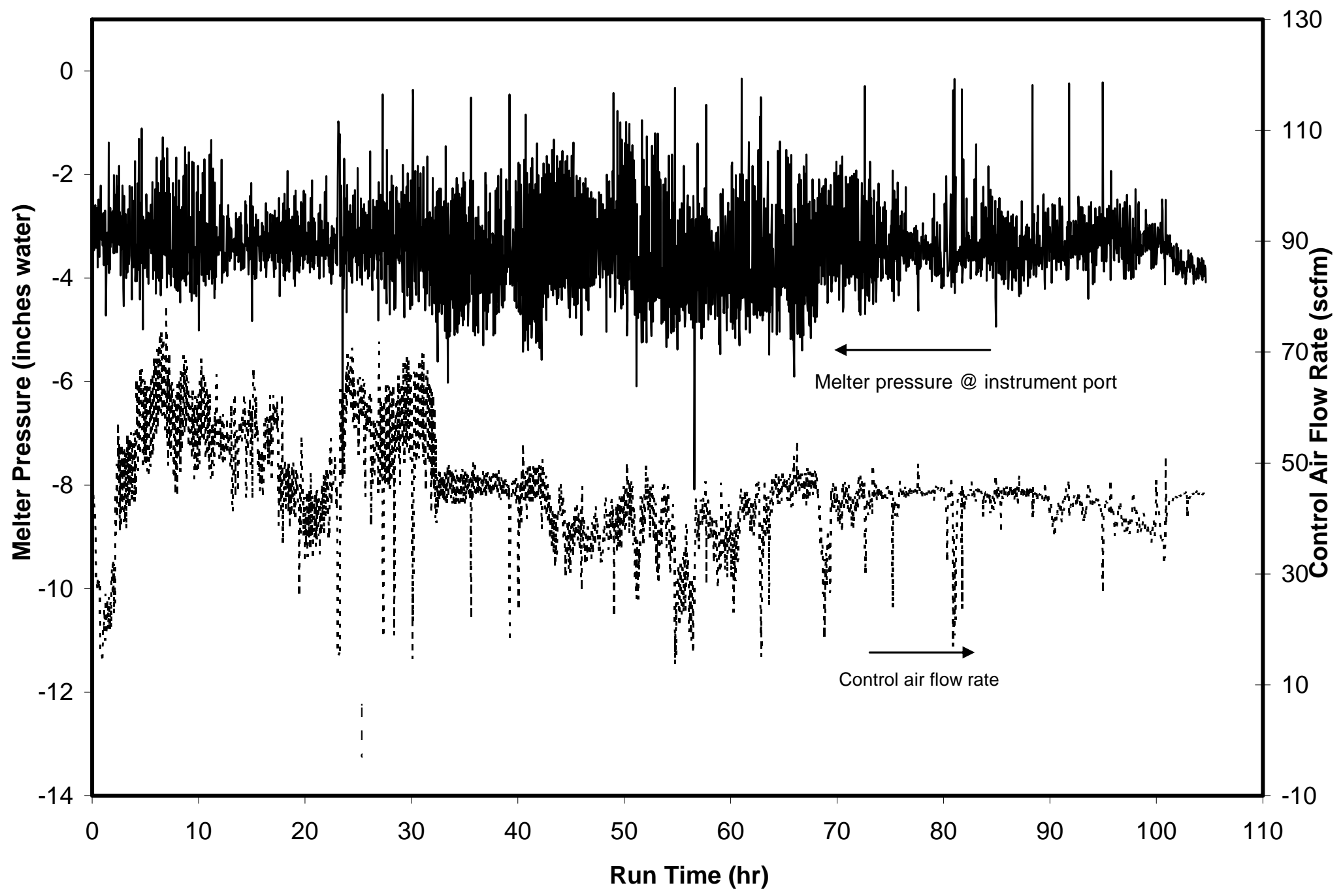

Figure 5.10.b. Melter pressure at instrument port and control air flow rate during Tests 2 and 3. 


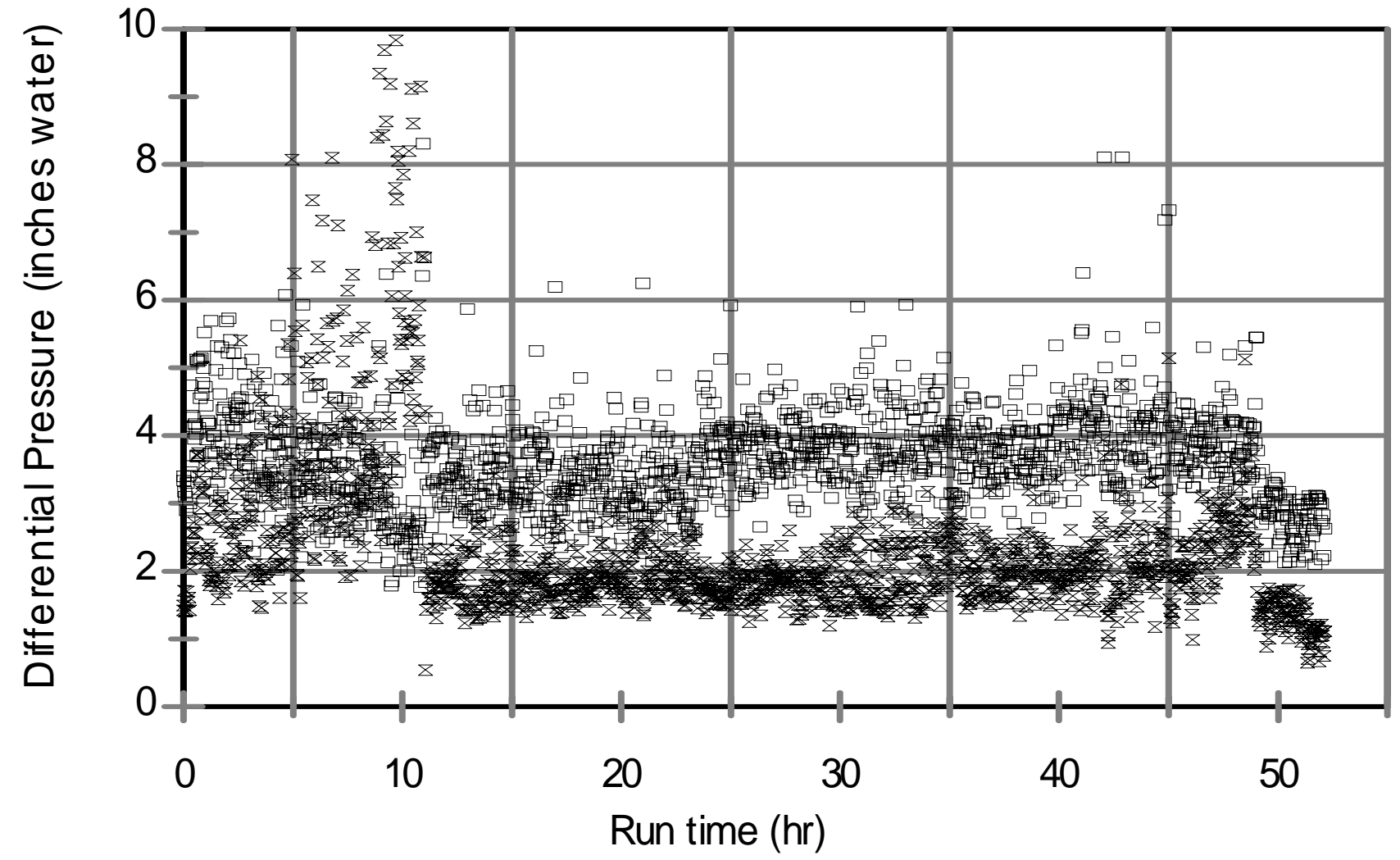

- Transition line

= Film Cooler

Figure 5.11.a. Differential pressure across the transition line and film cooler during DM1200 Test 1. 


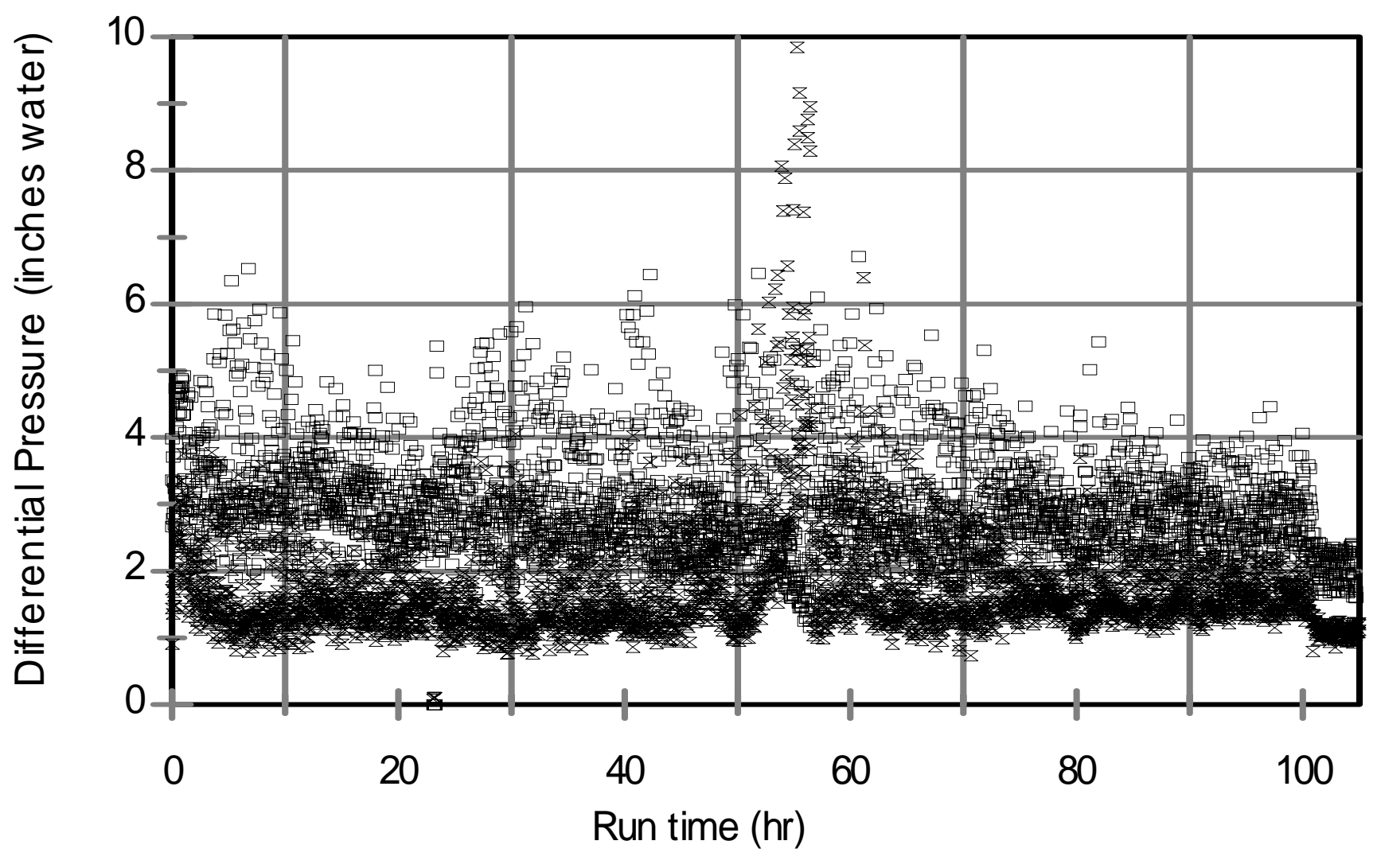

- Transition line × Film Cooler

Figure 5.11.b. Differential pressure across the transition line and film cooler during DM1200 Tests 2 and 3. 


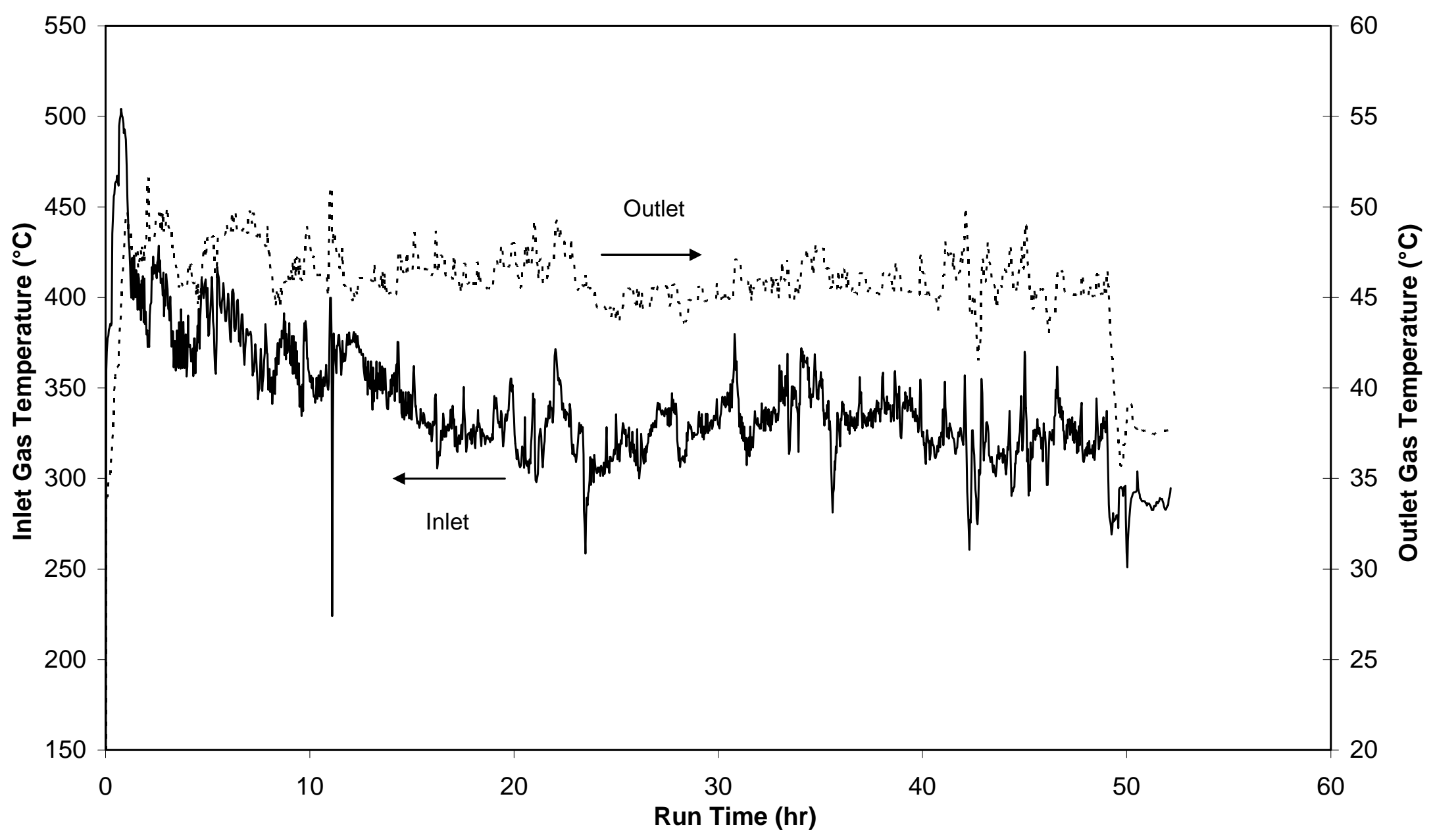

Figure 5.12.a. SBS inlet and outlet gas temperatures during Test 1. 


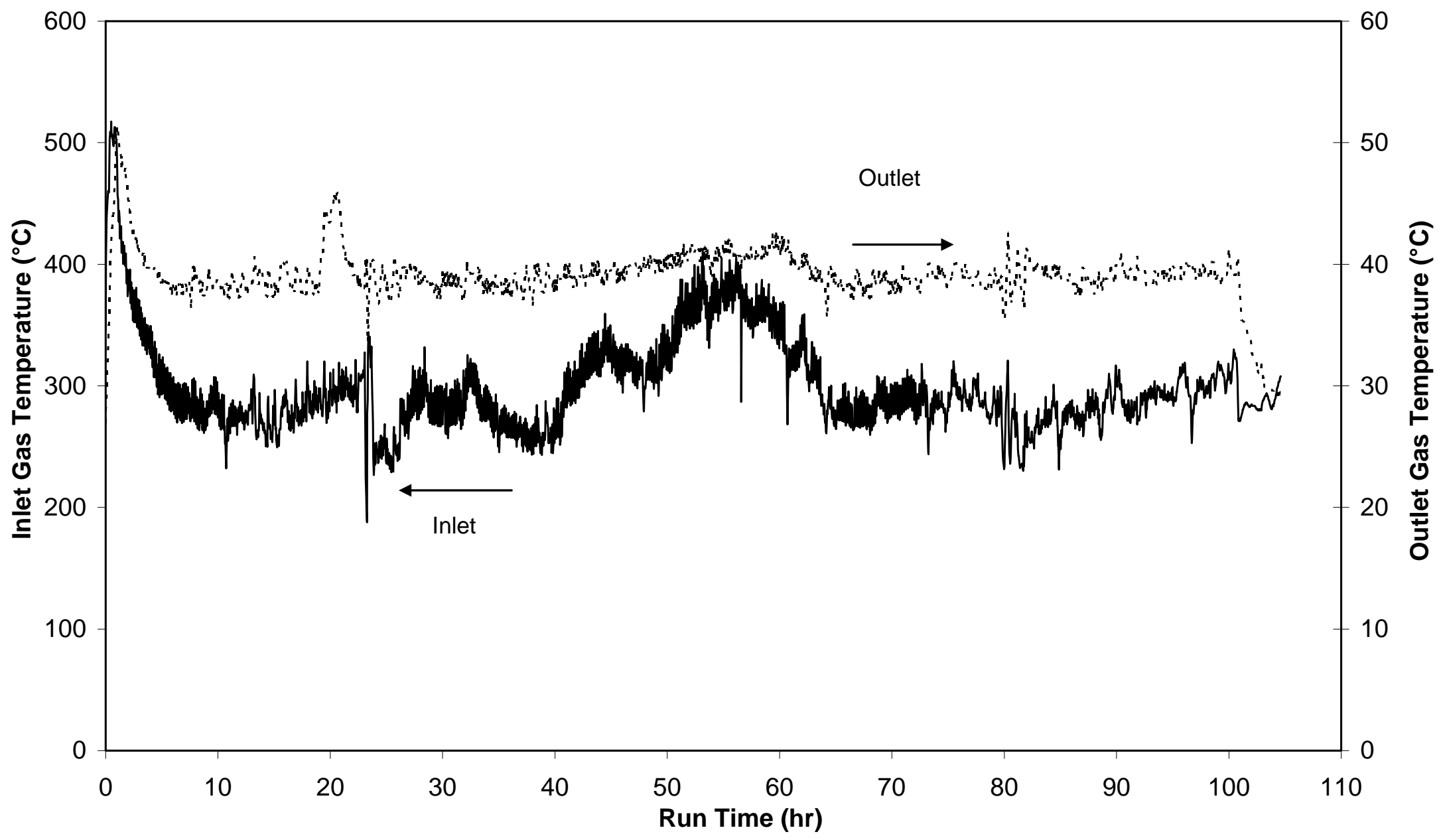

Figure 5.12.b. SBS inlet and outlet gas temperatures during Tests 2 and 3. 


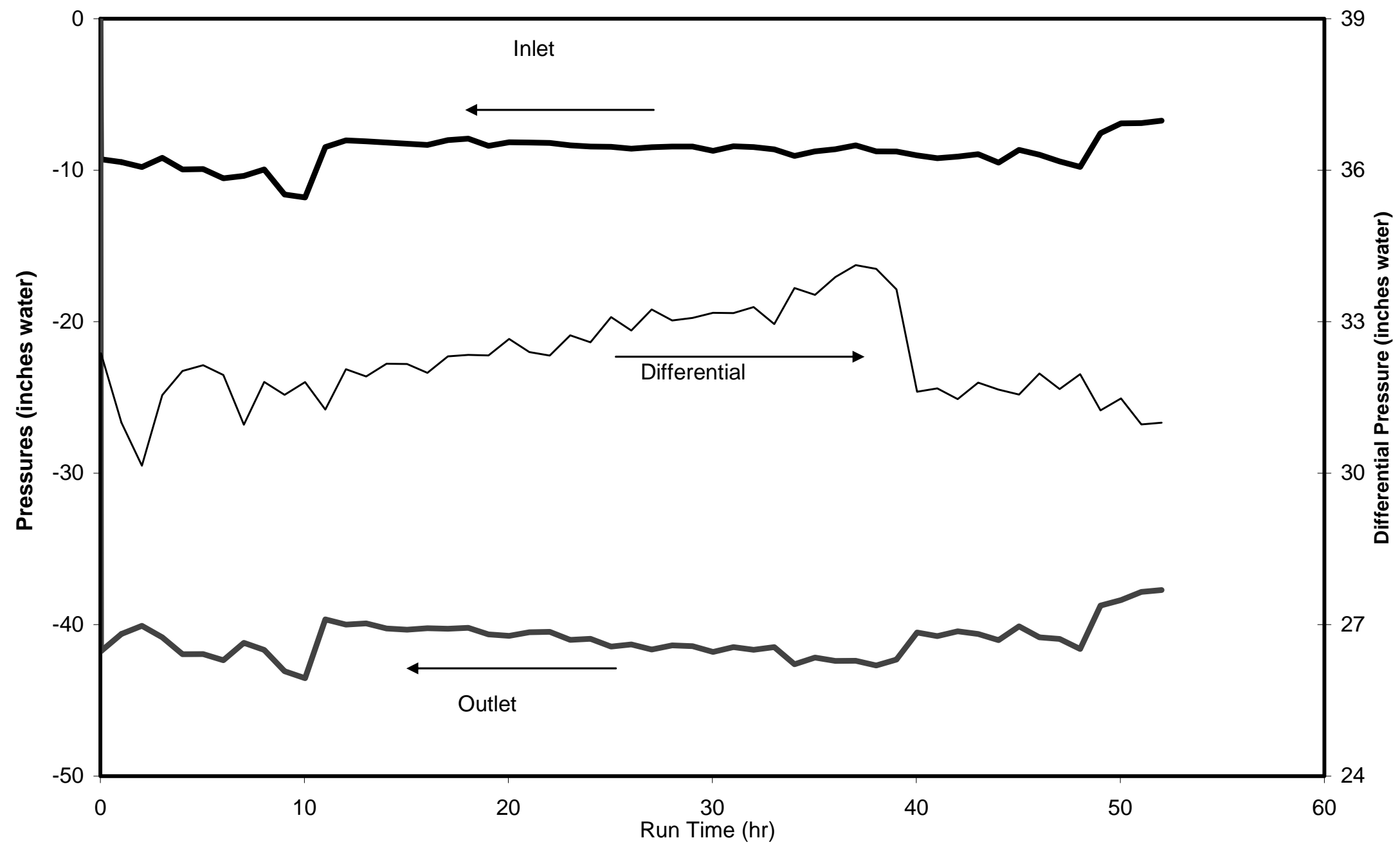

Figure 5.13.a. SBS inlet, outlet, and differential pressures (hourly average values) during Test 1. 


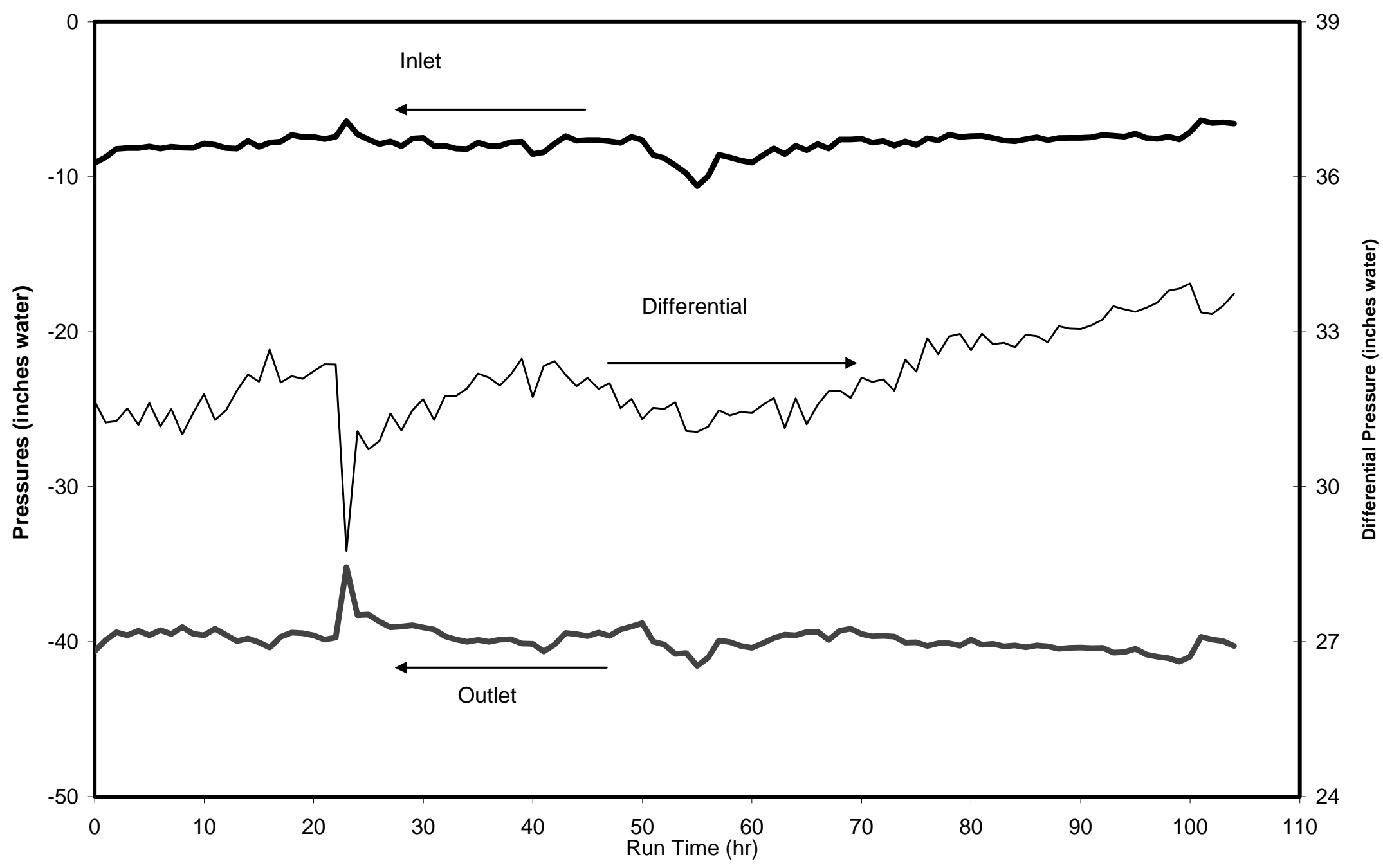

Figure 5.13.b. SBS inlet, outlet, and differential pressures (hourly average values) during Tests 2 and 3. 


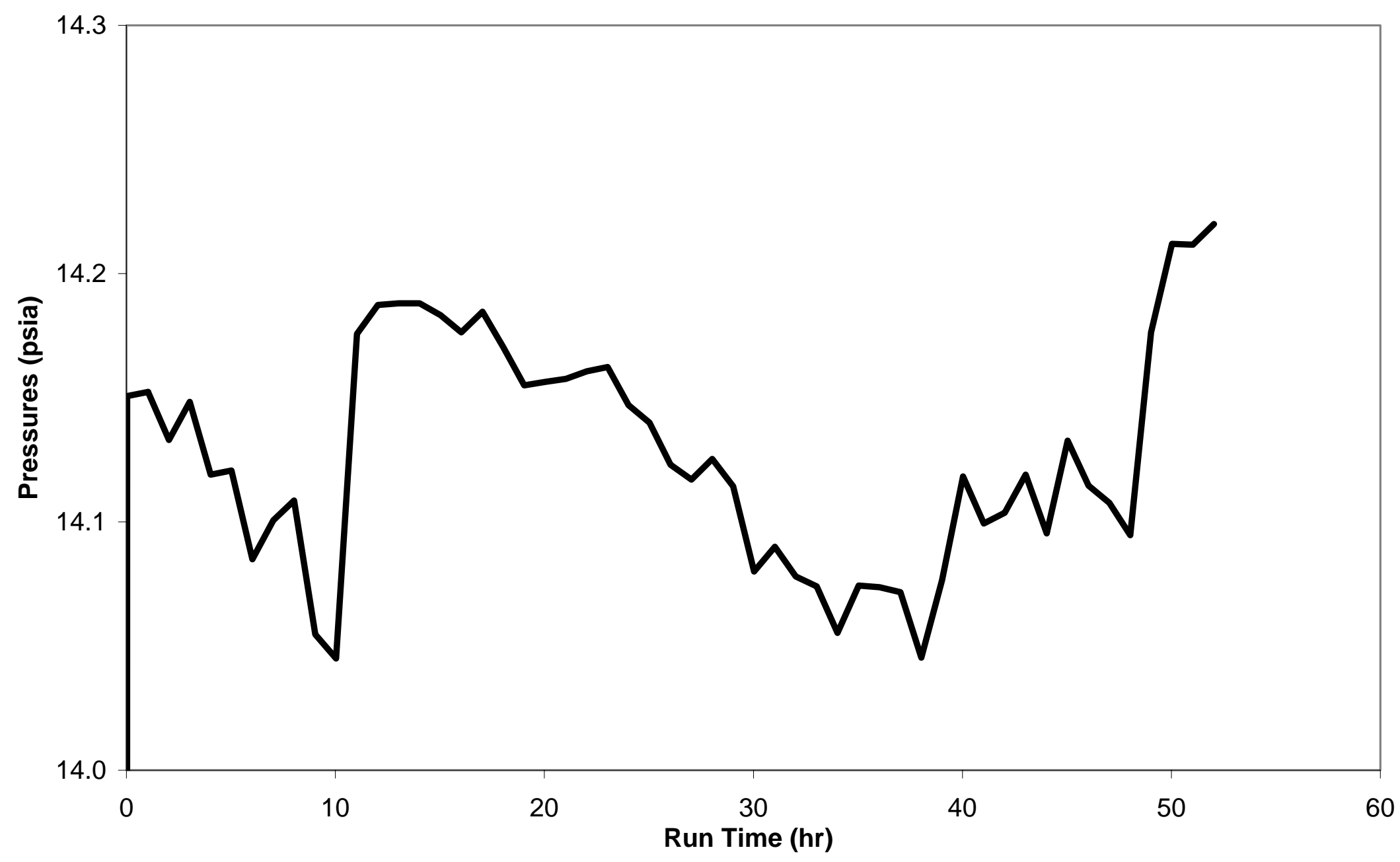

Figure 5.14.a. SBS downcomer annulus pressure (hourly average values) during Test 1. 


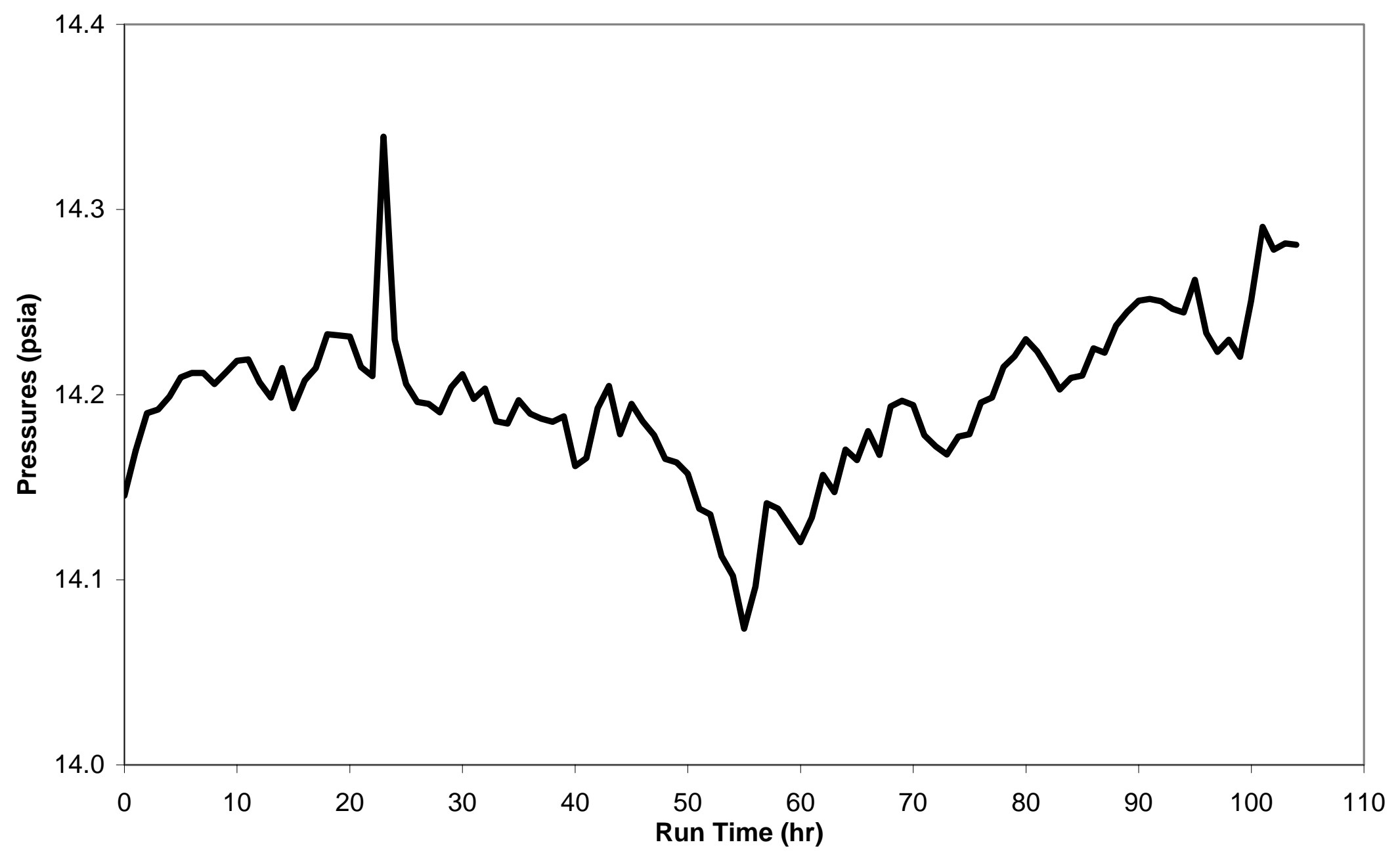

Figure 5.14.b. SBS downcomer annulus pressure (hourly average values) during Tests 2 and 3. 


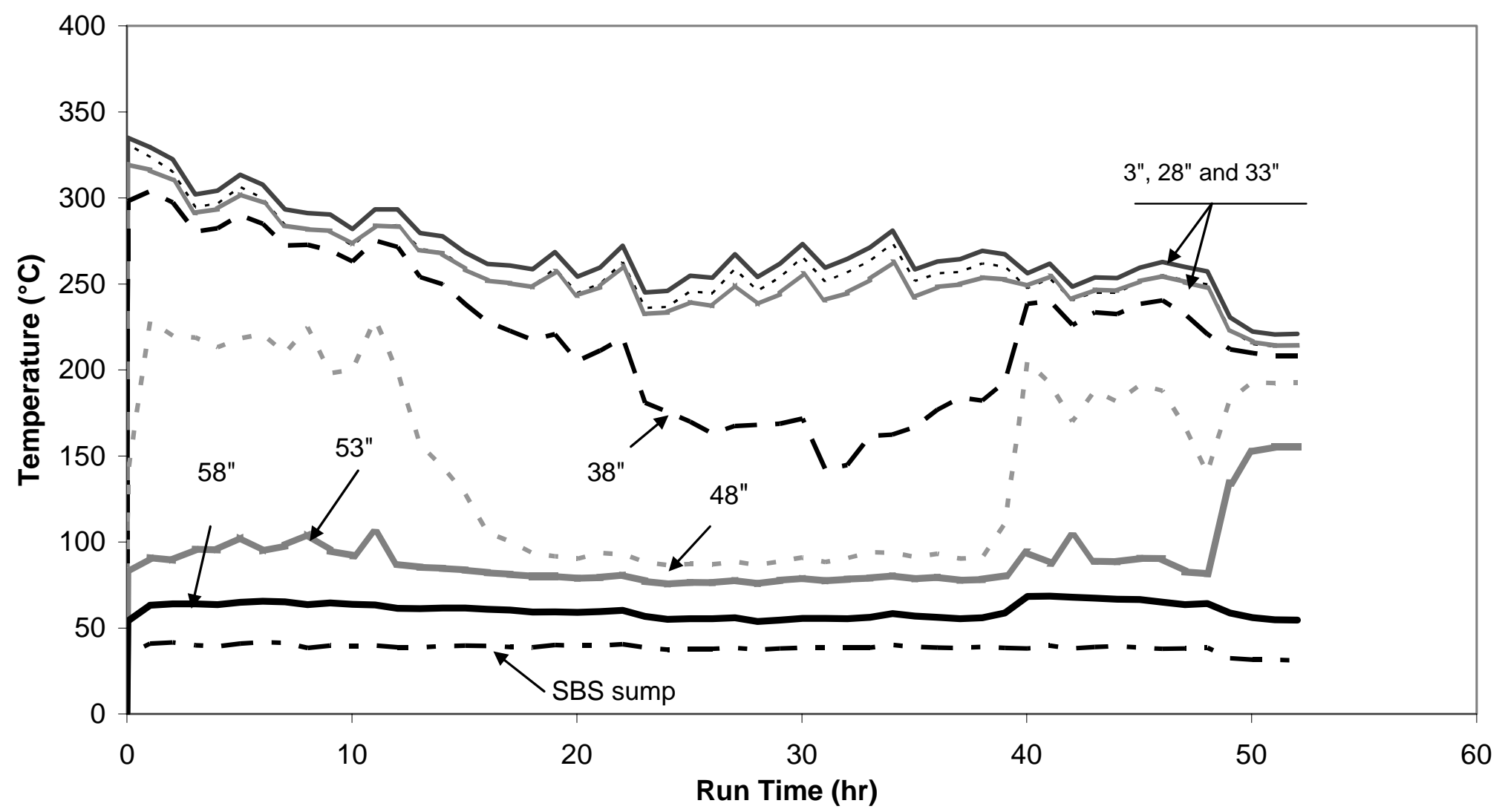

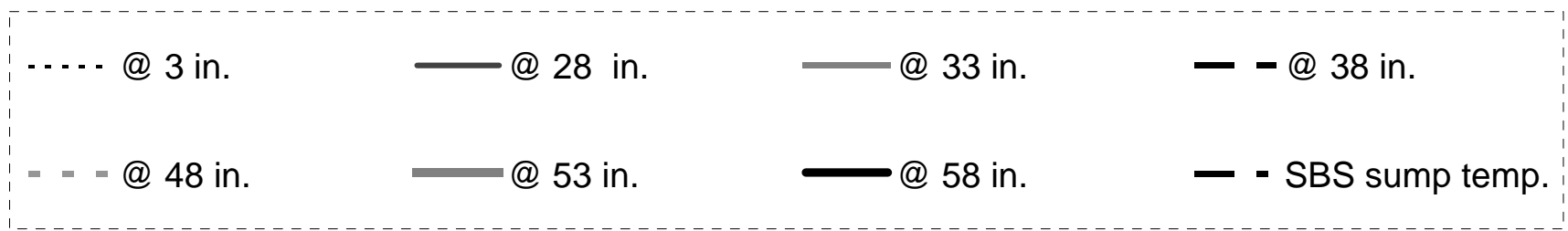

Figure 5.15.a. Off-gas temperatures in the SBS downcomer and sump water temperatures (hourly average values) during Test 1. 


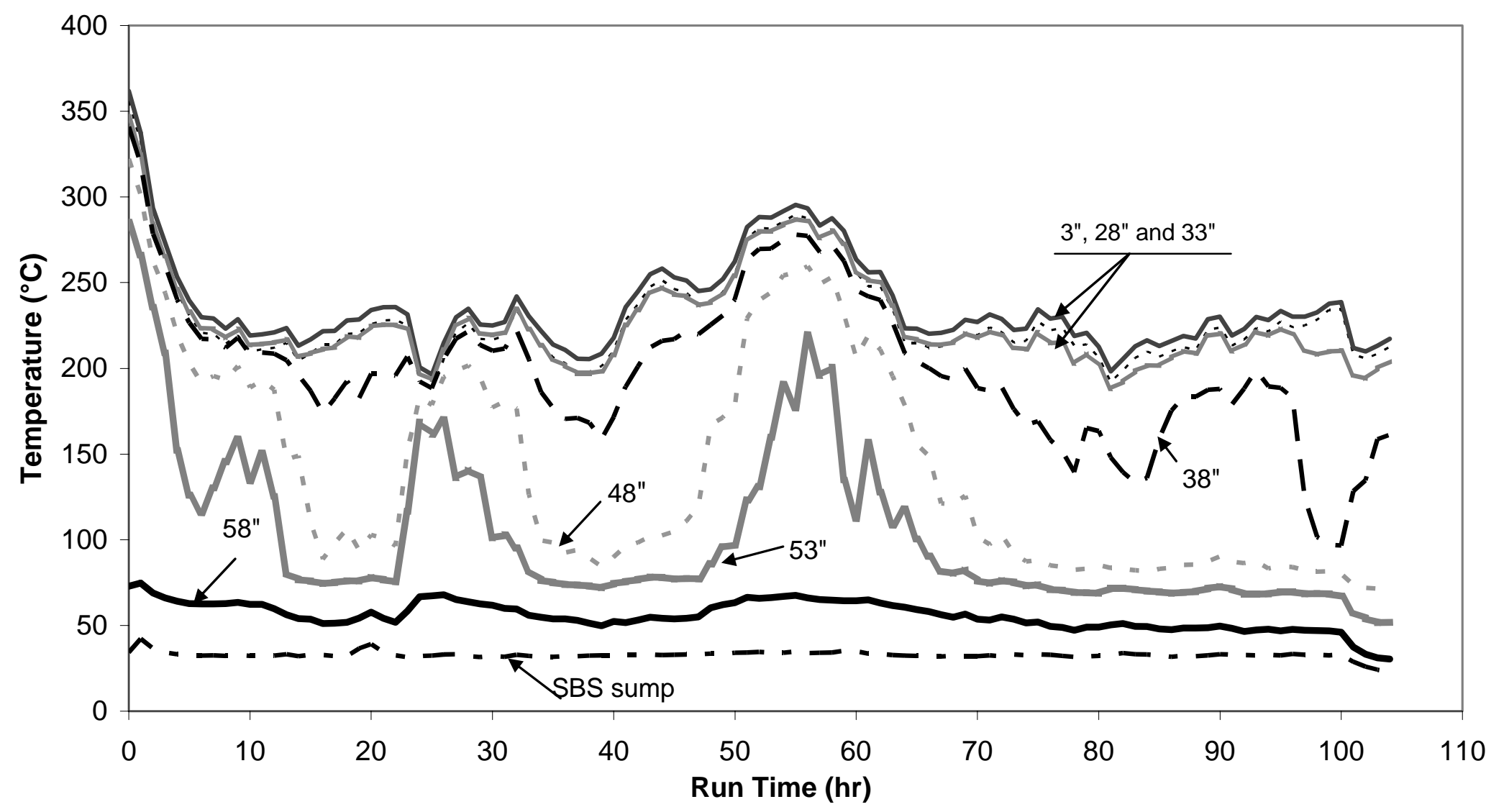

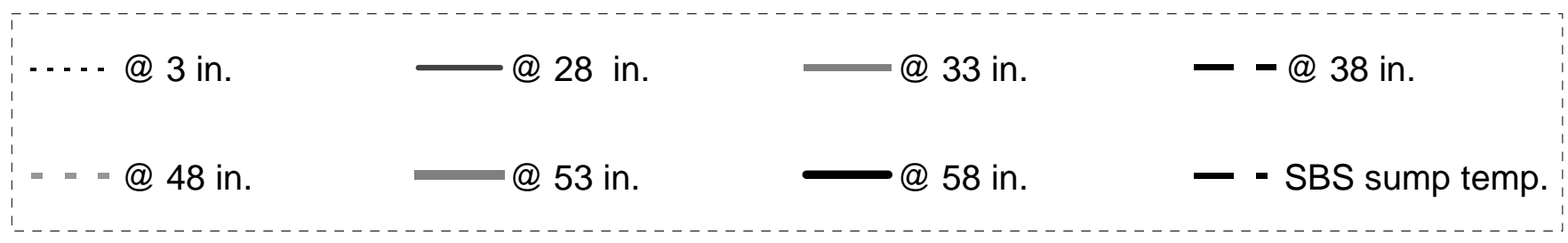

Figure 5.15.b. Off-gas temperatures in the SBS downcomer and sump water temperatures (hourly average values) during Tests 2 and 3. 


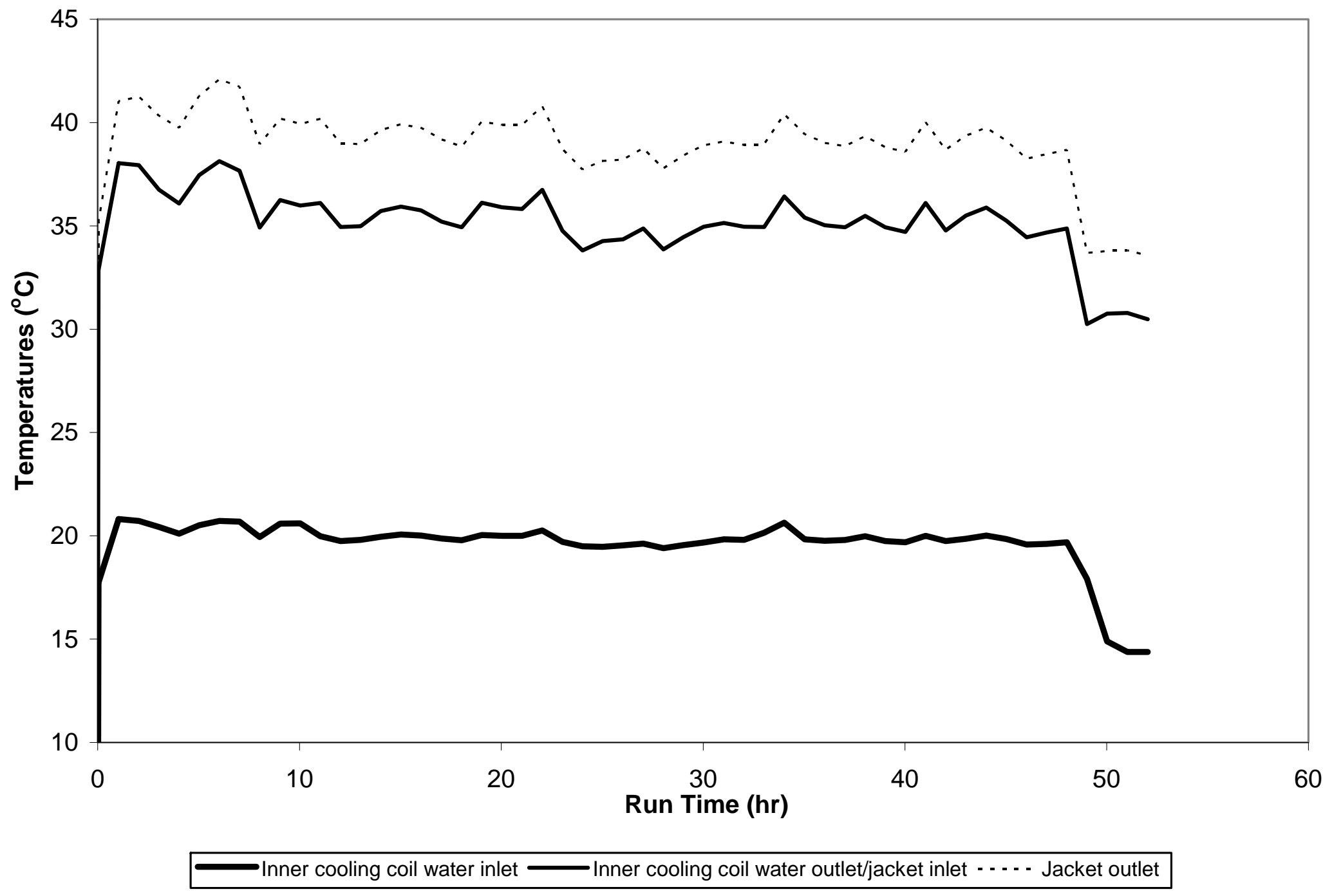

Figure 5.16.a. SBS cooling coil inlet, cooling coil outlet/jacket inlet and jacket outlet water temperatures (hourly average values) during Test 1. 


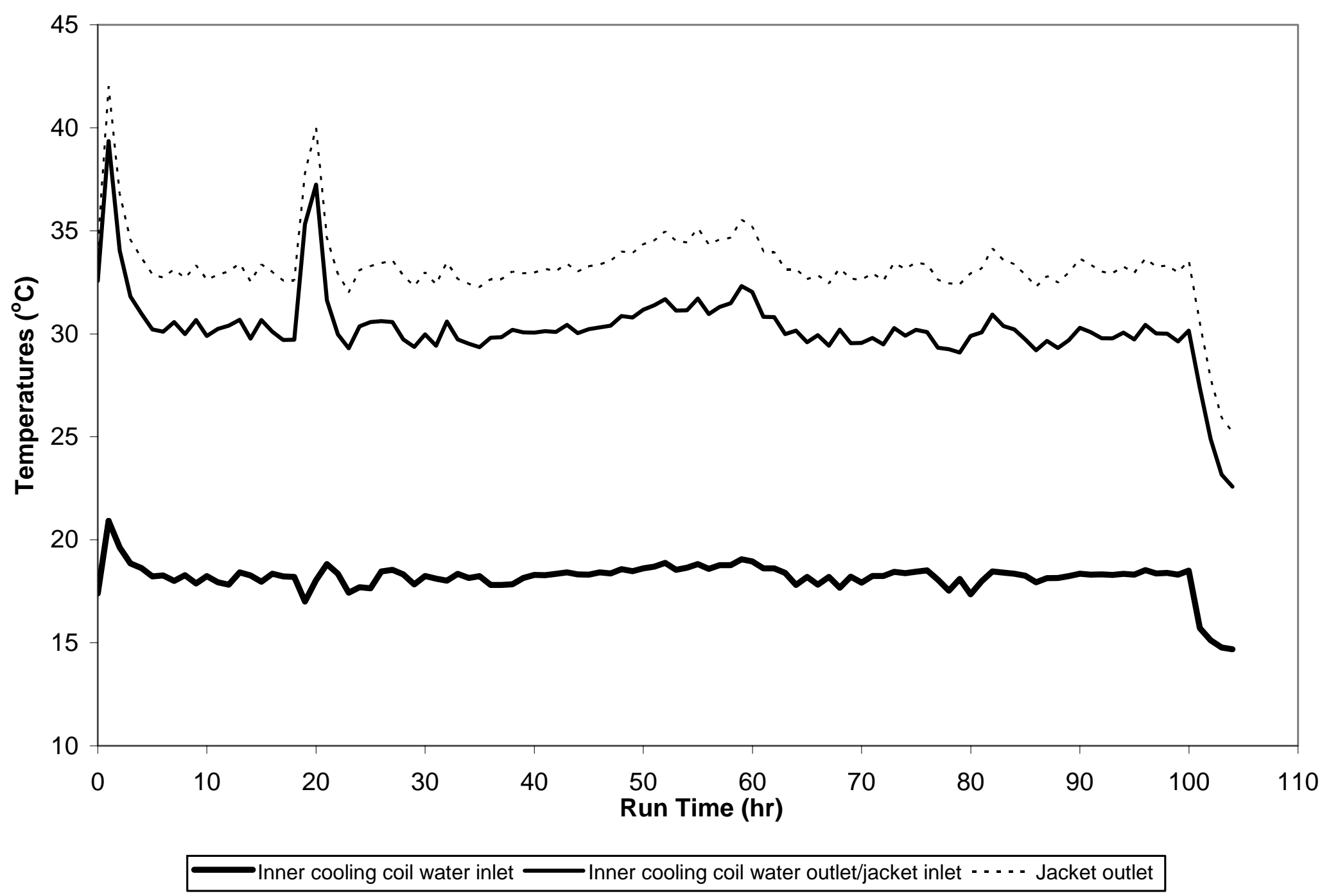

Figure 5.16.b. SBS cooling coil inlet, cooling coil outlet/jacket inlet and jacket outlet water temperatures (hourly average values) during Tests 2 and 3. 


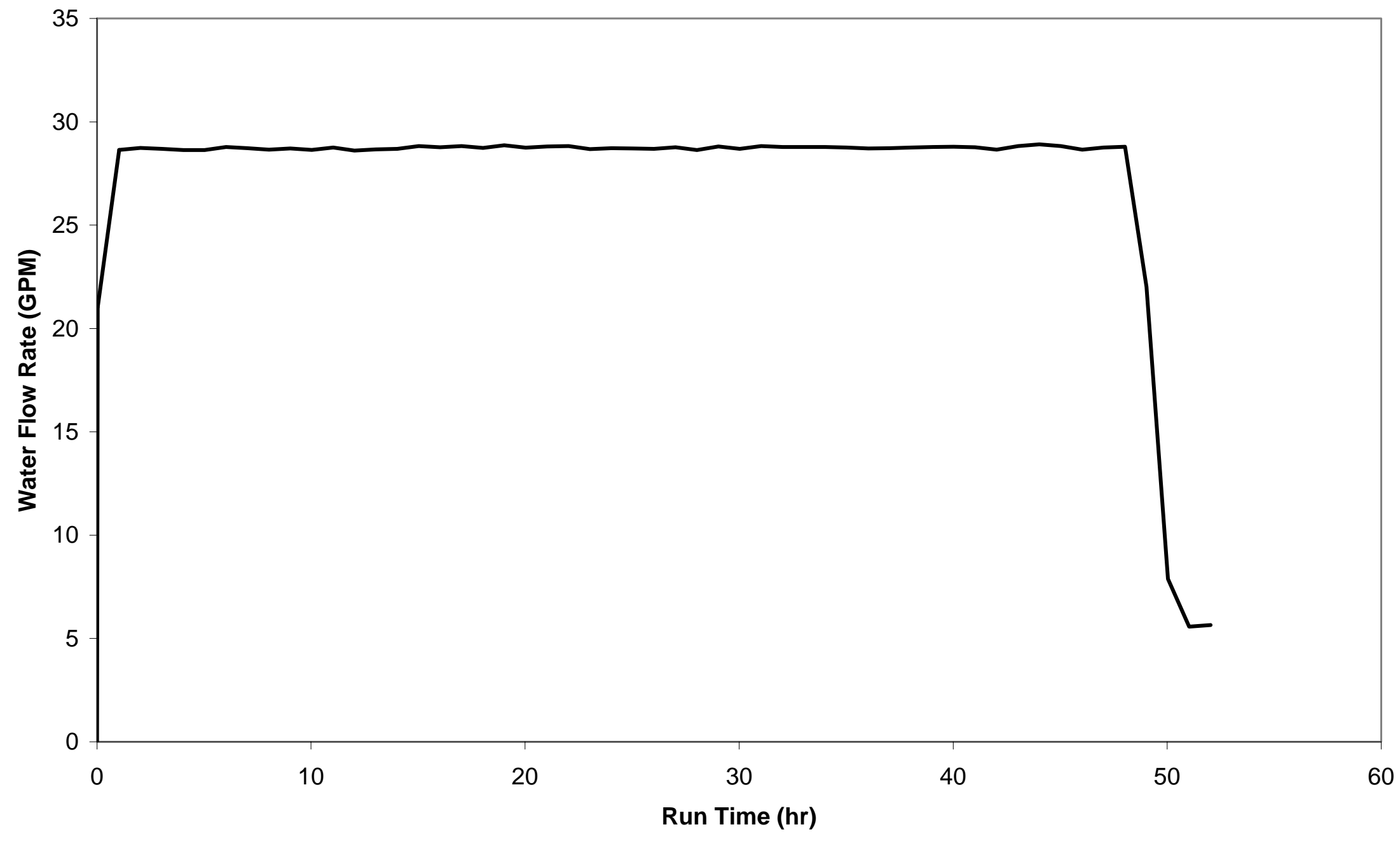

Figure 5.17.a. SBS cooling coil/jacket water flow rate (hourly average values) during Test 1. 


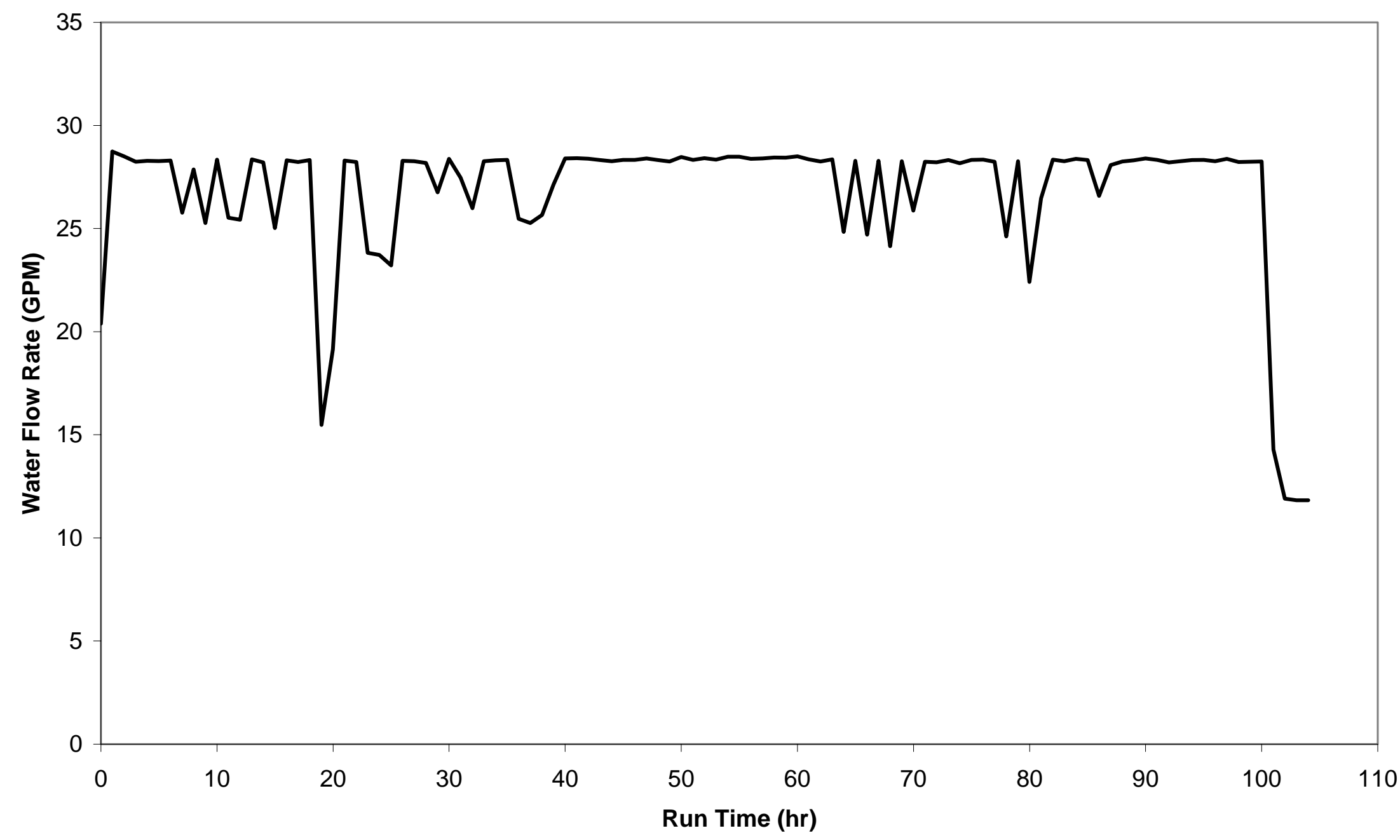

Figure 5.17.b. SBS cooling coil/jacket water flow rate (hourly average values) during Tests 2 and 3. 


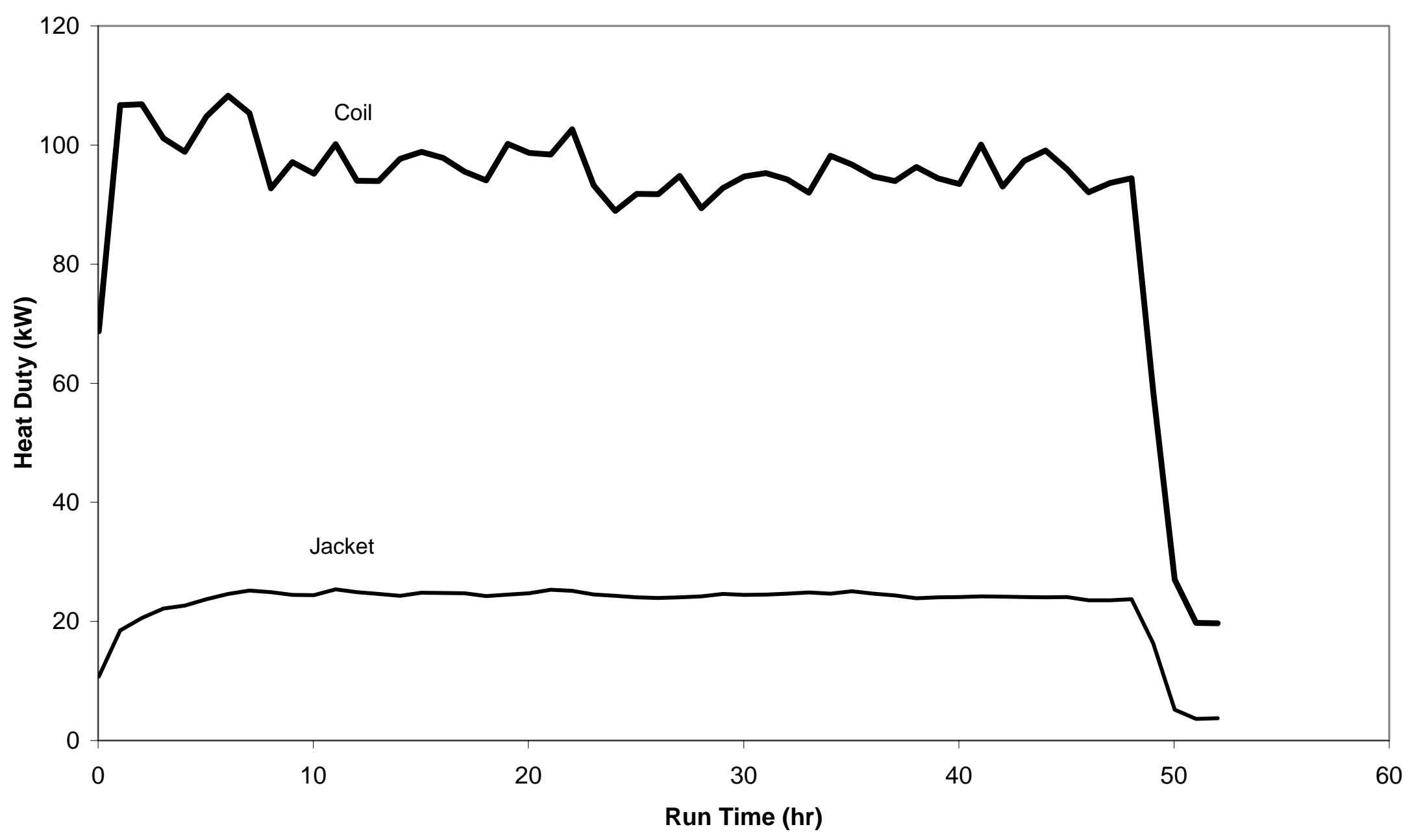

Figure 5.18.a. Calculated heat loads on the inner coil and jacket (hourly average values) during Test 1. 


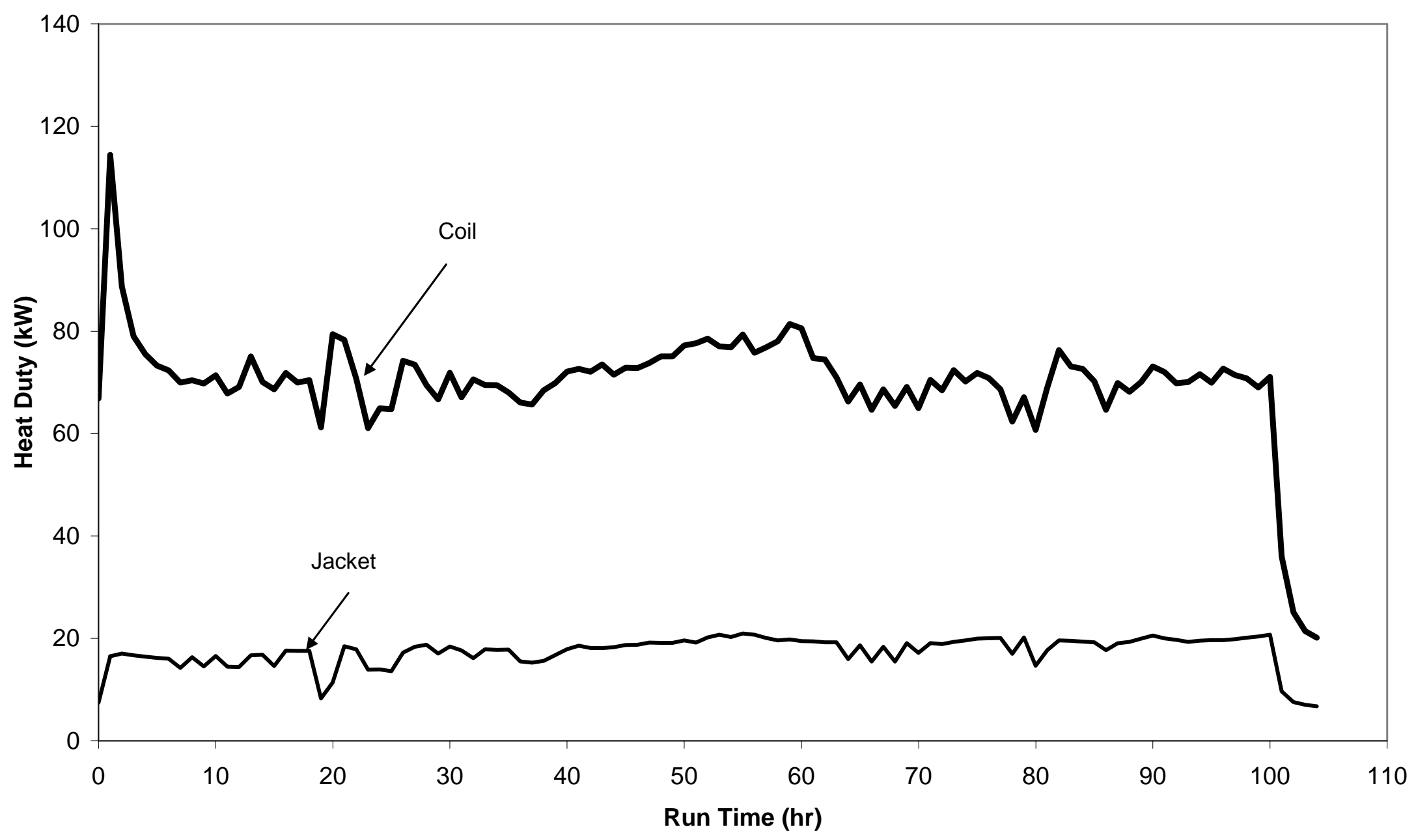

Figure 5.18.b. Calculated heat loads on the inner coil and jacket (hourly average values) during Tests 2 and 3. 


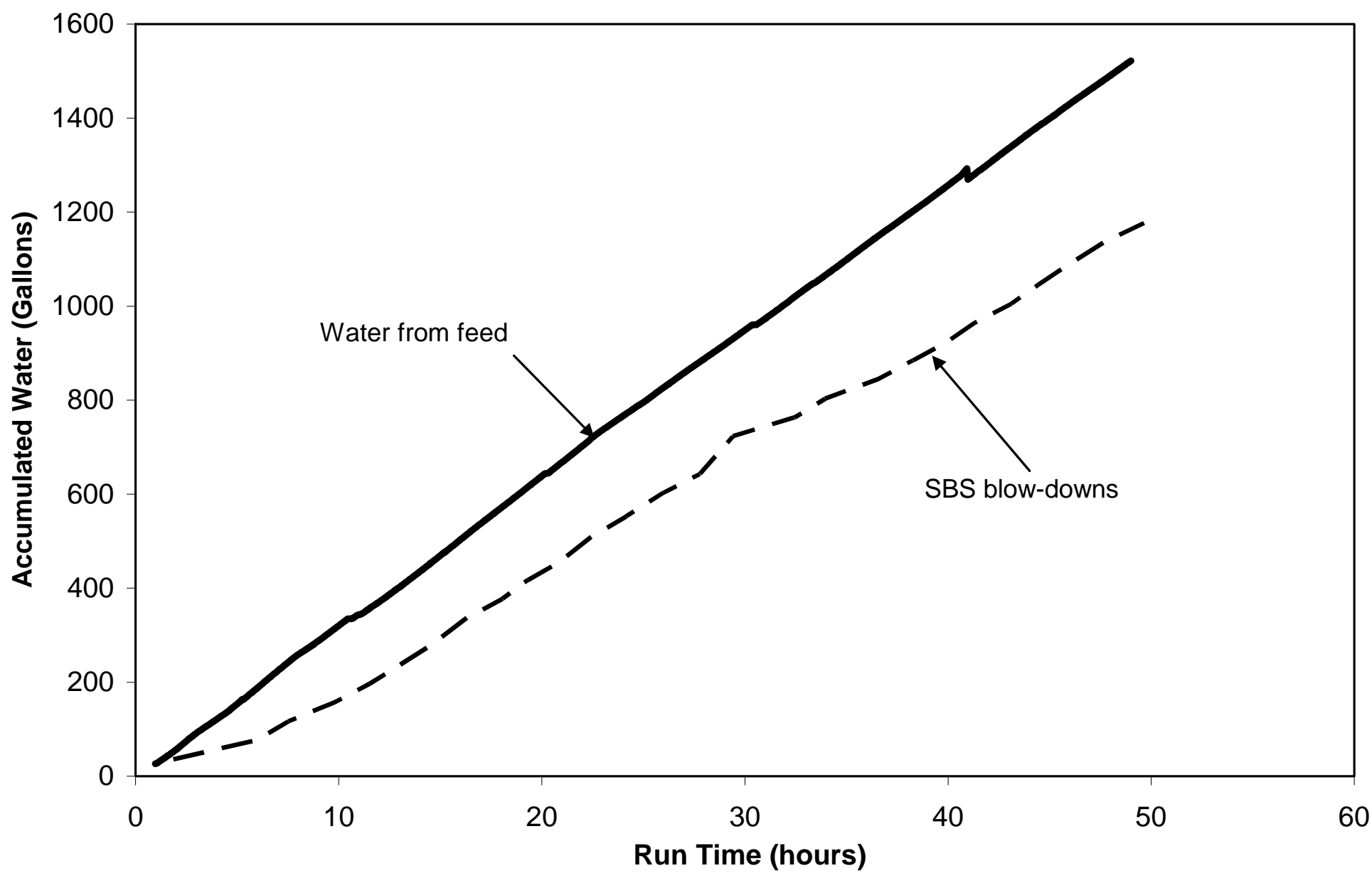

Figure 5.19.a. Accumulated SBS blowdown volume and accumulated feed water during Test 1. 


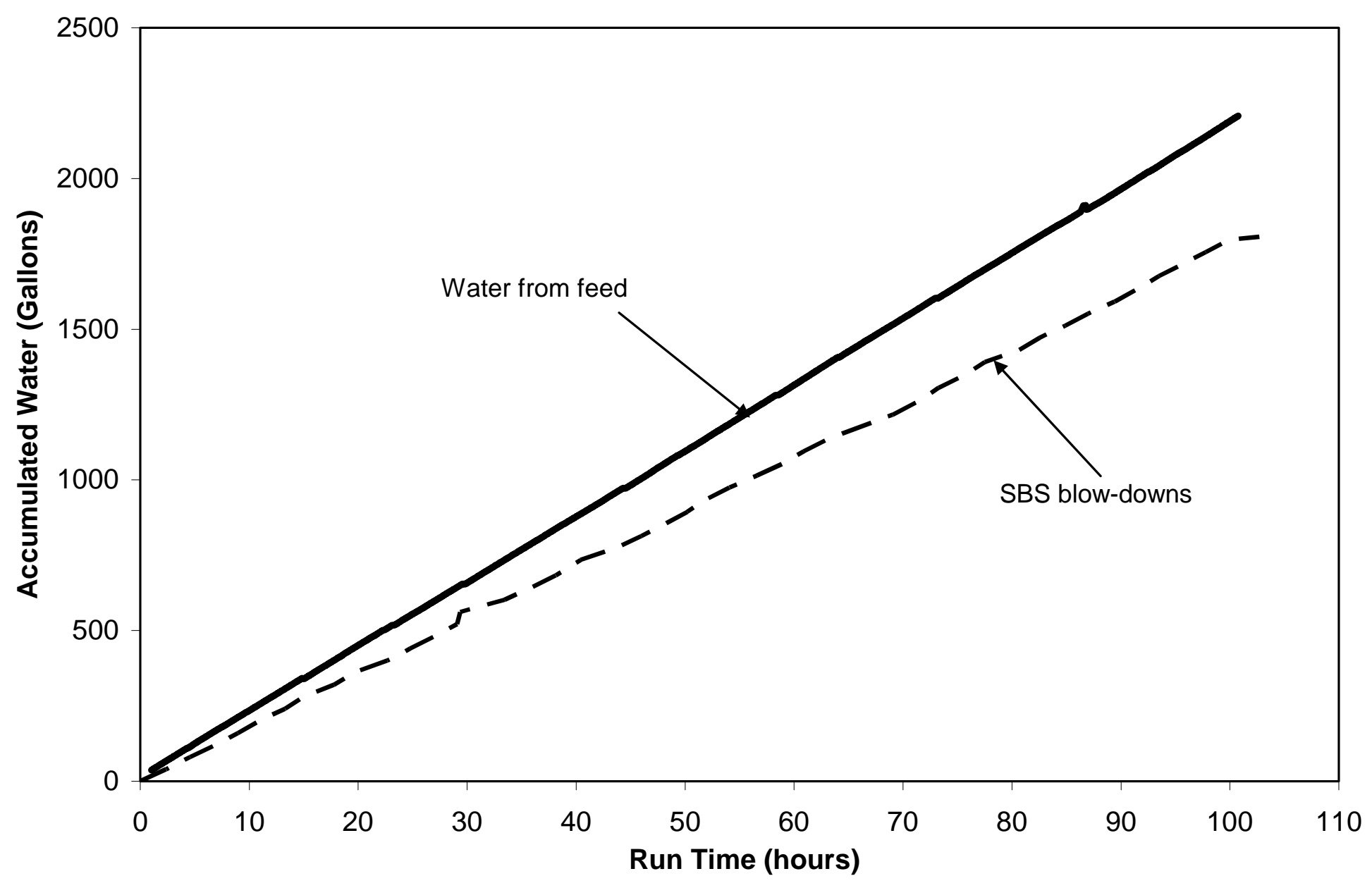

Figure 5.19.b. Accumulated SBS blowdown volume and accumulated feed water during Tests 2 and 3. 


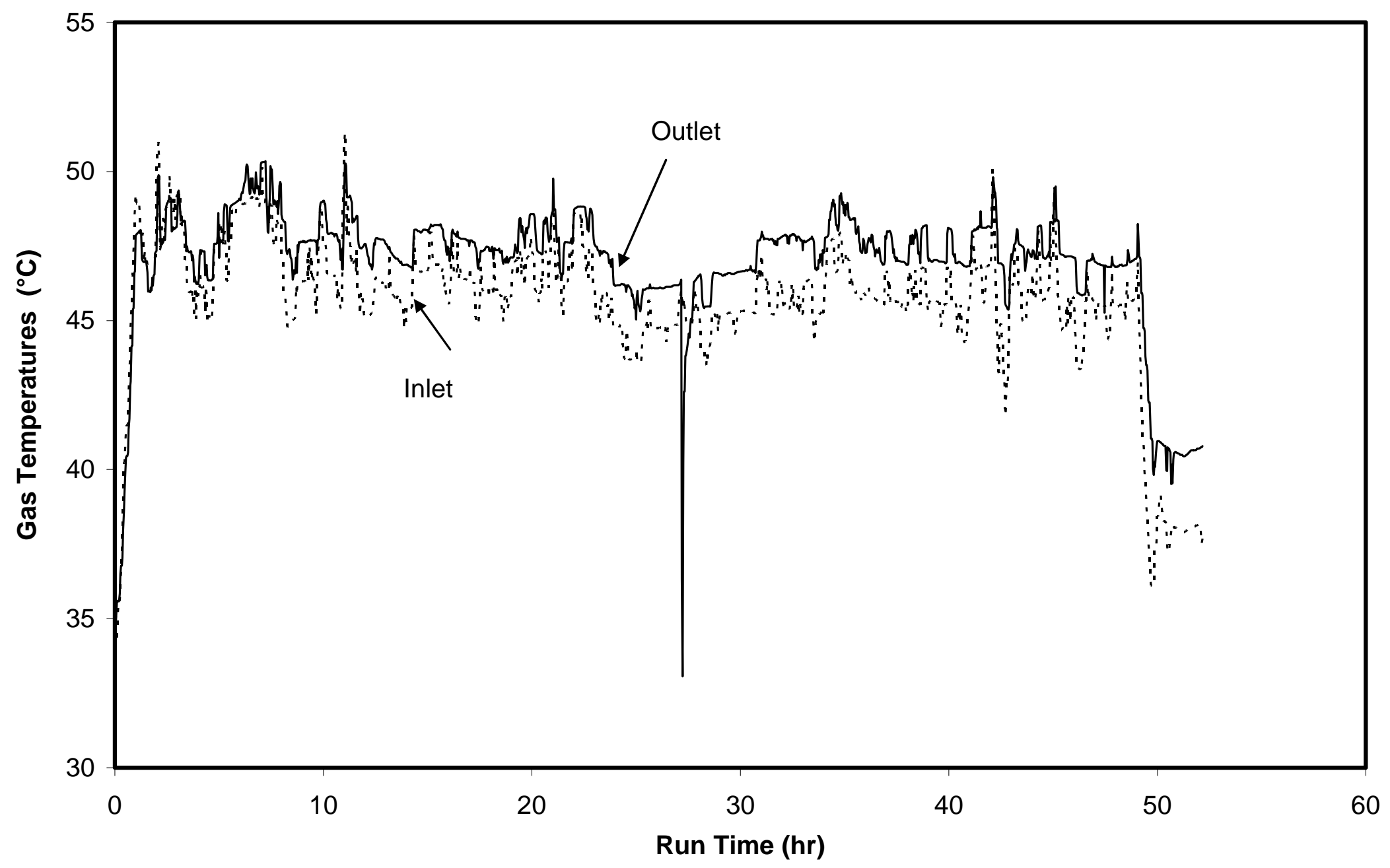

Figure 5.20.a. WESP inlet and outlet gas temperatures during Test 1. (Note: downward outlet temperature spikes are the result of WESP deluges.) 


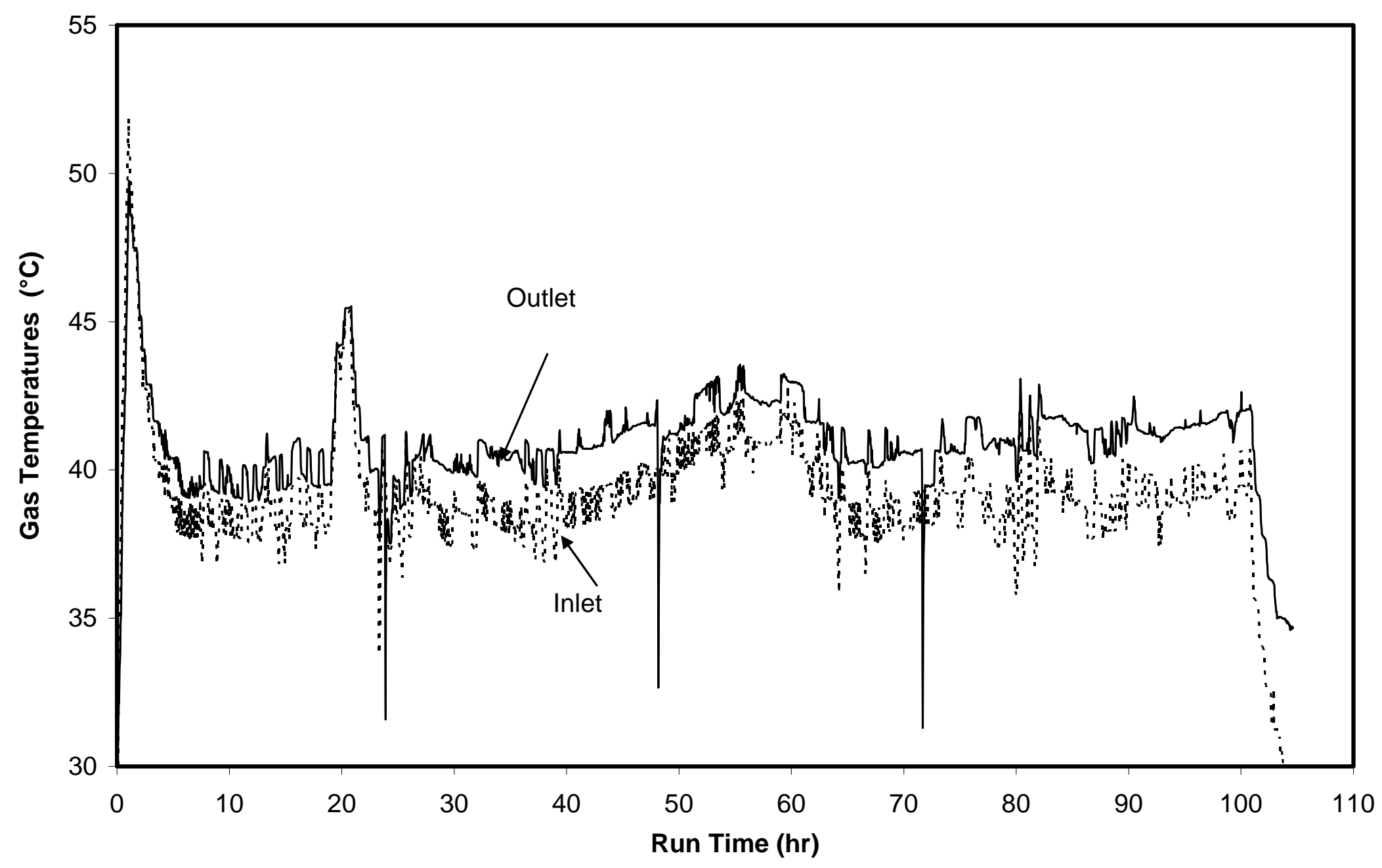

Figure 5.20.b. WESP inlet and outlet gas temperatures during Tests 2 and 3. (Note: downward outlet temperature spikes are the result of WESP deluges.) 


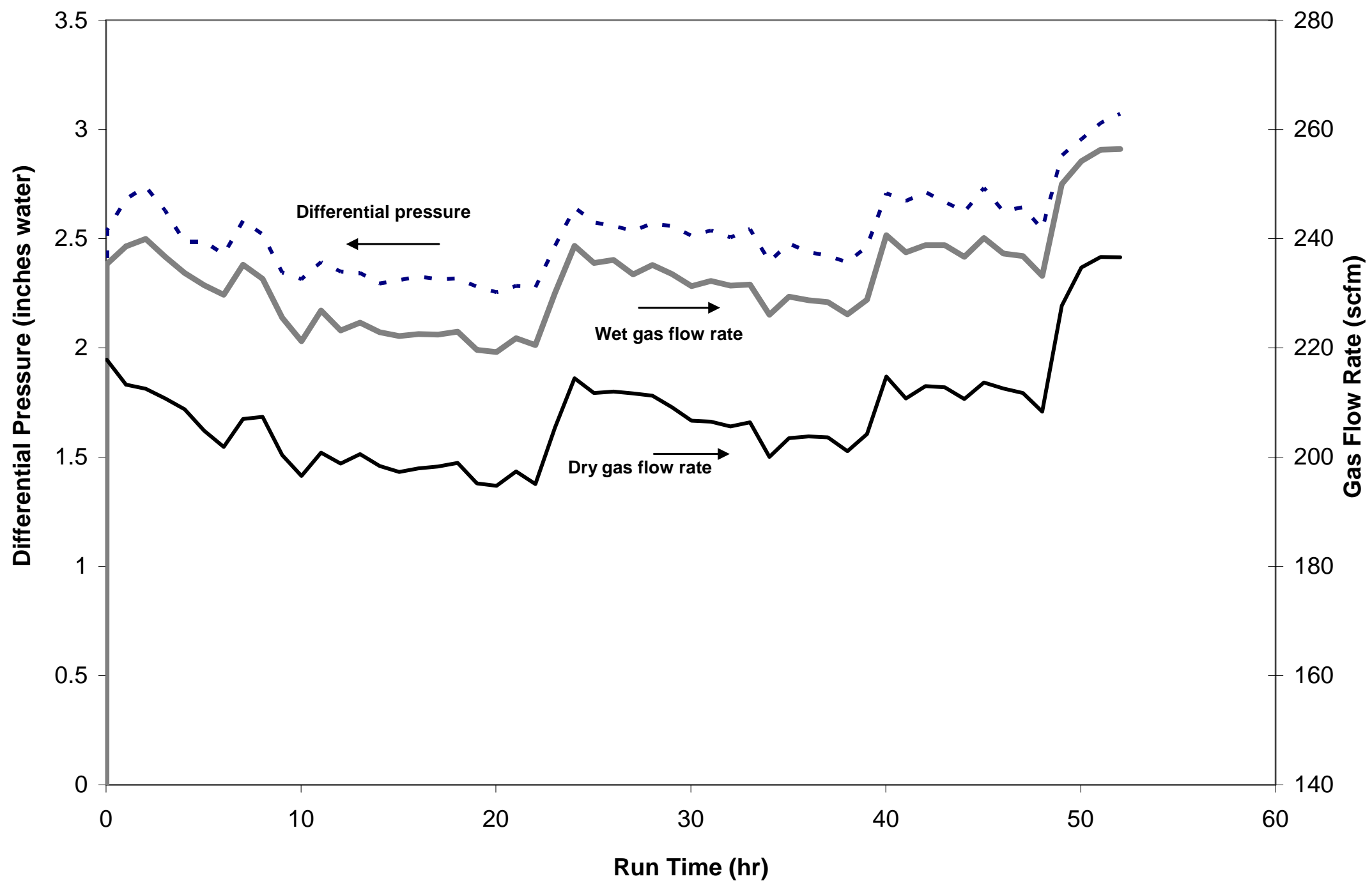

Figure 5.21.a. WESP differential pressure and outlet gas flow rate (hourly average values) during Test 1. 


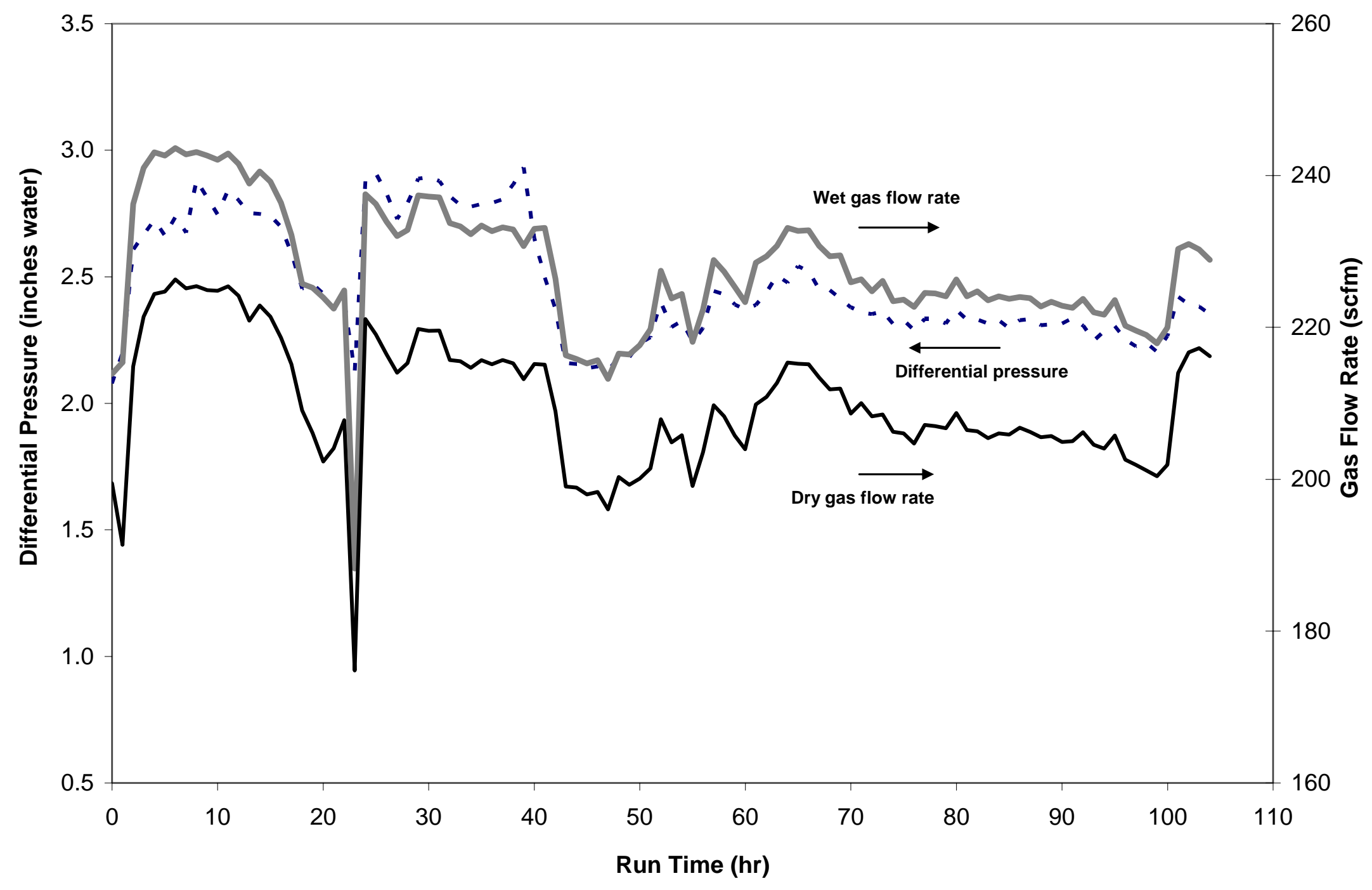

Figure 5.21.b. WESP differential pressure and outlet gas flow rate (hourly average values) during Tests 2 and 3. 


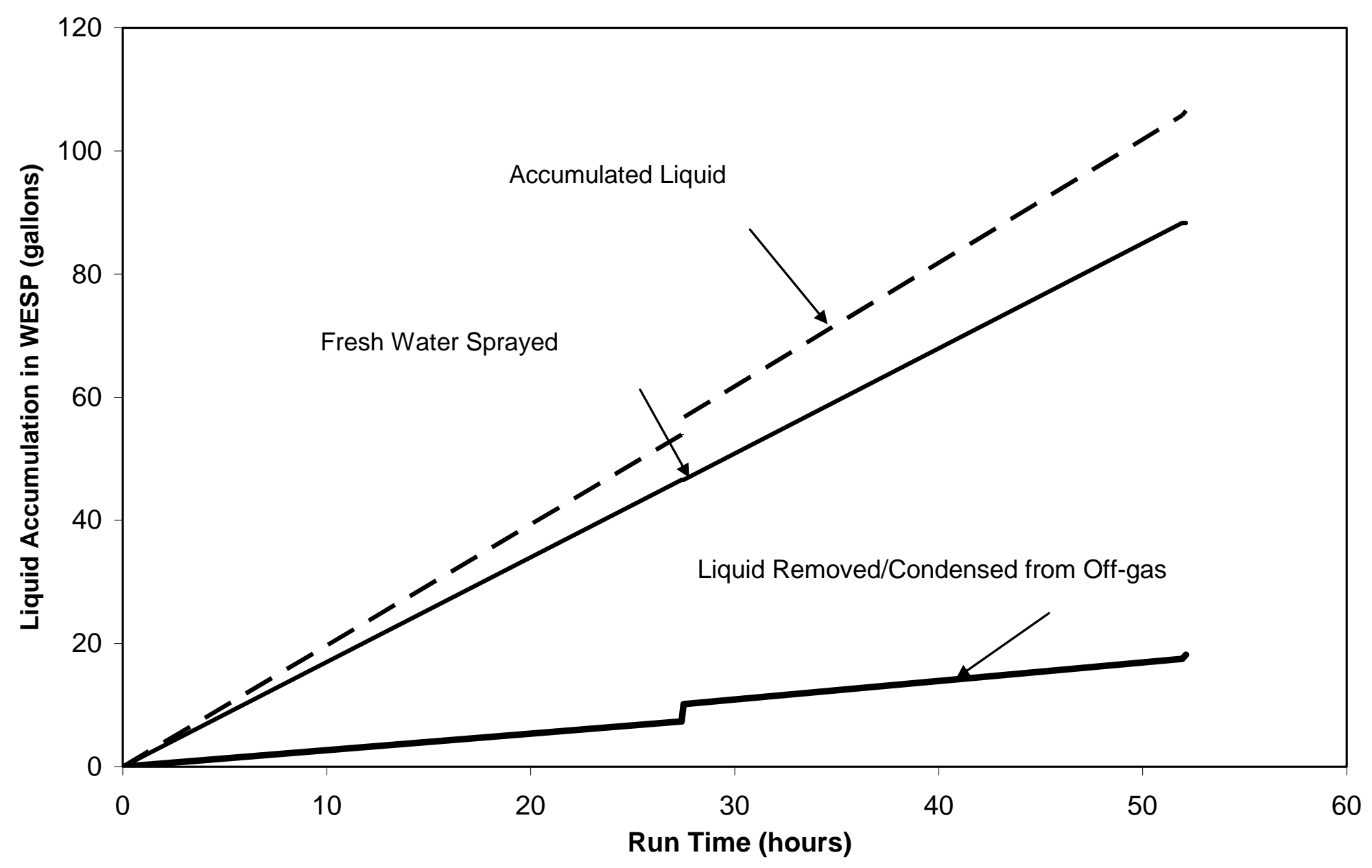

Figure 5.22.a. Accumulated WESP blowdown volume, accumulated fresh spray water, and water removed from off-gas during Test 1. 


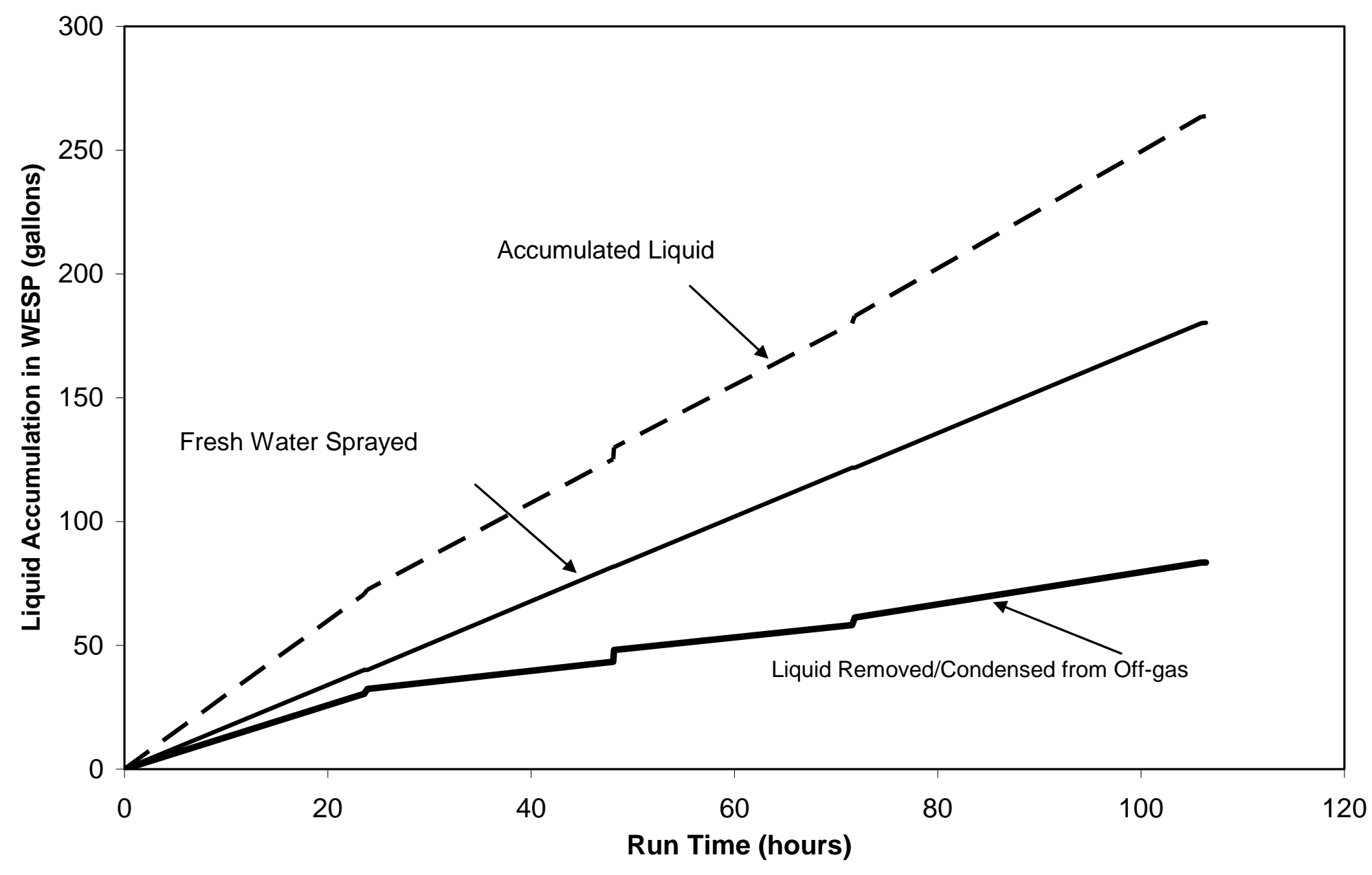

Figure 5.22.b. Accumulated WESP blowdown volume, accumulated fresh spray water, and water removed from off-gas during Tests 2 and 3. 


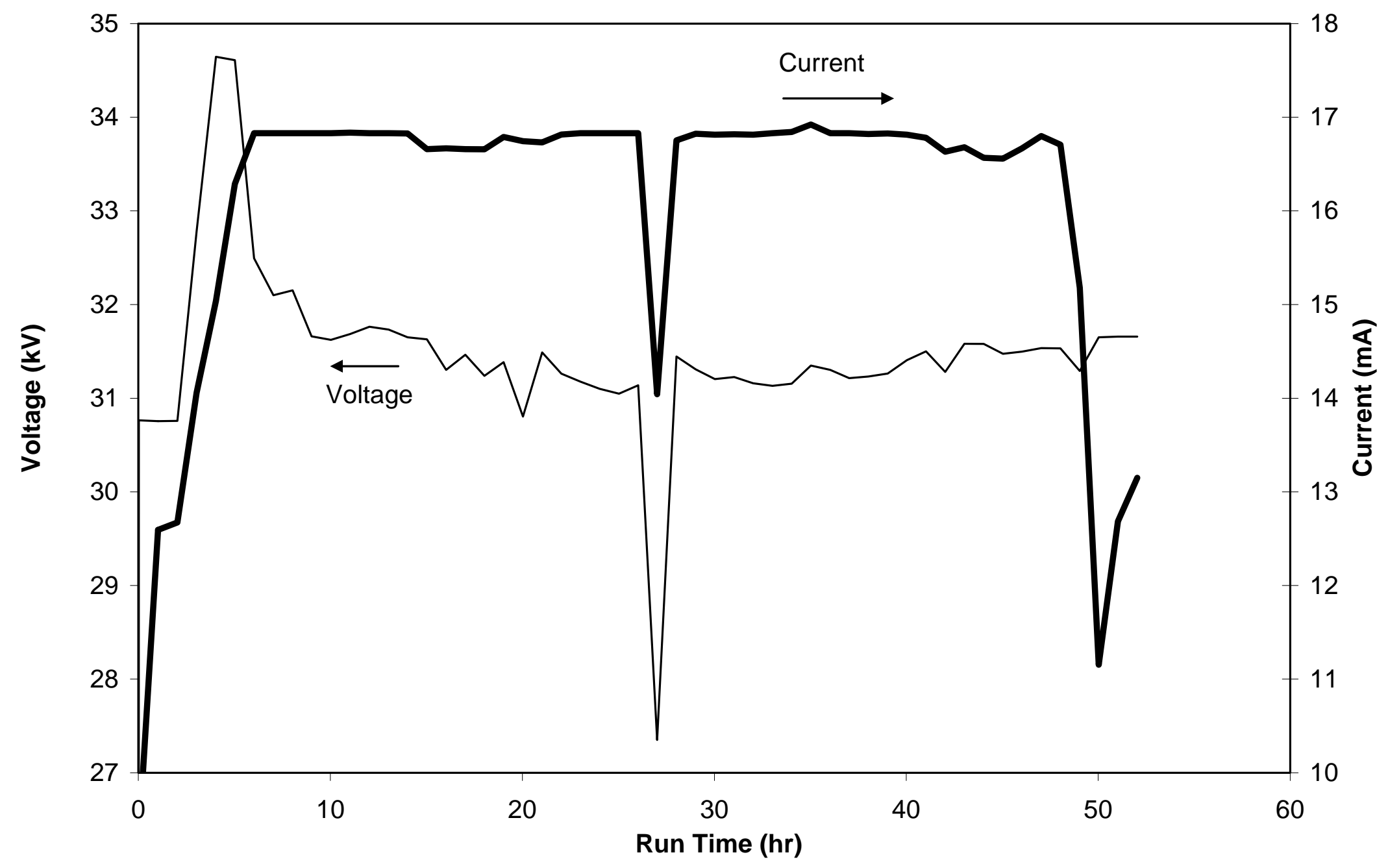

Figure 5.23.a. Voltage and current across the WESP during Test 1. 


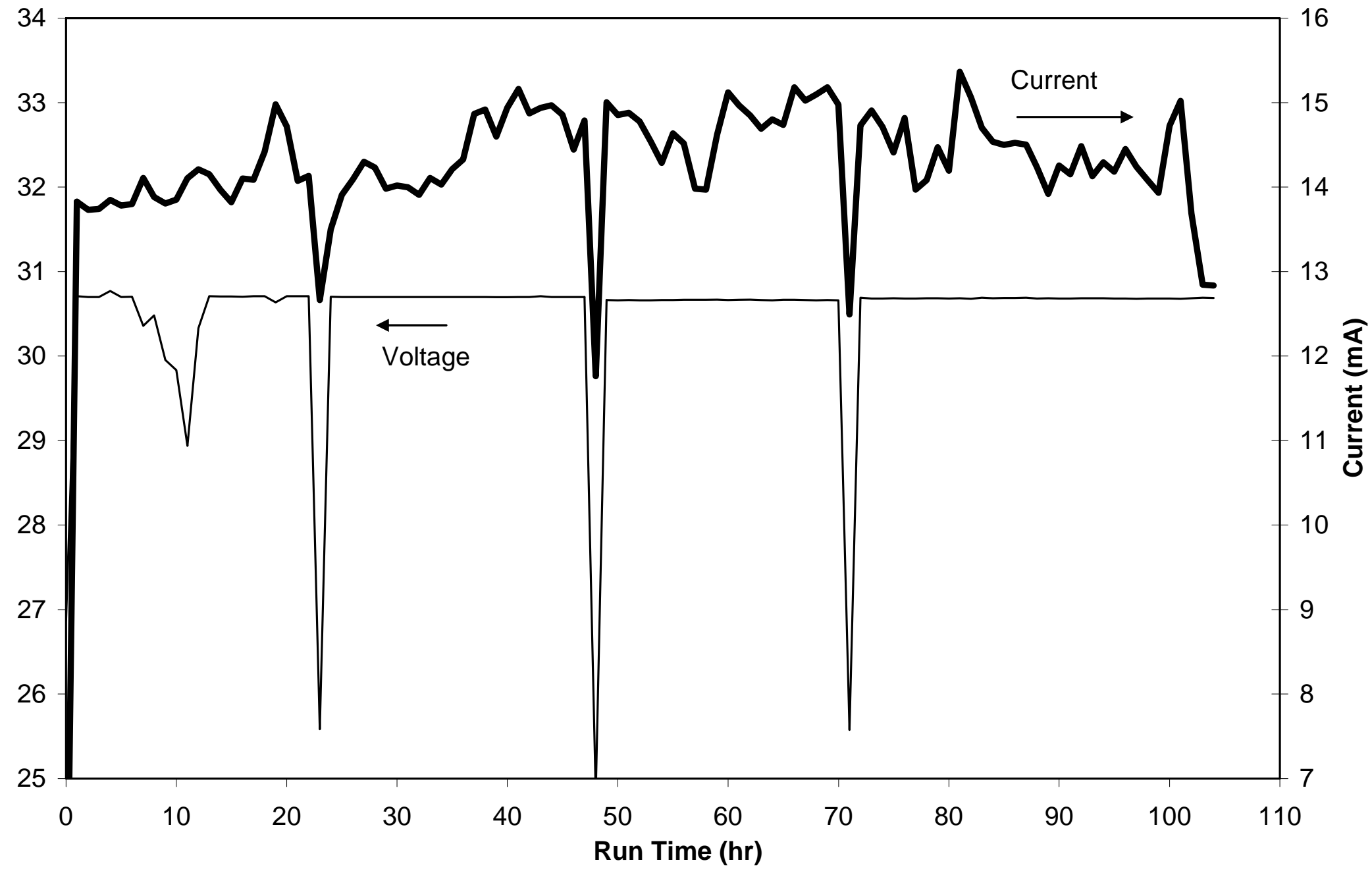

Figure 5.23.b. Voltage and current across the WESP during Tests 2 and 3. 


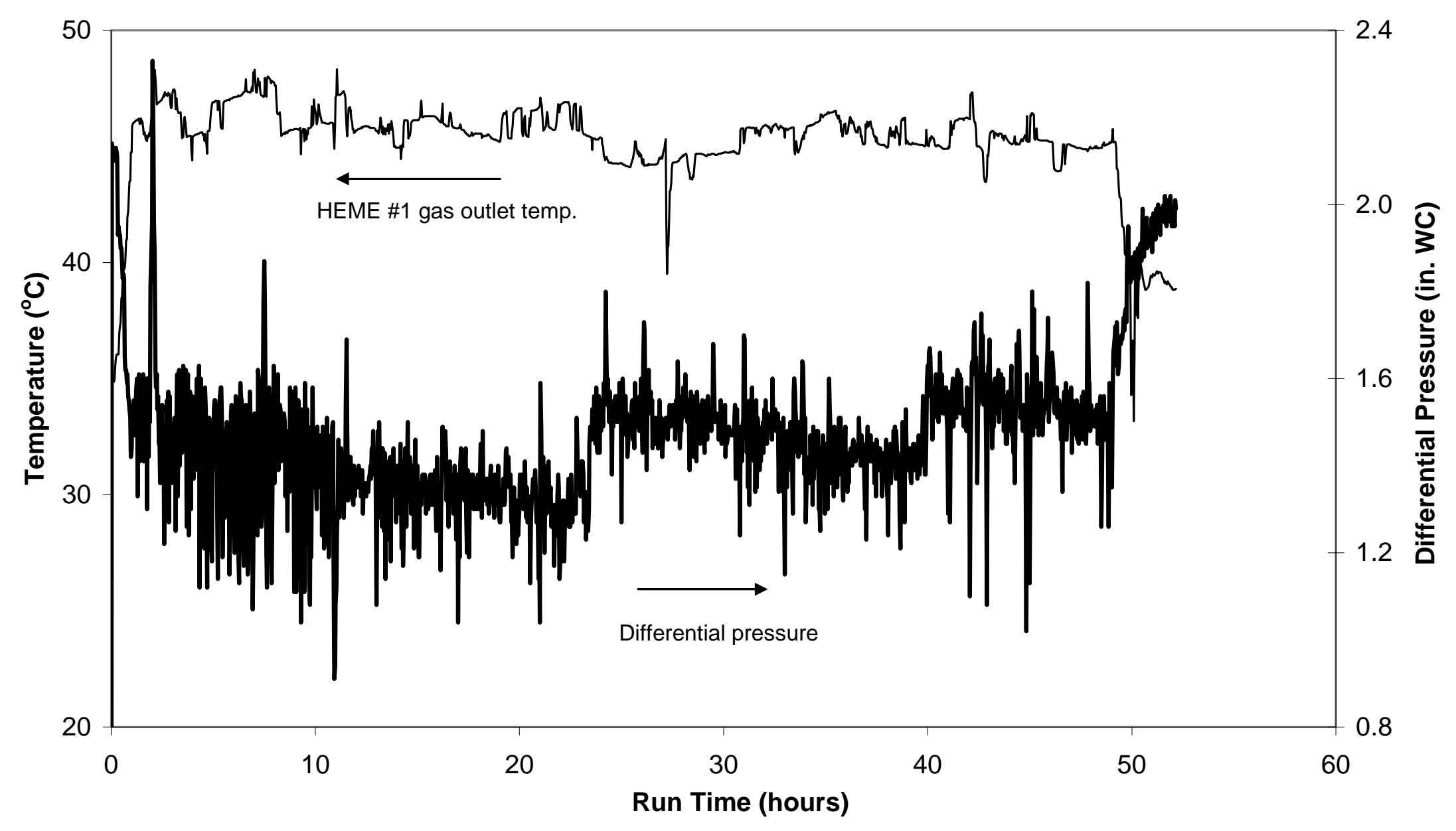

Figure 5.24.a. Outlet gas temperature and differential pressure for HEME \#1 during Test 1. 


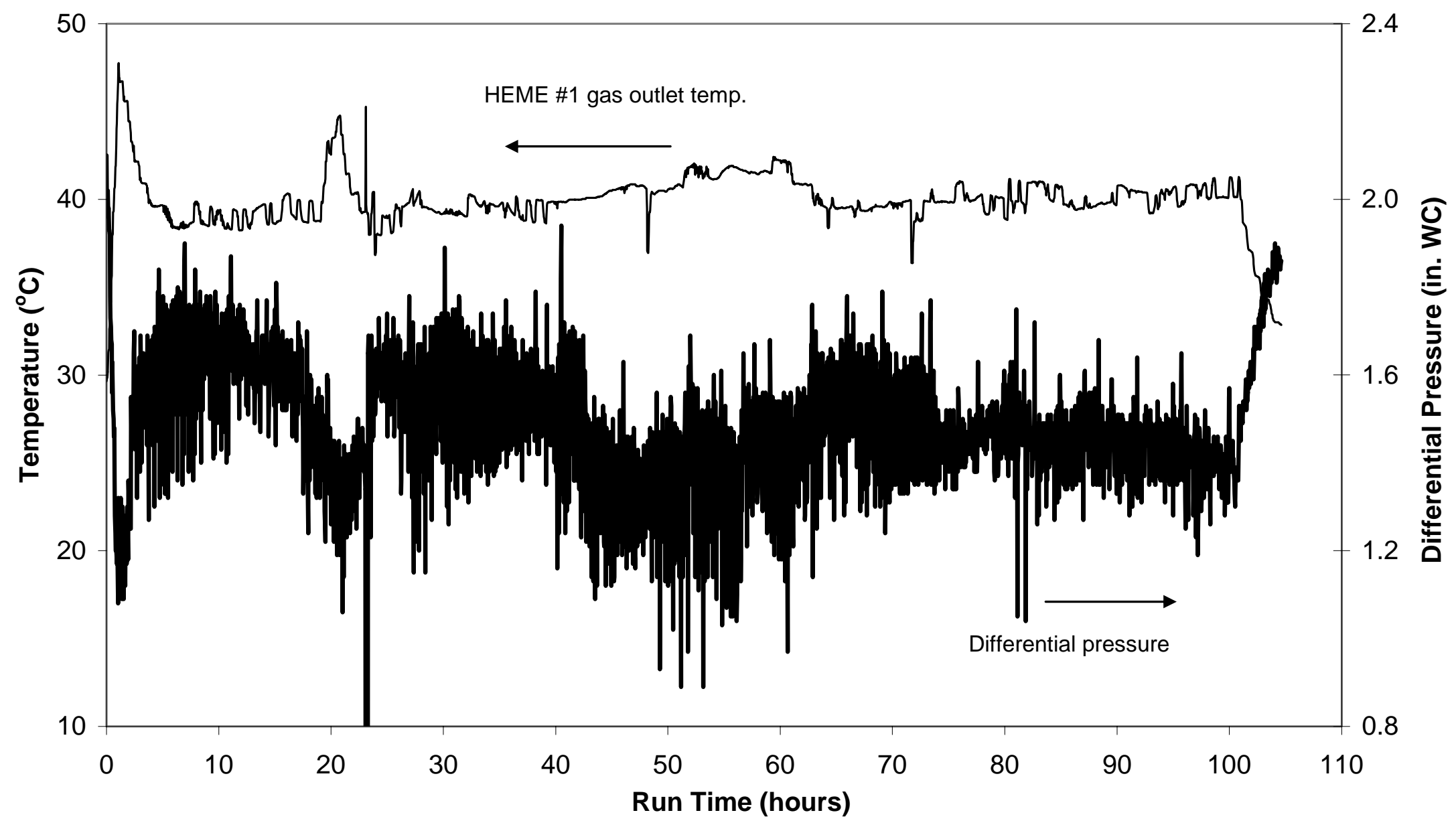

Figure 5.24.b. Outlet gas temperature and differential pressure for HEME \#1 during Tests 2 and 3. 


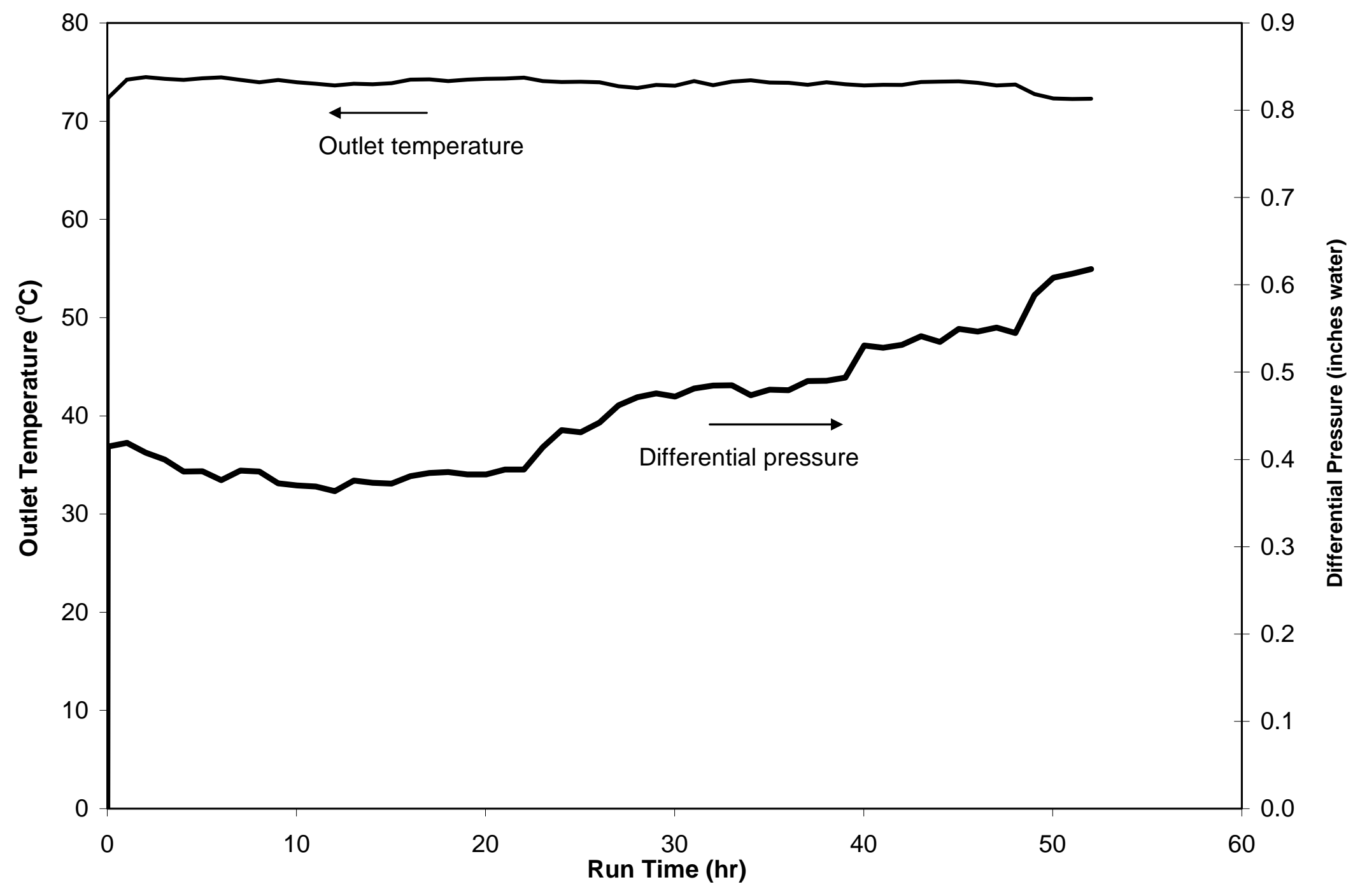

Figure 5.25.a. Outlet temperature and differential pressure for HEPA \#1 (hourly average values) during Test 1. 


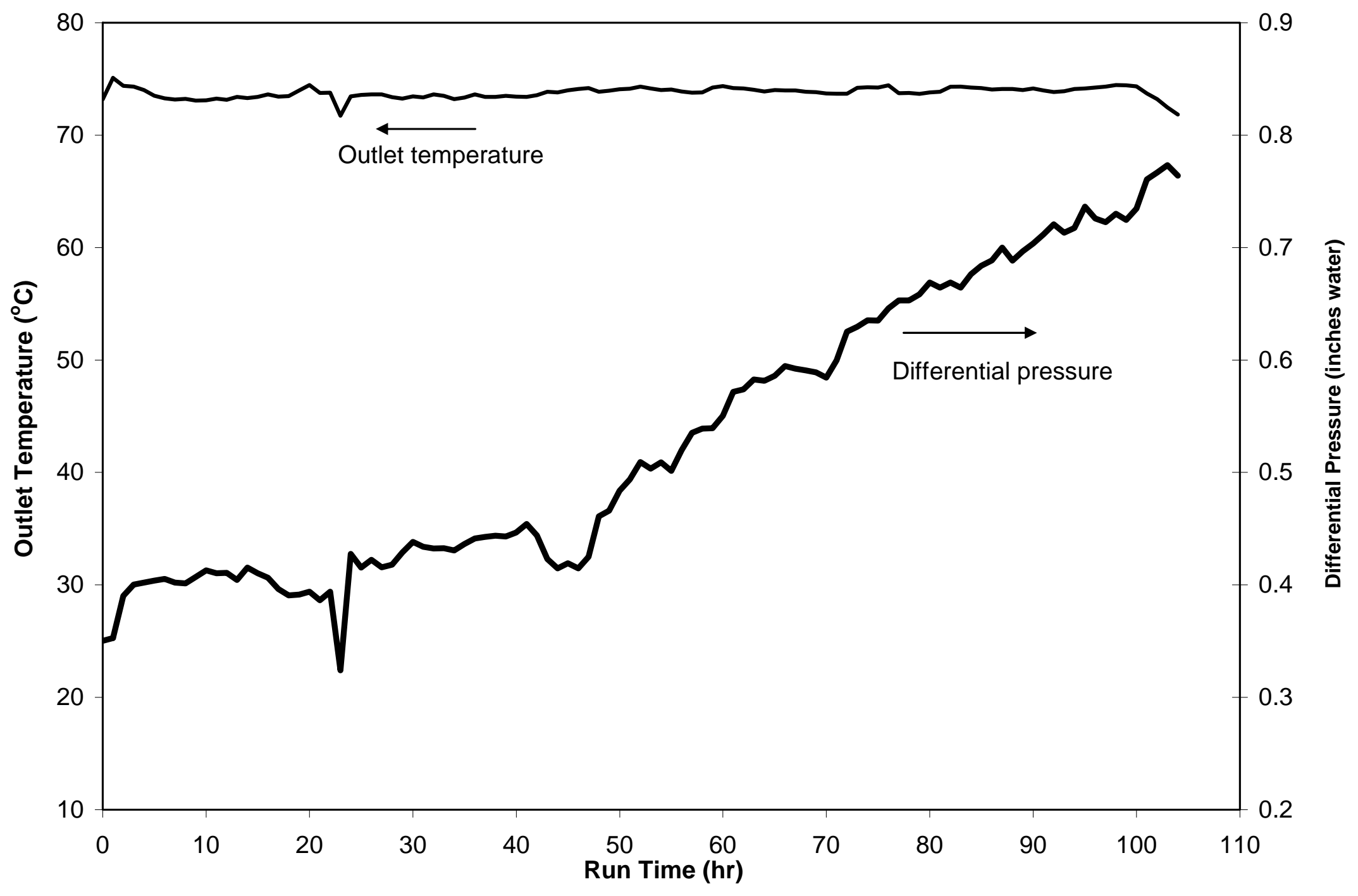

Figure 5.25.b. Outlet temperature and differential pressure for HEPA \#1 (hourly average values) during Tests 2 and 3. 


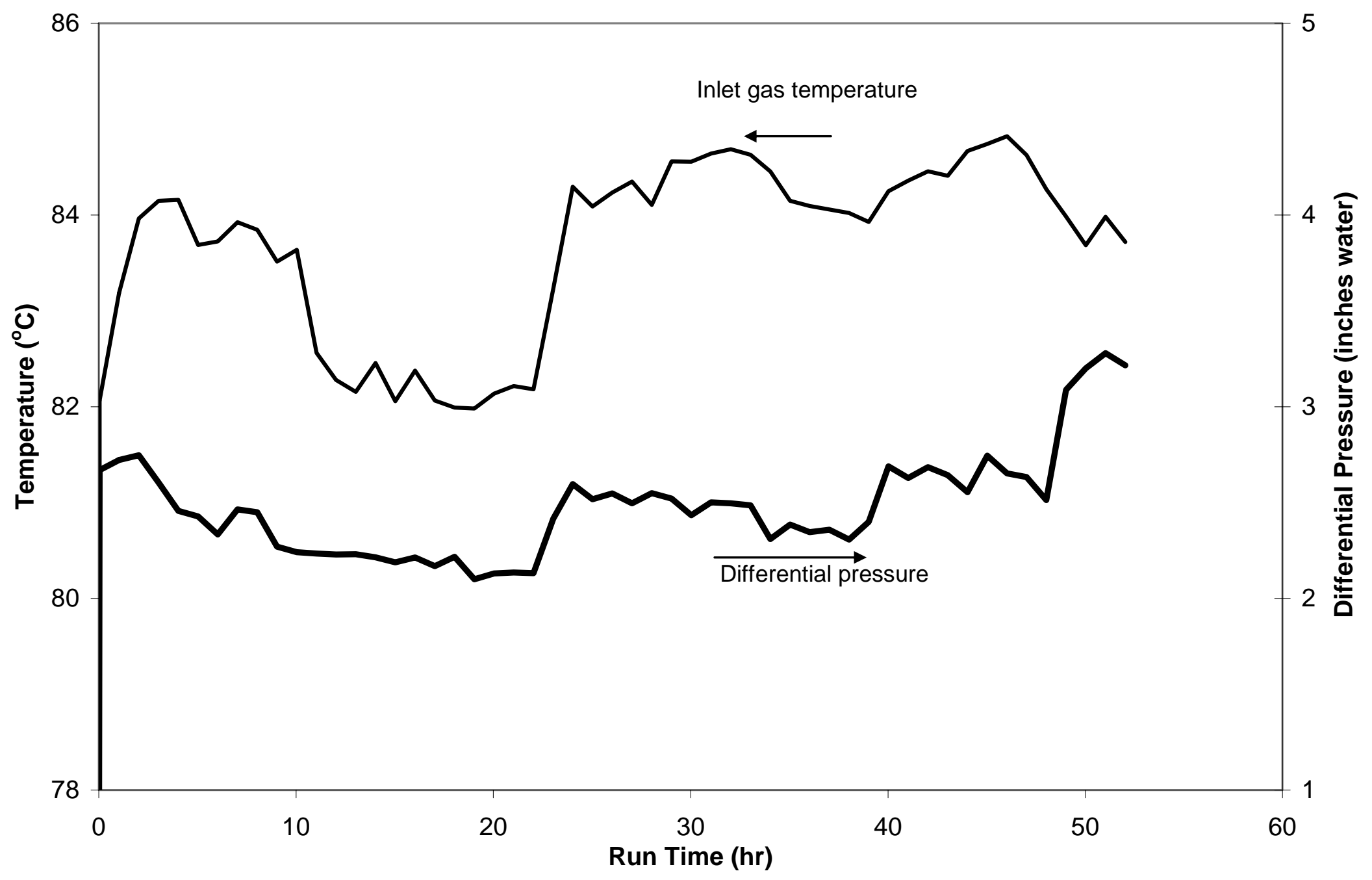

Figure 5.26.a. Inlet gas temperature and differential pressure for PBS (hourly average values) during Test 1. 


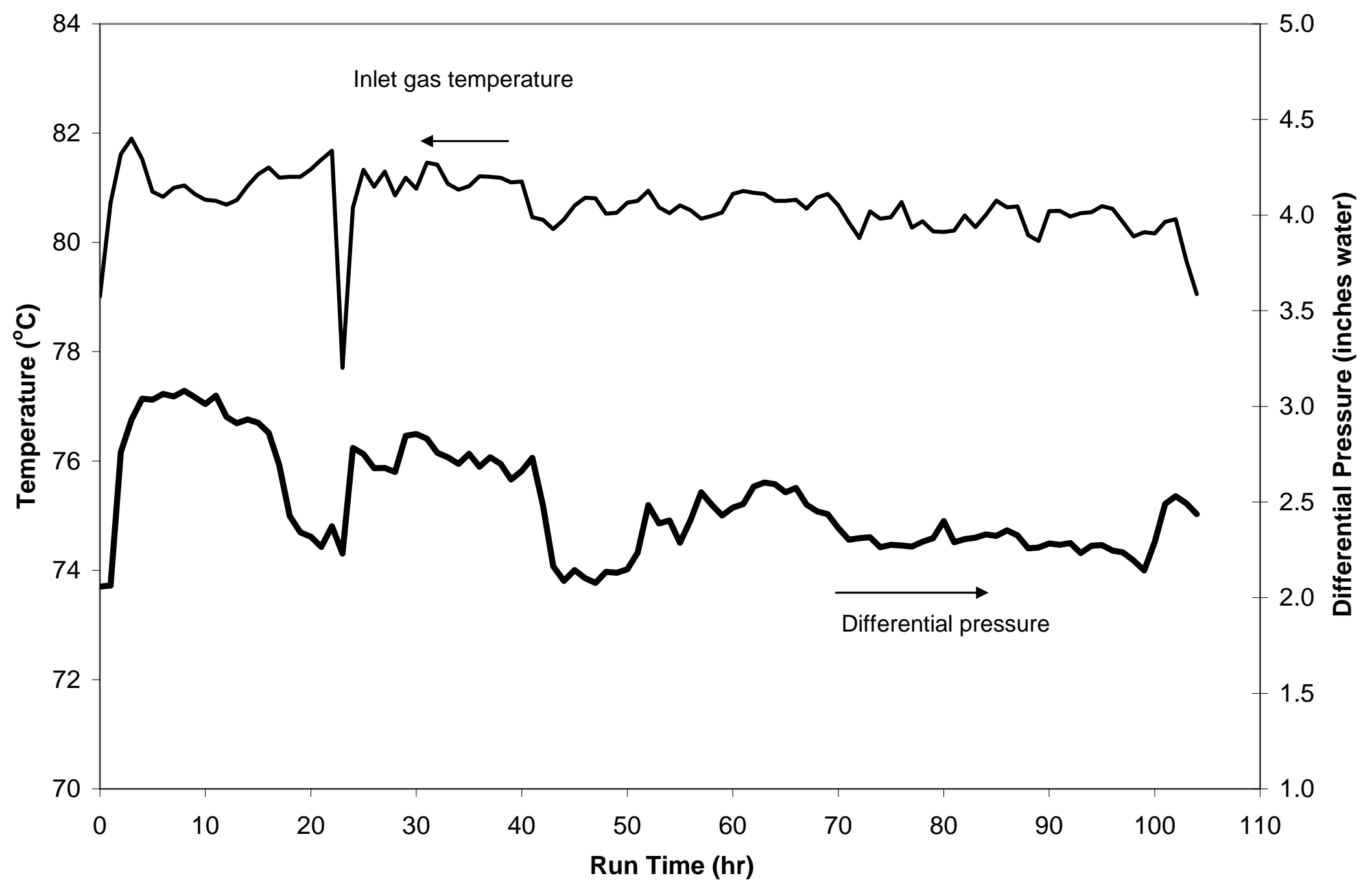

Figure 5.26.b. Inlet gas temperature and differential pressure for PBS (hourly average values) during Tests 2 and 3. 


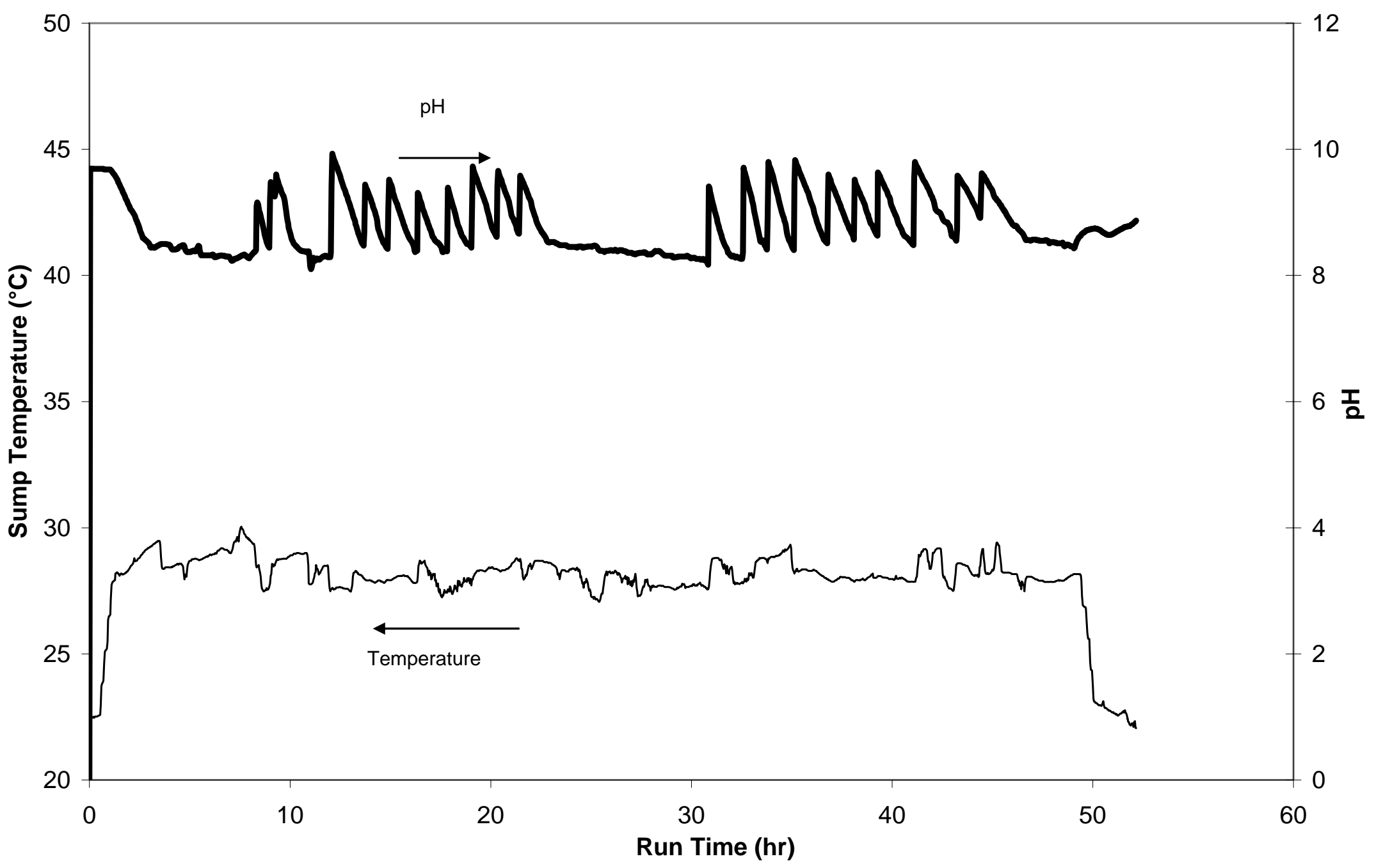

Figure 5.27.a. Sump temperature and pH for PBS (hourly average values) during Test 1. 


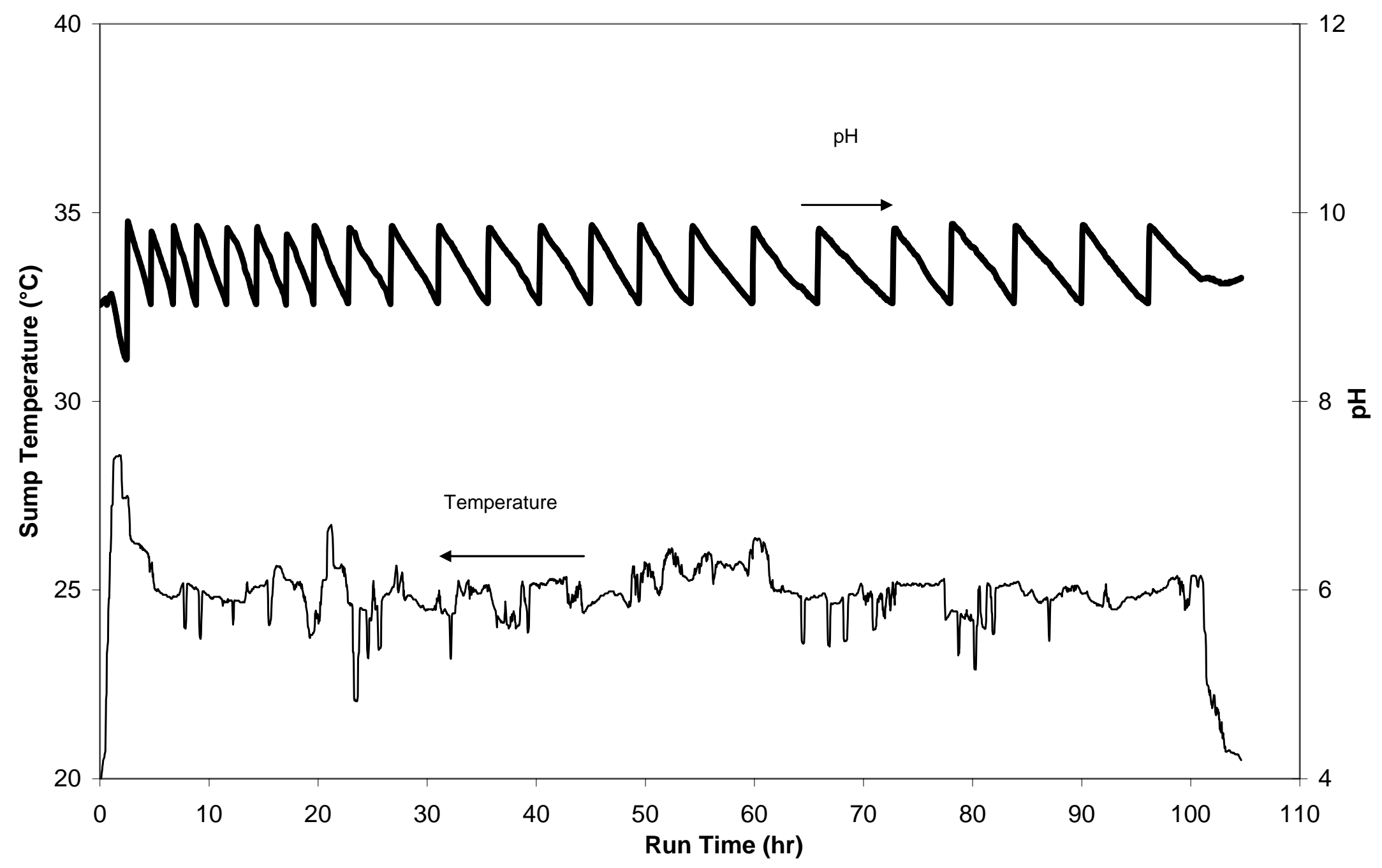

Figure 5.27.b. Sump Temperature and pH for PBS (hourly average values) during Tests 2 and 3. 
The Catholic University of America Vitreous State Laboratory
Melt Rate Enhancement for High Aluminum HLW Glass Formulations

Final Report, VSL-08R1360-1, Rev. 0
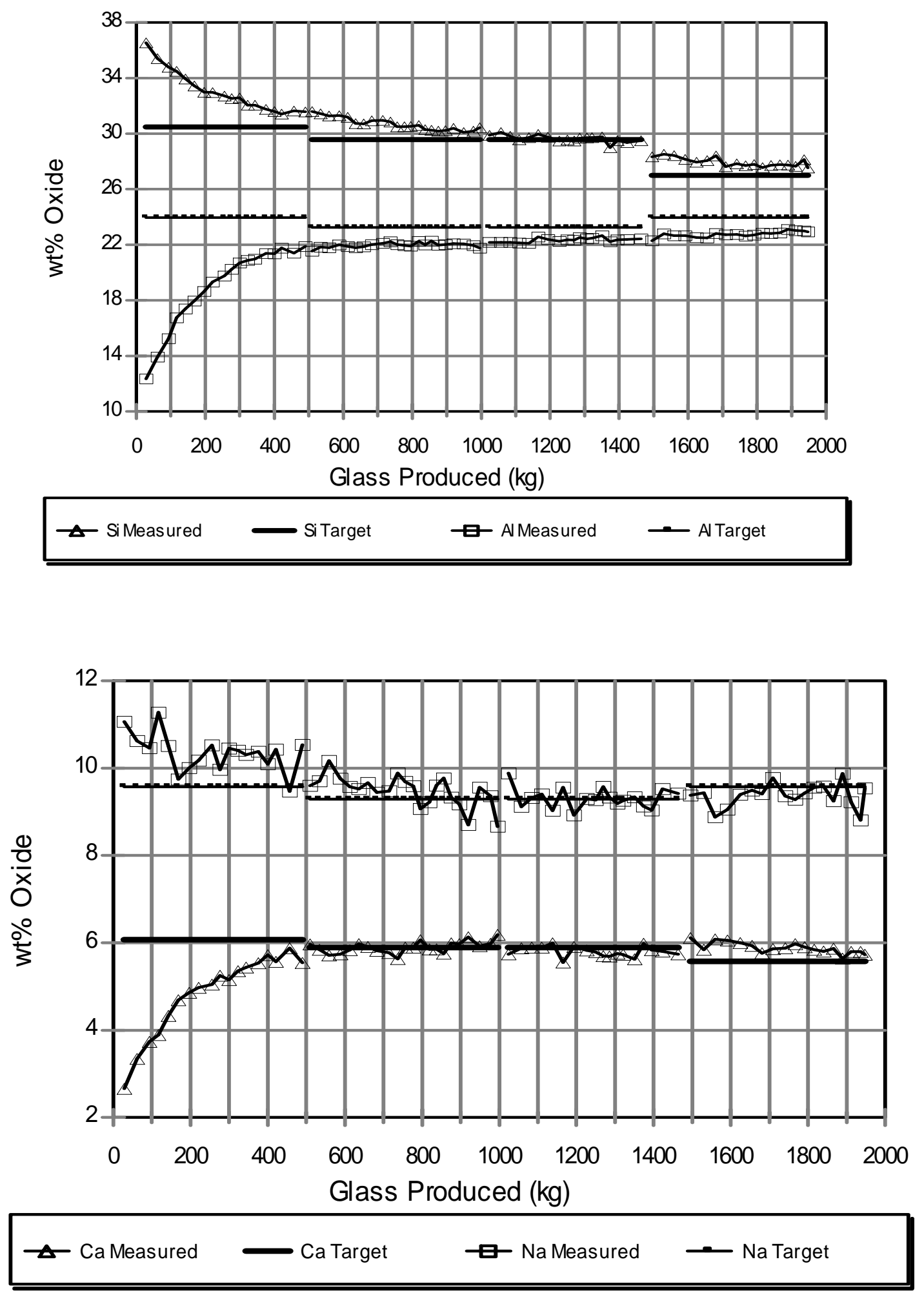

Figure 6.1.a. DM100 product and target glass compositions determined by XRF. 
The Catholic University of America Vitreous State Laboratory
ORP-56292 Rev. 0

Melt Rate Enhancement for High Aluminum HLW Glass Formulations

Final Report, VSL-08R1360-1, Rev. 0
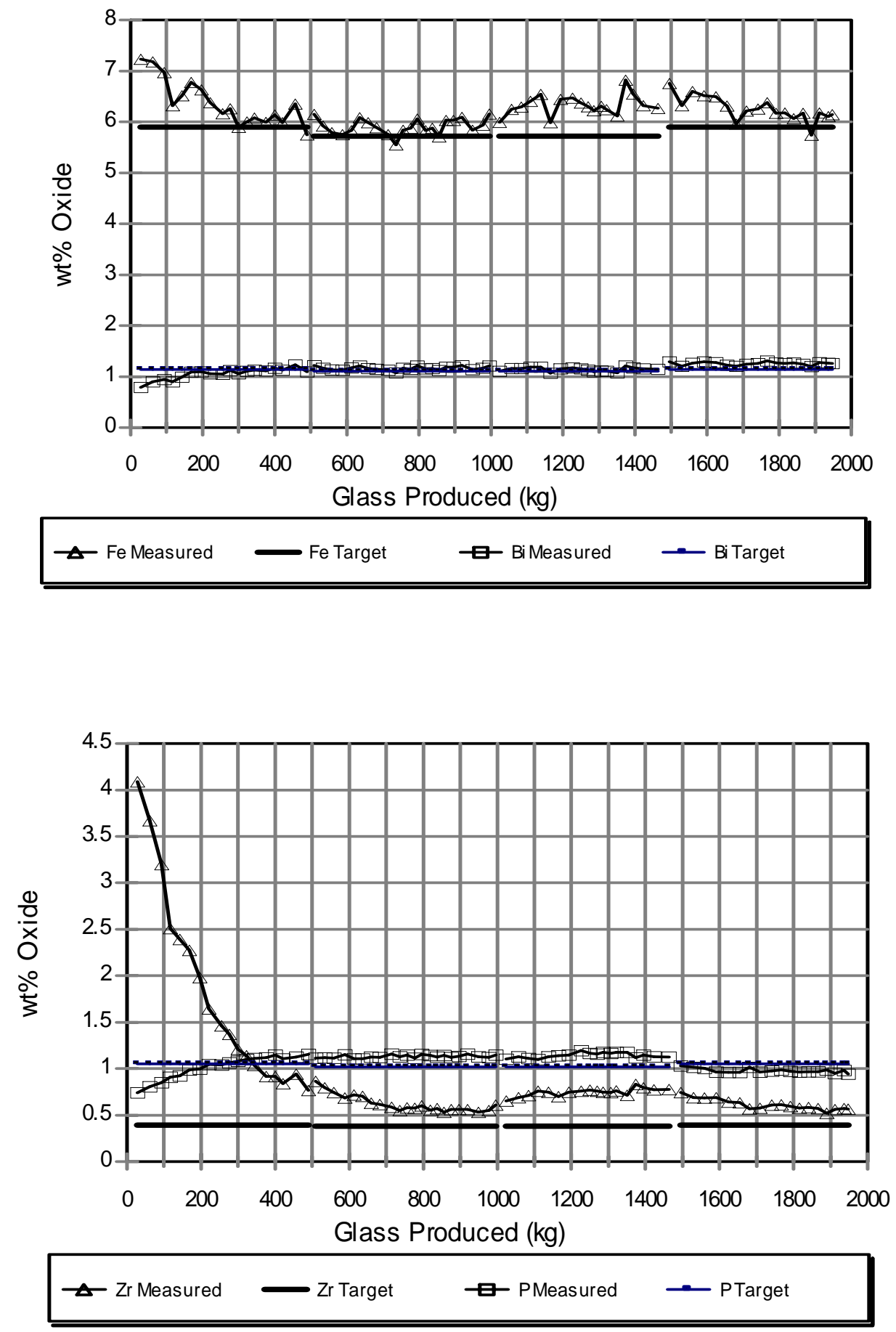

Figure 6.1.b. DM100 product and target glass compositions determined by XRF. 
The Catholic University of America Vitreous State Laboratory
Melt Rate Enhancement for High Aluminum HLW Glass Formulations

Final Report, VSL-08R1360-1, Rev. 0
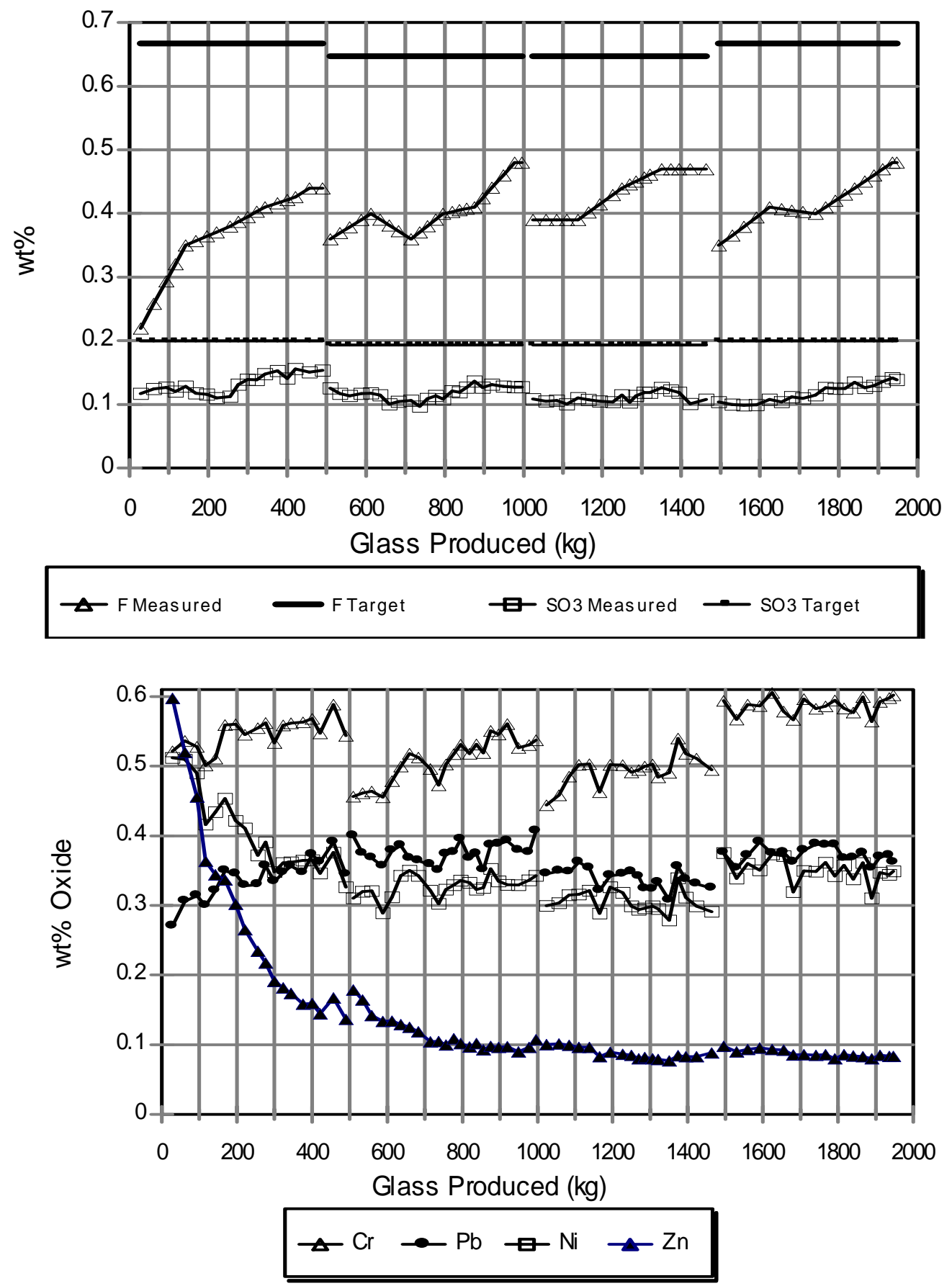

Figure 6.1.c. DM100 product and target glass compositions determined by XRF. 
The Catholic University of America Vitreous State Laboratory
Melt Rate Enhancement for High Aluminum HLW Glass Formulations

Final Report, VSL-08R1360-1, Rev. 0
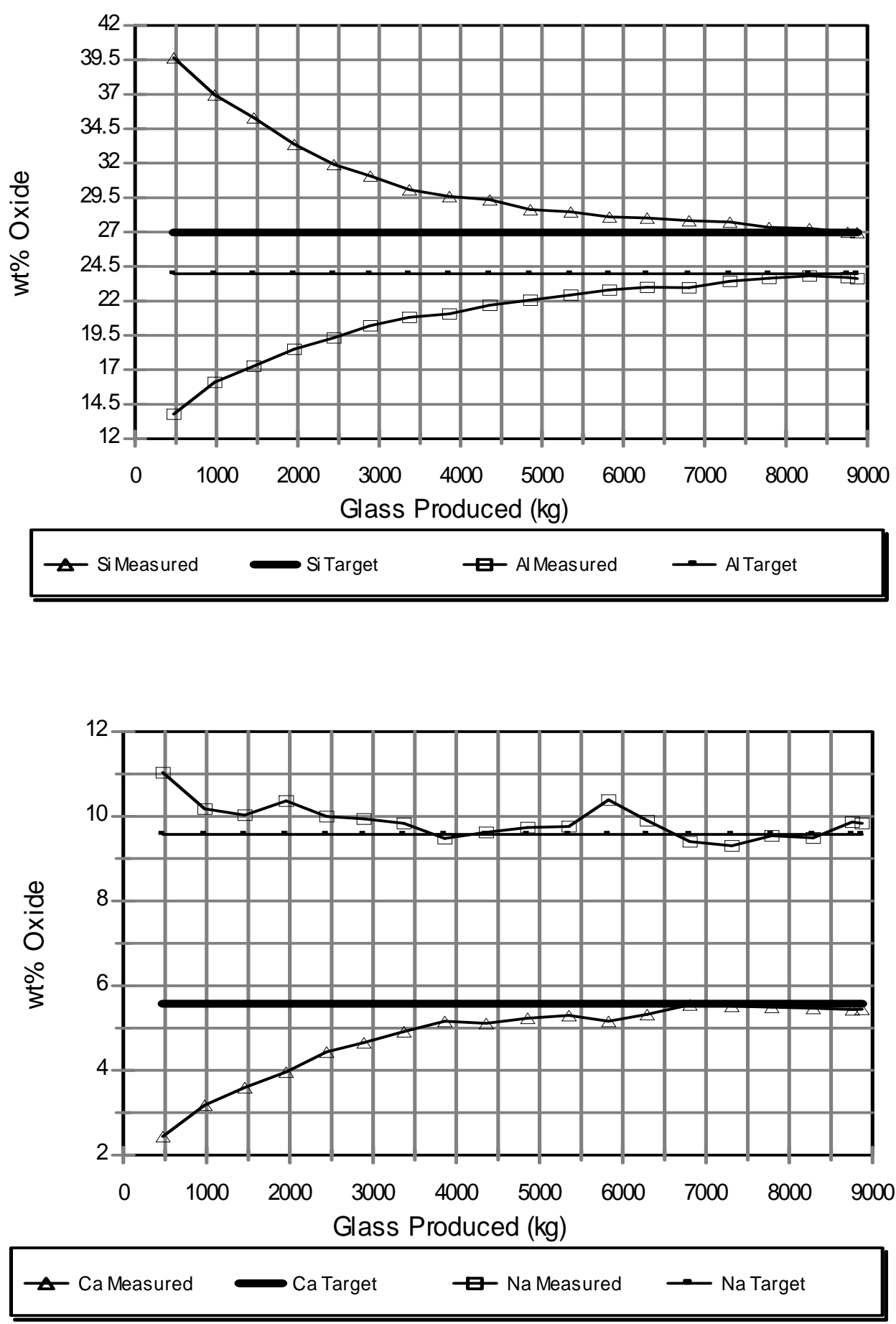

Figure 6.2.a. DM1200 product and target glass compositions determined by XRF. 

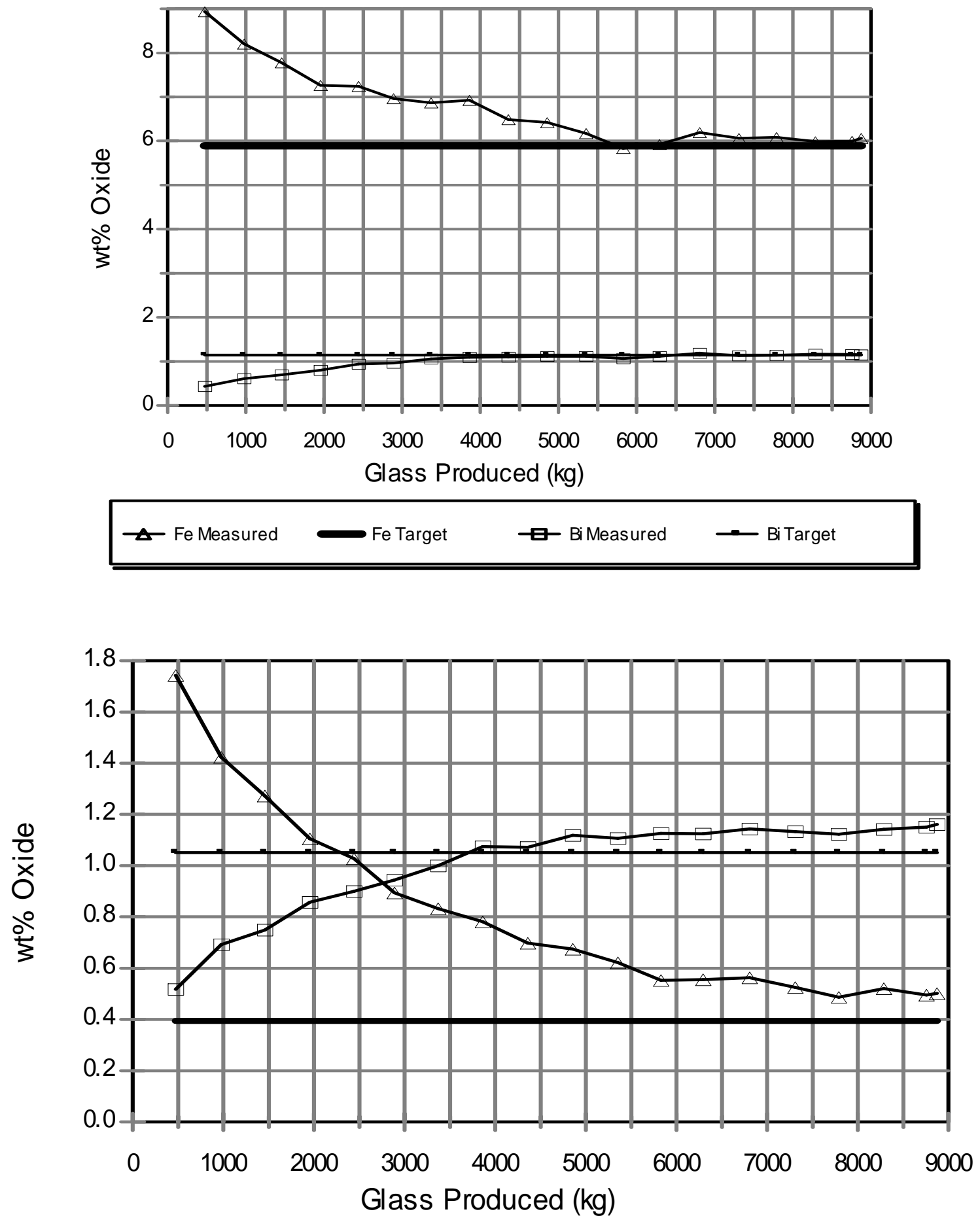

Figure 6.2.b. DM1200 product and target glass compositions determined by XRF. 
The Catholic University of America Vitreous State Laboratory
Melt Rate Enhancement for High Aluminum HLW Glass Formulations

Final Report, VSL-08R1360-1, Rev. 0
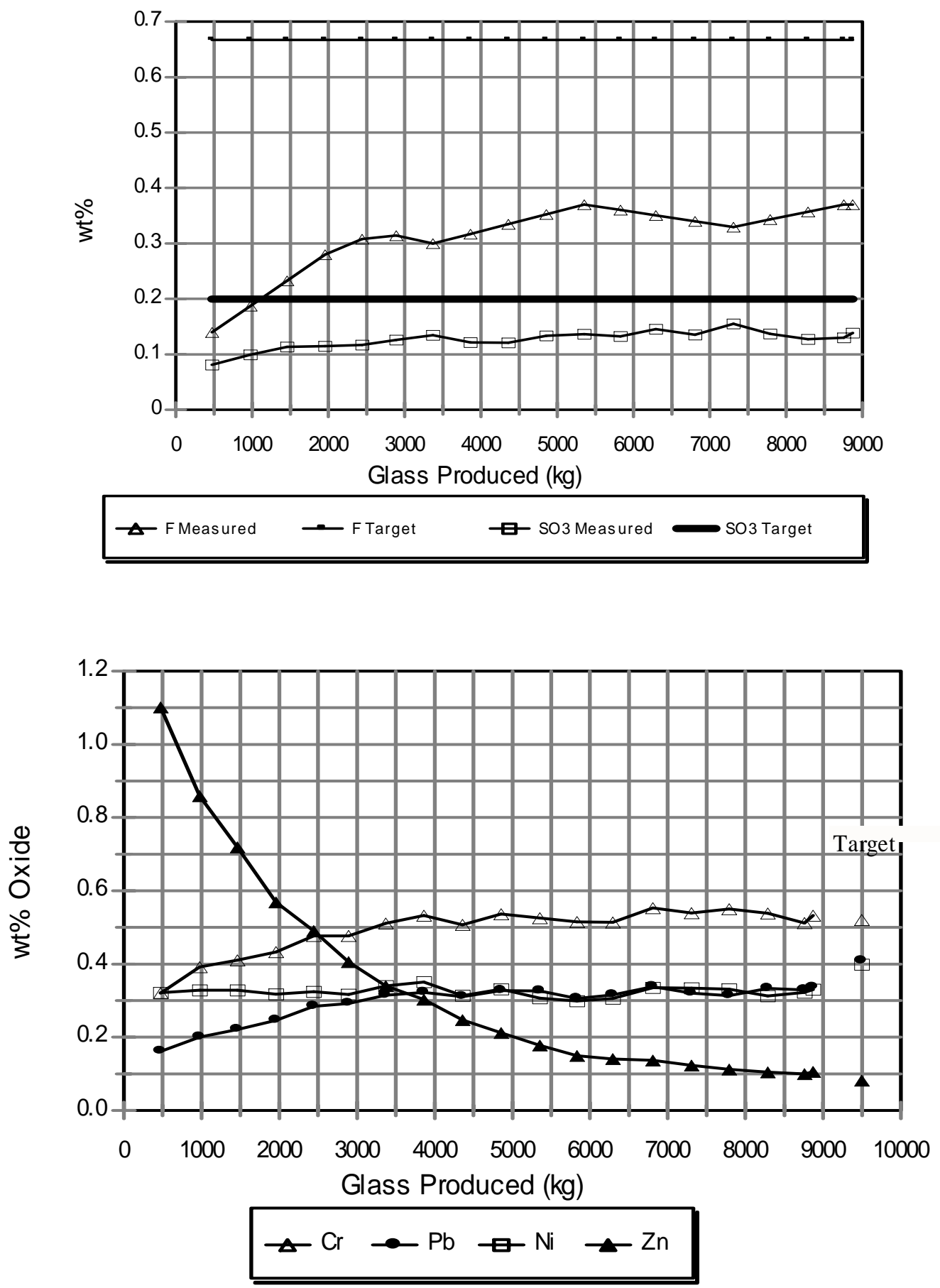

Figure 6.2.c. DM1200 product and target glass compositions determined by XRF. 
ORP-56292 Rev. 0

The Catholic University of America Vitreous State Laboratory
Melt Rate Enhancement for High Aluminum HLW Glass Formulations Final Report, VSL-08R1360-1, Rev. 0

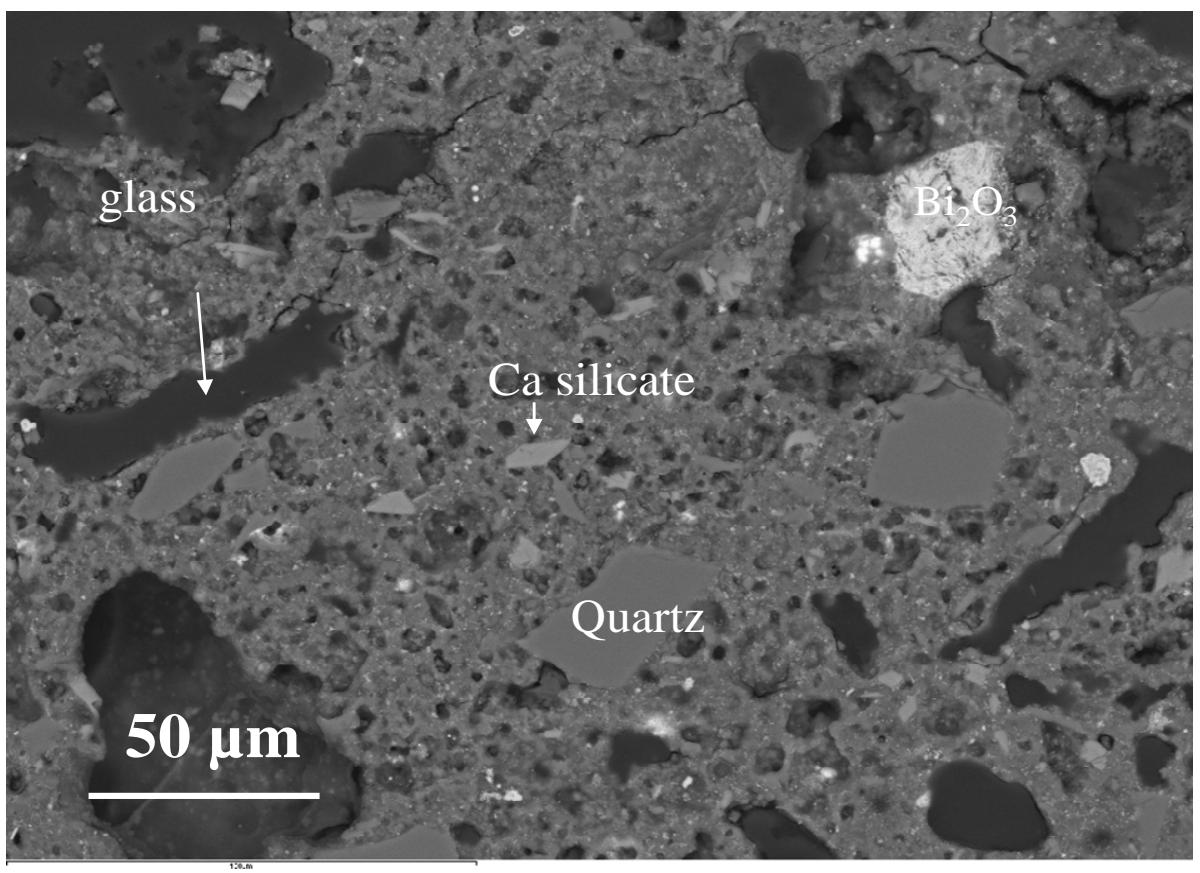

Backscattered electron image of a piece of cold cap sample (BLZ-O-37A)

Figure 6.3.a. SEM image of cold cap sample from DM100 Test 8. 
The Catholic University of America Vitreous State Laboratory
Melt Rate Enhancement for High Aluminum HLW Glass Formulations Final Report, VSL-08R1360-1, Rev. 0

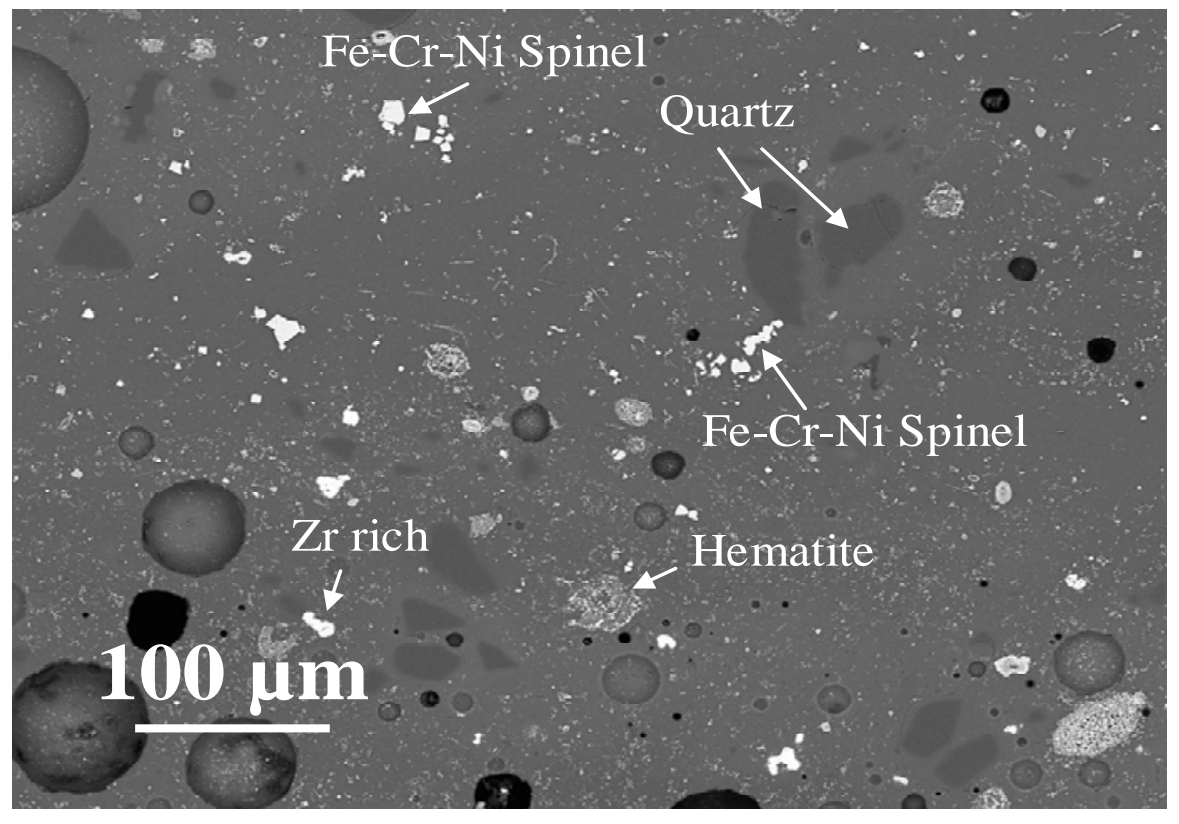

Backscattered electron image of cold cap sample (BLZ-O-35A)

Figure 6.3.b. SEM image of cold cap sample from DM100 Test 8. 
The Catholic University of America Vitreous State Laboratory
Melt Rate Enhancement for High Aluminum HLW Glass Formulations Final Report, VSL-08R1360-1, Rev. 0

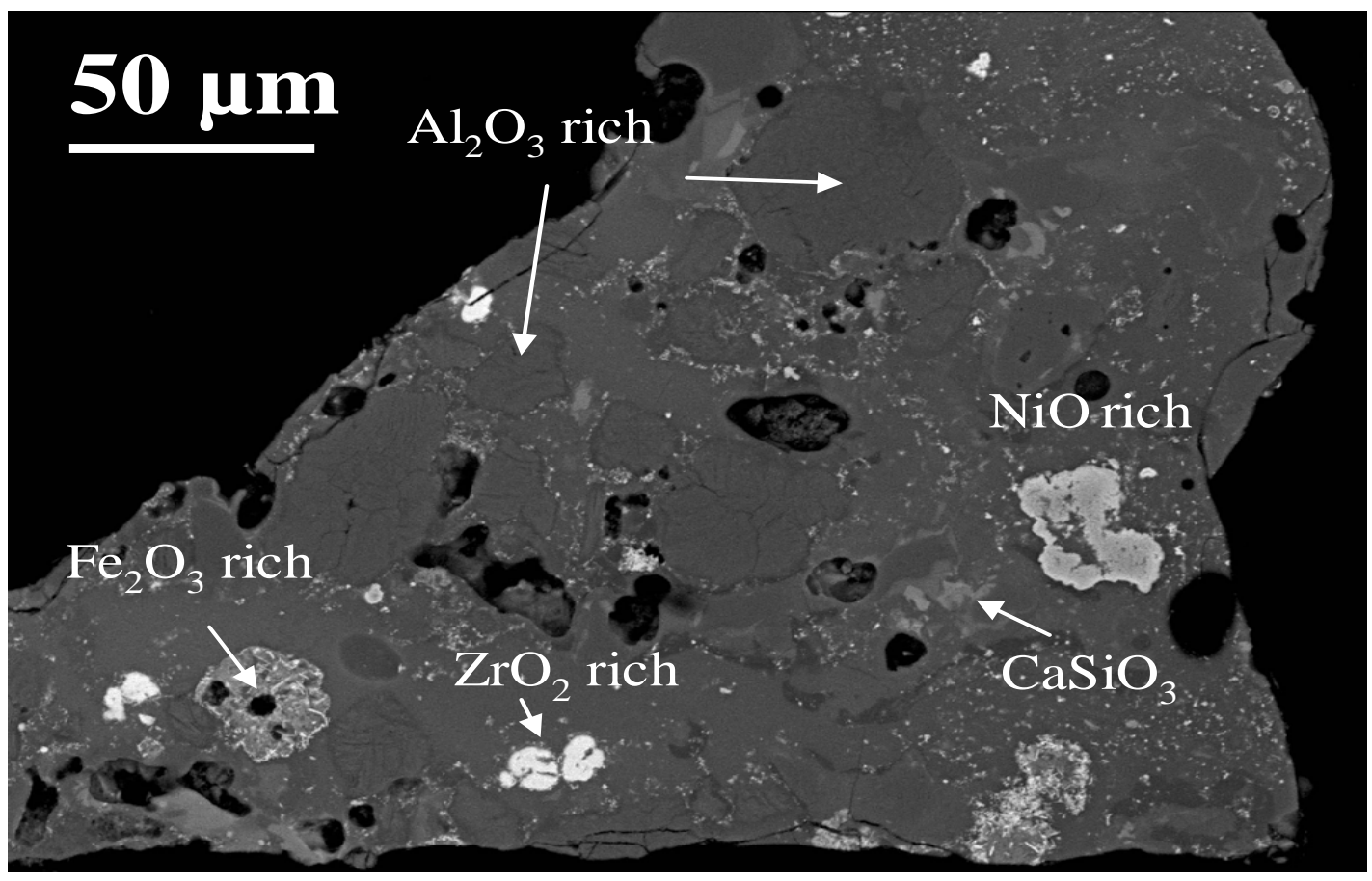

Backscattered electron image of the cold cap sample (O-12J-106A)

Figure 6.4. SEM image of cold cap sample from DM1200 Test 1. 
The Catholic University of America Vitreous State Laboratory
Melt Rate Enhancement for High Aluminum HLW Glass Formulations Final Report, VSL-08R1360-1, Rev. 0
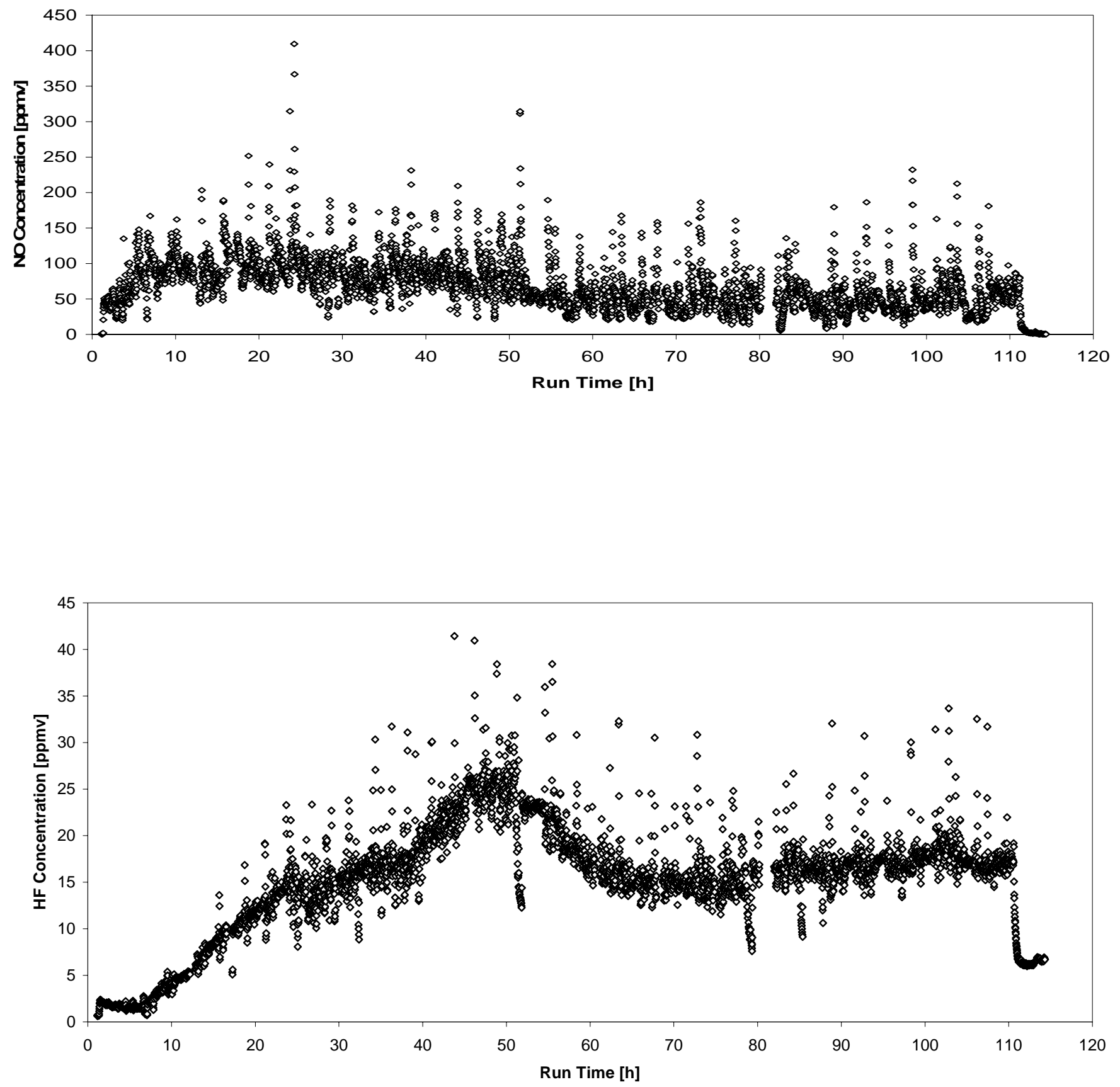

Figure 7.1. FTIR monitored NO and HF emissions during DM100 Tests 1 and 2. 
The Catholic University of America Vitreous State Laboratory
Melt Rate Enhancement for High Aluminum HLW Glass Formulations Final Report, VSL-08R1360-1, Rev. 0
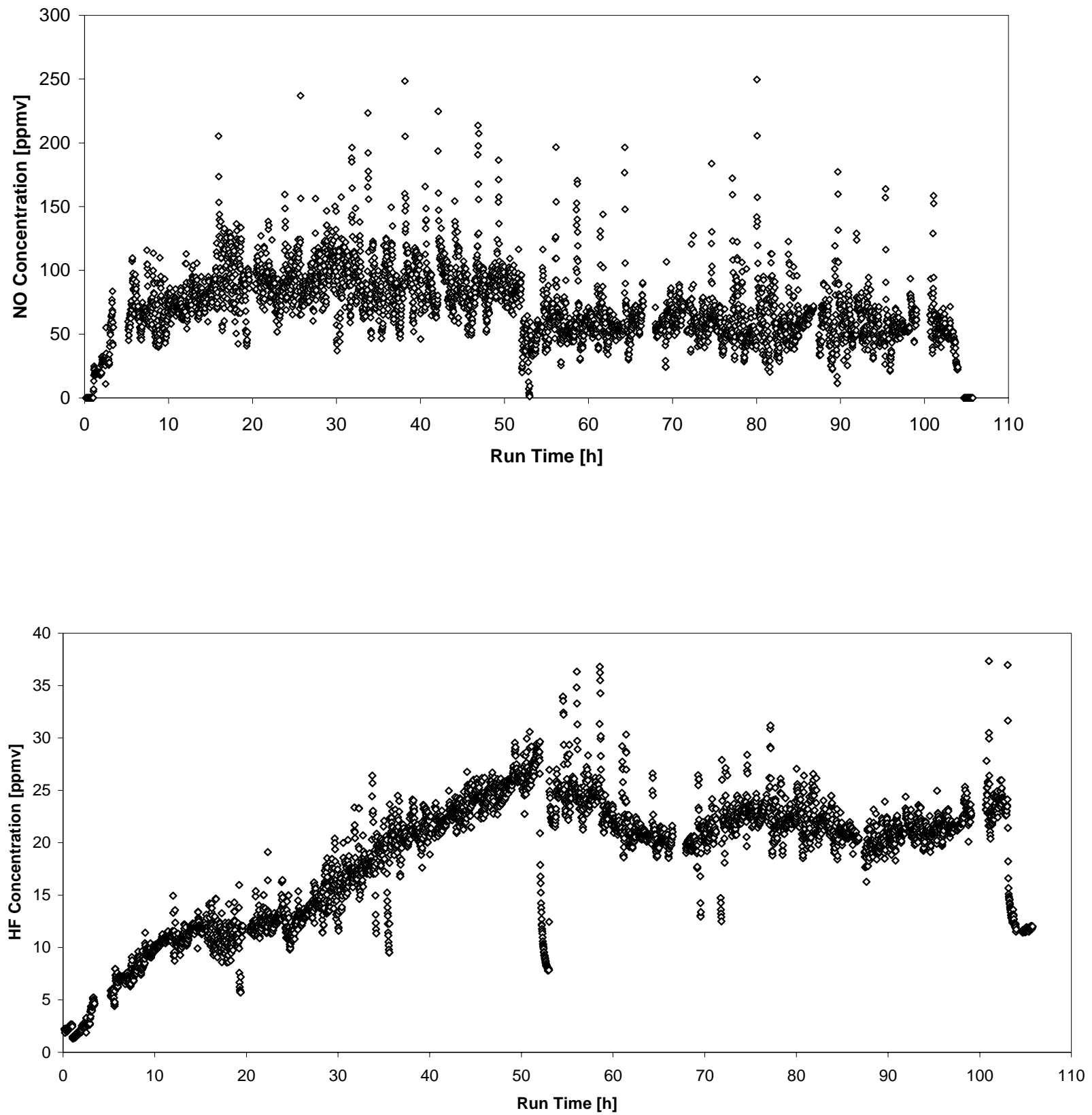

Figure 7.2. FTIR monitored NO and HF emissions during DM100 Tests 3 and 4. 

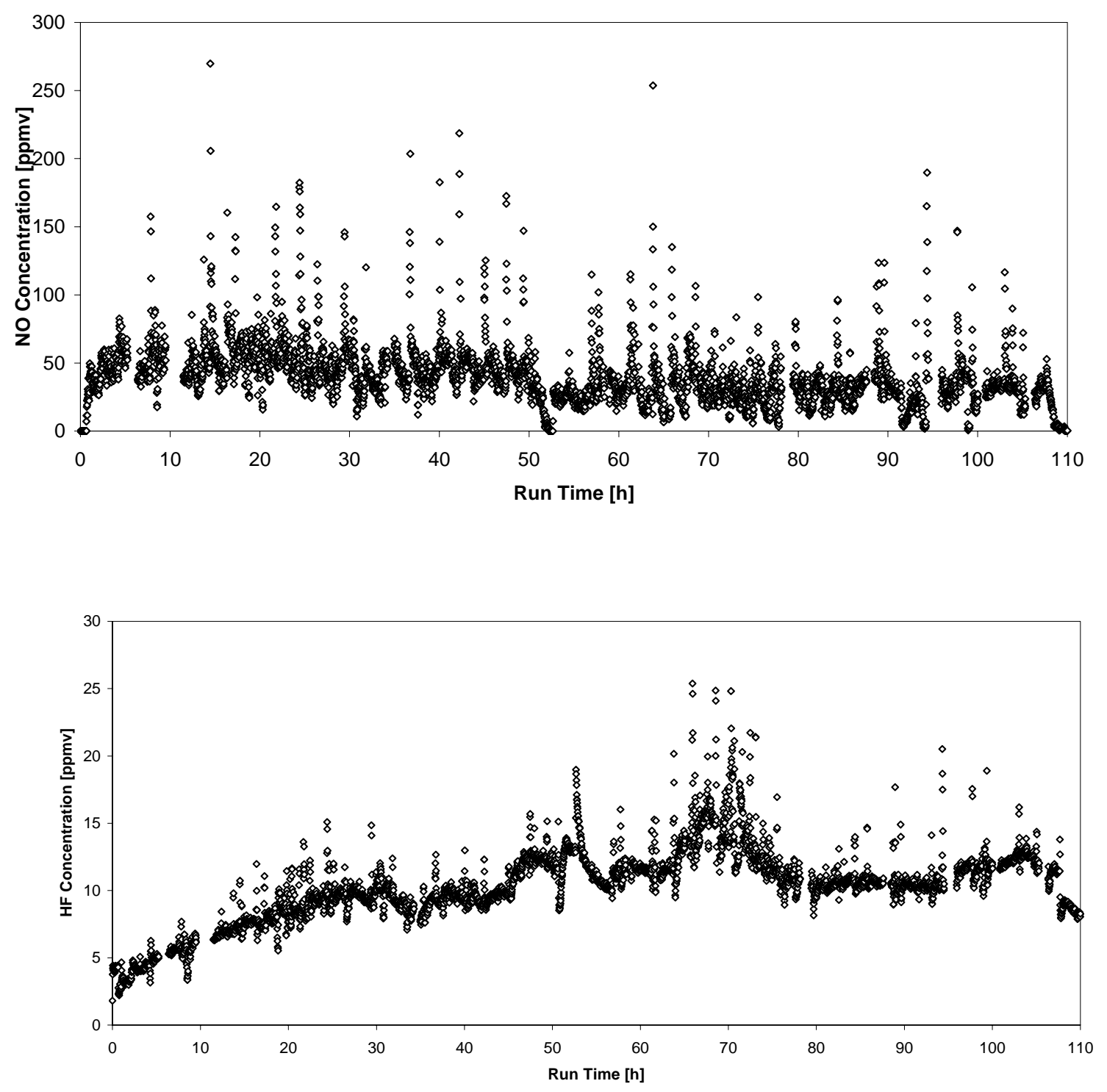

Figure 7.3. FTIR monitored NO and HF emissions during DM100 Tests 5 and 6. 
ORP-56292 Rev. 0

The Catholic University of America Vitreous State Laboratory
Melt Rate Enhancement for High Aluminum HLW Glass Formulations Final Report, VSL-08R1360-1, Rev. 0
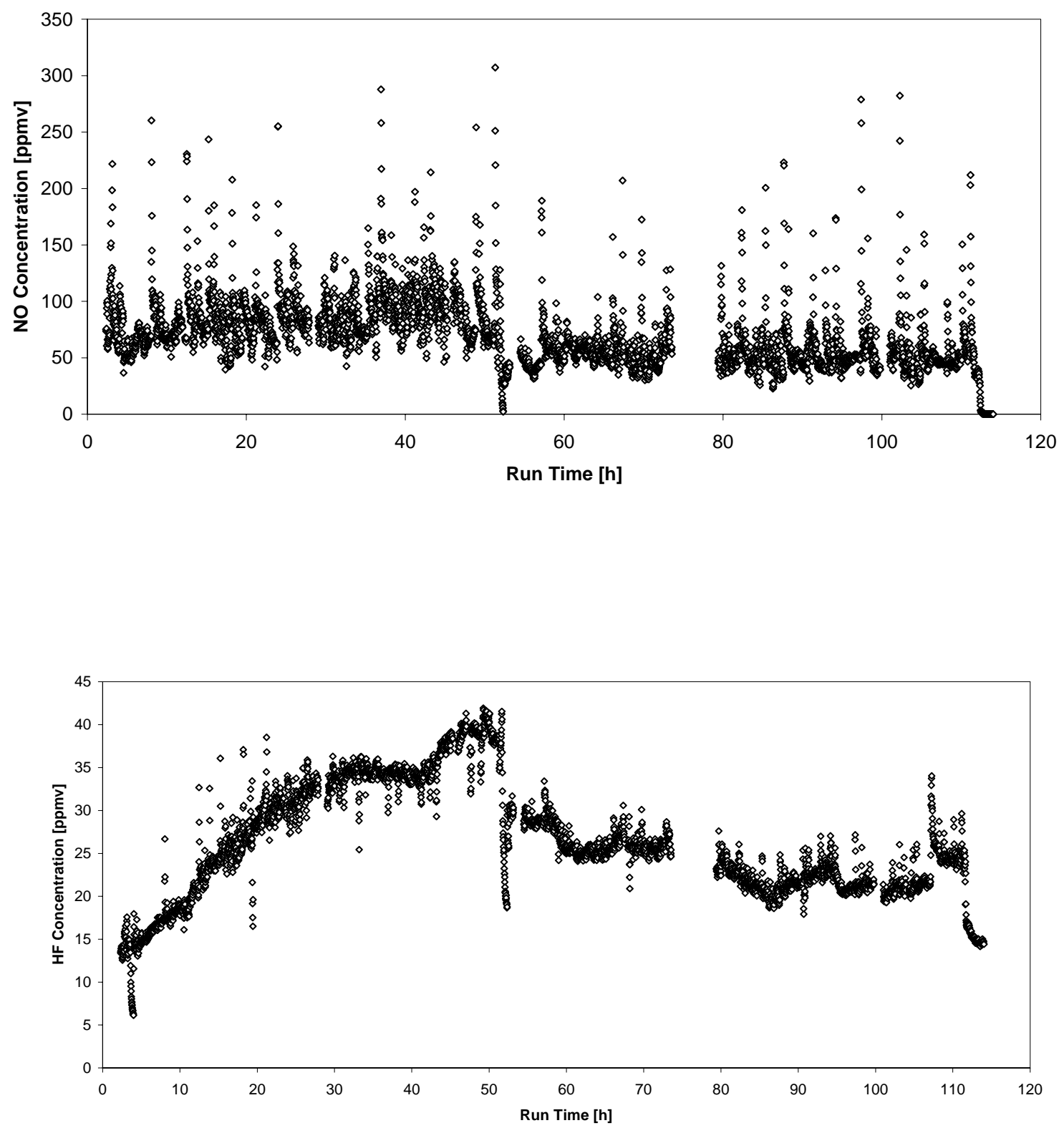

Figure 7.4. FTIR monitored NO and HF emissions during DM100 Tests 7 and 8. 


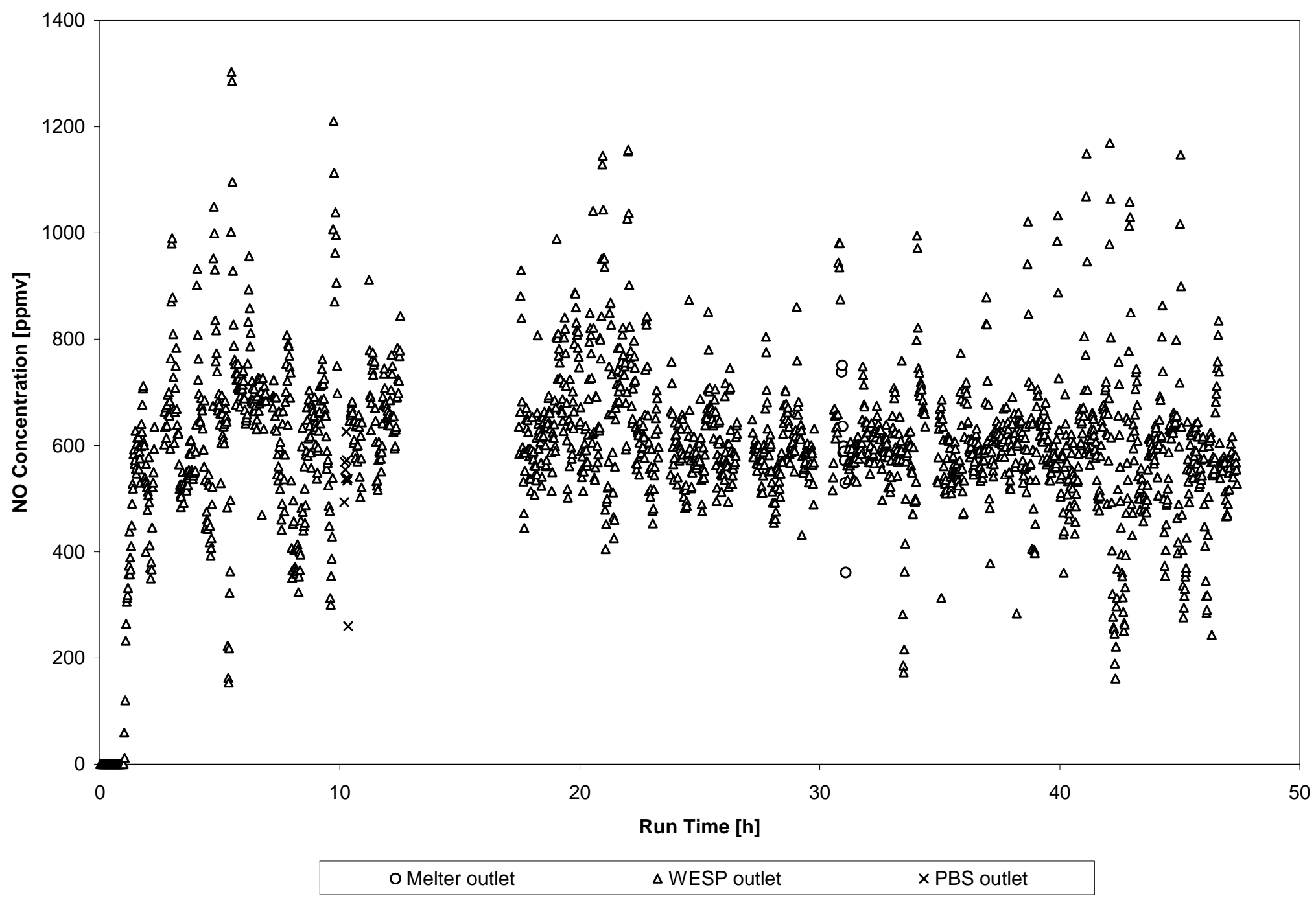

Figure 7.5. FTIR Monitored NO emissions during DM1200 Test 1. 


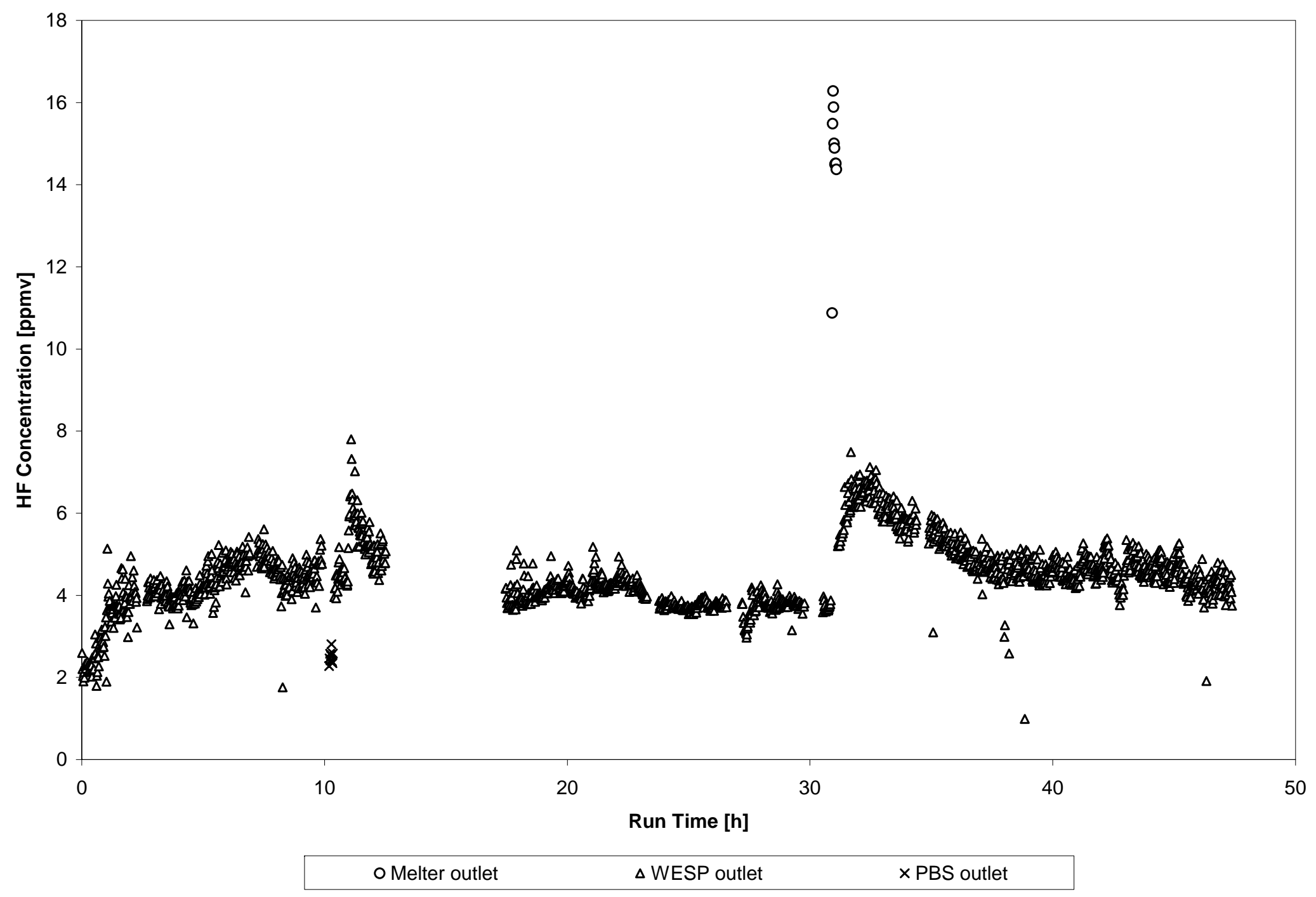

Figure 7.6. FTIR monitored HF emissions during DM1200 Test 1. 


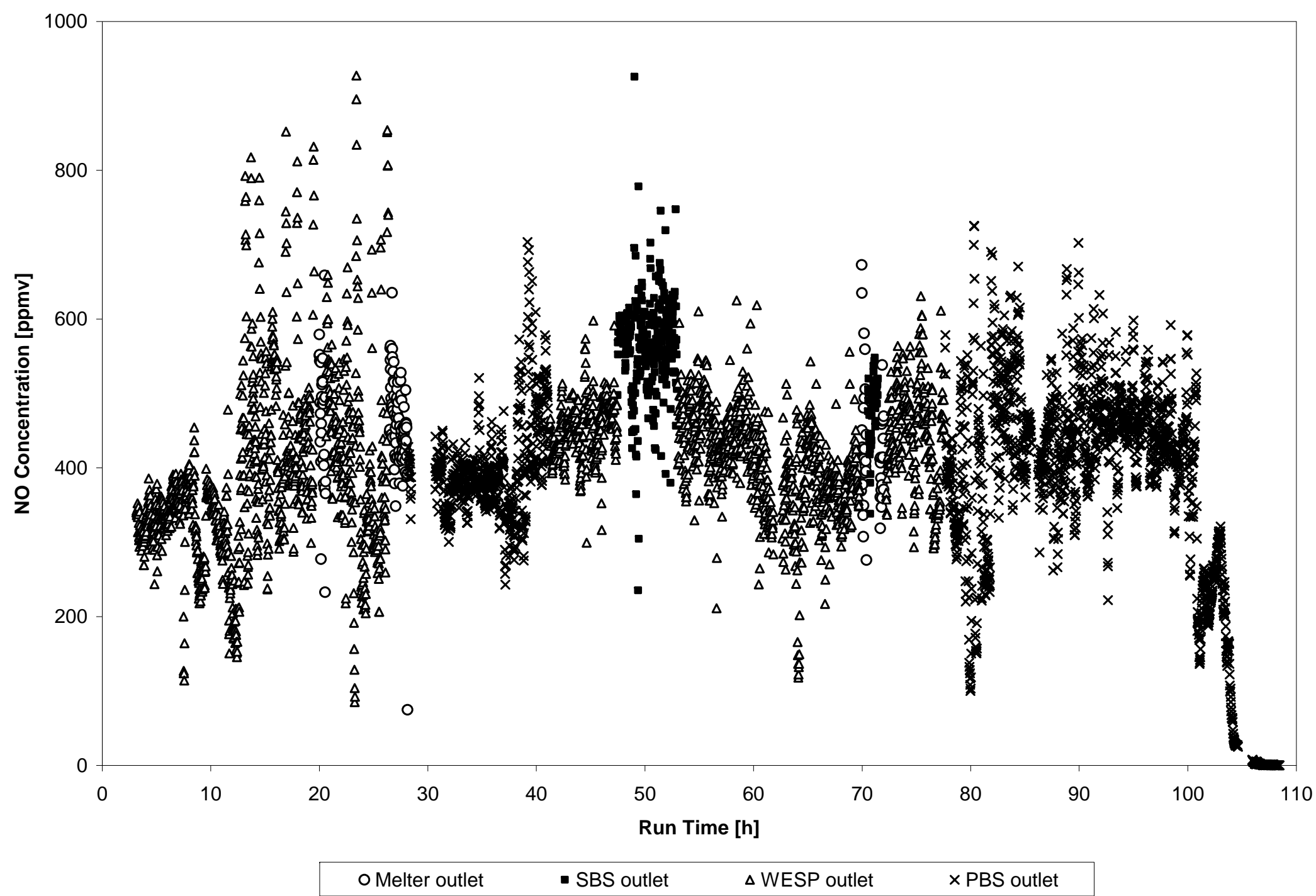

Figure 7.7. FTIR monitored NO emissions during DM1200 Tests 2 and 3. 


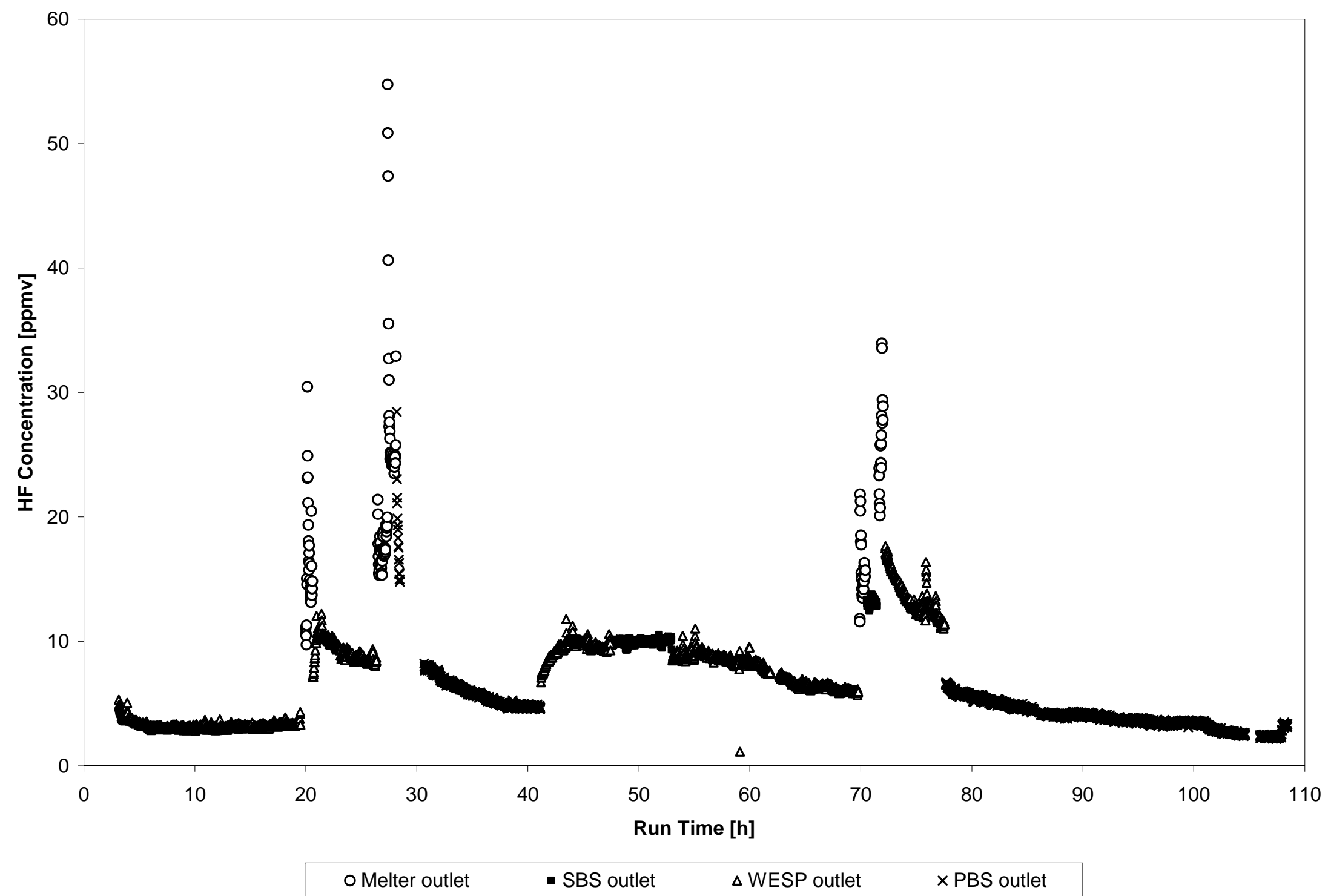

Figure 7.8. FTIR monitored HF emissions during DM1200 Tests 2 and 3. 